\title{
Amplificador Óptico Híbrido Raman/EDFA com Controle Automático de Ganho para Redes DWDM Reconfiguráveis
}

\author{
Juliano Rodrigues Fernandes de Oliveira
}

Tese de Doutorado Apresentada ao Programa

DE ENGENHARIA ELÉTRICA DA ESCOLA DE

ENGENHARIA DE SÃo CARLOS, DA UNIVERSIDADE

DE SÃo PaUlo, COMO PARTE dos Reguisitos

PARA OBTENÇ̃̃o Do TÍtUlo DE DOUTOR EM CiênCIAS

Área de Concentração: Telecomunicações

Programa: Programa de Pós-Graduação em Engenharia Elétrica da Escola de Engenharia de São Carlos

Orientador: Prof. Dr. Murilo Araujo Romero 



\section{Amplificador Óptico Híbrido Raman/EDFA com Controle Automático de Ganho para Redes DWDM Reconfiguráveis}

Comissão Julgadora:

- Prof. Dr. Murilo Araujo Romero

- Prof. Dra. Mônica de Lacerda Rocha

- Prof. Dr. Alexandre de Almeida Prado Pohl

- Dr. João Batista Rosolem

- Prof. Dr. Andrés Pablo López Barbero

Trata-se da versão corrigida da tese. A versão original se encontra disponível EESC/USP que aloja o Programa de Pós-Graduação de Engenharia Elétrica. 
AUTORIZO A REPRODUÇÃO TOTAL OU PARCIAL DESTE TRABALHO, POR QUALQUER MEIO CONVENCIONAL OU ELETRÔNICO, PARA FINS DE ESTUDO E PESQUISA, DESDE QUE CITADA A FONTE.

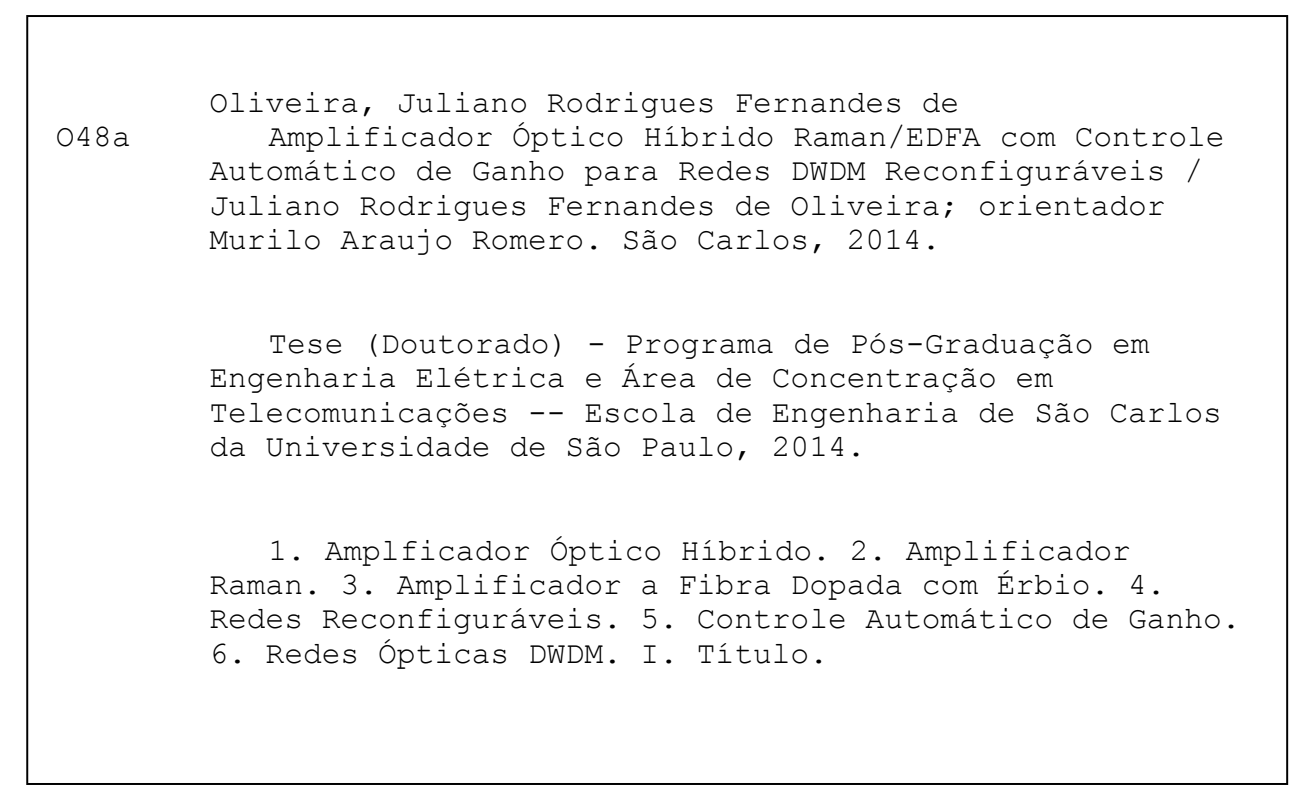




\section{FOLHA DE JULGAMENTO}

Candidato: Engenheiro JULIANO RODRIGUES FERNANDES DE OLIVEIRA.

Título da tese: "Amplificador Óptico Híbrido Raman/EDFA com Controle Automático de Ganho para Redes DWDM Reconfiguráveis".

Data da defesa: 27/05/2014

Comissão Julgadora:

Resultado:

Prof. Titular Murilo Araujo Romero (Orientador)

(Escola de Engenharia de São Carlos/EESC)

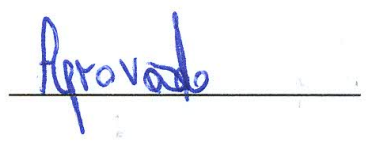

Profa. Dra. Mônica de Lacerda Rocha

APROVADO

(Escola de Engenharia de São Carlos/EESC)

Prof. Dr. Alexandre de Almeida Prado Pohl

APROVADO

(Universidade Tecnológica Federal do Paraná/UTFPR)

Dr. João Batista Rosolem

(Centro de Pesquisa e Desenvolvimento em Telecomunicações/CPqD)

Prof. Dr. Andrés Pablo López Barbero

(Universidade Federal Fluminense/UFF)

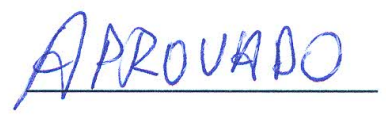

Coordenador do Programa de Pós-Graduação em Engenharia Elétrica e Presidente da Comissão de Pós-Graduação:

Prof. Titular Denis Vinicius Coury 



\section{Resumo}

DE OLIVEIRA, J.R.F. Amplificador Óptico Híbrido Raman/EDFA com Controle Automático de Ganho para Redes DWDM Reconfiguráveis. 2014. Tese de Doutorado - Escola de Engenharia de São Carlos, Universidade de São Paulo, São Carlos, 2014.

Visando atender a massificação das tecnologias da informação e comunicação (TIC) por meio de um aproveitamento mais eficiente da infra-estrutura de fibras ópticas, as redes ópticas DWDM vem passando por significativa evolução de capacidade, com base no uso de formatos de modulação avançados, para canais operando em taxas de 100 $\mathrm{Gb} / \mathrm{s}$ e superiores, bem como no emprego de topologias dinâmicas e reconfiguráveis.

Estas redes ópticas de nova geração impõe novos requisitos de desempenho aos amplificadores ópticos. Especificamente, as características dinâmicas da rede tornam obrigatório o uso de esquemas de controle que assegurem estrita planicidade espectral de ganho enquanto o emprego de formatos de modulação avançados e de alta ordem requer margens mais estreitas em termos da relação sinal-ruído aceitável para detecção dos sinais recebidos.

Neste contexto, esta tese propõe e avalia experimentalmente uma topologia de amplificação óptica híbrida Raman/EDFA, introduzindo um novo esquema de controle automático de ganho e apresentando desempenho superior aos amplificadores atualmente usados em redes DWDM reconfiguráveis. O amplificador óptico híbrido desenvolvido baseia-se em um estágio Raman distribuído contra-propagante, com excelente desempenho de figura de ruído (porém com baixa eficiência de conversão de bombeio em amplificação - PCE) seguido de um estágio EDFA, que assegura alta potência de saída, devido a sua elevada PCE. Ganho espectral plano foi obtido por meio de uma técnica de controle automático de ganho inovadora, baseada na atuação paralela e independente de duas malhas de controle automático de ganho, uma primeira aplicada ao estágio de amplificação Raman visando ganho-alvo variável com baixa variação espectral, enquanto outra malha de controle de ganho visa fornecer ganho alvo fixo ao estágio EDFA, com alta potência de saída.

Palavras-chave: Amplificador Óptico, EDFA, Amplificador Raman, Controle Automático de Ganho, Amplificador Óptico Híbrido. 


\section{Abstract}

DE OLIVEIRA, J.R.F. Raman/EDFA Hybrid Optical Amplifier with Automatic Gain Control for Reconfigurable DWDM Networks. 2014. Ph.D Thesis - Escola de Engenharia de São Carlos, Universidade de São Paulo, São Carlos, 2014.

Seeking to support the massive deployment of information and communication technologies (ICTs) by means of a more efficient usage of the optical fiber infrastructure, DWDM optical networks have been undergoing a significant capacity evolution, by using advanced modulation formats for optical channels operating at data rates of $100 \mathrm{~Gb} / \mathrm{s}$ and beyond, as well as by employing dynamic and reconfigurable network topologies.

These new generation optical networks impose new performance benchmarks on the optical amplifiers. Specifically, the dynamic characteristics of the network make mandatory the deployment of control schemes which assure stringent optical gain spectral flatness while the usage of high-order advanced modulation formats translate into more strict margins of signal-to-noise ratios for the detected signals.

In this context, this thesis proposes and experimentally evaluates an hybrid Raman/EDFA optical amplifier topology, introducing a novel automatic gain control scheme and demonstrating improved performance over the optical amplifiers already in use in DWDM reconfigurable networks. The developed hybrid optical amplifier is based on a distributed counter-propagating Raman stage, displaying excellent noise figure performance (albeit presenting low conversion efficiency - PCE) followed by an EDFA stage, which assures high output power, due to its high PCE. Flat spectral gain was achieved by means of a novel gain control technique, based on the parallel and independently acting of two control schemes, the first applied over the Raman amplifying stage, aiming at a variable target gain and low spectral gain ripple, while the other seeks to attain a fixed target gain at the EDFA, assuring a high output power.

Keywords: Optical Amplifier, EDFA, Raman, Automatic Gain Control, Hybrid Amplifiers. 


\section{Sumário}

$\begin{array}{ll}\text { Lista de Abreviaturas } & \text { ix }\end{array}$

Lista de Símbolos $\quad$ xiii

Lista de Figuras $\quad$ xv

Lista de Tabelas $\quad$ xxiii

1 Introdução $\quad 1$

1.1 Propostas do trabalho . . . . . . . . . . . . . . . 4

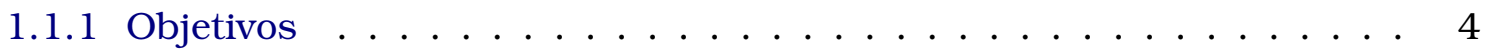

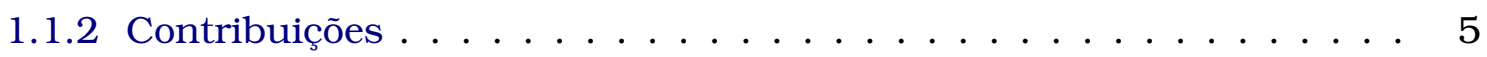

1.2 Descrição dos capítulos . . . . . . . . . . . . . . . . 6

2 Fundamentação Teórica $\quad 9$

2.1 Histórico e Evolução das Redes de Comunicações Ópticas . . . . . . . . . . . 10

2.1 .1 Amplificador Óptico Híbrido . . . . . . . . . . . . . . . . . 25

2.1.2 Amplificador Óptico Híbrido para Redes DWDM dinâmicas . . . . . . 32

3 Topologias de Amplificação Óptica Híbrida para Sistemas sem Repetição 35

3.1 Transmissor de $112 \mathrm{~Gb} / \mathrm{s}$ NRZ DP-QPSK $\ldots \ldots \ldots . \ldots . \ldots 38$

3.2 Receptor $112 \mathrm{~Gb} / \mathrm{s}$ NRZ DP-QPSK . . . . . . . . . . . . . . 38

3.3 Topologias de Amplificação Óptica Experimentadas . . . . . . . . . . . . . 40

3.3.1 Tx EDFA + Rx EDFA . . . . . . . . . . . . . . . . 41

$3.3 .2 \mathrm{Tx} \mathrm{EDFA}+\mathrm{Rx} \mathrm{DRA} \ldots \ldots \ldots \ldots . \ldots \ldots 42$

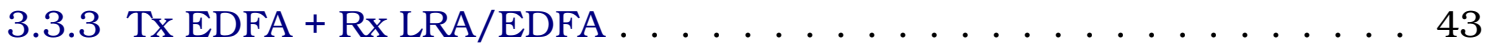

$3.3 .4 \mathrm{Tx} \mathrm{EDFA}+\mathrm{Rx} \mathrm{DRA} / \mathrm{LRA} \ldots \ldots \ldots \ldots . \ldots \ldots 4$

$3.3 .5 \mathrm{Tx} \mathrm{EDFA}+\mathrm{Rx} \mathrm{DRA} / \mathrm{EDFA} \ldots \ldots \ldots \ldots . \ldots \ldots$

$3.3 .6 \mathrm{Tx} \mathrm{EDFA}+\mathrm{Rx} \mathrm{DRA} / \mathrm{LRA} / \mathrm{EDFA} \ldots \ldots \ldots 46 \ldots . \ldots . \ldots$

3.3 .7 Tx EDFA/DRA + Rx DRA/EDFA . . . . . . . . . . . . 48

3.3 .8 Tx EDFA/DRA + Rx DRA/LRA/EDFA . . . . . . . . . . . . . 49

3.4 Avaliação Experimental de Sistema sem Repetição Mono-Canal com Topologias de Amplificação Óptica Simples/Híbridas . . . . . . . . . . . . . . 50

3.5 Sistema DWDM (40 canais) sem Repetição com Amplificadores Ópticos Híbridos . . . . . . . . . . . . . . . . . . . . 59

3.5.1 Projeto dos Amplificadores e Configuração Experimental . . . . . . 60 
3.5.2 Resultados Experimentais . . . . . . . . . . . . . . 61

3.6 Conclusões Parciais . . . . . . . . . . . . . . . . 65

4 Metodologia de Projeto de Amplificadores Ópticos com Controle Automático $\begin{array}{ll}\text { de Ganho } & 67\end{array}$

4.1 Controle Automático de ganho para Amplificadores Ópticos . . . . . . . . . . 68

4.1.1 EDFA com Estágio Único, GFF e AGC eletrônico realimentado . . . . 69

4.1.2 EDFA com Estágio Duplo, GFF, VOA e AGC eletrônico realimentado (controle acoplado) . . . . . . . . . . . . . . . 71

4.1.3 Amplificador Raman Distribuído com Controle Automático de Ganho 73

4.1.4 Amplificador Óptico Híbrido (Raman/EDFA) com Controle Automático de Ganho . . . . . . . . . . . . . . . . . . 76

4.2 Análise do Desempenho de Amplificador Óptico via Máscara de Potência . . 77

4.3 Projeto de Topologias de Amplificadores Ópticos com Controle Automático de Ganho em Software de Simulação Óptica . . . . . . . . . . . . . . . . . . 83

4.3.1 Metodologia de Projeto Otimizado de Amplificador a Fibra Dopada com Érbio para Redes DWDM Reconfiguráveis . . . . . . . . . . . 83

4.3.2 Projeto de EDFA com Estágio Único, GFF e AGC (Malha Aberta) em Simulação Óptica . . . . . . . . . . . . . . . . . . 86

4.3.3 Projeto de EDFA com Estágio Duplo, GFF, VOA e AGC Acoplado (Malha Aberta) em Simulação Óptica . . . . . . . . . . . . . . . . . . 94

4.3.4 Metodologia de Projeto de Amplificador Óptico Raman Distribuído . . 99

4.3.5 Projeto de Amplificador Raman Distribuído com AGC (Malha Aberta) em Simulação Óptica . . . . . . . . . . . . . . . . . 105

4.4 Proposta de um Amplificador Óptico para Redes Reconfiguráveis com Sinais de Alta Eficiência Espectral . . . . . . . . . . . . . . . . . . 111

4.5 Conclusões Parciais . . . . . . . . . . . . . . . . . . . . 112

5 Amplificador Óptico Híbrido para Redes DWDM Reconfiguráveis 115

5.1 Topologia Óptica do Amplificador Híbrido (Raman/EDFA) . . . . . . . . . . . 115

5.2 Método de Controle Automático de Ganho para o Amplificador Óptico Híbrido (Raman/EDFA) . . . . . . . . . . . . . . . 117

5.3 Metodologia de Projeto do Amplificador Óptico Híbrido (Raman/EDFA) . . . 118

5.3.1 Máscara de potência de operação do amplificador Híbrido . . . . . . . 119

5.3.2 Projeto dos Estágios de Amplificação EDFA e Amplificador Raman Distribuído para o Amplificador Híbrido . . . . . . . . . . . . . . 119

5.3.3 Integração do Controle de Ganho e Projeto do GFF . . . . . . . . . . . 124

5.4 Desempenho em Software de Simulação Óptica . . . . . . . . . . . . . . . . 129

5.4 .1 Enlace Único . . . . . . . . . . . . . . . . . . . . . . 130

5.4.2 Múltiplos Enlaces Concatenados (Rede DWDM Reconfigurável) . . . . 138

5.5 Desempenho Experimental . . . . . . . . . . . . . . . . . . . 145

5.5 .1 Enlace Único . . . . . . . . . . . . . . . . . . . . 146

5.5.2 Análise de controle de ganho com supressão de transientes . . . . . . 154

5.6 Conclusões Parciais . . . . . . . . . . . . . . . . . . 158 
6.1 Trabalhos Futuros . . . . . . . . . . . . . . . . . . . 162

6.2 Publicações Referentes a Tese . . . . . . . . . . . . . . . . 162

\section{Referências Bibliográficas}

A Tecnologias de Amplificação Óptica . . . . . . . . . . . . . . . . . . 175

A. 1 Amplificador a Fibra Dopada com Érbio . . . . . . . . . . . . . . . 175

A.2 Amplificadores Raman Discretos e Distribuídos . . . . . . . . . . . . . 182 


\section{Lista de Abreviaturas}

ADC Conversor Analógico Digital (Digital Analog Converter).

AGC Controle Automático de Ganho (Automatic Gain Control).

ASE Emissão espontânea amplificada (Amplified Spontaneous Emission).

CAPEX Despesas de Capital (Capital Expenditure).

CD Dispersão Cromática (Chromatic Dispersion).

CMOS Tecnologia Semicondutor-Oxido-Metal Complementar (Complementary MetalOxide-Semiconductor).

CPFL Laser a Fibra com Bombeio na Casca (Clad-Pumped Fiber Laser).

DCF Fibras de Compensação de Dispersão(Dispersion Compensation Fiber).

DCM Módulo de Compensação de Dispersão (Dispersion Compensation Module).

DP Polarização Dupla (Dual Polarization).

DP-QPSK Chaveamento em fase e quadratura em dupla polarização (Dual Polarization Quadrature Phase Shifting Keying).

DQPSK Modulação por Deslocamento de Fase e Quadratura Diferencial (Differential Quadrature Phase Shift Keying).

DRA Amplificador Raman distribuído (Distributed Raman Amplifier).

DRB Retro-espalhamento duplo de Rayleigh (Double Rayleigh Backscattering).

DSF Fibra de Dispersão Deslocada (Dispersion Shifted Fiber).

DSP Processador Digital de Sinais (Digital Signal Processing).

DWDM Multiplexação por divisão de comprimento de onda denso (Dense Wavelength Division Multiplexing).

EDF Fibra Dopada com Érbio (Erbium Doped Fiber).

EDFA Amplificador a fibra dopada com Érbio (Erbium Doped Fiber Amplifier).

ENOB Número Efetivo de Bits (Effective Number of Bits).

FEC Código Corretor de Erro Direto (Forward Error Correction).

FPGA Arranjo de Portas Programável em Campo (Field-Programmable Gate Array).

FWM Mistura de Quatro Ondas (Four Wave Mixing).

GaAs Arsenieto de Gálio (Gallium Arsenide).

GFF Filtro Aplainador de Ganho (Gain Flattening Filter).

GMPLS Múltiplos protocolos gerais para chaveamento via rótulo (Generalized Multi Protocol Label Switching).

HD-FEC FEC Definido por Hardware (Hardware Defined FEC).

IEC Comissão Internacional Eletrotécnica (International Electrotechnical Commission).

IMDD Modulação de Intensidade e Detecção Direta (Intensity Modulation Direct Detection). 
InGaAsP Arseneto de Gálio-Índio-Fósforo (Indium Gallium Arsenide Phosphide). ITU União internacional das telecomunicações (International Telecommunication Union). LRA Amplificador Raman concentrado (Lumped Raman Amplifier).

MDM Multiplexação por Divisão de Modo (Mode Division Multiplexing).

MPI Interferência de Múltiplos Caminhos (Multiple Path Interference).

NDSF Fibra com Zero de Dispersão Deslocada (Non Dispersion-shifted Fiber).

NF Figura de Ruído (Noise Figure).

N-GAM Modulação de Amplitude em N-níveis de Quadratura (N-Levels of Quadrature Amplitude Modulation).

NRZ Codificação binária sem retorno ao zero (Non Returning to Zero).

NZDSF Fibra de Dispersão Deslocada Não-Zero (Non-Zero Dispersion Shifted Fiber).

OADM Multiplexador de Adição e Remoção Óptico (Optical Add-Drop Multiplexer).

OEO Óptico-Elétrico-Óptico (Optical-Electric-Optical).

OFC Conferência sobre fibras e sistemas ópticos (Optical Fiber Conference).

OFDM Multiplexação por divisão de frequência ortogonal (Orthogonal.

OOK Chaveamento Liga Desliga (On-Off Keying).

OOK Chaveamento liga-desliga (On-Off Keying).

OPEX Despesas Operacionais (Operational Expenditure).

OSNR Relação sinal ruído óptica (Optical Signal to Noise Ratio).

OSPF Primeiro Menor Caminho Aberto (Open Shortest Path First).

OXC Conexão Cruzada de fibras Ópticas (Optical Cross-Connect).

PBC Combinador de Polarizações (Polarization Beam Combiner).

PBS Separador de Polarizações (Polarization Beam Splitter).

PCE Eficiência de Conversão de Bombeio em Amplificação(Pump Conversion Efficiency).

PDL Perda dependente de polarização (Polarization Dependent Loss).

PHB Buraco de queima na polarização (Polarization Hole Burning).

PLL Malha de Captura de Fase (Phase-Locked Loop).

PM Multiplexação de Polarização (Polarization Multiplexing).

PMD Dispersão por modo de polarização (Polarization Mode Dispersion).

POLMUX Multiplexação de Polarização (Polarization Multiplexing).

PSK Modulação por Deslocamento de Fase (Phase Shift Keying).

PSK Modulação por Deslocamento de Fase (Phase Shift Keying).

QAM Modulação de Amplitude em Guadratura (Quadrature Amplitude Modulation).

QPSK Modulação por Deslocamento de Fase e Quadratura (Quadrature Phase Shift Keying).

RFL Laser a Fibra Raman (Raman Fiber Laser).

RIN Ruído de Intensidade Relativa (Relative Intensity Noise).

ROADM Módulo insere/deriva re-configurável (Reconfigurable Optical Add and Drop Module).

RSVP Protocolo de Reserva de Recurso (Resource Reservation Protocol).

RZ Retorno a Zero (Return to Zero).

SD-FEC FEC Definido por Software (Software Defined FEC). 
SDM Multiplexação por Divisão de Espaço (Spatial Division Multiplexing).

SDO Óptica Definida por Software (Software Defined Optics).

SDR Rádio Definido por Software (Software Defined Radio).

SHB Buraco de queima no espectro (Spectral Hole Burning).

SNR Relação Sinal Ruído Signal to Noise Rate).

SOA Amplificador Óptico Semicondutor (Semiconductor Optical Amplifier).

SPM Auto Modulação de Fase (Self Phase Modulation).

SRS Espalhamento Raman Estimulado (Stimulated Raman Scattering).

SSMF Fibra monomodo padrão (Standard Single Mode Fiber).

TDM Multiplexação por Divisão no Tempo (Time Division Multiplexing).

USD Dólar Americano (Estados Unidos) (United States Dollar).

WDM Multiplexação por divisão de comprimento de onda (Wavelength Division Multiplexing).

wSS Chave Seletora de Frequência (Wavelength Selective Switch). 


\section{Lista de Símbolos}

$\alpha_{p}$ Coeficiente de perda no comprimento de onda do bombeio $[1 / \mathrm{m}]$.

$\alpha_{s}$ Coeficiente de perda no comprimento de onda do sinal $[1 / \mathrm{m}]$.

$\Delta v$ Resolução de frequência medida [Hz].

$\hbar$ Constante de Planck [6, $\left.626068 \times 10^{-34} \mathrm{~m}^{2} \mathrm{~kg} / \mathrm{s}\right]$.

$\hbar v_{p}$ Fóton de energia do bombeio.

$\hbar v_{s}$ Fóton de energia do sinal.

$\mu m$ Micrômetros $\left[10^{-6} \mathrm{~m}\right]$ (Micrometers).

$\omega p$ Frequência angular do bombeio [Hz].

$\omega s$ Frequência angular do sinal $[\mathrm{Hz}]$.

$v$ frequência óptica do sinal $[\mathrm{Hz}]$.

$v_{p}$ Frequência do bombeio $[\mathrm{Hz}]$.

$v_{s}$ Frequência do sinal [Hz].

${ }^{4} I_{11 / 2} \rightarrow{ }^{4} I_{13 / 2}$ Decaimento predominantemente não radioativo.

${ }^{4} I_{13 / 2} \rightarrow{ }^{4} I_{15 / 2}$ Emissão estimulada em $1550 \mathrm{~nm}$.

${ }^{4} I_{15 / 2} \rightarrow{ }^{4} I_{11 / 2}$ Absorção em $980 \mathrm{~nm}$.

${ }^{4} I_{15 / 2} \rightarrow{ }^{4} I_{13 / 2}$ Absorção em $1450 \mathrm{~nm}$.

$A_{\text {eff }}$ Área efetiva do núcleo da fibra $\left[\mathrm{m}^{2}\right]$.

$G_{N}$ Ganho de rede.

$g_{r}$ Coeficiente de ganho Raman $\left[W^{-1} m^{-1}\right]$.

$K_{\text {eff }}$ Fator de polarização da fibra .

$L$ Comprimento da fibra [m].

$L_{e f f}$ Comprimento efetivo.

$N F_{e q}$ Figura de ruído equivalente.

$P_{0}$ Potência lançada de bombeio [W].

$P_{B S}$ Potência do espalhamento Rayleigh.

$P_{D R B}$ Potência do espalhamento Rayleigh duplo.

$P_{p}$ Potência do Bombeio [W].

$P_{s}$ Potência do Sinal [W].

b/s/Hz Eficiência espectral em bits por segundo por Hertz.

$\mathbf{b} / \mathbf{s}$ Bits por segundo (bits per second).

$\mathbf{d B} / \mathbf{k m}$ Decibel por Quilômetros (Decibel per Kilometer).

dB Decibel.

dBm Decibel com relação a $1 \mathrm{~mW}$.

$\mathbf{G b} / \mathbf{s}$ Giga bits por segundo $\left[10^{9} \mathrm{~b} / \mathrm{s}\right]$ (Giga bits per second).

Gbaud Giga Baud $\left[10^{9}\right.$ Baud] (Velocidade de sinalização). 
GHz Giga-Hertz $\left[10^{9} \mathrm{~Hz}\right]$.

Hz Hertz $[1 / s]$.

$\mathbf{K b} / \mathbf{s}$ Kilo bits por segundo $\left[10^{3} \mathrm{~b} / \mathrm{s}\right.$ ] (Kilo bits per second).

km Quilômetros $\left[10^{3} \mathrm{~m}\right]$ (Kilometers).

$\mathbf{M b} / \mathbf{s}$ Mega bits por segundo $\left[10^{6} \mathrm{~b} / \mathrm{s}\right.$ ] (Mega bits per second).

MHz Mega-Hertz $\left[10^{6} \mathrm{~Hz}\right]$.

mm Milímetros $\left[10^{-6} \mathrm{~m}\right]$ (Milimetres).

mW Mili Watts $\left[10^{-3} W\right]$.

nm Nanômetros $\left[10^{-9} \mathrm{~m}\right]$ (Nanometers).

$\mathbf{T b} / \mathbf{s}$ Tera bits por segundo $\left[10^{12} b / s\right]$ (Tera bits per second).

THz Tera-Hertz $\left[10^{12} \mathrm{~Hz}\right]$.

W Watts $[\mathrm{J} / \mathrm{s}]$. 


\section{Lista de Figuras}

2.1 Principais experimentos de transmissão de dados em fibra óptica (marcadores), evolução de cada tecnologia de transmissão/recepção em fibras ópticas (curvas contínuas), seguidos da representação de cada tecnologia de roteamento de sinais ópticos (área hachurada). Adaptado da referência (Essiambre et al., 2010). . . . . . . . . . . . . . . . . . . 11

2.2 Transmissor com modulação de intensidade (a), intensidade no domínio do tempo e constelação do sinal óptico modulado em intensidade (b), receptor baseado em detecção direta (c), seção transversal das fibras utilizadas nessa geração (d), multiplexação por divisão de tempo (e) e topologia de rede ponto-a-ponto com regeneradores OEO (f) . . . . . . . . . . . . . . 13

2.3 Transmissor com modulação diferencial de fase e quadratura DQPSK (a), constelação do sinal óptico modulado DQPSK (b), receptor baseado em detecção diferencial balanceada (c), seção transversal das fibras utilizadas nessa geração (d), multiplexação por divisão de comprimento de onda (e) e topologia de rede ponto-a-multiponto fixo com OADMs e amplificadores ópticos a fibra dopada com érbio (f). . . . . . . . . . . . . . . 16

2.4 Perda espectral ao longo da fibra óptica monomodo padrão (preto) e sem o pico de absorção (vermelho). . . . . . . . . . . . . . . . 18

2.5 Transmissor com modulação em dupla polarização fase/quadratura DPGPSK(a), constelação do sinal óptico modulado DP-QPSK (b), receptor coerente com diversidade de polarização (c), seção transversal das fibras utilizadas nessa geração (d), multiplexação por divisão de comprimento de onda denso DWDM (e) topologia de rede em malha multi-ponto reconfigurável, amplificadores Raman e EDFA com AGC (f). . . . . . . . . . . . . 20

2.6 Transmissor com modulação em dupla polarização/fase/quadratura DPnQAM (a), constelação do sinal óptico modulado DP-16GAM (b), receptor coerente com diversidade de polarização (c), seção transversal das fibras utilizadas nessa geração (d), multiplexação por divisão de comprimento de onda denso DWDM, multiplexação por divisão espacial SDM (e) topologia de rede em malha multi-ponto reconfigurável com ROADMs independentes de cor-direção-contenção e flexível CDC-F, amplificadores híbridos com AGC (Raman/EDFA) (f). . . . . . . . . . . . . . . . . . . . 23

2.7 Amplificador Óptico Híbrido (EDFA/Raman concentrado) de Banda Larga. Extraido e adaptado da referência (Masuda et al., 1999). . . . . . . . . . . 27 
2.8 Amplificador Óptico Híbrido Raman distribuído/EDFA (a), Dependência do ganho com a temperatura no amplificador híbrido projetado (b). Extraido e adaptado da referência (Takeda et al., 2002). . . . . . . . . . . . . . . . 28

2.9 Fibras desenvolvidas para amplificadores Híbrido Raman Concentrado/EDFA (a), Dependência do ganho com a temperatura no amplificador híbrido projetado (b). Extraido e adaptado da referência (Seo et al., 2005). . . . . . . . . 29

2.10Amplificador Concentrado Raman - Tipo I (a), Amplificador Híbrido Raman concentrado/EDFA com re-uso de bombeio - Tipo II (b), Amplificador Híbrido EDFA/Raman Concentrado - Tipo III (c) e Amplificador Híbrido Raman Concentrado/EDFA - Tipo IV (d). Extraido e adaptado da referência (Lee et al., 2005). . . . . . . . . . . . . . . . . . . . . . . . 30

2.11 Espectro de ganho para os amplificadores testados: Amplificador Concentrado Raman - Tipo I (a), Amplificador Híbrido Raman Concentrado/EDFA com re-uso de bombeio - Tipo II (b), Amplificador Híbrido EDFA/Raman Concentrado - Tipo III (c) e Amplificador Híbrido Raman Concentrado/EDFA - Tipo IV (d). Extraido e adaptado da referência (Lee et al., 2005). . . . . . . . 31

2.12 Configuração do amplificador híbrido proposto. Extraido e adaptado da referência (Martini et al., 2009). . . . . . . . . . . . . . . . . . . . 32

2.13Espectros de ganho para o amplificador óptico híbrido com 2 lasers de bombeio para: $\mathrm{Ps}=-20 \mathrm{dBm}(\mathrm{a}), \mathrm{Ps}=-10 \mathrm{dBm}(\mathrm{b}), \mathrm{Ps}=-5 \mathrm{dBm}$ (c) $\mathrm{e}$ Espectro da figura de ruído para os casos avaliados (d). Extraido da referência (Martini et al., 2009). . . . . . . . . . . . . . . . . . . 33

3.1 (a) Enlace experimental com transmissor e receptor de $112 \mathrm{~Gb} / \mathrm{s}$ para avaliação das soluções de pré-amplificação híbrida em sistemas com fibra SSMF (G.652), (b) Transmissor 112Gb/s e (c) Bancada do subsistema testado (enlace e amplificadores). . . . . . . . . . . . . . . . . . . . . 36

3.2 (a) Constelação, (b) espectro e (c) diagrama de olho do sinal de transmissão $112 \mathrm{~Gb} / \mathrm{s}$ DP-QPSK. . . . . . . . . . . . . . . . . . . . 39

3.3 Passos do processamento digital de sinais executado sobre o sinal recebido de $112 \mathrm{~Gb} / \mathrm{s}$ NRZ DP-QPSK.

3.4 Circuito óptico do amplificador a fibra dopada com Érbio (EDFA) de transmissão e recepção. . . . . . . . . . . . . . . . . . . . . . . 4

3.5 (a) Circuito óptico do amplificador a fibra dopada com Érbio (EDFA) de transmissão e (b) circuito óptico do amplificador distribuído Raman (DRA) contra-propagante de recepção.

3.6 (a) Circuito óptico do amplificador a fibra dopada com Érbio (EDFA) de transmissão e (b) circuito óptico do amplificador híbrido composto pelo amplificador concentrado Raman em DCM (LRA) com EDFA na recepção.

3.7 (a) Circuito óptico do amplificador a fibra dopada com Érbio (EDFA) de transmissão e (b) circuito óptico do amplificador híbrido composto pelo amplificador Raman distribuído contra-propagante (DRA) combinado com um amplificador concentrado Raman em DCM (LRA) na recepção. . . . . . . 
3.8 (a) Circuito óptico do amplificador a fibra dopada com Érbio (EDFA) de transmissão e (b) circuito óptico do amplificador híbrido composto pelo amplificador Raman distribuído contra-propagante (DRA) combinado com um EDFA na recepção. . . . . . . . . . . . . . . . . . . . .

3.9 (a) Circuito óptico do amplificador a fibra dopada com Érbio (EDFA) de transmissão e (b) circuito óptico do amplificador híbrido composto pelo amplificador Raman distribuído contra-propagante (DRA) combinado amplificador Raman concentrado (LRA) e EDFA na recepção. . . . . . . . . . . .

3.10 (a) Circuito óptico do amplificador híbrido de potência EDFA com DRA copropagante na transmissão e (b) circuito óptico do amplificador híbrido DRA contra-propagante com EDFA na recepção. . . . . . . . . . . . . .

3.11 (a) Circuito óptico do amplificador híbrido de potência EDFA com DRA copropagante na transmissão e (b) circuito óptico do amplificador híbrido composto pelo amplificador Raman distribuído contra-propagante (DRA) combinado amplificador Raman concentrado (LRA) e EDFA na recepção. . .

3.12 (a) Constelações na recepção do sinal 112 Gb/s NRZ DP-QPSK back-to-back e (b) após passagem no enlace de $100 \mathrm{~km}$ com a topologia de amplificação óptica Tx EDFA + Rx DRA/EDFA. . . . . . . . . . . . . . . . . . . . .

3.13 (a) Constelações na recepção do sinal 112 Gb/s NRZ DP-QPSK back-to-back e (b) após passagem no enlace de $150 \mathrm{~km}$ com a topologia de amplificação óptica Tx EDFA + Rx DRA/EDFA. . . . . . . . . . . . . . . . . . . 54

3.14 (a) Constelações na recepção do sinal 112 Gb/s NRZ DP-QPSK back-to-back e (b) após passagem no enlace de $200 \mathrm{~km}$ com a topologia de amplificação óptica Tx EDFA + Rx DRA/EDFA. . . . . . . . . . . . . . . . . . . 56

3.15(a) Constelações na recepção do sinal 112 Gb/s NRZ DP-QPSK back-to-back e (b) após passagem no enlace de $250 \mathrm{~km}$ com a topologia de amplificação óptica Tx EDFA/DRA + Rx DRA/EDFA. . . . . . . . . . . . . . . . 5

3.16 (a) Constelações na recepção do sinal 112 Gb/s NRZ DP-QPSK back-to-back e (b) após passagem no enlace de $300 \mathrm{~km}$ com a topologia de amplificação óptica Tx EDFA/DRA + Rx DRA/EDFA. . . . . . . . . . . . . . . .

3.17 (a) Configuração experimental do sistema sem repetição WDM (40-canais) composto pela bancada de canais (com EDFA auxiliar), canal de teste modulado em $112 \mathrm{~Gb} / \mathrm{s}$, chave WSS, amplificador híbrido de transmissão, enlace de $302 \mathrm{~km}$ SSMF, amplificador híbrido de recepção e receptor coerente, (b) bancada 80 lasers ITU grid e (c) bancada com o enlace de $302 \mathrm{~km}$ e amplificadores. . . . . . . . . . . . . . . . . . .

3.18 Relação sinal ruído óptica (OSNR) no eixo vertical esquerdo e taxa de erro de bit (BER) no eixo vertical direito em função dos comprimentos de onda

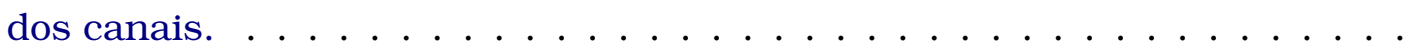

3.19 Constelação do sinal de teste modulado em 112Gb/s (back-to-back) (a), espectro de potência obtido na saída do sistema (b) e constelação do sinal de teste (H40) modulado em 112Gb/s (c). . . . . . . . . . . . . . . . 
3.20Espectro de potência obtido na saída do sistema (a) e constelação do sinal de teste (C40) modulado em $112 \mathrm{~Gb} / \mathrm{s}$ (b)

3.21 Espectro de potência obtido na saída do sistema (a) e constelação do sinal de teste (C21) modulado em 112Gb/s (b)

4.1 Circuito óptico do EDFA com um estágio e GFF. . . . . . . . . . . . 70

4.2 Malha de controle de ganho para o EDFA com um estágio e GFF. . . . . . . 70

4.3 Circuito óptico do EDFA com dois estágios, GFF e VOA. . . . . . . . . . . . 72

4.4 Malha de controle de ganho para o EDFA com dois estágios, GFF e VOA. . . 73

4.5 Circuito óptico do amplificador Raman distribuído contra-propagante com dois bombeios.

4.6 Malha de controle de ganho para o amplificador Raman distribuído contrapropagante com dois bombeios. . . . . . . . . . . . . . 75

4.7 Máscara de potência para um amplificador óptico. . . . . . . . . . . . . 78

4.8 Caracterizador de amplificador óptico discreto e distribuído em software de simulação numérica (a) e em bancada experimental experimental (b) . . . . 80

4.9 (a) Espectro de entrada e saída para o ponto inferior esquerdo da máscara de potência (b) Exemplo de uma máscara de potência onde a cor do ponto pode representar figura de ruído, planicidade espectral de ganho e precisão de AGC (c) Espectro de entrada e saída para o ponto superior direito da máscara de potência.

4.10Interface gráfica do programa de filtragem dos dados. A primeira coluna à esquerda mostra as especificações da máscara de potência, um menu drop down para escolha do comprimento da EDF e entradas para inserir perda de filtro equalizador de ganho (GFF) e resolução, que indica a precisão a ser considerada. . . . . . . . . . . . . . . . 8

4.11 Paleta de simulação desenvolvida para caracterização de amplificador óptico (a), topologia do EDFA co-propagante a ser caracterizado (b).

4.12 Dados simulados e regressão linear para os ganhos $14 \mathrm{~dB}(\mathrm{a})$ e $24 \mathrm{~dB}(\mathrm{~b})$. .

4.13 Perda do GFF projetado e Ganho com GFF X Ganho sem GFF (a), Espectros de entrada, perfil de perda do GFF, espectro de saída sem GFF e com GFF

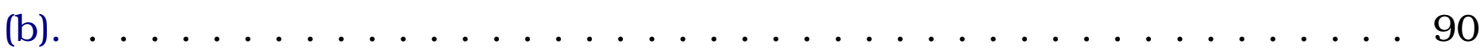

4.14 Paleta de simulação do EDFA com AGC em malha aberta. . . . . . . . . . . 91

4.15Diagrama de bloco do controle de ganho em malha aberta (a), fluxograma do controle em malha aberta (b). . . . . . . . . . . . . . . 92

4.16 Máscara de potência do amplificador estágio simples EDFA com GFF e AGC apresentando desempenho de figura de ruído (a), planicidade espectral de ganho (b) e precisão do controle automático de ganho (c). . . . . . . . . . . 93

4.17 Paleta de simulação desenvolvida para o amplificador óptico acoplado EDFAVOA-EDFA. . . . . . . . . . . . . . . . . . 95

4.18Espectro de entrada, perfil de perda do GFF, espectro de saída sem GFF e espectro de saída com GFF. 
4.19Diagrama de bloco do controle de ganho acoplado dos estágios EDFA e VOA no amplificador duplo estágio (a), fluxograma do controle de ganho acoplado (b). . . . . . . . . . . . . . . . . . 97

4.20 Máscara de potência do amplificador estágio simples EDFA com GFF e AGC apresentando desempenho de figura de ruído (a), planicidade espectral de ganho (b) e precisão do controle automático de ganho acoplado (c). . . . . . 98

4.21 Fluxograma da metodologia de projeto de amplificador Raman distribuído . 101

4.22 Paleta de simulação desenvolvida para o amplificador óptico Raman distribuído. . . . . . . . . . . . . . . . . . 106

4.23 Dados simulados e regressão linear para os ganhos $2 \mathrm{~dB}(\mathrm{a})$ e $12 \mathrm{~dB}(\mathrm{~b})$. . . . 108

4.24 Diagrama de bloco do controle de ganho on-off do amplificador Raman distribuído contra-propagante (a), fluxograma do controle de ganho on-off (b) . . . . . . . . . . . . . . . . . . . . 109

4.25 Máscara de potência do amplificador Raman distribuído com AGC on-off apresentando desempenho de figura de ruído (a), planicidade espectral de ganho (b) e precisão do controle automático de ganho acoplado (c). . . . . . 110

4.26Análise comparativa topologias de amplificação óptica com controle automático de ganho para sistemas com repetição dinâmicos. . . . . . . . . . . . 112

5.1 Circuito óptico do amplificador híbrido Raman distribuído contra-propagante com dois bombeios e EDFA com GFF. . . . . . . . . . . . . . . . 116

5.2 Malha de controle de ganho para o amplificador híbrido Raman distribuído contra-propagante com dois bombeios e EDFA com GFF. . . . . . . . . . 117

5.3 Máscara de potência do amplificador estágio simples EDFA com AGC para o amplificador híbrido, apresentando desempenho de figura de ruído (a), planicidade espectral de ganho (b) e precisão do controle automático de ganho (c). . . . . . . . . . . . . . . . . . . 121

5.4 Normalização do perfil espectral do amplificador Raman distribuído (a) e normalização invertida do perfil espectral do EDFA (b) . . . . . . . . . . . . 123

5.5 Comparativo de perfis espectrais de amplificadores Raman projetado no Capítulo 4 (1442/1447 nm), amplificador Raman (1425/1455 nm) e EDFA projetado para o amplificador híbrido.

5.6 Curvas das diferenças absolutas aproximadas dos DRAs e EDFA (a) e análise comparativa das áreas diferenciais dos DRAs com relação ao EDFA (b) . 125

5.7 Paleta de simulação desenvolvida para avaliação do amplificador Híbrido (Raman/EDFA) (a) e detalhes internos do amplificador óptico híbrido (b) . . 126

5.8 Perfil espectral de saída do amplificador híbrido com ganho de operação $25 \mathrm{~dB}$ (curva azul), com ganho de operação $15 \mathrm{~dB}$ (curva verde), média dos perfis espectrais ou perfil espectral do GFF não normalizado (curva vermelha) e perfil espectral final do GFF normalizado para o amplificador híbrido (curva azul claro). . . . . . . . . . . . . . . . . . . . 128 
5.9 Perfil espectral de atenuação do GFF para um ponto particular visando realização de uma análise comparativa entre os amplificadores EDFA, amplificador híbrido Raman 1442/1447 nm combinado com EDFA (metodologia de projeto não otimizado) e o amplificador híbrido Raman 1425/1455 nm combinado com EDFA (obtido por meio da metodologia de projeto apresentada nesta seção).

5.10 Paleta de simulação para caracterização/avaliação da propagação do sinal ao longo de um enlace de $75 \mathrm{~km}$ de fibra SSMF para o amplificador Híbrido (Raman/EDFA) (a) e para o amplificador EDFA-VOA-EDFA (b) . . . . . . . . 131

5.11 Máscara de potência do amplificador EDFA-VOA-EDFA testado em um enlace de comunicações ópticas apresentando desempenho de figura de ruído (a), planicidade espectral de ganho (b) e precisão do controle automático de ganho (c). . . . . . . . . . . . . . . . . . . .

5.12 Máscara de potência do amplificador Híbrido testado em um enlace de comunicações ópticas apresentando desempenho de figura de ruído (a), planicidade espectral de ganho (b) e precisão do controle automático de ganho (c) . . . . . . . . . . . . . . . . . . . . . .

5.13 Ganho por canal dos amplificadores testados em simulação óptica nos pontos de críticos da máscara de potência: Amplificador saturado com ganho alvo $15 \mathrm{~dB}$ - P1 (a), amplificador não saturado com ganho alvo $15 \mathrm{~dB}-\mathrm{P} 2$ (b), amplificador saturado com ganho alvo $25 \mathrm{~dB}$ - P3 (c), amplificador não saturado com ganho alvo $25 \mathrm{~dB}$ - P4 (d). . . . . . . . . . . . . .

5.14 OSNR dos amplificadores testados em simulação óptica nos pontos de críticos da máscara de potência: Amplificador saturado com ganho alvo $15 \mathrm{~dB}$ - P1 (a), amplificador não saturado com ganho alvo 15 dB - P2 (b), amplificador saturado com ganho alvo $25 \mathrm{~dB}$ - P3 (c), amplificador não saturado com ganho alvo $25 \mathrm{~dB}-\mathrm{P} 4$ (d) . . . . . . . . . . . . . . . . . 136

5.15OSNR de saída dos amplificadores híbrido e EDFA-VOA-EDFA para todos os ganhos alvo testados com os amplificadores operando em saturação. . 138

5.16Diagrama unifilar da rede óptica DWDM reconfigurável composta por múltiplos enlaces, para teste de desempenho do amplificador híbrido e amplificador EDFA-VOA-EDFA. . . . . . . . . . . . . . . . . . 138

5.17 Pontos de operação das topologias de amplificação óptica ilustrados em sua respectiva máscara de potência para o amplificador EDFA-VOA-EDFA (a) e amplificador Híbrido Raman/EDFA (b) . . . . . . . . . . . . . . . . . . 140

5.18Paleta de simulação para avaliação da propagação do sinal nos primeiros cinco enlaces do sistema DWDM com o amplificador Híbrido (Raman/EDFA) (a), Paleta de simulação para avaliação dos enlaces seguintes com o amplificador EDFA-VOA-EDFA (b) . . . . . . . . . . . . . . . . . 141

5.19Perfis de atenuações espectrais aplicado pelos nós de ROADMs para equalização espectral de potência por canal em um nó. . . . . . . . . . . . . . . . 142 
5.20 OSNR de saída das topologias de amplificação híbrida e EDFA-VOA-EDFA ao longo de múltiplos enlaces considerando: Ganho $15 \mathrm{~dB}$ e enlace de 75 km de SSMF (a), Ganho $20 \mathrm{~dB}$ e enlace de $100 \mathrm{~km}$ de SSMF (b), Ganho 25 $\mathrm{dB}$ e enlace de $125 \mathrm{~km}$ de SSMF (c).

5.21 Espectros de saída ao fim do $30^{\circ}$ enlace da rede óptica testada com a topologia de amplificação óptica EDFA-VOA-EDFA com enlace de $75 \mathrm{~km} \mathrm{(a),}$ $100 \mathrm{~km}$ (b) $125 \mathrm{~km}$ (c) e com a topologia de amplificação óptica híbrida com enlace de $75 \mathrm{~km}$ (a), $100 \mathrm{~km}$ (b) e $125 \mathrm{~km}$ (c). . . . . . . . . . . . . . . . . 144

5.22 Diferença de OSNR ao longo dos múltiplos enlaces de comunicações comparando o amplificador híbrido e o amplificador EDFA-VOA-EDFA operando no ganho alvo de $15 \mathrm{~dB}$ com enalce de $75 \mathrm{~km}$ (a), ganho alvo de $20 \mathrm{~dB}$ com enalce de $100 \mathrm{~km}$ (a) e ganho alvo de $25 \mathrm{~dB}$ com enalce de 125

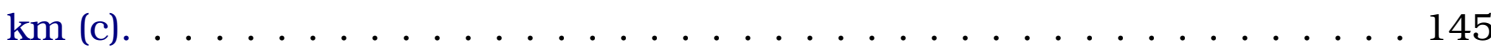

5.23 Configuração experimental construída para avaliação do amplificador Híbrido (Raman/EDFA) (a), visão interna do amplificador óptico híbrido (b) . . 147

5.24 Máscara de potência do amplificador EDFA-VOA-EDFA experimental apresentando desempenho de figura de ruído (a), planicidade espectral de ganho (b) e precisão do controle automático de ganho (c).

5.25Máscara de potência do amplificador híbrido (Raman/EDFA) experimental apresentando desempenho de figura de ruído (a), planicidade espectral de ganho (b) e precisão do controle automático de ganho (c) . . . . . . . . . . . . 149

5.26Espectros de entrada, saída e potência alvo para os pontos críticos de desempenho na máscara de potência, para as topologias de amplificação EDFA-VOA-EDFA P1 (a), P2 (c), P3 (e) e P4 (g), e a topologia de amplificação hibrida P1 (b), P2 (d), P3 (f) e P4 (h) respectivamente experimentadas. . . . . 150

5.27 Ganho por canal para ambas as topologias de amplificação experimentadas (EDFA-VOA-EDFA e amplificador híbrido) para os pontos críticos da máscara de potência P1 (a), P2 (b), P3 (c) e P4 (d). . . . . . . . . . . . . . . .

5.28 OSNR de saída por canal para ambas as topologias de amplificação experimentadas (EDFA-VOA-EDFA e amplificador híbrido) para os pontos críticos da máscara de potência P1 (a), P2 (b), P3 (c) e P4 (d). . . . . . . . . . . . . . . 152

5.29 OSNR de saída dos amplificadores híbrido e EDFA-VOA-EDFA experimentados para todos os ganhos alvo testados com os amplificadores operando em saturação.

5.30 Placa óptica (a), placa eletrônica (b) e protótipo pré-industrial amplificador óptico híbrido montado (c) . . . . . . . . . . . . . . . . . . . . . 155

5.31 Setup experimental para teste de supressão de transientes em amplificadores ópticos. . . . . . . . . . . . . . . . . . . . . . 155

5.32 Transiente de potência no canal sobrevivente, testado para $9 \mathrm{~dB}$ de adição/remoção, sem/com AGC (com supressão de transientes) no amplificador EDFA de estágio simples com ganho $14 \mathrm{~dB}(\mathrm{a}) / 24 \mathrm{~dB}(\mathrm{~b})$ e amplificador óptico híbrido com gnaho $15 \mathrm{~dB}(\mathrm{c}) / 25 \mathrm{~dB}(\mathrm{~d}) . \ldots \ldots$. . . . . . . . . . . 157

A.1 Níveis de energia envolvidos na amplificação a fibra dopada com érbio. . . . 176 
A.2 Configuração básica de amplificador a fibra dopada com érbio. Extraido da referência (de Oliveira, 2004). . . . . . . . . . . . . . . . . 177

A.3 Espectro de saída de um amplificador óptico a fibra dopada com Érbio, sinal e emissão espontânea amplificada. Extraido da referência (de Oliveira, 2004) . . . . . . . . . . . . . . . . . . . 177

A.4 (a) Curva de ganho em função da potência do sinal na entrada e (b) Curva de ganho em função da potência do sinal para um amplificador a fibra dopada com Érbio. Extraido da referência (de Oliveira, 2004). . . . . . . . . 178

A.5 Posicionamento do (a) amplificador de potência, (b) pré-amplificador e (c) amplificador de linha em um sistema de comunicações ópticas. . . . . . . 180

A.6 Produtos capacidade $\mathrm{x}$ distância ao longo dos anos dos enlaces experimentais. Extraido e adaptado da referência (Bromage, 2004). . . . . . . . . . . 183

A.7 Diagrama esquemático do processo quântico do espalhamento Raman. Extraido e adaptado da referência (Headley e Agrawal, 2005). . . . . . . . . . . 184

A.8 Sistema óptico com amplificação Raman. Extraido e adaptado da referência (Headley e Agrawal, 2005). . . . . . . . . . . . . . . . . . . . . . 184

A.9 Perfis de ganho Raman para três diferentes tipos de fibra e bombeio de 1510 nm. Extraido e adaptado da referência (Headley e Agrawal, 2005). . . 185

A.10Diagramas esquemáticos: (a) sistema amplificador Raman distribuído, (b) sistema equivalente enlace + EDFA. Extraido e adaptado da referência (Headley e Agrawal, 2005). . . . . . . . . . . . . . . . . . . 186

A.11(a) Contribuição individual para o ganho de diferentes comprimentos de onda de bombeio, resultado da superposição de todas as contribuições individuais e curva do ganho resultante levando em consideração as interações bombeio-bombeio, (b) Simulação da evolução da potência do bombeio em um amplificador Raman. Extraido e adaptado da referência (Emori e Namiki, 2001) . . . . . . . . . . . . . . . . . . . . 188

A.12Diagrama esquemático representando o crescimento do espalhamento Rayleigh duplo em uma fibra. $P_{B S}$ é a potência do espalhamento Rayleigh e $P_{D R B}$ a potência do espalhamento Rayleigh duplo. Extraido e adaptado da referência (Headley e Agrawal, 2005). . . . . . . . . . . . . . . . . . . 189

A.13Espectro do RIN calculado para as configurações contra e co-propagante. Extraido e adaptado da referência (Mermelstein et al., 2002). . . . . . . . . . 189

A.14Medição do ganho e da figura de ruído em função do comprimento de onda. Extraido e adaptado da referência (Kado et al., 2002). . . . . . . . . . . . . . 190

A.15Medidas de figura de ruído para quatro diferentes configurações de amplificadores. Extraido e adaptado da referência (Kado et al., 2002). . . . . . . . 191 


\section{Lista de Tabelas}

2.1 Faixa espectral das bandas ópticas para comunicações WDM. . . . . . . . . 17

2.2 Recomendações relativas à separação espectral e às bandas a serem utilizadas para diferentes faixas e número de canais. . . . . . . . . . . . . . . 18

3.1 Desempenho das topologias de amplificação óptica experimentadas para o enlace de $100 \mathrm{~km}$ de fibra SSMF (†BER estimada a partir do fator Q). . . . . 52

3.2 Desempenho das topologias de amplificação óptica experimentadas para o enlace de $150 \mathrm{~km}$ de fibra SSMF (†BER estimada a partir do fator Q). . . . . 53

3.3 Desempenho das topologias de amplificação óptica experimentadas para o enlace de $200 \mathrm{~km}$ de fibra SSMF (†BER estimada a partir do fator Q). . . . 55

3.4 Desempenho das topologias de amplificação óptica experimentadas para o enlace de $250 \mathrm{~km}$ de fibra SSMF (†BER estimada a partir do fator Q). . . . . 57

3.5 Desempenho da topologia de amplificação óptica experimentada para o enlace de $300 \mathrm{~km}$ de fibra SSMF (†BER estimada a partir do fator Q). . . . . . 58

3.6 Taxa de erro de bit por canal considerando compensação não-linear com DBP e MLSE . . . . . . . . . . . . . . . . . . . . . . . . . 64

3.7 Penalidade estima de OSNR por canal com relação a condição back-to-back (melhora da penalidade) sem e com o uso dos algoritmos DBP e MLSE. . . . 65

4.1 Comprimentos de onda, ganho on-off e planicidade espectral de ganho para cada tipo de procura no vetor de resultados. . . . . . . . . . . . . . . . . . 103

4.2 Resultado da simulação completa para cada tipo de procura (comprimentos de onda) realizado. . . . . . . . . . . . . . . . . . . . . 103

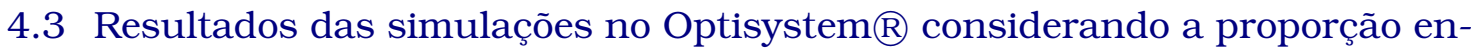
tre os bombeios máximo e mínimo para o amplificador Raman com dois Lasers de bombeio. . . . . . . . . . . . . . . . . . . . . 104

5.1 OSNR média, mínima e máxima para cada topologia de amplificação simulada e seu comparativo (aumento de OSNR). . . . . . . . . . . . . . 137

5.2 OSNR média e mínima no fim do $30^{\circ}$ enlace, e máxima para cada topologia de amplificação simulada e seu comparativo (aumento de OSNR). . . . . . . 142

5.3 OSNR média, ganho médio, planicidade e aumento médio de OSNR para cada topologia de amplificação experimentada. . . . . . . . . . . . . . . . . . 154 


\section{Capítulo 1}

\section{Introdução}

Com a massificação das redes de comunicações, principalmente devido à expansão e difusão da internet, a demanda por comunicações de dados aumentou substancialmente, exigindo uma maior capacidade das redes de telecomunicações. Neste contexto, a tecnologia DWDM apareceu como uma solução para o aumento do tráfego, possibilitando taxas de transmissão agregadas acima de $\mathrm{Tb} / \mathrm{s}$ nos enlaces de comunicações ópticas. Desta forma, a fibra óptica tornou-se a melhor alternativa para transmissões de altas capacidades em médio e longo alcance (suportada por regeneradores ópticos), devido à baixa atenuação experimentada pelo sinal óptico transmitido e ampla largura de banda disponibilizada pela fibra óptica. Um dos principais componentes que permitiram o estabelecimento das redes de comunicações ópticas DWDM de alta capacidade foram os amplificadores ópticos, mais precisamente o amplificador a fibra dopada com érbio (EDFA) (Desurvire et al., 1987; R.J. Mears et al., 1987).

As taxas de transmissão por comprimento de onda em redes de comunicações ópticas vêm evoluindo por meio do uso de formatos avançados de modulação, baseados na codificação de múltiplos bits sobre todos os graus de liberdade da onda eletromagnética (amplitude, fase, polarização e frequência), desta forma aumentando a eficiência espectral (otimizando o uso da fibra óptica), e consequentemente aumentando a taxa transmitida (Roberts et al., 2010). Já os receptores vêm evoluindo por meio do uso da tecnologia de recepção coerente aliada a processamento digital de sinais (DSP) (Savory, 2008), visando aumento da sensibilidade e da robustez contra as distorções lineares causadas pela fibra.

Adicionalmente, com a contínua disseminação das redes DWDM ópticas, aliada à necessidade por redução de custos capitais (CAPEX) e operacionais (OPEX), surgiram as redes ópticas DWDM reconfiguráveis (dinâmicas) com o objetivo de flexibilizar a rede óptica através do roteamento de comprimentos de onda (adição e remoção de canais), otimizando o uso da infraestrutura através da migração das redes ópticas DWDM estáticas ponto-a-ponto com capacidade fixa de transmissão para redes ópticas DWDM dinâmicas com capacidade variável e definida de acordo com a demanda por capacidade de transmissão (Zyskind e Srivastava, 2011).

Os responsáveis pelo aumento da eficiência espectral do transmissor óptico foram o desenvolvimento de novos moduladores ópticos (visando formatos de modulação avançados) e conversores digitais analógicos de altíssima taxa (DAC maior que 25G amos- 
tras) permitindo o uso de formatos de modulação digitais diretamente no domínio óptico, quais sejam, a modulação via chaveamento em quadratura e fase (QPSK), e a modulação em n-níveis de quadratura da amplitude (N-GAM), respectivamente (Gnauck et al., 2012). Com o uso de modulações de alta ordem, consegue-se uma eficiência espectral muito maior que nos sistemas com modulação de intensidade (OOK), os quais possuem uma eficiência espectral de $0,5 \mathrm{~b} / \mathrm{s} / \mathrm{Hz}$. Usando o formato QPSK, por exemplo, tem-se uma eficiência espectral de $1 \mathrm{~b} / \mathrm{s} / \mathrm{Hz}$, já para um formato de 16-QAM, chega-se a 2 b/s/Hz. Com o uso da multiplexação em polarização (PM) ou transmissão em dupla polarização (DP), é possível dobrar a eficiência espectral na mesma frequência (Seimetz, 2009). Já na recepção, a evolução se dá devido à utilização de detectores coerentes e circuitos de aplicação específica (ASIC) que realizam em tempo real o processamento digital de sinais (DSP) (Roberts et al., 2010).

Os elementos responsáveis por viabilizar redes ópticas reconfiguráveis (dinâmicas) foram os dispositivos insere/deriva ópticos reconfiguráveis (ROADM) e os módulos de conexão cruzada (OXC). Os ROADMs, que geralmente encontram-se nos nós de entroncamento da rede óptica, são capazes de prover a inserção, retirada e atenuação intencional de cada canal (comprimentos de onda) ou grupo de canais, provendo a capacidade de aprovisionar caminhos ópticos, além de possibilitar estratégias de proteção na camada óptica. Já os OXCs são dispositivos compostos por chaves ópticas que permitem o chaveamento de fibras ópticas (todos os canais de uma só vez), não permitindo o chaveamento por canal, como no ROADM. A utilização de componentes como ROADMs e OXCs nas redes ópticas tem se tornado cada vez mais frequente, representando uma realidade devido à redução de custos operacionais (OPEX) e otimização (reuso) da rede, conseguidos com a reconfiguração remota (Zyskind e Srivastava, 2011).

Com a introdução das redes ópticas DWDM dinâmicas, as variações de potência na entrada dos EDFAs, principalmente quando se encontram operando em modo saturado, implicam de forma direta em alterações no ganho proporcionado aos sinais amplificados (Agrawal, 2002; de Oliveira, 2004). O seu uso em sistemas ou redes DWDM, em que o número de canais acoplados ao amplificador varia em decorrência dos elementos que inserem e removem canais (ROADMs), pode ser severamente comprometido caso técnicas de controle de ganho não sejam empregadas. Vários trabalhos realizados obtiveram sucesso referente ao controle de ganho em EDFAs, seja este controle totalmente óptico (de Oliveira, 2007) ou controle eletrônico com supressão de transientes (de Oliveira, 2008). Estas técnicas de controle de ganho garantem ganho fixo antes e após a remoção de canais, sendo cruciais para operação de sistemas ou redes DWDM dinâmicas.

Na transmissão de sinais com formatos de modulação avançados em redes DWDM estáticas, o nível de qualidade do sinal necessário para decodificação sem erros (relação sinal ruído óptica - OSNR) cresce proporcionalmente de acordo com o aumento da eficiência espectral provido pelo formato de modulação empregado (der Borne, 2008; Nakazawa et al., 2010). Portanto, uma maneira de melhorar a qualidade dos sinais em uma rede óptica é através do desenvolvimento de amplificadores ópticos com figura de ruído reduzida e ganho espectral plano. Visando esta redução de figura de ruído, surgiram várias topologias de amplificação Raman distribuída (DRA) e concentrada (LRA) 
unidirecional e bidirecional (Bromage, 2004; Headley e Agrawal, 2005; Labrunie et al., 2001), assim como topologias de amplificação híbrida (Raman/EDFA) com ganho espectral plano (Lee et al., 2005; Tiwari et al., 2009), amplificadores Raman concentrados com compensação de dispersão cromática (LRA) (Liaw et al., 2010), amplificadores híbridos de banda larga (Namiki e Emori, 2001; Seo et al., 2005) e amplificadores Raman com controle automático de ganho (Ahmad et al., 2008; Dung et al., 2009; Kim e Park, 2005).

Porém, nenhum dos trabalhos acima considera o projeto específico de amplificadores ópticos que operam em um cenário com ambas as características citadas anteriormente (redes ópticas DWDM reconfiguráveis e com canais baseados em formatos de modulação avançados). Para que a capacidade das redes ópticas DWDM dinâmicas evolua de forma sustentável, os amplificadores ópticos devem sofrer constante evolução, visando prover controle automático de ganho (AGC) com supressão de transientes, ganho espectral plano, e níveis reduzidos de figura de ruído, ao longo de toda região de operação em uma rede DWDM dinâmica (faixa de potências de entrada e ganhos-alvo requeridos para operação em redes ópticas reconfiguráveis com formatos de modulação avançados).

Neste contexto, esta tese tem como um dos objetivos investigar e determinar qual a topologia de amplificação óptica híbrida mais adequada em termos de desempenho óptico para sistemas de comunicações ópticas DWDM dinâmicas onde trafegam canais de alta eficiência espectral (formatos avançados de modulação), bem como quais tecnologias devem compor essa topologia híbrida. Esta tese também tem como objetivo desenvolver o controle automático de ganho da topologia de amplificação óptica híbrida, visando maximizar o desempenho óptico (baixa figura de ruído aliado a planicidade espectral de ganho) ao longo de toda região de operação (potências de entrada e ganhos alvos) nos sistemas DWDM reconfiguráveis.

Neste contexto, as tecnologias mais empregadas para amplificação em redes ópticas DWDM são os EDFAs e os DRAs. Os EDFAs fornecem altos níveis de amplificação de sinal e potência de saída, por meio de lasers de bombeio de potência relativamente baixa, devido à alta eficiência de conversão de bombeio em amplificação (PCE). Além disso, o EDFA apresenta figura de ruído (NF) em torno de $4 \mathrm{~dB}$, próximo ao limite quântico de ruído em amplificadores discretos, de 3 dB (Agrawal, 2002). Os amplificadores distribuídos Raman (DRA) tem como sua principal característica uma menor figura de ruído (comparado aos amplificadores discretos), pois o processo de amplificação distribuída ocorre ao longo da fibra de transmissão. Desta forma, os DRAs efetivamente reduzem a figura de ruído do enlace. Porém, esta tecnologia de amplificação possui uma baixa PCE, necessitando altos níveis de bombeio para permitir amplificação aos sinais. Finalmente, o amplificador Raman concentrado (LRA) utiliza como meio de amplificação fibras de área efetiva reduzida, provendo amplificação para potências de bombeio mais baixas, e reduzindo o comprimento da fibra utilizada no meio de amplificação. O LRA fornece uma melhor PCE que o DRA, mas em contrapartida compromete o desempenho de ruído (Headley e Agrawal, 2005). Além disso, para o LRA que utiliza como meio de amplificação fibras de compensação de dispersão (DCF), o ganho é fornecido em conjunto com a compensação de dispersão cromática. 
Porém, como nos sistemas com recepção coerente o processamento digital de sinais (DSP) vários efeitos lineares impostos pela fibra são compensados, entre eles a dispersão cromática (Savory, 2010), a necessidade de compensação de dispersão cromática através de fibras compensadores de dispersão (DCF) no enlace de comunicações ópticas com recepção coerente é reduzida, diminuindo a vantagem potencial do uso do amplificador Raman concentrado com DCF.

Desta forma para composição de um amplificador híbrido, é ideal combinar tecnologias de amplificação óptica, aproveitando-se de suas características favoráveis em detrimento de suas deficiências. Neste trabalho isto é conseguido através da composição de uma topologia de amplificação óptica híbrida baseada nas tecnologias de amplificação Raman distribuída contra-propagante (bom desempenho de figura de ruído porém com baixa potência de saída), combinada com EDFA (figura de ruído aceitável com alta potência de saída) que, nesta ordem, fornecem desempenho de figura de ruído aliado a planicidade espectral de ganho e alta potência de saída, ao longo de toda região de operação do amplificador em redes DWDM reconfiguráveis, algo inédito em comparação com as topologias de amplificação óptica utilizadas atualmente em redes DWDM dinâmicas.

A inovadora técnica de controle automático de ganho proposta nesta tese para topologia de amplificação óptica híbrida Raman contra-propagante/EDFA, obtém ganho controlado com baixa variação espectral de ganho e reduzida figura de ruído através do controle do estágio Raman contra-propagante, combinado com alta potência de saída por meio do EDFA, provendo ganho espectral plano para qualquer ganho alvo por meio da combinação das duas tecnologias. Esta inovadora técnica será apresentada no Capítulo 5 .

\subsection{Propostas do trabalho}

\subsubsection{Objetivos}

Novos rumos no desenvolvimento de tecnologias de amplificação óptica precisam ser tomados para acompanhamento da evolução dos sistemas de comunicações reconfiguráveis onde trafegam sinais com formatos de modulação avançados. Estas necessidades apareceram em resposta às tendências dominantes das redes de amplificação óptica de vários graus de conectividade e à introdução de canais com altas taxas de transmissão. Características como controle automático de ganho com supressão de transientes de potência na saída dos amplificadores ópticos, aliado a um controle da equalização espectral de ganho devido à variação do carregamento de canais e da potência de entrada nos amplificadores ópticos, assim como o fornecimento de altos níveis de potência de saída e baixa figura de ruído são objetivos na pesquisa e desenvolvimento de novas tecnologias de amplificação óptica para atender aos requisitos das redes ópticas DWDM dinâmicas com trafego de canais com formatos de modulação avançados.

Dado que atualmente as redes ópticas usam principalmente os amplificadores a fibra dopada com Érbio, que já se encontram em seu limite de desempenho de figura de ruído, devido a tratar-se de uma tecnologia madura, novas tecnologias de amplificação 
óptica híbridas compostas por tecnologias de amplificação a fibra dopada com Érbio e amplificação Raman distribuída (Raman/EDFA) veem se firmando como uma forte opção para aproveitar os benefícios de cada tecnologia de amplificação, em particular para atender aos requisitos das redes ópticas DWDM dinâmicas.

Esta tese também teve como objetivo examinar as tendências tecnológicas em amplificação óptica das redes ópticas DWDM dinâmicas de alta capacidade, e propor novas soluções de amplificação óptica híbrida com controle automático de ganho para superar os problemas enfrentados nas redes reconfiguráveis devido ao contínuo aumento das taxas dos canais transmitidos de $10 \mathrm{~Gb} / \mathrm{s}$ e $40 \mathrm{~Gb} / \mathrm{s}$ para $100 \mathrm{~Gb} / \mathrm{s}, 400 \mathrm{~Gb} / \mathrm{s}$ e além.

Neste trabalho são identificados os requisitos ópticos das redes DWDM dinâmicas que devem ser levados em conta no projeto de amplificadores ópticos híbridos. Então, são sugeridas novas topologias de amplificadores ópticos híbridos compostas por combinações de diferentes tecnologias de amplificação óptica. Consequentemente novos métodos de controle automático de ganho para as topologias de amplificação óptica híbrida também são desenvolvidos e avaliados através de experimentos e simulação óptica.

Desta forma, neste trabalho busca-se o desenvolvimento de um amplificador híbrido Raman/EDFA com controle automático de ganho, visando fornecer o desempenho óptico necessário, principalmente em termos de ganho espectral plano e baixa figura de ruído para toda a faixa de ganhos controláveis e potências de entrada de operação do amplificador na rede DWDM dinâmica.

\subsubsection{Contribuições}

As principais contribuições deste trabalho são as seguintes:

- Determinação da melhor topologia de amplificação óptica híbrida em termos de desempenho de qualidade dos sinais transmitidos (OSNR) e consequentemente melhor figura de ruído. A topologia foi determinada por meio da avaliação experimental em enlace óptico sem repetição (100, 150, 200, 250 e $300 \mathrm{~km})$, das topologias de amplificação simples/híbridas baseadas em amplificador Raman distribuído e/ou amplificador Raman concentrado e/ou EDFA em sistemas DWDM com canais de $112 \mathrm{~Gb} / \mathrm{s}$.

- Desenvolvimento de uma metodologia de projeto de amplificadores Raman distribuído, otimizado para redes DWDM reconfiguráveis em conjunto com seu controle automático de ganho on-off via controle em malha aberta.

- Determinação da topologia de amplificação óptica híbrida que apresenta melhora de desempenho em sistemas com repetição DWDM reconfiguráveis (amplificação híbrida Raman distribuída contra-propagante combinado com EDFA), por meio da avaliação do desempenho obtido das tecnologias EDFA e Raman distribuído nestes sistemas ópticos.

- Desenvolvimento do controle automático de ganho para amplificador Raman distribuído combinado com EDFA, baseado na metodologia de controle desenvolvida nesta tese, fornecendo desempenho melhorado dos parâmetros de figura de ruído, 
planicidade espectral e precisão do controle de ganho para toda faixa de operação de potência de entrada e ganhos alvo do amplificador híbrido, garantindo desempenho óptico superior em comparação com os amplificadores ópticos e controles automáticos de ganho descritos na literatura.

- Desenvolvimento de uma metodologia de projeto otimizado para o amplificador óptico híbrido (Raman distribuído/EDFA) e seu respectivo filtro aplanador de ganho espectral (GFF)visando operação do mesmo em redes ópticas DWDM reconfiguráveis.

Todas as contribuições descritas anteriormente tratam-se de contribuições inovadoras (inéditas), e estão relacionadas a área da amplificação óptica híbrida com controle automático de ganho para redes DWDM dinâmicas e com canais de alta eficiência espectral.

\subsection{Descrição dos capitulos}

No Capítulo 2 é apresentada a fundamentação teórica necessária para realização do trabalho desta tese incluindo aspectos de redes ópticas DWDM e tecnologias de amplificação óptica híbrida. Esta fundamentação teórica inclui a evolução das redes de comunicações ópticas, assim como a revisão bibliográfica e estado da arte das tecnologias de amplificadores híbridos, e a necessidade por novos amplificadores híbridos no cenário atual e futuro das redes ópticas WDM reconfiguráveis com sinais utilizando formatos de modulação avançados.

No Capítulo 3 é descrito o experimento realizado com várias topologias de amplificação óptica híbrida, composta por combinações das tecnologias de amplificação Raman concentrado, Raman distribuída e EDFA, em sistemas comunicações ópticas monocanal e DWDM de $112 \mathrm{~Gb} / \mathrm{s}$ NRZ-DP-QPSK sem repetição. O experimento tem como objetivo avaliar diversas topologias de amplificadores ópticos híbridos visando definir a topologia de amplificação híbrida com a melhor relação custo/benefício para vários comprimentos de enlaces avaliados, que reduza efetivamente a figura de ruído efetiva em sistemas ópticos mono-canal e DWDM sem repetição ao longo do enlace.

No Capítulo 4 é apresentada uma revisão bibliográfica e o estado da arte das metodologias de controle automático de ganho desenvolvidas para as topologias de amplificação Raman concentrada, Raman distribuída, EDFA e amplificadores híbridos para redes ópticas DWDM reconfiguráveis. Após a revisão bibliográfica, neste capítulo é proposta uma metodologia de caracterização de desempenho de amplificadores ópticos em redes DWDM reconfiguráveis. Além disto, neste capítulo, foi realizado um extensivo estudo de simulação computacional em torno de amplificadores a fibra dopada com Érbio com controle automático de ganho, para as principais topologias utilizadas atualmente em sistemas DWDM reconfiguráveis metropolitanos e de longa distância (sistemas com repetição), analisando o desempenho com relação a planicidade espectral de ganho, precisão do controle automático de ganho e figura de ruído ao longo da região de operação (potências de entrada/saída). 
Considerando o desempenho das topologias de amplificação ópticas em redes reconfiguráveis DWDM em termos de de figura de ruído e planicidade espectral de ganho ao longo da máscara de potência, é proposto uma nova topologia e controle automático de ganho para um amplificador óptico híbrido (Raman/EDFA), visando fornecer melhor desempenho de figura de ruído e planicidade espectral de ganho, com relação as principais topologias de amplificação óptica com controle automático de ganho utilizadas atualmente em sistemas com repetição reconfiguráveis.

Finalmente, no Capítulo 5, a topologia de amplificação óptica híbrida (Raman distribuído contra-propagante/EDFA) para redes DWDM reconfiguráveis, tem sua metodologia de projeto e controle automático de ganho detalhadamente descritos, seguido do desenvolvimento e caracterização do mesmo em simulação óptica e protótipo experimental.

O desempenho do amplificador óptico híbrido é avaliado com relação a topologia de amplificação óptica com ganho espectral plano mais utilizada atualmente nos sistemas reconfiguráveis com repetição. A avaliação é realizada em enlace simples (experimentalmente e em simulação) e múltiplos enlaces (em simulação) de fibras SSMF (G.652) com roteadores ópticos (ROADMs) nos entroncamentos da rede. O resultado desta avaliação demonstra a melhoria de desempenho do amplificador híbrido em termos da qualidade do sinal transmitido e alcance dos sistemas utilizando tecnologia de amplificação híbrida.

No Capítulo 6 são apresentadas as conclusões do trabalho desenvolvido, as publicações geradas a partir dos estudos, assim como é apresentada a visão de futuro relativa à amplificação óptica para redes DWDM reconfiguráveis onde trafegam sinais com alta eficiência espectral.

No Capítulo 6.2 apresenta a fundamentação teórica sobre as tecnologias de amplificação óptica EDFA e amplificação óptica Raman distribuída e concentrada. 


\section{Capítulo 2}

\section{Fundamentação Teórica}

Neste capítulo são apresentados o histórico de evolução das redes de comunicações ópticas e o estado da arte das tecnologias de amplificação óptica, com o objetivo de prover as ferramentas necessárias para um melhor entendimento do trabalho desenvolvido nesta tese.

Inicialmente é apresentado um histórico das redes de comunicações ópticas em termos da flexibilidade e capacidade de transmissão de dados em uma única fibra óptica, partindo do primeiro sistema ponto-a-ponto monocanal até os sistemas DWDM reconfiguráveis com canais de alta eficiência espectral e altas taxas $(\geq 100 \mathrm{~Gb} / \mathrm{s})$.

Em seguida, devido a maior relevância nesta tese, apresenta-se o estado da arte das tecnologias de amplificação óptica para redes DWDM, descrevendo seus princípios de funcionamento, e as vantagens/desvantagens dessas tecnologias aplicadas a redes ópticas DWDM reconfiguráveis.

As redes de nova geração que contam com sofisticados nós de reconfiguração efetuando roteamento de comprimento de onda, terão seus subsistemas expostos e discutidos em detalhes, assim como seus efeitos físicos e impactos no desempenho do sistema serão relatados, juntamente com as formas de minimizá-los.

Com relação às principais tecnologias de amplificação óptica para sistemas óptico DWDM, os mecanismos de amplificação óptica, suas modelagens matemáticas, assim como os parâmetros que caracterizam os amplificadores a fibra dopada com érbio (EDFA) e amplificadores Raman distribuídos ou discretos são apresentados. É também alvo deste capítulo apresentar e discutir as topologias dos amplificadores ópticos híbridos baseados nessas tecnologias visando as aplicações em redes DWDM.

Com base nas limitações das tecnologias de amplificação óptica apresentadas, este capítulo descreve os requisitos de um amplificador óptico otimizado para operação em redes DWDM reconfiguráveis visando melhoria de desempenho dos sinais ópticos que são regenerados por este amplificador (planicidade espectral de ganho aliado à baixa figura de ruído para todos os pontos de operação, implicando em incremento da relação sinal-ruído), suprindo a melhora necessária para permitir a evolução da taxa dos canais transmitidos através do uso de formatos avançados de modulação (com taxas de 100 Gb/s e além) ao longo de fibras ópticas monomodo padrão (ITU-T G.652), evitando ações drásticas como a substituição da infraestrutura de fibras ópticas atuais para permitir que esses sistemas de comunicações ópticas reconfiguráveis operem livre de erros. 


\subsection{Histórico e Evolução das Redes de Comunicações Ópticas}

O uso de luz como meio de comunicação data da antiguidade, onde muitas civilizações utilizaram espelhos, fogueiras ou sinais de fumaça para transmitir informações. A mesma ideia foi utilizada até o fim do século 18 através de lâmpadas, bandeiras e outros dispositivos de sinalização (Agrawal, 2002). Claude Chappe em 1792 estendeu esta ideia, visando transmitir mecanicamente mensagens codificadas ao longo de distâncias de aproximadamente $100 \mathrm{~km}$, através do uso de estações de retransmissão (regeneradores ou repetidores), porém estes sistemas operavam a uma taxa de comunicação de aproximadamente $1 \mathrm{~b} / \mathrm{s}$.

Com o advento do telégrafo na década de 1830, deu-se início a era da comunicação elétrica (Jones, 1852). Através da utilização de técnicas de codificação, como o código Morse, e estações de retransmissão, foi possivel transmitir taxas de aproximadamente $10 \mathrm{~b} / \mathrm{s}$ ao longo de distâncias de aproximadamente $1000 \mathrm{~km}$.

A invenção do telefone em 1876 trouxe grandes mudanças por codificar a corrente elétrica analógica com a voz humana a ser transmitida. Esta técnica dominou as comunicações por aproximadamente um século. Inicialmente foram utilizados cabos de par trançado nas redes telefônicas, posteriormente, com o uso de cabos coaxiais, a capacidade de transmissão aumentou para $3 \mathrm{Mb} / \mathrm{s}$, porém a largura de banda desses sistemas começou a ser limitada pelas perdas dos cabos de cobre, que aumentam demasiadamente para frequências acima de $10 \mathrm{MHz}$ (Agrawal, 2002). Os cabos coaxiais ainda evoluíram, viabilizando sistemas com taxas de até $100 \mathrm{Mb} / \mathrm{s}$, mas à medida que a taxa aumentava, a curta distância entre os repetidores (aproximadamente $1 \mathrm{~km}$ ) inviabilizava a implantação em massa desses sistemas (Ramaswami e Sivarajan, 2001).

Ao longo das décadas de 1950-1960, foi identificado que a taxa e a distância da transmissão de dados poderiam aumentar expressivamente através do uso de ondas eletromagnéticas na faixa do visível como portadoras dos dados. Com a invenção do laser e sua demonstração em 1960 o problema da geração das ondas ópticas foi solucionado, enquanto as fibras ópticas surgiram como a solução para o guiamento da luz.

Sistemas de comunicações transmitem informações de um ponto a outro, que estão separados desde alguns metros a milhares de quilômetros. As informações são geralmente transmitidas via ondas eletromagnéticas (portadoras) com frequências que variam de alguns Mega-hertz a centenas de Tera-hertz. Sistemas de comunicações ópticas usam portadoras de alta frequência (em torno de $100 \mathrm{THz}$ ), que se situam na região visivel ou infravermelho do espectro eletromagnético. Estes sistemas têm sido implantados desde a década de 1980, e, juntamente com a microeletrônica, revolucionaram as telecomunicações (Agrawal, 2002; Ramaswami e Sivarajan, 2001).

A pesquisa em sistemas de comunicação em fibra óptica teve expressivo incremento em torno da década de 1980. O grande progresso realizado entre 1982 até 2013 pode ser classificado em gerações distintas dos sistemas (transmissores/receptores) e subsistemas ópticos (multiplexação, roteamento e amplificação).

A Figura 2.1 ilustra este crescimento da capacidade de transmissão de uma fibra óptica até os dias de hoje, para cada tecnologia de transmissão/recepção (descritos pe- 
los marcadores e suas respectivas curvas de evolução na mesma cor) assim como para cada tecnologia de multiplexação, roteamento e amplificação de sinais (áreas hachuradas na figura), com base nos experimentos publicados nas principais conferências mundiais (post-deadline papers) como a OFC (Optical Fiber Communication Conference and Exposition) e ECOC (European Conference and Exhibition on Optical Communication), que representam os principais resultados e recordes de transmissão em redes de comunicações ópticas alcançados ao longo de cada ano.

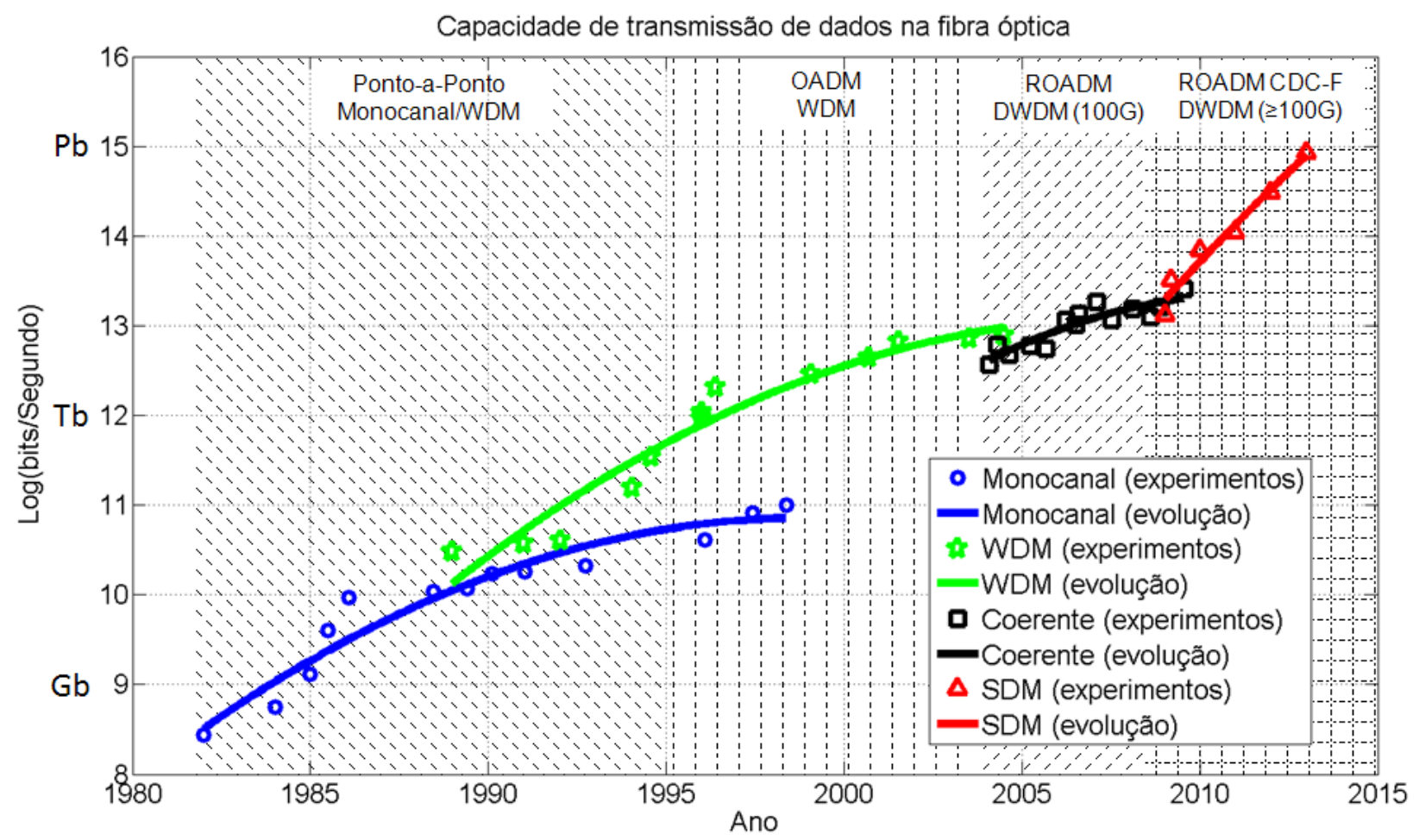

Figura 2.1: Principais experimentos de transmissão de dados em fibra óptica (marcadores), evolução de cada tecnologia de transmissão/recepção em fibras ópticas (curvas contínuas), seguidos da representação de cada tecnologia de roteamento de sinais ópticos (área hachurada). Adaptado da referência (Essiambre et al., 2010).

Podemos notar que na Figura 2.1 a capacidade de transmissão em uma fibra óptica evolui rapidamente nos primeiros anos pós surgimento de uma nova tecnologia, porém a evolução satura com o amadurecimento desta tecnologia, tornando necessário o surgimento de novas tecnologias que forneçam uma quebra de paradigma, para prover uma retomada da evolução rápida da capacidade de transmissão.

Na Figura 2.1 nota-se também que a evolução da capacidade de transmissão de dados na fibra óptica se dá basicamente com a evolução da tecnologia dos seguintes elementos que compõem a rede óptica: transmissor/receptor, tecnologia de multiplexação, roteador e amplificador óptico.

A Figura 2.1 ilustra as quatro gerações distintas dos sistemas e subsistemas de comunicações ópticas. Estas gerações podem ser descritas pelas principais tecnologias (transmissão/recepção, topologia de rede, multiplexação da comunicação e regeneração de sinais) que destacaram-se ao longo dos anos, descritas abaixo:

A) Primeira geração

- Transmissor com modulação de intensidade e recepção direta (até $10 \mathrm{~Gb} / \mathrm{s}$ ) 
- Sistema ponto-a-ponto fixo

- Sistema monocanal com multiplexação por divisão de tempo (TDM)

- Regeneração óptico-elétrico-óptico (OEO) dependente de formato de modulação e taxa transmitida

B) Segunda geração

- Transmissor com modulação OOK/DPSK/DQPSK e receptor com detecção direta/balanceada (até $40 \mathrm{~Gb} / \mathrm{s}$ )

- Sistema ponto-a-multiponto com roteamento fixo (OADM)

- Sistema multi-canal com multiplexação por divisão de comprimento de onda (WDM)

- Regeneração via amplificadores ópticos transparentes a formato de modulação e taxa transmitida (EDFA)

C) Terceira geração

- Transmissor com formatos de modulação avançados DP-QPSK e receptor com detecção coerente, diversidade de polarização e processamento digital de sinais compensando efeitos lineares impostos pela fibra (40 e $100 \mathrm{~Gb} / \mathrm{s}$ )

- Sistema multiponto com roteamento reconfigurável (ROADM) dependente de direção/cor/contenção e com grade de canais fixo (espaçamento de 50 ou $100 \mathrm{GHz}$ )

- Sistema multicanal com multiplexação por divisão de comprimento de onda denso (DWDM)

- Regeneração via EDFAs com controle automático de ganho e amplificadores Raman com bombeio fixo

D) Tendências de Evolução Recente

- Transmissor multi-portadoras com formato de modulação avançado e ocupação espectral flexível m-portadoras/DP-nGAM (200 Gb/s, $400 \mathrm{~Gb} / \mathrm{s}, 1 \mathrm{~Tb} / \mathrm{s}$ e além), com recepção de multi-portadoras coerente com processamento digital de sinais compensando efeitos lineares e não lineares impostos pela fibra

- Sistema multiponto (rede em malha) com roteamento reconfigurável independentemente de cor (colorless), direção (directionless), contenção (contentionless) e com espaçamento de canais flexível (granularidade de $12.5 \mathrm{GHz}$ de espaçamento)

- Sistema multi-canal, multi-núcleo e multi-modos (com poucos modos) com multiplexação por divisão de comprimento de onda (DWDM), divisão espacial (SDM) e divisão modal (MDM)

- Regeneração via amplificadores ópticos com tecnologias híbridas controle automático de ganho (EDFA e Raman) visando ganho espectral plano e baixa figura de ruído ao longo de toda região de operação do amplificador 
Nas subseções seguintes cada geração dos sistemas de comunicações ópticas acima será detalhada, com ênfase nos fatores que impactaram/impactam o desempenho das tecnologias e quais as formas de minimizar esses impactos de desempenho.

\section{Primeira Geração}

A geração que deu início a era das comunicações ópticas modernas ocorreu do início da década de 1980 até o final da década de 1990. A Figura 2.1 ilustra o histórico e evolução da capacidade de comunicação ao longo desta geração, por meio dos resultados experimentais (círculos azuis) e curva de evolução (curva azul). Nesta seção, são discutidas as tecnologias de comunicações ópticas que se destacaram no decorrer desta geração (Figura 2.2).
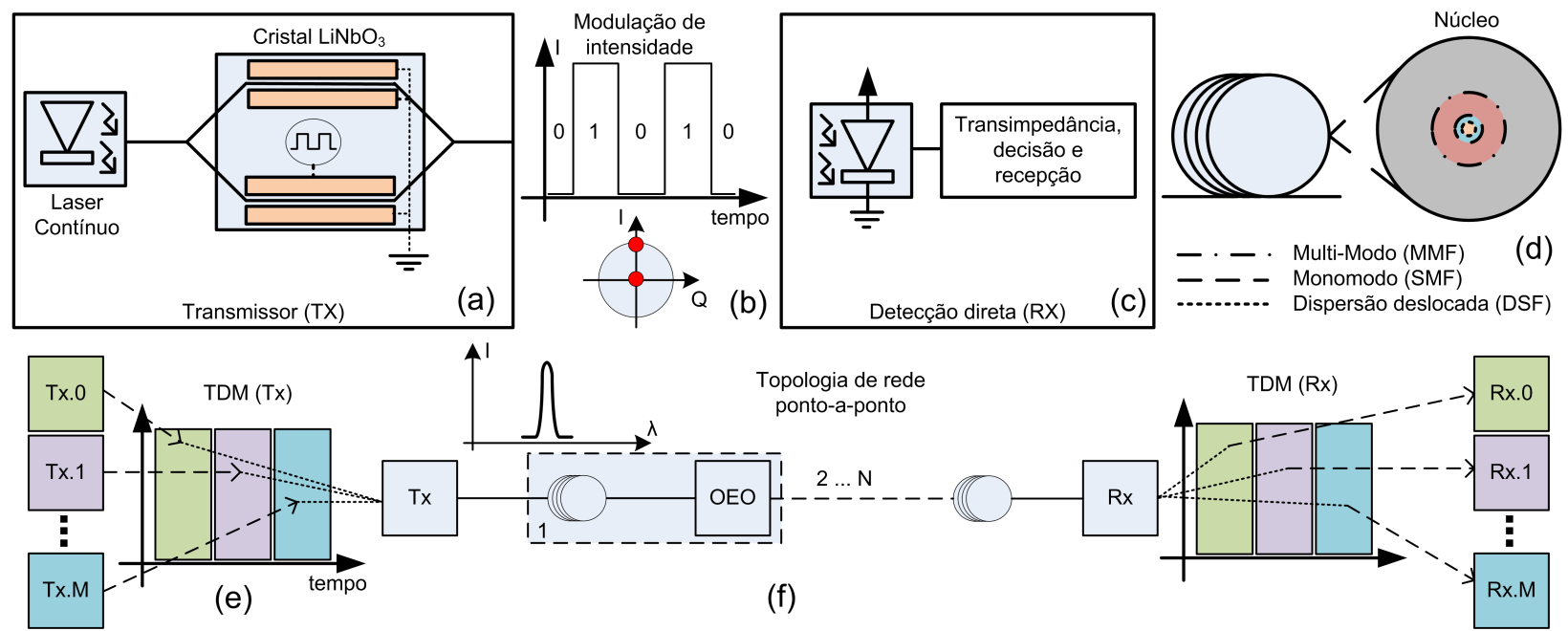

(b)

Detecção direta $(\mathrm{RX}$

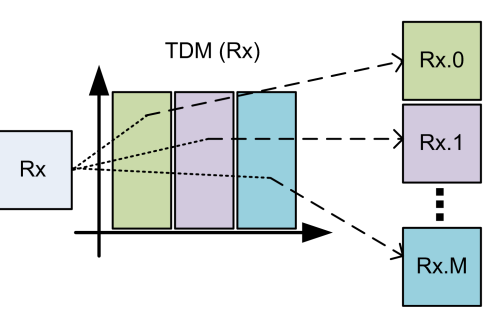

Figura 2.2: Transmissor com modulação de intensidade (a), intensidade no domínio do tempo e constelação do sinal óptico modulado em intensidade (b), receptor baseado em detecção direta (c), seção transversal das fibras utilizadas nessa geração (d), multiplexação por divisão de tempo (e) e topologia de rede ponto-a-ponto com regeneradores OEO (f).

Os transmissores da primeira geração das redes de comunicações ópticas foram compostos por modulação direta dos lasers contínuos com comprimento de onda na região

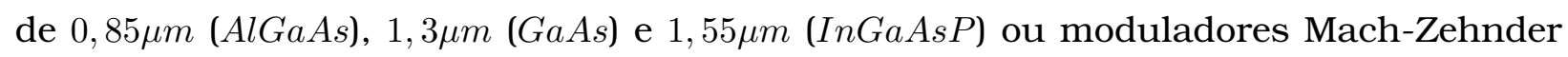
construídos em cristal de niobato de lítio $\left(\mathrm{LiNbO}_{3}\right)$ como ilustrado na Figura 2.2(a). O principal formato de modulação empregado nos transmissores desta geração foi a modulação de intensidade ou "On-Off Keying"(OOK). A Figura 2.2(b) ilustra os diagramas de intensidade no domínio do tempo e constelação no diagrama de intensidade e quadratura, respectivamente. Os receptores mais utilizados nesta geração foram fotodetectores semicondutores PIN (junção-p, semicondutor intrínseco levemente dopado-i, junção-n) e/ou fotodetectores de efeito avalanche (APD) em conjunto com circuito de transimpedância e decisão para detecção direta do sinal modulado, como ilustrado na Figura 2.2(c).

Os tipos de fibras mais utilizadas nos sistemas de comunicações ópticas que caracterizaram esta geração foram as fibras multi-modo "MMF - G.651" (ITU, 1998), fibras monomodo padrão "SSMF - G.652" (ITU, 2009a) e as fibras de dispersão deslocada "DSF - ITU-G.653" (ITU, 2010). As seções transversais dessas fibras são ilustradas na 
Figura 2.2(d). A fibra MMF apresenta um diâmetro de núcleo em torno de $50 \mu m$ permitindo a propagação de vários modos no núcleo da fibras, já a fibra SSMF apresenta um

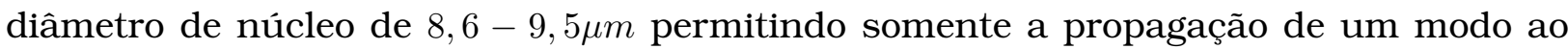
longo da fibra com zero de dispersão cromática em torno de $1,3 \mu \mathrm{m}$, e dispersão cromática em torno de $17 \mathrm{ps} / \mathrm{nm} / \mathrm{km}$ em torno de $1,55 \mu \mathrm{m}$, enquanto a fibra DSF apresenta um

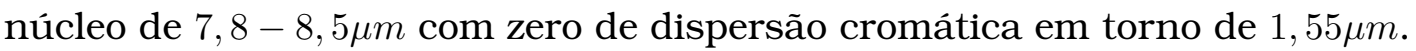

O método de multiplexação de dados mais utilizado na primeira geração dos sistemas de comunicações ópticas foi a multiplexação por divisão do tempo (TDM), um método de transmissão e recepção de vários sinais independentes (tributários) em um mesmo canal óptico, cada sinal utilizando sua janela de tempo, que pode ser de tamanho fixo (síncrona) como mostrado na Figura 2.2(e) ou variável (assíncrono).

Como ilustrado na Figura 2.2(f), a topologia de rede mais empregada em sistemas de primeira geração foi a topologia de rede ponto-a-ponto fixa (sem roteamentos de tributários ao longo do percurso), onde o sinal óptico era amplificado ao longo do caminho por meio de regeneradores óptico-eletrônico-óptico capazes de regenerar um único sinal óptico para uma única taxa e formato de modulação (regeneração não transparente).

Um dos primeiros sistemas de comunicações ópticas disponibilizados transmitiu um canal com taxa de $47 \mathrm{Mb} / \mathrm{s}$ em fibra multi-modo, com espaçamento entre os repetidores de $7 \mathrm{~km}$, e transmissão de informação modulada em intensidade (OOK) com detecção direta (Jacobs e Stauffer, 1980). O grande espaçamento entre os repetidores, comparados aos sistemas de cabo coaxiais de $1 \mathrm{~km}$ de espaçamento, foi a motivação mais importante para o estabelecimento dos sistemas de comunicações ópticas.

Os sistemas de comunicações ópticas ficaram limitados a taxas de $100 \mathrm{Mb} / \mathrm{s}$ ao longo da década 1980 devido a dispersão modal existente nas fibras multi-modo (Gloge et al., 1980). Esta limitação foi superada com o uso das fibras mono-modo padrão (Yamada et al., 1981), que removeram a dispersão modal e reduziram a perda na fibra para menos de $0,5 \mathrm{~dB} / \mathrm{km}$ na região de $1,3 \mu \mathrm{m}$. Com a fibra mono-modo padrão, em conjunto com lasers semicondutores ( $G a A s$ ) operando em temperatura ambiente, foram disponibilizados sistemas de até $274 \mathrm{Mb} / \mathrm{s}$ em 1982 (Runge et al., 1982) e logo em seguida sistemas de 1,7 Gb/s ao longo de $50 \mathrm{~km}$ em 1987 (JACOBS, 1995).

Com a evolução das fibras ópticas, as altas perdas apresentadas reduziram-se para

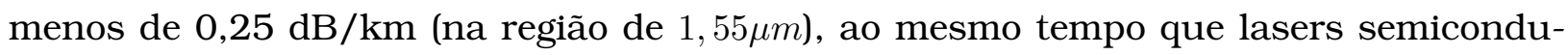

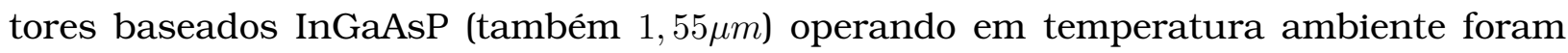
demonstrados. Porém, as fibras mono-modo padrão apresentavam altos níveis de dispersão cromática nessa região. O problema da dispersão cromática foi solucionado por meio do uso das fibras de dispersão deslocada (DSF), disponibilizando sistemas de 2,5 Gb/s (Alferness et al., 2000), $10 \mathrm{~Gb} / \mathrm{s}$ (Vodhanel et al., 1990), até $40 \mathrm{~Gb} / \mathrm{s}$ (Breuer et al., 1998) ao longo da década de 1990.

Desta forma, até metade da década de 1990, por meio das redes de comunicações ópticas de primeira geração foi possível observar um aumento de cinco ordens de grandeza na taxa de transmissão comparados com as redes de comunicação elétrica, em distâncias de até $10 \mathrm{mil} \mathrm{km}$.

Após superação dos problemas mencionados anteriormente, surgiu outro grande em- 
pecilho para o aumento da taxa e distância de comunicação com relação aos sistemas

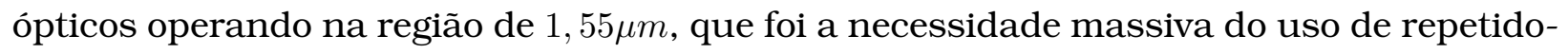
res/regeneradores eletrônicos (OEO ou 3R) espaçados a cada 60-70 km (Dawson e Rogerson, 1984; Metz, 1975). Os regeneradores do tipo OEO (óptico-eletrônico-óptico) realizavam a regeneração do sinal através da conversão do sinal óptico para o domínio eletrônico, retornando posteriormente para o domínio óptico para retransmissão. Já os regeneradores $3 R$, realizavam, além da retransmissão, o realinhamento, reformatação do sinal óptico, garantindo uma maior confiabilidade ao sinal regenerado.

O problema concentrou-se na não-escalabilidade dos regeneradores eletrônicos que eram desenvolvidos para uma determinada taxa e formato de modulação do sinal. Desta forma, um aumento de taxa e/ou mudança de formato de modulação, exigia mudança de todos os regeneradores instalados ao longo da linha, aumentando bastante os custos de instalação e operação (Capex e Opex) dos sistemas de comunicações ópticas.

Assim surgiu a necessidade por um regenerador transparente ao comprimento de onda, formato de modulação e taxa dos sinais transmitidos. Esta quebra de paradigma veio com a invenção do EDFA, que dispensaram o uso de regeneradores elétricos. A necessidade deste tipo de regenerador (amplificador óptico) viabilizou o surgimento da multiplexação por comprimento de onda (WDM), onde vários canais começaram a ser transmitidos/regenerados ao mesmo tempo em diferentes comprimentos de onda de sinal, caracterizando a segunda geração dos sistemas de comunicações ópticas.

\section{Segunda Geração}

A segunda geração dos sistemas de comunicações ópticas ocorreu do início da década de 1990 até metade da década de 2000, e foi a geração que apresentou a maior evolução na taxa transmitida na fibra, principalmente devido ao uso da multiplexação por divisão de comprimento de onda (WDM) e devido ao uso do EDFA. Com relação ao histórico e evolução da capacidade de comunicação ao longo desta geração, a Figura 2.1 ilustra os resultados experimentais (estrelas verdes) e a curva de evolução (curva verde). Nesta seção, são discutidas as tecnologias que se destacaram no decorrer desta geração (Figura 2.3), e cada tecnologia é descrita de forma introdutória, visando o entendimento da evolução e capacidade de transmissão durante esta geração.

Os transmissores da segunda geração das redes de comunicações ópticas evoluíram por meio do desenvolvimento de novas estruturas de modulação Mach-Zehnder que possibilitavam a modulação em fase e quadratura (modulador IQ), o qual em comparação com o formato OOK, permite robustez aumentada por meio do formato de modulação diferencial em fase (DPSK) ou aumento de taxa/eficiência espectral (de 10-40Gb/s por canal) por meio do formato de modulação diferencial de fase e quadratura (DQPSK), cujo transmissor e modulador são ilustrados na Figura 2.3(a) e sua constelação (diagrama de intensidade e quadratura) ilustrada na Figura 2.3(b). Os receptores mais utilizados nesta geração, para os formatos de modulação diferenciais, foram compostos por decodificadores diferenciais em conjunto com fotodetectores semicondutores PIN balanceados para detecção do sinal modulado, tal qual o receptor DQPSK ilustrado na Figura 2.3(c).

Os tipos de fibras mais utilizados nos sistemas de comunicações ópticas que carac- 

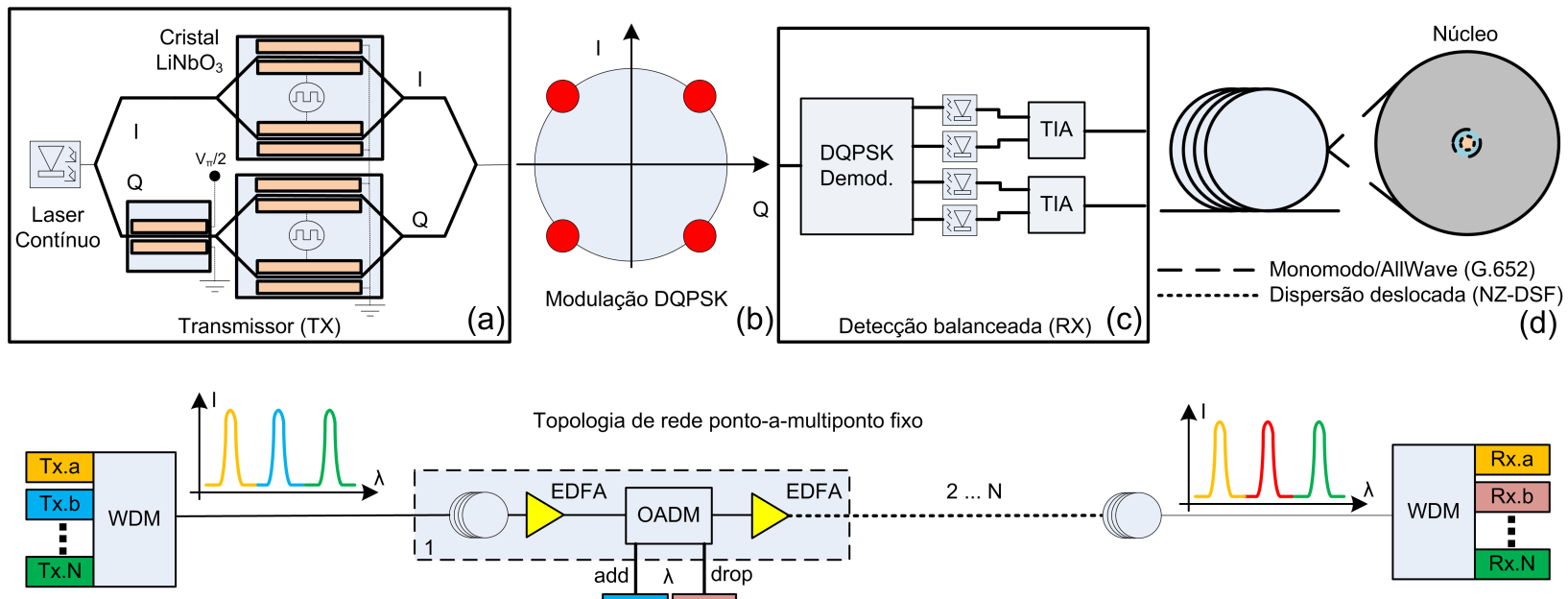

(e)

(f)

Figura 2.3: Transmissor com modulação diferencial de fase e quadratura DQPSK (a), constelação do sinal óptico modulado DQPSK (b), receptor baseado em detecção diferencial balanceada (c), seção transversal das fibras utilizadas nessa geração (d), multiplexação por divisão de comprimento de onda (e) e topologia de rede ponto-a-multiponto fixo com OADMs e amplificadores ópticos a fibra dopada com érbio $(f)$.

terizaram esta geração foram as fibras monomodo padrão "SSMF - G.652.A"a fibra monomodo padrão sem o pico de absorção na janela de 1400nm "AllWave - G.652.B-D" (ITU, 2009a), as fibras de dispersão deslocada diferente de zero "NZ-DSF - ITU-G.655" (ITU, 2009b) e as fibras compensadoras de dispersão cromática (DCF). As seções transversais das duas primeiras fibras são ilustradas na Figura 2.3(d). A fibra SSMF apresenta um diâmetro de núcleo de $8,6-9,5 \mu m$, permitindo somente a propagação de um modo ao longo da fibra com zero de dispersão cromática em torno de $1,3 \mu \mathrm{m}$, o que implica em uma dispersão cromática em torno de $17 \mathrm{ps} / \mathrm{nm} / \mathrm{km}$ em torno de $1,55 \mu \mathrm{m}$, enquanto a fibra NZ-DSF apresenta um núcleo de $8-11 \mu m$ com zero de dispersão cromática variando de $1-10 \mathrm{ps} / \mathrm{nm} / \mathrm{km}$ em torno de $1,55 \mu \mathrm{m}$. Com a propagação dos sinais por longas distâncias de fibras SSMF, o acúmulo de dispersão cromática tornou-se um problema, e visando a compensação da dispersão cromática, fibras com coeficientes negativos de dispersão cromática foram desenvolvidas, para compensação deste efeito em longos enlaces.

A tecnologia que mais impactou a evolução da capacidade dos sistemas ópticos de segunda geração foi a multiplexação por divisão de comprimento de onda (WDM), tecnologia capaz de multiplexar várias portadoras ópticas (diferentes comprimentos de onda) em uma única fibra. A tecnologia WDM fez com que a capacidade dos sistemas de comunicação evoluíssem exponencialmente, devido à possibilidade de transmissão e recepção de vários sinais independentes na mesma fibra óptica, apenas separando espectralmente as portadoras de modo a evitar interferências entre canais vizinhos, como ilustrado na Figura 2.3(e).

Como ilustrado na Figura 2.3(f), a topologia de rede mais empregada em sistemas de segunda geração foi a topologia de rede ponto-a-multiponto fixa, com roteamento de canais fixos realizados por meio de módulos de adição/remoção de canais ópticos $(\mathrm{OADM})$. O uso de regeneradores OEO dependentes de taxa e formato de modulação para regeneração de cada canal ao longo de cada $60-80 \mathrm{~km}$ era um fator impeditivo para 


\begin{tabular}{|c|c|}
\hline Banda & Faixa Espectral (nm) \\
\hline \hline $\mathrm{O}$ & 1300 a 1360 \\
$\mathrm{E}$ & 1360 a 1460 \\
$\mathrm{~S}$ & 1460 a 1530 \\
$\mathrm{C}$ & $1530 \mathrm{a} 1565$ \\
$\mathrm{~L}$ & 1565 a 1610 \\
$\mathrm{U}$ & $1610 \mathrm{a} 1640$ \\
\hline
\end{tabular}

Tabela 2.1: Faixa espectral das bandas ópticas para comunicações WDM.

evolução das redes WDM.

Portanto, o EDFA foi a invenção responsável pelo estabelecimento dos sistemas WDM, devido sua capacidade de regenerar toda banda-C (35 $\mathrm{nm}$ de alocação espectral de acordo com a Tabela 2.1 ou até 80 canais de acordo com a Tabela 2.2), amplificando opticamente todos os canais ao mesmo tempo, independente ("transparente") da taxa e formato de modulação, reduzindo drasticamente os custos de regeneração nos sistemas WDM.

Com o desenvolvimento das redes WDM e EDFAs, deu-se início a uma revolução nos sistemas ópticos, resultando na duplicação da capacidade transmitida a cada 6 meses, elevando a taxa de comunicação de $10 \mathrm{~Gb} / \mathrm{s}$ (década de 1990) até $10 \mathrm{~Tb} / \mathrm{s}$ (primeira metade da década de 2000). Em 1996, foi demonstrada a transmissão de $5 \mathrm{~Gb} / \mathrm{s}$ ao longo de $11300 \mathrm{~km}$ utilizando o sistema atual de cabos ópticos submarinos (Otani et al., 1995), fato que habilitou transmissões intercontinentais de altas taxas e, a partir do começo da década de 2000, o aumento das taxas transmitidas nos sistemas WDM foi realizada com base no aumento do número de canais transmitidos.

O desenvolvimento dos primeiros sistemas WDM aproveitou a região do espectro óptico de 1530 a $1565 \mathrm{~nm}$ (Banda C), região que provê menor atenuação da fibra SSMF por ser a região de funcionamento do EDFA. Com o crescimento da demanda por comunicações ópticas, novas bandas espectrais para operação dos sistemas de comunicações ópticas foram utilizadas (Tabela 2.1) para ampliar a capacidade dos sistemas.

As principais bandas próximas ao mínimo de atenuação da fibra são as chamadas bandas S, C e L, como ilustrado na Figura 2.4. Cabe observar que sistemas/amplificadores ópticos para as bandas C e L foram desenvolvidos nessa geração devido a compatibilidade espectral com o espectro amplificado pelo EDFA. Pesquisas foram iniciadas nessa geração em busca de novos amplificadores visando amplificação de banda larga.

Além das bandas C e L (80 nm de largura de banda), nas redes metropolitanas é comum o uso da segunda janela de comunicações (Banda O), em torno de $1300 \mathrm{~nm}$, como indica a Figura 2.4. Porém, como ilustrado na Figura 2.4 a existência de um pico de absorção em $1400 \mathrm{~nm}$, inviabiliza o uso da banda E nas fibras SSMF. Então, visando o uso de todas largura espectral disponivel na fibra óptica foi desenvolvida a fibra óptica sem o pico de absorção.

A Tabela 2.2 ilustra a recomendação relativa à alocação de canais nas bandas espectrais da fibra óptica, de acordo com o número de canais e à separação espectral entre estes. Estas opções de separações entre canais foram padronizadas pelo ITU-T.

Uma grande dificuldade que surgiu está relacionada à variação da dispersão ao longo 


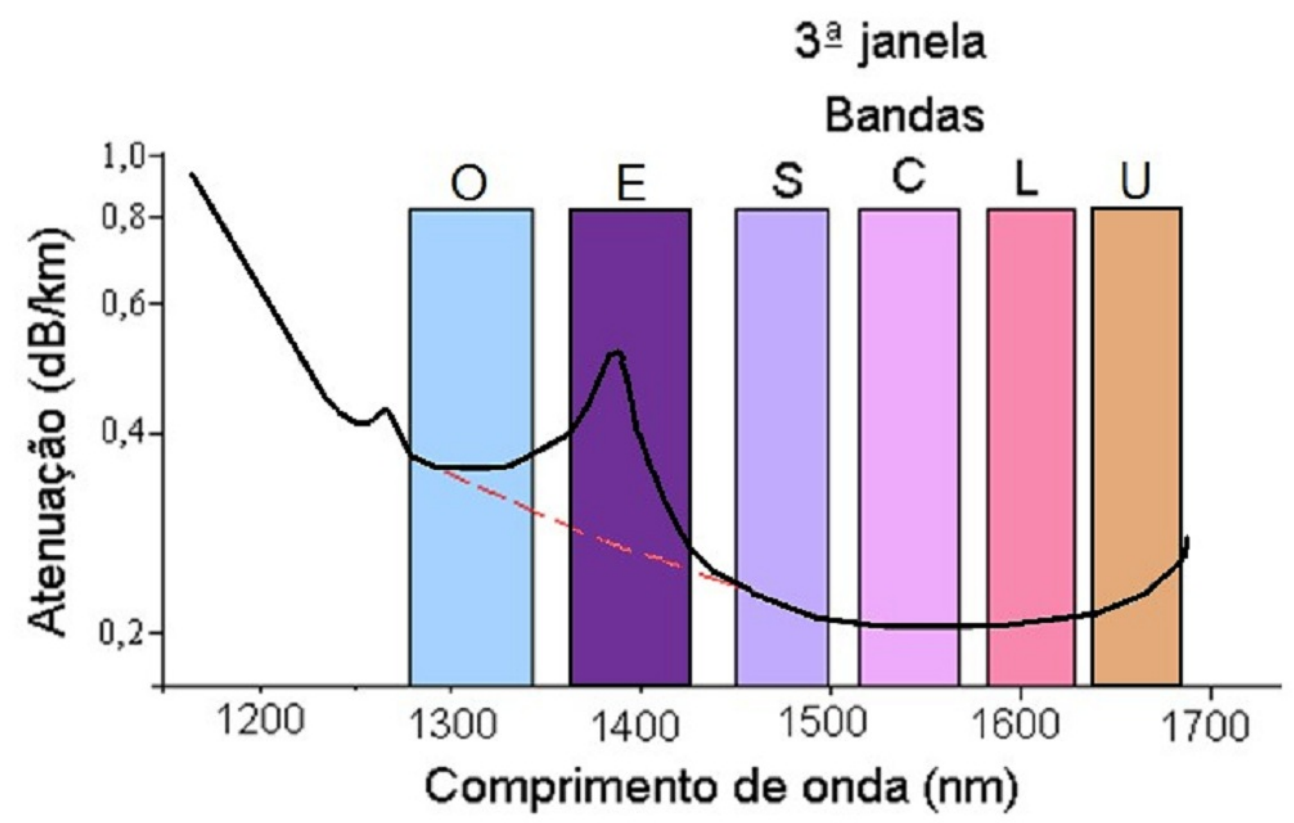

Figura 2.4: Perda espectral ao longo da fibra óptica monomodo padrão (preto) e sem o pico de absorção (vermelho).

\begin{tabular}{|c|c|}
\hline Número de Canais & Recomendações (Separação Espectral/Banda) \\
\hline \hline 0 a 40 & $100 \mathrm{GHz}$ na banda C \\
\hline 41 a 80 & $50 \mathrm{GHz}$ na banda C \\
\hline 81 a 120 & $50 \mathrm{GHz}$ na banda C \\
& $100 \mathrm{GHz}$ na banda L \\
\hline 120 a 160 & $50 \mathrm{GHz}$ na banda C \\
& $50 \mathrm{GHz}$ na banda L \\
\hline & $50 \mathrm{GHz}$ na banda C \\
& $50 \mathrm{GHz}$ na banda L \\
& Banda S começa a ser usada \\
\hline
\end{tabular}

Tabela 2.2: Recomendações relativas à separação espectral e às bandas a serem utilizadas para diferentes faixas e número de canais.

de toda a região espectral ocupada, que requer o uso de diversos compensadores de dispersão diferentes.

As fibras DSF (ITU-T G.653) podem solucionar o problema da dispersão acumulada em sistemas ópticos. Porém, quando empregadas em sistemas WDM, sua pequena área efetiva em comparação com a fibra monomodo padrão (SSMF, ITU-T G.652) e seu ponto de zero de dispersão localizado na janela de $1550 \mathrm{~nm}$, reduzem bastante o limiar de potência que produz efeitos não lineares na fibra, em especial o efeito da mistura de quatro ondas (FWM), devido ao zero de dispersão estar localizado na mesma janela dos sinais transmitidos. Dessa forma, a capacidade de transmissão de canais em fibras DSF é drasticamente limitada nesse tipo de fibra para evitar a geração de efeitos não lineares.

Para solução deste problema da geração dos efeitos não lineares, surgiram as fibras NZDSF (ITU-T G.655), com dispersão diferente de zero na janela de $1550 \mathrm{~nm}$ (1 $10 \mathrm{ps} / \mathrm{nm} / \mathrm{km}$ ), que pode ser positiva (NZDSF+) ou negativa (NZDSF-). Com o uso desta 
fibra são mitigados os efeitos não lineares, em especial FWM.

O contínuo aumento da demanda por banda tornou necessário o aumento da eficiência espectral dos canais transmitidos, que pode ser feito por meio da redução da ocupação espectral dos canais modulados e/ou a alocação de mais informação no espectro disponível nas redes de comunicações ópticas. Com esse objetivo surgiram os formatos avançados de modulação, juntamente com as redes WDM densas (DWDM).

Além disso, devido aos custos de estabelecimento de uma rede WDM, o requisito de uma gerência eficiente da infra-estrutura de rede de comunicações ópticas tornouse mandatório, sendo necessário o desenvolvimento de um elemento de roteamento de canais operado remotamente, o que foi suprido com o desenvolvimento dos multiplexadores de adição e remoção de canais reconfigurável (ROADM).

Redes ópticas DWDM com sinais modulados com formatos de modulação avançados e os ROADMs, tornaram as redes mais eficientes, porém trouxeram dificuldades adicionais, pois o aumento da eficiência espectral implica na necessidade de uma maior relação sinal ruído (OSNR) óptica para recepção dos sinais, e a reconfigurabilidade da rede óptica afeta bastante o desempenho do EDFA devido variação de potência na entrada, afetando o ganho provido aos canais que passam pelo amplificador. Estas características e sua solução justificam as redes de terceira geração, que serão discutidas na próxima seção.

\section{Terceira Geração}

A terceira geração dos sistemas de comunicações ópticas ocorreu desde a metade da década de 2000, e foi a geração que apresentou a maior evolução em termos de aproveitamento da largura espectral (eficiência espectral) da fibra, por meio do uso da multiplexação por divisão de comprimento de onda denso (DWDM), em conjunto com os formatos de modulação avançados e a recepção coerente nas redes de comunicações ópticas.

A alocação e gerenciamento de canais que tornam a rede dinâmica foi realizado por meio dos ROADMs (módulos de adição e remoção de canais operados remotamente), desta forma requerendo funcionalidades de controle automático de ganho (AGC) e largura espectral de ganho estendida para os EDFAs, visando a manutenção do desempenho do amplificador neste cenário de rede reconfigurável. Adicionalmente amplificadores Raman distribuídos podem ser empregados visando a extensão da banda espectral de ganho junto com a melhora da figura de ruído dos enlaces (melhora da OSNR dos canais transmitidos), facilitando/suportando o aumento da taxa transmitida e a recepção dos canais com formatos de modulação complexos nesta geração de redes ópticas.

Com relação ao histórico e evolução da capacidade de comunicação ao longo desta geração, a Figura 2.1 ilustra os resultados experimentais (quadrados pretos) e a curva de evolução (curva preta). Nesta seção, são apresentadas as tecnologias que se destacaram no decorrer desta geração, ilustradas na Figura 2.5, e cada tecnologia é descrita de forma introdutória visando o entendimento da evolução e capacidade de transmissão durante esta geração.

Os transmissores da terceira geração das redes de comunicações ópticas evoluíram 

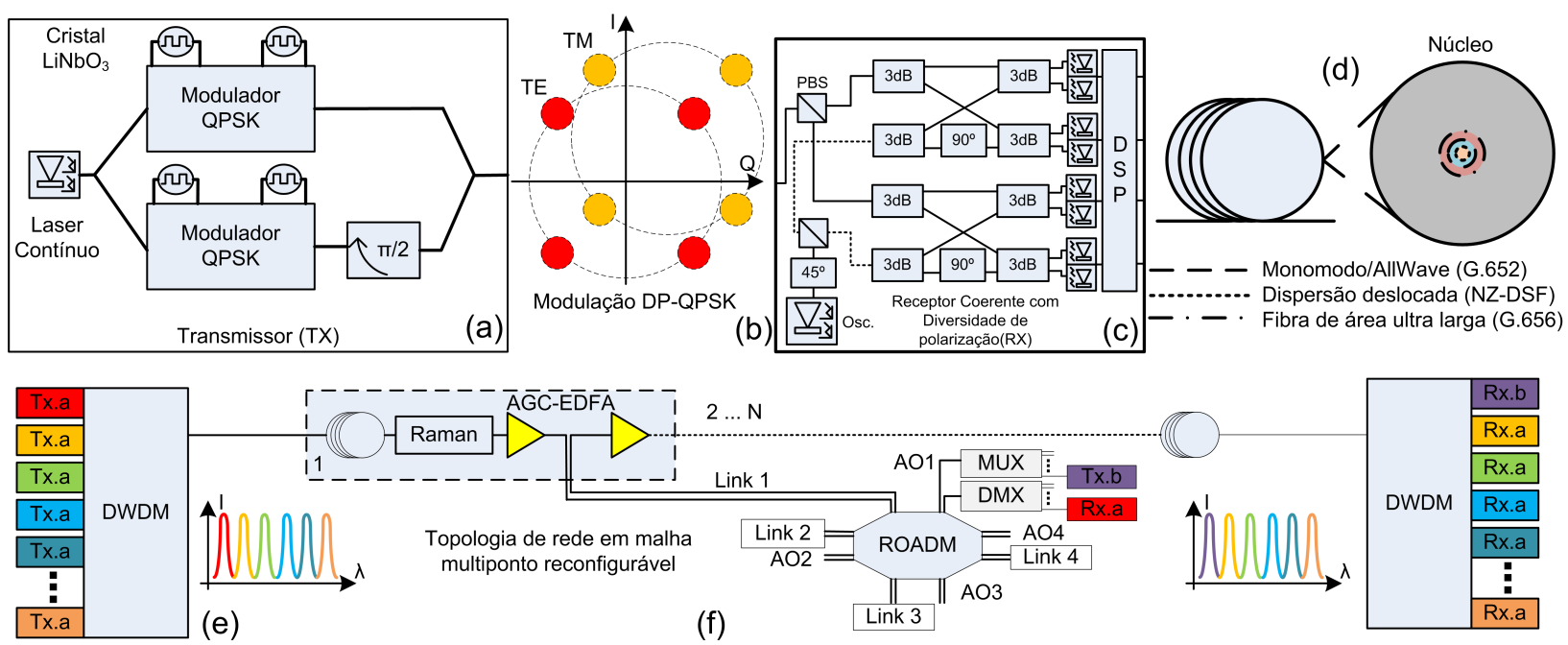

Figura 2.5: Transmissor com modulação em dupla polarização fase/quadratura DP-QPSK(a), constelação do sinal óptico modulado DP-QPSK (b), receptor coerente com diversidade de polarização (c), seção transversal das fibras utilizadas nessa geração (d), multiplexação por divisão de comprimento de onda denso DWDM (e) topologia de rede em malha multi-ponto reconfigurável, amplificadores Raman e EDFA com AGC (f).

por meio da modulação em dupla polarização (DP) QPSK, que, em comparação com o sinal de $10 \mathrm{~Gb} / \mathrm{s}$ de polarização simples, pulso NRZ e modulação OOK (eficiência espectral $0,5-\mathrm{b} / \mathrm{s} / \mathrm{Hz}$ ) permite um aumento de eficiência espectral de 4 vezes (eficiência espectral de 1-b/s/Hz para o QPSK, com dupla polarização atinge 2-b/s/Hz). Com relação à taxa transmitida, quando o modulador DP-QPSK é alimentado por 4 linhas de 25 $\mathrm{Gb} / \mathrm{s}$ (Lang et al., 2011), uma taxa agregada de 100Gb/s (Wuth et al., 2008) é obtida (10 vezes a mais que o $10 \mathrm{~Gb} / \mathrm{s}$ OOK e 2,5 vezes maior que o 40Gb/s DQPSK). O transmissor DP-QPSK é composto por dois moduladores QPSK e um rotacionador de polarização como ilustrado na Figura 2.5(a), enquanto sua constelação (diagrama de intensidade e quadratura para as polarizações TE e TM) é ilustrada na Figura 2.5(b).

Nesta geração, o aumento da complexidade dos formatos de modulação permitiu o aumento da eficiência espectral, por outro lado requerendo um aumento da qualidade do sinal (OSNR) necessária para realizar uma recepção livre de erros. Desta forma, visando uma melhora na sensibilidade do receptor que permita redução da OSNR requerida para recepção livre de erros, surgiu o receptor coerente intradino com diversidade de polarização, ilustrado na Figura 2.5(c).

Diferentemente da recepção coerente homodina, a qual necessita de uma diferença de fase nula para recepção do sinal, e da heteródina, a qual, para evitar a necessidade dessa diferença de fase nula, requer o uso de componentes eletrônicos que empreguem pelo menos o dobro da banda do sinal recebido. A recepção intradina (Nakazawa et al., 2010; Savory, 2008) requer um oscilador local que opere próximo à frequência do sinal recebido (porém não necessariamente igual) e requisita que os componentes eletrônicos suportem apenas a banda nominal do sinal a ser recebido, deixando a cargo de algoritmos de processamento digital de sinais a compensação das diferenças.

O receptor ilustrado na Figura 2.5(c) é composto por dois divisores de polarização (PBS), um para o sinal e um para o oscilador local, com o objetivo de separar as infor- 
mações das polarizações ortogonais TE e TM, seguindo estes sinais para duas híbridas $\left(90^{\circ} 2 \times 4\right.$, uma para cada polarização) onde o batimento entre sinal e oscilador local é realizado, recuperando de forma coerente a amplitude, fase e o estado da polarização do sinal. Desta forma, a detecção é realizada por meio de fotodetectores balanceados, amostrados por conversores analógico-digitais (ADC) de alta velocidade, e processados pelo bloco de processamento digital de sinais (DSP), para remoção dos efeitos lineares impostos pelas imperfeições da transmissão e recepção, recuperando assim a informação do sinal óptico transmitido.

Os tipos de fibras mais utilizados nos sistemas de comunicações ópticas que caracterizam esta geração foram as fibras monomodo padrão sem o pico de absorção na janela de 1400nm "AllWave - G.652.B-D" (ITU, 2009a), as fibras de dispersão deslocada diferente de zero "NZDSF - ITU-G.655" (ITU, 2009b) e as fibras de área ultra-larga "ultra-LEAF G.654" (ITU, 2012b). As seções transversais das fibras são ilustradas na Figura 2.5(d). A fibra SSMF apresenta um diâmetro de núcleo de 8,6-9,5 $\mu \mathrm{m}$ permitindo somente a propagação de um modo ao longo da fibra com zero de dispersão cromática em torno de $1,3 \mu \mathrm{m}$, que implica em uma dispersão cromática em torno de $17 \mathrm{ps} / \mathrm{nm} / \mathrm{km}$ em torno de $1,55 \mu \mathrm{m}$, enquanto a fibra NZDSF apresenta um núcleo de $8-11 \mu \mathrm{m}$ com zero de dispersão cromática variando de $1-10 \mathrm{ps} / \mathrm{nm} / \mathrm{km}$ em torno de $1,55 \mu \mathrm{m}$, e a fibra ULEAF que apresenta núcleo de $9,5-10,5 \mu \mathrm{m}$ com dispersão cromática em torno de $1550 \mathrm{~nm}$ de $20 \mathrm{ps} / \mathrm{nm} / \mathrm{km}$, como definido na norma G.654 (ITU, 2012b).

Devido à capacidade do DSP de remoção de efeitos lineares dos sinais recebidos (Savory, 2008), o acúmulo de dispersão cromática com a propagação dos sinais por longas distâncias de fibras, que antes era tido como um problema a ser solucionado por fibras compensadoras de dispersão cromática (DCF), assim como a dispersão por modo de polarização (PMD), agora passam a não ser mais problema nos sistemas coerentes.

A multiplexação por divisão de comprimento de onda denso (DWDM) foi usada na terceira geração dos sistemas ópticos com o objetivo de dobrar a capacidade dos sistemas, reduzindo o espaçamento, de canais de $100 \mathrm{GHz}$ para $50 \mathrm{GHz}$ como descrito na Tabela 2.2 e ilustrado na Figura 2.5(e).

Adicionalmente como ilustrado na Figura 2.3(f), essa geração se caracteriza por um grande avanço com relação ao uso eficiente das bandas espectrais em um enlace, devido à possibilidade de alocação dinâmica/reconfigurável por meio de roteadores ópticos remotamente configuráveis (ROADM).

Com a utilização dos ROADMs, a rede óptica se torna uma rede reconfigurável. Desta forma, as potências na entrada dos amplificadores ao longo dos enlaces ópticos se tornam uma variável aleatória. Como os amplificadores ópticos (principalmente os EDFAs) possuem uma dependência muito forte entre o ganho provido e seu nível de potência de entrada, é extremamente necessário o uso de controle automático de ganho (AGC) nos amplificadores ópticos usados nestas redes. Ademais, o amplificador deve prover controle automático de ganho rápido o suficiente (comparado ao tempo de transição entre os níveis de energia dos íons de érbio), para suprimir transientes de potência, evitando a geração de erros na transmissão/recepção de dados (devido a falta de potência durante o transiente), e danos aos componentes ao longo do enlace óptico (devido ao excesso de 
potência durante o transiente).

Os EDFAs com controle automático de ganho (AGC) foram desenvolvidos com o objetivo de assegurar a operação da rede, mantendo o ganho alvo do amplificador bem como a planicidade espectral de ganho (para o ganho nominal do amplificador). Já os amplificadores Raman distribuídos passaram a ser usados com o objetivo de prover uma melhora de OSNR para os canais amplificados, por meio da redução da figura de ruído dos enlaces, atingindo o nível de OSNR requerido para recepção dos sinais com formatos de modulação avançados. Porém, como os amplificadores Raman nesta geração operam em bombeio fixo, estes foram empregados somente em sistemas de longa distância semi-estáticos ou com variação de potência baixa e conhecida.

Um grande problema relativo ao uso de sistemas DWDM com alta eficiência espectral são efeitos não-lineares intensos, devido à interação entre as bandas espectrais, que restringem a potência de lançamento dos canais nas fibras ópticas de forma a evitar que estes efeitos não-lineares deteriorem o sinal ao longo da transmissão. Dentre os principais efeitos estão o espalhamento Raman (SRS) e a mistura de quatro ondas (FWM). Para redução de FWM foram desenvolvidas as fibras NZDSF e ULEAF mencionadas anteriormente.

Porém para redução do SRS foi desenvolvida a fibra de baixa perda na janela de 1550 nm e área larga (Ultra LEAF, ITU-T G.654). Esta fibra possui um núcleo de área larga (bem superior à fibra padrão), aumentando o limiar de potência requerido para excitação de efeitos não lineares. Seu núcleo é constituído de Sílica pura para reduzir a atenuação na janela de $1550 \mathrm{~nm}$.

Comunicações ópticas nas bandas $\mathrm{O}, \mathrm{E}$ e $\mathrm{U}$ tornaram-se possíveis por meio do uso da fibra AllWave Fiber e amplificadores Raman distribuídos, devido a evolução dos lasers de bombeio Raman para banda-C/L que ultrapassaram a barreira dos $500 \mathrm{~mW}$ de potência (Electric, 2012; Uniphase, 2011) por comprimento de onda, e aos lasers Raman para amplificação nas bandas-O/E/S (GmbH, $2011 \mathrm{a}, \mathrm{b})$. O emprego destas bandas depende do número de canais desejado.

\section{Tendências de Evolução Recente}

A nova geração dos sistemas de comunicações ópticas teve início a partir de 2010 e continua em evolução até os dias de hoje. Essa geração vem apresentando uma nova quebra de paradigma com relação à multiplexação de sinais e novas fibras ópticas, apresentando várias inovações em termos de eficiência espectral dos transmissores/receptores, maior flexibilidade para os roteadores ópticos (ROADMs), além de novas tecnologias de amplificação e/ou novas funcionalidades de controle que visam maximização de performance óptica para sistemas reconfiguráveis.

Dado que a demanda futura de comunicações estará em torno de 100 vezes a capacidade atual, a nova geração de sistemas de comunicações ópticas tem que evoluir não só em termos de capacidade e flexibilidade, mas também em torno dos custos capitais e operacionais (CAPEX e OPEX) para assegurar soluções com melhor relação custo/bit (Glingener, 2011). Nestes termos as áreas chaves são: técnicas de gerenciamento/roteamento de canais ópticos mais eficientes, técnicas avançadas de modulação, 
técnicas de codificação de canais ópticos, técnicas mais eficientes de amplificação óptica e desenvolvimento de novas fibras ópticas.

Com relação ao histórico e evolução da capacidade de comunicação ao longo desta geração, a Figura 2.1 ilustra os resultados experimentais (triângulos vermelhos) e a curva de evolução (curva vermelha). É possivel observar na Figura 2.1, que os resultados reportados até o momento nesta geração mostram que a mesma vem apresentando maior crescimento da taxa de transmissão com relação a todas as outras gerações dos sistemas de comunicações ópticas. Nesta seção, são ilustradas as tecnologias que se destacaram no decorrer desta geração na Figura 2.6, e cada tecnologia é descrita de forma introdutória visando seu entendimento, assim como a tendência da evolução da flexibilidade e da capacidade de transmissão nesta geração.
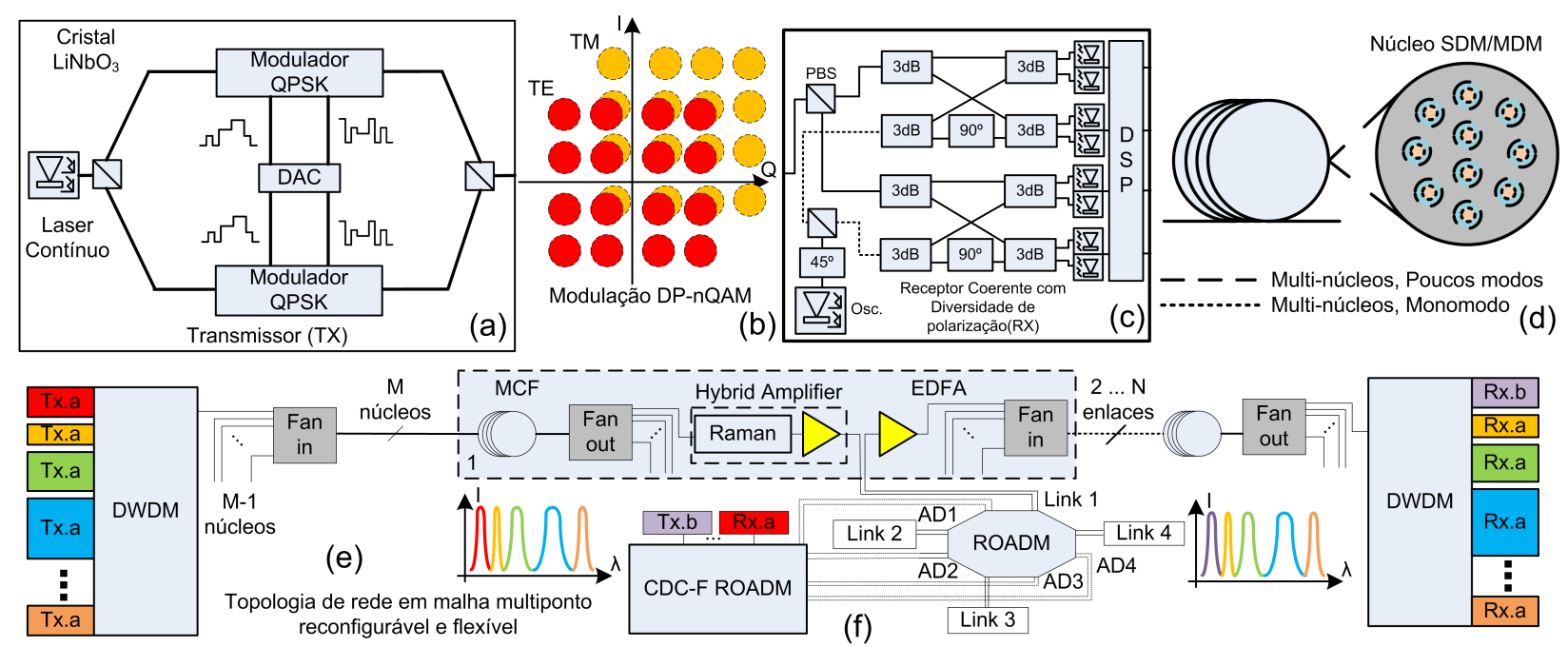

Figura 2.6: Transmissor com modulação em dupla polarização/fase/quadratura DP-nQAM (a), constelação do sinal óptico modulado DP-16QAM (b), receptor coerente com diversidade de polarização (c), seção transversal das fibras utilizadas nessa geração (d), multiplexação por divisão de comprimento de onda denso DWDM, multiplexação por divisão espacial SDM (e) topologia de rede em malha multi-ponto reconfigurável com ROADMs independentes de cor-direção-contenção e flexível CDC-F, amplificadores híbridos com AGC (Raman/EDFA) (f).

Com o aumento exponencial da demanda por largura de banda, torna-se ainda mais necessário o aumento da eficiência espectral dos canais transmitidos, que pode ser atingida com a evolução dos formatos de modulação DP-QPSK para DP-nQAM (n igual a 16 resulta em eficiência espectral de $8 \mathrm{~b} / \mathrm{s} / \mathrm{Hz}$, com $\mathrm{n}$ igual a 32 eficiência espectral de 16 $\mathrm{b} / \mathrm{s} / \mathrm{Hz}$ e assim por diante), pois, com o desenvolvimento dos moduladores de $\mathrm{LiNbO}_{3}$, a codificação de um maior número de bits na constelação do sinal transmitido tornou-se o meio preferencial para aumento da eficiência espectral no transmissor óptico.

Visando a codificação de múltiplos símbolos nos transmissores, a Figura 2.6(a) ilustra o transmissor DP-nQAM de nova geração, composto por um laser contínuo que tem suas polarizações separadas por um PBS (TE e TM), sendo modulado em dois moduladores QPSK (compatíveis com ambas polarização TE ou TM). Porém, ao invés do uso da estratégia das quatro linhas digitais de alta frequência para modulação DP-QPSK, agora é utilizado um conversor digital analógico (DAC) de altíssima taxa 65GSa/s e 8-bits (Europe, 2012) que permite a geração de até 256 níveis (256QAM), ou seja, mo- 
dulação 16QAM, 32QAM até 256QAM, os quais após recombinação via PBS na saída do transmissor, geram o sinal óptico modulado DP-nQAM. A Figura 2.6(b) ilustra a constelação do sinal DP-16QAM. Para geração do sinal com qualidade, torna-se cada vez mais necessário a utilização de lasers com largura de linha muito estreita $(<100 \mathrm{kHz})$ e DAC com alta taxa de amostragem (> $25 \mathrm{GSa} / \mathrm{s}$ ).

Com relação as técnicas avançadas de modulação, a evolução deve focar no desenvolvimento de canais com taxas de $400 \mathrm{~Gb} / \mathrm{s}$ e $1000 \mathrm{~Gb} / \mathrm{s}$ com OFDM ou DP-nQAM com recepção coerente. A chave desta evolução se concentra no desenvolvimento da eletrônica de alta velocidade baseada na tecnologia CMOS e integração fotônica, assim como a integração híbrida (fotônica/eletrônica).

O receptor ilustrado na Figura 2.6(c) trata-se praticamente do mesmo receptor da geração anterior, exceto pelo fato de que, para recepção de sinais DP-16QAM, DP-32QAM e assim por diante, torna-se necessário a redução da largura de linha do laser do oscilador local (< $100 \mathrm{kHz}$ ), assim como o conversor analógico digital (ADC) deve possuir uma largura de banda igual ou melhor que o mesmo utilizando no DAC da transmissão. Além desses aspectos, o conjunto de algoritmos DSP deve ser revisado visando adequar cada bloco para os formatos de modulação diferentes do DP-QPSK (DP-16QAM até DP-256QAM) (Savory, 2010).

Com a implementação de canais com os formatos de modulação avançados citados acima, o nível de OSNR necessário para decodificar sem erros o sinal transmitido é bastante elevado quando comparado aos formatos de modulação tradicionais. Desta forma, são extremamente necessárias técnicas de codificação de canais ópticos para redução da OSNR para recepção dos canais com formatos de modulação avançados. Para isto, são requeridas novas técnicas de correção de erros (FEC). A tendência será a utilização de FEC com decisão via hardware (HD-FEC) em conjunto com FEC com decisão via software (SD-FEC), e aumento do código de redundância de erro de 7\% para 23\% (Renaudier et al., 2011). Outra tendência é a implementação de técnicas do tipo rádio definido por software (SDR) no domínio óptico (SDO) (Glingener, 2011).

Mesmo com o grau de recofigurabilidade fornecido pelos ROADMs nas redes de terceira geração, nota-se que a estrutura do ROADM de terceira geração é bastante rudimentar em termos da flexibilidade de adição e remoção dos canais, com relação a cor (mux/demux fixam as cores nas portas do ROADM), direção (cada cor deve ingressar e regressar em uma determinada porta de add/drop para que possa ser adicionado ao enlace desejado), contenção (canais da mesma cor não podem ser alocados em diferentes fibras de saída devido a interferência entre os mesmos ao passar pelo ROADM) e principalmente flexibilidade de alocação espectral (na terceira geração este foi fixado em 100 ou $50 \mathrm{GHz}$ de espaçamento espectral por canal).

Devido à dependência de cor/direção/contenção e da grade espectral fixa de alocação de comprimentos de onda, a eficiência espectral da infra-estrutura de rede com ROADMs de terceira geração pode evoluir significativamente. Com essas deficiências, tornou-se necessário o desenvolvimento de estruturas (cartões de linha) de adição e remoção de canais nos ROADMs, visando a flexibilização da adição e remoção de canais nestes entroncamentos de rede, tornando suas entradas e saídas independentes de cor, 
direção, contenção e com espaçamento espectral flexível (CDC-F) (Zyskind e Srivastava, 2011). A Figura 2.6(e) ilustra a rede com um nó ROADM que internamente é composto por módulos WSS com grade flexível de $12.5 \mathrm{GHz}$ de granularidade espectral, de acordo com a norma ITU (ITU, 2012a), onde o módulo CDC-F ROADM consiste em módulos multi-cast-switch (MCS), chaves WSS flexgrid e amplificadores ópticos para compensação das perdas dos dois elementos anteriores, interligados de forma a possibilitar a adição e remoção de canais CDC-F (Way, 2012).

Na terceira geração dos sistemas de comunicações ópticas, diversos métodos de controle automático de ganho (AGC) foram desenvolvidos para EDFAs com o objetivo de manter o desempenho óptico em redes reconfiguráveis, enquanto que amplificadores Raman distribuídos foram usados com bombeio fixo visando prover uma melhora de OSNR em sistemas não dinâmicos. Com relação aos amplificadores ópticos nesta nova geração dos sistemas de comunicações ópticas, será extremamente desejável o desenvolvimento de amplificadores ópticos híbridos (Raman/EDFA), e sua respectiva técnica de controle automático de ganho (controlando ambas as tecnologias), para melhorar o desempenho do mesmo em todos os pontos de operação de uma rede reconfigurável (ganho espectral plano aliado a baixa figura de ruído e controle com supressão de transientes).

Esta tese tem como objetivo exatamente o desenvolvimento de amplificadores ópticos híbridos e suas técnicas de controle automático de ganho visando melhora de figura de ruído e planicidade espectral de ganho para o amplificador operando em redes reconfiguráveis de nova geração. Nas próximas seções deste capítulo, serão apresentados os fundamentos das tecnologias de amplificação óptica mais utilizadas atualmente, visando facilitar o entendimento do trabalho desenvolvido nesta tese.

\subsubsection{Amplificador Óptico Híbrido}

No Apêndice A é apresentada uma revisão bibliográfica das tecnologias de amplificação óptica EDFA, Raman distribuído e Raman concentrado, que são as tecnologias mais empregadas na amplificação de sinais ópticos em redes DWDM. Cada tecnologia em particular, quando empregada na regeneração de canais nas redes ópticas DWDM, provê bom desempenho considerando os parâmetros de desempenho (potência de saída, figura de ruído, planicidade espectral de ganho e controle automático de ganho) para uma determinada região de operação de potência de entrada do amplificador. Porém nenhuma dessas tecnologias citadas fornece bom desempenho para simultaneamente todos os parâmetros de desempenho em toda a faixa de operação de potência de entrada.

A tecnologia de amplificação Raman distribuída tem como ponto forte a baixa inserção de ruído, porém fornece um baixo nível de ganho e potência de saída. A tecnologia de amplificação a fibra dopada com érbio (EDFA) tem como ponto forte o alto nível de ganho e potência de saída, com um nível de inserção de ruído intermediário. Já a tecnologia de amplificação Raman concentrado tem como ponto forte o alto nível de ganho e potência de saída, com possibilidade de compensação de dispersão durante a amplificação, porém fornece um nível de inserção de ruído pior que o EDFA e o Raman distribuído.

A tendência na evolução dos amplificadores ópticos DWDM gira em torno da necessidade de um amplificador óptico com controle de ganho variável que forneça desempenho 
melhorado em todos os seus parâmetros de performance (potência de saída, figura de ruído, planicidade espectral de ganho e controle automático de ganho) para qualquer valor de ganho requerido. Em busca disso, vêm sendo investigado o desenvolvimento de amplificadores ópticos baseados em tecnologias de amplificação ópticas híbridas, que combinam variadas tecnologias de amplificação óptica, para melhorar suas características de amplificação.

Entre os diversos tipos de amplificadores híbridos desenvolvidos na literatura, podemos destacar as seguintes topologias: Amplificadores Raman/EDFA, Raman/Paramétrico, Raman/SOA ((Reichmann et al., 2006)) e TDFA/EDFA ((Sakamoto et al., 2006)). Porém, para redes ópticas DWDM (metropolitanas e de longa distância), as principais tecnologias de amplificação empregadas são os EDFAs, amplificadores Raman distribuídos e concentrados.

Nesta seção serão descritos os principais trabalhos realizados no âmbito do desenvolvimento de amplificadores híbridos Raman concentrado e/ou Raman distribuído e/ou EDFA para redes ópticas DWDM. Com base nestes trabalhos, e nas características ópticas demandadas (amplificadores com baixa figura de ruído e alta potência de entrada) para amplificadores em redes ópticas DWDM dinâmica, considerando canais com formatos de modulação avançados (100 Gb/s e além), procura-se uma topologia de amplificação óptica híbrida que atenda estes requisitos.

\section{Topologias de Amplificação Óptica Híbrida Raman Concentrado e/ou Distribuído e/ou EDFA}

Em (Masuda et al., 1999) foi desenvolvido um amplificador híbrido para prover banda de ganho espectral larga e plana. Bandas contínuas de ganho de $80 \mathrm{~nm}, 76 \mathrm{~nm}$ e 69 $\mathrm{nm}$, com planicidade de ganho relativas de $11,3 \%, 4,7 \%$ e $3,7 \%$ foram conseguidas. $\mathrm{O}$ amplificador desenvolvido consistiu de um estágio de amplificação à fibra de fluoreto dopada com érbio, e um amplificador Raman concentrado composto por dois trechos de fibra DCF isolados e bombeados simultaneamente com três comprimentos de onda, e um filtro espectral para equalização de ganho. $\mathrm{O}$ amplificador apresentou figuras de ruído abaixo de $6 \mathrm{~dB}$. A Figura 2.7 ilustra o circuito óptico do amplificador híbrido desenvolvido.

O amplificador apresentado em (Masuda et al., 1999) busca a maximização da banda espectral de ganho através de estágios com as tecnologias de amplificação EDFA e Raman concentrado. A fibra de fluoreto dopada com érbio é utilizada para prover melhor planicidade espectral, e o amplificador Raman com dois estágios é utilizado para reduzir o efeito do duplo espalhamento Rayleigh (DRB), reduzindo a figura de ruído final do amplificador híbrido desenvolvido. Este amplificador foi avaliado somente para potência de entrada total de $-20 d B m$, assim sendo aplicado somente em redes WDM ponto-a-ponto.

Em (Takeda et al., 2002) foi desenvolvido um amplificador híbrido (RAMAN distribuído/EDFA) para compensação do efeito de variação de ganho dependente com a tem-

peratura. Este projeto foi realizado utilizando bombeios Raman com grades de bragg especiais, que aplicam uma variação de ganho espectral com a temperatura inverso com relação ao mesmo efeito ocorrido no EDFA. A variação de planicidade de ganho obtida 


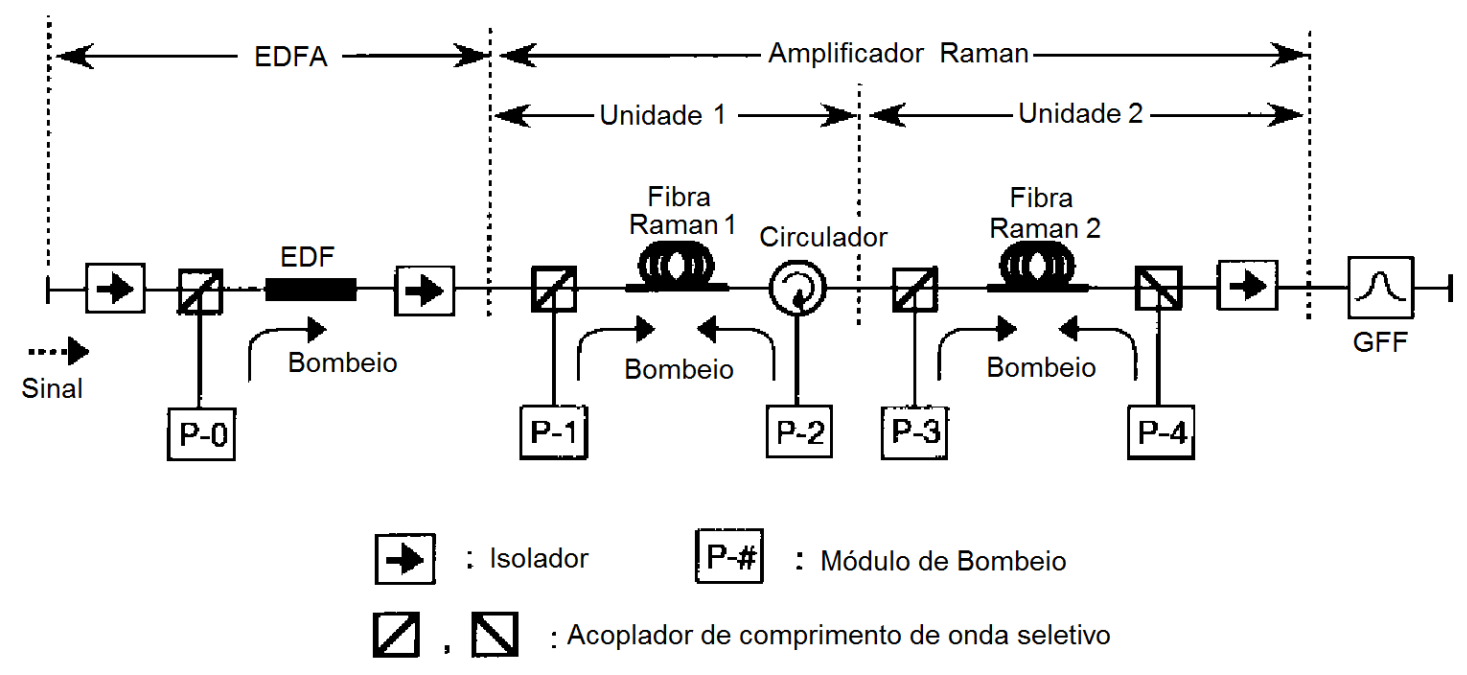

Figura 2.7: Amplificador Óptico Híbrido (EDFA/Raman concentrado) de Banda Larga. Extraido e adaptado da referência (Masuda et al., 1999).

foi de 0,14 dB para uma variação de temperatura de -5 a 65 graus Celsius.

As grades de Bragg que estabilizam o comprimento de onda de bombeio dos amplificadores Raman distribuídos tiveram seu coeficiente de sensibilidade térmica invertido, para que, quando incorporado ao esquema de amplificação híbrida ilustrado na Figura 2.8 (a), tornem o espectro de ganho insensivel a variação temperatura, compensando o efeito de sensibilidade à temperatura de forma ativa, como ilustrado na Figura 2.8 (b).

O amplificador apresentado em (Takeda et al., 2002), remove o efeito de variação espectral de ganho do amplificador Raman/EDFA com a temperatura, porém, assim como em (Masuda et al., 1999), é projeto somente para redes WDM ponto-a-ponto.

Em (Seo et al., 2005) foi apresentado um esquema de amplificação híbrida de banda larga (105 nm de largura de banda), cobrindo as bandas $\mathrm{S}+\mathrm{C}+\mathrm{L}$, usando uma fibra dopada especial e esquema de fibras DCF e EDF. O princípio de amplificação é baseado nas transições radioativas estimuladas pelos íons de Érbio na banda-C e pelo espalhamento Raman estimulado nas bandas S e L respectivamente (Raman concentrado). Neste artigo foram analisadas as características de amplificação em dois tipos de fibra, via simulação numérica. O primeiro tipo foi uma fibra de sílica com a casca dopada com Érbio e o núcleo dopado com Germânio, enquanto o outro tipo de fibra trata de um meio híbrido composto por um enlace de EDF e um enlace de DCF (e vice-versa).

A Figura 2.9 (a) ilustra o diagrama esquemático proposto para amplificação híbrida de banda larga. A Figura 2.9 (b) ilustra o ganho fornecido pela primeira fibra para uma potência de entrada de $-4,78 \mathrm{dBm}$ (105 canais com $-25 \mathrm{dBm}$ por canal, espaçados de 1 $\mathrm{nm}$, partindo de 1500 a $1605 \mathrm{~nm}$ ), considerando bombeio total Raman variando de 1,9 a 2,7 W, e considerando bombeio total EDFA variando de 1,5 a $70 \mathrm{~mW}$.

O amplificador apresentado em (Seo et al., 2005) utilizou novos modelos de fibra para o desenvolvimento de amplificadores híbridos Raman concentrado/EDFA de banda larga (Bandas $\mathrm{S}+\mathrm{C}+\mathrm{L}$ ). Mais de uma vez, tanto neste trabalho como em (Masuda et al., 1999; Takeda et al., 2002), o amplificador desenvolvido é avaliado para somente um valor de 


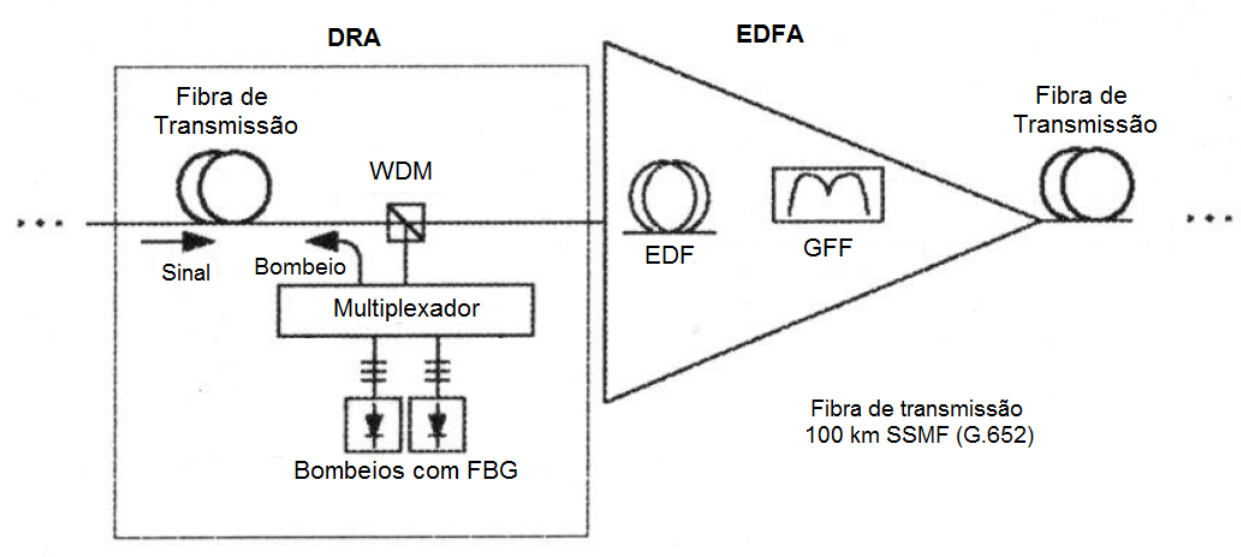

(a)
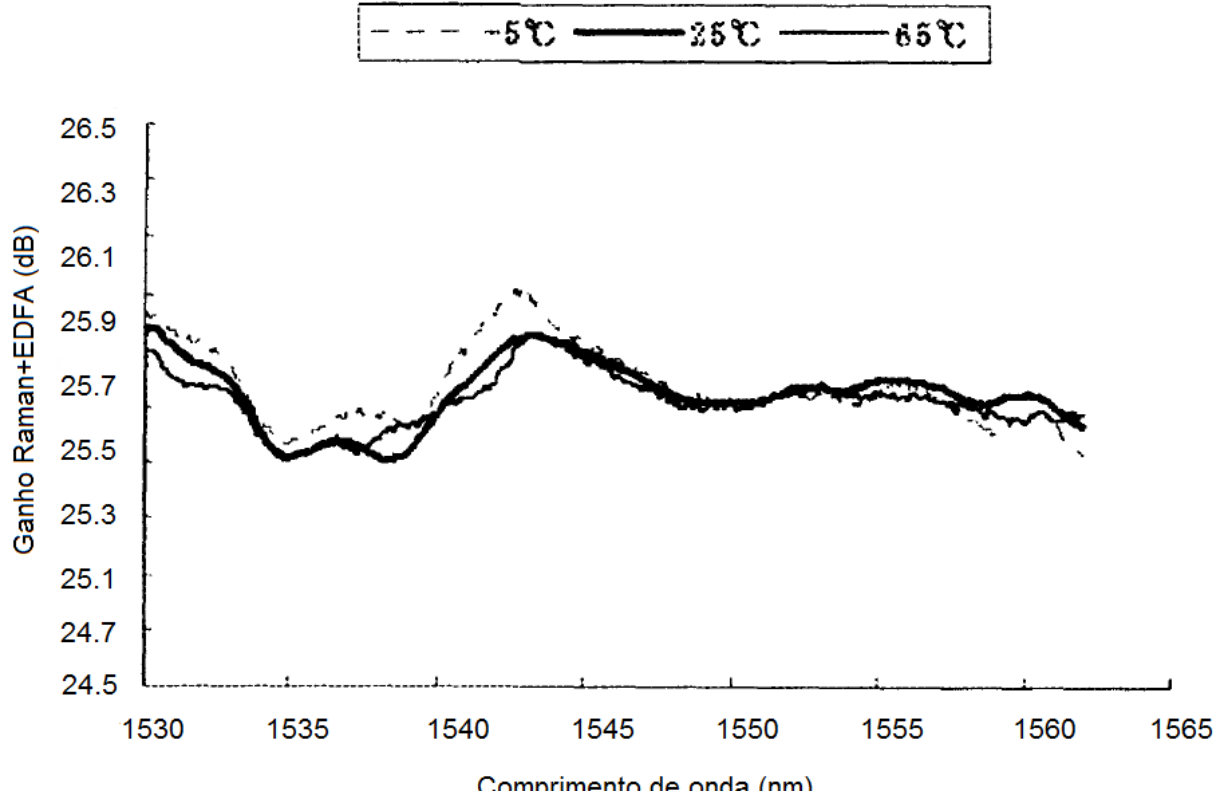

(b)

Figura 2.8: Amplificador Óptico Híbrido Raman distribuído/EDFA (a), Dependência do ganho com a temperatura no amplificador híbrido projetado (b). Extraido e adaptado da referência (Takeda et al., 2002).

potência de entrada, sendo utilizável apenas em redes WDM ponto-a-ponto.

Em (Lee et al., 2005) foi apresentado um estudo experimental que realiza uma comparação dos desempenhos (estáticos e dinâmicos) entre um esquema de amplificação somente Raman concentrado em fibra DCF (tipo I) e outros três esquemas de amplificação híbrida, um amplificador Raman concentrado/EDFA com reciclagem de bombeio residual do Raman para o EDFA (tipo II), um amplificador EDFA/Raman concentrado (tipo III), e um amplificador Raman concentrado/EDFA (tipo IV). As Figuras 2.10 ilustram os circuitos ópticos testados(tipo I, II, III e IV), enquanto as Figuras 2.11 ilustram o espectro de ganho para três diferentes níveis de potência de entrada nos amplificadores avaliados (tipo I, II, III e IV, considerando o nível de bombeio constante).

Entre os amplificadores apresentados em (Lee et al., 2005), com relação ao ganho estático, os amplificadores híbridos (tipos II, III e IV) apresentaram nível de ganho supe- 

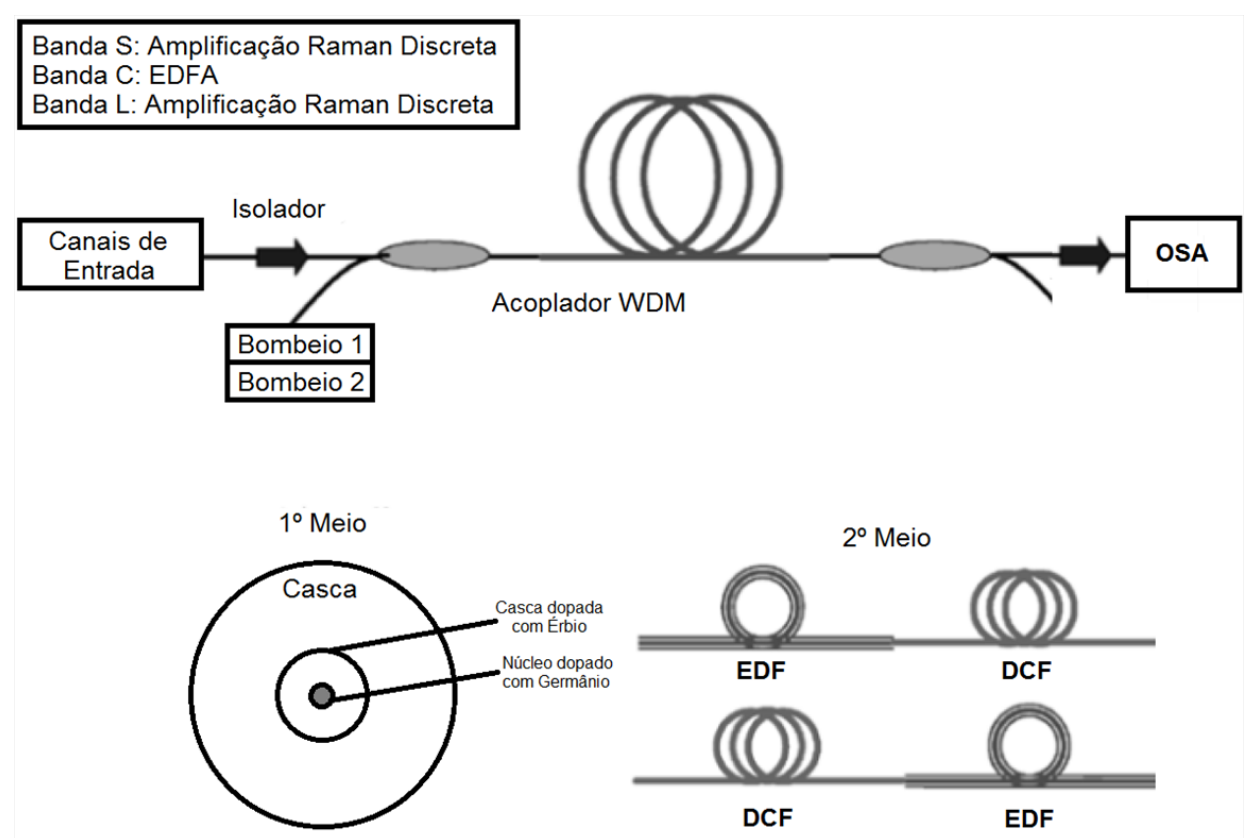

(a)

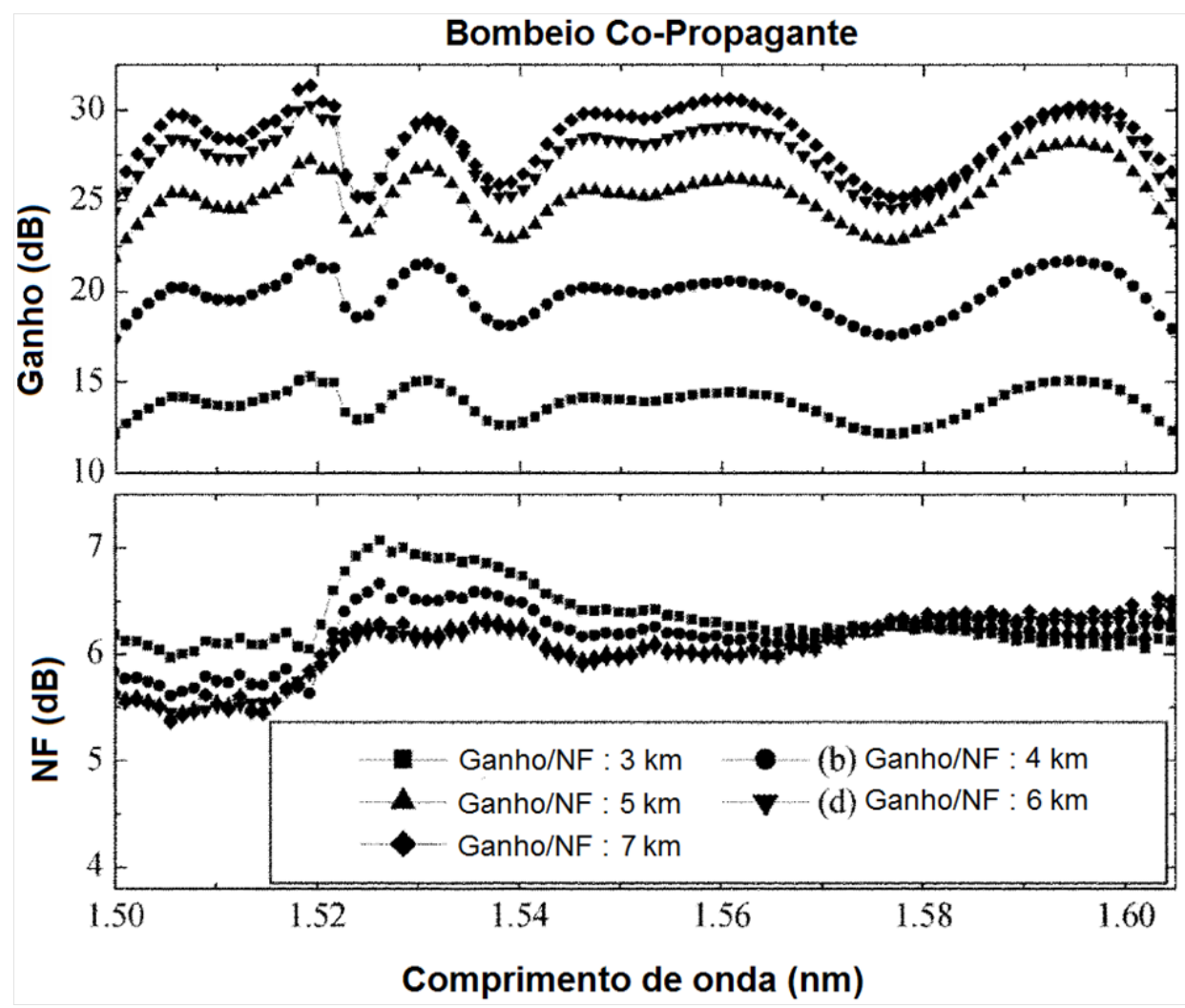

(b)

Figura 2.9: Fibras desenvolvidas para amplificadores Hibrido Raman Concentrado/EDFA (a), Dependência do ganho com a temperatura no amplificador híbrido projetado (b). Extraido e adaptado da referência (Seo et al., 2005). 


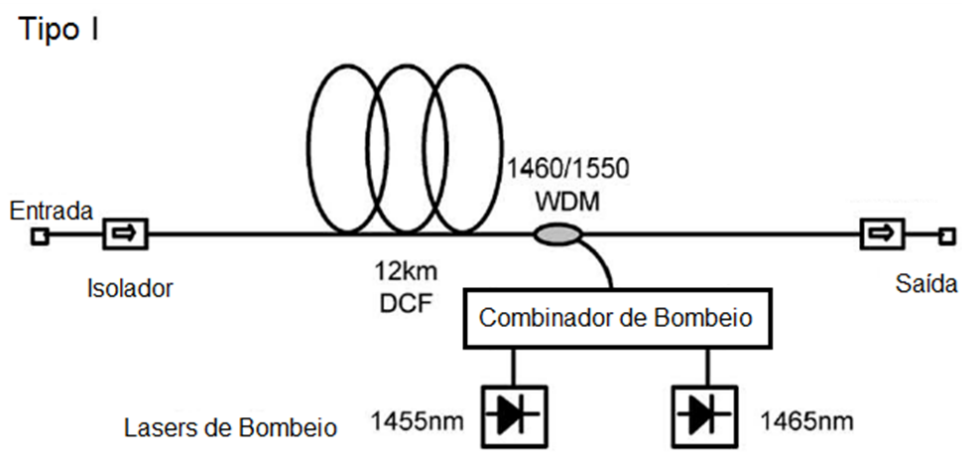

(a)

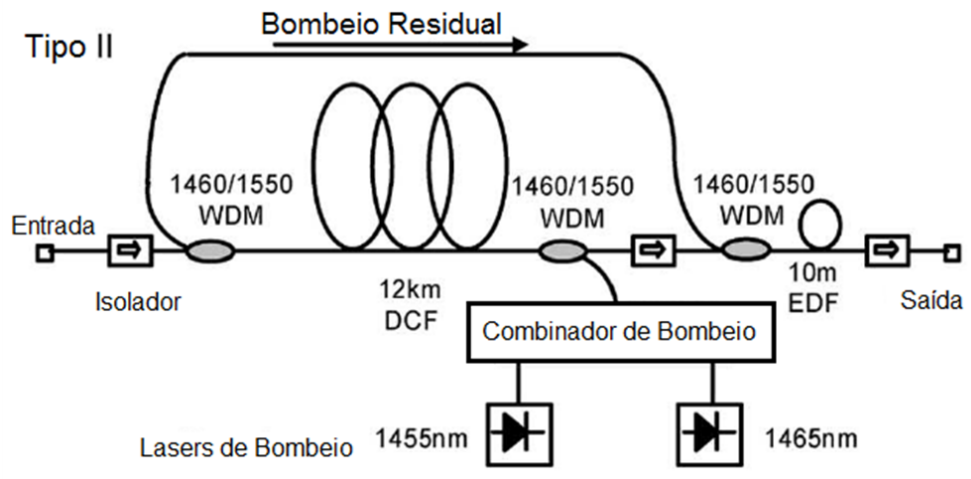

(b)

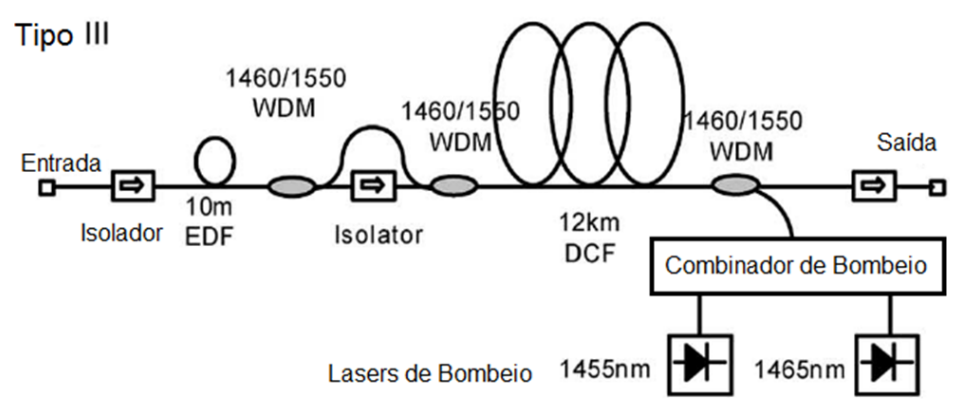

(c)

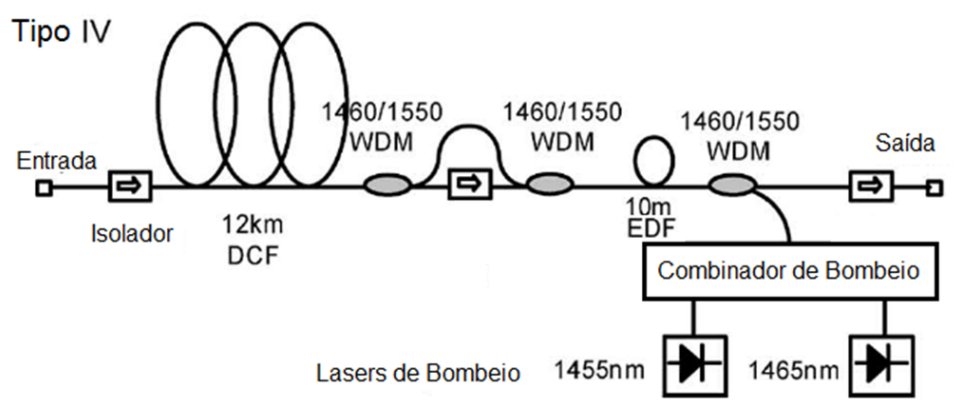

(d)

Figura 2.10: Amplificador Concentrado Raman - Tipo I (a), Amplificador Híbrido Raman concentrado/EDFA com re-uso de bombeio - Tipo II (b), Amplificador Híbrido EDFA/Raman Concentrado Tipo III (c) e Amplificador Híbrido Raman Concentrado/EDFA - Tipo IV (d). Extraido e adaptado da referência (Lee et al., 2005). 
riores quando comparados ao amplificador baseado somente na tecnologia Raman concentrado (I). Contrariamente, quando avaliado a variação de ganho espectral (comportamento dinâmico) dos amplificadores, o amplificador Raman concentrado (I), mostrou-se muito mais tolerante a variação da potência de entrada quando comparado com os amplificadores que contem a tecnologia EDFA.

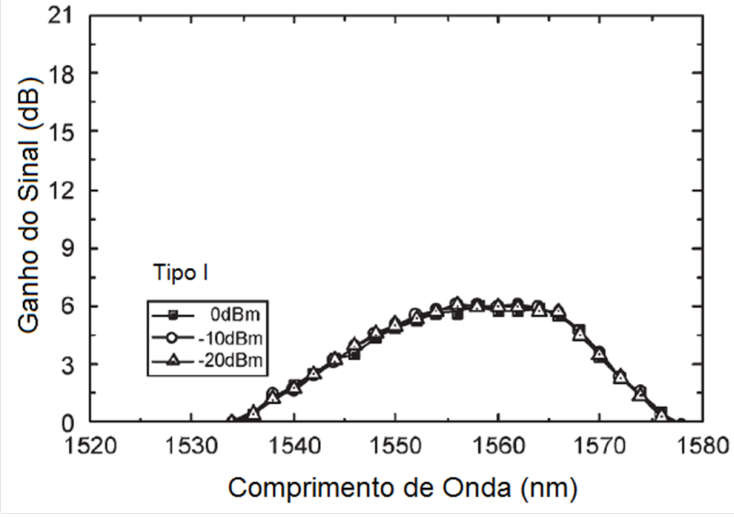

(a)

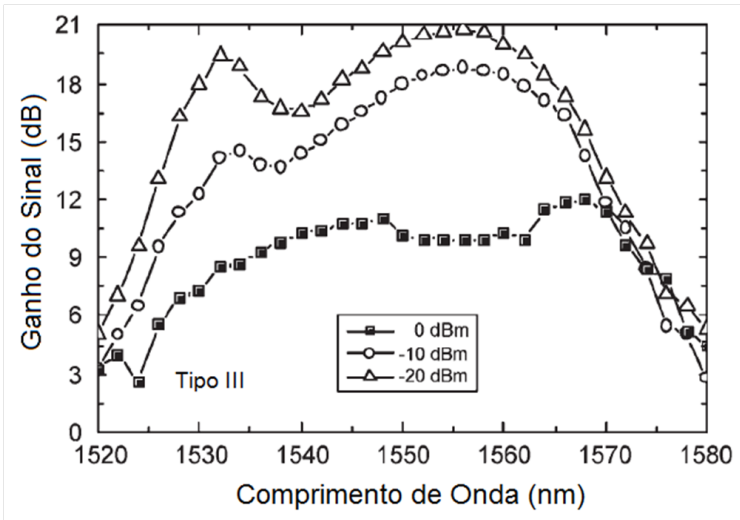

(c)

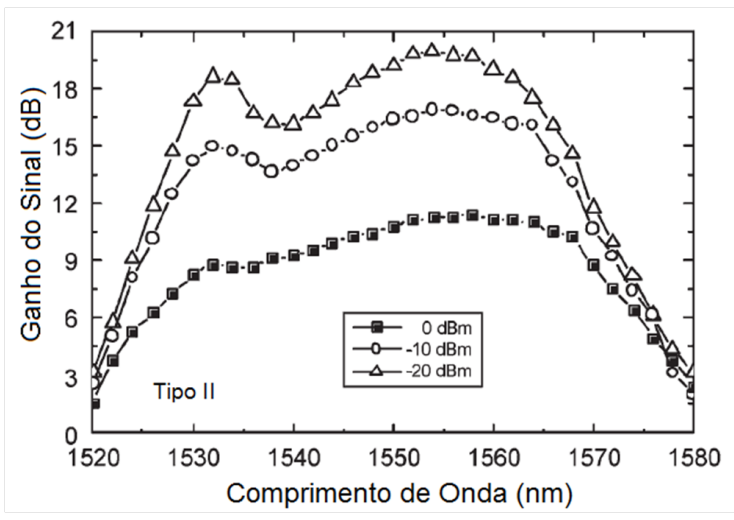

(b)

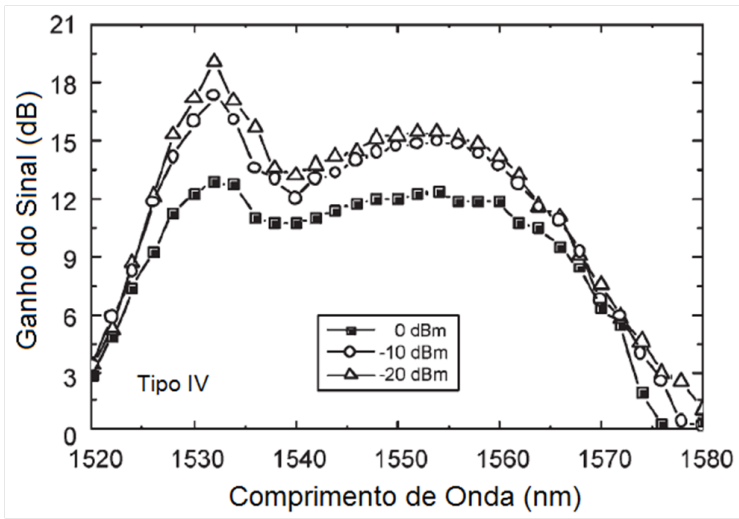

(d)

Figura 2.11: Espectro de ganho para os amplificadores testados: Amplificador Concentrado Raman - Tipo I (a), Amplificador Híbrido Raman Concentrado/EDFA com re-uso de bombeio - Tipo II (b), Amplificador Híbrido EDFA/Raman Concentrado - Tipo III (c) e Amplificador Híbrido Raman Concentrado/EDFA - Tipo IV (d). Extraido e adaptado da referência (Lee et al., 2005).

Analisando os resultados obtidos em (Lee et al., 2005), fica claro que devemos utilizar amplificadores híbridos para melhora dos parâmetros de figura de ruído, porém é necessário um melhor entendimento destes para que seja possível desenvolver um amplificador com ganho variável e planicidade espectral de ganho para operação em redes DWDM reconfiguráveis. Em (Lee et al., 2005) é visto que os amplificadores híbridos projetados não fornecem essa característica.

Em (Martini et al., 2009), foi desenvolvida uma técnica para otimizar o perfil de ganho de amplificadores híbridos Raman concentrado + EDFA com reciclagem de bombeio. A equalização do espectro de ganho do EDFA foi realizada através do ajuste do perfil de ganho do estágio de amplificação Raman via potências dos bombeios. Para aumentar a eficiência da conversão da potência de bombeio em amplificação, o bombeio residual Raman é reutilizado pelo trecho de EDF. Valores de variação de planicidade menores que $1 \mathrm{~dB}$ foram obtidos em uma banda de aproximadamente $30 \mathrm{~nm}$ para configuração 
de dois e três lasers de bombeio.

A mesma configuração apresentada em (Lee et al., 2005) foi utilizada, porém foram utilizados múltiplos bombeios Raman para compensação do perfil de ganho espectral gerado no EDFA (ilustrado na Figura 2.12), gerando um amplificador híbrido com característica de ganho espectral plano. São utilizados métodos de otimização iterativos para selecionar os comprimentos de onda de bombeio Raman, e suas respectivas intensidades (considerando o comprimento de onda de 1400-1480 nm e a intensidade de 50-300 $\mathrm{mW}$ ).

A Figura 2.13 ilustra os perfis de ganho espectrais para o amplificador óptico híbrido proposto em (Martini et al., 2009). A efetividade da técnica proposta pode ser vista na Figura 2.13 (a, b e c) para diferentes níveis de potência de sinal. Para a faixa de comprimento de onda de $1535 \mathrm{~nm}$ a $1565 \mathrm{~nm}$, ou seja, uma largura de banda de $30 \mathrm{~nm}$, onde os valores de ondulação foram de 1,2 dB, 0,4 dB e 0,3 dB para as potências de sinal de $-20 \mathrm{dBm},-10 \mathrm{dBm}$ e $-5 \mathrm{dBm}$, respectivamente.

A Figura 2.13 (d) mostra o perfil da figura de ruído (NF) do amplificador híbrido otimizado. Apesar da otimização de planicidade espectral de ganho, a figura de ruído média ficou em torno de $10 \mathrm{~dB}$, considerada alta para redes WDM.

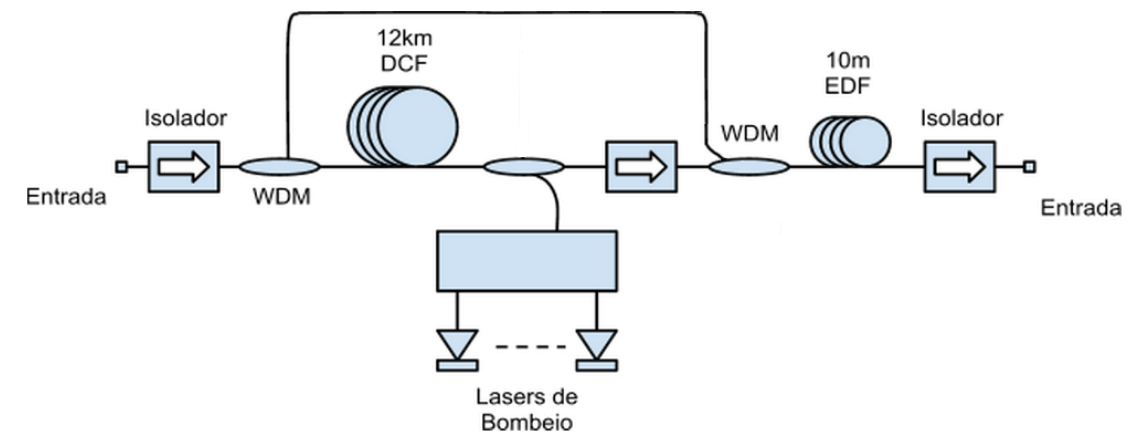

Figura 2.12: Configuração do amplificador híbrido proposto. Extraido e adaptado da referência (Martini et al., 2009).

O amplificador proposto e simulado em (Martini et al., 2009), provê planicidade espectral de ganho em redes WDM dinâmicas (banda C) para uma determinada faixa de ganhos alvo. Porém, o autor não visa a otimização do parâmetro de figura de ruído (em torno de $10 \mathrm{~dB}$ ), e insere uma quantidade ruído relativamente alta, inviabilizando seu uso em redes WDM com canais com formatos de modulação avançados de $100 \mathrm{~Gb} / \mathrm{s}$ e além (Zyskind e Srivastava, 2011).

\subsubsection{Amplificador Óptico Híbrido para Redes DWDM dinâmicas}

Dentre as topologias de amplificação óptica híbrida para redes WDM disponíveis na literatura e reportadas na seção 2.1.1, a maioria delas focam aplicações de ganho em banda larga, ou otimização de planicidade espectral de ganho, ou otimização de figura de ruído, não buscando os requisitos necessários a amplificadores ópticos híbrido para redes ópticas DWDM dinâmicas e com formatos de modulação avançados (Zyskind e Srivastava, 2011), que requerem o desenvolvimento de amplificadores ópticos híbridos e seus respectivos métodos de controle de ganho, visando a otimização 


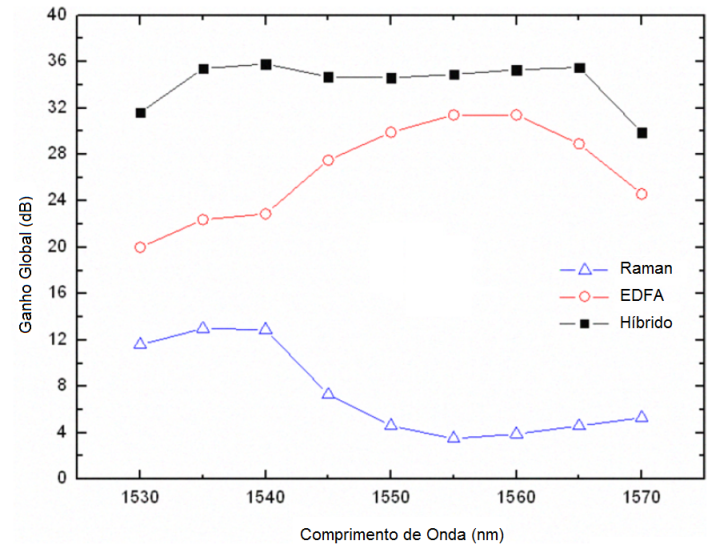

(a)

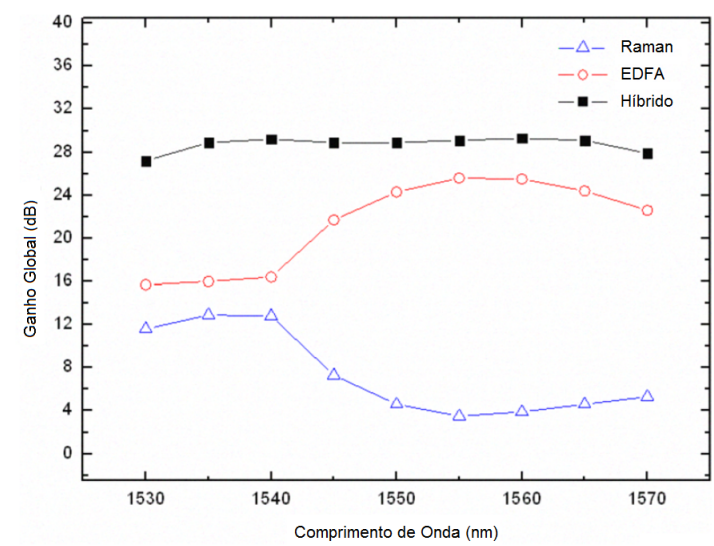

(b)

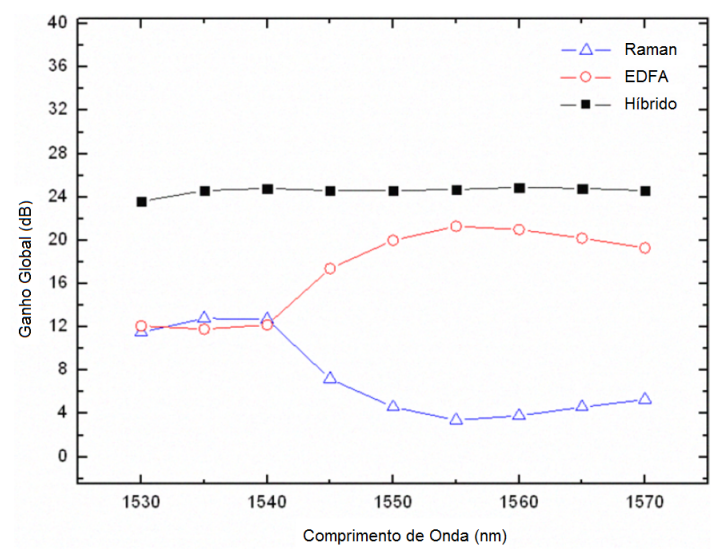

(c)

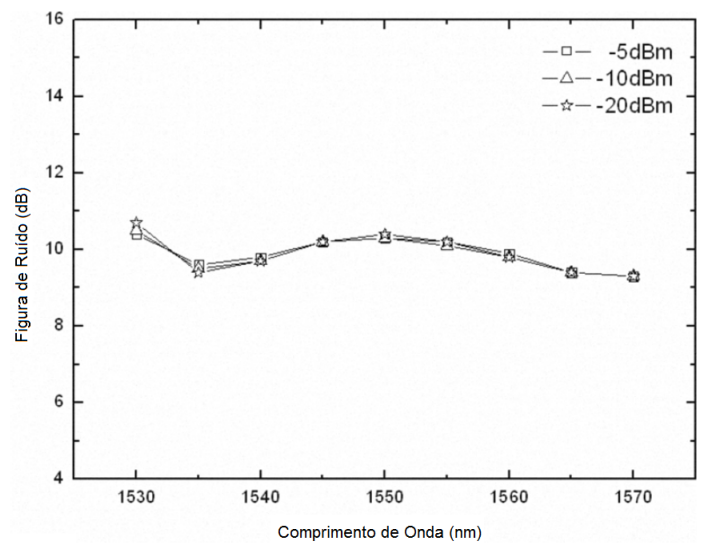

(d)

Figura 2.13: Espectros de ganho para o amplificador óptico híbrido com 2 lasers de bombeio para: $P s=-20 \mathrm{dBm}(a), P s=-10 \mathrm{dBm}(\mathrm{b}), P s=-5 \mathrm{dBm}$ (c) e Espectro da figura de ruido para os casos avaliados (d). Extraido da referência (Martini et al., 2009).

de ambos os parâmetros de desempenho (planicidade espectral de ganho e figura de ruído) ao longo de toda região de operação do amplificador óptico na rede DWDM.

Ao longo dos próximos capítulos, diversas topologias de amplificação óptica híbrida serão simuladas e experimentadas, considerando as tecnologias EDFA, e/ou Raman concentrado e/ou Raman distribuído, com o objetivo de determinar a topologia de amplificação óptica híbrida que fornece melhor desempenho de figura de ruído para sistemas sem repetição. Nos capítulos subsequentes será investigada a melhor topologia de amplificação óptica híbrida para sistemas com repetição DWDM reconfiguráveis, com base na análise do desempenho das tecnologias utilizadas atualmente em conjunto com suas respectivas metodologias de controle automático de ganho. Em seguida, para a topologia de amplificação híbrida determinada, será desenvolvido sua metodologia de projeto e controle automático de ganho, visando a otimização do desempenho da planicidade espectral de ganho aliado a baixa figura de ruído, ao longo de toda a faixa de operação dinâmica do amplificador. 


\section{Capítulo 3}

\section{Topologias de Amplificação Óptica Híbrida para Sistemas sem Repetição}

Levando em consideração a menor inserção de ruído causada pelo amplificador Raman distribuído (DRA), a capacidade de amplificação em conjunto com a compensação de dispersão cromática do amplificador Raman discreto em DCF (LRA) e à amplificação com alta eficiência/potência de saída fornecida pelo EDFA, é razoável pensar em soluções de amplificadores híbridos compostos por tecnologias DRA e/ou EDFA e/ou LRA, visando atingir altos níveis de amplificação com baixa inserção de ruído e/ou compensação de dispersão cromática.

Partindo dessas premissas, investigou-se experimentalmente o impacto gerado pela introdução dessas tecnologias de amplificação e pela combinação delas (amplificador híbrido), considerando as tecnologias EDFA, DRA e LRA, em um sistema de transmissão ponto-a-ponto sem repetição com diversos comprimento de enlace, partindo de enlaces de $100 \mathrm{~km}$ de extensão de fibra SSMF (G.652) e incrementando-o em passos de $50 \mathrm{~km}$.

Nesses sistemas foram transmitidos canais com taxa e formato de modulação 112 Gb/s NRZ-DP-QPSK, partindo do sistema mono-canal sem repetição até o maior número possivel de canais em um sistema DWDM sem repetição, utilizando os amplificadores disponíveis em laboratório. O experimento teve o intuito de avaliar o desempenho dos sistemas com relação às topologias de amplificadores testadas, para vários comprimentos de enlace.

Inicialmente foi considerado um sistema mono-canal para o teste de amplificadores compostos pelas tecnologias de amplificação DRA e/ou EDFA, com compensação de dispersão cromática realizada através de processamento digital de sinais (DSP) executado no sinal recebido (Savory, 2008). Em seguida o teste dos amplificadores baseados nas tecnologias DRA e/ou EDFA e na tecnologia LRA, onde o meio de amplificação é um módulo DCM (com fibra DCF) foi realizado, e como a DCF realiza a compensação de dispersão cromática nestas topologias, não foi considerado para as mesmas a compensação de dispersão cromática via DSP.

Para todos os comprimentos de enlaces testados, a condição de potência total lançada 
na fibra foi a mesma ( $10 \mathrm{dBm})$, devido esta ser a condição de potência lançada necessária para atingir o maior comprimento de enlace $(300 \mathrm{~km})$. Essa condição é mantida/fixada com o intuito de avaliar o desempenho dos amplificadores testados com o mesmo nível de potência total e o mesmo nível de não linearidades devido a potência lançada na fibra, em qualquer condição testada neste experimento.

A Figura 3.1(a) ilustra o experimento realizado, dividido em três blocos principais: transmissor, receptor e amplificador. Para o bloco de transmissão e recepção, a Figura 3.1(a) ilustra o transmissor e receptor $112 \mathrm{~Gb} / \mathrm{s}$ NRZ-DP-QPSK (foto do mesmo ilustrado na Figura 3.1(b)), que será detalhado ao longo deste capítulo. O subsistema experimental (enlaces e amplificadores) são ilustrados na Figura 3.1(c).

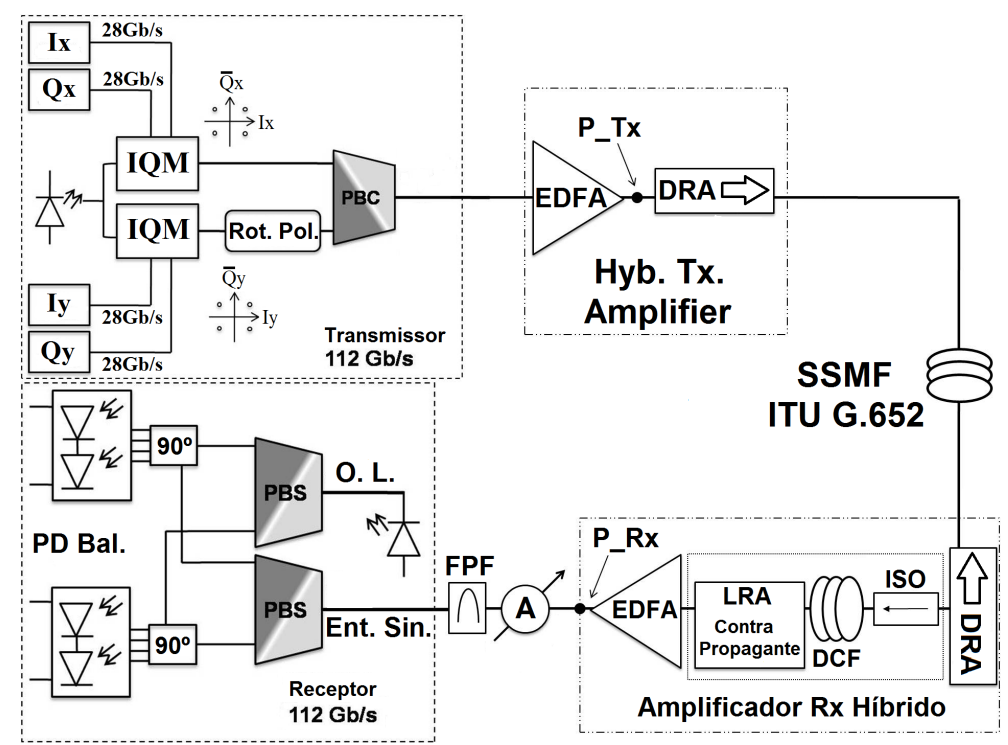

(a)

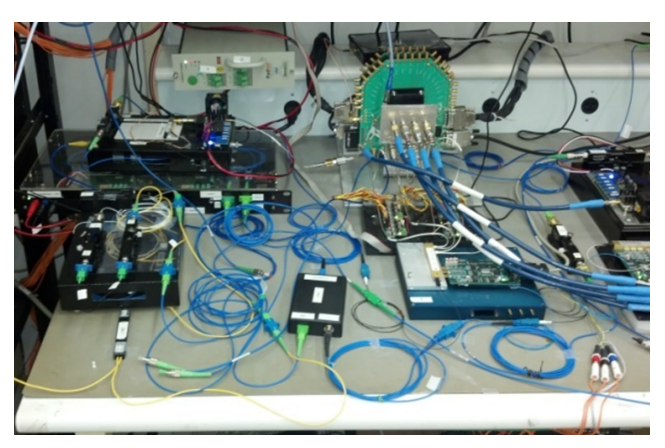

(b)

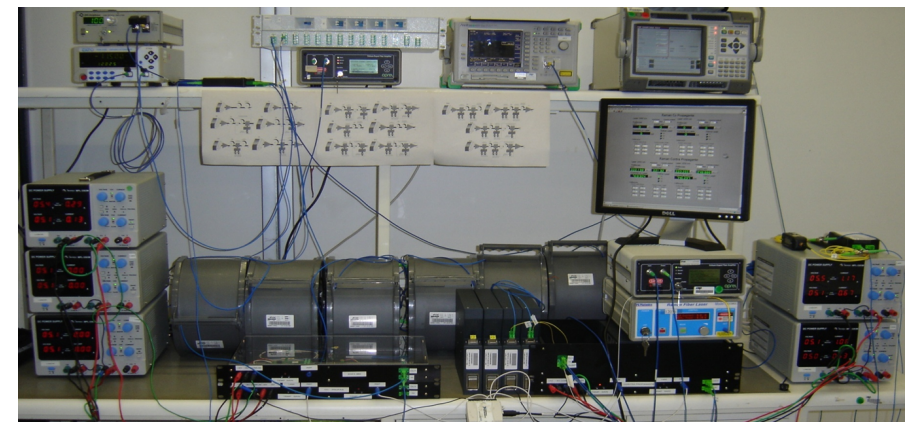

(c)

Figura 3.1: (a) Enlace experimental com transmissor e receptor de $112 \mathrm{~Gb} / \mathrm{s}$ para avaliação das soluções de pré-amplificação híbrida em sistemas com fibra SSMF (G.652), (b) Transmissor $112 \mathrm{~Gb} / \mathrm{s}$ e (c) Bancada do subsistema testado (enlace e amplificadores).

Para o bloco de amplificação (descrito na Figura 3.1(a)), a topologia de amplificação híbrida mais complexa utilizada experimentalmente é composta pelas tecnologias EDFA/DRA co-propagante na transmissão e DRA contra-propagante/LRA/EDFA na recepção. Na transmissão experimenta-se também o amplificador composto somente pela tecnologia EDFA, e na recepção são experimentados amplificadores compostos pelas combinações das tecnologias DRA contra-propagante, LRA e EDFA. 
Ao longo deste capítulo serão detalhados, para cada comprimento de enlace e topologia de amplificação óptica experimentada, os níveis de bombeio utilizados nas tecnologias de amplificação, as configurações de compensação de dispersão cromática utilizadas (compensação eletrônica ou discreta, de forma completa ou parcial), e os resultados serão caracterizados através do nível de OSNR e taxa de erro de bit (BER) obtidos no sinal recebido para cada topologia de amplificação e cada comprimento de fibra experimentado.

No experimento mono-canal, para cada comprimento de fibra (100, 150 e $200 \mathrm{~km})$, são experimentadas inicialmente as topologias de amplificação não-híbridas na transmissão e ambas na recepção. Com o aumento do comprimento da fibra para $250 \mathrm{~km}$, a degradação da OSNR na recepção, requisita o uso de estruturas híbridas de amplificação não só na recepção mas também na transmissão, visando aumento da OSNR por meio de incremento da potência de lançamento/recepção (EDFA), e/ou ganho distribuído na fibra de transmissão (DRA).

Porém, para o comprimento de enlace acima de $250 \mathrm{~km}$, além das estruturas híbridas de amplificação, a potência de lançamento teve que ser cuidadosamente ajustada, visando minimizar os efeitos não-lineares gerados ao longo da fibra e maximizar a OSNR do sinal na recepção, permitindo assim alcançar comprimentos de enlaces sem repetição de até $300 \mathrm{~km}$. Após realização do experimento mono-canal, analisados os dados experimentais e definida a topologia de amplificação que apresentou o melhor desempenho, esta topologia é utilizada no experimento DWDM.

No experimento DWDM foi investigada a melhor alocação dos canais transmitidos assim como o número de canais transmitidos, seguido dos ajustes de potência lançada visando minimizar os efeitos não-lineares e maximizar a OSNR de todos os canais transmitidos. Desta forma, foi possivel alcançar uma distância de $302 \mathrm{~km}$ para 40 canais de $112 \mathrm{~Gb} / \mathrm{s}$ transmitidos no sistema sem repetição, ou seja, um produto largura de banda x distância de 1353 Tb-km (de Oliveira et al., 2013a), um marco importante na transmissão sem repetição de canais $112 \mathrm{~Gb} / \mathrm{s}$ coerentes ao longo de fibras SSMF (ITU-T G.652) quando comparado aos experimentos publicados no estado-da-arte.

Verificando os experimentos sem repetição publicados recentemente, em (il Chang et al., 2012), uma transmissão similar sem repetição com 12 canais e $112 \mathrm{~Gb} / \mathrm{s}$ por canal ao longo de 347,2 km de fibra SSMF utilizando pré-compensação de dispersão foi reportada, porém resultando em um produto banda x distância em torno de $500 \mathrm{~Tb}-\mathrm{km}$. Também, em (CHANG et al., 2013) foi reportado uma cascata de dois spans com diferentes distâncias (303 e 343 km, respectivamente, com cabos submarinos) porém somente carregando 8 canais. Adicionalmente, em (Zhu et al., 2013), foi conduzido um experimento, que reportou uma distância mais longa $(445 \mathrm{~km}$ contra $302 \mathrm{~km}$ no caso demonstrado nesta tese), porém empregando fibras especiais (LEAF) para mitigar as não linearidades e permitir uso de amplificação Raman de altas ordens. Mesmo assim, obtém-se uma taxa banda $\mathrm{x}$ distância agregada menor $(3,2 \mathrm{~Tb} / \mathrm{s}$ x 4,48 Tb/s).

Nas próximas seções, inicialmente serão apresentados os componentes utilizados no experimento, assim como será dado foco no experimento mono-canal que visa determinar a melhor configuração de topologia de amplificação óptica híbrida para cada enlace, 
por meio da medida de performance (OSNR) dos canais transmitidos. Em seguida será descrito detalhadamente o experimento com 40 canais DWDM empregando a topologia de amplificação híbrida que apresentou melhor performance, e permitiu atingir o resultado de transmissão sem repetição no estado da arte.

\subsection{Transmissor de 112 Gb/s NRZ DP-QPSK}

Para cada uma das topologias de amplificadores e comprimentos de enlace experimentados, foi transmitido um canal óptico com taxa e formato de modulação $112 \mathrm{~Gb} / \mathrm{s}$ NRZ-DP-QPSK (no experimento DWDM, dos 40 canais transmitidos apenas o canal de teste é modulado), como ilustrado na Figura 3.1(a).

O transmissor $112 \mathrm{~Gb} / \mathrm{s}$ ilustrado na Figura 3.1(a), utiliza formato de modulação NRZ Dual Polarization-Quadrature Phase Shift Keying (NRZ DP-QPSK). No transmissor, um laser de comprimento de onda de 1550,8 nm (experimento mono-canal) é dividido via divisor óptico e acoplado a dois moduladores de fase e quadratura (IQ) com duas linhas de dados de $28 \mathrm{~Gb} / \mathrm{s}$ (56 Gbaud/s) cada. Entretanto, para que seja possível transmitir $112 \mathrm{~Gb} / \mathrm{s}$ de maneira independente, os sinais de 56 Gbaud/s são transmitidos em polarizações ortogonais, de modo que não ocorra interferência entre eles. Portanto, um dos sinais passa por um componente rotacionador de polarização de $90^{\circ}$. Por fim, ambas as polarizações são combinadas por um combinador de polarização (PBC), resultando em um sinal modulado com $112 \mathrm{~Gb} / \mathrm{s}$ DP-QPSK utilizando a codificação binária NRZ.

Na saída dos transmissores há um EDFA e/ou DRA co-propagante para amplificar o sinal modulado antes de lançá-lo no sistema óptico. A potência total de saída do amplificador é ajustada para um valor em torno de $10 \mathrm{dBm}$ (por canal), visando uma melhor relação entre potência de saída com baixa excitação de efeitos não lineares (otimizado para o maior comprimento de enlace testado). A Figura 3.2(a) ilustra a constelação do sinal $112 \mathrm{~Gb} / \mathrm{s}$ DP-QPSK ao ser transmitido no sistema com os amplificadores a serem testados, a Figura 3.2(b) ilustra o espectro do sinal de transmissão e a Figura 3.2(c) ilustrada o diagrama de olho do mesmo sinal de transmissão 112 Gb/s DP-QPSK.

\subsection{Receptor 112 Gb/s NRZ DP-QPSK}

O receptor do canal de 112 Gb/s NRZ DP-QPSK ilustrado na Figura 3.1(a) é utilizado para realizar a recepção coerente do sinal que foi modulado em duas polarizações, fase e quadratura. O sinal recebido passa por um filtro óptico (passa banda com largura espectral de $100 \mathrm{GHz}$ ), que tem por objetivo separar somente o canal a ser recebido, além de reduzir a potência de ruído que será detectada no receptor. Uma vez separado o canal a ser recebido dos demais canais, este sinal passa por um divisor ortogonal de polarizações (PBS), e o sinal produzido por um laser oscilador local (LO) com o mesmo comprimento de onda do laser da transmissão $(1550,8 \mathrm{~nm})$ também tem suas polarizações divididas por outro PBS. Ambas as polarizações, do sinal e do oscilador local, são direcionadas para as híbridas de $90^{\circ}$, que realizam interferência (batimento) destes componentes (como já ilustrado na Figura 2.5). Em seguida, os sinais de saída das híbri- 


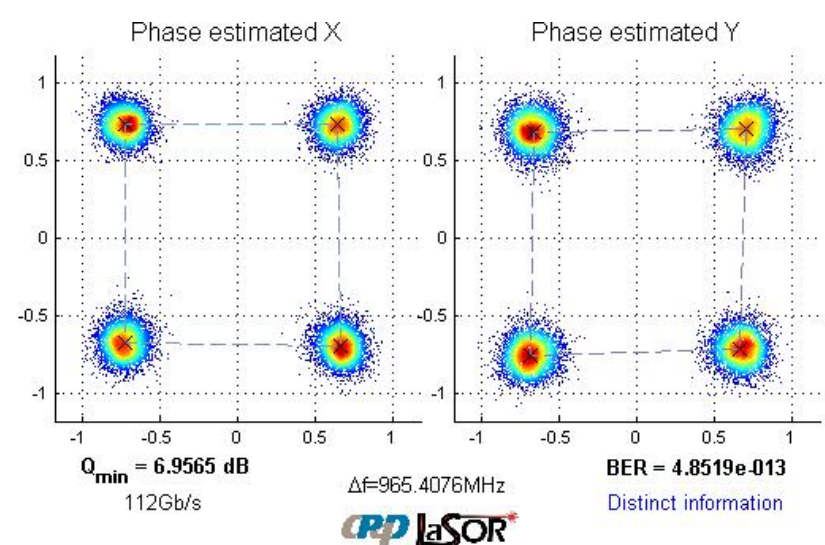

(a)

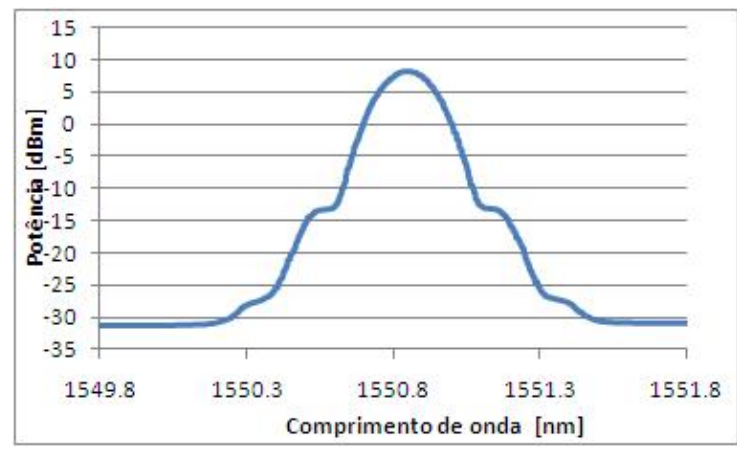

(b)

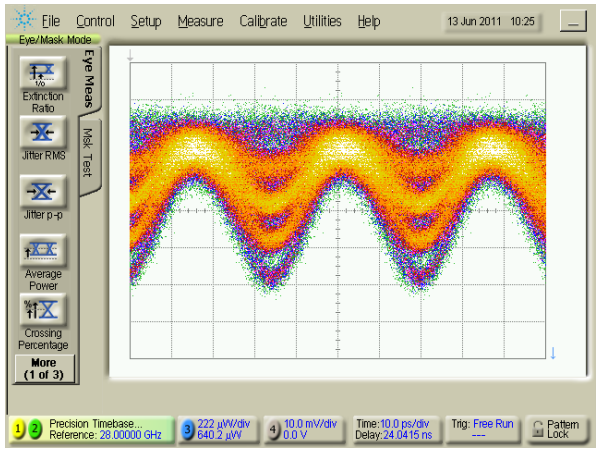

(c)

Figura 3.2: (a) Constelação, (b) espectro e (c) diagrama de olho do sinal de transmissão $112 \mathrm{~Gb} / \mathrm{s}$ $D P-Q P S K$.

das de 90 graus são detectadas por fotodetectores balanceados, que produzirão quatro linhas de $28 \mathrm{~Gb} / \mathrm{s}$. A Figura 3.2 ilustra a constelação, espectro e diagrama de olho de um sinal transmitido de $112 \mathrm{~Gb} / \mathrm{s}$ NRZ DP-QPSK.

Os sinais foto-detectados passam pelo processamento digital de sinais (DSP) executado off-line (devido uso de um osciloscópio de alta amostragem) para equalização de efeitos impostos pela propagação do sinal na fibra óptica, para que após o DSP, o sinal transmitido seja recuperado (Oliveira et al., 2011b). A Figura 3.3 mostra os passos realizados pelo processamento digital de sinais para recuperação do sinal. No DSP os seguintes procedimentos são realizados: ortonormalização, compensação de dispersão cromática (CD), recuperação de relógio, demultiplexação de polarização, estimação de frequência e estimação de fase.

Como discutido anteriormente, com a utilização de formatos de modulação avançados, a eficiência espectral é aumentada, porém em contrapartida, o sinal torna-se mais sensível ao ruído, assim é necessário que a inserção de ruído do sistema óptico seja menor em comparação aos sistemas atuais, para permitir o tráfego de sinais de 112 $\mathrm{Gb} / \mathrm{s}$.

Além disso, os níveis de potência e OSNR devem ser maiores para tais formatos de modulação serem recebidos livre de erros. Assim, a utilização de uma topologia de amplificação híbrida que reduza efetivamente a inserção de ruído aliado a alta potência de saída é fundamental para garantir a eficiência do sistema. Desta forma, a topologia 


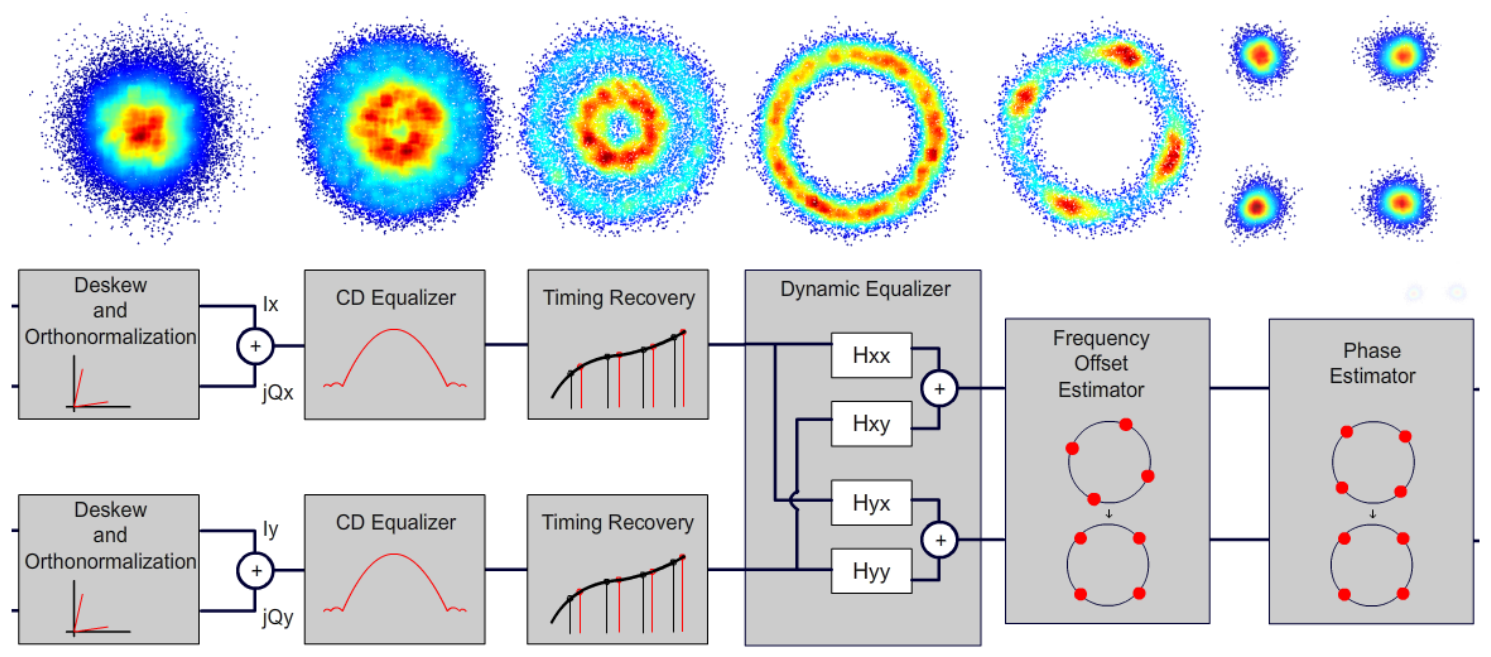

Figura 3.3: Passos do processamento digital de sinais executado sobre o sinal recebido de $112 \mathrm{~Gb} / \mathrm{s}$ NRZ DP-QPSK.

de amplificação ilustrada na Figura 3.1(a), e as demais topologias de amplificação óptica simples/híbridas experimentadas são detalhadas a seguir.

\subsection{Topologias de Amplificação Óptica Experimentadas}

Nesta seção são descritas as topologias de amplificação óptica simples ou híbrida investigadas (Figura 3.1(a)), visando determinar o desempenho de cada nos sistemas sem repetição, compostos por diversos comprimentos de fibra padrão (SSMF), carregado com um canal de $112 \mathrm{~Gb} / \mathrm{s}$ NRZ DP-QPSK (monocanal).

Na construção das topologias de pré-amplificação óptica simples ou híbrida, vale salientar que, devido à alta potência de saída fornecida pela tecnologia EDFA, a mesma sempre foi utilizada no estágio de amplificação diretamente ligado à saída da topologia construída, enquanto à tecnologia DRA contra-propagante sempre foi utilizada no estágio ligado diretamente na entrada da topologia construída, por fornecer ganho distribuído no enlace de transmissão. Nas configurações de LRA em DCM o uso do bombeio contra-propagante foi priorizado devido ao melhor custo/desempenho de amplificação e ruído, frente à configuração de bombeio co-propagante (Headley e Agrawal, 2005).

Para enlaces de fibra SSMF maiores que $200 \mathrm{~km}$, foram testadas duas diferentes topologias de amplificação de potência, uma composta somente pela tecnologia EDFA, e outra baseada em uma topologia de amplificação híbrida EDFA combinada com Raman distribuído co-propagante. Essa necessidade surge devido à alta atenuação imposta por enlaces maiores que $200 \mathrm{~km}$ sem repetição.

Como a tecnologia de transmissão de $112 \mathrm{~Gb} / \mathrm{s}$ NRZ DP-QPSK com recepção coerente realiza a compensação de efeitos lineares através de algoritmos de processamento digital de sinais (DSP) aplicados sobre o sinal recebido (Savory, 2008), compensando o efeito de dispersão cromática com maior precisão que fibras discretas DCF (Alfiad et al., 2009a), neste experimento, sempre que possivel, foi dada prioridade à compensação de dispersão via DSP. Desta forma, só não será compensada a CD através de DSP, quando a topologia Raman concentrado (LRA) estiver presente no amplificador híbrido avaliado, 
onde a compensação de dispersão é realizada na fibra do meio de amplificação (DCF). Desta forma, as topologias de amplificação simples e híbrida a serem avaliadas são:

- Booster EDFA na transmissão e EDFA na recepção (Tx EDFA + Rx EDFA);

- Booster EDFA na transmissão e Raman distribuído contra-propagante na recepção (Tx EDFA + Rx DRA);

- Booster EDFA na transmissão e Híbrido LRA/EDFA na recepção (Tx EDFA + Rx LRA/EDFA);

- Booster EDFA na transmissão e Híbrido DRA contra-propagante/LRA na recepção (Tx EDFA + Rx DRA/LRA);

- Booster EDFA na transmissão e Híbrido DRA contra-propagante/EDFA na recepção (Tx EDFA + Rx DRA/EDFA);

- Booster EDFA na transmissão e Híbrido DRA contra-propagante/LRA/EDFA na recepção (Tx EDFA + Rx DRA/LRA/EDFA);

- Híbrido Booster EDFA/DRA co-propagante na transmissão e Híbrido DRA contrapropagante/EDFA na recepção (Tx EDFA/DRA + Rx DRA/EDFA);

- Híbrido Booster EDFA/DRA co-propagante na transmissão e Híbrido DRA contrapropagante/LRA/EDFA na recepção (Tx EDFA/DRA + Rx DRA/LRA/EDFA);

Nas próximas subseções serão detalhadas as estruturas (circuito óptico) dos amplificadores, suas configurações de bombeio para cada comprimento de enlace (quando possível o teste) e será descrito o esquema de compensação de dispersão (compensação eletrônica, completa ou parcial com DCM).

\subsubsection{Tx EDFA + Rx EDFA}

A primeira topologia de amplificação testada no sistema de comunicações ópticas com canal de $112 \mathrm{~Gb} / \mathrm{s}$ utilizou amplificador de potência (Booster) EDFA para amplificar o sinal transmitido na fibra SSMF (G.652) do enlace, e utilizou um pré-amplificador EDFA para amplificar o sinal antes do receptor. O circuito óptico dos EDFAs são ilustrados na Figura 3.4.

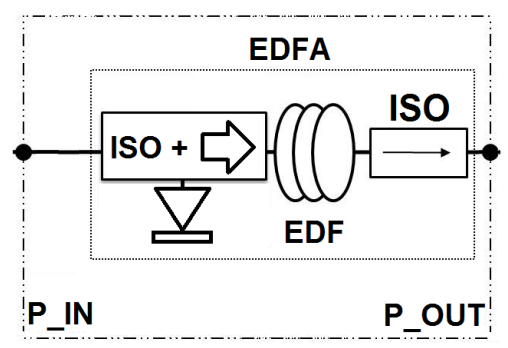

Figura 3.4: Circuito óptico do amplificador a fibra dopada com Érbio (EDFA) de transmissão e recepção. 
Como ilustrado na Figura 3.4, os EDFAs utilizados empregam bombeio co-propagante, com comprimento de onda de $980 \mathrm{~nm}$ (este comprimento de onda foi escolhido devido a característica de ruído melhorada em comparação com o bombeio de $1480 \mathrm{~nm}$ ). Sinal e bombeio foram acoplados na fibra dopada com Érbio (meio de amplificação) através de um acoplador WDM/ISO, composto por filtros passa banda, que combinam diferentes faixas espectrais, integrados a um isolador para evitar retro-espalhamentos para o enlace de transmissão. Na saída do amplificador utilizou-se outro isolador para evitar que retro-espalhamentos do enlace interferissem na amplificação.

Com essa topologia de amplificação óptica foi possível testar o sistema mono-canal de $112 \mathrm{~Gb} / \mathrm{s}$ nos comprimentos de enlace de 100, 150 e $200 \mathrm{~km}$. Uma vez que nenhum dos amplificadores dessa topologia utilizou fibras compensadoras de dispersão, o esquema de compensação de dispersão escolhido emprega processamento digital de sinais (DSP) no receptor.

Para o sistema mono-canal de $112 \mathrm{~Gb} / \mathrm{s}$, no amplificador da transmissão foi utilizado um nível de bombeio em torno de $70 \mathrm{~mW}$ (que forneceu uma potência de saída em torno de $10 \mathrm{dBm}$ ) para que o sinal transmitido na fibra possuísse o melhor compromisso entre amplificação e geração de efeitos não lineares, reduzindo principalmente o efeito de auto modulação de fase (SPM). No amplificador de recepção o sinal foi amplificado com um nível de bombeio em torno de $200 \mathrm{~mW}$ (potência de saída em torno de $14 \mathrm{dBm}$ ), e na recepção o ruído fora da banda do sinal foi filtrado (através de um filtro com largura de banda de $100 \mathrm{GHz}$ ). Quando necessário, utilizou-se um atenuador variável para evitar saturação no receptor.

\subsubsection{Tx EDFA + Rx DRA}

A segunda topologia de amplificação testada no sistema de comunicações ópticas com canal de $112 \mathrm{~Gb} / \mathrm{s}$ utilizou amplificador de potência (Booster) EDFA para amplificar o sinal transmitido na fibra SSMF (G.652) do enlace, e utilizou um amplificador Raman distribuído (DRA) contra-propagante para amplificar o sinal antes do receptor. Os circuitos ópticos dos amplificadores são ilustrados na Figura 3.5.

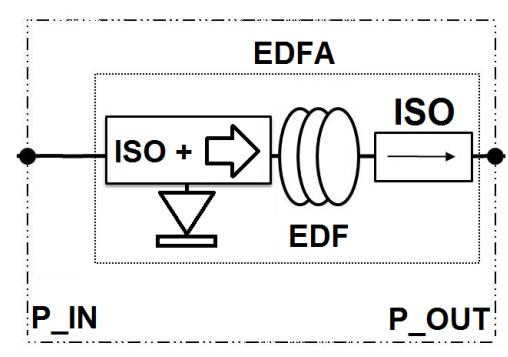

(a)

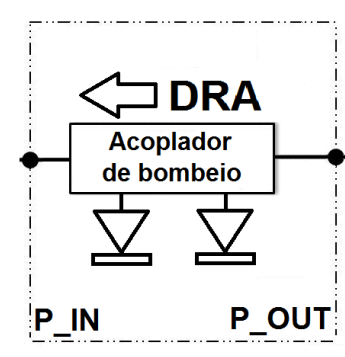

(b)

Figura 3.5: (a) Circuito óptico do amplificador a fibra dopada com Érbio (EDFA) de transmissão e (b) circuito óptico do amplificador distribuído Raman (DRA) contra-propagante de recepção.

O EDFA ilustrado na Figura 3.5(a) foi o mesmo amplificador da Figura 3.4. O DRA ilustrado na Figura 3.5(b) foi um amplificador Raman distribuído com dois bombeios contra-propagantes nos comprimentos de onda de 1440 nm e 1450 nm (os comprimen- 
tos de onda foram escolhidos com o objetivo de maximizar o ganho na Banda C). Os bombeios foram multiplexados em um combinador de bombeios Raman, e lançados no enlace de transmissão na direção contra-propagante.

Com essa topologia de amplificação óptica foi possível testar o sistema mono-canal de $112 \mathrm{~Gb} / \mathrm{s}$ somente para o comprimento de enlace de $100 \mathrm{~km}$ (devido à baixa potência de saída fornecida pelo amplificador DRA). O esquema de compensação de dispersão escolhido foi a compensação de CD via processamento digital de sinais (DSP) no receptor.

Para o sistema mono-canal de $112 \mathrm{~Gb} / \mathrm{s}$, no amplificador da transmissão foi utilizado a mesma configuração de bombeio da seção 3.3.1. No amplificador de recepção o sinal foi amplificado com um nível de bombeio em torno de $460 \mathrm{~mW}$, sendo $230 \mathrm{~mW}$ para cada bombeio do amplificador DRA contra-propagante. Na saída, o ruído fora da banda do sinal foi filtrado através de um filtro com largura de banda de $100 \mathrm{GHz}$ antes do sinal ser recebido (devido ao baixo nível de sinal recebido, não foi necessária atenuação antes da recepção).

O uso da topologia DRA contra-propagante na recepção forneceu baixo nível de sinal amplificado com relação à tecnologia EDFA, porém forneceu um nível de ruído reduzido, também quando comparado a tecnologia EDFA.

\subsubsection{Tx EDFA + Rx LRA/EDFA}

A terceira topologia de amplificação testada utilizou amplificador de potência (Booster) EDFA para amplificar o sinal transmitido na fibra SSMF (G.652) do enlace, e utilizou um amplificador híbrido composto por Raman concentrado (LRA) e EDFA para amplificar o sinal antes do receptor. Os circuitos óptico dos amplificadores são ilustrados na Figura 3.6.

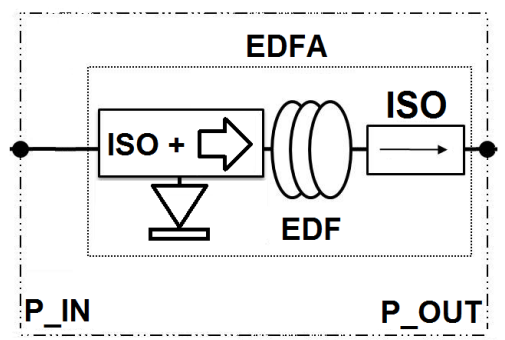

(a)

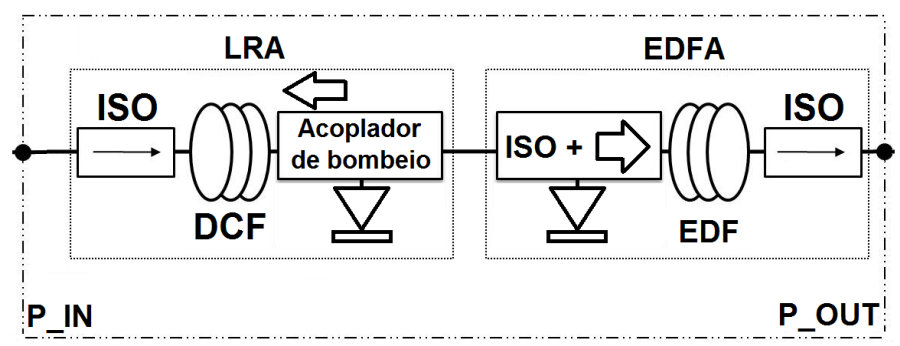

(b)

Figura 3.6: (a) Circuito óptico do amplificador a fibra dopada com Érbio (EDFA) de transmissão e (b) circuito óptico do amplificador híbrido composto pelo amplificador concentrado Raman em DCM (LRA) com EDFA na recepção.

O EDFA ilustrado na Figura 3.6(a) foi o mesmo amplificador da Figura 3.4. O amplificador híbrido ilustrado na Figura 3.6(b) foi um amplificador Raman concentrado com bombeio contra-propagante no comprimento de onda de $1450 \mathrm{~nm}$, seguido por um amplificador EDFA igual ao da seção 3.3.1. O bombeio do LRA foi combinado com o sinal em um acoplador e lançado na direção contra-propagante na DCF (fibra contida no módulo de compensação de dispersão - DCM), onde o sinal se propagou na direção co-propagante e foi amplificado ao longo da DCF, chegando o sinal amplificado na 
saída do amplificador LRA. Foi utilizado um isolador na entrada do amplificador Raman concentrado para evitar o retro-espalhamentos do LRA para a fibra do enlace de transmissão.

As características da fibra DCF que constituíram os módulos DCM foram: atenuação de $0,578 \mathrm{~dB} / \mathrm{km}$, coeficiente de dispersão cromática de $-168,598 \mathrm{ps} / \mathrm{nm} / \mathrm{km}$ e coeficiente de inclinação da dispersão cromática de $-0,606 \mathrm{ps} / \mathrm{nm}^{2} / \mathrm{km}$. Os módulos DCM disponíveis foram projetados para compensação de 1700ps de CD (composto por $10 \mathrm{~km}$ de fibra DCF e produzindo aproximadamente $6,8 d B$ de atenuação, usado para compensar dispersão cromática em $100 \mathrm{~km}$ de fibra SSMF G.652), 1360ps de CD (8km de fibra DCF e 5, $62 \mathrm{~dB}$ de atenuação para compensar CD em $80 \mathrm{~km}$ de fibra SSMF), 1020ps ( $6 \mathrm{~km}$ de fibra DCF e 4, $47 \mathrm{~dB}$ de atenuação para compensar CD em $60 \mathrm{~km}$ de fibra SSMF) e $680 \mathrm{ps}$ ( $4 \mathrm{~km}$ de fibra DCF e 3, 31 dB de atenuação para compensar CD em $40 \mathrm{~km}$ de fibra SSMF).

Com essa topologia de amplificação óptica foi possível testar o sistema mono-canal de $112 \mathrm{~Gb} / \mathrm{s}$ para os comprimentos de enlace de 100 e $150 \mathrm{~km}$ (devido aos níveis de ruído gerados pela combinação de LRA/EDFA e a atenuação adicional da DCM). Para essa topologia de amplificação o esquema de compensação de dispersão cromática foi realizado através dos módulos DCM que foram utilizados no amplificador LRA no receptor (a compensação eletrônica neste caso foi desativada). Para compensação CD no enlace de $100 \mathrm{~km}$ foi utilizado um módulo DCM capaz de compensar 1700 ps de CD no LRA (compensação completa), enquanto no enlace de $150 \mathrm{~km}$ foi utilizado dois módulos de DCM totalizando 2380 ps de compensação de CD no LRA (compensação parcial).

Para o sistema mono-canal de $112 \mathrm{~Gb} / \mathrm{s}$, no EDFA da transmissão e recepção foi utilizado a mesma configuração de bombeio da seção 3.3.1. No amplificador LRA da recepção o sinal foi amplificado com um nível de bombeio em torno de $300 \mathrm{~mW}$ no comprimento de onda de $1450 \mathrm{~nm}$ (contra-propagante). Na saída, o ruído fora da banda do sinal foi filtrado através de um filtro com largura de banda de $100 \mathrm{GHz}$ antes do sinal ser recebido (quando necessário, utilizou-se um atenuador variável para evitar saturação no receptor).

O uso da topologia de amplificação híbrida LRA/EDFA na recepção forneceu amplificação, aliada à compensação de dispersão cromática para o sinal amplificado, porém produziu um nível de ruído maior para as tecnologias de amplificação combinadas, quando comparado somente à tecnologia EDFA.

\subsubsection{Tx EDFA + Rx DRA/LRA}

A quarta topologia de amplificação testada utilizou amplificador de potência (Booster) EDFA para amplificar o sinal transmitido na fibra SSMF (G.652) do enlace, e utilizou um amplificador híbrido composto por um Raman distribuído (DRA) contra-propagante combinado com um Raman concentrado (LRA) para amplificar o sinal antes do receptor. Os circuitos ópticos dos amplificadores são ilustrados na Figura 3.7.

O EDFA ilustrado na Figura 3.7(a) foi o mesmo amplificador da Figura 3.4. O Amplificador híbrido ilustrado na Figura 3.7(b) foi a combinação do mesmo amplificador Raman distribuído com dois bombeios contra-propagantes da seção 3.3.2 seguido pelo mesmo amplificador Raman concentrado com bombeio contra-propagante da seção 3.3.3. 


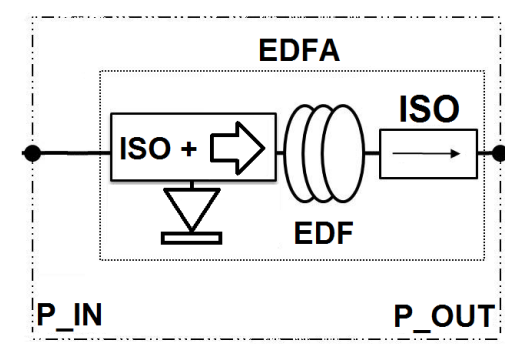

(a)

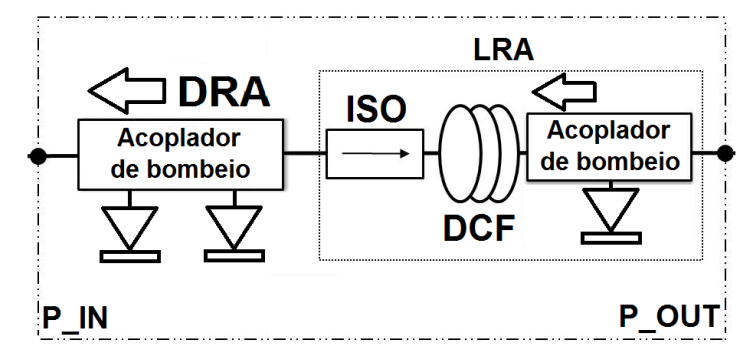

(b)

Figura 3.7: (a) Circuito óptico do amplificador a fibra dopada com Érbio (EDFA) de transmissão $e$ (b) circuito óptico do amplificador híbrido composto pelo amplificador Raman distribuído contrapropagante (DRA) combinado com um amplificador concentrado Raman em DCM (LRA) na recepção.

Com essa topologia de amplificação óptica foi possivel testar o sistema mono-canal de $112 \mathrm{~Gb} / \mathrm{s}$ somente para o comprimento de enlace de $100 \mathrm{~km}$ (devido à baixa potência de saída gerada pela combinação do DRA/LRA e a atenuação adicional da DCM). Para essa topologia de amplificação o esquema de compensação de dispersão cromática foi realizado através dos módulos DCM que foram utilizados no amplificador LRA no receptor (a compensação eletrônica neste caso foi desativada). Para compensação CD no enlace de $100 \mathrm{~km}$ foi utilizado um módulo DCM capaz de compensar 1700 ps de CD no LRA (compensação completa).

Para o sistema mono-canal de $112 \mathrm{~Gb} / \mathrm{s}$, no EDFA da transmissão foi utilizado a mesma configuração de bombeio da seção 3.3.1. No amplificador LRA de recepção o sinal foi amplificado com um nível de bombeio em torno de $200 \mathrm{~mW}$ no comprimento de onda de $1450 \mathrm{~nm}$ (contra-propagante), e para o amplificador Raman distribuído foi utilizado a mesma configuração de bombeios do DRA da seção 3.3.2. Na saída, o ruído fora da banda do sinal foi filtrado através de um filtro com largura de banda de $100 \mathrm{GHz}$ antes da recepção do sinal.

O uso da topologia de amplificação híbrida DRA/LRA na recepção forneceu amplificação com baixo nível de ruído, aliado a compensação de dispersão cromática para o sinal amplificado, porém produziu um baixo nível de potência de saída para as tecnologias de amplificação combinadas, quando comparado a somente à tecnologia EDFA e/ou tecnologia de amplificação híbrida com EDFA.

\subsubsection{Tx EDFA + Rx DRA/EDFA}

A quinta topologia de amplificação testada utilizou amplificador de potência (Booster) EDFA para amplificar o sinal transmitido na fibra SSMF (G.652) do enlace, e utilizou um amplificador híbrido composto por um Raman distribuído (DRA) contra-propagante combinado com EDFA para amplificar o sinal antes do receptor. Os circuitos ópticos dos amplificadores são ilustrados na Figura 3.8.

O EDFA ilustrado na Figura 3.8(a) foi o mesmo amplificador da Figura 3.4. O Amplificador híbrido ilustrado na Figura 3.8(b) foi a combinação do mesmo amplificador Raman distribuído com dois bombeios contra-propagantes da seção 3.3.2 seguido pelo mesmo EDFA da seção 3.3.1. 


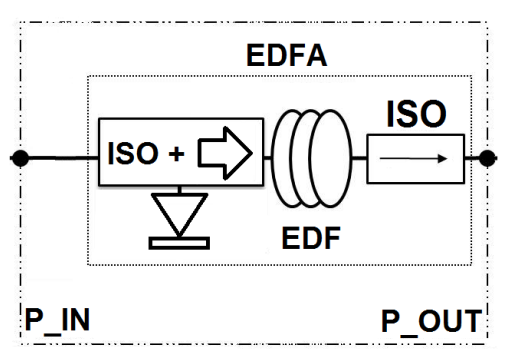

(a)

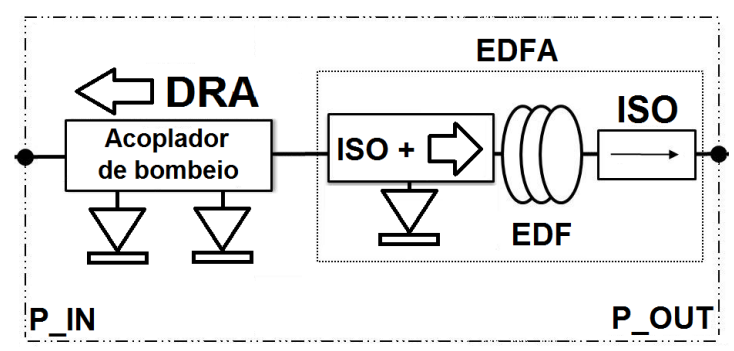

(b)

Figura 3.8: (a) Circuito óptico do amplificador a fibra dopada com Érbio (EDFA) de transmissão $e$ (b) circuito óptico do amplificador híbrido composto pelo amplificador Raman distribuído contrapropagante (DRA) combinado com um EDFA na recepção.

Com essa topologia de amplificação óptica foi possivel testar o sistema mono-canal de $112 \mathrm{~Gb} / \mathrm{s}$ para os comprimentos de enlace de 100, 150, 200 e $250 \mathrm{~km}$. Como nenhum dos amplificadores dessa topologia utilizou fibras compensadoras de dispersão, o esquema de compensação de dispersão escolhido foi a compensação de CD via processamento digital de sinais (DSP) no receptor.

Para o sistema mono-canal de $112 \mathrm{~Gb} / \mathrm{s}$, no EDFA da transmissão e recepção foi utilizado a mesma configuração de bombeio da seção 3.3.1. No amplificador Raman distribuído contra-propagante com dois bombeios foi utilizado a mesma configuração de bombeios do DRA da seção 3.3 .2 para o enlace de $100 \mathrm{~km}$, porém, para os enlaces de 150, 200 e $250 \mathrm{~km}$ os níveis de potência dos lasers de bombeio de 1440/1450 nm foram respectivamente 220/220,360/360 e 360/360 mW. Na saída, o ruído fora da banda do sinal foi filtrado através de um filtro com largura de banda de $100 \mathrm{GHz}$ antes do sinal ser recebido (quando necessário, utilizou-se um atenuador variável para evitar saturação no receptor).

O uso da topologia de amplificação híbrida DRA/EDFA na recepção forneceu baixo nível de ruído no DRA aliado a alta potência de saída para o sinal amplificado no EDFA, fazendo com que esta topologia atingisse comprimentos de enlace até $250 \mathrm{~km}$. Além disso, devido à utilização da compensação de dispersão eletrônica, que evitou a atenuação do sinal por não requerer compensação via módulo DCM, aumentando a margem de potência do sistema.

\subsubsection{Tx EDFA + Rx DRA/LRA/EDFA}

A sexta topologia de amplificação testada utilizou amplificador de potência (Booster) EDFA para amplificar o sinal transmitido na fibra SSMF (G.652) do enlace, e utilizou um amplificador híbrido composto por um Raman distribuído (DRA) contra-propagante combinado com amplificador Raman concentrado (LRA) e EDFA, para amplificar o sinal antes do receptor. Os circuitos ópticos dos amplificadores são ilustrados na Figura 3.9.

O EDFA ilustrado na Figura 3.9(a) foi o mesmo amplificador da Figura 3.4. O amplificador híbrido ilustrado na Figura 3.9(b) foi a combinação do mesmo amplificador Raman distribuído com dois bombeios contra-propagantes da seção 3.3.2 seguido pelo mesmo LRA da seção 3.3.3 e o mesmo EDFA da seção 3.3.1. 


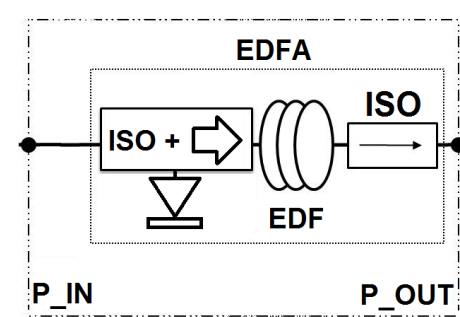

(a)

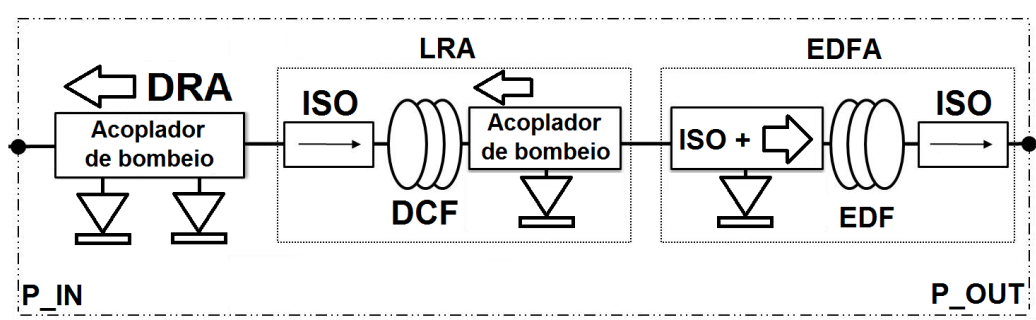

(b)

Figura 3.9: (a) Circuito óptico do amplificador a fibra dopada com Érbio (EDFA) de transmissão $e$ (b) circuito óptico do amplificador híbrido composto pelo amplificador Raman distribuído contrapropagante (DRA) combinado amplificador Raman concentrado (LRA) e EDFA na recepção.

Com essa topologia de amplificação óptica foi possível testar o sistema mono-canal de $112 \mathrm{~Gb} / \mathrm{s}$ para os comprimentos de enlace de 100, 150, 200 e $250 \mathrm{~km}$. Para essa topologia de amplificação, o esquema de compensação de dispersão cromática emprega os módulos DCM que foram utilizados no amplificador LRA no receptor (a compensação eletrônica neste caso foi desativada). Para compensação de CD no enlace de $100 \mathrm{~km}$ foi utilizado um módulo DCM capaz de compensar 1700 ps de CD no LRA (compensação completa). Para compensação de CD no enlace de $150 \mathrm{~km}$ foi utilizado um módulo DCM capaz de compensar 2380 ps de CD no LRA (compensação residual). Para compensação de CD no enlace de $200 \mathrm{~km}$ foi utilizado dois módulos DCM capaz de compensar 3400 ps de CD no LRA (compensação completa). Para reduzir a ASE retro-espalhada dentro do LRA, foi utilizado um isolador entre os módulos DCM no LRA. Para compensação de CD no enlace de $250 \mathrm{~km}$, utilizou-se um esquema de compensação residual de CD baseado no mesmo esquema de compensação do enlace de $100 \mathrm{~km}$ (DCM de 1700 ps) no LRA, combinado com um módulo DCM capaz de compensar 2380 ps de CD na saída do EDFA.

Para o sistema mono-canal de $112 \mathrm{~Gb} / \mathrm{s}$, no EDFA da transmissão e recepção foi utilizada a mesma configuração de bombeio da seção 3.3.1. No amplificador Raman concentrado, para todos os enlaces o nível de potência do laser de bombeio de 1450 $\mathrm{nm}$ foi sempre $150 \mathrm{~mW}$. No amplificador Raman distribuído contra-propagante com dois bombeios, para os enlaces de 100,150, 200 e $250 \mathrm{~km}$ os níveis de potência dos lasers de bombeio de 1440/1450 $\mathrm{nm}$ foram respectivamente 220/220, 220/220, 220/220 e $360 / 360 \mathrm{~mW}$. Na saída, o ruído fora da banda do sinal foi filtrado através de um filtro com largura de banda de $100 \mathrm{GHz}$ antes do sinal ser recebido (quando necessário, utilizou-se um atenuador variável para evitar saturação no receptor).

O uso da topologia de amplificação híbrida DRA/LRA/EDFA na recepção forneceu baixo nível de ruído devido ao DRA, aliado à amplificação com compensação de dispersão no LRA e alta potência de saída para o sinal amplificado no EDFA, fazendo com que esta topologia atingisse comprimentos de enlace até $250 \mathrm{~km}$. O grande problema do uso dessa topologia de amplificação híbrida é a complexidade e custo da fabricação deste amplificador. 


\subsubsection{Tx EDFA/DRA + Rx DRA/EDFA}

A sétima topologia de amplificação testada utilizou um amplificador híbrido de potência (Hybrid Booster) com as tecnologias EDFA com DRA co-propagante para amplificar o sinal transmitido antes e ao longo da fibra SSMF (G.652) do enlace, e utilizou um amplificador híbrido composto pela tecnologia DRA contra-propagante combinada com EDFA para amplificar o sinal antes de sua recepção. Os circuitos ópticos dos amplificadores são ilustrados na Figura 3.11.

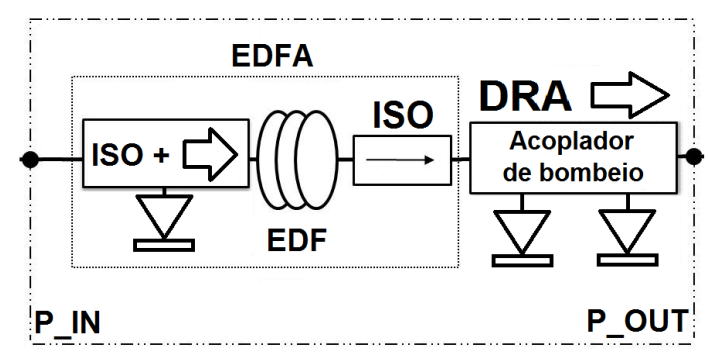

(a)

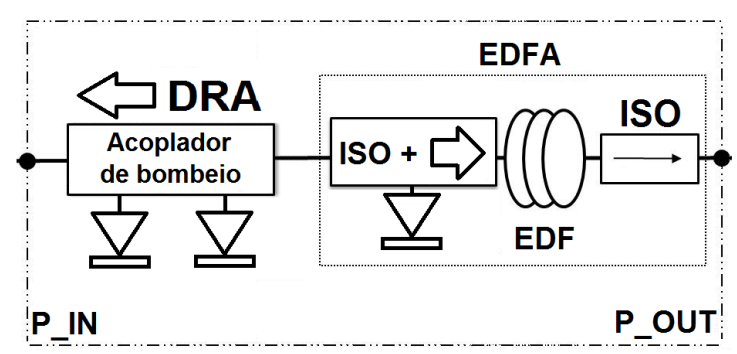

(b)

Figura 3.10: (a) Circuito óptico do amplificador híbrido de potência EDFA com DRA co-propagante na transmissão e (b) circuito óptico do amplificador híbrido DRA contra-propagante com EDFA na recepção.

O EDFA ilustrado no amplificador híbrido da Figura 3.10(a) foi o mesmo amplificador da Figura 3.4. O DRA co-propagante ilustrado na Figura 3.10(a) foi um amplificador Raman distribuído com dois bombeios contra-propagantes e comprimentos de onda de $1440 \mathrm{~nm}$ e $1450 \mathrm{~nm}$. Os bombeios foram combinados em um acoplador de bombeios Raman, e lançados no enlace de transmissão na direção co-propagante junto com o sinal amplificado pelo EDFA. Assim foi possível amplificar este sinal também ao longo do enlace de transmissão. O amplificador híbrido ilustrado na Figura 3.10(b) foi a combinação do mesmo amplificador Raman distribuído com dois bombeios contra-propagantes da seção 3.3.2 seguido do mesmo EDFA da seção 3.3.1.

Com essas topologias de amplificação óptica foi possivel testar o sistema monocanal de $112 \mathrm{~Gb} / \mathrm{s}$ para os comprimentos de enlace de 250 e $300 \mathrm{~km}$. Como nenhum dos amplificadores dessas topologias utilizaram como meio de amplificação fibras compensadoras de dispersão, o esquema de compensação de dispersão escolhido foi processamento digital de sinais (DSP) no receptor. Para compensação de CD no enlace de 250 e $300 \mathrm{~km}$ foi informado no algoritmo de processamento digital de sinais (DSP) o coeficiente de dispersão cromática de $17 \mathrm{ps} / \mathrm{nm} / \mathrm{km}$ da fibra SSMF utilizada na transmissão e seu respectivo comprimento de enlace, para que o algoritmo de compensação de CD eletrônico calculasse a quantidade de CD acumulada (respectivamente 4250 e 5100 ps), e realizasse a compensação de CD via DSP.

No que se refere ao amplificador híbrido de transmissão para o sistema mono-canal de $112 \mathrm{~Gb} / \mathrm{s}$, no EDFA, para o enlace de $250 \mathrm{~km}$, foi utilizado a mesma configuração de bombeio da seção 3.3.1 (70 $\mathrm{mW}$ de bombeio e potência de saída em torno de 10 $\mathrm{dBm}$ ), e os bombeios do DRA co-propagantes foram ajustados para $100 \mathrm{~mW}$ de bombeio cada (1440 e $1450 \mathrm{~nm}$ ). Porém, para alcançar o comprimento de enlace de $300 \mathrm{~km}$, foi 
necessário o ajuste dos bombeios do amplificador híbrido de transmissão, ou seja, os bombeios do EDFA e DRA co-propagantes, foram ajustados para maximizar o ganho distribuído, minimizando a geração de efeitos não-lineares. Desta forma, foi alcançada a transmissão em enlace de $300 \mathrm{~km}$ por meio do ajuste do bombeio do EDFA para 55 $\mathrm{mW}$ (potência de saída em torno de 9,34 dBm), e os bombeios do DRA co-propagante de $1440 / 1450 \mathrm{~nm}$ foram ajustados para 160/260 $\mathrm{mW}$ respectivamente.

No amplificador híbrido de recepção o ajuste dos bombeios dos amplificadores foram os mesmos. Para o amplificador Raman distribuído contra-propagante com dois bombeios para os enlaces de 250 e $300 \mathrm{~km}$, os níveis de potência dos lasers de bombeio de 1440/1450 $\mathrm{nm}$ foram respectivamente $360 / 360 \mathrm{~mW}$, e o bombeio do EDFA foi ajustado para $200 \mathrm{~mW}$ (potência de saída em torno de $14 \mathrm{dBm}$ ). Na saída, o ruído fora da banda do sinal foi filtrado através de um filtro com largura de banda de $100 \mathrm{GHz}$ antes do sinal ser recebido (quando necessário, utilizou-se um atenuador variável para evitar saturação no receptor).

O uso da topologia de amplificação híbrida DRA/EDFA, tanto na transmissão quanto na recepção, forneceu baixo nível de ruído devido ao DRA, aliado a alta potência de saída para o sinal amplificado no EDFA, fazendo com que somente esta topologia vá além dos $250 \mathrm{~km}$ de alcance conseguidos pela topologia da seção 3.3.5.

\subsubsection{Tx EDFA/DRA + Rx DRA/LRA/EDFA}

A oitava e última topologia de amplificação testada utilizou um amplificador híbrido de potência com as tecnologias EDFA com DRA co-propagante para amplificar o sinal transmitido antes e ao longo da fibra SSMF (G.652) do enlace, e utilizou um amplificador híbrido composto pelas tecnologias DRA contra-propagante combinada com LRA e EDFA para amplificar o sinal antes de sua recepção. Os circuitos ópticos dos amplificadores são ilustrados na Figura 3.11.

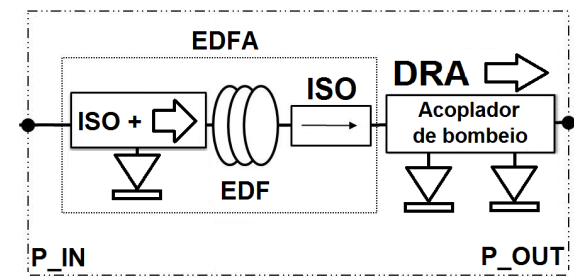

(a)

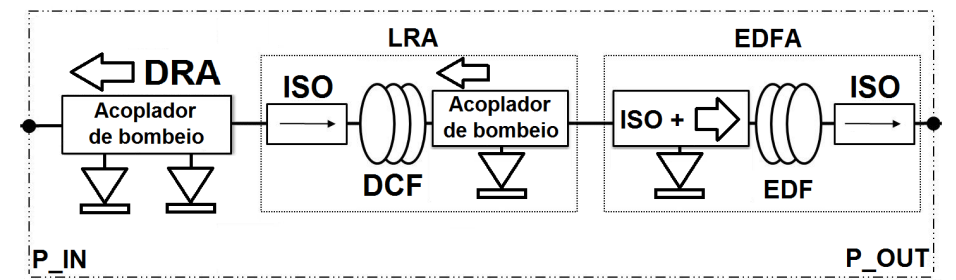

(b)

Figura 3.11: (a) Circuito óptico do amplificador híbrido de potência EDFA com DRA co-propagante na transmissão e (b) circuito óptico do amplificador híbrido composto pelo amplificador Raman distribuído contra-propagante (DRA) combinado amplificador Raman concentrado (LRA) e EDFA na recepção.

O amplificador híbrido de potência ilustrado na Figura 3.11(a) foi o mesmo amplificador da Figura 3.10(a). O amplificador híbrido ilustrado na Figura 3.11(b) foi a combinação do mesmo amplificador Raman distribuído com dois bombeios contra-propagantes da seção 3.3.2 seguido pelo mesmo LRA da seção 3.3.3 e o mesmo EDFA da seção 3.3.1.

Essa topologia de amplificação óptica foi utilizada para testar o sistema mono-canal de $112 \mathrm{~Gb} / \mathrm{s}$ para os comprimentos de enlaces de 250 e $300 \mathrm{~km}$. Porém a topologia de 
amplificação só obteve sucesso para o comprimento de enlace até $250 \mathrm{~km}$. Para essa topologia de amplificação o esquema de compensação de dispersão cromática foi realizado através dos módulos DCM que foram utilizados no amplificador LRA no receptor (a compensação eletrônica neste caso foi desativada). Para compensação de CD no enlace de $250 \mathrm{~km}$, utilizamos um esquema de compensação residual de CD baseado no mesmo esquema de compensação do enlace de $200 \mathrm{~km}$ (duas DCMs de 1700 ps) no LRA, combinado com um módulo DCM capaz de compensar 680 ps de CD (o equivalente a dispersão provocada por $40 \mathrm{~km}$ de SSMF) na saída do EDFA.

No que se refere ao amplificador híbrido de transmissão para o sistema mono-canal de $112 \mathrm{~Gb} / \mathrm{s}$, no EDFA para o enlace de $250 \mathrm{~km}$ foi utilizado a mesma configuração de bombeio da seção 3.3.1 (70 $\mathrm{mW}$ de bombeio e potência de saída em torno de $10 \mathrm{dBm}$ ), e os bombeios do DRA co-propagante foram ajustados para $100 \mathrm{~mW}$ de bombeio cada (1440 e $1450 \mathrm{~nm})$.

No amplificador híbrido de recepção, para o amplificador Raman distribuído contrapropagante com dois bombeios e enlace de $250 \mathrm{~km}$, os níveis de potência dos lasers de bombeio de 1440/1450 $\mathrm{nm}$ foram respectivamente 360/360 $\mathrm{mW}$. Para o amplificador Raman concentrado o nível de potência do laser de bombeio de $1450 \mathrm{~nm}$ foi $150 \mathrm{~mW}$, e o bombeio do EDFA foi ajustado para $200 \mathrm{~mW}$ (potência de saída em torno de $14 \mathrm{dBm}$ ). $\mathrm{Na}$ saída, o ruído fora da banda do sinal foi filtrado através de um filtro com largura de banda de $100 \mathrm{GHz}$ antes do sinal ser recebido (quando necessário, utilizou-se um atenuador variável para evitar saturação no receptor).

O uso da topologia de amplificação híbrida EDFA/DRA na entrada do enlace e DRA/LRA/EDFA na recepção forneceu baixo nível de ruído devido ao DRA, aliado à amplificação com compensação de dispersão no LRA e alta potência de saída para o sinal amplificado no EDFA, fazendo com que esta topologia atingisse comprimentos de enlace até $250 \mathrm{~km}$.

O grande problema do uso dessa topologia de amplificação híbrida reside na complexidade e custo da fabricação deste amplificador. Ademais, devido a utilização do LRA, apesar da mesma amplificar o sinal e compensar a dispersão cromática, o LRA insere um nível de ruído adicional em comparação com a topologia da seção 3.3.7, desta forma degradando a OSNR e não possibilitando essa topologia atingir comprimentos de enlace até $300 \mathrm{~km}$ para sistemas mono-canal de $112 \mathrm{~Gb} / \mathrm{s}$ com recepção coerente.

\subsection{Avaliação Experimental de Sistema sem Repetição Mono- Canal com Topologias de Amplificação Óptica Simples/Hi- bridas}

Para execução do experimento do sistema sem repetição mono-canal de $112 \mathrm{~Gb} / \mathrm{s}$ foram testados as topologias de amplificação óptica listadas na seção 3.3, para vários comprimentos de enlaces de fibra óptica padrão SSMF (G.652). Os comprimentos de enlace de fibra testados foram: 100, 150, 200, 250 e $300 \mathrm{~km}$, considerando apenas a amplificação na entrada e na saída do sistema (sistema sem repetição). A fibra SSMF 
disponível em laboratório é disposta em rolos de $50 \mathrm{~km}$ de fibra com conectores SC/APC na entrada e saída de cada rolo de fibra, dispersão em torno de 16,8-17 ps $/ \mathrm{nm} / \mathrm{km}$ para o comprimento de onda de $1550,8 \mathrm{~nm}$ e atenuação média de 0,18-0,19 dB/ km $(0,19$ $0,20 \mathrm{~dB} / \mathrm{km}$ considerando as perdas dos conectores de entrada e saída). A topologia de amplificação óptica híbrida na transmissão (EDFA/DRA co-propagante) só foi utilizada para comprimentos de enlaces maiores que $200 \mathrm{~km}$, devido a necessidade por uma melhora de OSNR visando atingir ao menos o nível mínimo de OSNR requerida na recepção do canal de $112 \mathrm{~Gb} / \mathrm{s}$ para os comprimentos de enlace de 250 e $300 \mathrm{~km}$.

Os resultados apresentados foram categorizados em função de três parâmetros fundamentais: OSNR recebida $(\mathrm{dB})$, potência recebida $(\mathrm{dBm})$ e taxa de erro de bit (BER) por comprimento de enlace para cada topologia de amplificação óptica testada, para o sistema mono-canal de $112 \mathrm{~Gb} / \mathrm{s}$.

A taxa de erro de bit (BER) medida pode ser contada até a BER de $2,50 \cdot 10^{-05}$ (devido aos 40000 símbolos adquiridos para cada medida experimental). Valores menores que este foram estimados a partir do fator $\mathrm{Q}$ (medidas marcadas com $\dagger$ ). Foram consideradas apenas as topologias de amplificação óptica que forneceram BER antes do FEC menores que $4 \cdot 10^{-03}$, por esta ser a taxa limite (FEC limit) que pode ser corrigida para taxa para $1,00 \cdot 10^{-13}$ (situação livre de erro) utilizado o código corretor de erro interleaved BCH(1020,988) 10-fold iterative decoding (ITU-T G.975-1 I9). Porém há um problema adicional no receptor para sinais com OSNR acima de $25 \mathrm{~dB}$ (que fornecem medidas de BER abaixo de $1,00 \cdot 10^{-09}$ ). Nestes casos, o ruído óptico começa a ser mascarado pelo ruído de quantização do conversor analógico digital do receptor devido ao baixo número de bits efetivos (ENOB) dos conversores $\mathrm{ADC}$ de alta velocidade. Assim, duas medidas nesta situação que diferem em até uma casa decimal, podem ser consideradas iguais (exemplo: para sinais acima de $25 \mathrm{~dB}$ de OSNR, um sinal com BER estimada de $1,00 \cdot 10^{-09}$ pode ser considerado aproximadamente igual a um sinal com BER estimada de $1,00 \cdot 10^{-10}$ ).

Por esta razão (sinais com BER estimada a partir do fator $\mathrm{Q}$ acima de $1,00 \cdot 10^{-09}$ e OSNR maior que $25 \mathrm{~dB}$ ), nestes casos a BER não foi considerada como o parâmetro principal para classificação da performance das topologias de amplificação óptica experimentadas, sendo considerado nesses casos (enlaces de 100 e $150 \mathrm{~km}$ ) a OSNR e a potência do sinal recebida como os parâmetros mais relevantes de avaliação das topologias de amplificação óptica experimentadas.

Contudo, para os enlaces acima de $150 \mathrm{~km}$, o parâmetro da BER contada ou estimada foi considerado como parâmetro principal para classificação das topologias de amplificação ópticas testadas experimentalmente.

Para todos os enlaces e topologias de amplificação, a potência lançada na fibra pelo EDFA de transmissão foi em torno de $10 \mathrm{dBm}$, por ser esta a potência lançada necessária para o pior caso testado (enlace de até $300 \mathrm{~km}$ ). Com potência lançada fixa, quando avaliamos os comprimentos mais curtos de enlace (menores que $250 \mathrm{~km}$ ), a BER obtida pode ser um pouco deteriorada com relação ao caso ótimo devido a presença de efeitos não-lineares. Porém, com a OSNR e potência recebida é possivel inferir a informação sobre a inserção de ruído produzida por cada topologia de amplificação óptica experi- 
mentada (quanto maior a OSNR medida no sinal recebido, menor o ruído inserido pela topologia testada).

Com estas considerações citadas acima, foram realizados os experimentos das topologias de amplificação óptica citadas na seção 3.3. A seguir são apresentados e discutidos os resultados, e no final desta seção é definida a melhor topologia de amplificação óptica híbrida, alvo de desenvolvimento nesta tese para um novo amplificador com controle automático de ganho para redes reconfiguráveis WDM com características de baixa inserção de ruído e ganho plano sobre toda máscara de operação de potências de entrada e saída.

\section{Enlace de $100 \mathrm{~km}$}

Para o enlace de $100 \mathrm{~km}$ de fibra SSMF G.652 o desempenho das topologias de amplificação óptica experimentadas é apresentado na Tabela 3.1.

Tabela 3.1: Desempenho das topologias de amplificação óptica experimentadas para o enlace de $100 \mathrm{~km}$ de fibra SSMF (†BER estimada a partir do fator $\mathrm{Q})$.

\begin{tabular}{|c|c|c|c|c|}
\hline $\begin{array}{c}\text { Topologia de } \\
\text { Amplificação }\end{array}$ & OSNR (dB) & $\begin{array}{c}\text { Potência } \\
\text { Rx }(\mathrm{dBm})\end{array}$ & BER & Desempenho \\
\hline Back-to-Back & 39,34 & $-5,00$ & $3,25 \cdot 10^{-13} \dagger$ & - \\
\hline Tx EDFA + Rx DRA/EDFA & 38,91 & 10,95 & $2,99 \cdot 10^{-09} \dagger$ & $1^{\text {o }}$ \\
\hline Tx EDFA + Rx DRA & 38,91 & $-8,41$ & $4,79 \cdot 10^{-08} \dagger$ & $2^{\text {o }}$ \\
\hline Tx EDFA + Rx LRA & 38,42 & $-7,88$ & $2,39 \cdot 10^{-07} \dagger$ & $3^{\text {o }}$ \\
\hline Tx EDFA + Rx DRA/LRA/EDFA & 38,36 & 11,44 & $1,98 \cdot 10^{-10} \dagger$ & $4^{\text {o }}$ \\
\hline Tx EDFA + Rx EDFA & 37,84 & 11,26 & $1,95 \cdot 10^{-09} \dagger$ & $5^{\text {o }}$ \\
\hline Tx EDFA + Rx LRA/EDFA & 36,33 & 11,66 & $1,36 \cdot 10^{-09} \dagger$ & $6^{\text {o }}$ \\
\hline
\end{tabular}

Devido ao reduzido comprimento de enlace não houve necessidade de teste das topologias com amplificação EDFA/DRA na transmissão, pois somente à amplificação EDFA na transmissão já foi suficiente para alinhar o sistema com qualquer topologia de amplificação na recepção. Desta forma, foram testadas somente as topologias de amplificação óptica com a tecnologia de amplificação EDFA na transmissão seguido das diversas topologias de amplificação óptica na recepção. Para todas as topologias testadas que apresentaram BER abaixo de $4 \cdot 10^{-3}$ (FEC-limit), a BER contada foi igual a zero. Então, a Tabela 3.1 apresenta os valores da BER estimada a partir do fator $\mathrm{Q}$, e as topologias de amplificação foram avaliadas em função da OSNR e nível de potência medido na recepção.

Tanto a topologia de amplificação DRA quanto a DRA/EDFA inseriram o mesmo nível de ruído, porém a topologia DRA/EDFA fornece alta potência ao sinal na recepção comparado a topologia DRA. Desta forma, a topologia Tx EDFA + Rx DRA/EDFA foi avaliada como a melhor topologia em termos de inserção de ruído e nível de potência de saída dentre todas as topologias avaliadas para o enlace de $100 \mathrm{~km}$.

As topologias de amplificação com LRA possuem pior desempenho devido ao nível de inserção de ruído e efeitos não lineares (devido amplificação na DCM) resultante desta 
topologia de amplificação, porém esta topologia já provê a compensação de dispersão ao sinal transmitido enquanto as outras topologias precisam da compensação de dispersão eletrônica via DSP.

Comparando a topologia EDFA com a topologia de amplificação híbrida DRA/EDFA, nota-se que, para aproximadamente os mesmos níveis de potência recebida do sinal, temos a degradação de OSNR (com relação a OSNR em Back-to-Back) reduzida de 1,5 $\mathrm{dB}$ para 0,43 $\mathrm{dB}$ (melhora de 1,07 $\mathrm{dB}$ na OSNR).

A Figura 3.12 apresenta as constelações recebidas para o sinal de $112 \mathrm{~Gb} / \mathrm{s} \mathrm{NRZ}$ DP-QPSK em back-to-back (Figura 3.12(a)) e as constelações recebidas após passagem no enlace de $100 \mathrm{~km}$ utilizando a topologia de amplificação Tx EDFA + Rx DRA/EDFA (Figura 3.12(b)).

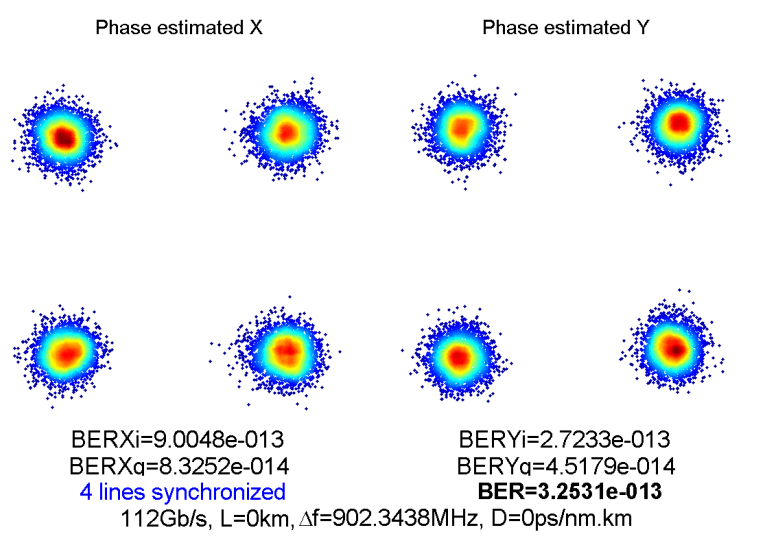

(a)

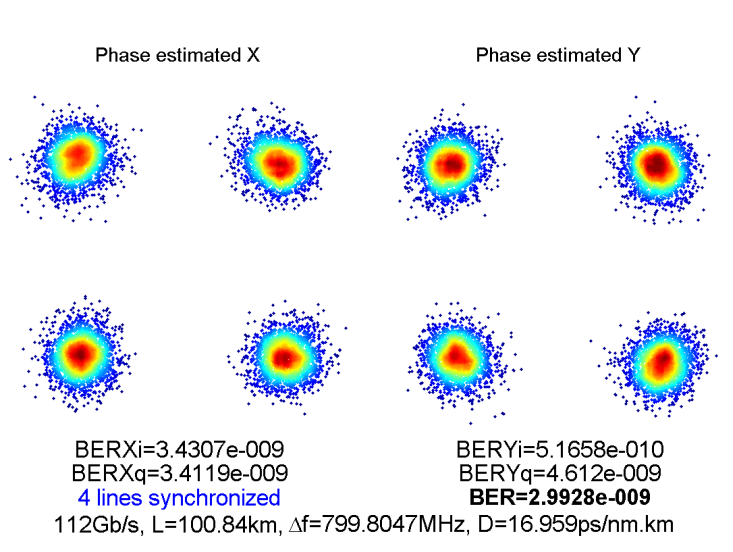

(b)

Figura 3.12: (a) Constelações na recepção do sinal $112 \mathrm{~Gb} / \mathrm{s} N R Z$ DP-QPSK back-to-back $e$ (b) após passagem no enlace de $100 \mathrm{~km}$ com a topologia de amplificação óptica Tx EDFA + Rx DRA/EDFA.

\section{Enlace de $150 \mathrm{~km}$}

Para o enlace de $150 \mathrm{~km}$ de fibra SSMF G.652 o desempenho das topologias de amplificação óptica experimentadas é apresentado na Tabela 3.2.

Tabela 3.2: Desempenho das topologias de amplificação óptica experimentadas para o enlace de $150 \mathrm{~km}$ de fibra SSMF (†BER estimada a partir do fator $\mathrm{Q})$.

\begin{tabular}{|c|c|c|c|c|}
\hline $\begin{array}{c}\text { Topologia de } \\
\text { Amplificação }\end{array}$ & OSNR $(\mathrm{dB})$ & $\begin{array}{c}\text { Potência } \\
\mathrm{Rx}(\mathrm{dBm})\end{array}$ & BER & Desempenho \\
\hline Back-to-Back & 39,34 & $-5,00$ & $3,25 \cdot 10^{-13} \dagger$ & - \\
\hline Tx EDFA + Rx DRA/EDFA & 34,27 & 11,74 & $1,68 \cdot 10^{-09} \dagger$ & $1^{\text {o }}$ \\
\hline Tx EDFA + Rx DRA/LRA/EDFA & 31,44 & 11,34 & $2,64 \cdot 10^{-09} \dagger$ & $2^{\text {o }}$ \\
\hline Tx EDFA + Rx EDFA & 31,26 & $-2,94$ & $4,00 \cdot 10^{-10} \dagger$ & $3^{\text {o }}$ \\
\hline Tx EDFA + Rx LRA/EDFA & 24,71 & 6,19 & $5,55 \cdot 10^{-10} \dagger$ & $4^{\text {o }}$ \\
\hline
\end{tabular}

Devido ao comprimento de enlace, não houve necessidade de teste das topologias com amplificação híbrida (EDFA/DRA) na transmissão, pois somente à amplificação EDFA na transmissão já foi suficiente atuando em conjunto com as outras topologias 
de amplificação na recepção. Desta forma, foram testadas somente as topologias de amplificação óptica com a tecnologia de amplificação EDFA na transmissão, seguida das diversas topologias de amplificação óptica na recepção. Para todas as topologias testadas que apresentaram BER abaixo de $4 \cdot 10^{-3}$ (FEC-limit), a BER contada foi igual a zero. Então, a Tabela 3.2 apresenta os valores da BER estimada a partir do fator $\mathrm{B}$, e as topologias de amplificação foram avaliadas em função da OSNR e nível de potência medido na recepção.

Apesar das topologias de amplificação óptica EDFA e LRA/EDFA apresentarem BER estimada a partir do fator $Q$ menores que a topologia de amplificação DRA/EDFA, devido ao problema da precisão do osciloscópio, explicado no início da seção, essas medidas podem ser consideradas aproximadamente iguais. Porém, comparando qualquer das topologias de amplificação óptica testadas com a topologia DRA/EDFA, podemos observar através da Tabela 3.2 que a topologia DRA/EDFA efetivamente insere menos ruído ao sinal transmitido (melhor OSNR na recepção), apresentando no mínimo uma melhora de aproximadamente $3 \mathrm{~dB}$ em comparação a topologia DRA/LRA/EDFA e EDFA.

Além disso, a topologia DRA/EDFA é menos complexa que a topologia DRA/LRA/EDFA e fornece alta potência ao sinal na recepção. Desta forma, a topologia Tx EDFA + Rx DRA/EDFA foi avaliada como a melhor topologia em termos de inserção de ruído e nível de potência de saída dentre todas as topologias avaliadas para o enlace de $150 \mathrm{~km}$.

Comparando somente a OSNR recebida entre as topologias EDFA e DRA/EDFA temos uma melhora de 3,01 dB na OSNR do sinal recebido pela topologia DRA/EDFA. Comparando a topologia DRA/LRA/EDFA com a topologia de amplificação híbrida DRA/EDFA, nota-se que, para aproximadamente os mesmos níveis de potência recebida do sinal, temos a degradação de OSNR (comparado com a OSNR em Back-to-Back) reduzida de 7,9 dB para 5,07 dB (melhora de 2,02 dB na OSNR).

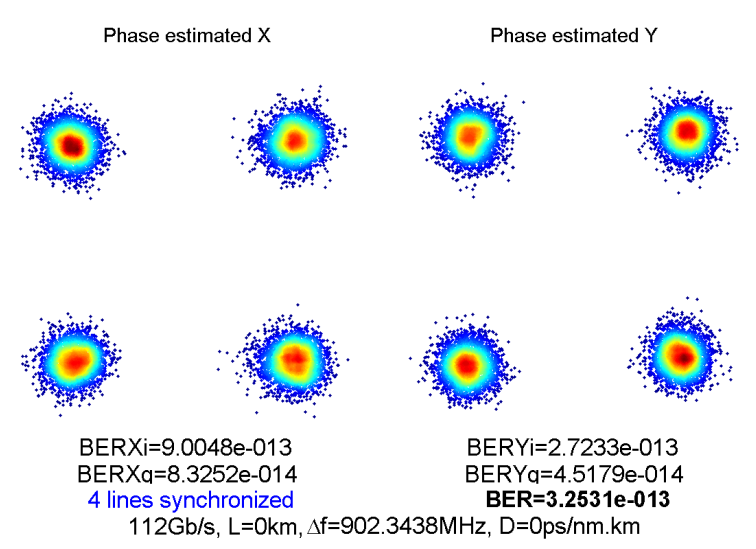

(a)

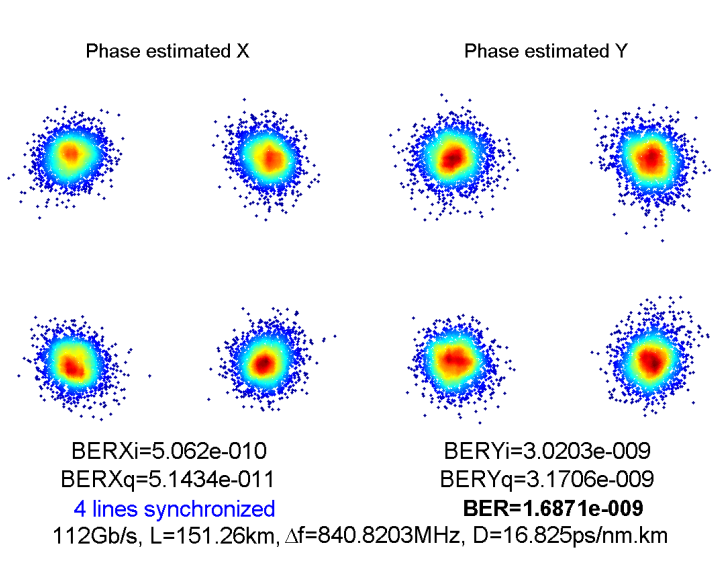

(b)

Figura 3.13: (a) Constelações na recepção do sinal $112 \mathrm{~Gb} / \mathrm{s}$ NRZ DP-QPSK back-to-back $e$ (b) após passagem no enlace de $150 \mathrm{~km}$ com a topologia de amplificação óptica Tx EDFA + Rx DRA/EDFA.

Nota-se que a BER obtida na topologia DRA/EDFA para o enlace de $150 \mathrm{~km}$ foi melhor que a obtida para o enlace de $100 \mathrm{~km}\left(1,68 \cdot 10^{-9}\right.$ contra $\left.2,99 \cdot 10^{-9}\right)$. Isto acontece devido à manutenção da potência lançada em aproximadamente $10 \mathrm{dBm}$ para todos os enlaces testados, que combinado com o bombeio Raman contra-propagante gera um 
nível de potência distribuída maior no enlace de $100 \mathrm{~km}$, desta forma, intensificando os efeitos não-lineares e degradando mais a BER medida em comparação ao enlace de 150 $\mathrm{km}$.

A Figura 3.13 apresenta as constelações recebidas para o sinal de $112 \mathrm{~Gb} / \mathrm{s}$ NRZ DP-QPSK em back-to-back (Figura 3.13(a)) e as constelações recebidas após passagem no enlace de $150 \mathrm{~km}$ utilizando a topologia de amplificação Tx EDFA + Rx DRA/EDFA (Figura 3.13(b)).

\section{Enlace de $200 \mathrm{~km}$}

Para o enlace de $200 \mathrm{~km}$ de fibra SSMF G.652 o desempenho das topologias de amplificação óptica experimentadas é apresentado na Tabela 3.3.

Tabela 3.3: Desempenho das topologias de amplificação óptica experimentadas para o enlace de $200 \mathrm{~km}$ de fibra SSMF (†BER estimada a partir do fator $\mathrm{Q})$.

\begin{tabular}{|c|c|c|c|c|}
\hline $\begin{array}{c}\text { Topologia de } \\
\text { Amplificação }\end{array}$ & OSNR $(\mathrm{dB})$ & $\begin{array}{c}\text { Potência } \\
\mathrm{Rx}(\mathrm{dBm})\end{array}$ & BER & Desempenho \\
\hline Back-to-Back & 39,34 & $-5,00$ & $3,25 \cdot 10^{-13} \dagger$ & - \\
\hline Tx EDFA + Rx DRA/EDFA & 22,77 & 0,01 & $3,28 \cdot 10^{-08} \dagger$ & $1^{\mathrm{o}}$ \\
\hline Tx EDFA + Rx EDFA & 17,03 & $-10,52$ & $5,54 \cdot 10^{-05}$ & $2^{\mathrm{o}}$ \\
\hline Tx EDFA + Rx DRA/LRA/EDFA & 14,32 & $-5,72$ & $6,41 \cdot 10^{-04}$ & $3^{\mathrm{o}}$ \\
\hline
\end{tabular}

Devido ao comprimento de enlace, não houve necessidade de teste das topologias com amplificação híbrida (EDFA/DRA) na transmissão. Desta forma, foram testadas somente as topologias de amplificação óptica com a tecnologia de amplificação EDFA na transmissão seguida das diversas topologias de amplificação óptica na recepção. Para as topologias testadas que apresentaram BER abaixo de $4 \cdot 10^{-3}$ (FEC-limit), isso indica que a BER contada foi igual a zero. Nestes casos devemos considerar o valor da BER estimada pelo fator $\mathrm{Q}$. A Tabela 3.3 apresenta os valores da BER, e as topologias de amplificação são avaliadas em função da BER, OSNR e nível de potência medido na recepção.

Comparando qualquer das topologias de amplificação óptica testadas com a topologia DRA/EDFA, podemos ver através da Tabela 3.3 que a topologia DRA/EDFA insere efetivamente menos ruído no sinal transmitido (melhor OSNR na recepção), apresentando, no mínimo, uma melhora de OSNR em aproximadamente 5,74 dB em comparação a topologia EDFA e 8,45 dB em comparação a topologia DRA/LRA/EDFA, além de fornecer um maior nivel de potência recebida.

Nota-se por meio da Tabela 3.3 que a topologia EDFA na transmissão e DRA/EDFA na recepção fornece a menor BER, mostrando que esta topologia é bastante robusta em termos inserção de ruído quando comparada as outras topologias utilizadas neste experimento.

Comparando somente a OSNR recebida entre as topologias DRA/LRA/EDFA e DRA/EDFA temos uma melhora de $8,45 \mathrm{~dB}$ na OSNR do sinal recebido pela topologia DRA/EDFA. Comparando a topologia DRA/LRA/EDFA com a topologia de amplificação híbrida DRA/EDFA, nota-se uma degradação de OSNR (comparado com a OSNR em Back-to-Back) reduzida 
de 22,31 para 16,57 dB (melhora de 5,74 dB na OSNR).

Após as análises a topologia Tx EDFA + Rx DRA/EDFA foi avaliada como a melhor topologia em termos de inserção de ruído e nível de potência de saída dentre todas as topologias avaliadas para o enlace de $200 \mathrm{~km}$

A Figura 3.14 apresenta as constelações recebidas para o sinal de $112 \mathrm{~Gb} / \mathrm{s}$ NRZ DP-QPSK em back-to-back (Figura 3.14(a)) e as constelações recebidas após passagem no enlace de $200 \mathrm{~km}$ utilizando a topologia de amplificação Tx EDFA + Rx DRA/EDFA (Figura 3.14(b)).

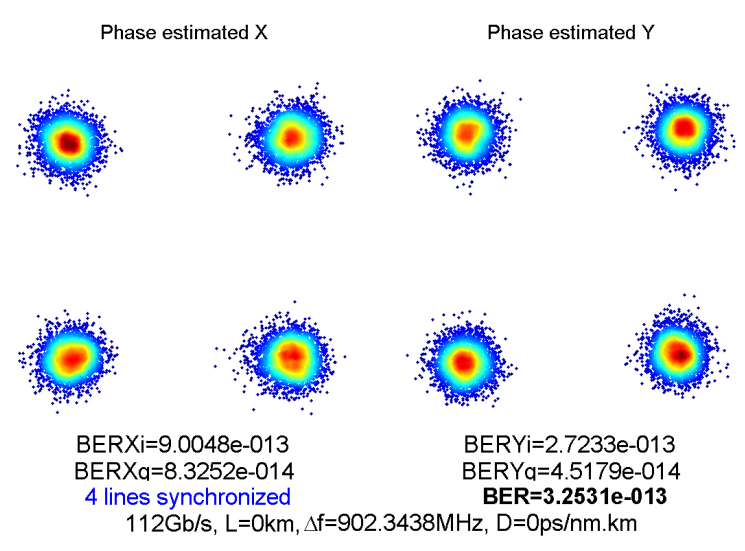

(a)

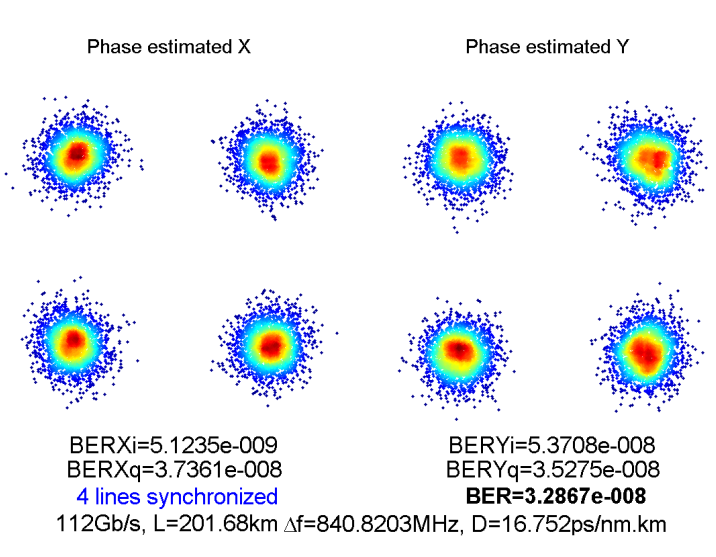

(b)

Figura 3.14: (a) Constelações na recepção do sinal $112 \mathrm{~Gb} / \mathrm{s}$ NRZ DP-QPSK back-to-back $e$ (b) após passagem no enlace de $200 \mathrm{~km}$ com a topologia de amplificação óptica Tx EDFA + Rx DRA/EDFA.

\section{Enlace de $250 \mathrm{~km}$}

Para o enlace de $250 \mathrm{~km}$ de fibra SSMF G.652 o desempenho das topologias de amplificação óptica experimentadas é apresentado na Tabela 3.4. Devido ao longo comprimento do enlace testado, na transmissão além do teste somente com a topologia EDFA, foi testada também a topologia de amplificação híbrida (EDFA/DRA). Desta forma, foram testadas as topologias de amplificação óptica com a tecnologia de amplificação EDFA ou EDFA/DRA na transmissão seguidas das diversas topologias de amplificação óptica na recepção. A Tabela 3.4 apresenta os valores da BER, e as topologias de amplificação foram avaliadas em função da BER, OSNR e nível de potência medido na recepção. Para todas as topologias testadas que apresentaram BER abaixo de $4 \cdot 10^{-3}$ (FEC-limit) consideramos o valor da BER contada.

Somente as topologias de amplificação com DRA/EDFA ou DRA/LRA/EDFA na recepção forneceram BER abaixo do FEC-limit. Porém, Com o uso da topologia híbrida EDFA/DRA na transmissão, o desempenho de OSNR foi incrementado em aproximadamente $3 \mathrm{~dB}$ em comparação com somente a topologia EDFA na transmissão.

As topologias de amplificação híbrida na recepção DRA/EDFA e DRA/LRA/EDFA possuem desempenhos similares, porém, a topologia DRA/EDFA possui uma menor complexidade/custo que a topologia DRA/LRA/EDFA.

Após as análises a topologia Tx EDFA/DRA + Rx DRA/EDFA foi avaliada como a 
Tabela 3.4: Desempenho das topologias de amplificação óptica experimentadas para o enlace de $250 \mathrm{~km}$ de fibra SSMF (†BER estimada a partir do fator $\mathrm{Q})$.

\begin{tabular}{|c|c|c|c|c|}
\hline $\begin{array}{c}\text { Topologia de } \\
\text { Amplificação }\end{array}$ & OSNR (dB) & $\begin{array}{c}\text { Potência } \\
\mathrm{Rx}(\mathrm{dBm})\end{array}$ & BER & Desempenho \\
\hline Back-to-Back & 39,34 & $-5,00$ & $3,25 \cdot 10^{-13} \dagger$ & - \\
\hline Tx EDFA/DRA + Rx DRA/EDFA & 16,56 & $-8,08$ & $1,30 \cdot 10^{-04}$ & $1^{\mathrm{o}}$ \\
\hline Tx EDFA/DRA + Rx DRA/LRA/EDFA & 16,37 & $-7,22$ & $3,92 \cdot 10^{-04}$ & $2^{\mathrm{o}}$ \\
\hline Tx EDFA + Rx DRA/LRA/EDFA & 13,11 & $-9,23$ & $1,80 \cdot 10^{-03}$ & $3^{\mathrm{o}}$ \\
\hline Tx EDFA + Rx DRA/EDFA & 12,96 & $-10,00$ & $1,90 \cdot 10^{-03}$ & $4^{\mathrm{o}}$ \\
\hline
\end{tabular}

melhor topologia em termos de inserção de ruído e nível de potência de saída dentre todas as topologias avaliadas para o enlace de $250 \mathrm{~km}$.

A Figura 3.15 apresenta as constelações recebidas para o sinal de $112 \mathrm{~Gb} / \mathrm{s}$ NRZ DPQPSK em back-to-back (Figura 3.15(a)) e as constelações recebidas após passagem no enlace de $250 \mathrm{~km}$ utilizando a topologia de amplificação Tx EDFA/DRA + Rx DRA/EDFA (Figura 3.15(b)).

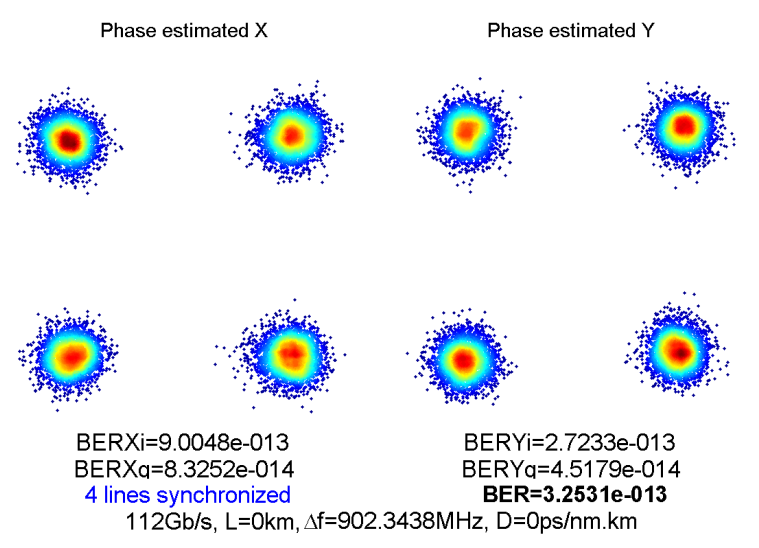

(a)

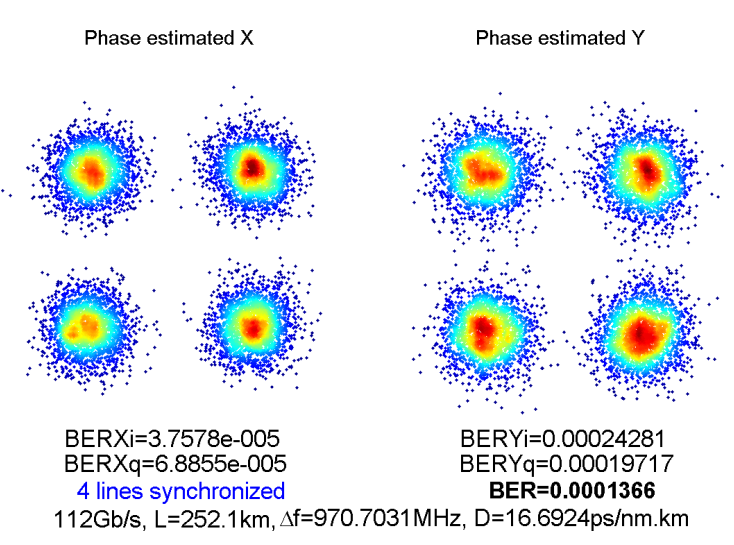

(b)

Figura 3.15: (a) Constelações na recepção do sinal $112 \mathrm{~Gb} / \mathrm{s} N R Z$ DP-QPSK back-to-back e (b) após passagem no enlace de $250 \mathrm{~km}$ com a topologia de amplificação óptica Tx EDFA/DRA + Rx DRA/EDFA.

\section{Enlace de $300 \mathrm{~km}$}

Para o enlace de $300 \mathrm{~km}$ de fibra SSMF G.652 o desempenho da topologia de amplificação óptica experimentada é apresentado na Tabela 3.5. Este foi o máximo comprimento de enlace para o qual alguma topologia de amplificação conseguiu alcançar BER abaixo de $4 \cdot 10^{-3}$ (FEC-limit). Devido ao longo comprimento do enlace testado, somente a topologia de amplificação híbrida EDFA/DRA na transmissão com DRA/EDFA na recepção apresentou BER abaixo do FEC-limit para o valor da BER contada.

A Tabela 3.5 mostra que, considerando esta topologia de amplificação com as potências de bombeio ajustadas de acordo com a seção 3.3.7 e compensação de dispersão eletrônica via DSP, consegue-se operar o sistema de $300 \mathrm{~km}$ com um canal de $112 \mathrm{~Gb} / \mathrm{s}$ 
Tabela 3.5: Desempenho da topologia de amplificação óptica experimentada para o enlace de 300 $\mathrm{km}$ de fibra SSMF (†BER estimada a partir do fator $Q$ ).

\begin{tabular}{|c|c|c|c|c|}
\hline $\begin{array}{c}\text { Topologia de } \\
\text { Amplificação }\end{array}$ & OSNR (dB) & $\begin{array}{c}\text { Potência } \\
\text { Rx }(\mathrm{dBm})\end{array}$ & BER & Desempenho \\
\hline Back-to-Back & 39,34 & $-5,00$ & $3,25 \cdot 10^{-13} \dagger$ & - \\
\hline Tx EDFA/DRA + Rx DRA/EDFA & 13,50 & $-7,37$ & $3,90 \cdot 10^{-03}$ & $1^{\text {o }}$ \\
\hline
\end{tabular}

com OSNR de 13,50 dB, potência de recebida de -7,37 $\mathrm{dBm}$ e com BER de $3,90 \cdot 10^{-3}$.

Porém, o desempenho de BER contada abaixo do FEC-limit só foi possível devido ao ajuste cuidadoso da potência lançada pelo amplificador híbrido de transmissão (EDFA/DRA) realizado em (de Oliveira et al., 2013a), que buscou obter o melhor compromisso entre alta potência lançada e redução dos efeitos não-lineares por meio do ajuste dos bombeios disponíveis no amplificador híbrido de transmissão (um bombeio EDFA e dois bombeios Raman de comprimento de onda 1440 e $1450 \mathrm{~nm}$ ).

A Figura 3.16 apresenta as constelações recebidas para o sinal de $112 \mathrm{~Gb} / \mathrm{s}$ NRZ DPQPSK em back-to-back (Figura 3.16(a)) e as constelações recebidas após passagem no enlace de $300 \mathrm{~km}$ utilizando a topologia de amplificação Tx EDFA/DRA + Rx DRA/EDFA (Figura 3.16(b)).

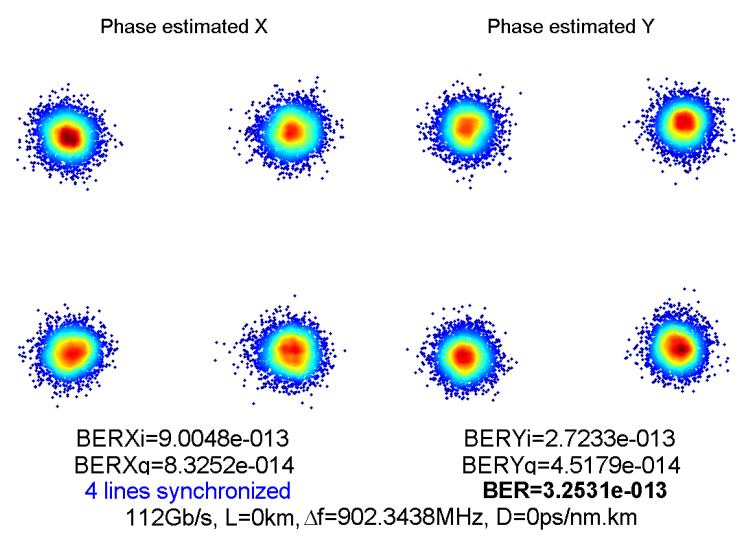

(a)

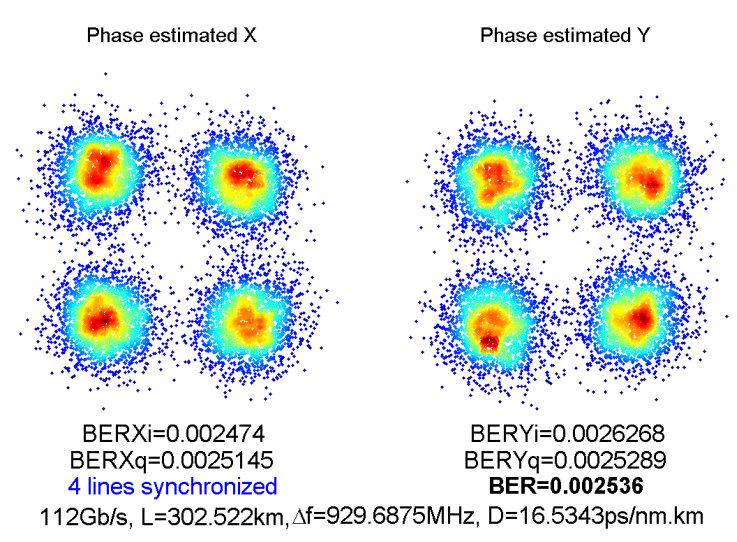

(b)

Figura 3.16: (a) Constelações na recepção do sinal $112 \mathrm{~Gb} / \mathrm{s}$ NRZ DP-QPSK back-to-back e (b) após passagem no enlace de $300 \mathrm{~km}$ com a topologia de amplificação óptica Tx EDFA/DRA + Rx DRA/EDFA.

Com as análises de todas as topologias de amplificação óptica testadas nos diversos comprimentos de enlaces de fibra SSMF, uma das contribuições desta tese é que a topologia de amplificação óptica de recepção DRA/EDFA é a melhor topologia em termos de inserção de ruído e nível de potência de saída dentre todas as topologias baseadas em DRA, LRA e EDFA, para os enlaces de 100 a $300 \mathrm{~km}$ mono-canal. 


\subsection{Sistema DWDM (40 canais) sem Repetição com Amplifica- dores Ópticos Híbridos}

A Figura 3.17(a) ilustra a configuração experimental para demonstrar a transmissão de 40 canais DWDM (espaçamento de $50 \mathrm{GHz}$ ao longo da região alta da banda C) em 302 km de fibra SSMF (G.652), utilizando o esquema de amplificação híbrida que forneceu melhor performance na seção anterior, com o amplificador híbrido na transmissão (EDFA de potência com DRA co-propagante) e o amplificador híbrido também na recepção (DRA contra-propagante com amplificação de linha EDFA).

O experimento visou transmitir o máximo número de canais em um sinal DWDM ao longo de $302 \mathrm{~km}$ de enlace sem repetição, simultaneamente determinando os pontos de operação dos amplificadores híbridos que permitem, pelo menos, ao pior canal a OSNR mínima requerida correspondente a BER de $4 \cdot 10^{-3}$, BER limite passível de correção pelo FEC.

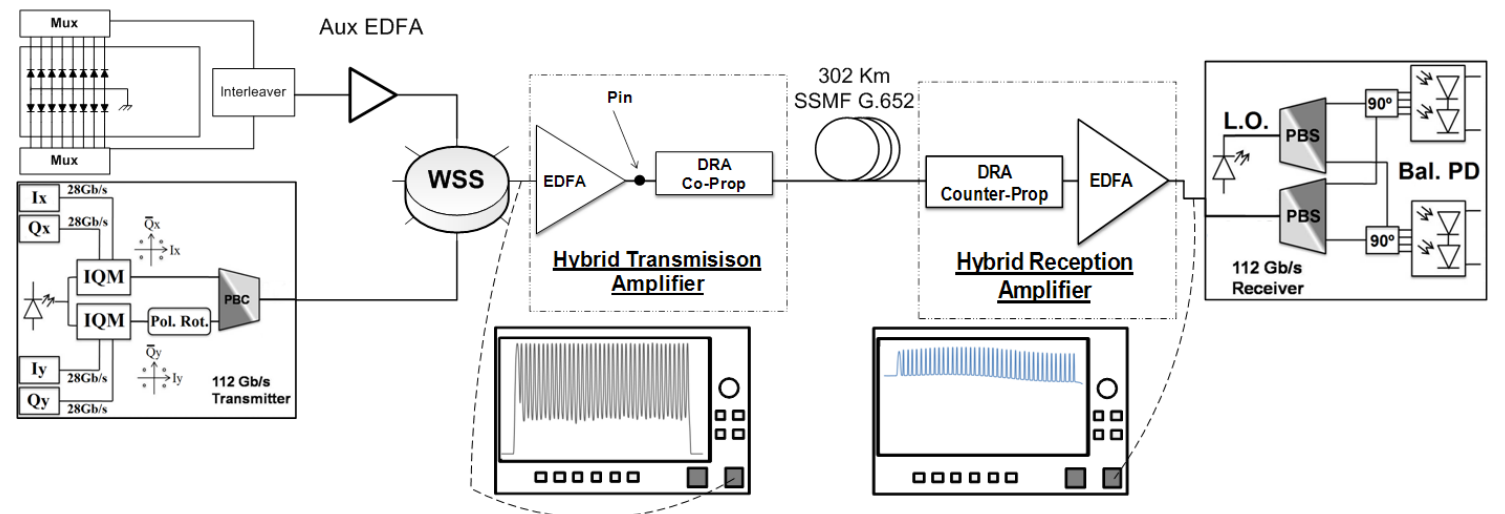

(a)

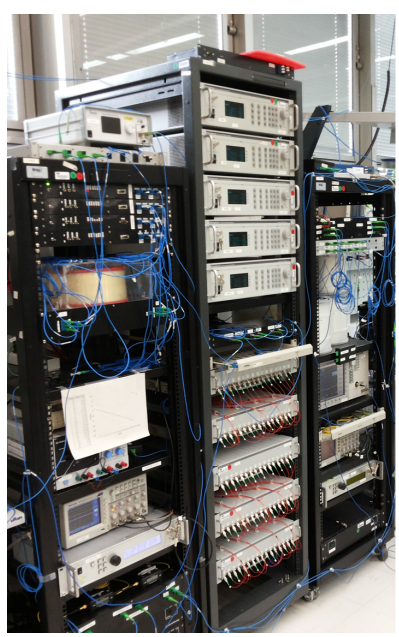

(b)

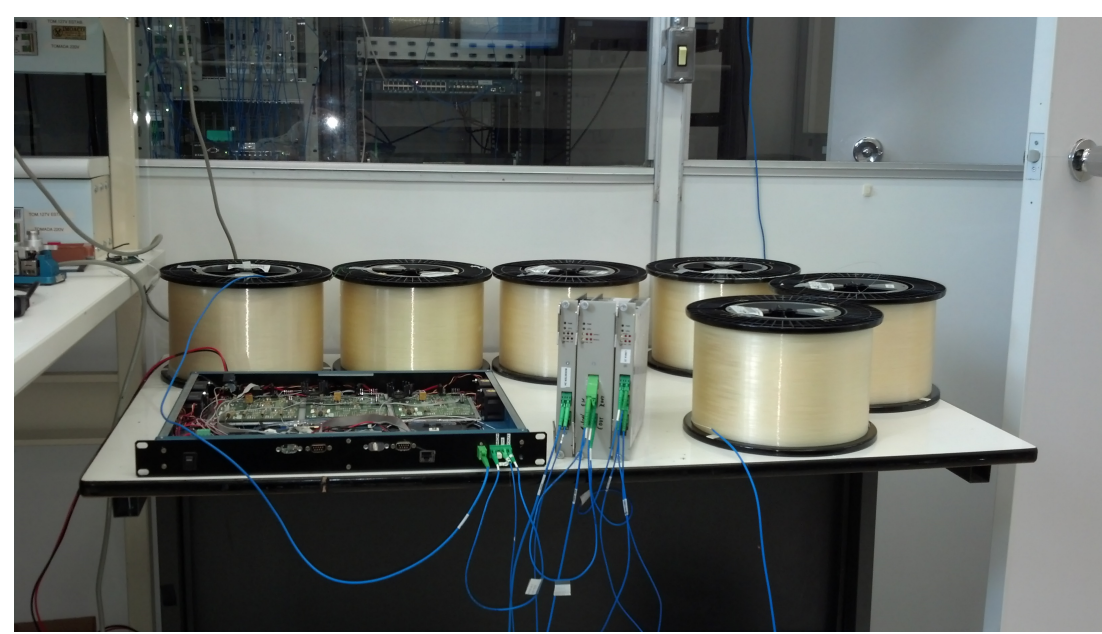

(c)

Figura 3.17: (a) Configuração experimental do sistema sem repetição WDM (40-canais) composto pela bancada de canais (com EDFA auxiliar), canal de teste modulado em $112 \mathrm{~Gb} / \mathrm{s}$, chave WSS, amplificador híbrido de transmissão, enlace de $302 \mathrm{~km}$ SSMF, amplificador híbrido de recepção e receptor coerente, (b) bancada 80 lasers ITU grid e (c) bancada com o enlace de $302 \mathrm{~km}$ e amplificadores. 


\subsubsection{Projeto dos Amplificadores e Configuração Experimental}

Uma bancada de canais DWDM foi utilizada para popular a banda-C. Esta bancada foi montada combinando 40 canais (frequências impares) com um multiplexador enquanto os 40 canais (frequências pares) foram combinados com outro multiplexador. Ambas as saídas multiplexadas foram então combinadas por meio de um interleaver, provendo 80 canais DWDM, como ilustrado na Figura 3.17(a). As frequências da bancada de canais variam de 192,1 THz até 196,05 THz, com espaçamento entre canais de $50 \mathrm{GHz}$. Um amplificador de potência (EDFA) auxiliar foi utilizado para amplificar a bancada de sinais ao mesmo nível do canal de teste modulado em $112 \mathrm{~Gb} / \mathrm{s}$ DP-QPSK. Um controlador automático das correntes de polarização do modulador foi utilizado para evitar erros de quadratura na constelação, e o canal modulado sintonizável foi utilizado como canal de teste para obtenção das taxas de erro de bit (BER) ao longo da banda-C.

O canal sintonizável de $112 \mathrm{~Gb} / \mathrm{s}$ DP-QPSK e a bancada de sinais amplificada foram multiplexadas por meio de uma chave seletora de comprimento de onda (WSS). O WSS além de multiplexar os sinais realiza a equalização dos níveis de potência dos comprimentos de onda, fornecendo um espectro de saída plano, como ilustrado na Figura 3.17(a). Em seguida, a saída DWDM combinada passa pelo amplificador híbrido de transmissão, composto por um EDFA de potência e um amplificador Raman distribuído co-propagante (DRA), igual ao amplificador descrito para o experimento mono-canal. Após percorrer sem repetição os $302 \mathrm{~km}$ de fibra SSMF (G.652) compostos por seis rolos de fibra (50 km cada) emendados por fusão óptica, com coeficiente de atenuação de $0.196 \mathrm{~dB} / \mathrm{km}$ (as cinco emendas totalizaram uma perda de $0.182 \mathrm{~dB}$ ), totalizando uma perda de $60.1 \mathrm{~dB}$ para todo o enlace e $16,7 \mathrm{ps} / \mathrm{nm} / \mathrm{km}$ de dispersão cromática na janela de $1550 \mathrm{~nm}$, o sinal alcança o amplificador híbrido de recepção, composto por um DRA contra-propagante e um amplificador de linha EDFA. Finalmente, o sinal chega ao receptor coerente, é fotodetectado e passa por um processamento de sinais off-line para recuperação da constelação DP-QPSK transmitida.

O experimento foi inicialmente realizado utilizando todos os 80 canais DWDM. Contudo, mesmo com ajustes cuidadosos dos pontos de operação dos amplificadores híbridos, visando obter a melhor OSNR para os canais transmitidos, foi verificado que, após propagação ao longo de $302 \mathrm{~km}$ de fibra sem repetição, todos os canais pertencentes a metade baixa da banda-C (banda azul) alcançavam o receptor com OSNR abaixo da mínima requerida $(13,4 \mathrm{~dB})$ para que após correção sejam recebidos sem erros. Como consequência, o número de canais DWDM foi reduzido, de modo a determinar o máximo número de canais com pelo menos 13,4 dB de OSNR, o que levou a um carregamento de 40 canais, populando a parte alta da banda-C (banda vermelha), e os amplificadores híbrido foram ajustados para prover a melhor desempenho de planicidade espectral de ganho combinado à baixa figura de ruído. Neste caso, as frequências transmitidas foram de $192.1 \mathrm{THz}$ até $195.45 \mathrm{THz}$ com espaçamento de $50 \mathrm{GHz}$, e potência total de saída de -3.5 dBm (sem equalização espectral).

O transmissor $112 \mathrm{~Gb} / \mathrm{s}$ sintonizável ilustrado na Figura 3.17(a) provê $0 \mathrm{dBm}$ de potência total de saída. Antes da multiplexação, foi necessário utilizar um amplificador de potência para amplificação da bancada de canais, visando nivelar a potência destes 
canais com o canal de teste modulado. Especificamente, o EDFA de potência foi utilizado para prover 23,5 dB de ganho, fazendo com que os canais da bancada de sinais atinjam uma potência total de $20 \mathrm{dBm}$. Então, o canal modulado e a bancada de sinais são multiplexadas pelo WSS que ajusta apropriadamente suas respectivas atenuações para equalizar espectralmente o nível de todos na saída. Considerando $8 \mathrm{~dB}$ de perda de inserção e os 4,1 dB de atenuação adicionada pelo processo de equalização espectral, a potência total disponível na saída do WSS foi de 8,1 dBm (-7,9 dBm por canal).

Por outro lado, durante o experimento mono-canal com o sinal de $112 \mathrm{~Gb} / \mathrm{s}$ DPQPSK ao longo de $302 \mathrm{~km}$, foi determinado que a configuração do amplificador híbrido fornece melhor resultado lançando na fibra 9,34 dBm por canal, em conjunto com os níveis de bombeio Raman co-propagante (160/240 mW em 1440/1450 nm), minimizando os efeitos não lineares (de Oliveira et al., 2013a). Tomando este dado como um ponto inicial e ajustando a potência lançada por canal para alcançar o melhor resultado para o experimento DWDM, a melhor potência de saída por canal lançada foi $9 \mathrm{dBm}$, que resultou em um amplificador híbrido de transmissão operando com seu EDFA operando com aproximadamente $17 \mathrm{~dB}$ de ganho, e $25 \mathrm{dBm}$ de potência total lançada na fibra para obtenção do melhor nível de OSNR para os canais.

Isto foi alcançado através do projeto do amplificador híbrido de transmissão, onde o EDFA é composto por um amplificador de dois estágios EDFA (com dois bombeios de 600 mW em $980 \mathrm{~nm}$ ) e um GFF cuidadosamente projetado e inserido entre os estágios, para atingir $25 \mathrm{dBm}$ de potência de saída com ganho nominal plano de $17 \mathrm{~dB}$. O amplificador co-propagante DRA foi construído para prover um ganho on-off adicional de $4 \mathrm{~dB}$ ao longo da fibra de transmissão.

Ao fim do enlace, o sinal chega ao amplificador híbrido composto por um DRA contrapropagante e um amplificador de linha EDFA. O amplificador DRA contra-propagante foi projetado com dois lasers de bombeio semicondutores de $360 \mathrm{~mW}$ de bombeio, nos comprimentos de onda de 1440 e $1450 \mathrm{~nm}$ respectivamente, provendo $16 \mathrm{~dB}$ de ganho Raman on-off. Considerando a perda do enlace de aproximadamente $60 \mathrm{~dB}$, a potência total que atinge o EDFA fica em torno de -16,6 dBm. Neste contexto, o EDFA da recepção que trata-se de um amplificador com duplo estágio fornece um alto ganho $(26,2 \mathrm{~dB}) \mathrm{com}$ potência total de saída de $9,6 \mathrm{dBm}$, adequada para recepção dos canais $(-6,4 \mathrm{dBm}$ por canal).

\subsubsection{Resultados Experimentais}

No experimento, cada um dos 40 canais de bancada de laser foi substituído (um por vez) pelo canal de teste $112 \mathrm{~Gb} / \mathrm{s}$ para realização da medida de BER. Desta forma (1 canal de $112 \mathrm{~Gb} / \mathrm{s}$ modulado mais 39 canais não modulados), a medida é válida se os canais modulados não são afetados por efeitos não-lineares ou efeitos de cross-talk (ou com penalidade desprezivel). Particularmente, com todos os canais modulados em 112 $\mathrm{Gb} / \mathrm{s}$ espaçados de $50 \mathrm{GHz}$ (padrão ITU), é necessário analisar o impacto dos seguintes efeitos: auto modulação de fase (SPM), mistura de quatro ondas (FWM), interferência cruzada entre canais (cross-talk) e modulação cruzada de fase (XPM).

A literatura indica que o uso da técnica de um canal modulado com 39 canais não 
modulados é consistente. Especificamente, o efeito SPM relacionado a cada um dos 40 canais modulados não difere em sua natureza com o SPM produzido pelo próprio sinal (Agrawal, 2007). Com relação ao FWM, a referência (Mateo et al., 2008) demonstrou que o FWM induz impacto desprezível comparado ao efeito XPM (que o efeito dominante na geração de não linearidade neste caso) em sistemas com fibra SSMF e $50 \mathrm{GHz}$ de espaçamento. Adicionalmente, a referência (Maeda et al., 1990), mostrou que o uso de lasers contínuos em torno do canal modulado, como feito neste experimento, representa o pior caso do impacto do efeito FWM no canal modulado. Com relação a interferência cruzada (cross-talk), as referências (Oliveira et al., 2013a) e e (Renaudier et al., 2010) demonstram que mesmo com todos os canais modulados em $112 \mathrm{~Gb} / \mathrm{s}$ DP-QPSK, com $50 \mathrm{GHz}$ de espaçamento, existe uma penalidade desprezível quando a BER está próxima do limite do FEC.

A XPM é o efeito não linear mais relevante para transmissão $112 \mathrm{~Gb} / \mathrm{s}$ DP-QPSK DWDM com espaçamento de $50 \mathrm{GHz}$ (Mateo et al., 2008). Todavia, a referência (Stark et al., 2012) demonstrou que em enlaces com fibra SSMF, para comprimentos até $640 \mathrm{~km}$ sem compensação de dispersão cromática mesmo considerando todos os canais modulados e com espaçamento $50 \mathrm{GHz}$, a penalidade do efeito XPM é menor que 0,25 dB para todas potências lançadas testadas.

A Figura 3.18 ilustra a BER e OSNR obtidas com as medições realizadas utilizando a metodologia acima. Analisando a Figura 3.18 temos a indicação que todos as medidas de BER dos 40 canais ficam abaixo do limiar do FEC.

O canal com pior desempenho localizou-se alocado na frequência 194,05 THz (1544.94 nm, ITU grid H40) que apresentou o menor valor de OSNR (caso 1) e na frequência 194,00 THz (1545.30 nm, ITU grid C40) que apresenta o maior valor de BER (caso 2). A melhor BER e OSNR foram medidas no canal alocado na frequência 192,1 THz (1560.60 nm, ITU grid C21), que se refere ao caso 3. Todos as frequências menores que 194.05 $\mathrm{THz}$ mostraram valores de OSNR abaixo do limiar de $13,4 \mathrm{~dB}$ e não puderam ser detectados em uma condição livre de erros pelo receptor coerente. Por um outro lado, considerando o caso 2 , é possível ver que a penalidade induzida pelos canais vizinhos (ambos os lados) não é significante, dado que a OSNR está acima do limite.

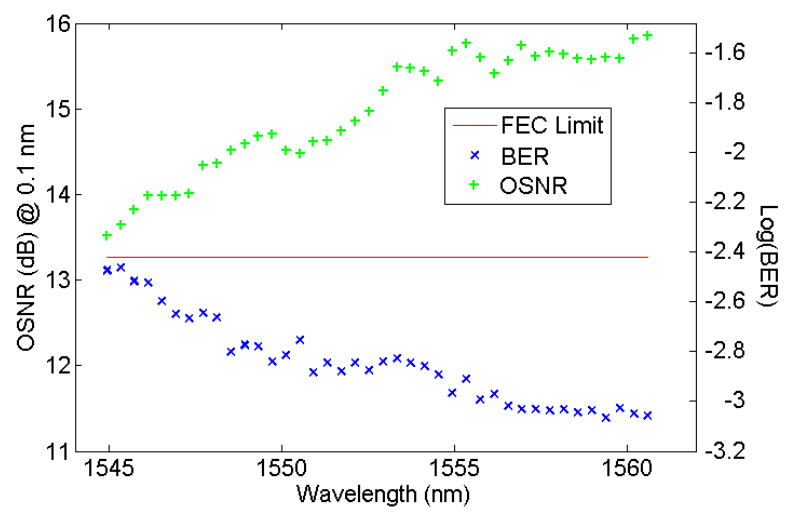

Figura 3.18: Relação sinal ruído óptica (OSNR) no eixo vertical esquerdo e taxa de erro de bit (BER) no eixo vertical direito em função dos comprimentos de onda dos canais.

As Figuras 3.19-3.21 ilustram o espectro óptico DWDM e as constelações recebidas 
e tratadas pelo DSP, para os casos back-to-back, transmissão caso 1, caso 2 e caso 3 . Pode ser visto que todos os canais apresentam pre-FEC BER abaixo do limite de $4 \cdot 10^{-3}$, respectivamente.

Para o caso 1 (112 Gb/s em 194,05 THz/1544,94 nm/H40) ilustrado na Figura 3.19, a BER contada foi de $3,35 \cdot 10^{-3}$, a potência de pico medida para o canal foi de $-4,765$ $\mathrm{dBm}$, o menor valor de potência de pico medida foi de $-5,184 \mathrm{dBm}$ em $1559,82 \mathrm{~nm}$ (192,2 THz/ITU-T C22) e o maior valor de potência de pico medida foi de $-2,863 \mathrm{dBm}$ em 1550, 12 nm (193,4 THz/ITU-T C34). A ondulação espectral de ganho foi 2,951 dB.

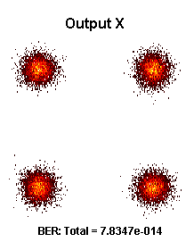

(a)

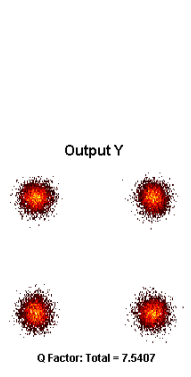

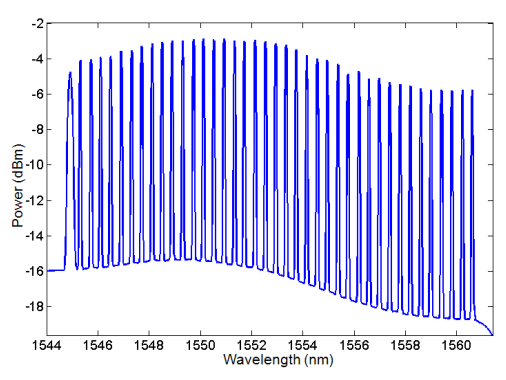

(b)

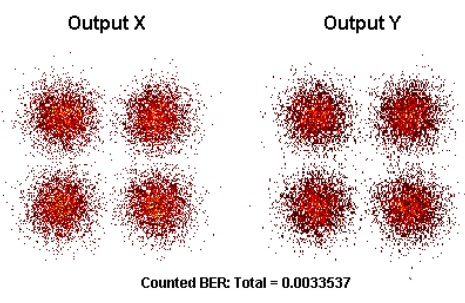

(c)

Figura 3.19: Constelação do sinal de teste modulado em 112Gb/s (back-to-back) (a), espectro de potência obtido na saida do sistema (b) e constelação do sinal de teste (H40) modulado em $112 \mathrm{~Gb} / \mathrm{s}(\mathrm{c})$.

Para o caso 2 (112 Gb/s em 194,0 THz/1545,30 nm/C40) ilustrado na Figura 3.20, a BER contada obtida foi de $3,44 \cdot 10^{-3}$, a potência de pico medida para o canal foi de $-4,696 \mathrm{dBm}$, o menor valor de potência de pico medida foi de $-5,974 \mathrm{dBm}$ em 1559,82 nm (192,2 THz/ITU-T C22) e o maior valor de potência de pico medida foi de $-2,819 \mathrm{dBm}$ em 1549,30 nm (193,5 THz/ITU-T C35). A ondulação espectral de ganho foi 3,155 dB.

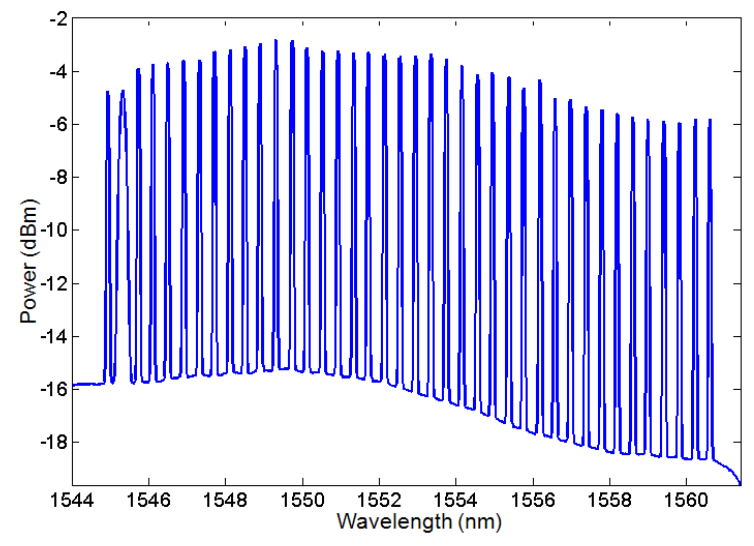

(a)

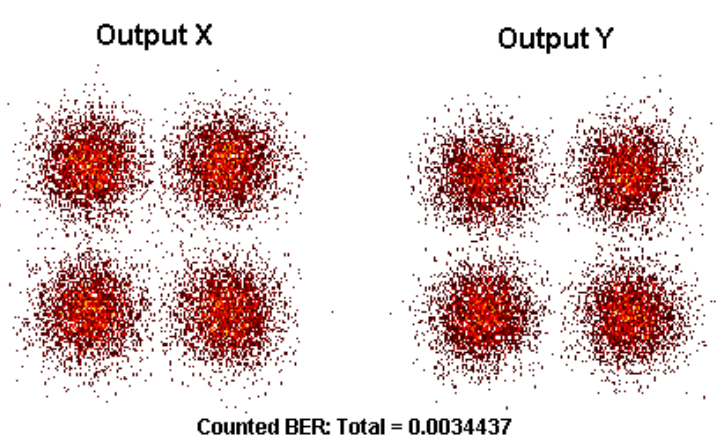

(b)

Figura 3.20: Espectro de potência obtido na saída do sistema (a) e constelação do sinal de teste (C40) modulado em $112 \mathrm{~Gb} / \mathrm{s}$ (b).

Finalmente, para o caso 3 (112 Gb/s em $192.1 \mathrm{THz} / 1560,60 \mathrm{~nm} / \mathrm{C} 21)$ ilustrado na Figura 3.21, a BER contada obtida foi de $8,73 \cdot 10^{-4}$, a potência pico medida para o canal foi de $-5,746 \mathrm{dBm}$, o menor valor de pico medida foi de $-5,974 \mathrm{dBm}$ em $1559,4 \mathrm{~nm}$ (192,25 THz/ITU-T H22) e o maior valor de potência de pico medida foi de $-2,962 \mathrm{dBm}$ em 1549,74 nm (193,45 THz/ITU-T H34). A ondulação espectral de ganho foi 3,012 dB. 


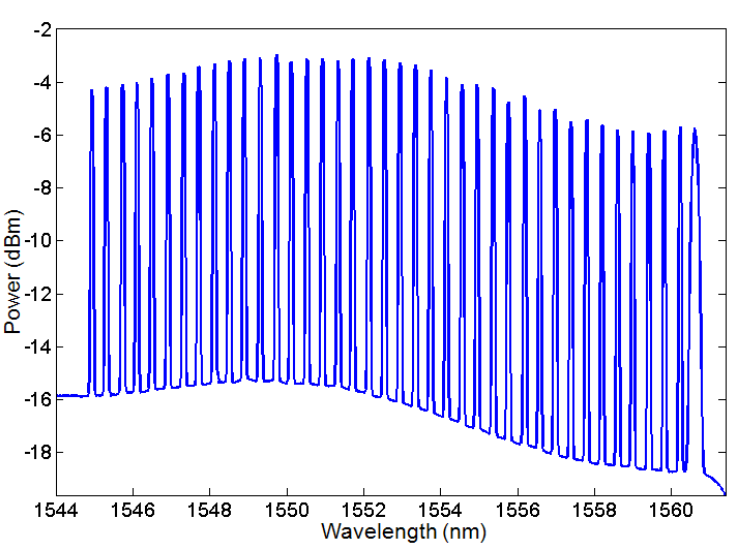

(a)

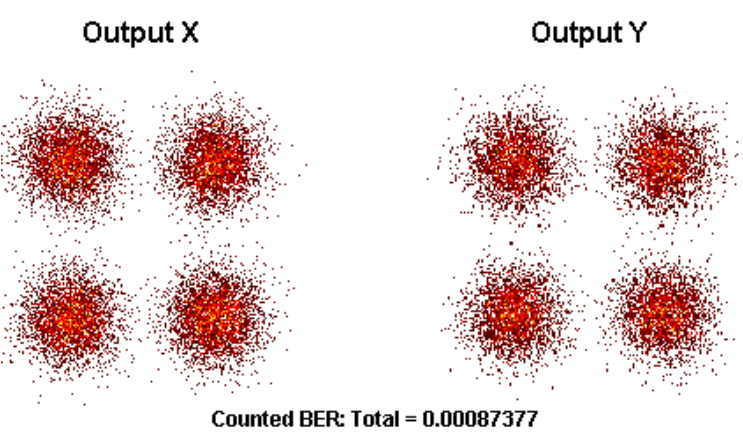

(b)

Figura 3.21: Espectro de potência obtido na saída do sistema (a) e constelação do sinal de teste (C21) modulado em $112 \mathrm{~Gb} / \mathrm{s}(\mathrm{b})$.

Considerando o desempenho do pior (C40) e do melhor (C21) canal, os dados recebidos são submetidos off-line aos seguintes algoritmos de compensação de não-linearidades: digital back propagation (DBP) (Ip e Kahn, 2008) e maximum likelihood sequence detection (MLSE) (Alfiad et al., 2009b). O objetivo foi avaliar a melhora de desempenho oferecida pela compensação não linear, assim como identificar quais efeitos não-lineares foram mais relevantes no experimento realizado.

Tabela 3.6: Taxa de erro de bit por canal considerando compensação não-linear com DBP e MLSE.

\begin{tabular}{|c|c|c|c|}
\hline $\begin{array}{c}\text { Comprimento de } \\
\text { onda (Grid ITU) }\end{array}$ & $\begin{array}{c}\text { BER sem compensação } \\
\text { não linear }\end{array}$ & $\begin{array}{c}\text { BER com } \\
\text { DBP }\end{array}$ & $\begin{array}{c}\text { BER com } \\
\text { MLSE }\end{array}$ \\
\hline $\mathbf{1 5 4 5 , 3 0 ~ n m ~ ( C 4 0 ) ~}$ & $3,4 \cdot 10^{-3}$ & $3,4 \cdot 10^{-3}$ & $1,9 \cdot 10^{-3}$ \\
\hline $1545,30 \mathrm{~nm}(\mathrm{C} 21)$ & $8,7 \cdot 10^{-4}$ & $5,8 \cdot 10^{-4}$ & $2,5 \cdot 10^{-4}$ \\
\hline
\end{tabular}

Como pode ser visto por meio da Tabela 3.6, utilizando o algoritmo DBP (que compensa principalmente o efeito SPM), uma melhora de BER é registrada para o canal C21, mas não para o canal C40. Isto ocorreu devido ao canal C21 estar localizado no extremo da grade de alocação, sendo o canal mais afetado em termos de SPM pelo efeito Raman entre-canais em comparação com todos os outros canais transmitidos.

Também na Tabela 3.6, pode ser visto que quando o algoritmo MLSE foi utilizado, uma melhora de BER foi identificada para ambos os canais. Isto ocorreu devido a capacidade de compensação dos efeitos SPM, XPM, FWM e dispersão cromática residual pelo algoritmo MLSE, mostrando que estes efeitos são relevantes no experimento realizado.

Finalmente, a Tabela 3.7 compara ambos os canais transmitidos com relação a operação em back-to-back, visando mensurar a penalidade de OSNR com e sem compensação não linear. O canal C40 sofreu uma penalidade de 1,27 dB de OSNR em relação ao sinal back-to-back sem a compensação de efeitos não lineares ou somente com a compensação via DBP. Utilizando a compensação MLSE a penalidade baixa para 0,59 dB (ganho de 0,68 dB) em comparação com o caso sem compensação. Para o canal C21, a penalidade final quando o MLSE é utilizado, reduz-se para 0,76 dB (apresentando um 
Tabela 3.7: Penalidade estima de OSNR por canal com relação a condição back-to-back (melhora da penalidade) sem e com o uso dos algoritmos DBP e MLSE.

\begin{tabular}{|c|c|c|c|}
\hline $\begin{array}{l}\text { Comprimento de } \\
\text { onda (Grid ITU) }\end{array}$ & $\begin{array}{c}\text { Sem compensação } \\
\text { não linear (dB) }\end{array}$ & $\begin{array}{l}\text { Com DBP } \\
\text { (dB) }\end{array}$ & $\begin{array}{l}\text { Com MLSE } \\
\text { (dB) }\end{array}$ \\
\hline $1545,30 \mathrm{~nm}(\mathrm{C} 40)$ & 1,27 /referência & $1,27 / 0,00$ & $0,59 / 0,68$ \\
\hline $1545,30 \mathrm{~nm}(\mathrm{C} 21)$ & $1,87 /$ referência & $1,50 / 0,37$ & $0,76 / 1,11$ \\
\hline
\end{tabular}

ganho de $1,11 \mathrm{~dB})$.

\subsection{Conclusões Parciais}

Foi apresentado neste capítulo um estudo experimental sobre topologias de amplificadores híbridos para sistemas sem repetição DWDM, e foi reportada uma transmissão de 4,48 Tb/s ao longo de $302 \mathrm{~km}$ de fibra SSMF sem repetição, que apresentou produto banda $\mathrm{x}$ distância no estado da arte.

Especificamente, uma das contribuições desta tese descrita neste Capítulo foi a determinação da topologia de amplificação óptica híbrida composta pelas tecnologias Raman distribuída e EDFA, como a melhor topologia em termos de desempenho para os sistemas de $112 \mathrm{~Gb} / \mathrm{s}$ DP-QPSK para sistemas DWDM ponto-a-ponto sem repetição.

Determinada a melhor topologia de amplificação óptica híbrida para sistemas sem repetição, o próximo capítulo visa determinar a melhor topologia de amplificação óptica híbrida para sistemas DWDM com repetição e reconfiguráveis.

Assim, no próximo capítulo, serão estudadas as topologias de amplificação óptica com controle automático de ganho utilizadas atualmente para redes com repetição reconfiguráveis, e com base nas análises resultantes será sugerida a melhor topologia de amplificação óptica híbrida para sistemas ópticos DWDM reconfiguráveis. 


\section{Capítulo 4}

\section{Metodologia de Projeto de Amplificadores Ópticos com Controle Automático de Ganho}

As redes ópticas DWDM reconfiguráveis permitiram a otimização da infraestrutura disponivel de fibras ópticas por meio da flexibilidade de adição e remoção de sinais em comprimentos de onda, fornecida pelos ROADMs nos sistemas de comunicações. Nestas redes, a configuração, proteção e restauração de caminhos ópticos são processos dinâmicos e automáticos, proporcionando assim um elevado grau de reconfigurabilidade.

Com a introdução dos dispositivos capazes de proverem a adição/remoção dos comprimentos de onda em cada nó da rede, o número de comprimentos de onda que se propagam pela fibra torna-se uma variável aleatória, provocando consequentemente flutuações aleatórias na potência de entrada dos amplificadores ópticos localizados entre os nós da rede.

Os amplificadores utilizados nos enlaces DWDM (em sua grande maioria EDFAs), geralmente operam no regime de saturação, com nível de bombeio fixo (valor nominal de operação do bombeio). Desta forma, em um cenário de rede reconfigurável existe uma forte dependência do ganho com a potência de entrada, como ilustrado na Figura A.4(a) (no anexo A).

Essa variação de ganho altera criticamente o desempenho do amplificador de acordo com o nível de potência óptica na entrada. A recepção pode ser comprometida devido ao excesso (saturando o fotodetector), falta (potência abaixo da sensibilidade) ou oscilação de potência óptica no receptor (de Oliveira, 2007). Com o intuito de evitar variações de ganho nos amplificadores utilizados em redes ópticas, a utilização de técnicas de controle automático de ganho é então empregada (de Oliveira, 2008, 2004).

Para avaliação da performance do amplificador óptico com controle automático de ganho operando em redes DWDM reconfiguráveis, além do desempenho de controle de ganho (precisão de controle de ganho), a planicidade espectral de ganho e figura de ruído também devem ser avaliadas considerando toda faixa de ganho na qual o amplificador foi projetado para operar. Estes parâmetros de desempenho podem ser descritos por gráficos de máscara de potência, que ilustram os parâmetros de desempenho (precisão 
de controle de ganho, figura de ruído e planicidade espectral de ganho) em função das variações de potências de entrada e saída do amplificador óptico (Cowle, 2010).

Ao longo deste capítulo diversas topologias de amplificação óptica para operação em redes DWDM reconfiguráveis serão simuladas e experimentadas, com o intuito de determinar qual topologia fornece melhor desempenho em termos de precisão de controle de ganho, planicidade espectral de ganho e figura de ruído ao longo de toda região de operação do amplificador. Para atender esta necessidade, utiliza-se nesta tese a metodologia de caracterização de amplificadores ópticos (de Moura et al., 2012) que provê as máscaras de potência (precisão de AGC, figura de ruído e planicidade espectral de ganho), permitindo a avaliação de desempenho dos amplificadores para redes DWDM dinâmicas.

Neste capítulo será descrito o estado da arte dos diversos métodos de controle automático de ganho utilizados para as tecnologias de amplificação EDFA, Raman e tecnologias híbridas operando em redes ópticas reconfiguráveis. Também será apresentada a metodologia de caracterização de desempenho de amplificadores ópticos (discretos e/ou distribuídos) em sua região de operação dinâmica por meio de máscara de potência. Em seguida, será descrito o projeto de amplificadores ópticos com controle automático de ganho em software de simulação óptica, detalhando o projeto de EDFAs com GFF e estágio simples ou duplo (Paiva et al., 2012), posteriormente incluindo também o amplificador Raman distribuído (de Oliveira et al., 2011; Oliveira et al., 2012).

Ao final deste capítulo, será proposta uma metodologia de controle automático de ganho para topologia de amplificação híbrida Raman distribuída contra-propagante/EDFA para redes ópticas DWDM reconfiguráveis (de Oliveira et al., 2011; Oliveira et al., 2012), visando fornecer desempenho superior do conjunto de parâmetros avaliados pela máscara de potência (baixa figura de ruído, planicidade espectral de ganho e precisão de controle de ganho), em comparação com os métodos de controle automático de ganho desenvolvidos para as topologias de amplificação empregadas atualmente e apresentadas neste capítulo.

\subsection{Controle Automático de ganho para Amplificadores Ópti- $\cos$}

Existem vários métodos de controle automático de ganho aplicáveis aos amplificadores à fibra dopada com érbio. Como comentado anteriormente, variações na potência de entrada dos EDFAs podem levar o sistema à degradação da taxa de erro de bit (BER) dos canais transmitidos devido, por exemplo, ao desalinhamento de potência em relação ao limiar de sensibilidade do receptor. Além disto, tais variações podem levar o sistema à degradação da OSNR, violando a mínima OSNR requerida na recepção, e à degradação da transmissão devido à excitação de efeitos não lineares causados pelo excesso de potência e à interferência entre os canais ópticos.

Desta maneira, o ganho dos amplificadores ópticos utilizados em sistemas de comunicações devem ser controlados, de modo a evitar grandes flutuações de potência causadas por falha ou reconfigurações nas redes. Com este intuito, técnicas de controle 
automático de ganho para amplificadores ópticos têm sido propostas e demonstradas. Nas subseções seguintes, estas técnicas serão descritas e comparadas.

Especificamente, serão descritas as técnicas de controle automático de ganho (AGC) desenvolvidas para as topologias de EDFA com estágio de amplificação único com GFF, EDFA com estágio de amplificação duplo com GFF e VOA e amplificador Raman distribuído, por serem estas as topologias mais empregadas atualmente em redes ópticas DWDM reconfiguráveis (Zyskind e Srivastava, 2011). Finalmente, será sugerida uma técnica de controle de ganho para amplificadores híbridos.

Serão apresentadas as vantagens e desvantagens dessas topologias de amplificação em termos de desempenho dos parâmetros de planicidade espectral de ganho, figura de ruído e precisão de AGC, o que será ilustrado através de sua respectiva máscara de potência, considerando a operação em redes ópticas DWDM reconfiguráveis.

As técnicas de controle automático de ganho (AGC) eletrônicas são preferencialmente avaliadas devido ao bom desempenho tanto na região de pequenos sinais quanto na região de saturação dos amplificadores ópticos. As técnicas de AGC totalmente ópticas não são o foco principal por só operarem adequadamente na região de pequenos sinais ópticos (de Oliveira, 2008, 2004, 2007).

\subsubsection{EDFA com Estágio Único, GFF e AGC eletrônico realimentado}

A topologia de amplificação óptica EDFA com estágio único, GFF e controle automático de ganho eletrônico realimentado é uma das estruturas mais simples de serem implementadas. Sendo assim, esta estrutura é largamente utilizada pelos fornecedores de EDFAs (de Oliveira, 2008; JDSU, 2011; Zyskind e Srivastava, 2011).

Um filtro aplainador espectral de ganho (GFF) trata-se de um filtro passivo óptico customizado, que pode aplicar um perfil fixo de perda espectral em um sinal óptico que passa através deste dispositivo. Os GFFs são geralmente fabricados em tecnologias de filtros de filme fino (thin film filters), grades de bragg, guia de ondas planares, microóptica ou dispositivos micro mecânicos (Sargent, 2004). A vantagem dos filtros de filme fino na fabricação dos GFFs são devido a passividade da tecnologia (dispositivo não ativo), robustez, facilidade de manuseio e insensibilidade a temperatura (Sargent, 2004).

Os materiais mais usados na construção de GFFs com filtros de filme fino são materiais não absorventes perfeitamente homogêneos tais como $\mathrm{SiO}_{2}$ e $\mathrm{Ta}_{2} \mathrm{O}_{5}$ com vidro e meio incidente ar (Carniglia, 2000). Com a curva desejada para construção do GFF, os fabricantes do mesmo usam algoritmos proprietários de otimização projetar o filtro desejado por meio de concatenação de vários filtros de filme fino (Carniglia, 2000).

A Figura 4.1 ilustra o circuito óptico do EDFA com GFF e sua unidade de controle. O circuito óptico é constituído basicamente por quatro componentes ópticos, dois fotodetectores, um laser de bombeio $(980 \mathrm{~nm})$ e um trecho de fibra dopada com Érbio (EDF), dispostos em uma configuração de bombeio co-propagante.

O primeiro componente óptico é um componente híbrido TAP/ISO/WDM, onde a derivação (TAP) retira uma parcela da potência de entrada (geralmente de 1-5\%) para monitoramento através do fotodetector de entrada, o isolador (ISO) provê isolação para o sinal de luz propagante na direção contrária (retro espalhamento), e o acoplador WDM 


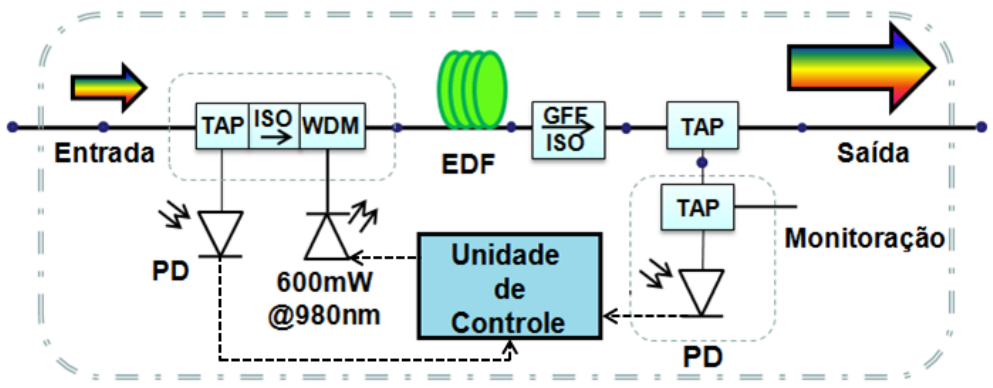

Figura 4.1: Circuito óptico do EDFA com um estágio e GFF.

combina o bombeio e o sinal na fibra dopada com Érbio (EDF), para que o sinal possa ser amplificado na EDF. Após o sinal ter sido amplificado ao longo da EDF, outro componente híbrido ISO/GFF tem a função de isolar o amplificador dos sinais retro espalhados na saída do amplificador/entrada do enlace (ISO), enquanto o GFF é um filtro aplanador espectral de ganho, que visa remover as diferenças entre os ganhos fornecidos para cada frequência do sinal WDM na banda C, provendo ganho espectral plano.

Porém, para que o amplificador forneça ganho espectral plano com baixa figura de ruído, o comprimento da fibra dopada com Érbio e o perfil de perda espectral do GFF devem ser cuidadosamente projetados. Para isto, foi desenvolvida uma metodologia de projeto de amplificadores de alto desempenho para redes reconfiguráveis (Paiva et al., 2012).

A unidade de controle do amplificador óptico consiste do elemento onde a malha de controle de ganho é processada para realização do controle de ganho do amplificador. Geralmente a unidade de controle é composta por um micro controlador, processador digital de sinais (DSP) ou FPGA.

A Figura 4.2 ilustra a malha de controle de ganho que é processada no interior da unidade de controle da Figura 4.1. Esta malha de controle consiste em um código que utiliza as medidas da potência total de entrada e saída do EDFA para calcular o ganho real e sua diferença com relação ao ganho alvo (setpoint de ganho). Então, esta diferença é fornecida como dado de entrada para um controlador PI (proporcional integral) que atua no laser de bombeio para atingir o ganho alvo no estado permanente. As constantes $P$ e $I$ podem ser ajustadas para prover controle de ganho com supressão de transientes (de Oliveira, 2008; Zyskind e Srivastava, 2011).

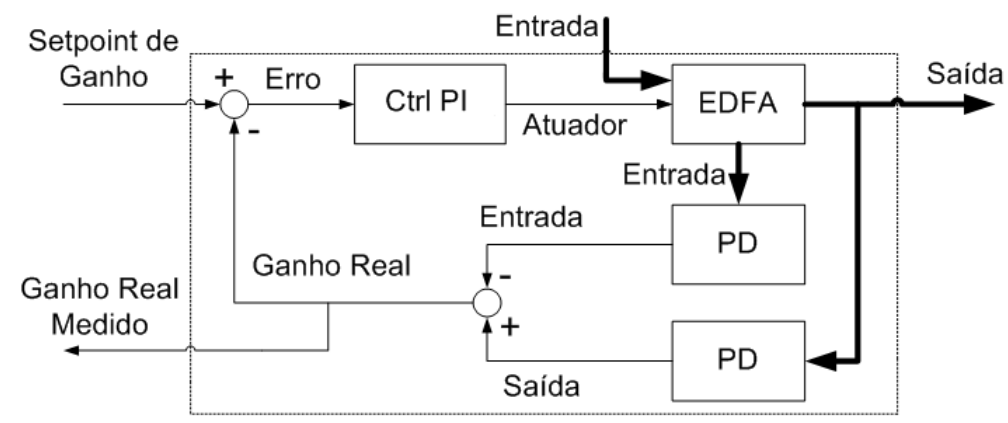

Figura 4.2: Malha de controle de ganho para o EDFA com um estágio e GFF.

Em termos de desempenho de planicidade espectral de ganho e figura de ruído exis- 
tem algumas vantagens e desvantagens que podem ser identificadas via sua máscara de potência.

A grande vantagem é que, para ganhos alvos e potências de entrada variáveis, devido ao amplificador possuir somente um estágio de amplificação, a figura de ruído é baixa e praticamente constante ao longo de toda máscara de potência de operação (Paiva et al., 2012).

Porém como descrito em (Pal et al., 2007), a planicidade espectral de ganho de um EDFA com estágio único de amplificação só é mantida constante para um único valor de ganho alvo, devido ao ganho e a planicidade estarem intrinsecamente relacionada a um mesmo nível de inversão de população na EDF. Desta forma, o ganho espectral plano pode ser mantido para qualquer que seja o nível de potência de entrada através do ajuste da potência de bombeio, para manter o mesmo nível de inversão de população na EDF. Porém isto só é possível para um único valor de ganho no caso do EDFA com estágio único de amplificação.

Então, a grande desvantagem relacionada ao desempenho desta topologia é que, para ganhos alvo variáveis, não é possível manter o ganho espectral plano para toda faixa de ganho de operação, e sim, somente para o ganho alvo no qual o GFF foi projetado para fornecer ganho espectral plano (Paiva et al., 2012).

\subsubsection{EDFA com Estágio Duplo, GFF, VOA e AGC eletrônico realimentado (controle acoplado)}

A topologia de amplificação óptica EDFA com duplo estágio de amplificação GFF, atenuador óptico variável (VOA), e controle automático de ganho eletrônico realimentado (controle de ganho acoplado) é uma estrutura complexa de amplificação que visa fornecer planicidade espectral de ganho para toda a faixa de ganhos alvos controláveis (Abu Bakar et al., 2011; Mahdi et al., 2009), algo que o amplificador EDFA de estágio simples não é capaz de realizar (Paiva et al., 2012; Pal et al., 2007).

A Figura 4.3 ilustra o circuito óptico do amplificador em questão e sua unidade de controle. O circuito óptico é constituído por dois estágios de ganho EDFA similares ao apresentado na seção 4.1.1, na configuração de bombeio co-propagante (porém sem GFF), com um estágio intermediário com VOA e GFF (visando ganho espectral plano para os dois estágios operando em ganho nominal).

A utilização de mais de um estágio de amplificação de EDFA e um VOA nesta topologia tem como objetivo fornecer planicidade espectral de ganho para toda faixa de ganhos alvo controláveis. Trabalhos similares foram realizados para amplificadores com quatro estágios de amplificação em (Abu Bakar et al., 2011; Mahdi et al., 2009).

Para que o amplificador forneça ganho espectral plano para toda faixa, os comprimentos das fibras dopada com Érbio de ambos os estágios devem ser cuidadosamente projetados, para que esses estágios de amplificação possuam uma figura de ruído baixa em seus ganhos nominais (ganho onde o amplificador fornece melhor desempenho). Além disso, deve-se projetar os comprimentos das EDFs dos estágios de amplificação de tal forma que a soma dos ganhos nominais subtraído da perda do GFF e a perda de inserção do VOA, seja igual ao máximo ganho alvo da faixa de ganho projetada. Assim 


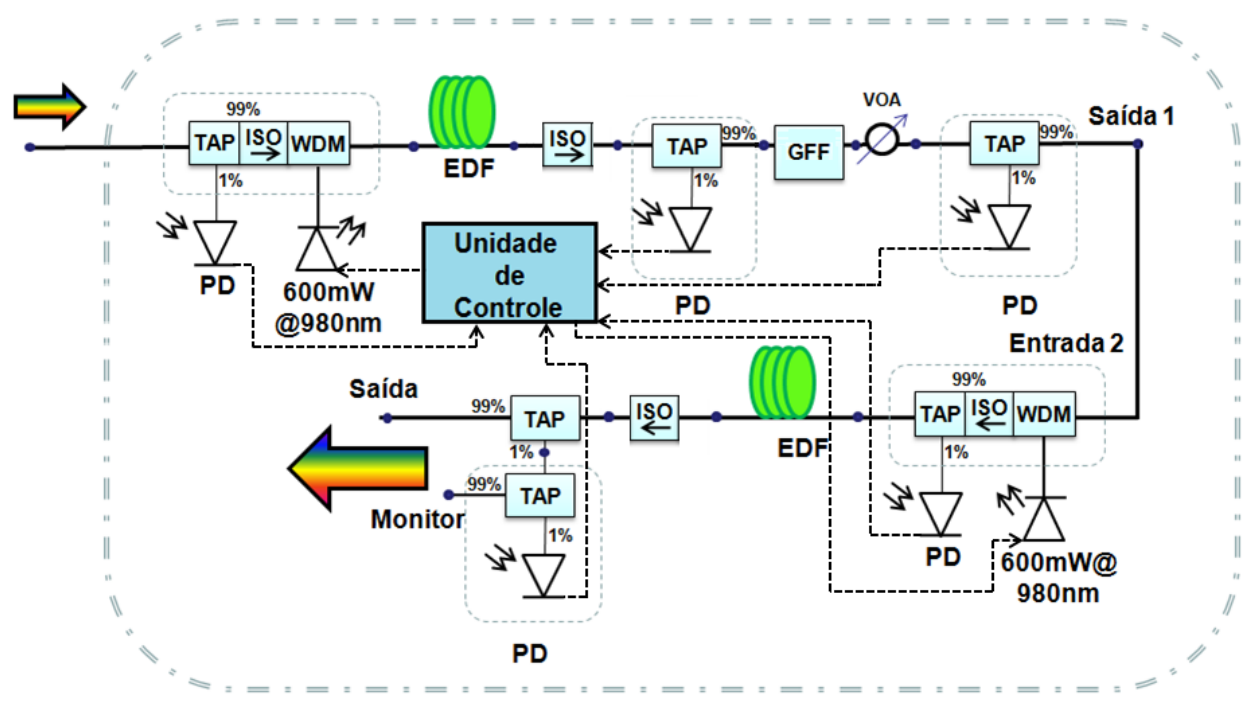

Figura 4.3: Circuito óptico do EDFA com dois estágios, GFF e VOA.

o GFF deve ser projetado para fornecer ganho espectral plano nesta condição (EDFAs acoplados) (Paiva et al., 2012).

Desta forma, como mencionado em (Abu Bakar et al., 2011; Mahdi et al., 2009), o AGC acoplado fornece planicidade espectral de ganho através do controle de ganho individual dos estágios EDFA sempre em seus ganhos nominais, aplicando a atenuação necessária através do estágio intermediário do VOA, para atingir o ganho alvo (setpoint) desejado. É possível atingir o ganho alvo máximo da faixa projetada fornecendo atenuação mínima no VOA, e atingir os ganhos mais baixos da faixa de ganhos alvo, aplicando atenuação no estágio intermediário igual a diferença entre o ganho máximo e o ganho alvo. O ganho alvo é ajustado por meio de mensagem binária (comunicação serial) enviada para o processador de controle do amplificador óptico (geralmente um microcontrolador).

A Figura 4.4 ilustra à malha de controle de ganho que é processada no interior da unidade de controle da Figura 4.3. Os amplificadores EDFA 1 e EDFA 2 executam a mesma malha de controle de ganho individual do EDFA ilustrada na Figura 4.2, e com base no setpoint de ganho requisitado (ganho alvo), o controle da atenuação é realizada no estágio do VOA.

Esta malha de controle de atenuação consiste em um código que utiliza as medidas da potência total de entrada e saída dos estágios e do VOA para calcular a atenuação real medida e sua diferença com relação ao setpoint de atenuação alvo. Então, esta diferença (erro de controle) é fornecida como dado de entrada para um controlador PI (proporcional integral) que atua no VOA para prover a atenuação alvo no estado permanente.

Em termos de desempenho de planicidade espectral de ganho e figura de ruído existem algumas vantagens e desvantagens que podem ser facilmente identificadas através do desempenho deste amplificador via sua máscara de potência.

A grande desvantagem relacionada ao desempenho desta topologia é que, para ganhos alvo e potências de entrada variáveis, devido ao amplificador possuir dois estágios de amplificação e um estágio intermediário de atenuação, a figura de ruído é maior que a do EDFA com estágio único, e aumenta gradativamente de acordo com a diminuição 


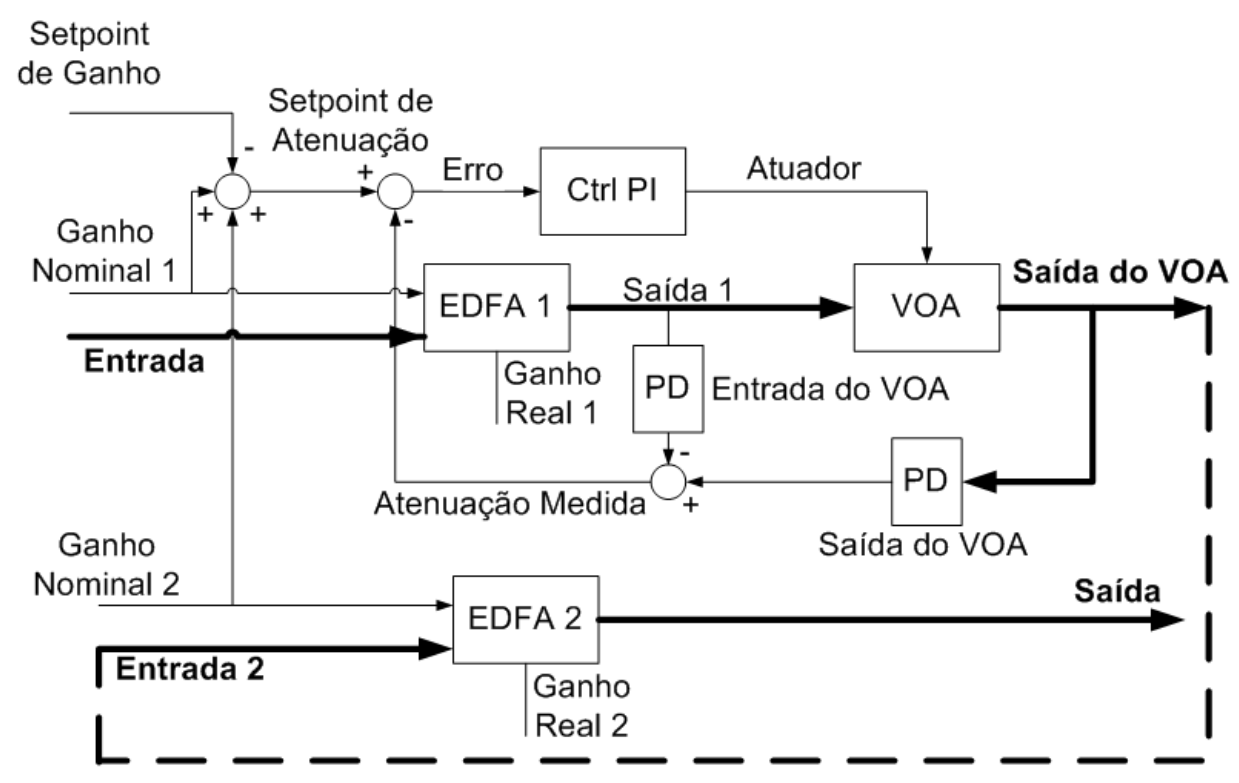

Figura 4.4: Malha de controle de ganho para o EDFA com dois estágios, GFF e VOA.

do ganho alvo ao longo de toda máscara de potência de operação (Paiva et al., 2012).

Porém, a grande vantagem é que, para ganhos alvos diferentes, o ganho espectral plano é mantido para toda faixa de ganho de operação, não importando qual o ganho alvo nem qual a potência de entrada do amplificador (Paiva et al., 2012).

\subsubsection{Amplificador Raman Distribuído com Controle Automático de Ganho}

Diferentemente dos EDFAs usados em sistemas de transmissão DWDM (amplificadores discretos ou lumped amplifiers), que fornecem ganho em pontos específicos do enlace (entrada, estágio intermediário ou saída), os amplificadores Raman distribuído, fornecem ganho ao sinal transmitido ao longo da fibra do enlace, apresentando melhor performance frente aos EDFAs principalmente em termos de figura de ruído.

Como sistemas com formatos de modulação avançados são bastante sensíveis a efeitos não lineares devido à alta eficiência espectral de seus transmissores e receptores, e estas não linearidades são diretamente proporcionais à potência de sinal lançada na fibra (der Borne, 2008), em (Namiki e Emori, 2001) foi mostrado que os amplificadores distribuídos Raman são ideais para fornecer amplificação para estes tipos de sistemas, por fornecerem ganho distribuído ao longo do enlace, e consequentemente dispensando amplificadores lançando altas potências na fibra de transmissão, reduzindo os efeitos não lineares (FWM e SPM), além de melhorar o desempenho, reduzindo o nível de ruído quando comparado aos EDFAs, e aumentarem a margem de potência do enlace.

A grande deficiência da tecnologia de amplificação Raman frente ao EDFA é a baixa eficiência de conversão de bombeio em amplificação (consequentemente baixa potência de saída). Devido a esta baixa eficiência, uma fração significativa do bombeio Raman é perdida no meio de amplificação devido à atenuação passiva da fibra e sem transferir energia do bombeio para sinal, tornando o amplificador Raman quase um amplificador linear ideal (homogêneo) com alta potência de saturação (Fludger, 2000), enquanto, 
o EDFA possui baixa potência de saturação, tornando o EDFA um amplificador não linear (inomogêneo) (Namiki e Emori, 2001). Em (Bigo et al., 1999) foi realizado um estudo mostrando que, em um enlace de $100 \mathrm{~km}$ de fibra SSMF, o espalhamento Raman estimulado (SRS) entre os canais transmitidos contribui com uma ondulação espectral de ganho abaixo de $1 \mathrm{~dB}$, para transmissão de 32 canais na fibra com potência total de 20,61 dBm (5,56 dBm por canal).

Em (Lee et al., 2005) análises estáticas (bombeio fixo) e dinâmicas (somente um caso de adição e remoção de canais, e três diferentes valores de potência de entrada) foram realizadas para quatro diferentes topologias de amplificadores ópticos, onde um dos amplificadores, é um amplificador Raman e os outros empregam diferentes topologias de amplificação híbrida (Raman/EDFA e EDFA/Raman com reuso de bombeio). Neste estudo foi mostrado que, dentre os amplificadores avaliados, somente o amplificador Raman possui planicidade invariante com relação à potência de entrada (devido às potências de entrada avaliadas estarem abaixo da potência de saturação), aliado à alta imunidade a transientes devido à reconfigurações na rede, por apresentar apenas 0,02 $\mathrm{dB}$ de variação no sinal sobrevivente para um evento de adição e remoção de $10 \mathrm{~dB}$ (9 em 10 canais).

Desta forma, o amplificador distribuído Raman surge como uma ótima alternativa para amplificação em sistemas DWDM reconfiguráveis com formatos de modulação avançados, por apresentar características de alta potência de saturação (transmissores com formatos de modulação avançados requerem idealmente potências lançadas em torno de $0 \mathrm{dBm}$ por canal) e não apresentarem variação espectral de ganho dependente do nível de potência de entrada e/ou devido a eventos de reconfiguração de canais (adições e remoções de canais). O grande problema deste amplificador é o baixo nível de potência de saída e a necessidade de bombeio de alta potência para uma amplificação adequada.

Dentre os diversos métodos de controle de ganho para amplificadores Raman distribuído disponíveis na literatura, apresenta-se a seguir os métodos mais empregados experimentalmente. A topologia de amplificação óptica Raman distribuída contrapropagante com duplo bombeio e controle automático de ganho eletrônico em malha aberta é uma estrutura de amplificação simples que visa fornecer planicidade espectral de ganho para vários valores de ganhos alvo.

A Figura 4.5 ilustra o circuito óptico do amplificador em questão e sua unidade de controle. O circuito óptico é constituído por dois bombeios Raman que são combinados com o sinal através de um combinador de bombeios e sinal Raman, onde o bombeio se propaga de maneira contra-propagante com relação ao sinal (com destino a fibra de enlace onde ocorre a amplificação Raman). Um fotodetector é utilizado na saída do amplificador Raman distribuído (após acoplador de sinal bombeio) para que seja possível realizar a medição do sinal de saída do amplificador.

Em (Feng et al., 2004, 2005), foi mostrado que, para amplificadores Raman distribuídos contra-propagante com controle de ganho, um perfil de ganho on-off inverso pode ser aplicado no controle das potências dos bombeios do amplificador através de uma simples aproximação linear, gerando um ganho espectral de rede plano tanto na condi- 


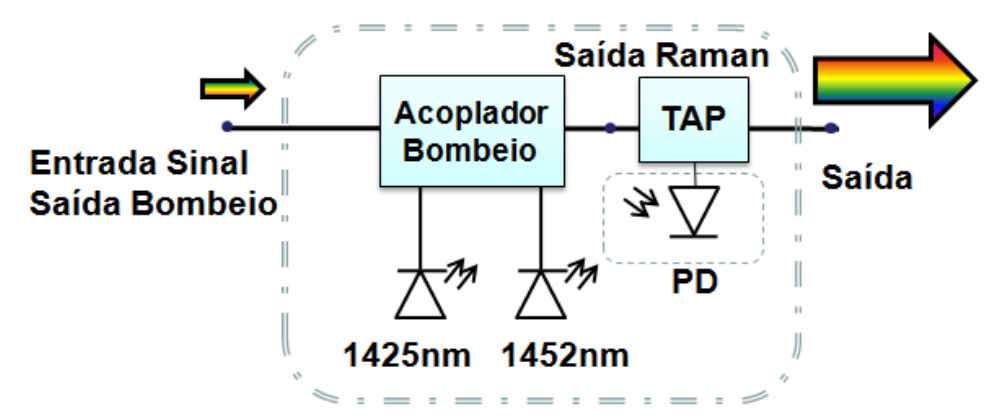

Figura 4.5: Circuito óptico do amplificador Raman distribuído contra-propagante com dois bombeios.

ção de amplificação não saturada quanto na condição de amplificação saturada. Neste estudo, erros máximos de 0,2 a 0,4 dB foram obtidos para amplificação nas bandas $\mathrm{C}+\mathrm{L}$ em um enlace de $100 \mathrm{~km}$ de fibra SSMF.

Em (Kim e Park, 2005) foi proposto um algoritmo semi-analítico de controle de ganho para amplificadores Raman a fibra trabalhando na condição de saturação, apresentando excursão de ganho de $0,5 \mathrm{~dB}$ para uma condição de adição/remoção de 78/80 canais ( $+5 \mathrm{dBm}$ de potência por canal) no amplificador, com resposta temporal em escala de tempo de milissegundos.

Em (Zhou et al., 2006) é proposto um algoritmo de controle de ganho em malha aberta o qual, em função somente da potência de entrada total dos sinais no enlace, é capaz de controlar o ganho do amplificador Raman distribuído (co-propagante). Para implementação do algoritmo proposto, torna-se necessário realizar uma caracterização prévia do amplificador Raman com relação ao tipo de fibra usada. Desta caracterização prévia são retirados via regressão polinomial, os coeficientes de ajuste dos múltiplos bombeios para que cada ganho alvo possa ser fornecido com planicidade espectral.

Porém a metodologia de controle automático de ganho para amplificadores Raman distribuído apresentada neste trabalho (Oliveira et al., 2013b, 2012) é a mais adequada para utilização em sistemas DWDM práticos, pois não necessita de informações adicionais de outros nós da rede, como em outros métodos de controle de ganho apresentados anteriormente.

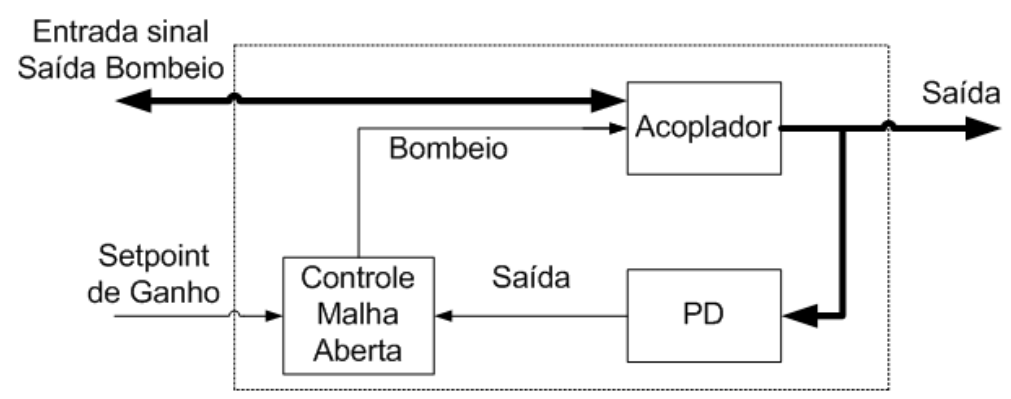

Figura 4.6: Malha de controle de ganho para o amplificador Raman distribuído contra-propagante com dois bombeios.

Desta forma, nesta tese é proposto um algoritmo de controle de ganho de amplificadores Raman distribuídos com bombeios contra-propagante utilizando o mesmo con- 
ceito de controle de malha aberta (ilustrado na Figura 4.6) dos bombeios, por meio da medida de potência total no amplificador apresentado em (Oliveira et al., 2013b, 2012; Zhou et al., 2006).

Porém, no caso do DRA contra-propagante, obtém-se a potência lançada na fibra de maneira cega (sem conhecimento prévio), baseado na potência de sinal amplificado medido no fotodetector de saída do DRA, junto com dados da perda do enlace e do ganho alvo (Oliveira et al., 2013b, 2012), como explicitado na equação 4.1, e consequentemente, estimamos a potência do sinal com o bombeio desligado através da equação 4.2. Os dados de perda do enlace e ganho alvo são enviados para o processador do amplificador via mensagem binária (comunicação serial) pela gerencia do sistema.

$$
\begin{gathered}
P_{L}=P_{P D}-G_{\text {alvo }}+\text { Perda } a_{\text {enlace }} \\
P_{O F F}=P_{L}-\text { Perda } a_{\text {enlace }}
\end{gathered}
$$

onde $P_{L}$ é a potência estimada de sinal lançada na fibra no início do enlace, $P_{P D}$ é o valor de potência obtido a partir da medida realizada pelo fotodetector de saída do amplificador Raman, $G_{a l v o}$ é o valor de ganho on-off a ser atingido pelo amplificador, Perd $a_{\text {enlace }}$ é a perda em dB do enlace do sistema e $P_{O F F}$ é a potência de sinal estimada com os bombeios desligados.

Após estimação da potência de sinal com os bombeios desligados, esta é aplicada à equação polinomial (que será explicada mais adiante neste capítulo), com os coeficientes obtidos previamente, determinando-se o nível de cada bombeio Raman de forma a fornecer o ganho alvo desejado com planicidade espectral de ganho.

Este algoritmo é executado no controle em malha aberta da malha de controle de ganho apresentada na Figura 4.6, proporcionando controle automático de ganho para amplificadores distribuídos Raman com bombeios contra-propagante, que vai ser utilizado no desenvolvimento do AGC para o amplificador híbrido alvo desta tese.

\subsubsection{Amplificador Óptico Híbrido (Raman/EDFA) com Controle Automá- tico de Ganho}

Na literatura existem vários trabalhos relatando o desenvolvimento de amplificadores híbridos baseados na combinação das tecnologias de amplificação Raman (discreto ou distribuído) e EDFA. Porém, poucos desses trabalhos tiveram como objetivo o desenvolvimento de técnicas de controle automático de ganho para estes amplificadores híbridos, e, quando o desenvolveram, o principal alvo foram os amplificadores híbridos Raman discreto combinados com EDFA, com objetivo de fornecer amplificação aliado à compensação de dispersão cromática, algo agora desnecessário com a presença dos sistemas coerentes com alta eficiência espectral.

Nesta subseção o objetivo é descrever a evolução destes principais trabalhos realizados no campo de desenvolvimento de amplificadores híbridos com controle automático de ganho.

Em (Lee et al., 2005) foram realizados experimentos em quatro diferentes topologias 
de amplificadores ópticos, onde três destas empregavam amplificadores híbridos Raman discreto/EDFA com reuso de bombeio, objetivando a avaliação do ganho e a planicidade espectral de ganho (cenário estático) para vários níveis de potência de entrada, além de avaliar o comportamento do transiente de potência no canal sobrevivente na condição de adição e remoção de canais. Contudo, todos os experimentos foram executados com bombeio fixo, desta forma não avaliando controle automático de ganho.

Em (Mowla e Granpayeh, 2009) é proposto e projetado um amplificador híbrido EDFA/Raman discreto com ganho espectral plano $(2,91$ - 2,03 dB) para Banda $\mathrm{C}+\mathrm{L}$, utilizando de 6 a 10 lasers de bombeio. No entanto, este desenvolvimento visou somente a otimização da planicidade espectral de ganho, sem propor uma técnica de controle de ganho.

Em (Bilal et al., 2012) foi projetado um enlace com amplificação híbrida Raman distribuído contra-propagante e EDFA objetivando planicidade espectral de ganho para sistemas de longa distância WDM. Foi obtido um ganho espectral aproximadamente plano $(0,7 \mathrm{~dB})$, porém, além de não se tratar do projeto de uma unidade de amplificação híbrida, não se propõe uma técnica de controle automático de ganho.

Em (Ahmad et al., 2008) foram utilizadas três das topologias desenvolvidas em (Lee et al., 2005) para desenvolvimento de controle automático de ganho, porém tal controle é verificado somente para um dado ganho alvo, não sendo permitido a variação deste ganho alvo, fator extremamente necessário para redes WDM reconfiguráveis.

Em (Dung et al., 2009) uma técnica de controle automático de ganho totalmente óptico (baseado em realimentação óptica da ASE) é desenvolvida e aplicada a uma topologia de amplificação híbrida de EDFA/Raman discreto (em DCF) com reuso de bombeio. Assim como em (Ahmad et al., 2008), o controle de ganho é desenvolvido para somente um ganho alvo, e não permite variação do ganho alvo de operação.

Dentre os trabalhos publicados na literatura, alguns desenvolvem técnicas de controle automático de ganho, porém não foram encontrados trabalhos propondo técnicas de controle automático de ganho de amplificadores híbridos DRA contra-propagante/EDFA para aplicação para redes DWDM reconfiguráveis, que é a topologia que pode otimizar a performance de amplificação para sistemas coerentes.

Buscando preencher esta lacuna tecnológica, torna-se necessário desenvolver para esta topologia de amplificação baseada em tecnologias híbridas de amplificação, técnicas de controle automático de ganho que forneçam características de ganho espectral plano e baixa figura de ruído para uma faixa de ganhos alvo de operação do amplificador.

\subsection{Análise do Desempenho de Amplificador Óptico via Más- cara de Potência}

Em uma rede óptica DWDM reconfigurável, torna-se necessário que o amplificador opere de forma satisfatória em uma determinada faixa de potências de entrada (diferentes carregamentos de canais), uma vez que este carregamento consequentemente pode alterar a potência de entrada de forma dinâmica e imprevisível. Além disso, variações na potência de entrada também podem ser causadas por outros fatores, como modifica- 
ções nos níveis de potências advindas de amplificadores/sistemas localizados no mesmo enlace.

Outra necessidade está relacionada à operação do amplificador em diferentes faixas de potências de entrada, definida por uma faixa de diferentes valores de ganhos controláveis. Neste caso, a região de operação do amplificador é definida pelas faixas de potências de entrada e ganhos alvos de operação, para os quais o desempenho do amplificador é garantido, sendo esta região de operação denominada máscara de potência de um amplificador óptico (Cowle, 2010; JDSU, 2011). Seu desempenho dinâmico pode ser medido por meio dos valores de figura de ruído, planicidade espectral de ganho e precisão do controle automático de ganho ao longo de sua máscara de potência.

A Figura 4.7 ilustra uma máscara de potência de um amplificador óptico. Os limites da máscara de potência podem ser facilmente definidos em termos dos seguintes valores de operação: ganho máximo, ganho mínimo, potência máxima de saída e potência mínima de entrada.

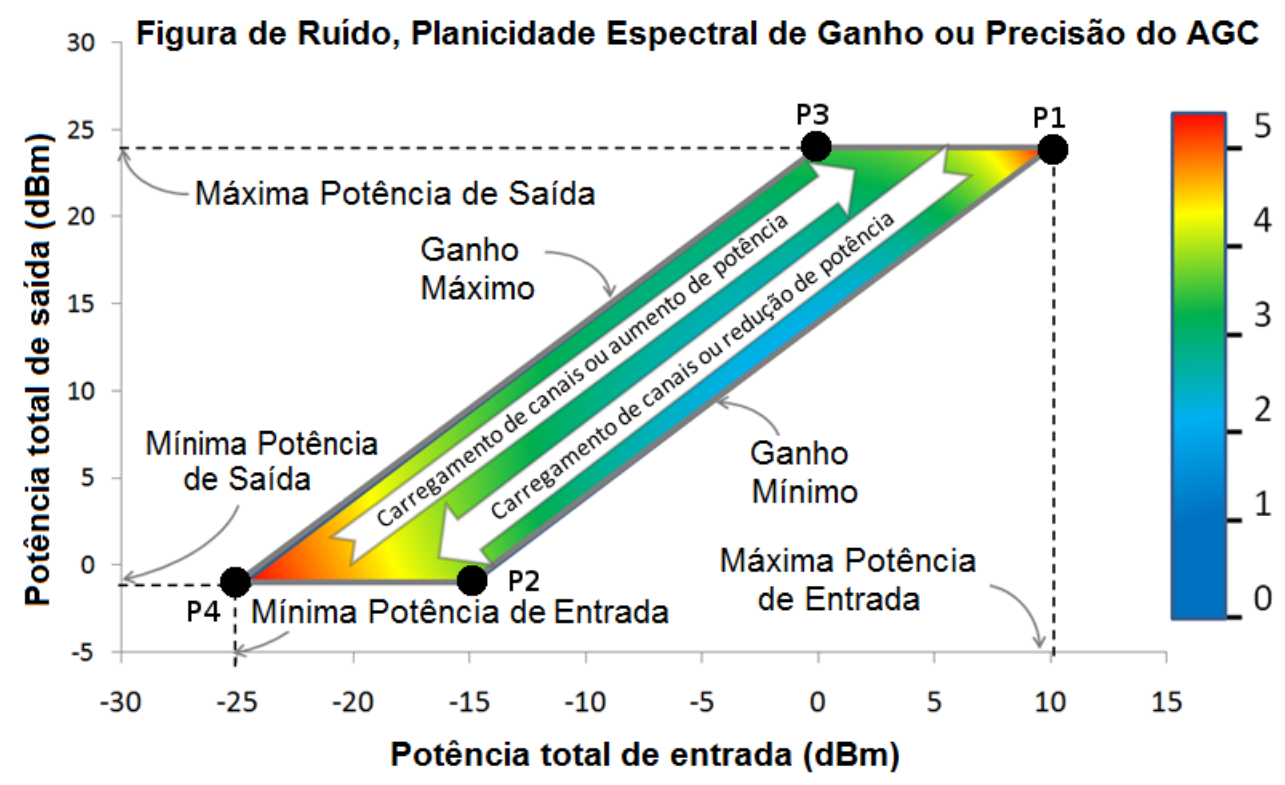

Figura 4.7: Máscara de potência para um amplificador óptico.

Importantes relações matemáticas podem ser extraídas da máscara de potência. Estas expressões definem os intervalos de operação do amplificador analisado. Abaixo, as equações 4.3 a 4.6 apresentam tais relações (em dBm).

$$
\begin{gathered}
P_{O U T}^{M I N}=P_{I N}^{M I N}+G_{M A X} \\
P_{I N}^{M A X}=P_{O U T}^{M A X}-G_{M I N} \\
P_{I N}^{G M A X}=P_{O U T}^{M A X}-G_{M A X} \\
F D=P_{I N}^{G M A X}-P_{I N}^{M I N}
\end{gathered}
$$


onde $P_{O U T}^{M I N}$ é o valor de potência de saída mínima, $P_{I N}^{M I N}$ é o valor mínimo de potência de entrada, $G_{M A X}$ é o valor de ganho máximo desejado, $P_{I N}^{M A X}$ é o valor de potência de entrada máxima do amplificador, $P_{O U T}^{M A X}$ é o valor de potência de saída máxima fornecida pelo amplificador, $G_{M I N}$ é o valor de ganho mínimo provido pelo amplificador, $P_{I N}^{G M A X}$ é o valor máximo de potência de entrada para o ganho máximo e, finalmente, $F D$ é a faixa dinâmica de operação do amplificador projetado.

O desempenho do amplificador dentro da máscara pode ser obtido por meio de caracterização laboratorial (de Moura et al., 2012) e/ou caracterização via software de simulação numérica (Oliveira et al., 2012).

Para realização de uma caracterização, é necessário informar os parâmetros básicos da região de interesse (máxima potência de saída, mínima potência de entrada, ganhos máximo e ganho mínimo de operação), e seu respectivo passo de caracterização (por exemplo, 1 dB). Tanto no âmbito de simulação quanto no experimental, uma bancada de lasers DWDM geralmente com 40 canais (192,1 - 196 THz) é necessária visando popular toda a banda de operação do amplificador (neste caso a banda C) com canais (lasers) nos seus comprimentos de onda adequados, para realização da caracterização contendo a informação do comportamento do amplificador óptico ao longo de toda largura de banda amplificada.

A Figura 4.8 ilustra os caracterizadores desenvolvidos em ambiente de simulação (ilustrado na Figura 4.8(a)) e experimental (ilustrado na Figura 4.8(b)). No caracterizador experimental, um amplificador auxiliar é utilizado para fornecer uma potência total máxima de 21,5 dBm para bancada de sinais de entrada, enquanto uma chave WSS é utilizada para equalizar a bancada de sinais utilizada como entrada do sistema a ser caracterizado. Este procedimento é realizado para que o sinal na entrada do amplificador seja o mais plano possível, garantindo maior precisão e uniformidade a caracterização do amplificador óptico (de Moura et al., 2012).

Em seguida, um atenuador variável permite ajustar a potência de entrada do sistema a ser caracterizado. O sistema em caracterização é composto por um amplificador óptico e/ou várias dezenas até uma centena de quilômetros de fibra óptica. Nesta tese utilizou-se $100 \mathrm{~km}$ de fibra SSMF G.652 para caracterização de amplificadores Raman distribuídos e amplificadores híbridos, porém qualquer enlace acima de $60 \mathrm{~km}$ de SSMF G.652 pode ser utilizado, devido o comprimento efetivo da fibra relativo ao efeito de amplificação Raman manter-se aproximadamente o mesmo, em torno de 17 km (Headley e Agrawal, 2005).

A partir deste ponto, uma amostra do sinal de entrada e uma amostra do sinal de saída do sistema seguem para a uma chave óptica $2 \times 1$, permitindo medição de ambos os espectros e potências, bastando ajustar a posição da chave óptica que direciona o sinal a ser medido diretamente pelo analisador de espectro óptico (OSA). A comunicação destes equipamentos com o software de caracterização é feita por meio de interfaces GPIB, USB, Ethernet e serial, todas suportadas pelo computador utilizado para realizar o controle do caracterizador experimental. O software de caracterização experimental foi desenvolvido em Labview, e fica responsável por todas as comunicações, controles e 


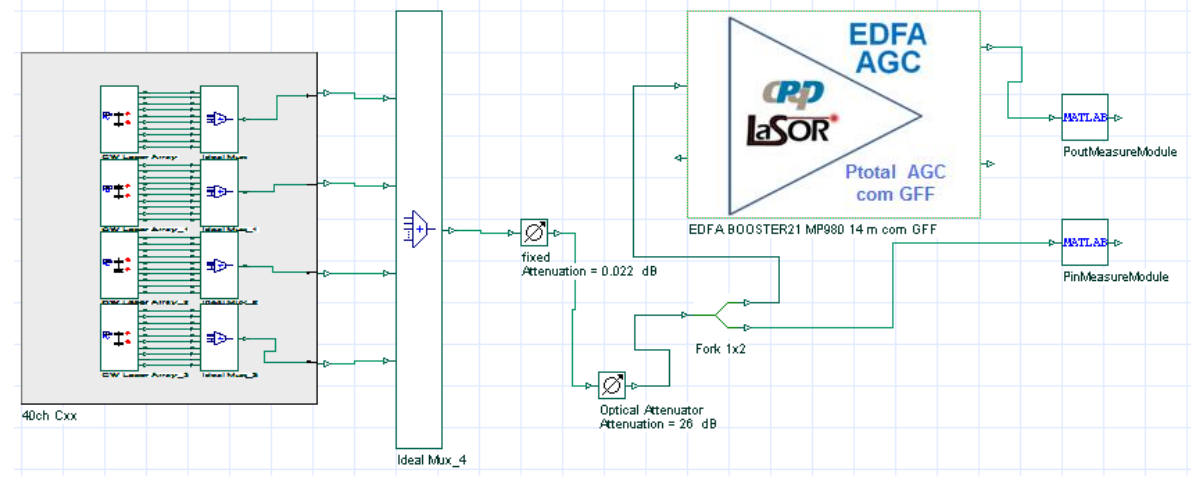

(a)

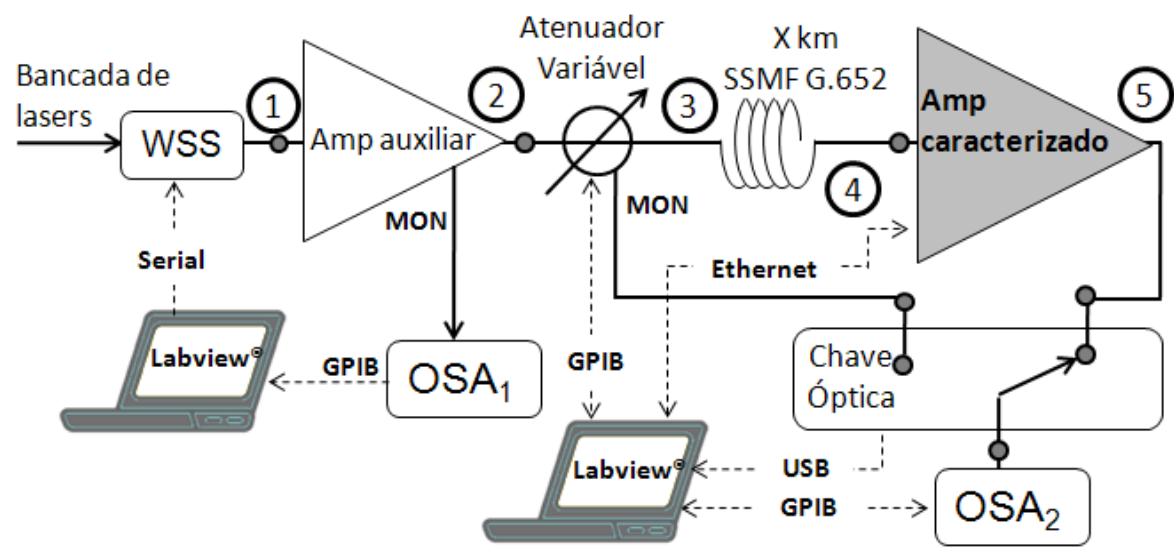

(b)

Figura 4.8: Caracterizador de amplificador óptico discreto e distribuído em software de simulação numérica (a) e em bancada experimental experimental (b)

aquisições necessárias para realização da caracterização (de Moura et al., 2012).

O fluxograma do software de caracterização experimental é descrito em (de Moura et al., 2012). Em resumo, o programa inicia com a entrada dos parâmetros que definem a região da máscara de potência e a granularidade (passo de caracterização), definindo a quantidade de pontos de varredura da máscara. Antes de iniciar a caracterização, uma rotina para determinar qual a máxima potência possível na entrada do sistema é executada. Se este valor for suficiente para caracterização da máscara especificada, o programa prossegue a caracterização.

A partir deste ponto, a caracterização ajusta o ganho alvo do amplificador para seu valor mínimo, e a entrada para seu valor máximo de potência. Em seguida, os valores de potência total na entrada e saída, bem como o ganho configurado e medido, seguido do ajuste da chave óptica de forma que o OSA capture o espectro na entrada e, logo em seguida, por meio de outro ajuste da chave óptica, o espectro de saída seja obtido. Estes dados são salvos em arquivos de texto. Quando todas as potências de entrada foram ajustadas para um dado ganho, este é incrementado e o programa segue até que o valor do ganho ultrapasse o ganho máximo, que corresponde a uma das entradas dos parâmetros da máscara, assim finalizando a aquisição experimental do amplificador óptico. 
O caracterizador simulado ilustrado na Figura 4.8(a) funciona de forma mais simples devido ao fato de que no mundo virtual os recursos são abundantes e sempre disponíveis. Desta forma, no caracterizador simulado, não temos a necessidade de amplificação prévia da bancada de lasers, ou seja, a bancada de lasers vai direto para o sistema em caracterização, assim como não temos restrições com relação aos equipamentos de medição. Então, a aquisição dos dados é realizada de acordo com o mesmo fluxograma (de Moura et al., 2012), porém os dados são adquiridos diretamente por meio dos scripts desenvolvido em MATLAB (Oliveira et al., 2012).

Após finalizado o processo de caracterização, algoritmos desenvolvidos em MATLAB tratam todos os dados adquiridos (de Moura et al., 2012; Oliveira et al., 2012), processando cada conjunto de espectros (entrada/saída) e calculando, para cada ponto de operação, as máscaras de potência de planicidade espectral de ganho, figura de ruído (pior caso, canal com maior figura de ruído) e a precisão do controle automático de ganho ao longo de toda região de operação do amplificador. A Figura 4.9(b) ilustra um exemplo de máscara de potência, enquanto as Figuras 4.9(a) e 4.9(c) ilustram dois pontos da máscara, visando mostrar que cada ponto na máscara corresponde a espectros de entrada/saída, permitindo desta forma que os dados da máscara sejam calculados a partir destes.

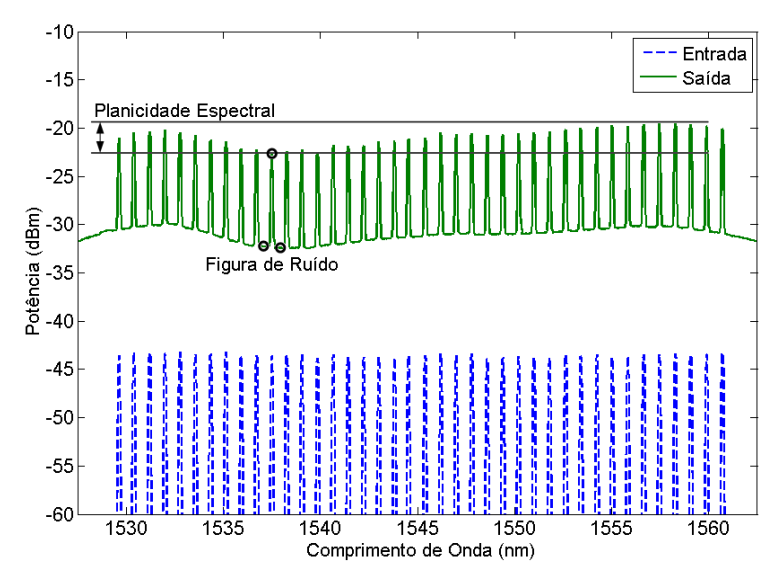

(a)

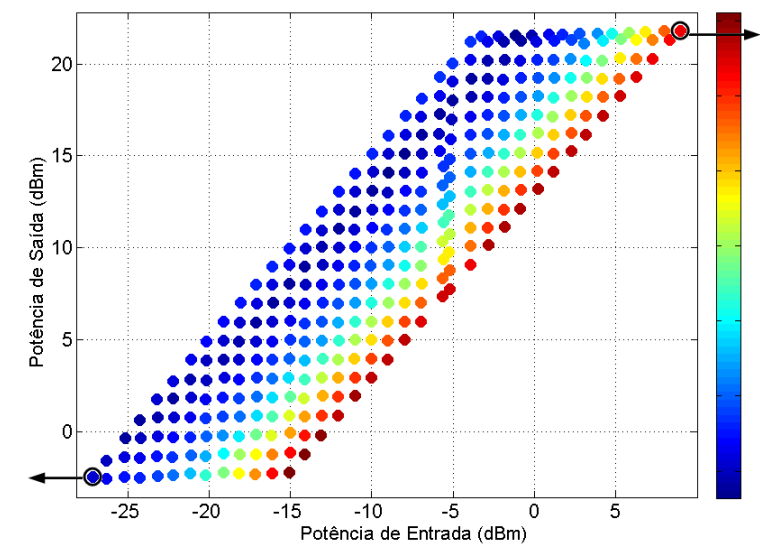

(b)

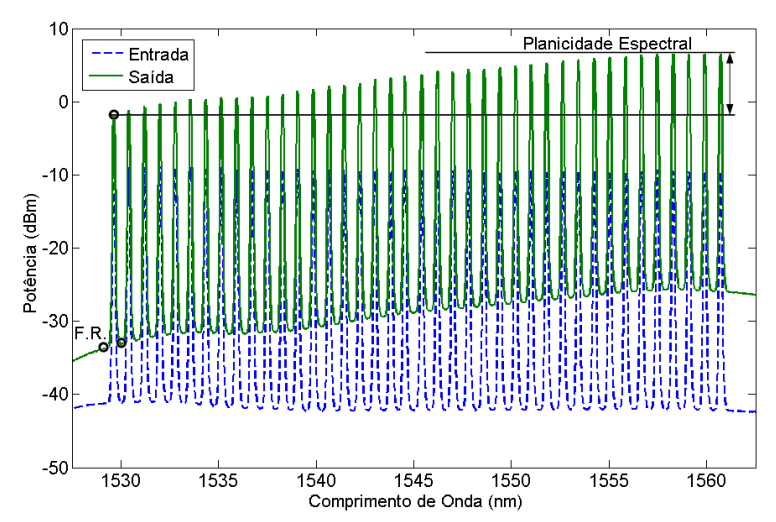

(c)

Figura 4.9: (a) Espectro de entrada e saída para o ponto inferior esquerdo da máscara de potência (b) Exemplo de uma máscara de potência onde a cor do ponto pode representar figura de ruído, planicidade espectral de ganho e precisão de AGC (c) Espectro de entrada e saída para o ponto superior direito da máscara de potência. 
Com relação ao processamento dos dados adquiridos, a planicidade espectral de ganho é calculada por meio da diferença entre o máxima potência de pico e a mínima potência de pico entre os canais do espectro de saída do amplificador, como ilustrado nas Figuras 4.9(a) e 4.9(c). A figura de ruído por sua vez, é calculada, por canal, de acordo com a equação 4.7, que se refere à figura de ruído para amplificadores em cascata com enlaces/perdas entre eles (Becker et al., 1999), devido ao presença do amplificador auxiliar no caracterizador experimental. Não temos a necessidade do uso desta equação para o caracterizador simulado.

$$
N F_{15}^{c h}=N F_{12}^{c h}+\frac{N F_{45}^{c h} A t t_{24}^{c h}}{G_{12}^{c h}}
$$

Na equação $4.7 A t t_{24}^{c h}$ corresponde à atenuação entre os pontos 2 e 4 (Figura 4.8(b)) e $G_{12}^{c h}$ se refere ao ganho do amplificador auxiliar, ambos por canal. A figura de ruído entre os pontos 1 e 5 (Figura 4.8(b)), $N F_{15}^{c h}$, e a figura de ruído do amplificador auxiliar (entre os pontos 1 e 2 da Figura 4.8(b)), $N F_{12}^{c h}$ também por canal, são calculadas por meio da equação 4.8 (Becker et al., 1999).

$$
N F^{c h}=10 \log _{10}\left(\frac{P a s e^{c h}}{h v^{c h} G \Delta v^{c h}}+\frac{1}{G^{c h}}\right)
$$

Na equação $4.8 \mathrm{Pase}^{\text {ch }}$ se refere à potência de ruído de ASE no canal correspondente, $h$ é a constante de Planck, $v^{c h}$ é a frequência do canal, $\Delta v$ é a largura de banda de medição do canal, e $G^{c h}$ é o ganho do canal entre os pontos de medição de $N F$. Por fim, a precisão de controle de ganho é a diferença entre os valores do ganho total configurado e ganho total medido.

A única diferença entre a caracterização de amplificadores discretos (EDFA e amplificadores Raman discretos) e a caracterização de amplificadores distribuídos (Raman contra-propagante e co-propagante com múltiplos bombeios) e híbridos (Raman/EDFA) consiste na medição da figura de ruído, pois na caracterização dos amplificadores discretos realiza-se a medição e cálculo da figura de ruído como descrito em (Becker et al., 1999), enquanto nos amplificadores distribuídos realiza-se a medição da figura de ruído equivalente como descrito em (Headley e Agrawal, 2005).

Dessa forma, através do caracterizador de amplificadores ópticos é possível obter o desempenho ao longo de todos seus pontos de operação via máscara de potência. Além disso, a máscara de potência mostra-se como uma ferramenta útil para obtenção indireta da performance de um amplificador óptico com base nas leituras de potência e ganho. A máscara de potência do amplificador pode também servir para as redes dinâmicas com o objetivo de prever o desempenho dos sistemas de acordo com a variação de carregamento de canais e/ou potência de entrada. 


\subsection{Projeto de Topologias de Amplificadores Ópticos com Con- trole Automático de Ganho em Software de Simulação Óp- tica}

Com base nas tecnologias de amplificação óptica com controle automático de ganho e na possibilidade de descrição de desempenho por meio da máscara de potência, apresentados nas seções anteriores, esta seção tem como objetivo projetar os amplificadores, e aplicar essas metodologias de controle automático de ganho nos amplificadores EDFA e Raman distribuído, otimizando o projeto em termos de planicidade espectral de ganho e figura de ruído, para operação em redes DWDM reconfiguráveis.

Para manter a simulação o mais fiel possivel com relação aos sistemas experimentais, as características dos amplificadores (perdas dos componentes, níveis de ruído e características das fibras utilizadas) foram medidas experimentalmente em laboratório.

A partir deste ponto, uma metodologia de projeto de EDFAs foi desenvolvida para as topologias de amplificação EDFA de estágio simples e estágio duplo com atenuador óptico variável (VOA), ambas com filtro de planificação de ganho espectral (GFF) projetado de acordo com a faixa de ganhos de operação dos amplificadores desenvolvidos (Paiva et al., 2012), assim como foi desenvolvida uma metodologia de projeto de amplificadores Raman distribuídos (DRAs) considerando as restrições físicas dos componentes ópticos para amplificadores com 2, 3 e 4 lasers de bombeio (Oliveira et al., 2011a). Os controles automáticos de ganho apresentados para amplificadores EDFA e Raman distribuídos simulados foram desenvolvidos por meio de caracterização prévia dos amplificadores, em conjunto com algoritmos de regressão linear/polinomial, visando precisão no controle de ganho e otimização do tempo de simulação dos amplificadores com AGC (de Oliveira et al., 2011).

\subsubsection{Metodologia de Projeto Otimizado de Amplificador a Fibra Dopada com Érbio para Redes DWDM Reconfiguráveis}

Com o estabelecimento das especificações de projeto do amplificador óptico por meio da máscara de potência, de acordo com a seção 4.2, os valores limites de operação (máximo ganho, mínimo ganho, máxima potência de saída e mínima potência de entrada), alimentam a metodologia de projeto de EDFAs, que busca projetar o amplificador, maximizando o desempenho de figura de ruído e planicidade espectral de ganho dentro da máscara de potência.

Considerando a busca por um projeto de EDFA de alto desempenho óptico, nesta tese a topologia de EDFA com bombeio co-propagante e GFF sempre é considerada, devido ao desempenho superior com relação à figura de ruído frente às topologias contrapropagante e bi-direcionais (Pal et al., 2007). Porém, para esta topologia o ganho espectral plano é possível somente para o ganho nominal projetado. Devido a esta restrição, a topologia de EDFA duplo (com bombeio co-propagante) e atenuador variável entre os estágios de amplificação é utilizada. Porém, neste caso, a figura de ruído é degradada em detrimento do ganho plano ao longo da máscara de potência (Abu Bakar et al., 2011). 
Com estas restrições em mente, a metodologia de projeto otimizado realiza a determinação do tipo e comprimento da fibra dopada com érbio para um amplificador óptico a operar em redes DWDM reconfiguráveis. Finalizando, com a análise dos dados de caracterização ao longo da máscara, o controle automático de ganho é desenvolvido em simulação óptica e o desempenho ao longo da máscara de potência é obtido também por meio do simulador óptico.

\section{Determinação do Tipo e do Comprimento Ótimo de Fibra Dopada com Érbio}

Para se determinar o tipo e o comprimento de fibra dopada com érbio (EDF) mais indicado para um determinado EDFA, isto é, que atenda às especificações de projeto referentes à planicidade espectral de ganho, figura de ruído dentro da região da máscara de potência, definimos inicialmente os parâmetros de operação da máscara de potência do amplificador:

- $14 \mathrm{~dB}$ de ganho mínimo

- $24 \mathrm{~dB}$ de ganho máximo

- $21 \mathrm{dBm}$ de potência total de saída máxima

- $-25 \mathrm{dBm}$ de potência total de entrada mínima

Estes pontos são determinados de forma empírica, baseado na operação de um amplificador óptico de potência em sistemas com repetição reconfigurável, que operam geralmente com potência de saída máxima de $21 \mathrm{dBm}$, ou seja, até 80 canais considerando potência de saída de até $2 \mathrm{dBm}$ por canal, faixa dinâmica de até $22 \mathrm{~dB}$ (19 dB devido à adição/remoção de até 80 canais, somados a $3 \mathrm{~dB}$ de margem sistêmica) e espaçamento de enlaces variando de 70 a $120 \mathrm{~km}$ (ganhos de 14 a $24 \mathrm{~dB}$ ).

Para determinação do comprimento ótimo da fibra dopada com érbio, é considerada apenas a região de saturação do amplificador, a região que apresenta os maiores desafios para atendimento dos requisitos. Com base nisto, diversas simulações foram realizadas variando tanto o tipo de EDF quanto o comprimento de cada EDF e sua potência de bombeio, considerados os seguintes intervalos de valores:

- EDF: $5 \mathrm{~m}$ a $30 \mathrm{~m}$, com incrementos de $1 \mathrm{~m}$, para as fibras dopadas fornecidas pela OFS $^{\circledR}$ (HP980, MP980 ou R37004, R37003).

- Potência de bombeio: $10 \mathrm{~mW}$ a $600 \mathrm{~mW}$ em $980 \mathrm{~nm}$.

Buscando-se a otimização do esforço computacional, os valores de potência de entrada do amplificador foram tomados a partir dos vértices desta região, uma vez que atendidas as especificações nos vértices, estas também o serão no interior da região (Cowle, 2010). A Figura 4.7 ilustra os pontos em questão através do ponto crítico 3 (P3) que corresponde ao maior ganho saturado da faixa de operação, e o ponto crítico 1 (P1) corresponde ao menor ganho saturado da faixa de operação do amplificador. 


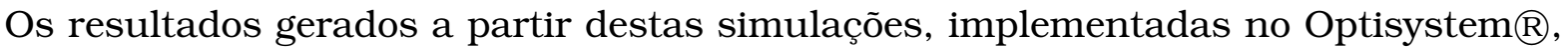
são processados por programas de filtragem de dados desenvolvidos nesta tese em Matlabß para tornar a análise automatizada (Paiva et al., 2012). A Figura 4.10 mostra a tela do programa desenvolvido e utilizado nesta filtragem.

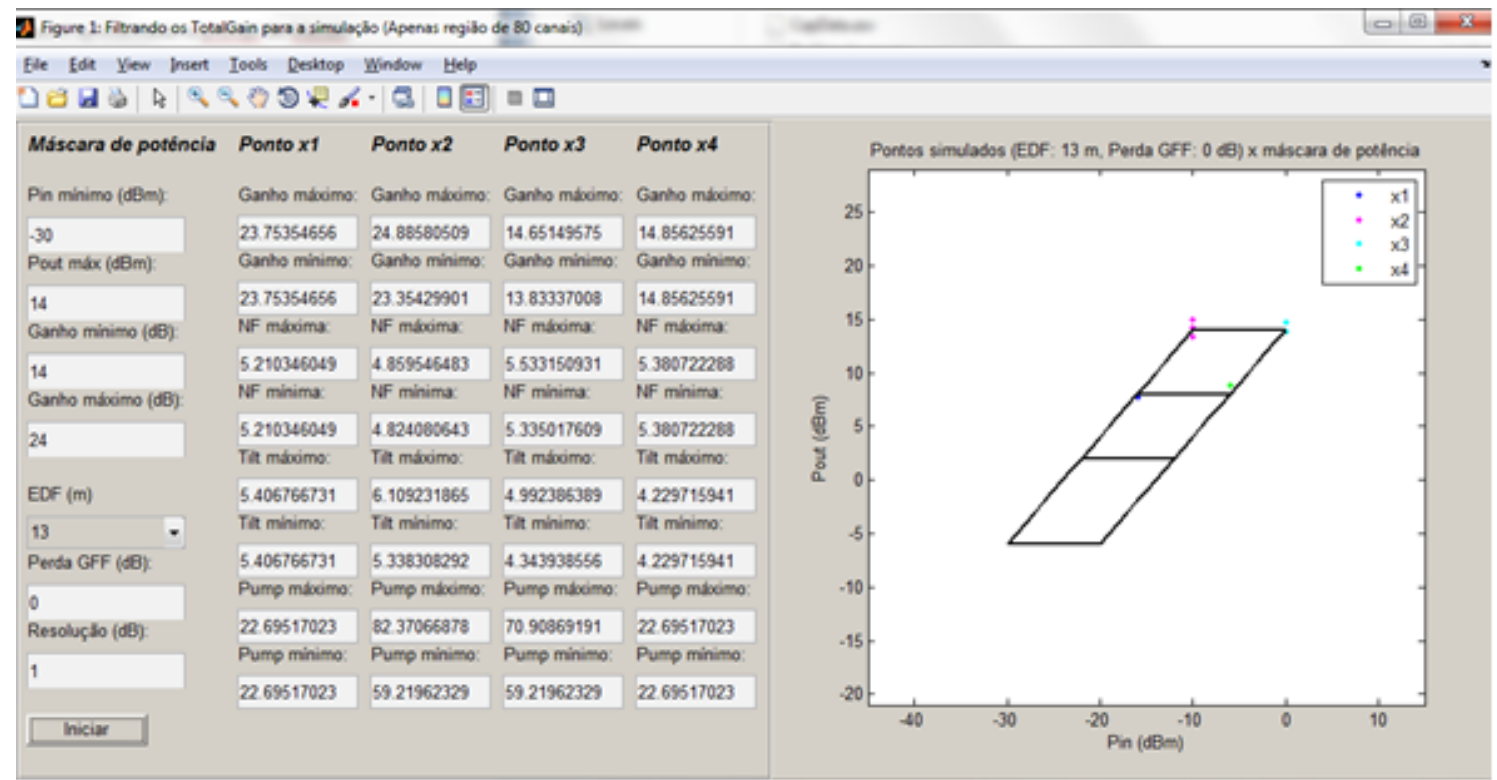

Figura 4.10: Interface gráfica do programa de filtragem dos dados. A primeira coluna à esquerda mostra as especificações da máscara de potência, um menu drop down para escolha do comprimento da EDF e entradas para inserir perda de filtro equalizador de ganho (GFF) e resolução, que indica a precisão a ser considerada.

$\mathrm{Na}$ interface gráfica com o usuário (GUI) ilustrada na Figura 4.10, o resultado da caracterização é carregado sendo fornecidos pelo usuário os limites da máscara de potência para o amplificador caracterizado, os valores alvo de figura de ruído, planicidade espectral de ganho e a tolerância permissivel (em dB). A partir deste ponto a GUI processa as informações da caracterização, buscando, em torno dos pontos críticos da máscara de potência, o comprimento otimizado da fibra dopada com érbio que atende os parâmetros de figura de ruído e ganho espectral plano dentro dos valores e tolerância desejados. Caso nenhum comprimento otimizado de EDF seja retornada pela GUI, o usuário deve aumentar a tolerância $(\mathrm{em} \mathrm{dB}$ ) até que seja encontrada a metragem de EDF otimizada para o amplificador caracterizado.

A escolha do tipo e do comprimento de fibra EDF adequados leva em consideração tanto a figura de ruído como o ganho espectral plano, mas prioriza a primeira. Por meio da utilização de um filtro equalizador de ganho, a planicidade espectral de ganho será minimizada mais adiante.

Obtido o comprimento e o tipo de fibra mais de acordo com as especificações da máscara de potência requeridas, as próximas seções tratam da finalização do projeto de um amplificador óptico por meio do desenvolvimento do filtro de planicidade espectral de ganho (GFF) adequado, e por meio do desenvolvimento do controle automáticos de ganho para as duas topologias de EDFA. 


\subsubsection{Projeto de EDFA com Estágio Único, GFF e AGC (Malha Aberta) em Simulação Óptica}

Esta subseção tem como objetivo o desenvolvimento de um EDFA de estágio único com controle automático de ganho (AGC) em software de simulação óptica com baixo custo computacional. Nesta seção é apresentada a metodologia de projeto deste amplificador com AGC, visando obter um EDFA com ganho controlado a ser utilizado em longos enlaces de comunicações ópticas.

O Optisystem $\AA$ possui um recurso para emulação do controle automático de ganho de EDFAs utilizando controle de ganho realimentado. Porém, este método realiza o controle de ganho a um custo computacional altíssimo (1200-1800 segundos para estabilização do controle de ganho), tornando inviável seu uso para avaliação de longos enlaces de comunicações ópticas contendo EDFAs com AGC. Entretanto o método de controle automático de ganho para EDFAs apresentado nesta seção utiliza-se de regressão linear realizada nos dados de caracterização do EDFA a ser controlado, obtendo os coeficientes dos polinômios (um para cada ganho alvo) que, operando em malha aberta

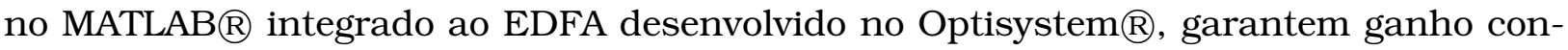
trolado ao EDFA com um custo computacional baixo, 60-90 vezes mais rápido que o controle de ganho embutido no Optisystem (em torno de 20 segundos de processamento para estabilização do controle de ganho).

A metodologia de projeto de EDFA com AGC em software de simulação numérica aqui apresentado é composta por quatro fases:

- Caracterização do EDFA para uma determinada topologia (co-propagante, contrapropagante ou ambos) e comprimento de EDF determinado pela metodologia da seção 4.3

- Regressão linear (potência de bombeio X potência de entrada) para cada ganho alvo, visando a determinação dos coeficientes dos polinômios de controle de ganho

- Projeto de filtro planificador espectral de ganho (GFF) para o ganho nominal de operação do EDFA

- Integração do controle de ganho ao amplificador no simulador óptico numérico

As próximas sub-seções apresentarão com detalhes todas as fases que compreendem essa metodologia de desenvolvimento de EDFA com AGC em simulação óptica, concluindo com o resultado de simulação do EDFA com AGC ao longo de sua máscara de potência (figura de ruído, planicidade espectral de ganho e precisão de AGC).

\section{Caracterização do EDFA}

Com o comprimento da fibra dopada com érbio determinado por meio da metodologia de projeto apresentada na seção 4.3, o mesmo é incluído no amplificador óptico da Figura 4.11(a) que ilustra a paleta de simulação construída para caracterização do amplificador. O EDFA construído nesta paleta de simulação é baseado em uma topologia 
co-propagante como ilustrado na Figura 4.11(b), que foi devidamente configurado com os parâmetros necessários para dar-se continuidade ao projeto do amplificador óptico.

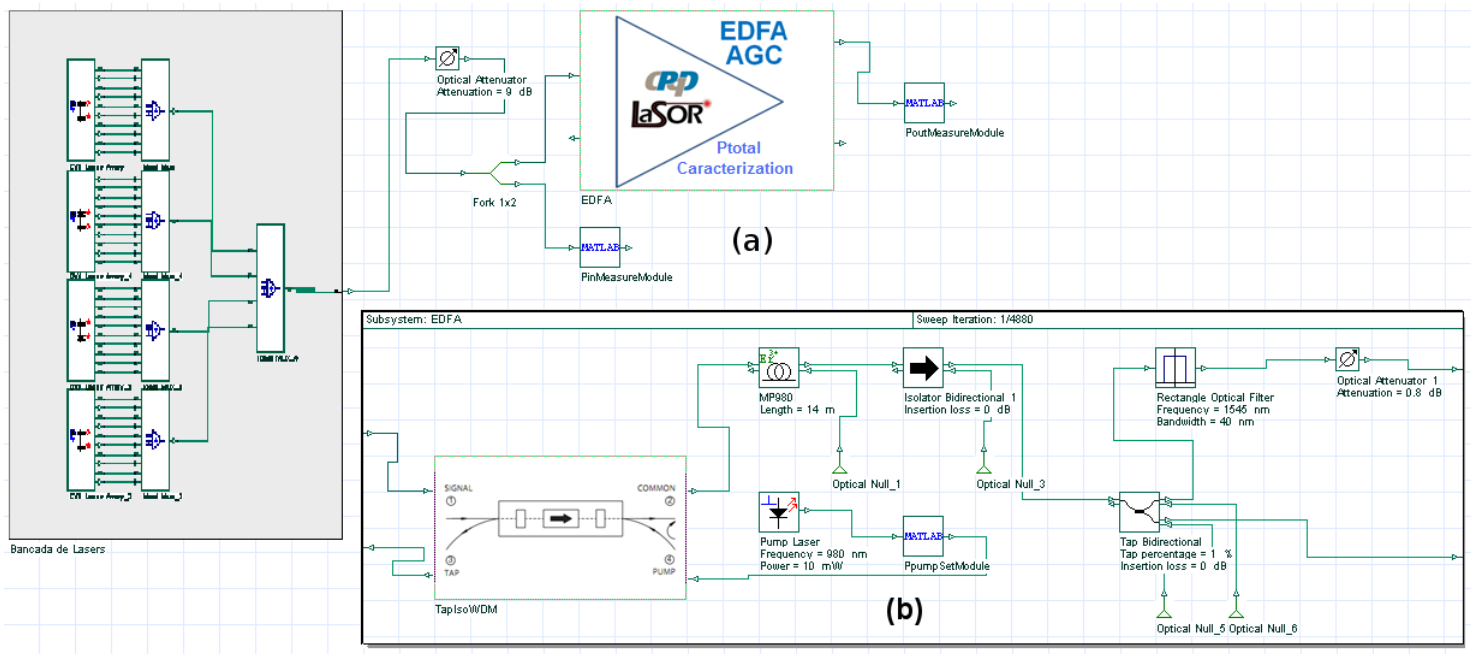

Figura 4.11: Paleta de simulação desenvolvida para caracterização de amplificador óptico (a), topologia do EDFA co-propagante a ser caracterizado (b).

Para que o amplificador simulado represente fielmente o amplificador experimental, os parâmetros de perdas de inserção dos componentes, frequência central de ruído, banda e resolução de ruído foram calibrados a partir de componentes e amplificadores experimentais como segue na lista abaixo (EDFA de potência):

- Perda de entrada: separador 99\%/1\% combinado com acoplador WDM e isolador (TapIsoWDM)

Perda de inserção de sinal: $1,6 d B$

Perda de inserção de bombeio: $0,8 d B$

- Fibra dopada com érbio: 14 metros

- Perda de saída: Isolador combinado com separador 99\%/1\%:

Perda de sinal: $0,8 d B$

- características de ruído

Frequência central de ruído: $1545 \mathrm{~nm}$

Faixa espectral de simulação do ruído: $36 \mathrm{~nm}$

Resolução do ruído (largura de banda): 0,1nm

A caracterização ilustrada na Figura 4.11(a) utiliza uma bancada de 40 lasers equalizados em potência, com frequência na banda C variando de 192,1THz(1560,61nm) à 196, 0 THz $(1529,55 \mathrm{~nm})$ com espaçamento de 100GHz. Fixados os componentes ópticos e comprimento de fibra dopada com érbio o desempenho do EDFA varia com base no nível de potência de entrada e nível de potência de bombeio. Desta forma, o processo de caracterização consiste em armazenar a resposta do EDFA projetado, considerando a variação aninhada dos parâmetros de potência de entrada e potência de bombeio, de acordo com a regra descrita nos itens abaixo: 
- $1^{\circ}$ nível: Variação da atenuação dos sinais de entrada em 61 passos com granularidade de 0,5 dB (potência total de entrada do EDFA variando de 0 a $-30 \mathrm{dBm}$ )

- $2^{\circ}$ nível: Variação da potência de bombeio do amplificador em 80 passos em espalhamento exponencial de base 10 entre a potência mínima $(10 \mathrm{~mW})$ e potência máxima do bombeio $(600 \mathrm{~mW})$.

Desta forma o processo de caracterização é realizado apenas uma vez por projeto de EDFA, executando 4880 iterações (15 segundos por iteração), levando assim em torno de 21 horas para finalização, onde para cada iteração são armazenados 128 parâmetros de desempenho do EDFA (saída da simulação) listados abaixo (a matriz 4880x128 é armazenada em arquivo texto):

- Potência de bombeio em mW (1)

- Potência total de entrada em mW (1) e dBm (1)

- Potência total de saída em mW (1) e dBm (1)

- Potência total de ruído de saída em mW (1) e dBm (1)

- Ganho total em dB (1)

- Potência de entrada por canal em dBm (40)

- potência de saída por canal em dBm (40)

- potência de ruído por canal em dBm (40)

Os passos seguintes do projeto do EDFA com AGC processam a matriz de dados resultante do passo de caracterização (4880x128) para obtenção dos polinômios de controle de ganho e projeto do filtro planificador de ganho (GFF).

\section{Obtenção dos Polinômios de Controle de Ganho}

Nesta seção é descrito o processo do desenvolvimento da função de ajuste da potência de bombeio para cada ganho alvo, visando o controle de ganho em malha aberta para o amplificador caracterizado na seção anterior.

Para o desenvolvimento de um controle automático de ganho em malha aberta para o EDFA, visando redução do custo computacional com relação ao controle realimentado, os dados resultantes da caracterização foram organizados por meio de um algoritmo desenvolvido em MATLABR, em função de cada ganho da faixa de ganhos controláveis (10-30 dB) passados como parâmetro juntamente com a granularidade $(+/-0.5 \mathrm{~dB})$. Desta forma os dados são organizados para cada ganho, potência de entrada e potência de bombeio caracterizadas, posteriormente removendo as duplicidades de dados, ou sejam, ganhos iguais (considerando a granularidade) para condições de simulação diferentes. 

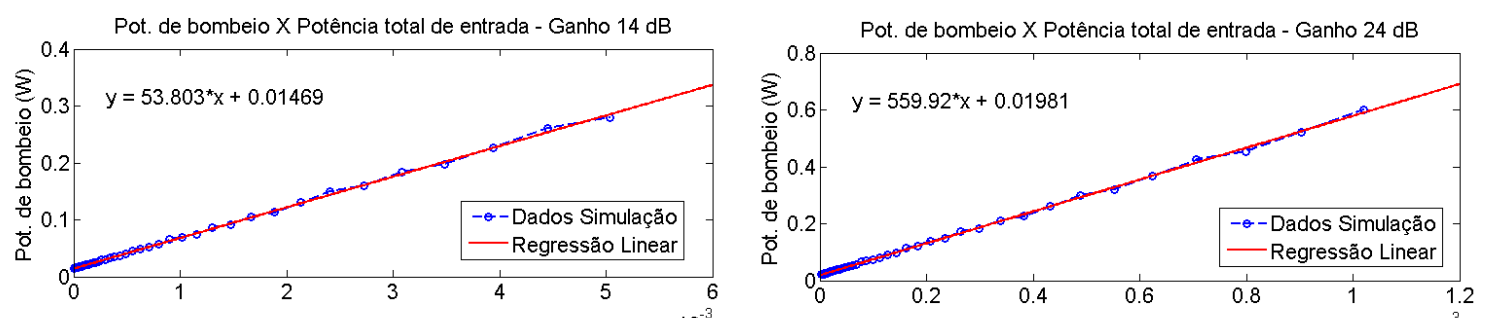

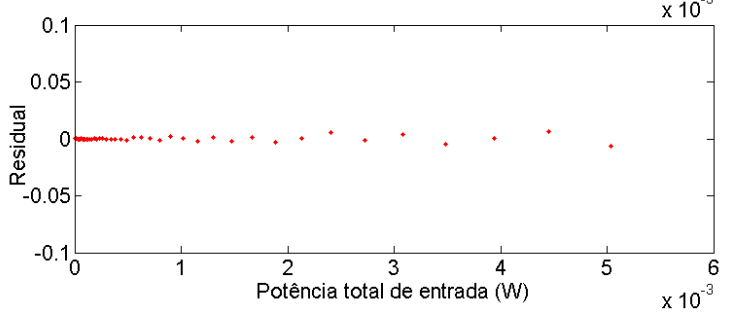

(a)

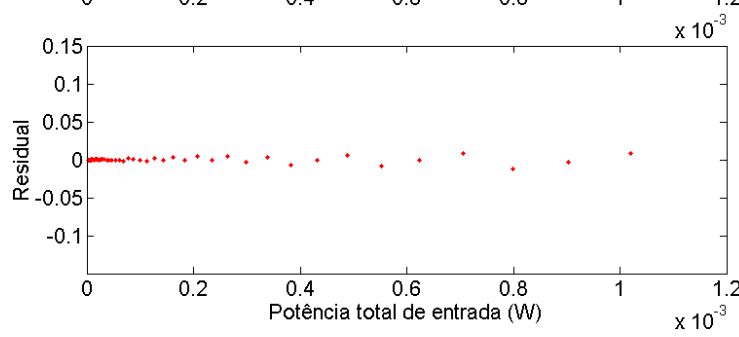

(b)

Figura 4.12: Dados simulados e regressão linear para os ganhos $14 \mathrm{~dB}(a)$ e $24 \mathrm{~dB}(\mathrm{~b})$.

Em seguida, foi analisado qual valor de potência de bombeio é necessário para cada valor de potência total de entrada, e para cada ganho alvo a ser controlado. A Figura 4.12 ilustra dois diferentes ganhos alvos (14 e $24 \mathrm{~dB}$ ).

Por meio da Figura 4.12 foi constatado que o comportamento de potência de bombeio com a potência total de entrada para manutenção do ganho alvo é uma relação linear, e que para diferentes ganhos alvos o coeficiente angular muda bruscamente enquanto o coeficiente linear varia de forma mínima.

Desta forma o algoritmo de ordenação dos dados da caracterização em função do ganho alvo foi mapeado por uma regressão linear (função polyfit do MATLABß) para determinação dos valores otimizados do polinômio linear, para cada valor de ganho alvo de controle desejado.

Assim, com a informação da caracterização, faixa de ganhos alvo de controle (em $\mathrm{dB}$ ) e granularidade (em dB), o algoritmo desenvolvido ordena os dados caracterizados, remove as duplicidades e realiza a regressão linear para cada ganho alvo de controle, armazena em arquivo texto os valores limites de bombeio com base nos dados da caracterização (amplifierPumpPowerLimits.txt), a faixa de ganhos controláveis com passo determinado pelo valor da granularidade (polynomyGainsSetpoint.txt), e os coeficientes do polinômio linear para cada ganho alvo, que baseado na potência de entrada, determina qual a potência de bombeio necessária para realização do controle de ganho em malha aberta.

\section{Projeto do GFF}

Devido à natureza não-linear do processo de amplificação em fibra dopada com érbio, o ganho espectral fornecido aos canais a serem amplificados varia para cada comprimento de onda, assim gerando um perfil de ganho espectral não-plano.

Em (Pal et al., 2007) foi demonstrado que o perfil espectral de ganho do EDFA varia também de acordo com o nível de inversão de população na EDF, e este nível de inversão de população é diretamente proporcional ao ganho fornecido pelo EDFA. Assim, um 
EDFA com controle automático de ganho (AGC), que controle o nível de potência de bombeio visando manter o ganho alvo desejado ao sinal de entrada na saída do EDFA, por consequência mantém o nível de inversão de população para fornecer este ganho alvo. O problema é que, como mostrado em (Pal et al., 2007), diferentes ganhos alvo implicam em diferentes níveis de inversão de população e consequentemente diferentes perfis espectrais de ganho.

Desta forma, o projeto de um filtro para prover planicidade espectral de ganho (GFF) em um EDFA não é realizável para todos os ganhos alvo da faixa de ganhos desejada. Assim, um ganho nominal de operação deve ser escolhido e o GFF projetado deve possuir um perfil de atenuação espectral inverso ao perfil espectral de ganho gerado pelo EDFA, visando fornecer ganho espectral ganho neste ponto de operação (ganho calculado após inclusão do GFF).

Então, o projeto do GFF para um EDFA com AGC, foi realizado por meio de um

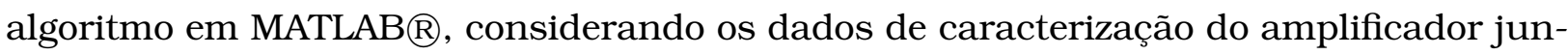
tamente com o parâmetro de perda de inserção do GFF, calculando assim para cada ganho alvo de operação (10-30 dB) os possíveis perfis de GFF, utilizando sempre o ponto de máxima potência de saída para cada ganho alvo (ponto de saturação) e gerando como saída o gráfico ilustrado na Figura 4.13(a), contendo o ganho sem GFF, com GFF e a atenuação causada ao sinal pelo GFF para cada ganho alvo.

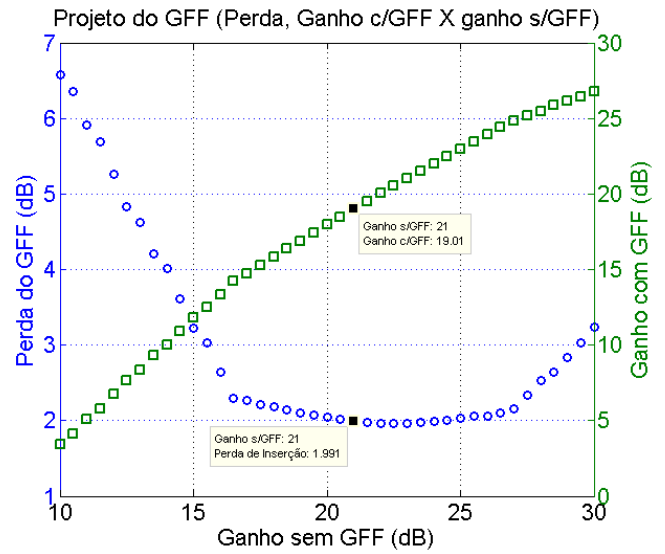

(a)

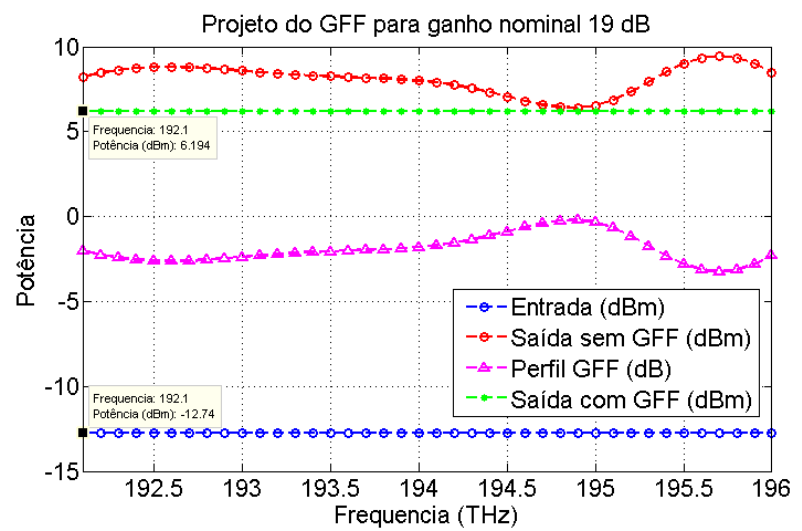

(b)

Figura 4.13: Perda do GFF projetado e Ganho com GFF X Ganho sem GFF (a), Espectros de entrada, perfil de perda do GFF, espectro de saida sem GFF e com GFF (b).

Analisando o gráfico ilustrado na Figura 4.13(a), a escolha ideal seria o GFF que oferece menor atenuação ao sinal amplificado. Porém, como busca-se um EDFA que opere em uma faixa de ganhos alvo de 14-24 dB, determina-se o valor médio da faixa de ganhos alvo como o ganho nominal (19 dB), com o objetivo de minimizar a variação espectral para os outros ganhos alvo da faixa requerida. Passa-se este ganho como parâmetro para obtenção do gráfico do perfil de GFF e sua aplicação no amplificador, ilustrado na Figura 4.13(b).

Portanto, como ilustrado na Figura 4.13(a), para fornecimento de um ganho espectral plano com GFF de $19 \mathrm{~dB}$, deve-se operar no ganho de $21 \mathrm{~dB}$ sem GFF e adicionar o GFF com uma perda de inserção de $2 d B$ ilustrado na Figura 4.13(b), apresentando o perfil 
do GFF a ser utilizado (curva rosa e marcador triangular) para fornecimento de ganho espectral plano de $19 \mathrm{~dB}$ (curva verde e marcador ponto). Os marcadores ilustrados na Figura 4.13(b) mostram que a diferença entre a saída com GFF e a entrada com GFF atinge o ganho alvo de $19 \mathrm{~dB}$ para todos os canais (40) ao longo da banda C na saída do EDFA com o GFF projetado.

\section{Integração do Controle de Ganho em Malha Aberta ao EDFA com GFF em simulação óptica}

Após determinação do comprimento da EDF, determinação dos polinômios de controle automático de ganho em malha aberta e projeto do GFF, esta seção tem como objetivo descrever como integrar este desenvolvimento ao EDFA com controle automático de ganho em simulação óptica.

Na Figura 4.14 é ilustrado o EDFA com AGC em malha aberta no ambiente de simulação Optisystem $囚$. Trata-se basicamente do EDFA ilustrado nas Figuras 4.1 e 4.11(b), onde, com relação a última, adiciona-se somente os blocos em destaque na Figura 4.14,

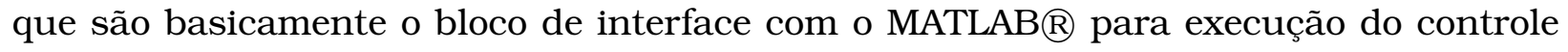
automático de ganho em malha aberta e o bloco do GFF, onde é adicionado o perfil de atenuação espectral de ganho projetado na seção anterior.

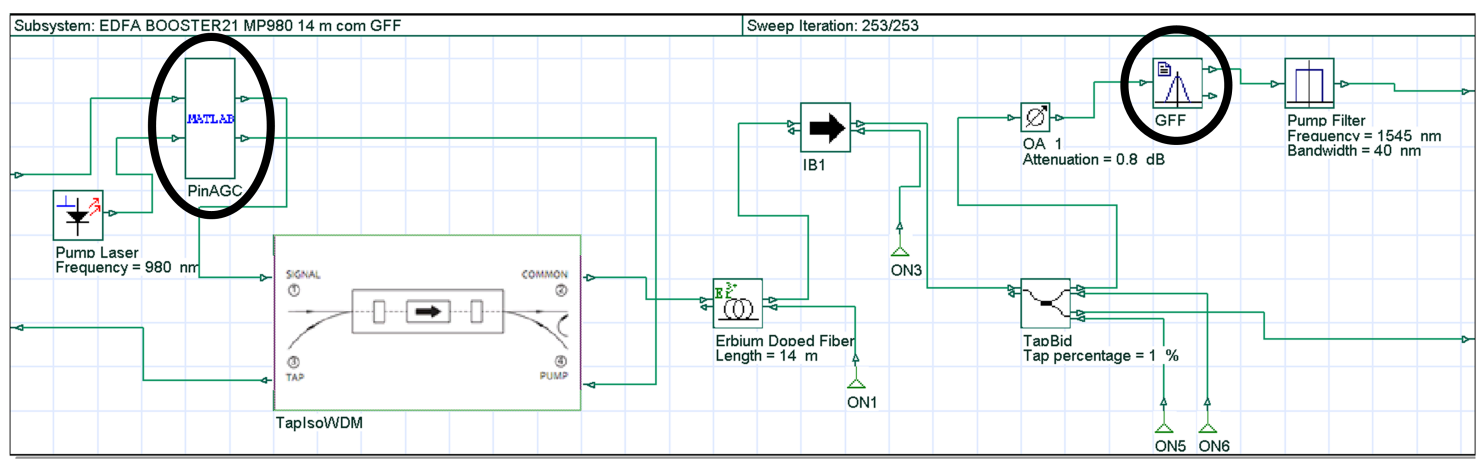

Figura 4.14: Paleta de simulação do EDFA com AGC em malha aberta.

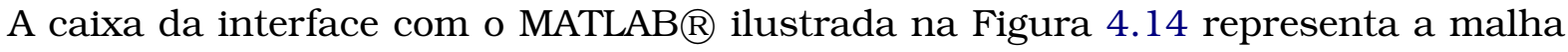
aberta de controle de ganho. A Figura 4.15(a) ilustra o diagrama de blocos da malha aberta de controle de ganho, que basicamente realiza a medida da potência de entrada, ganho alvo desejado e atenuação do GFF projetado, adiciona a perda do GFF ao ganho alvo e envia para execução do controle em malha aberta descrito pelo fluxograma ilustrado na Figura 4.15(b). Dado o ganho alvo e potência de entrada, busca os coeficientes do polinômio linear que determina com base na potência de entrada a potência de bombeio necessária para garantir o ganho alvo. Caso a potência de bombeio seja maior ou menor que os limiares do bombeio, este último é limitado.

Com este EDFA emulado em software de simulação óptica com baixo custo computacional e otimizado para operação em redes ópticas DWDM reconfiguráveis. A próxima seção tem como objetivo realizar a avaliação do desempenho ao longo de toda a máscara de potência. 


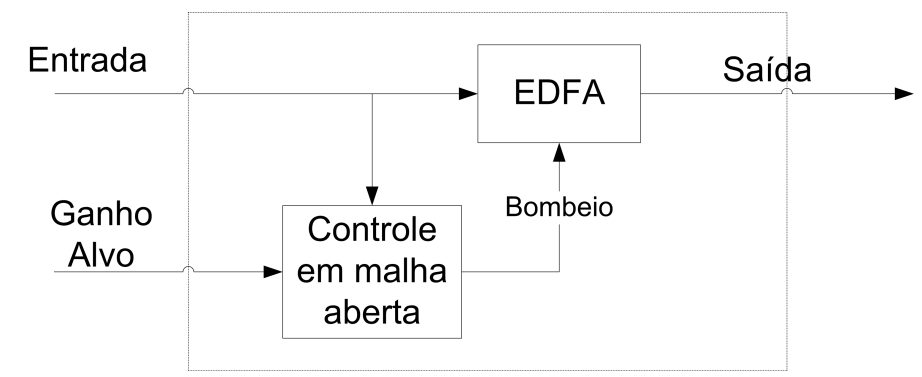

(a)

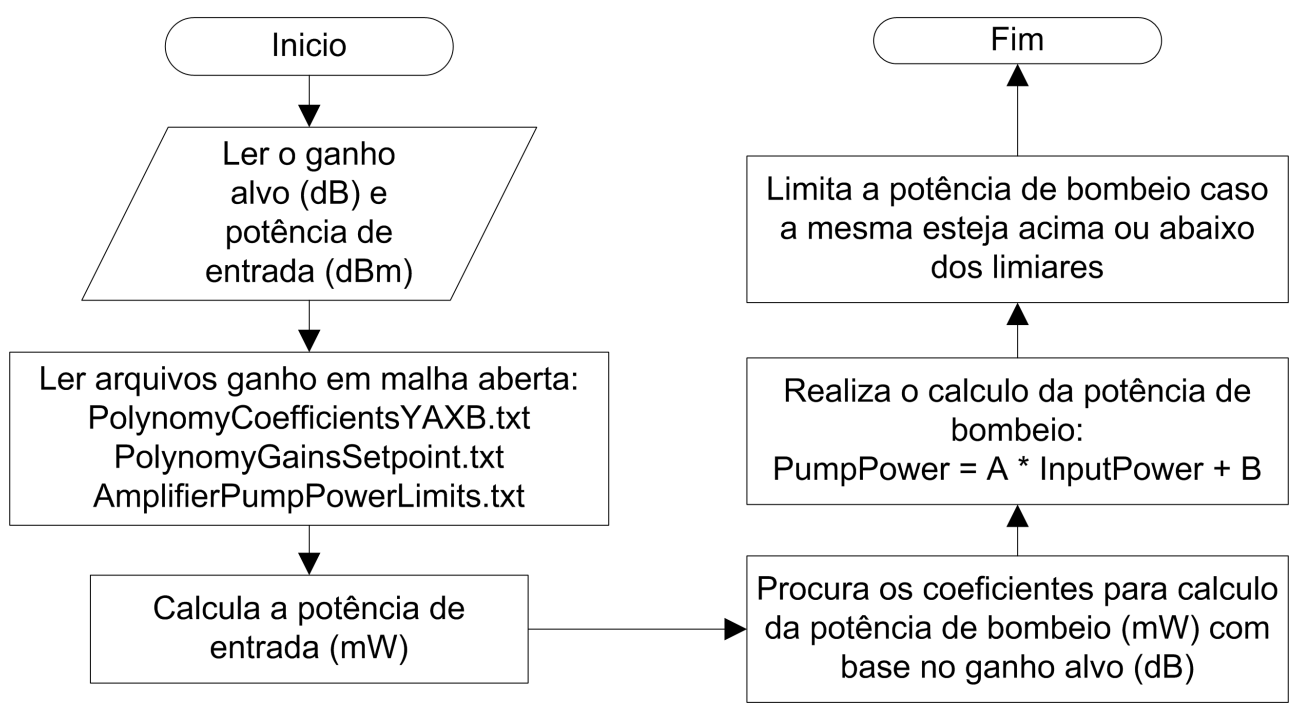

(b)

Figura 4.15: Diagrama de bloco do controle de ganho em malha aberta (a), fluxograma do controle em malha aberta (b).

\section{Desempenho do EDFA estágio único com GFF e AGC em simulação óptica}

Para avaliação do EDFA com AGC e GFF, ajusta-se o ganho alvo variando de 14-24 $\mathrm{dB}$ com granularidade de $1 \mathrm{~dB}$, e a potência de entrada varia ao longo de $22 \mathrm{~dB}$ de faixa dinâmica de acordo com o ganho avaliado. Para $14 \mathrm{~dB}$ de ganho, a potência de entrada varia de $21-14=7 \mathrm{dBm}$ até $21-14-22=-15 \mathrm{dBm}$, até $24 \mathrm{~dB}$ de ganho onde a potência de entrada varia de $21-24=-3 d B m$ até $21-24-22=-25 d B m$. Desta forma são avaliados 11 diferentes ganhos cada um com 23 diferentes potências de entrada, resultando em 253 iterações para definição de toda a máscara de potência do EDFA com AGC e GFF.

Após a caracterização, os resultados são armazenados no mesmo padrão de arquivo

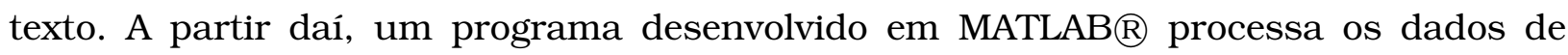
caracterização e ilustra graficamente as máscaras de potência de figura de ruído, planicidade espectral de ganho e precisão de controle de ganho. A Figura 4.16 ilustra o resultado das máscaras de potências para o EDFA com AGC e GFF (booster $21 \mathrm{dBm}$ ) desenvolvido nas seções anteriores.

Na Figura 4.16(a) é ilustrada a máscara de potência de figura de ruído para o EDFA com AGC e GFF estágio simples desenvolvido nas seções anteriores. O EDFA apresenta uma variação da figura de ruído de $4,62-5,37 d B$ onde a região de ganhos mais altos apresenta menor figura de ruído. 


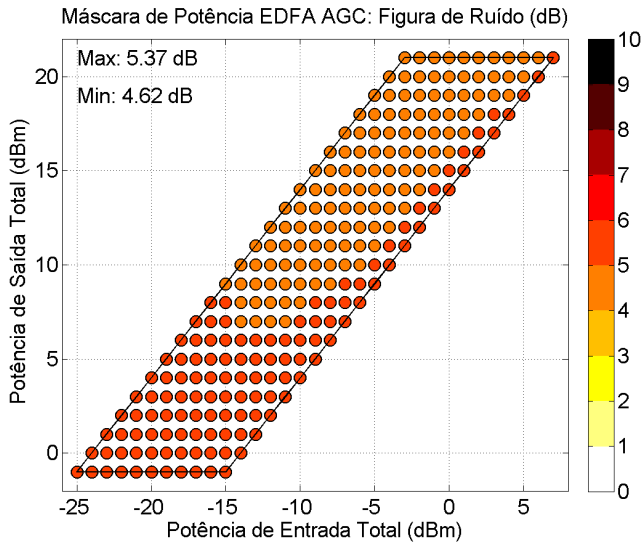

(a)

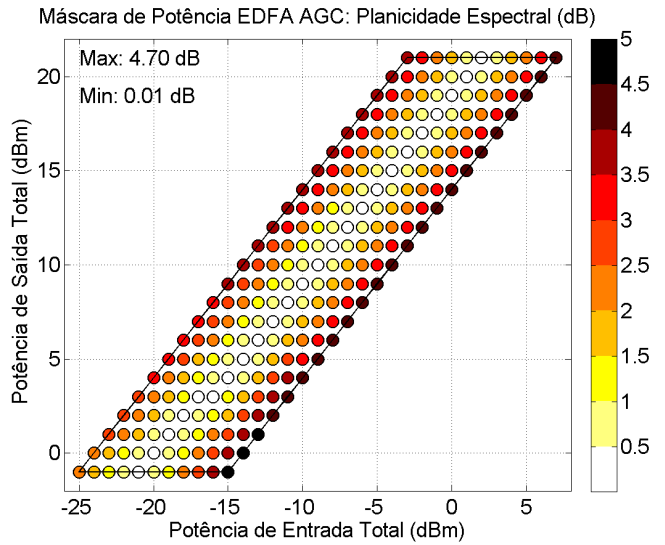

(b)

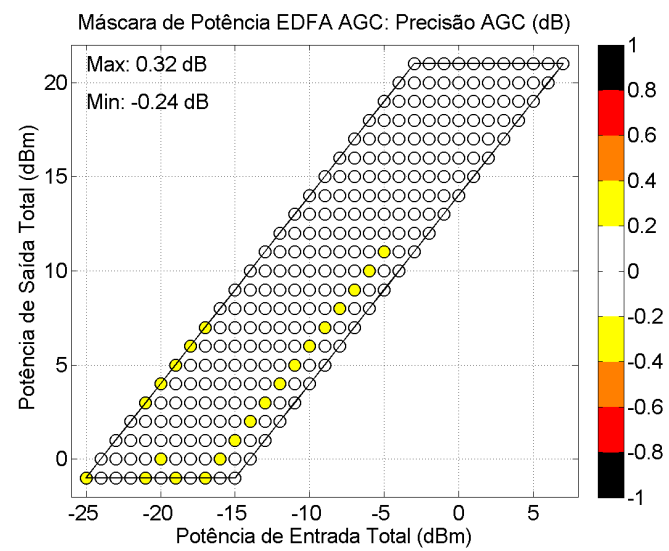

(c)

Figura 4.16: Máscara de potência do amplificador estágio simples EDFA com GFF e AGC apresentando desempenho de figura de ruido (a), planicidade espectral de ganho (b) e precisão do controle automático de ganho (c).

Na Figura 4.16(b) é ilustrada a máscara de potência de planicidade espectral de ganho para o EDFA com AGC e GFF estágio simples. Como esperado, foi obtido uma planicidade espectral de ganho em torno de $0 d B$ para o ganho nominal do amplificador $(19 d B)$, enquanto para ganhos alvo maiores e menores que o ganho nominal, o ganho espectral varia aproximadamente $1 d B$ a cada acréscimo/decrescimo de $1 d B$ no ganho alvo, variando até $4,7 d B$ para os ganhos 14 e $24 d B$.

Na Figura 4.16(c) é ilustrada a máscara de potência de precisão do controle automático de ganho. Apresenta-se uma variação de precisão de AGC de $-0,24$ até $0,32 d B$ com relação ao ganho alvo, indicando a eficácia do método de controle de ganho em malha aberta para EDFAs. Como este tipo de controle em malha aberta não é recomendável para amplificadores experimentais devido à degradação dos componentes ópticos e eletrônicos ao longo do tempo, não se garante a precisão do controle de ganho por toda vida útil do amplificador.

Desempenho sumarizado do EDFA de estágio único com GFF e AGC: precisão de AGC $\odot$, figura de ruído $\odot$, planicidade espectral de ganho $\odot$ e potência de saída $\odot$.

Em resumo, foi desenvolvido com sucesso e descrito nas seções anteriores, um método de projeto de EDFAs com AGC e GFF para operação em sistemas de comunicações 
ópticas DWDM, sendo apresentado seu desempenho ao longo da máscara de potência. Com os resultados do desempenho na máscara de potência, fica claro que o EDFA com AGC e GFF em estágio simples apresenta uma figura de ruído razoável, porém a planicidade espectral de ganho só é conseguida para o ganho nominal.

Visando uma topologia de amplificação com ganho plano para toda faixa de ganhos alvo, a próxima seção trata do desenvolvimento de outra topologia de amplificação.

\subsubsection{Projeto de EDFA com Estágio Duplo, GFF, VOA e AGC Acoplado (Ma- lha Aberta) em Simulação Óptica}

Com a necessidade de um amplificador com planicidade espectral de ganho ao longo de toda a máscara de potência esta seção visa o desenvolvimento de uma topologia de amplificação óptica baseada em duplo estágio EDFA, com GFF e atenuador óptico variável (VOA) entre estes estágios. Emprega-se o esquema de controle de ganho acoplado baseado em (Abu Bakar et al., 2011) e desenvolvido em software de simulação óptica

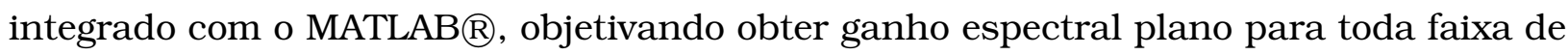
ganhos e ao longo da máscara de potência.

Amplificadores ópticos com ganho espectral plano são geralmente utilizados em amplificação de linha. Por se tratarem de amplificadores localizados em posições intermediárias (ao longo) do enlace de comunicações ópticas, geralmente possuem estágios intermediários onde pode-se compensar efeitos lineares impostos pela fibra (dispersão cromática) ou transpassar ROADMs. Assim, estes amplificadores necessitam operar em uma máscara de potência com diferentes níveis de ganho quando comparados ao amplificador de transmissão (booster) e recepção (pré) desenvolvido anteriormente. De acordo com este requisito, segue abaixo a máscara de potência do amplificador duplo estágio EDFA a ser desenvolvido nesta seção:

- $17 \mathrm{~dB}$ de ganho mínimo

- 27 dB de ganho máximo

- $21 \mathrm{dBm}$ de potência total de saída máxima

- $-28 \mathrm{dBm}$ de potência total de entrada mínima

Estes pontos são determinados de forma empírica, baseado na operação de um amplificador óptico de linha em sistemas com repetição reconfigurável, que operam geralmente com potência de saída máxima de $21 \mathrm{dBm}$, ou seja, até 80 canais considerando potência de saída de até $2 \mathrm{dBm}$ por canal, faixa dinâmica de até $22 \mathrm{~dB}$ (19 dB devido à adição/remoção de até 80 canais, somados a $6 \mathrm{~dB}$ de margem sistêmica) e espaçamento de enlaces variando de 85 a 135km (ganhos de 17 a $27 \mathrm{~dB}$ ).

A configuração EDFA acoplado com VOA e GFF visa fornecer ganho espectral plano para todos ganhos alvo da faixa de operação, tomando como base o conceito apresentado em (Pal et al., 2007), o qual demostra que o EDFA com estágio simples garante perfil espectral de ganho fixo (não plano) quando operando em controle automático de ganho, apresentando um perfil espectral de ganho distinto para cada ganho controlado. 
Desta forma, como descrito em (Abu Bakar et al., 2011), o conceito do EDFA acoplado com ganho plano para toda faixa de ganhos alvo, opera com seus estágios de EDFA sempre no seu ganho nominal, onde a soma destes ganhos subtraídas das perdas de inserção do VOA e do GFF (incluindo o perfil espectral de atenuação para compensação do ganho espectral não equalizado dos estágios EDFA acoplados) deve ser no mínimo igual ao máximo ganho da faixa de operação requerida. O ganho máximo da faixa alvo requerida já é fornecido com ganho espectral plano. Para obter os outros valores de ganhos alvo com planicidade espectral, basta realizar um controle da atenuação do VOA, aumentando a atenuação do VOA de acordo com a diferença entre o ganho alvo e o ganho máximo, assim garantindo ganho espectral plano para todos os ganhos alvos da faixa requerida.

Para compor os estágios de amplificação da topologia EDFA acoplado com VOA e GFF, é necessário que a soma dos ganhos seja maior que o máximo ganho requerido da faixa de ganhos alvo. Desta forma, como o EDFA desenvolvido anteriormente possui ganho nominal $19 d B$ e a soma de dois desses estágios implica em até $38 d B$ de ganho, tem-se uma margem de até $11 d B$ para a perda de inserção do VOA e perda de inserção e perfil do GFF. Assim o mesmo amplificador desenvolvido nas seções anteriores será utilizado para compor os estágios de amplificação do EDFA acoplado com VOA e GFF.

A Figura 4.17 ilustra a paleta de simulação desenvolvida para compor o EDFA acoplado com VOA e GFF em simulação óptica, alvo desta seção. Para caracterização deste amplificador será utilizada a mesma paleta ilustrada na Figura 4.11, somente substituindo o amplificador pelo amplificador desenvolvido nesta seção, e modificando a máscara de caracterização.

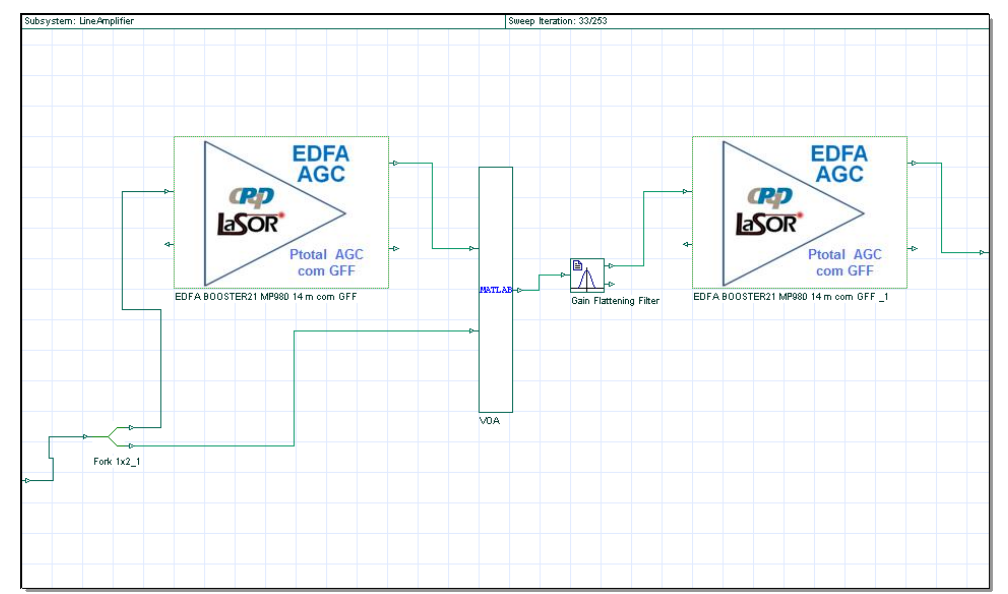

Figura 4.17: Paleta de simulação desenvolvida para o amplificador óptico acoplado EDFA-VOAEDFA.

Para o projeto do GFF qualquer ponto de saturação do amplificador pode ser escolhido, dado que apresentará ganho espectral plano para qualquer ganho alvo da faixa de operação. Nesta seção, o ponto de operação escolhido para o projeto do GFF foi a potência total de entrada de $-1 \mathrm{dBm}$ (40 canais com $-17 \mathrm{dBm}$ por canal) e o ganho de operação de $22 d B$, com uma atenuação fixa no VOA de $10 d B$ (para evitar operação fora da máscara no segundo estágio do EDFA). Com o ponto de operação e o VOA ajustado, o espectro de saída deve ser capturado e o GFF é projetado com base nos picos deste 
espectro, normalizados e invertidos (a atenuação do GFF projetado foi de $3,624 d B$ com pico de $5,7 d B$ em $192,5 T H z$ ).

A Figura 4.18 ilustra o espectro do sinal de entrada (curva azul, marcador circular), espectro de saída sem GFF (curva vermelha, marcador circular), o perfil do GFF desenvolvido (curva rosa, marcador triangular) e o espectro de saída com GFF (curva verde, marcador ponto).

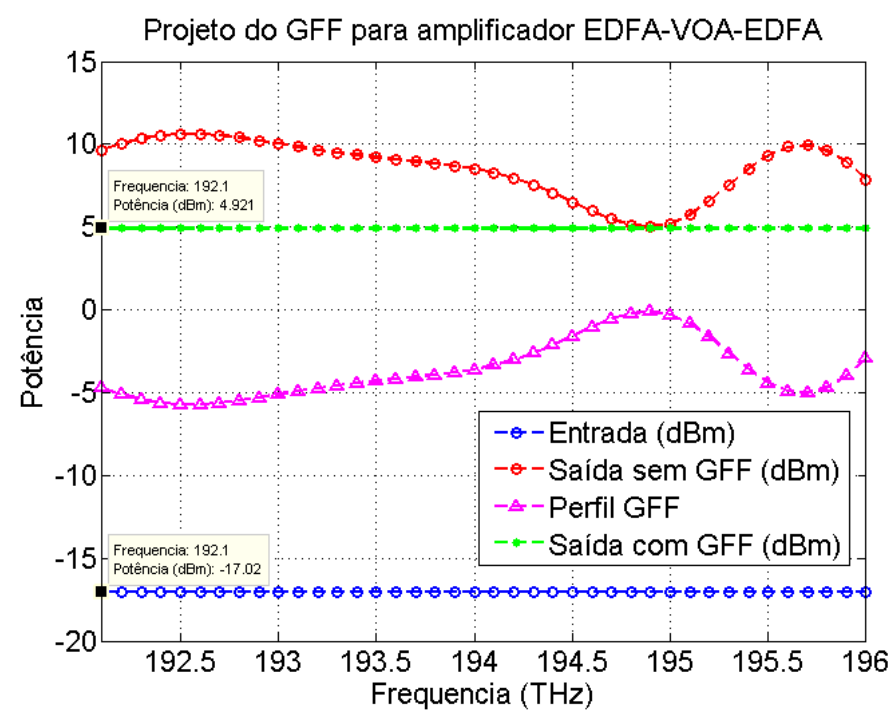

Figura 4.18: Espectro de entrada, perfil de perda do GFF, espectro de saída sem GFF e espectro de saida com GFF.

O controle de ganho acoplado desta topologia de amplificação é composto por dois controles de ganho em malha aberta, idênticos ao ilustrado na Figura 4.15, operando em conjunto com o controle de atenuação do VOA, que recebe como parâmentros de entrada a potência de saída do primeiro estágio EDFA, a atenuação do GFF projetado e a potência máxima permitida no segundo estágio EDFA.

A interface com o MATLAB $囚$, ilustrada na Figura 4.17, realiza o controle de atenuação do VOA. A Figura 4.19(a) ilustra o diagrama de blocos do controle de ganho acoplado do amplificador EDFA-VOA-EDFA, o qual, basicamente, requisita dos estágios EDFA o controle de seu ganho nominal, de forma que o VOA calcula e controla a atenuação adequada para atingir o ganho alvo desejado.

A Figura 4.19(b) ilustra com detalhes o fluxograma de controle do EDFA-VOA-EDFA. O controle de ganho alvo nominal nos estágios EDFA é feito de acordo com a malha de controle e fluxograma da Figura 4.15. Para controle do VOA, o erro de saturação do primeiro estágio EDFA é calculado (e se existir deve ser compensado pelo VOA), seguido do cálculo da atenuação do VOA $(v o a=($ ganhoNominal1 + ganhoNominal 2$)-$ ganhoAlvo erroDeSaturao1 - perdaGFF), que pode ser para atingir o ganho alvo, caso a potência de entrada do segundo estágio EDFA esteja acima de seu limite permitido (evitando saturação e erro de controle de ganho por meio do aumento da atenuação do VOA).

Para realização da caracterização do EDFA com AGC e GFF, ajusta-se o ganho alvo variando de 17-27 dB com granularidade de $1 \mathrm{~dB}$, e a potência de entrada varia ao longo de $22 \mathrm{~dB}$ de faixa dinâmica, avaliando 11 diferentes valores de ganho, cada um com 23 diferentes potências de entrada, resultando em 253 iterações para caracterização de 


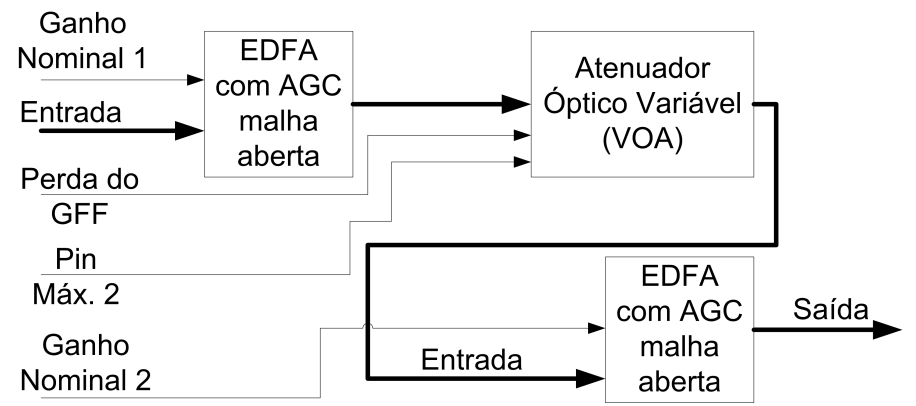

(a)

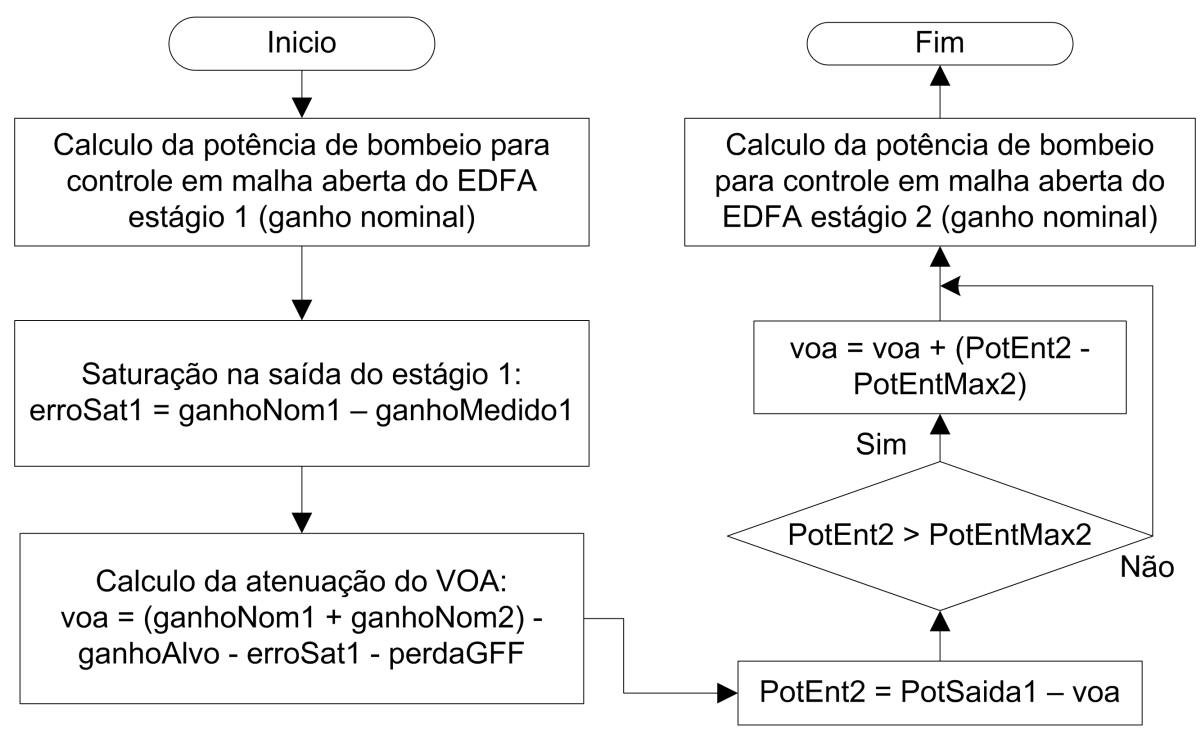

(b)

Figura 4.19: Diagrama de bloco do controle de ganho acoplado dos estágios EDFA e VOA no amplificador duplo estágio (a), fluxograma do controle de ganho acoplado (b).

toda a máscara de potência do EDFA-VOA-EDFA com GFF e AGC acoplado.

Após a caracterização, os resultados são armazenados no mesmo padrão da caracterização de arquivo texto. A partir daí, um programa desenvolvido em MATLAB $®$ processa os dados de caracterização e ilustra graficamente as máscaras de potência de figura de ruído, planicidade espectral de ganho e precisão de controle de ganho. A Figura 4.20 ilustra o resultado das máscaras de potências para o EDFA-VOA-EDFA com GFF e AGC acoplado.

Na Figura 4.20(a) é ilustrada a máscara de potência de figura de ruído para o EDFAVOA-EDFA com GFF e AGC acoplado, o qual apresenta uma variação da figura de ruído de 5, 50-10,02dB onde a região de ganhos mais altos apresenta menor figura de ruído, devido, basicamente, ao alto nível de atenuação do VOA, imposto para atingir os ganhos alvo mais baixos, os quais, de acordo com a equação 4.7 geram impacto negativo direto na figura de ruído do amplificador.

Na Figura 4.20(b) é ilustrada a máscara de potência da planicidade espectral de ganho para o EDFA-VOA-EDFA com GFF e AGC acoplado. Como esperado, é obtido o ganho espectral plano $(0.01 \mathrm{~dB})$ para a maior parte da máscara de potência, somente falhando em atingir este nivel quando o amplificador opera em potências de entrada baixas $(<-14 \mathrm{dBm})$, pois abaixo desta potência o bombeio atinge seu valor mínimo e 


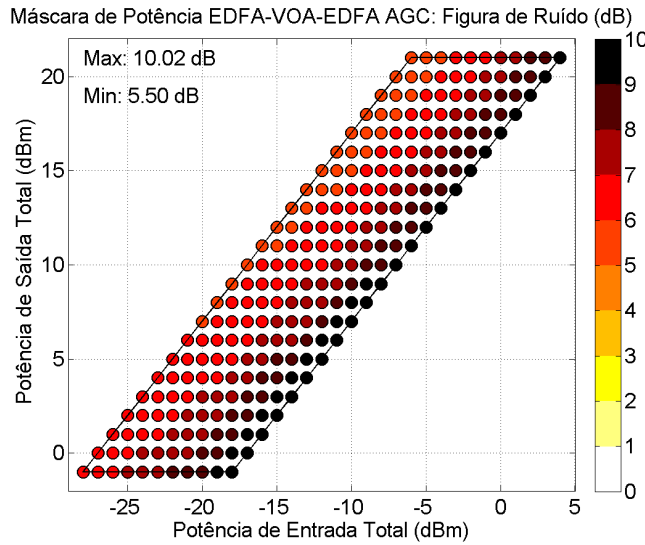

(a)

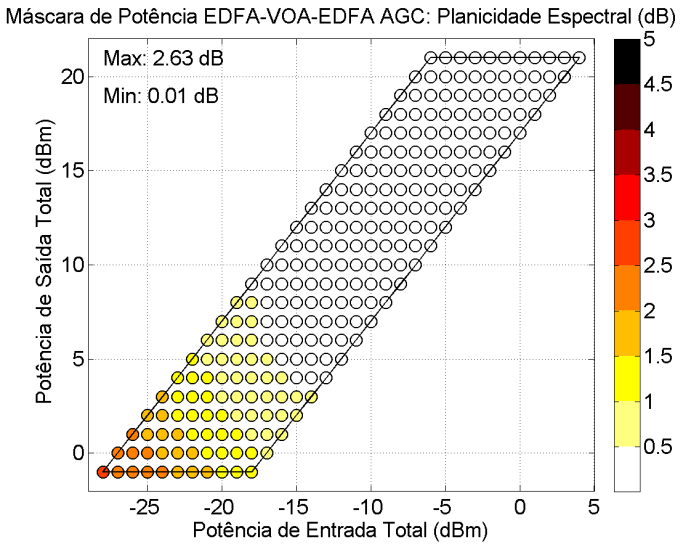

(b)

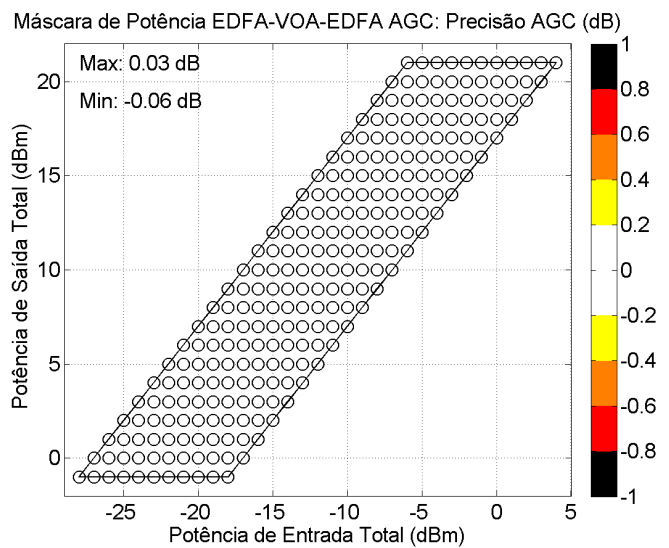

(c)

Figura 4.20: Máscara de potência do amplificador estágio simples EDFA com GFF e AGC apresentando desempenho de figura de ruido (a), planicidade espectral de ganho (b) e precisão do controle automático de ganho acoplado (c).

ainda assim o ganho fornecido ultrapassa o ganho nominal de operação.

Na Figura 4.20(c) é ilustrada a máscara de potência de precisão do controle automático de ganho, apresentando uma variação de precisão de AGC de $-0,06$ até $0,03 d B$ com relação ao ganho alvo, provando a eficácia do método de controle de ganho acoplado por meio dos estágios EDFA com controle em malha aberta e o controle de atenuação do VOA.

Desempenho sumarizado do EDFA de estágio duplo, GFF, VOA e AGC acoplado: precisão de AGC $\odot$, figura de ruído $\odot$, planicidade espectral de ganho $\odot$ e potência de saída $\odot$.

Em resumo, foi desenvolvido com sucesso a topologia de amplificação composta por EDFA-VOA-EDFA com AGC acoplado e GFF para operação em sistemas de comunicações ópticas DWDM. Com os resultados do desempenho na máscara de potência, o objetivo de manter a ondulação espectral de ganho a menor possível ao longo de toda a máscara de potência não foi cumprido somente devido à imprecisão para os pontos de baixíssima potência de entrada. Porém, em contrapartida, o nível de figura de ruído deste amplificador ficou bastante superior ao EDFA estágio simples.

Desta forma, o problema da planicidade espectral de ganho foi quase que completa- 
mente solucionado, por meio da topologia de amplificação EDFA-VOA-EDFA com GFF e AGC acoplado, em detrimento do desempenho de figura de ruído do amplificador. Com a disseminação dos sistemas de $112 \mathrm{~Gb} / \mathrm{s}$ DP-QPSK torna-se necessário o desenvolvimento de uma topologia de amplificação óptica que possa fornecer ganho espectral plano aliado a baixa figura de ruído, algo que não pode ser solucionado com as atuais topologias de amplificação baseadas somente em EDF.

Devido à baixa figura de ruído apresentada pela tecnologia de amplificação óptica Raman distribuída, a próxima seção descreve uma metodologia de projeto de amplificadores Raman distribuídos, assim como seu esquema de controle automático de ganho, e avalia seu desempenho na máscara de potência, para prover base para o desenvolvimento do amplificador óptico híbrido com controle automático de ganho, que atenda aos requisitos de planicidade espectral de ganho (+/- $1 \mathrm{~dB}$ para toda faixa de ganhos alvo) e baixa figura de ruído (menor que $6 \mathrm{~dB}$ para toda faixa de ganhos alvo) em sistemas DWDM de $112 G b / s$ DP-QPSK.

\subsubsection{Metodologia de Projeto de Amplificador Óptico Raman Distribuido}

Algumas das dificuldades no projeto de amplificadores Raman com múltiplos lasers de bombeios e perfil espectral de ganho plano são: natureza não-linear do ganho Raman, e influência das interações bombeio-bombeio, bombeio-sinal e sinal-sinal. Procedimentos de otimização para aperfeiçoar sistemas com múltiplos parâmetros e múltiplos alvos (Coskun et al., 2003) podem ser empregados no projeto otimizado de amplificadores Raman distribuídos. Porém, este processo demanda muito tempo de processamento, uma vez que a potência de bombeio para fornecer um determinado ganho Raman é afetada por diversos fatores, incluindo o coeficiente de ganho Raman, efeitos de polarização, comprimento da fibra, perda na fibra no comprimento de onda de bombeio, depleção do bombeio e interação Raman entre bombeios (Emori et al., 2002), e a convergência do processo depende bastante da escolha apropriada dos valores iniciais de seus parâmetros de entrada.

Por esse motivo, é necessário fornecer ao processo de otimização um ponto de partida preciso para os parâmetros de entrada, especialmente em relação aos comprimentos de onda (Coskun et al., 2003; Emori et al., 2002) na otimização de um amplificador Raman distribuído (DRA).

Com esta finalidade, nesta seção foi desenvolvida uma metodologia para definir os comprimentos de onda dos bombeios, e os valores iniciais das potências em um amplificador óptico Raman distribuído, visando prover um bom ponto de partida a um otimizador de múltiplos parâmetros (LMS Levenberg-Marquardt), para projeto de um DRA que forneça uma boa relação de desempenho entre o ganho on-off com perfil espectral de ganho plano.

Nesta seção é apresentado o modelo numérico utilizado na simulação do DRA, seguido da descrição da metodologia de projeto de amplificadores Raman alvo deste trabalho via projeto exemplo de um DRA com dois lasers de bombeio.

Este método para o projeto de amplificadores Raman com dois, três e quatro bombeios foi inicialmente apresentado em (Oliveira et al., 2011a), porém nesta seção o pro- 
cedimento foi aprimorado por meio da escolha dos bombeios considerando somente o ganho on-off, a planicidade espectral de ganho para os canais operando na banda C WDM (1529-1561 nm), além de considerar a largura de linha de cada laser Raman (decompondo a potência nominal de cada bombeio Raman em três componentes de frequência, emulando a largura de linha e a potência por componente de frequência).

\section{Modelo Numérico do Amplificador Raman}

Para desenvolvimento da metodologia de projeto de DRAs considerou-se a modelagem de amplificador Raman empregada no software de simulação OptiSystem $\AA$. O modelo

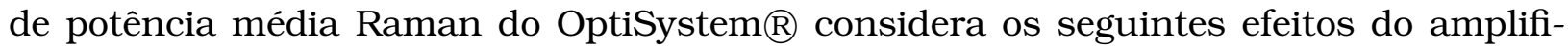
cador Raman distribuído: interações bombeio-bombeio, sinal-sinal, bombeio-sinal, dependência da emissão espontânea Raman com a temperatura, o espalhamento Raman estimulado, depleção de bombeio devido à transferência de energia Raman, geração de ordens superiores do efeito Stokes, múltiplos retro espalhamentos Rayleigh, perdas na fibra e a emissão espontânea de ruído. O modelo analítico que considera estes efeitos é apresentado na Equação 4.9 (Optisystem Average Raman Power Model):

$$
\begin{aligned}
\frac{d P_{f}(z, v)}{d z} & =\alpha(v) P_{f}(z, v)+\gamma(v) P_{b}(z, v) \\
& +P_{f}(z, v) \sum_{v<\zeta} \frac{g_{r}(v-\zeta)}{K_{e f f} A_{e f f}}\left[P_{f}(z, \zeta)+P_{b}(z, \zeta)\right] \\
& +h \Delta v \sum_{v<\zeta} \frac{g_{r}(v-\zeta)}{A_{e f f}}\left[P_{f}+P_{b}\right]\left[1+\exp ([h(\zeta-v) / k T]-1)^{-1}\right] \\
& -P_{f}(z, v) \sum_{v>\zeta} \frac{g_{r}(v-\zeta)}{K_{e f f} A_{e f f}} \frac{v}{\zeta}\left[P_{f}(z, \zeta)+P_{b}(z, \zeta)\right] \\
& -2 h v \Delta v P_{f}(z, v) \sum_{v>\zeta} \frac{g_{r}(v-\zeta)}{A_{e f f}}\left[1+\exp ([h(v-\zeta) / k T]-1)^{-1}\right]
\end{aligned}
$$

onde $v$ e $\zeta$ são as frequências $[\mathrm{Hz}]$ dos sinais que estão interagindo, $\alpha(v)$ é o coeficiente de atenuação da fibra $[\mathrm{N} / \mathrm{m}], \gamma$ é o coeficiente de retro-espalhamento Rayleigh $[\mathrm{N} / \mathrm{m}]$, $g_{r}(v-\zeta)$ é o coeficiente de ganho Raman para diferença de frequência $v-\zeta[\mathrm{m} / \mathrm{W}]$, e $P_{b}$ representa a potência refletida em [W]. Já os parâmetros $A_{e f f}, K_{e f f}, \Delta v, h, k$ e $T$ são respectivamente a área efetiva do núcleo da fibra $\left[\mathrm{m}^{2}\right]$, o fator de polarização, a resolução de frequência [Hz], a constante de Planck (6.6260693 $10^{-34}$ [Js]), a constante de Boltzmann $\left(1.3806503 \cdot 10^{-23}[\mathrm{~J} / \mathrm{K}]\right)$ e a temperatura $(\mathrm{K})$.

Devido ao fato de se considerar um grande número de efeitos, esta modelagem exige uma grande capacidade computacional, o que leva a um consumo de tempo relativamente elevado para realização das simulações. Para efeito de redução do tempo de processamento o OptiSystem $\AA$ utiliza uma técnica de cálculo a qual divide o comprimento total de fibra em segmentos menores concatenados a fim de calcular a propagação para pequenos sinais. Para eliminar a dependência da distância $z$, um cálculo da potência média é transmitido de um trecho a outro. 
Metodologia de Projeto de um Amplificador Raman Distribuido

A metodologia proposta neste trabalho é executada em duas fases. Na primeira fase, o número de bombeios é escolhido, considerando suas potências nominais distribuídas entre três componentes com largura de linha de $1 \mathrm{~nm}$ para cada bombeio (empiricamente obtido por meio de medição de laser Raman semicondutor comercial), visando maior proximidade entre o ambiente simulado e experimental. Através de um modelo analítico simplificado do amplificador Raman, o resultado gerado é analisado (ganho espectral combinado), em busca das melhores configurações de comprimentos de onda que forneçam alto ganho e planicidade espectral de ganho. Na segunda fase, o modelo numérico completo do amplificador Raman é utilizado para avaliar mais realisticamente seu ganho e planicidade espectral de ganho, através do ajuste das potências dos lasers de bombeio. A partir deste ponto o ganho espectral é melhorado através de algoritmos de correção de inclinação espectral por meio de atuação nas potências dos bombeios, finalizando a otimização dos comprimentos de onda de bombeio e potência via algoritmo LMS Levenberg-Marquardt no OptiSystem $\AA$.

A Figura 4.21 ilustra o fluxograma da metodologia de projeto de amplificadores Raman distribuído proposta neste trabalho. O método será descrito nas próximas seções através do projeto de um amplificador Raman distribuído contra-propagante, com dois lasers de bombeio.

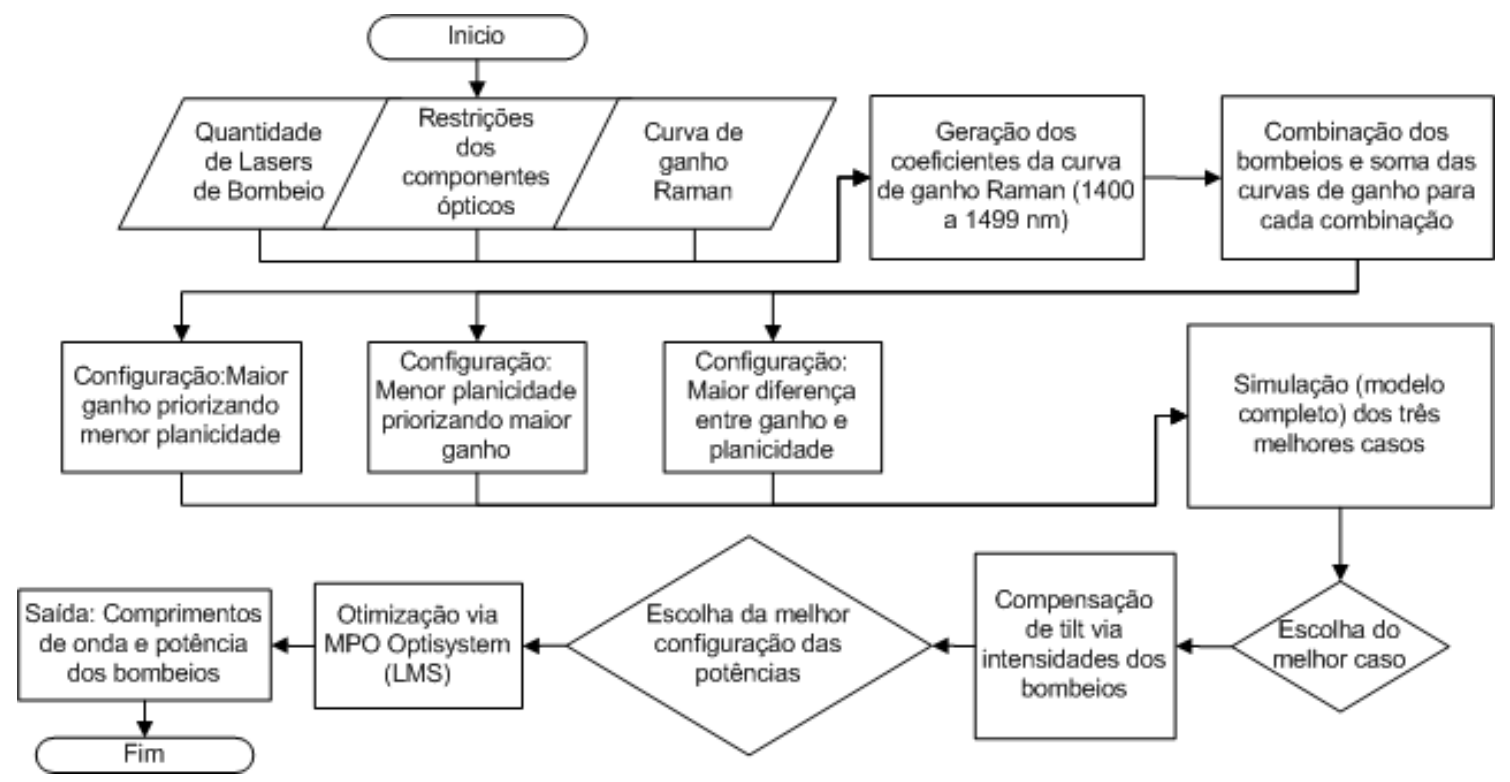

Figura 4.21: Fluxograma da metodologia de projeto de amplificador Raman distribuído

\section{Restrições físicas dos componentes ópticos}

Para o projeto de um amplificador Raman distribuído, deve-se inicialmente escolher o número de lasers de bombeio e considerar as restrições físicas dos componentes ópticos. Nesta metodologia, as seguintes restrições foram consideradas:

- Lasers de bombeio com comprimento de onda na região de 14XX nm (1400 a 1499 $\mathrm{nm})$ 
- Resolução de $1 \mathrm{~nm}$ para os lasers de bombeio, devido aos lasers comerciais apresentarem esta granularidade

- Espaçamento mínimo de $5 \mathrm{~nm}$ entre os lasers de bombeio, que corresponde ao espaçamento mínimo prático entre bombeios em um acoplador de um bombeio Raman WDM

- Nível máximo de potência de $360 \mathrm{~mW}$ para todos os bombeios

Com estas restrições, o espaço de soluções pode ser reduzido, acarretando em um tempo menor de avaliação das combinações de bombeio.

\section{Determinação dos comprimentos de onda dos lasers de bombeio}

A partir das considerações da seção anterior e dos dados experimentais do coeficiente de ganho Raman normalizado para fibra standard (SSMF) (Coskun et al., 2003), a Equação 4.10 apresentada em (Felinskyi, 2006) foi utilizada, e através do toolbox de ajuste

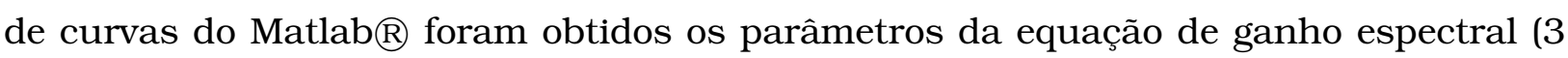
coeficientes x 10 estágios, por bombeio) para todos os bombeios (1400 a $1499 \mathrm{~nm}$ ). A Equação 4.10 aproxima com fidelidade a curva de ganho Raman em fibras ópticas

$$
g_{R}(\omega)=g_{R \max } \sum_{i=1}^{N_{m}} A_{i} \exp \left[-\left(\omega-\varpi_{v, i}\right)^{2} / \Gamma_{i}^{2}\right]
$$

Na Equação 4.10, $g_{R}$ é o coeficiente de ganho Raman, $N_{m}$ é o número de taps usados para a decomposição, $\omega_{v, i}$ é a frequência central do n-ésimo perfil gaussiano, $\Gamma_{i}=F W H M_{i} /(2 \sqrt{\ln 2})_{i} \approx 0.6 \cdot F W H M_{i}$, onde $F W H M_{i}$ é a largura espectral entre os pontos de meio-máximo.

Em seguida, foram calculadas todas as combinações possíveis entre 100 comprimentos de onda de lasers de bombeio, tomados $\mathrm{n}$ a $\mathrm{n}$, onde $\mathrm{n}$ é o número de lasers de bombeio do amplificador Raman. Para cada bombeio individual, foi calculado o ganho Raman considerando um enlace de $70 \mathrm{~km}$ de fibra standard (SSMF), utilizando uma modelagem mais simplificada do que aquela descrita na Equação 4.9. Isto foi feito para reduzir o tempo de processamento e adquirir o ponto de partida confiável para que se possa utilizar a Equação 4.9 nos passos seguintes de otimização dos lasers de bombeio.

Esta abordagem simplificada leva em consideração apenas o efeito Raman estimulado (SRS) e a perda por atenuação na fibra, como ilustrado a Equação 4.11 (Headley e Agrawal, 2005):

$$
\begin{aligned}
\frac{d P_{S}}{d z} & =\frac{g_{R}}{A_{e f f}} P_{P} P_{S}-\alpha_{S} P_{S} \\
\frac{d P_{P}}{d z} & =-\alpha_{P} P_{P}
\end{aligned}
$$

Na equação $4.11, z$ é a distância $(\mathrm{km}), P_{S}$ e $P_{P}$ são os níveis de potência do sinal e 
de bombeio respectivamente [W], $\alpha(v)$ é o coeficiente de atenuação na fibra $[\mathrm{N} / \mathrm{m}], g_{R}$ é o coeficiente do ganho Raman [m/W] e $A_{e f f}$, a área efetiva do núcleo [ $\left.\mathrm{m}^{2}\right]$.

Após o cálculo do ganho Raman para cada bombeio, a contribuição de ganho para cada uma das combinações de bombeios foi somada (Coskun et al., 2003; Emori et al., 2002). O ganho máximo e a planicidade espectral de ganho resultante da soma espectral dos ganhos de cada combinação de comprimentos de onda de bombeios foram calculados e dispostos em um vetor. A partir desses valores, a escolha dos comprimentos de onda dos lasers de bombeio Raman é realizada.

Especificamente, a escolha dos comprimentos de onda foi realizada analisando o vetor com os valores de ganho máximo e planicidade por meio de três diferentes buscas visando minimização/maximização dos parâmetros de performance como descrito abaixo:

- Busca 1: Procurando primeiro o maior ganho e depois a menor ondulação

- Busca 2: Procurando primeiro a menor ondulação e depois o maior ganho

- Busca 3: Procurando a máxima diferença entre ganho e a ondulação

Para o amplificador Raman contra-propagante com dois lasers de bombeios, os valores encontrados para cada busca encontram-se na Tabela 4.1.

Tabela 4.1: Comprimentos de onda, ganho on-off e planicidade espectral de ganho para cada tipo de procura no vetor de resultados.

\begin{tabular}{|c|c|c|c|c|}
\hline $\begin{array}{c}\text { Tipo de } \\
\text { Procura }\end{array}$ & $\begin{array}{c}\text { P1 } \\
(\mathrm{nm})\end{array}$ & $\begin{array}{c}\text { P2 } \\
(\mathrm{nm})\end{array}$ & $\begin{array}{c}\text { Ganho on-off } \\
(d B)\end{array}$ & $\begin{array}{c}\text { Planicidade } \\
(d B)\end{array}$ \\
\hline 1 & 1443 & 1448 & 15.70 & 1.67 \\
\hline 2 & 1442 & 1447 & 15.67 & 1.57 \\
\hline 3 & 1442 & 1447 & 15.67 & 1.57 \\
\hline
\end{tabular}

Cada caso apresentado na Tabela 4.1 foi simulado no Optisystem $\AA$, considerando os efeitos da equação 4.9. Nas simulações foram considerados quarenta sinais de entrada na Banda C, a partir de $192.1 \mathrm{THz}$ (C20) a 196,0 THz (C60) espaçados de $100 \mathrm{GHz}$, com potência de $-6 \mathrm{dBm} /$ canal ( $10 \mathrm{dBm}$ de potência total).

Tabela 4.2: Resultado da simulação completa para cada tipo de procura (comprimentos de onda) realizado.

\begin{tabular}{|c|c|c|c|}
\hline $\begin{array}{c}\text { Tipo de } \\
\text { Procura }\end{array}$ & $\begin{array}{c}\text { Ganho on-off } \\
(d B)\end{array}$ & $\begin{array}{c}\text { Planicidade } \\
(d B)\end{array}$ & $\begin{array}{c}\text { Bombeio } \\
(\mathrm{mW})\end{array}$ \\
\hline 1 & 15.43 & 2.067 & 360 \\
\hline 2 & 13.43 & 1.568 & 360 \\
\hline 3 & 13.43 & 1.568 & 360 \\
\hline
\end{tabular}

Analisando os resultados das simulações apresentadas na Tabela 4.2, o tipo de procura 2 e 3 (1442 e $1447 \mathrm{~nm}$ ) apresentou-se como a melhor configuração de comprimentos de onda de bombeio entre todas as combinações possíveis para fornecimento de 
ganho aliado a plancidade espectral na banda $\mathrm{C}$, considerando as restrições físicas dos componentes ópticos no desenvolvimento de amplificadores Raman distribuídos.

\section{Determinação das intensidades dos lasers de bombeio}

Para melhorar a planicidade espectral de ganho da combinação de comprimentos de onda determinada para o amplificador Raman, foi feito um ajuste da inclinação do perfil a partir da escolha adequada das potências dos lasers bombeio. Para tanto, os ganhos on-off de cada canal foram utilizados para determinar a inclinação de ganho, e com os valores das potências de bombeio com uma inclinação oposta (aplicado sobre as potências dos bombeios), a inclinação do perfil de ganho foi compensada. Vários índices de inclinação foram utilizados, fixando uma das potências no máximo (360 mW) e variando as proporções das demais, para em seguida determinar a que melhor ajusta a ondulação, considerando os efeitos não-lineares presentes no modelo simulado no Optisystem $\AA$. Os resultados da simulação de cada proporção entre bombeios máximo e mínimo encontram-se na Tabela 4.3.

Tabela 4.3: Resultados das simulações no Optisystem $($ considerando a proporção entre os bombeios máximo e mínimo para o amplificador Raman com dois Lasers de bombeio.

\begin{tabular}{|c|c|c|c|c|}
\hline$\%$ & $\begin{array}{c}\text { P1 } \\
(m W)\end{array}$ & $\begin{array}{c}\text { P2 } \\
(m W)\end{array}$ & $\begin{array}{c}\text { Ganho on-off } \\
(d B)\end{array}$ & $\begin{array}{c}\text { Planicidade } \\
(d B)\end{array}$ \\
\hline 100 & 360 & 360 & 13.43 & 1.568 \\
\hline 80 & 288 & 360 & 12.07 & 1.466 \\
\hline 60 & 216 & 360 & 10.79 & 1.364 \\
\hline
\end{tabular}

\section{Otimização do amplificador Raman projetado}

Analisando a Tabela 4.3, identifica-se que, quando a potência do primeiro bombeio cai de $100 \%$ para $80 \%$ da potência máxima, o ganho on-off reduz-se mais rápido do que com a redução da potência do primeiro bombeio de $80 \%$ para $60 \%$ da potência máxima, enquanto a planicidade é afetada uniformemente. Desta forma, um ponto intermediário entre $100 \%$ e $80 \%$ foi escolhido como o ponto inicial para realizar otimização de múltiplos parâmetros via algoritmo LMS Levenberg-Marquardt, com os dados dos pontos de 100\% e 80\% sendo utilizados como os limites superiores e inferiores, respectivamente.

Fixando a potência do bombeio 1 (P1) em $360 \mathrm{~mW}$ e passando como parâmetros para o algoritmo LMS as potências de bombeio 2 (P2), com seu respectivo valor de bombeio inicial (90\%), buscou-se o ganho máximo, e a ondulação espectral de ganho mínima. O resultado da otimização para o amplificador distribuído com 2 lasers de bombeio foi: $360 \mathrm{~mW}$ para o laser de $1447 \mathrm{~nm}$ e $321,317 \mathrm{~mW}$ para o laser de $1442 \mathrm{~nm}$. Com ganho de on-off de $12,7 d B$ e planicidade espectral de ganho de $1,5 d B$.

Porém, este projeto de amplificador Raman compreende somente a otimização deste operando em redes DWDM, sem considerar outras tecnologias (por exemplo EDFA) operando em conjunto com este amplificador Raman distribuído. Como o amplificador Ra- 
man não fornece alta potência de saída, uma tendência é a combinação desta tecnologia com outras que forneçam esta alta potência de entrada. Neste caso, o ideal seria projetar o amplificador Raman otimizado considerando o perfil espectral do conjunto das tecnologias utilizadas (e não somente o amplificador Raman), para que a planicidade espectral de ganho da combinação dos dois possa ser otimizada, invés de somente a planicidade espectral do amplificador Raman.

\subsubsection{Projeto de Amplificador Raman Distribuido com AGC (Malha Aberta) em Simulação Óptica}

Esta seção tem como objetivo o desenvolvimento de um controle automático de ganho on-off (ganho calculado pela diferença de potência de saída do amplificador com bombeios ativos com relação a saída com os bombeios inativos) para um amplificador Raman distribuído contra-propagante, e sua avaliação com base na caracterização da sua máscara de potência. É também objetivo deste desenvolvimento que o amplificador Raman distribuído com controle de ganho on-off forneça uma baixa variação espectral de ganho para diferentes ganhos alvo, pela sua operação em regime não saturado, em conjunto com uma baixa figura de ruído equivalente para todos os ganhos alvo da faixa de operação do amplificador.

$\mathrm{Na}$ seção anterior foi apresentada a metodologia de projeto de amplificadores Raman distribuídos com múltiplos bombeios e desempenho otimizado quando somente do amplificador Raman está em operação no enlace de comunicações ópticas. Nesta seção seria natural utilizar-se deste amplificador Raman distribuído contra-propagante, no qual os bombeios de $1442 \mathrm{~nm}$ e $1447 \mathrm{~nm}$ foram obtidos para fornecer um melhor custo/benefício, para desenvolvimento do controle automático de ganho.

Entretanto, como esta tese visa o desenvolvimento de um amplificador híbrido (Raman/EDFA), que no capítulo seguinte terá sua metodologia de projeto detalhadamente apresentada, o amplificador Raman distribuído contra-propagante utiliza-se da técnica de projeto descrita anteriormente com uma ligeira modificação, que visa obter na saída deste um perfil espectral de ganho complementar ao perfil espectral de ganho do EDFA parte do mesmo amplificador híbrido. Desta forma, foram determinados os bombeios com comprimentos de onda de $1425 \mathrm{~nm}$ e $1455 \mathrm{~nm}$ (ambos com potência nominal 360 $\mathrm{mW}$ ) como os mais adequados para compor o amplificador Raman contido no amplificador híbrido (Raman/EDFA), por isto estes serão os comprimentos de ondas de bombeio considerados nesta seção.

Projetado o amplificador Raman distribuído contra-propagante, o controle automático de ganho on-off apresentado nesta seção utiliza-se do desenvolvimento semelhante ao empregado no EDFA, apenas excluindo o projeto do GFF (este será realizado na metodologia de projeto do amplificador híbrido), considerando a fibra SSMF G.652 (meio onde ocorre o ganho Raman) na modelagem do amplificador, além da mudança na ordem da regressão linear (obtenção dos coeficientes de controle de ganho) para uma regressão polinomial de quinta ordem, por esta mostrar-se mais efetiva que a regressão linear (neste caso).

Desta forma, o projeto do controle de ganho consiste em quatro fases: caracteriza- 
ção do amplificador Raman distribuído contra-propagante, processamento do resultado da caracterização via regressão polinomial de quinta ordem para obtenção dos polinômios do AGC Raman, desenvolvimento e integração do AGC no amplificador Raman e caracterização de desempenho do amplificador ao longo da máscara de potência.

Amplificadores Raman distribuídos contra-propagante são geralmente utilizados como pré-amplificadores, visando melhor OSNR dos canais recebidos através da amplificação distribuída ao longo da fibra do enlace, devido à baixa figura de ruído equivalente (baixa eficiência de conversão de bombeio em ganho - PCE). Porém estes amplificadores operam provendo baixo ganho ao longo de uma grande faixa dinâmica devido à baixa eficiência de PCE. De acordo com estas características, a seguinte máscara de potência descrita abaixo foi determinada para compor a região de caracterização do amplificador Raman:

- $2 \mathrm{~dB}$ de ganho on-off mínimo

- $12 \mathrm{~dB}$ de ganho on-off máximo

- $6 \mathrm{dBm}$ de potência total de saída máxima

- $-30 \mathrm{dBm}$ de potência total de entrada mínima

A Figura 4.22(a) ilustra a paleta de simulação desenvolvida para modelagem do amplificador Raman distribuído contra-propagante, enquanto a Figura 4.22(b) ilustra em detalhes o amplificador, que é basicamente composto por dois lasers de bombeio e um acoplador de dois bombeios contra-propagante com sinal.

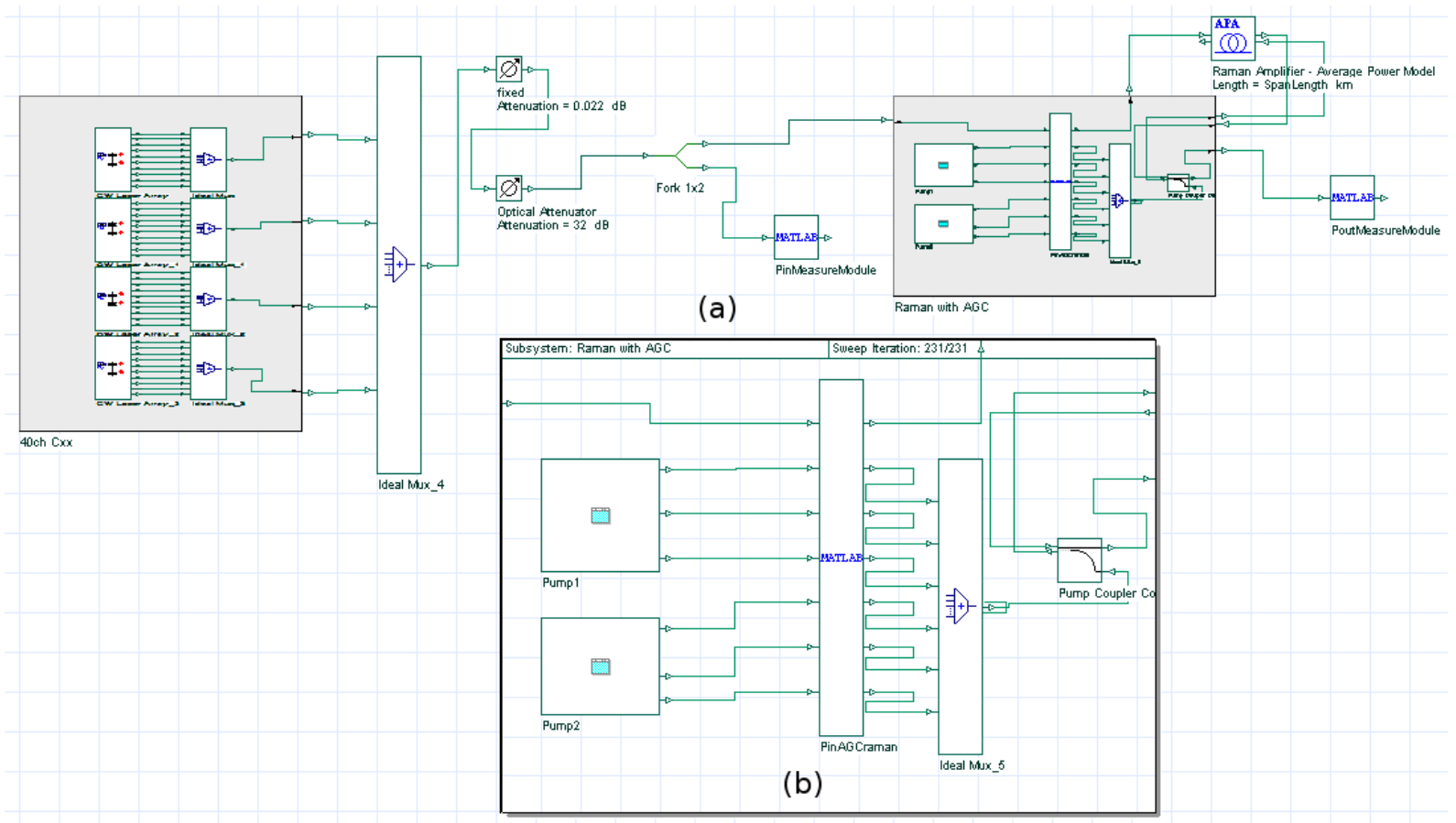

Figura 4.22: Paleta de simulação desenvolvida para o amplificador óptico Raman distribuído.

Para que o amplificador Raman simulado represente fielmente o amplificador experimental, os parâmetros de perdas de inserção dos componentes, frequência central de ruído, banda e resolução de ruído foram calibrados a partir de componentes e amplificadores experimentais como segue abaixo: 
- Enlace de fibra SSMF (G.652): $70 \mathrm{~km}$ de fibra padrão com perda 0,2 dB/km (14 $\mathrm{dB})$

- Lasers de bombeio semicondutores com largura de linha de 0,8 nm (comprimento de onda central com $50 \%$ da potência nominal e componentes laterais com $25 \%$ da potência nominal cada)

Potência nominal $360 \mathrm{~mW}$, comprimento de onda $1425 \mathrm{~nm}$ (componentes laterais de $1424,2 \mathrm{~nm}$ e $1425,8 \mathrm{~nm}$ )

Potência nominal $360 \mathrm{~mW}$, comprimento de onda $1455 \mathrm{~nm}$ (componentes laterais de $1454,2 \mathrm{~nm}$ e $1455,8 \mathrm{~nm})$

- Acoplador para os dois bombeios contra-propagantes e sinal

Perda de inserção de sinal: $0,7 d B$

Perda de inserção de bombeio: $1,2 d B$

- características de Ruído

Frequência central de ruído: $1545 \mathrm{~nm}$

Largura de banda do ruído: $36 \mathrm{~nm}$

Resolução do ruído: $0,1 \mathrm{~nm}$

A simulação ilustrada na Figura 4.22(a) utiliza uma bancada de 40 lasers equalizada em potência com frequência localizada na banda C desde 192, 1 THz $(1560,61 \mathrm{~nm})$ a 196, 0 T Hz $(1529,55 \mathrm{~nm})$ com espaçamento de $100 \mathrm{GHz}$, variando a partir deste ponto o nível de potência de entrada e nível das potências dos bombeios. O processo de caracterização armazena a resposta do comportamento amplificador Raman projetado considerando a variação aninhada dos parâmetros de potência de entrada e as potências de bombeios, de acordo com a regra descrita nos itens abaixo:

- $1^{\circ}$ nível: Variação da atenuação dos sinais de entrada em 61 passos com granularidade de 0,5 dB (potência lançada na fibra de 20 a $-16 \mathrm{dBm}$, ou seja, potência na saída do amplificador Raman com bombeio desligado de 4 a -30 dBm)

- $2^{\circ}$ nível: Variação das potências dos bombeios Raman do amplificador em 80 passos com espalhamento exponencial de base 10 entre a potência mínima $(10 \mathrm{~mW})$ e potência máxima do bombeio $(360 \mathrm{~mW})$, mesmo nível para ambos os bombeios (1425 nm e $1455 \mathrm{~nm}$ ).

O processo de caracterização é realizado apenas uma vez, executando 4880 iterações (55 segundos por iteração), levando assim em torno de 57 horas para finalização, onde para cada iteração são armazenados 129 parâmetros de desempenho listados abaixo (a matriz 4880x129 é armazenada em arquivo texto):

- Potências dos bombeios em mW (2)

- Potência total de entrada com bombeios Raman desligados em mW (1) e dBm (1) 
- Potência total de saída em mW (1) e dBm (1)

- Potência total de ruído de saída em mW (1) e dBm (1)

- Ganho on-off total em dB (1)

- Potência de entrada com bombeios Raman desligados por canal em dBm (40)

- potência de saída por canal em dBm (40)

- potência de ruído por canal em dBm (40)

Para o desenvolvimento do controle automático de ganho on-off em malha aberta os dados resultantes da caracterização foram organizados por meio de um algoritmo

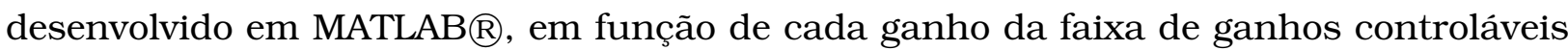
(2-12 dB) passados como parâmetro juntamente com a granularidade (+/- $0.5 \mathrm{~dB})$. Desta forma, os dados são organizados para cada ganho, potência de entrada e potências dos bombeios caracterizados, posteriormente removendo as duplicidades de dados.

Em seguida, foi analisado qual valor de potência de bombeio é necessária para fornecer cada ganho on-off, considerando o valor da potência total de entrada com os bombeios Raman desligados. A Figura 4.23 ilustra o resultado para dois diferentes ganhos alvos (2 e $12 \mathrm{~dB})$.
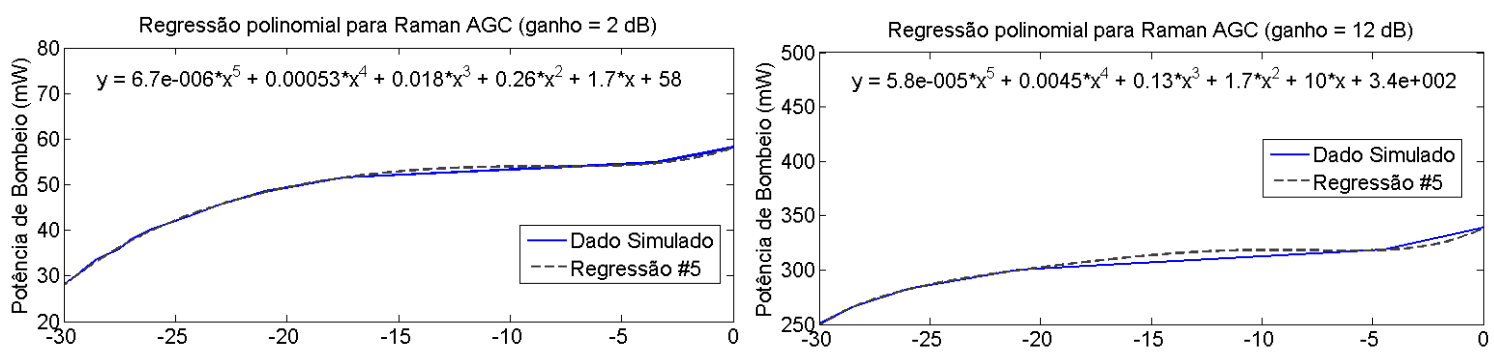

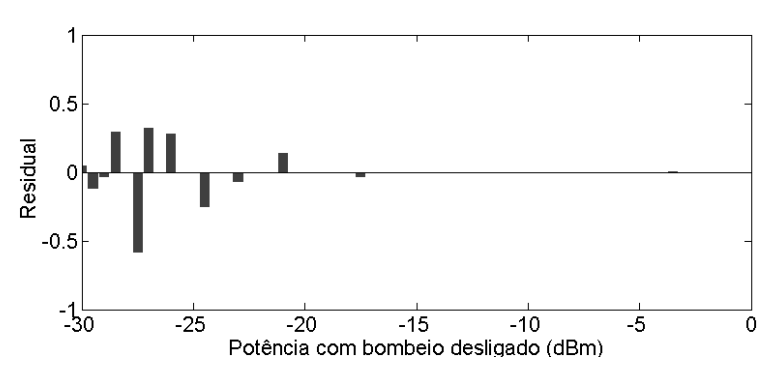

(a)

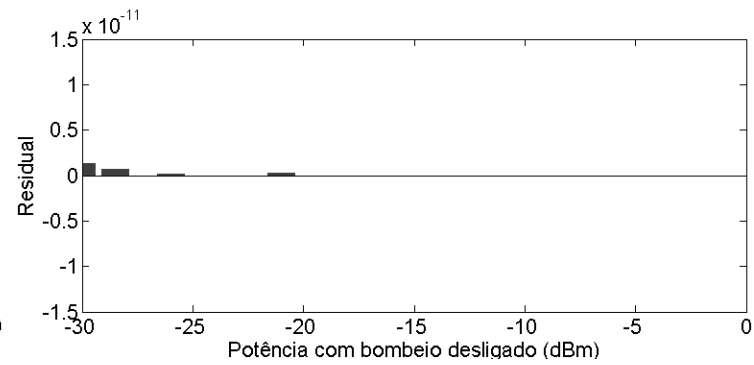

(b)

Figura 4.23: Dados simulados e regressão linear para os ganhos $2 d B(a)$ e $12 d B(b)$.

Por meio da Figura 4.23 foi constatado que o comportamento de potência de bombeio com a potência total de entrada para manutenção do ganho alvo pode ser mapeado por um polinômio de quinta ordem ilustrado na equação 4.12 .

$$
P_{\text {Bombeio }}=a_{5} * P_{o f f}^{5}+a_{4} * P_{o f f}^{4}+a_{3} * P_{o f f}^{3}+a_{2} * P_{o f f}^{2}+a_{1} * P_{o f f}+a_{0}
$$

onde $P_{o f f}$ é potência de saída com bombeio desligado e $P_{\text {Bombeio }}$ é a potência de bombeio que deve ser atribuída para ambos os bombeios para fornecer o ganho on-off desejado. Desta forma, o algoritmo de ordenação dos dados da caracterização em função do 
ganho alvo foi complementado com a regressão polinomial de quinta ordem (por meio da função polyfit do MATLAB $R$ ) para determinação dos valores otimizados dos coeficientes do polinômio para cada valor de ganho alvo de controle da faixa de operação.

Assim, após cada regressão polinomial executada para cada ganho on-off da faixa de operação, os coeficientes são armazenando em arquivo texto com os valores limites de bombeio (amplifierPumpPowerLimits.txt), a faixa de ganhos controláveis com passo determinado pelo valor da granularidade (polynomyGainsSetpoint.txt), e os coeficientes do polinômio para cada ganho alvo (polynomyCoefficients.txt).

A Figura 4.24(b) ilustra com detalhes o fluxograma de controle de ganho on-off para o amplificador Raman em simulação óptica. A potência lançada é lida e os parâmetros de comprimento do enlace (ou perda do enlace) e ganho alvo são passados ao amplificador Raman com AGC on-off. De posse dos dois primeiros parâmetros (potência lançada e o comprimento/perda do enlace) a potência de saída com os bombeios Raman desligados é calculada, e, com este valor, o cálculo da potência de bombeio é realizado e aplicado aos bombeios Raman para fornecer o ganho alvo desejado.

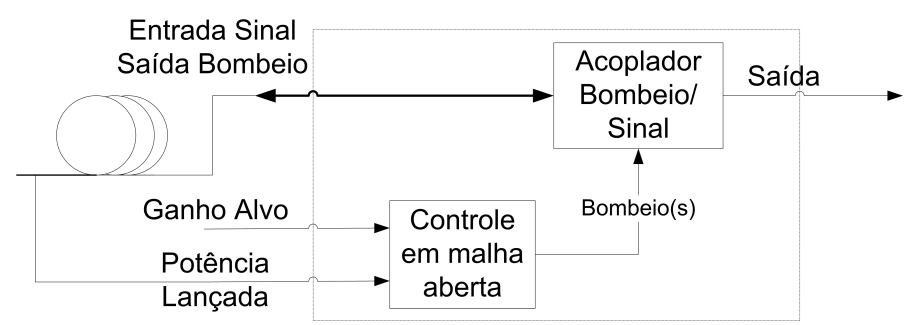

(a)

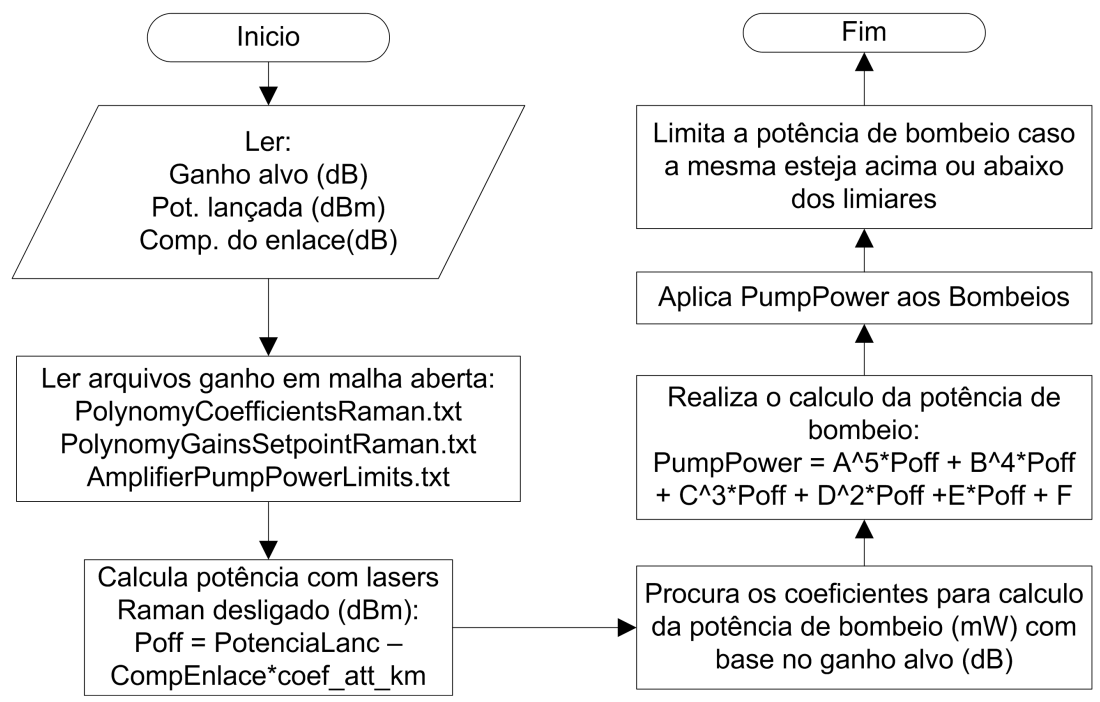

(b)

Figura 4.24: Diagrama de bloco do controle de ganho on-off do amplificador Raman distribuído contra-propagante (a), fluxograma do controle de ganho on-off (b).

Após desenvolvido, o controle automático de ganho on-off é integrado no código da

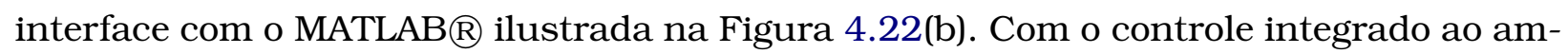
plificador Raman distribuído contra-propagante, os limites da máscara de potência são ajustados (ganho mínimo, ganho máximo, potência máxima de saída e potência mínima de entrada), a granularidade de $1 d B$ é assumida, as iterações configuradas adequada- 
mente na simulação e a caracterização do desempenho ao longo da máscara de potência é realizada.

Após a caracterização, os resultados são processados por uma rotina desenvolvida em MATLAB $R$ e as máscaras de potência de figura de ruído, planicidade espectral de ganho e precisão de controle de ganho são ilustradas graficamente. A Figura 4.25 ilustra o resultado das máscaras de potências para o amplificador Raman desenvolvido nesta seção.

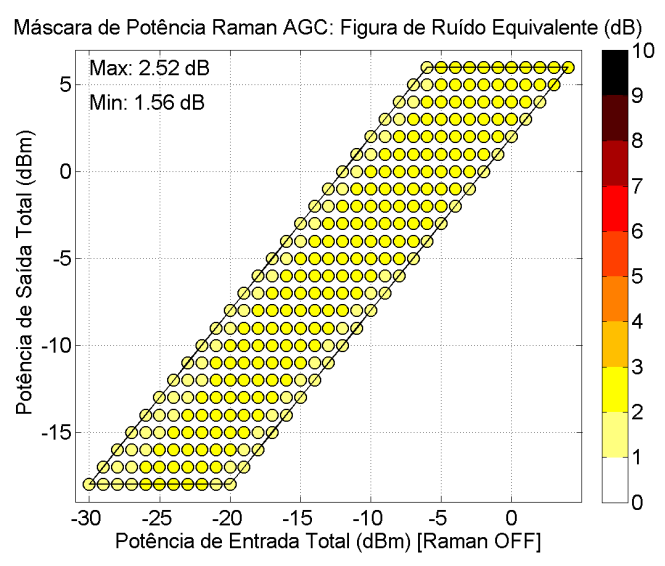

(a)

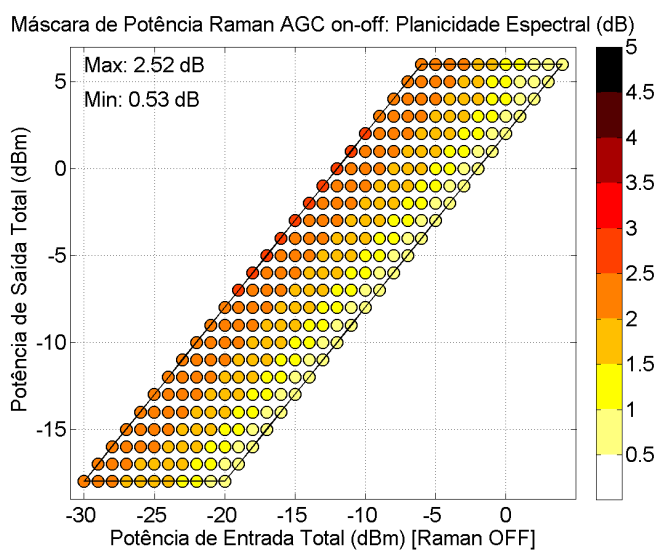

(b)

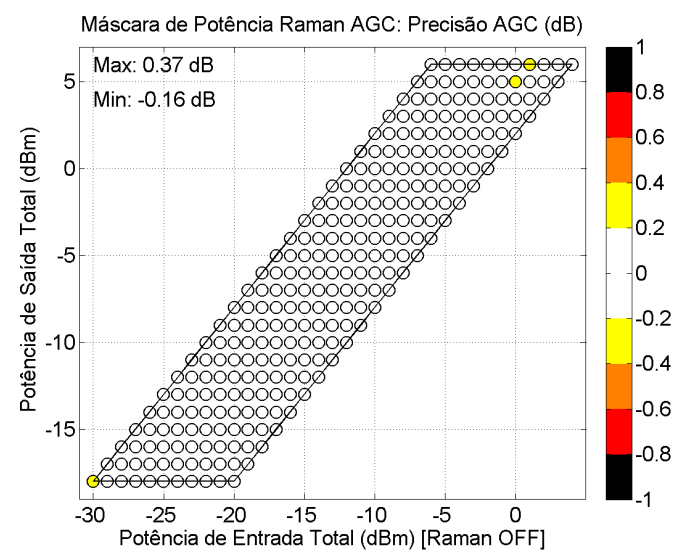

(c)

Figura 4.25: Máscara de potência do amplificador Raman distribuído com AGC on-off apresentando desempenho de figura de ruído (a), planicidade espectral de ganho (b) e precisão do controle automático de ganho acoplado (c).

Na Figura 4.25(a) é ilustrada a máscara de potência de figura de ruído equivalente para o amplificador Raman distribuído contra-propagante apresentando uma variação da figura de ruído de $1,56-2,52 d B$, onde a região de ganhos mais altos apresenta menor figura de ruído equivalente, devido os ganhos altos exigirem um alto nível de bombeio, gerando efeito Raman mais intenso distribuído na fibra, e consequentemente reduzindo a figura de ruído equivalente.

Na Figura 4.25(b) é ilustrada a máscara de potência da planicidade espectral de ganho. Como o amplificador Raman está operando sem GFF, o ganho espectral plano obtido variou em torno de $0,53-2,52 d B$.

Na Figura 4.25(c) é ilustrada a máscara de potência de precisão do controle automá- 
tico de ganho, apresentando uma variação de precisão de AGC de $-0,16$ até $0,37 d B$ com relação ao ganho alvo, provando a eficácia do método de controle de ganho on-off para amplificadores Raman distribuídos.

Desempenho sumarizado do amplificador Raman distribuído com AGC: precisão de AGC $\odot$, figura de ruído $\odot$, planicidade espectral de ganho $\odot$ e potência de saída $\odot$.

Em resumo, a topologia de amplificação Raman distribuída contra-propagante com controle de ganho on-off foi desenvolvida com sucesso para operação em sistemas de comunicações ópticas DWDM. Com os resultados do desempenho na máscara de potência, foi cumprido o objetivo de obter uma tecnologia de amplificação com controle de ganho que fornece baixíssima figura de ruído (equivalente) apresentando resultados melhores que as duas topologias de amplificação EDFA apresentadas anteriormente, e com uma ondulação espectral com variação menor que $2 \mathrm{~dB}$ para toda a faixa de ganhos alvo (que pode ser reduzida para $1 \mathrm{~dB}$ com a utilização de um GFF adequadamente projetado), enquanto para o EDFA estágio simples esta variação é de aproximadamente $5 \mathrm{~dB}$ (com GFF projetado) e para o EDFA-VOA-EDFA é de até 2,63 (com GFF projetado) para toda máscara de potência.

\subsection{Proposta de um Amplificador Óptico para Redes Reconfi- guráveis com Sinais de Alta Eficiência Espectral}

Com base no desempenho dos amplificadores apresentados nas seções anteriores, foi identificado que a topologia de amplificação de estágio simples EDFA é capaz de fornecer ganho plano somente para seu ganho nominal, com uma figura de ruído aceitável e alta potência de saída, enquanto a topologia de amplificação óptica EDFA-VOA-EDFA com GFF e AGC acoplado fornece ganho espectral plano para quase toda a faixa de ganhos desejados e com alta potência de saída em detrimento de sua figura de ruído. Já a tecnologia de amplificação Raman distribuída contra-propagante demonstrou um ótimo desempenho de figura de ruído com baixa variação espectral de ganho porém fornecendo uma baixa potência de saída.

A Figura 4.26 ilustra as topologias de amplificação óptica com controle automático de ganho para sistemas com repetição usados atualmente e detalhadamente desenvolvidos em simulação óptica nesta seção.

Analisando o desempenho sumarizado das topologias de amplificação óptica descritas na Figura 4.26, uma nova topologia de amplificação óptica híbrida baseada nas tecnologias Raman distribuído/EDFA é proposta visando suprir a necessidade por baixa figura de ruído combinadas com planicidade espectral de ganho, ao longo de toda máscara de potência de operação do amplificador em sistemas com repetição com sinais de alta eficiência espectral e dinâmicos.

Devido fornecimento de baixa figura de ruído e baixa variação de ganho espectral para diferentes ganhos desejados pelo amplificador Raman distribuído contra-propagante, esta tecnologia pode ser utilizada como o estágio de amplificação de entrada na topologia de amplificação óptica híbrida. A baixa potência de saída apresentada pelo amplificador Raman distribuído é compensada através do uso de um estágio de amplificação EDFA 


\begin{tabular}{|c|c|c|c|c|}
\hline Topologia Amplificador & $\begin{array}{l}\text { Precisão } \\
\text { AGC (dB) }\end{array}$ & $\begin{array}{l}\text { Figura de } \\
\text { Ruído (dB) }\end{array}$ & $\begin{array}{c}\text { Planicidade } \\
\text { (dB) }\end{array}$ & $\begin{array}{l}\text { P. Saída } \\
\text { (dBm) }\end{array}$ \\
\hline EDFA com AGC & $(-)$ & $\ominus$ & $\ddot{\partial}$ & $(-)$ \\
\hline EDFA-VOA-EDFA com AGC & $(-)$ & $\ddot{\theta}$ & $\Theta$ & $(-)$ \\
\hline $\begin{array}{l}\text { Amplificador Raman Distribuído } \\
\text { com AGC }\end{array}$ & $(-)$ & $(-)$ & $(-)$ & $\ddot{\theta}$ \\
\hline $\begin{array}{l}\text { Amplificador Híbrido (AGC) } \\
\text { [Raman Distribuído/EDFA] }\end{array}$ & (ن) & (ن) & (ن) & (ن) \\
\hline
\end{tabular}

Figura 4.26: Análise comparativa topologias de amplificação óptica com controle automático de ganho para sistemas com repetição dinâmicos.

com AGC e GFF no estágio de saída da topologia de amplificação hibrida.

Para mitigar o desempenho ruim de planicidade espectral de ganho do EDFA incluso no amplificador híbrido, o mesmo deve ser operado sempre com ganho alvo igual ao seu ganho nominal (e este deve ser o ganho mínimo de operação), fornecendo ganho espectral plano e alta potência de saída. Desta forma, para todo ganho alvo maior que o ganho nominal do EDFA, a diferença de ganho necessária é fornecida pelo amplificador Raman distribuído com AGC, maximizando o desempenho de figura de ruído e fornecendo altos níveis de potência na saída do amplificador híbrido.

\subsection{Conclusões Parciais}

Neste capítulo foram descritas as topologias de amplificação óptica EDFA (estágio único e duplo estágio com VOA) e Raman com AGC utilizados em sistemas ópticos com repetição dinâmicos atualmente.

Também foram apresentadas as metodologias de projeto otimizado de EDFAs (estágio único e duplo estágio com VOA), a metodologia de projeto otimizado de amplificador Raman distribuído, e um método de análise de desempenho dos amplificadores ópticos em redes dinâmicas via máscara de potência de planicidade espectral, figura de ruído e precisão de AGC.

Além disso, foi desenvolvida e apresentada como contribuição, uma técnica de controle automático de ganho on-off para amplificador Raman distribuído, baseado em estimação cega da potência lançada no enlace da rede óptica.

Com base na análise de desempenho de cada topologia de amplificação óptica com AGC estudada e desenvolvida neste Capítulo, foi proposta como contribuição original, uma topologia de amplificação óptica híbrida para redes reconfiguráveis com sinais de alta eficiência espectral, baseada na concatenação das tecnologias Raman distribuída com EDFA, controladas por um novo algoritmo AGC, visando maximizar desempenho da figura de ruído e planicidade espectral de ganho para toda região de operação do amplificador. 
No Capítulo 5, a topologia de amplificação óptica híbrida proposta neste Capítulo será detalhadamente descrita, assim como sua metodologia de projeto e AGC. Em seguida seu desempenho será apresentado por meio de simulações ópticas e experimentais em enlace único e simulação óptica em múltiplos enlaces, comparando seu resultado com a topologia EDFA-VOA-EDFA, visando mostrar o aumento de desempenho fornecido pela topologia híbrida com AGC proposto nesta tese. 
114 METODOLOGIA DE PROJETO DE AMPLIFICADORES ÓPTICOS COM CONTROLE AUTOMÁTICO DE GANHO

4.5 


\section{Capítulo 5}

\section{Amplificador Óptico Híbrido para Redes DWDM Reconfiguráveis}

Com base na necessidade de um amplificador híbrido com controle automático de ganho que forneça baixa figura de ruído e planicidade espectral de ganho para a faixa de controle determinada pela máscara de potência de operação do amplificador, esta seção detalha a topologia do amplificador híbrido proposto nesta tese para redes DWDM reconfiguráveis, assim como descreve o método de controle automático de ganho proposto, detalhando a metodologia de projeto do mesmo.

Após projetado e desenvolvido em software de simulação óptica e experimentalmente, o amplificador óptico híbrido terá seu desempenho simulado, experimentado e comparado com o amplificador óptico com ganho plano mais utilizado atualmente nos sistemas de comunicações ópticas DWDM reconfiguráveis (EDFA-VOA-EDFA).

A análise de desempenho dos amplificadores em questão (híbrido Raman/EDFA e EDFA-VOA-EDFA), será realizada através do software de simulação óptica com os amplificadores operando em um sistema composto por um único enlace e por múltiplos enlaces de comunicações ópticas DWDM reconfiguráveis.

Também será analisado o desempenho dos amplificadores experimentais (híbrido Raman/EDFA e EDFA-VOA-EDFA) em um sistema de comunicações ópticas composto por um único enlace de comunicações ópticas.

Após apresentados, os resultados serão detalhadamente analisados e discutidos, visando demonstrar os benefícios alcançados pelo amplificador óptico híbrido (Raman/EDFA) frente a topologia de amplificação óptica EDFA-VOA-EDFA.

\subsection{Topologia Óptica do Amplificador Híbrido (Raman/EDFA)}

A Figura 5.1 ilustra o circuito óptico do amplificador óptico híbrido DRA contrapropagante/EDFA proposto no Capítulo 4 e demonstrado nas referências (de Oliveira et al., 2013b, 2011; Oliveira et al., 2013b, 2012).

O amplificador óptico híbrido é composto por um estágio de amplificação distribuída Raman com dois lasers de bombeio contra-propagantes e um estágio único de EDFA com bombeio co-propagante com GFF como ilustrado na Figura 5.1. 


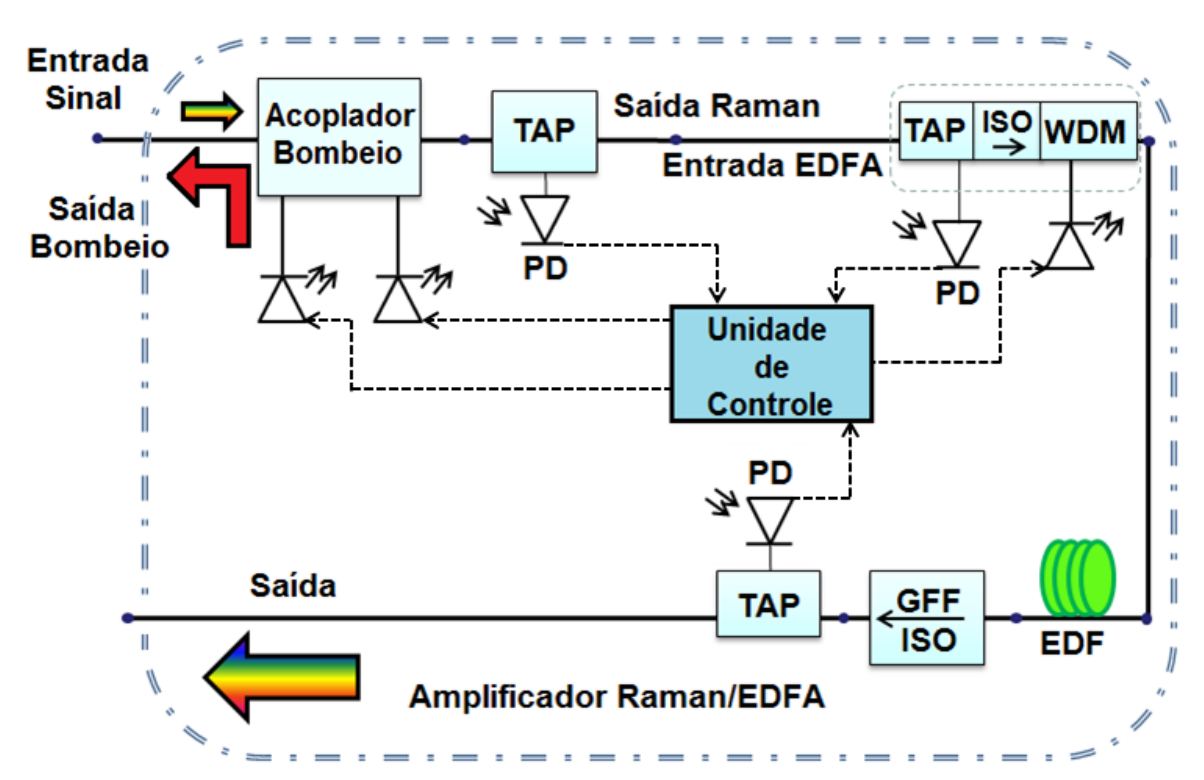

Figura 5.1: Circuito óptico do amplificador híbrido Raman distribuído contra-propagante com dois bombeios e EDFA com GFF.

O circuito óptico do estágio de amplificação Raman distribuído contra-propagante é composto por dois lasers de bombeio (comprimentos de onda de 1400 a $1499 \mathrm{~nm}$ ), combinados através de um filtro acoplador Raman de bombeios na fibra de transmissão, na direção contra-propagante ao sinal, onde a fibra de saída deste acoplador segue para um separador de sinal (99/1\%), visando monitoração da potência de saída do amplificador Raman.

O circuito óptico do estágio de amplificação EDFA é composto por um bombeio copropagante $(980 \mathrm{~nm})$ combinado com o sinal por meio de um componente óptico híbrido (separador 99/1\%, isolador e acoplador WDM) que visa disponibilizar uma parte do sinal de entrada para monitoração, isolação da rede com relação ao retro-espalhamento oriundo do processo de amplificação, e combinação do comprimento de onda de bombeio juntamente com o sinal na direção co-propagante na fibra dopada com érbio (EDF). Na EDF ocorre o processo de amplificação, em seguida passando por um componente híbrido isolador/GFF que visa evitar perda de eficiência no processo de amplificação na EDF devido a retro-espalhamento de luz oriundo do sistema de saída, e por meio do GFF, provê ganho espectral plano (seção 4.1.1).

No amplificador híbrido tem-se três sensores compostos pelos fotodetectores para medição da potência de saída do amplificador Raman, medição da potência de entrada e de saída do EDFA, além de três atuadores descritos por três lasers de bombeio semicondutores, dois para o amplificador Raman (com potência nominal de $360 \mathrm{~mW}$ e comprimento de onda $14 \mathrm{XX} \mathrm{nm}$ ) e um para o EDFA (com potência nominal de $500 \mathrm{~mW}$ e comprimento de onda $980 \mathrm{~nm}$ ). Por meio destes sensores e atuadores, a unidade de controle ilustrada na Figura 5.1 executa a malha de controle de ganho do amplificador híbrido descrita na seção seguinte. 


\subsection{Método de Controle Automático de Ganho para o Amplifi- cador Óptico Híbrido (Raman/EDFA)}

A malha de controle automático de ganho desenvolvida nesta tese para controle do amplificador híbrido (Raman/EDFA) descrito pelo circuito óptico da Figura 5.1 é ilustrado na Figura 5.2. O controle de ganho do amplificador híbrido utiliza os fotodetectores como parâmetro de entrada do controle de ganho para o algoritmo de processamento que controla o nível de potência dos bombeios (atuadores) do amplificador híbrido, para execução do controle do ganho por meio de um controle proporcional integral.

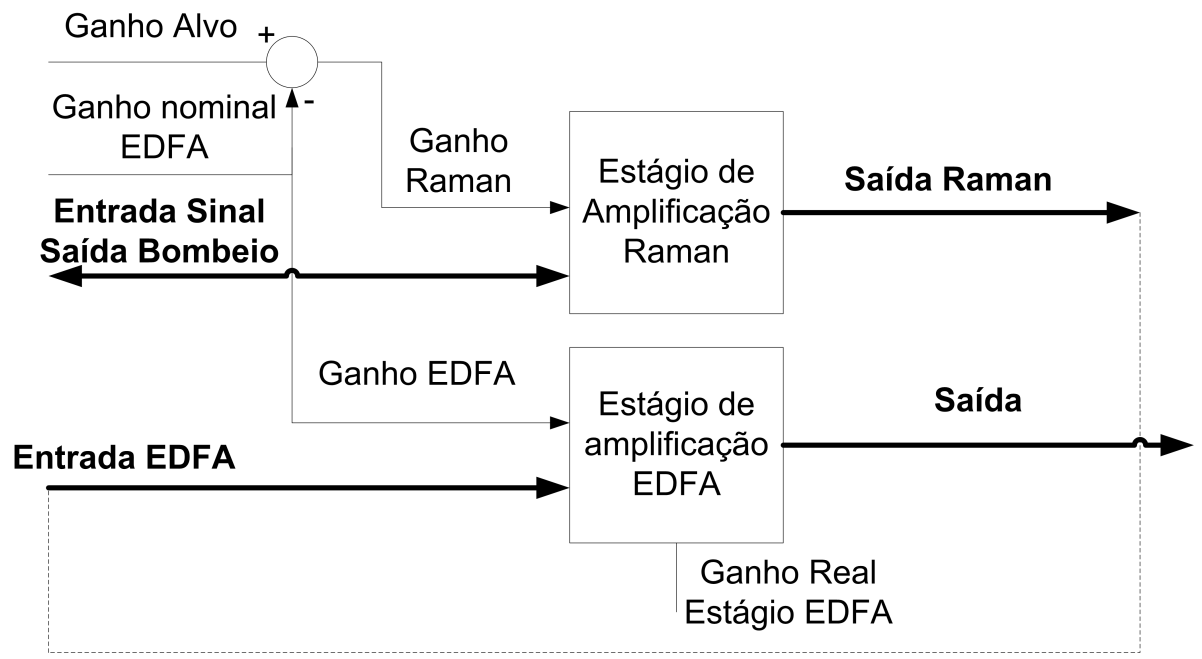

Figura 5.2: Malha de controle de ganho para o amplificador híbrido Raman distribuído contrapropagante com dois bombeios e EDFA com GFF.

O controle de ganho do amplificador híbrido é realizado em duas partes. Na primeira parte, cada estágio de amplificação controla seu ganho independentemente. O estágio de amplificação Raman distribuído executa o controle do ganho on-off do amplificador Raman por meio do controle em malha aberta apresentado na Figura 4.6 (amplificador experimental) ou pelo controle em malha aberta apresentado na Figura 4.24(a) (amplificador simulado).

No caso do amplificador Raman simulado, o controle em malha aberta estima diretamente a potência de saída do amplificador Raman com os bombeios desligados, como descrito na seção 4.3.5 por meio de subtração direta da atenuação do enlace na potência lançada medida. No caso do amplificador Raman experimental, o controle de ganho em malha aberta realiza uma estimação cega da potência de saída do amplificador Raman com os bombeios desligados como descrito na seção 4.1.3. Com base nesta medida, os níveis de potência dos bombeios são calculados por meio do polinômio de controle de ganho on-off (coeficientes determinados na fase de caracterização para o tipo de fibra de enlace utilizado), para fornecer o ganho alvo desejado.

Enquanto isso o estágio de amplificação EDFA realiza o controle automático de ganho realimentado apresentado na Figura 4.2 no caso do amplificador experimental, e o controle de ganho em malha aberta apresentado na Figura 4.15(a) (por meio do polinômino de controle de ganho).

Na segunda parte, de acordo com o ganho alvo desejado, o controle automático de 
ganho híbrido determina o ganho alvo de cada tecnologia (Raman/EDFA) com base na faixa de controle de ganho desejada (para qual as tecnologias do amplificador híbrido são projetadas).

O controle de ganho híbrido sempre atribui ao EDFA ganho alvo fixo igual a seu ganho nominal, visando manter o ganho espectral plano fornecido pelo EDFA. Devido ao ganho alvo do EDFA ser igual ao seu ganho nominal, o mesmo torna-se o ganho mínimo fornecido pelo amplificador híbrido. Caso o ganho alvo do amplificador híbrido necessite ser maior que o ganho nominal do EDFA, a diferença é fornecida pelo controle de ganho on-off do amplificador Raman distribuído, que tem seu ganho alvo ajustado de acordo com a equação 5.1. Desta forma a faixa de controle de ganho do amplificador híbrido varia entre o ganho nominal do EDFA até este valor acrescido do máximo ganho fornecido pelo amplificador Raman distribuído com controle automático de ganho on-off.

$$
\text { Ganho }_{\text {Raman }}=\text { Ganho }_{\text {Alvo }}-\text { GanhoEDF }_{\text {Nominal }}
$$

Na equação 5.1, o Ganho Raman representa o ganho-alvo do estágio Raman, Ganho Alvo é o ganho-alvo do amplificador híbrido e GanhoEDF $A_{N o m i n a l}$ é o ganho nominal do estágio EDFA.

Com a topologia do amplificador híbrido, sua malha de controle de ganho e sua faixa de controle de ganho definidas, a próxima seção descreve a metodologia de projeto do amplificador híbrido.

\subsection{Metodologia de Projeto do Amplificador Óptico Híbrido (Raman/EDFA)}

Nesta seção é descrita detalhadamente a metodologia de projeto do amplificador híbrido (Raman/EDFA) para operação em redes DWDM reconfiguráveis com canais de alta eficiência espectral. A metodologia de projeto do amplificador óptico híbrido utiliza como parâmetros de entrada a faixa de ganhos alvo e potências de entrada e saída de operação, descritos pela máscara de potência do amplificador a ser desenvolvido.

Com a máscara de potência definida determina-se a quantidade de bombeios Raman necessária para atingir tal nível de ganho visando cobrir toda diferença (ganho máximo - ganho mínimo) e determina-se o ganho nominal do EDFA.

A partir deste ponto, projeta-se o EDFA para o ganho nominal determinado utilizando a metodologia de projeto apresentada no capítulo 4, e projeta-se o Raman utilizando-se também a metodologia apresentada no capítulo 4, considerando agora a obtenção de um perfil espectral de ganho plano com ambas tecnologias em operação (Raman/EDFA). Desta forma, o perfil de ganho espectral Raman é complementar ao fornecido pelo EDFA. A metodologia de projeto é finalizada com o projeto do GFF para planificar o perfil espectral remanescente. 


\subsubsection{Máscara de potência de operação do amplificador Híbrido}

Visando o desenvolvimento de um amplificador híbrido (Raman/EDFA) que venha a substituir tanto pré-amplificadores quanto amplificadores de linha, dado que o mesmo terá seu desempenho sistêmico avaliado em enlaces de comunicações ópticas com repetição que varia em comprimento de 75 a $125 \mathrm{~km}$, considerando um coeficiente de atenuação de aproximadamente $0,20 \mathrm{~dB} / \mathrm{km}$ para fibra SSMF (G.652), e implicando em atenuação de 15 à $25 \mathrm{~dB}$ por enlace. Com base nesta faixa de ganho de operação, na máxima potência de saída e mínima potência de entrada apresentada no projeto dos amplificadores no Capítulo 4, define-se a máscara de potência de operação do amplificador híbrido a ser desenvolvido através dos parâmetros descritos abaixo:

- $15 \mathrm{~dB}$ de ganho mínimo

- $25 \mathrm{~dB}$ de ganho máximo

- $21 \mathrm{dBm}$ de potência total de saída máxima

- $-28 \mathrm{dBm}$ de potência total de entrada mínima (potência com os bombeios Raman desligados)

Lembrando que em termos de amplificadores com tecnologia de amplificação Raman distribuído, a potência de entrada considerada como parâmetro da máscara de potência é medida sempre com os bombeios Raman desligados.

\subsubsection{Projeto dos Estágios de Amplificação EDFA e Amplificador Raman Distribuído para o Amplificador Híbrido}

Determinada a faixa de operação do amplificador híbrido, nesta subseção é descrito o projeto dos estágios de amplificação EDFA e amplificação Raman distribuída no contexto do amplificador híbrido. Inicialmente serão determinados os ganhos de operação, seguido do projeto de cada tecnologia, primeiramente o EDFA e em seguida o amplificador Raman, considerando o desempenho do EDFA desenvolvido previamente, visando desta forma otimizar o desempenho do amplificador híbrido como um todo e não mais otimizar o desempenho de cada tecnologia separadamente.

Com os parâmetros da máscara de potência definidos, o amplificador Raman a ser desenvolvido deve prover uma faixa de $10 \mathrm{~dB}$ de ganho on-off, devido ser esta a diferença entre os ganhos alvo máximo e mínimo (25 - $15 \mathrm{~dB})$ de operação. Considerando um amplificador Raman distribuído contra-propagante com este nível de ganho on-off, dois lasers de bombeio são suficientes em uma topologia de amplificação Raman distribuída para suprir este nível de ganho on-off (dois bombeios fornecem até $12 \mathrm{~dB}$ de ganho on-off).

Como o ganho fornecido pelo amplificador Raman ultrapassa os $10 \mathrm{~dB}$ necessários, podemos maximizar o desempenho do amplificador híbrido maximizando o nível de ganho on-off Raman, determinando-se que o mínimo ganho de operação do amplificador Raman neste caso será seu máximo ganho alcançável, subtraído da diferença de ganho 
desejada (12 - $10=2 \mathrm{~dB}$ ), conseguido por meio da utilização de dois lasers de bombeio com potência nominal de $360 \mathrm{~mW}$ no amplificador Raman distribuído.

Determinada a faixa de ganho do amplificador Raman distribuído contra-propagante contido na topologia de amplificação híbrida, o ganho nominal do EDFA é descrito como o ganho remanescente necessário, o qual, quando adicionado ao ganho on-off fornecido pelo amplificador Raman distribuído, fornece a faixa de ganho desejada. Desta forma, como a faixa de ganho desejada é 15-25 dB e a faixa de ganho on-off Raman é de 2-12 $\mathrm{dB}$, subtraindo os limites dessas faixas obtém-se que o ganho nominal do EDFA a ser projetado para o amplificador híbrido é $13 \mathrm{~dB}$.

Dado que o ganho nominal do EDFA contido na topologia de amplificação óptica híbrida deve ser $13 \mathrm{~dB}$, com este parâmetro em mãos e a máscara de potência descrita no início da seção, foi aplicada a metodologia de projeto do estágio simples EDFA apresentado na seção 4.3.2 excluindo-se intencionalmente o projeto e uso do GFF, o qual deverá ser realizado somente após integração do EDFA com o amplificador Raman distribuído.

Desta forma, a aplicação da metodologia de projeto produziu uma estrutura de EDFA com bombeio de $980 \mathrm{~nm}$ co-propagante de até $600 \mathrm{~mW}$ de potência nominal, seguido de 9,5m de fibra dopada com érbio (MP980), com controle de ganho fornecido por meio da malha de controle de ganho realimentada apresentada na seção 4.1.1.

A Figura 5.3 ilustra o resultado das máscaras de potências para o EDFA com AGC desenvolvido para compor o estágio de amplificação EDFA do amplificador híbrido por meio de metodologia apresentada na seção 4.3.2.

Como o GFF do amplificador híbrido será implementado após o projeto do amplificador Raman, devido a necessidade de considerar ambas tecnologias no amplificador híbrido para o projeto do GFF, e, dado que o GFF será posicionado na saída do amplificador híbrido (visando otimização da figura de ruído do amplificador híbrido), o EDFA contido no amplificador híbrido deverá fornecer $13 \mathrm{~dB}$ de ganho nominal incluindo o GFF. Para o EDFA contido no amplificador híbrido atingir $13 \mathrm{~dB}$ de ganho com GFF na saída, o mesmo deverá operar em um ganho maior que $13 \mathrm{~dB}(13 \mathrm{~dB}+$ perda de inserção do GFF combinado com o perfil espectral de atenuação do mesmo). Portanto, a Figura 5.3 ilustra a máscara de potência para a faixa de ganho alvo de 13 à $18 \mathrm{~dB}$.

Após projeto do estágio EDFA, torna-se necessário projetar o amplificador Raman distribuído com dois lasers de bombeio e seus respectivos comprimentos de onda, visando o fornecimento de um perfil espectral de ganho o qual, combinado com o perfil espectral de ganho do estágio EDFA projetado anteriormente, resulte em um perfil espectral de ganho plano (ou o mais plano possível).

Para projeto do estágio Raman distribuído contra-propagante contido no amplificador híbrido, a mesma metodologia de projeto apresentada na seção 4.3 .5 foi utilizada. Porém, ao invés da busca pelos comprimentos de onda de bombeio que forneçam perfil espectral de ganho plano na saída do amplificador Raman, no projeto do amplificador híbrido, o perfil espectral de ganho do EDFA deve ser considerado. Através da metodologia apresentada na seção 4.3.5 combinada com os cálculos adicionais apresentados a seguir, para que seja possível realizar a busca pelo conjunto de comprimentos de onda de bombeio Raman que minimizem o perfil espectral de ganho do amplificador híbrido 


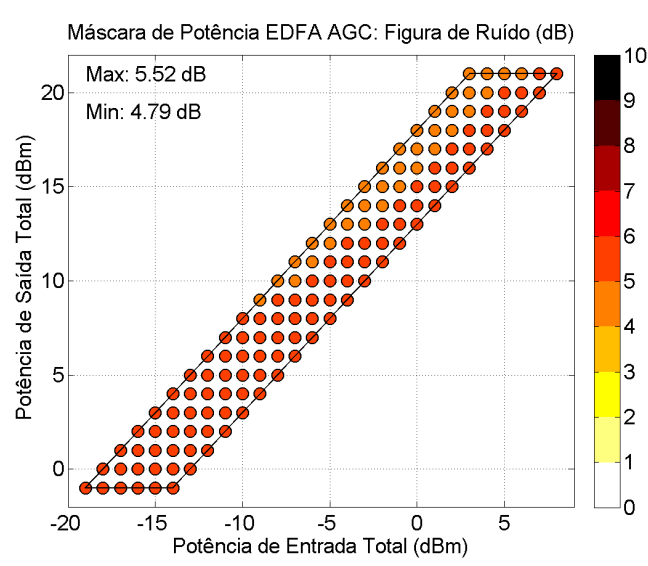

(a)

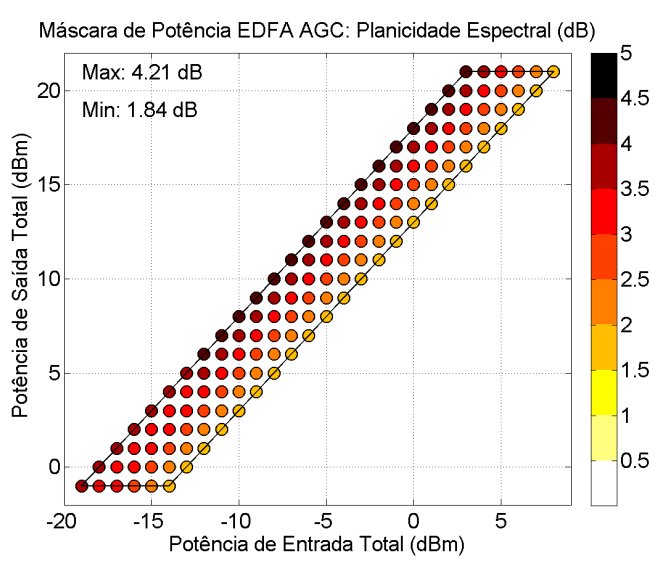

(b)

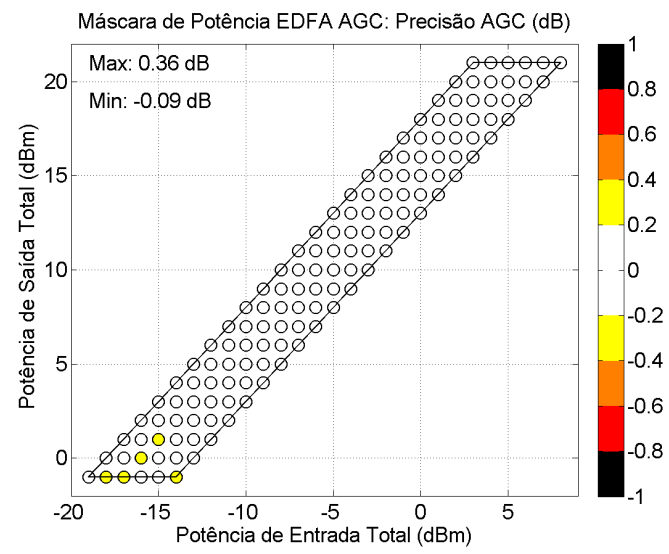

(c)

Figura 5.3: Máscara de potência do amplificador estágio simples EDFA com AGC para o amplificador híbrido, apresentando desempenho de figura de ruído (a), planicidade espectral de ganho (b) e precisão do controle automático de ganho (c).

como um todo (perfil espectral plano do amplificador Raman distribuído combinado com o EDFA).

Os cálculos adicionados na metodologia de projeto do amplificador Raman contido no amplificador híbrido, têm como objetivo avaliar, para cada combinação de bombeio, a semelhança do perfil espectral de ganho Raman com o inverso do perfil espectral de ganho do EDFA contido no amplificador híbrido, pois quanto mais próximos forem estes perfis espectrais de ganho, o resultado da combinação dos mesmos implica em um ganho espectral plano na saída do amplificador híbrido. Caso não seja possível obter um conjunto de comprimentos de onda de bombeio Raman que forneça ganho espectral plano para o amplificador híbrido, é escolhido um conjunto de bombeios que forneça melhor planicidade espectral ao amplificador híbrido.

Para avaliar a semelhança do perfil espectral de ganho do amplificador Raman com o inverso do perfil do EDFA é necessário fornecer os picos de potência de saída dos canais após amplificação ao longo da banda-C (neste caso foram utilizados 40 pontos/canais) para ambas as tecnologias que vão compor o amplificador híbrido (pontos obtidos nas mesmas frequências para ambos os amplificadores).

Considerando um sinal com espectro plano na entrada das tecnologias EDFA (com 
ganho nominal $13 \mathrm{~dB}$ ) e Raman (com ambos os bombeios em $360 \mathrm{~mW}$ ) os picos de potência de saída para ambas as tecnologias são fornecidos, e por meio da equação 5.2, o perfil de ganho Raman é normalizado/escalado com relação ao seu valor mínimo de potência de pico, enquanto para os picos EDFA são obtidos o inverso do perfil normalizado/escalado com relação ao seu valor máximo, por meio da subtração do pico máximo EDFA por cada pico medido.

$$
\begin{aligned}
& \text { compScalePeakEDFA }_{\text {MaxPeakNum }}=\operatorname{peakEDFA(\operatorname {max})-\text {peakEDFA}} \text { MaxPeakNum }_{\text {max }} \\
& \operatorname{scalePeakRaman}_{\text {MaxPeakNum }}=\operatorname{peakRaman}_{\text {MaxPeakNum }}-\operatorname{peakRaman}(\min )
\end{aligned}
$$

A Figura 5.4(a) ilustra um exemplo da aplicação da normalização de espectro do amplificador Raman, executado por meio da equação 5.2, enquanto a Figura 5.4(b) ilustra o exemplo de normalização invertida do espectro do EDFA por meio da equação 5.2.

Com os perfis espectrais obtidos e normalizados por meio da equação 5.2 , foi utilizado o método forward difference approximation (Phillips, 2003) para obter a diferença aproximada direta entre todos os picos tomados dois-a-dois para ambos os amplificadores (considerando a distância entre picos h igual a um) como ilustrado na equação 5.4, representando a variação espectral para cada vetor de pico normalizado de ambas tecnologias (para n picos são retornados n-1 inclinações).

$$
\begin{aligned}
\Delta \text { peakRaman }(i) & =\quad \frac{(\text { scalePeakRaman }(i)-\operatorname{scalePeakRaman}(i+h))}{h} \\
\Delta \text { compPeakEDFA }(i) & =\frac{(\text { compScalePeakEDFA }(i)-\operatorname{compScalePeakEDFA}(i+h))}{h}
\end{aligned}
$$

Após este passo, a comparação dos perfis espectrais é realizada pela equação 5.6, por meio do somatório das diferenças aproximadas absolutas das tecnologias Raman e EDFA para cada frequência, onde o valor total é proporcional à diferença do perfil espectral do amplificador Raman com relação ao inverso do perfil espectral do EDFA. Quanto mais próximo de zero for o resultado da equação 5.6, mais próximo será o perfil espectral do amplificador Raman comparado com o inverso do perfil espectral do EDFA, e a combinação das duas tecnologias resultará em um perfil espectral plano para o amplificador híbrido:

spectralGainProfDiff ${ }_{\text {MaxPumpComb }}=\left[\sum_{i=1}^{\text {MaxPeakNum-1 }} \mid\right.$ peakRaman $(i)-\operatorname{compPeakEDFA(i)|]}$

Desta forma as equações 5.2, 5.4 e 5.6, juntamente com o espectro de saída do EDFA operando em seu ganho nominal, são adicionados a metodologia de projeto do amplificador Raman distribuído apresentado no Capítulo 4, otimizando o projeto do amplificador Raman distribuído projetado para compor o amplificador Híbrido (Raman/EDFA) objetivo desta tese.

No Capítulo 4 foi executada a metodologia de projeto do amplificador Raman dis- 


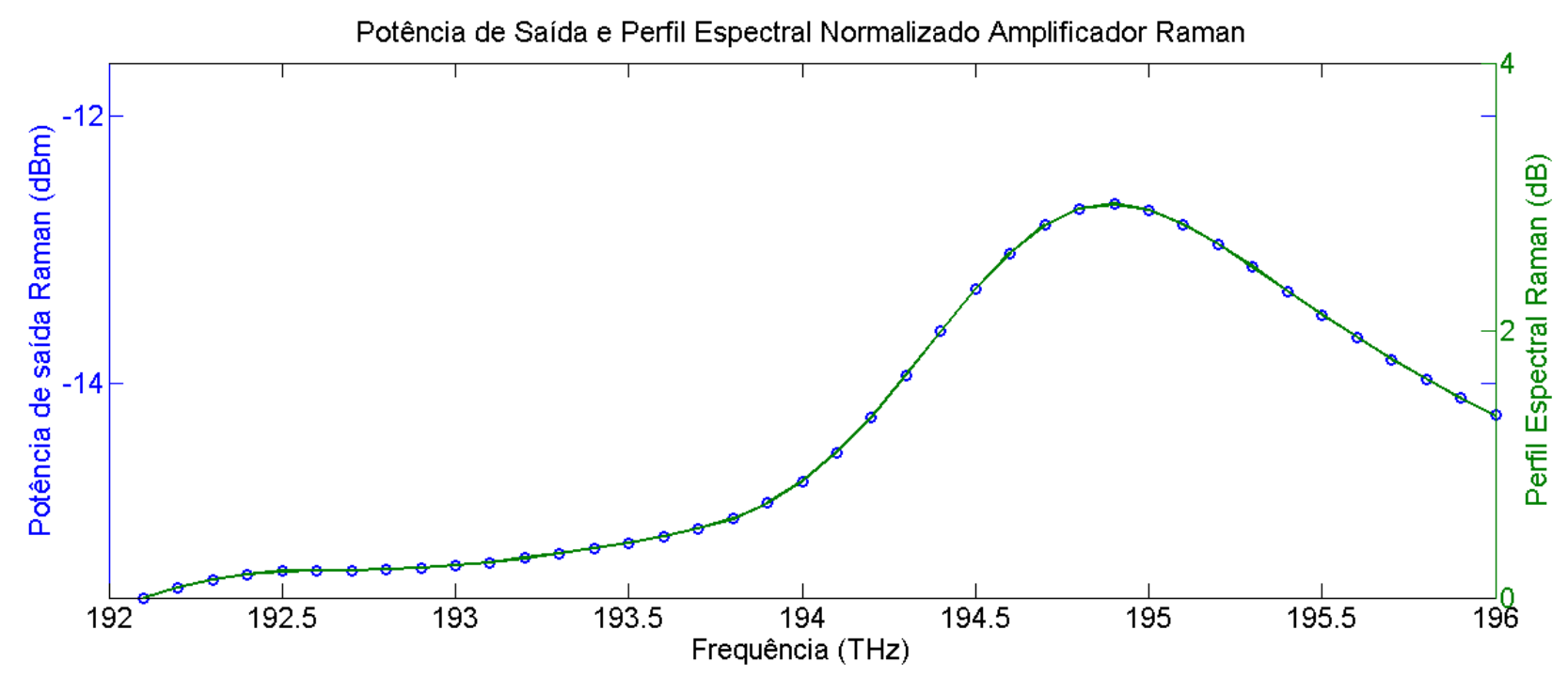

(a)

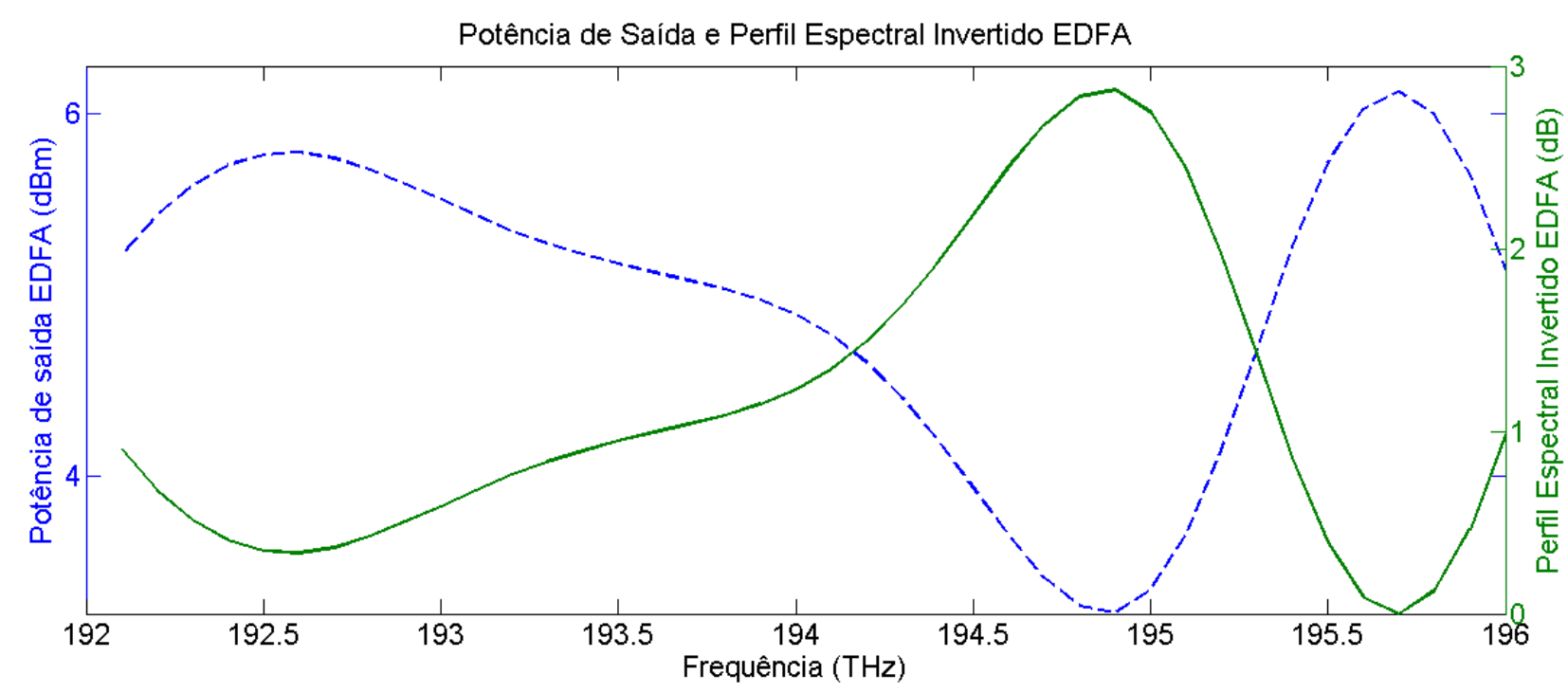

(b)

Figura 5.4: Normalização do perfil espectral do amplificador Raman distribuído (a) e normalização invertida do perfil espectral do EDFA (b)

tribuído contra-propagante com dois lasers de bombeio, visando a melhor planicidade espectral de ganho possivel, obtendo-se os bombeios 1442/1447 nm como o conjunto que fornece melhor planicidade espectral de ganho (aproximadamente 1,6 dB de planicidade espectral de ganho). Utilizando a metodologia similar, alterada pelas modificações apresentadas anteriormente, o projeto do amplificador Raman distribuído para compor o amplificador híbrido (Raman/EDFA) resultou como a melhor combinação de bombeios o conjunto composto pelos comprimentos de onda de 1425/1455 nm, apresentando uma ondulação espectral de ganho de $2,9 \mathrm{~dB}$.

A Figura 5.5 ilustra o perfil espectral de ganho invertido do EDFA, juntamente com os perfis espectrais de ganho do DRA, que fornece melhor planicidade espectral de ganho (projetado no Capítulo 4, 1442/1447 nm) e do DRA projetado com base na metodologia do apresentada no Capítulo 4 adicionado dos cálculos apresentados anteriormente (1425/1455 nm). 


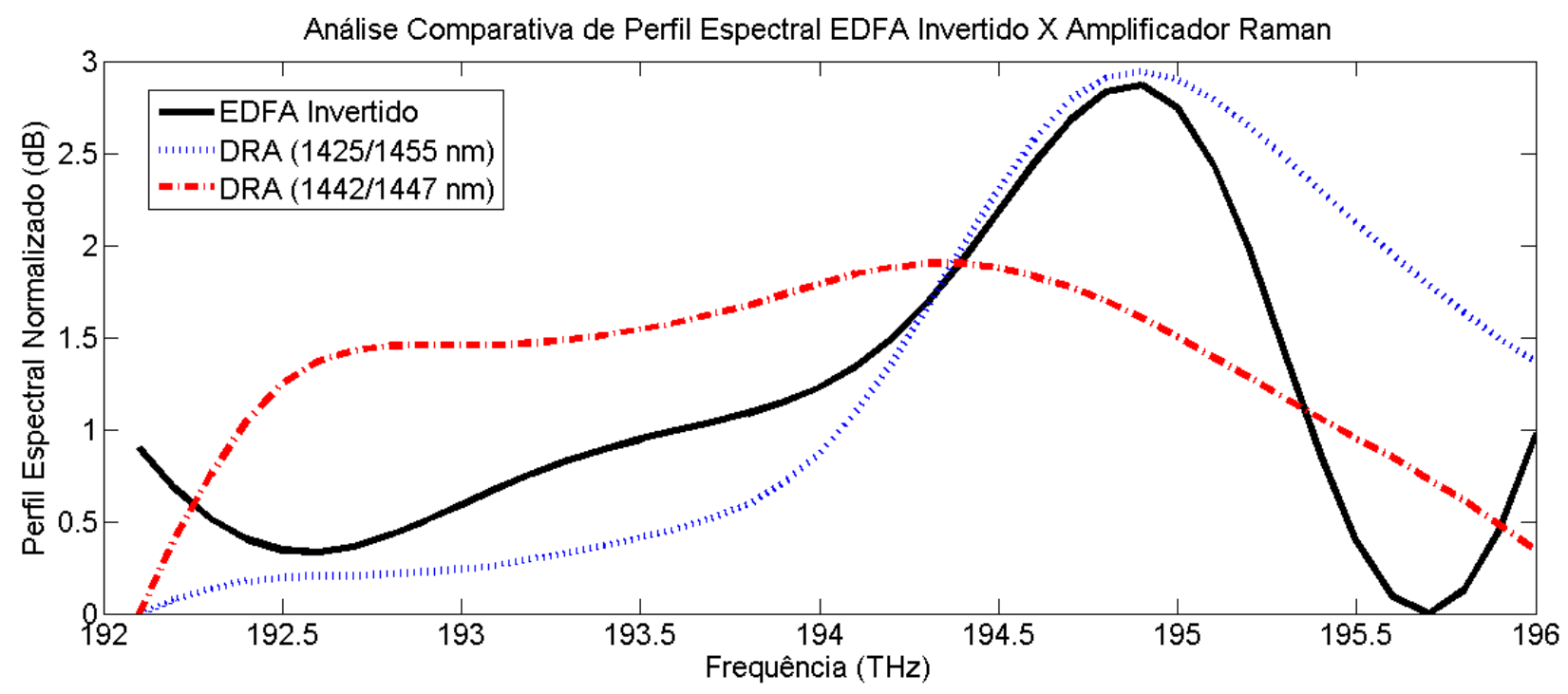

Figura 5.5: Comparativo de perfis espectrais de amplificadores Raman projetado no Capítulo 4 $(1442 / 1447 \mathrm{~nm})$, amplificador Raman $(1425 / 1455 \mathrm{~nm})$ e EDFA projetado para o amplificador híbrido.

Nota-se por meio da Figura 5.5 que, apesar do DRA projetado nesta seção (1425/1455 $\mathrm{nm}$ ) apresentar uma planicidade espectral de ganho melhor que o projetado com a metodologia do Capítulo 4 (1442/1447 nm), o DRA com os bombeios de 1425/1455 nm apresenta um perfil espectral de ganho mais próximo do perfil do EDFA invertido que o DRA com os bombeios 1442/1447 nm. Desta forma, a combinação do DRA 1425/1455 nm com o EDFA fornecerá uma planicidade espectral de ganho melhor que a combinação do DRA 1442/1447 nm com o mesmo EDFA.

A Figura 5.6(a) ilustra as diferenças absolutas aproximadas para o perfil do EDFA invertido e os DRAs projetados no Capítulo 4 e neste Capítulo, que são determinadas pelo valor absoluto resultante da equação 5.4 tomados dois-a-dois ao longo de todo o perfil espectral de ganho do EDFA e dos DRAs.

Já a Figura 5.6(b) ilustra, as diferenças entre os perfis espectrais de ganho dos DRAs em comparação com o perfil invertido do EDFA. Fica claro na Figura 5.6(b), devido a menor área apresentada pela diferença entre o DRA 1425/1455 nm com relação ao perfil invertido do EDFA, que esta combinação de bombeios Raman, apesar de apresentar uma planicidade espectral de ganho maior, este perfil espectral combinado com o EDFA irá otimizar a planicidade espectral do amplificador híbrido.

\subsubsection{Integração do Controle de Ganho e Projeto do GFF}

A Figura 5.7(a) ilustra a paleta de simulação desenvolvida para o amplificador óptico híbrido (Raman/EDFA) visando a integração do controle de ganho desenvolvido anteriormente e o projeto do filtro planificador de ganho (GFF), assim finalizando o projeto otimizado do amplificador óptico híbrido para redes reconfiguráveis que será utilizado nas seções subsequentes para avaliação simulada e experimental dos sistemas de comunicações ópticas DWDM de curto e longo alcance.

Como ilustrado na Figura 5.7(b), o amplificador Raman distribuído com controle 


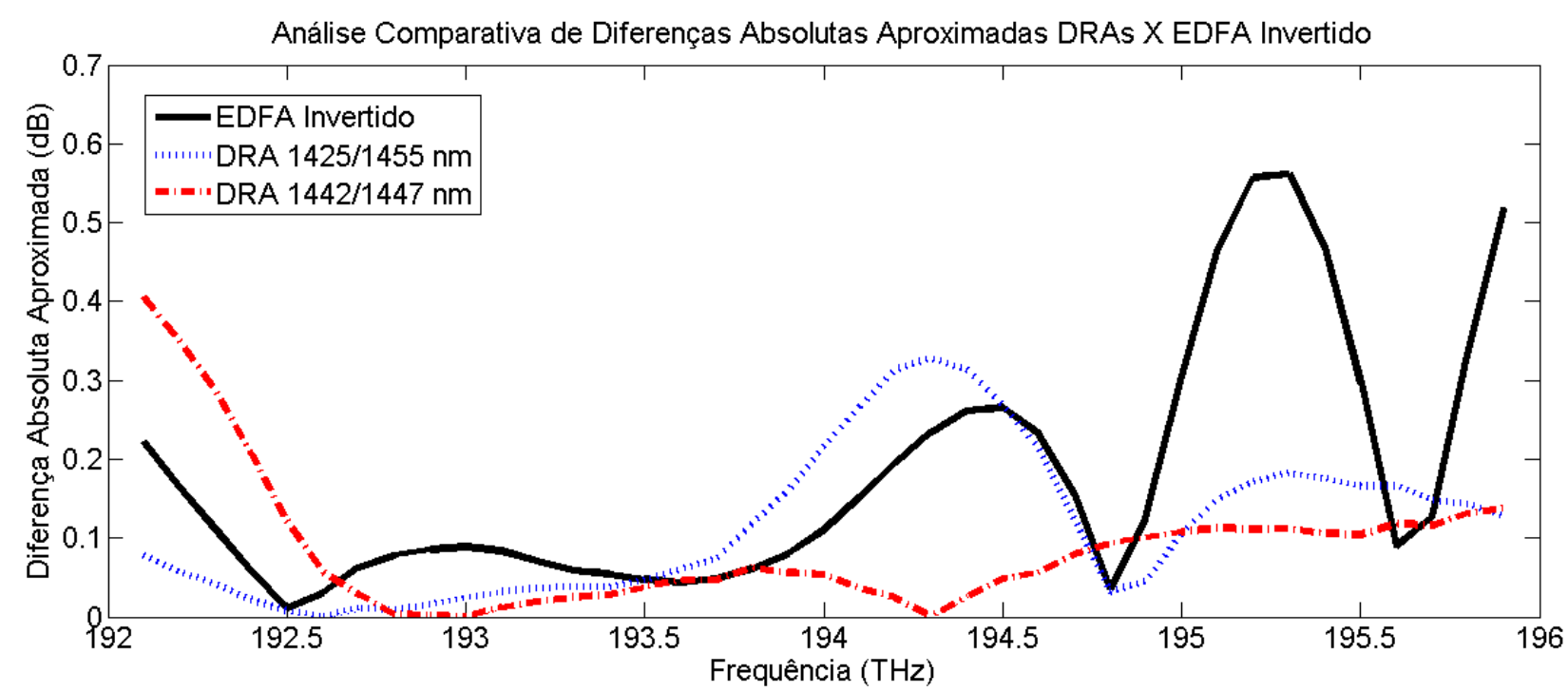

(a)

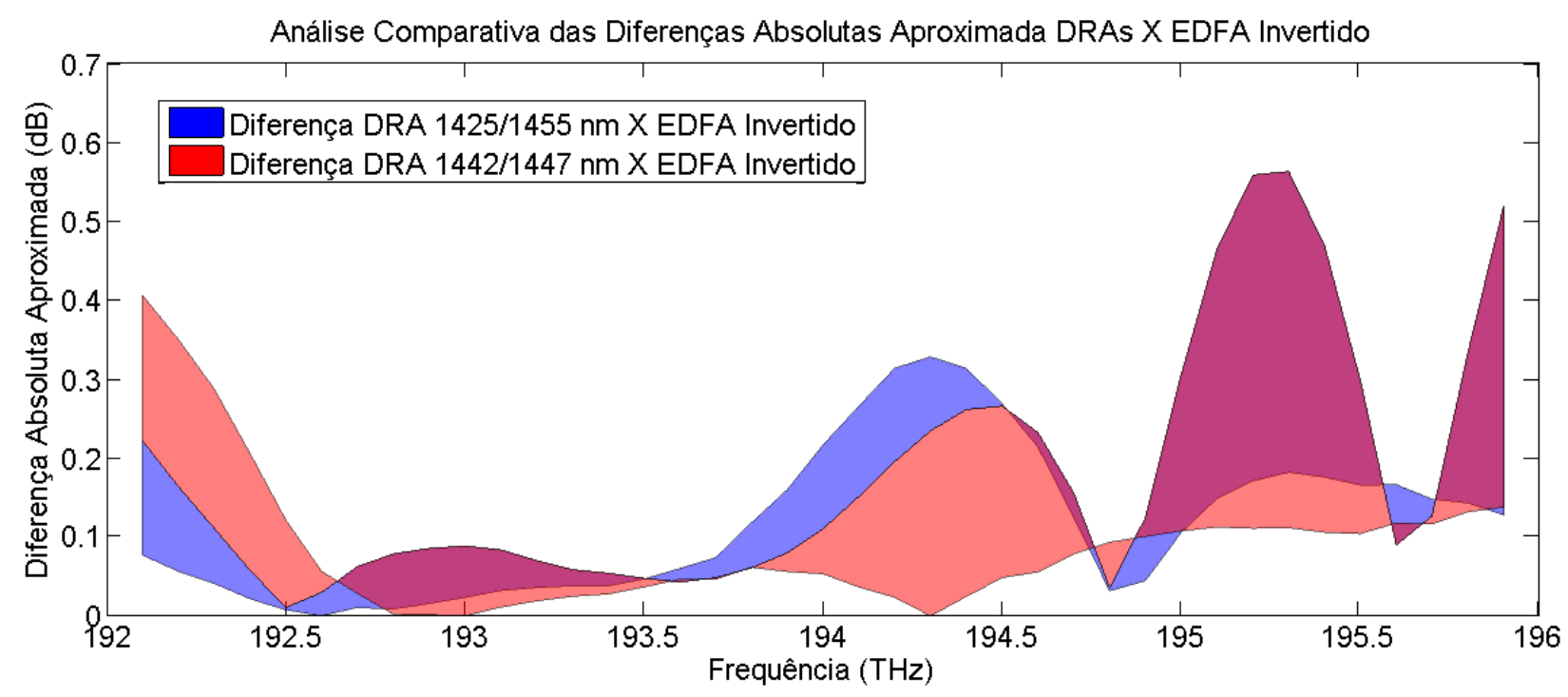

(b)

Figura 5.6: Curvas das diferenças absolutas aproximadas dos DRAs e EDFA (a) e análise comparativa das áreas diferenciais dos DRAs com relação ao EDFA (b)

automático de ganho utilizado no amplificador híbrido foi o mesmo desenvolvido na seção anterior e ilustrado na Figura 4.22(b), o qual tem seu desempenho ao longo da máscara de potência ilustrado na seção 4.3.5. Já o EDFA com controle automático de ganho ilustrado na Figura 5.7(b) utilizado no amplificador híbrido foi o mesmo EDFA desenvolvido na seção anterior e ilustrado na Figura 4.11(b), com desempenho ao longo da máscara de potência descrito na Figura 5.3.

O controle de ganho utilizado, tanto no amplificador experimental quanto o simulado é descrito pela Figura 5.2, as únicas diferenças foram relativas ao controle de ganho do EDFA que, em simulação é realizado por meio de controle de malha aberta como ilustrado na Figura 4.15(a), enquanto experimentalmente é realizado por meio de controle em malha fechada ilustrado na Figura 4.2. Já para o amplificador Raman distribuído experimental o controle em malha aberta é realizado com estimativa cega da 


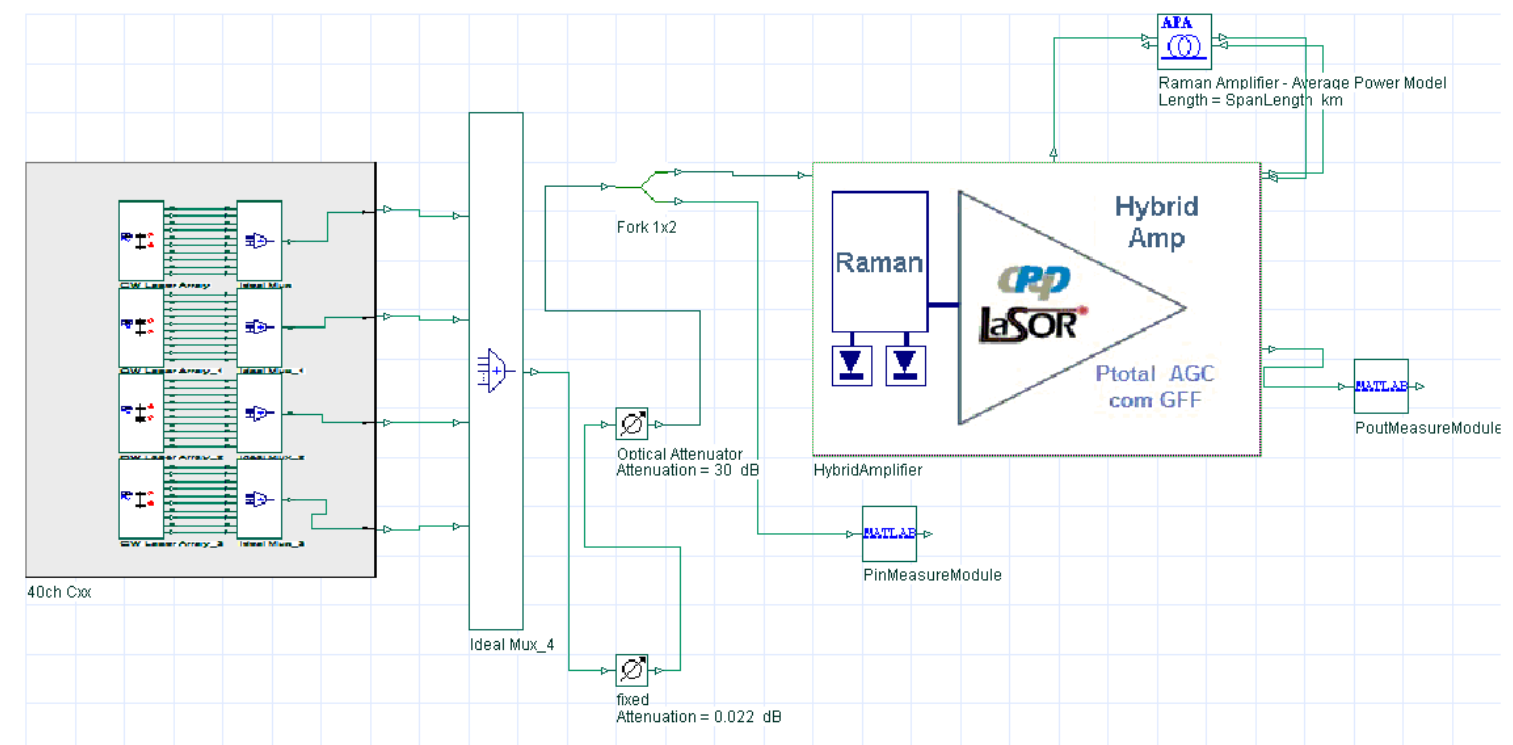

(a)

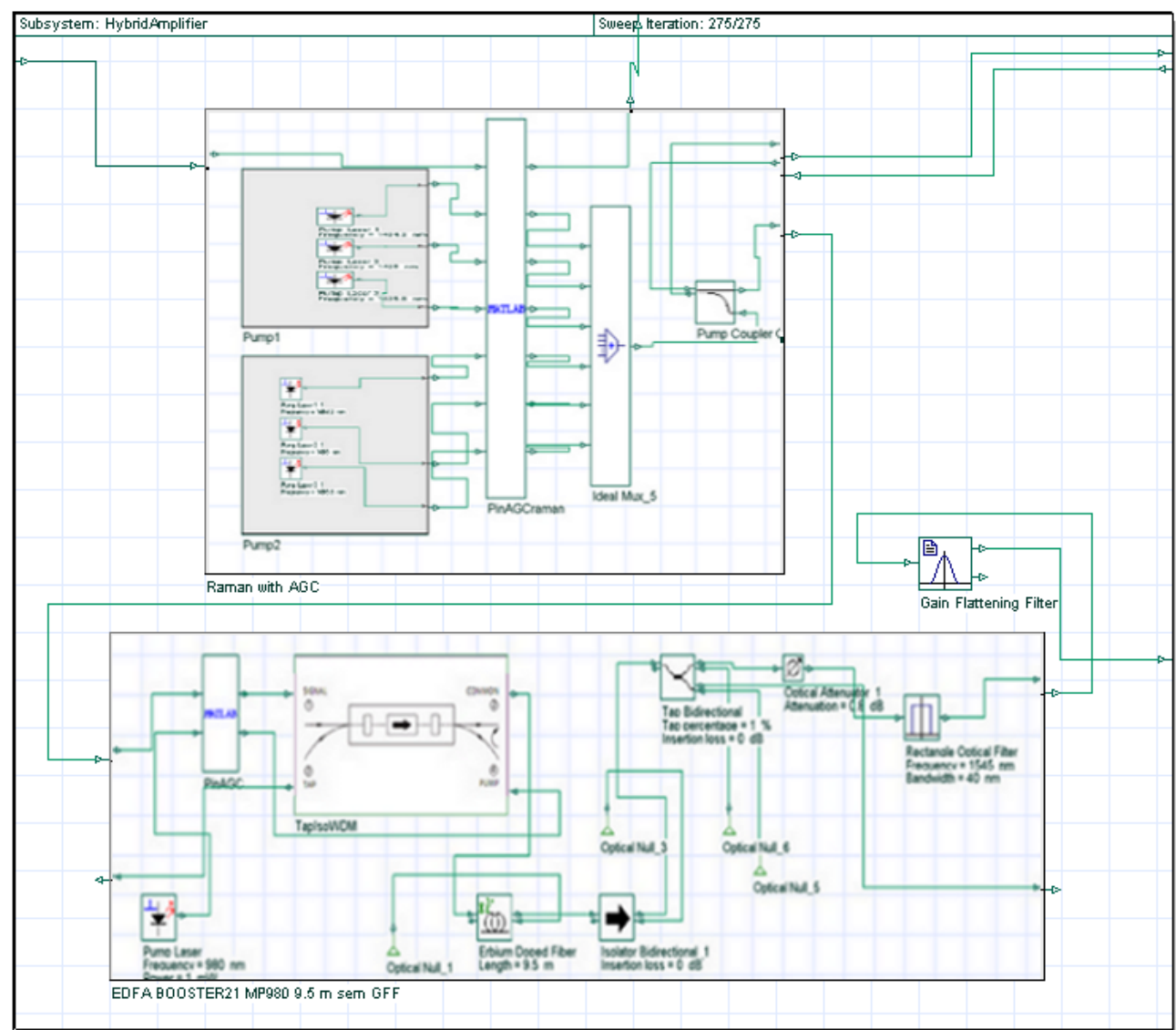

(b)

Figura 5.7: Paleta de simulação desenvolvida para avaliação do amplificador Híbrido (Raman/EDFA) (a) e detalhes internos do amplificador óptico híbrido (b) 
potência lançada como ilustrado na Figura 4.6, enquanto na simulação é utilizado o controle em malha aberta com estimativa direta da potência lançada como ilustrado na Figura 4.24(a).

Para o controle de ganho no amplificador híbrido simulado, as interfaces com o MATLAB $R$ ilustradas na Figura 5.7(b) representam os pontos onde os controles de ganho Raman e EDFA são executados.

Antes da realização do projeto do GFF para o amplificador híbrido, deve-se recordar que, de acordo com a malha de controle do amplificador híbrido ilustrada na Figura 5.2, o EDFA com AGC opera sempre em seu ganho nominal (13 dB), enquanto o amplificador Raman distribuído com AGC opera em uma faixa de ganhos alvo de 2-12 dB, resultando na faixa de ganhos controláveis requerida pela máscara de potência (15-25 dB) para o amplificador híbrido.

Para o projeto do GFF os pontos de saturação do amplificador para o ganho máximo ( $25 \mathrm{~dB}$ com potência de entrada de $-4 \mathrm{dBm}$ ) e mínimo ( $15 \mathrm{~dB}$ com potência de entrada de $6 \mathrm{dBm}$ ) de operação são escolhidos, pois estes pontos apresentam a máxima diferença entre os perfis espectrais de ganho, devido operação do amplificador Raman em seu menor (2 dB) e maior ganho de operação (12 dB) na topologia de amplificação híbrida. Com os pontos de operação determinados, a topologia de amplificação híbrida foi simulada utilizando 40 canais de entrada equalizados (192.1-196 THz), considerando uma fibra SSMF de $75 \mathrm{~km}$ com potência lançada na fibra de $21 \mathrm{dBm}$ ( $5 \mathrm{dBm}$ por canal), sem GFF, por meio da paleta ilustrada na Figura 5.7(a).

Após simulação dos pontos de saturação extremos da máscara de potência do amplificador híbrido, os picos do espectro de saída são capturados e normalizados. Em seguida o cálculo da perda do GFF por canal é realizado por meio da equação 5.7, visando minimizar a planicidade espectral de ganho ao longo de toda a máscara de potência. Por fim, ao finalizar o cálculo da perda média do GFF para todos os canais, o vetor é normalizado para minimizar a perda introduzida pelo GFF projetado. Após normalização da curva do GFF projetado para o amplificador híbrido, a perda total é calculada $(0,38 \mathrm{~dB})$ por meio da equação 5.8 .

$$
\begin{aligned}
& \operatorname{gffAttPerCh}_{\mathrm{dB}}=10 \cdot \log 10\left[\frac{10^{\left(\text {NormPeakMaxGain }_{\mathrm{dB}} / 10\right)}+10^{\left(\text {NormPeakMinGain }_{\mathrm{dB}} / 10\right)}}{2}\right] \\
& \operatorname{gffTotalLoss}_{d B}=10 \cdot \log 10\left(\frac{1}{\text { MaxPeakNum }} \cdot \sum_{i=1}^{\text {MaxPeakNum }_{10}\left(\frac{\text { peak }_{d B m}(i)-\text { peak }_{d B m}(\min )}{10}\right)}\right)
\end{aligned}
$$

Devido à perda introduzida pelo GFF $(0,38 \mathrm{~dB})$, que está posicionado na saída do amplificador híbrido, como ilustrado na Figura 5.7(b), o ganho nominal do estágio EDFA de $13 \mathrm{~dB}$ combinado com GFF implica em um ganho de operação inferior aos $13 \mathrm{~dB}$ de ganho requeridos. Desta forma, realiza-se o mesmo procedimento de projeto do GFF descrito anteriormente, porém aumenta-se o ganho de operação do estágio EDFA de acordo com a perda total devido ao perfil de atenuação do GFF, até que se obtenha 
um ganho de operação de 13 dB para o estágio EDFA combinado com o GFF projetado para o amplificador híbrido. Após duas iterações do projeto do GFF, foi obtido ganho de operação do EDFA com GFF do amplificador híbrido de $13 \mathrm{~dB}$, considerando um ganho nominal do EDFA de 13,5 dB em conjunto com o perfil do GFF do amplificador híbrido ilustrado na Figura 5.8, que introduz uma atenuação total de aproximadamente 0,5 dB.

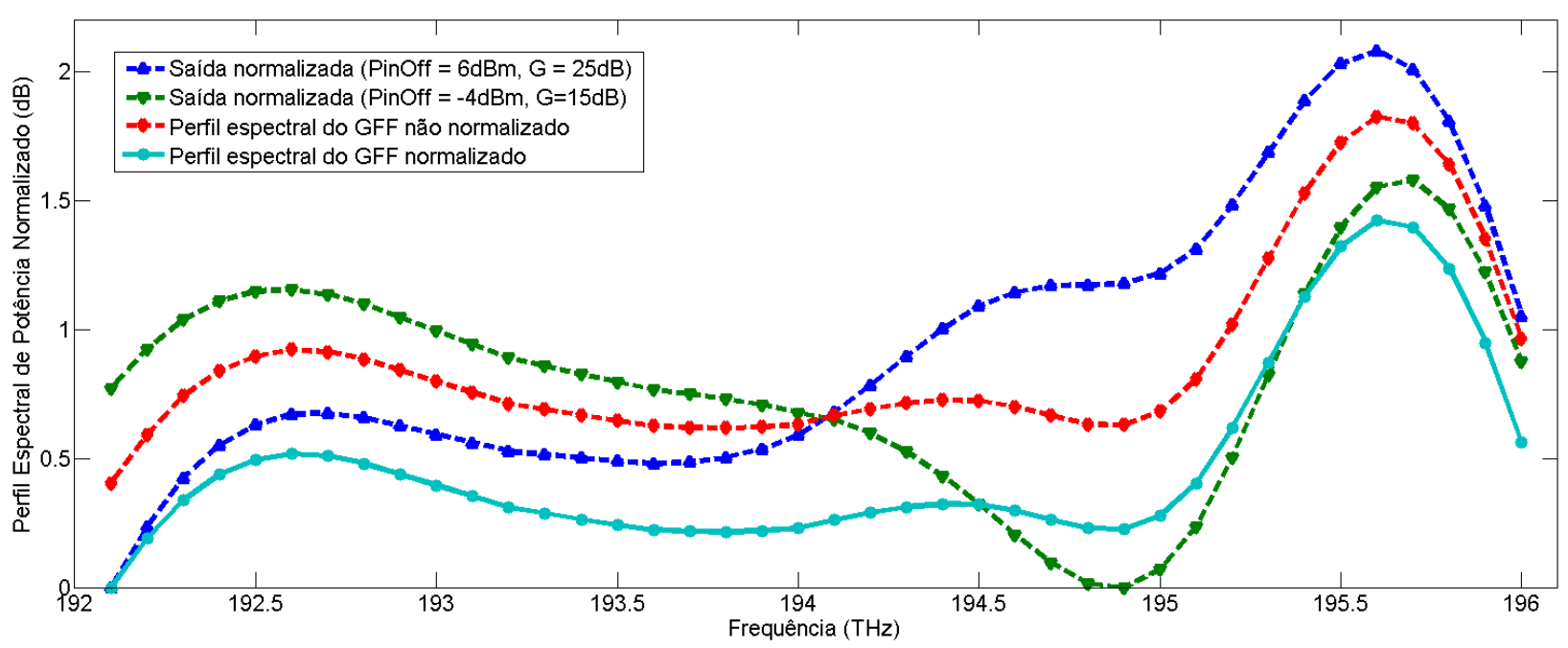

Figura 5.8: Perfil espectral de saída do amplificador híbrido com ganho de operação $25 d B$ (curva azul), com ganho de operação $15 \mathrm{~dB}$ (curva verde), média dos perfis espectrais ou perfil espectral do GFF não normalizado (curva vermelha) e perfil espectral final do GFF normalizado para o amplificador híbrido (curva azul claro).

São ilustrados na Figura 5.9 os perfis de ganho espectral produzidos pelo amplificador híbrido projetado com a metodologia descrita nesta seção (bombeios Raman 1425/1455 nm combinado com EDFA), o amplificador híbrido projetado sem a metodologia de projeto desta seção (bombeios Raman 1442/1447 nm combinado com EDFA) e somente o EDFA contido no amplificador híbrido projetado nesta seção (operando na mesma potência de entrada com ganho alvo nominal).

Com base nos perfis de ganho ilustrados, observa-se que um GFF desenvolvido para o amplificador híbrido projetado com a metodologia descrita nesta seção, introduz a menor perda para planificação espectral do ganho, quando comparado com o GFF projetado para o amplificador híbrido sem a metodologia de projeto desta seção ou somente o EDFA contido no amplificador híbrido desta seção.

Neste caso, considerando somente o EDFA (9,5m de EDF) a perda média introduzida pelo GFF projetado somente para planificação do perfil espectral no ganho nominal (13 dB) foi de 1,35 dB. Já para amplificador híbrido composto pelo amplificador Raman 1442/1447 nm (amplificador com dois lasers de bombeio com melhor planicidade) combinado com o EDFA (9,5 m EDF) implica em um GFF projetado que produz uma atenuação total de 0,717 dB, enquanto para o amplificador híbrido projetado por meio da metodologia apresentada nesta seção obteve um GFF com atenuação total de 0,49 dB. Desta forma fica comprovada a eficácia da metodologia de projeto do amplificador híbrido otimizado descrito nesta seção.

O desempenho do amplificador óptico híbrido simulado nesta seção ao longo da máscara de potência será descrito ao longo da próxima seção, por já representar a análise de 


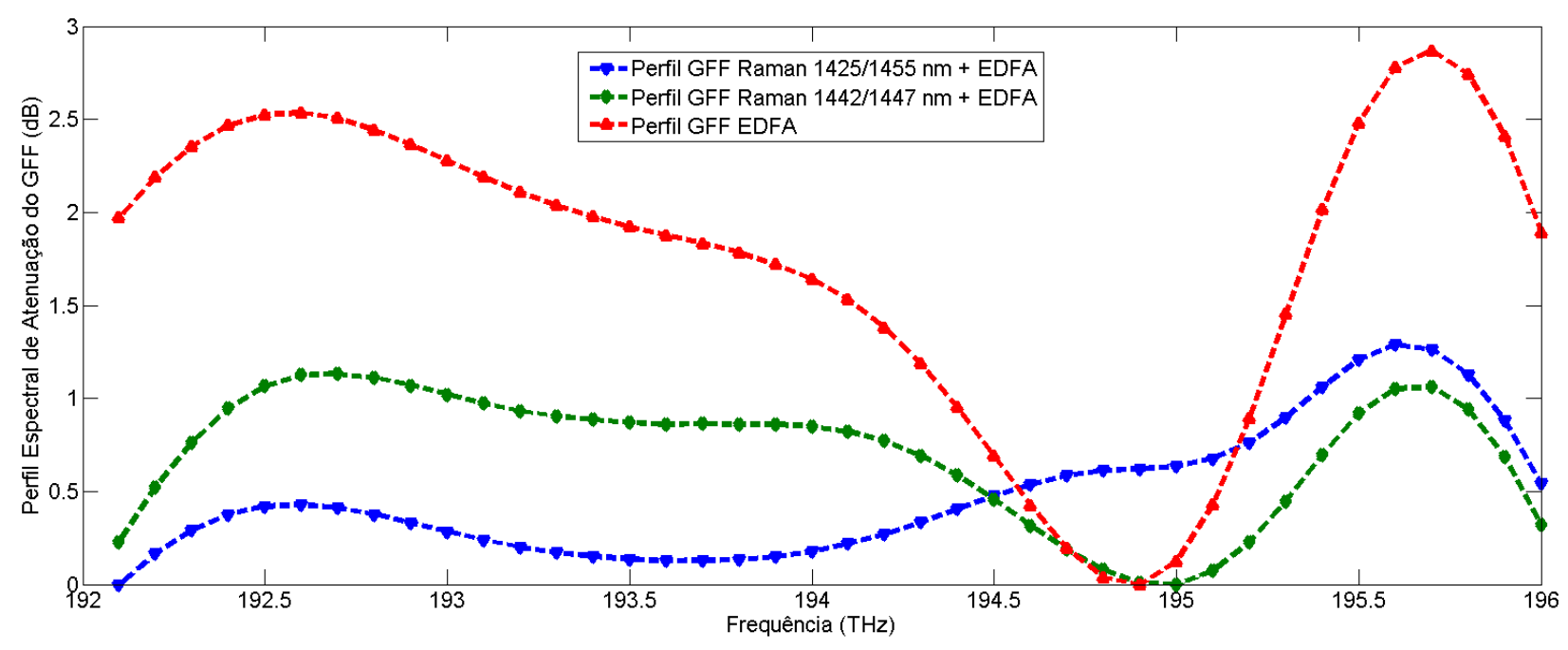

Figura 5.9: Perfil espectral de atenuação do GFF para um ponto particular visando realização de uma análise comparativa entre os amplificadores EDFA, amplificador híbrido Raman 1442/1447 $\mathrm{nm}$ combinado com EDFA (metodologia de projeto não otimizado) e o amplificador híbrido Raman 1425/1455 nm combinado com EDFA (obtido por meio da metodologia de projeto apresentada nesta seção).

desempenho em software de simulação óptica do amplificador em enlace único. Desta forma, as próximas seções descrevem o desempenho ao longo da máscara de potência do amplificador híbrido aqui projetado tanto em simulação óptica quanto experimentalmente em enlaces únicos, seguido do desempenho do amplificador híbrido versus EDFA-VOA-EDFA nos pontos críticos de desempenho em múltiplos enlaces nas redes DWDM reconfiguráveis.

\subsection{Desempenho em Software de Simulação Óptica}

Esta seção visa apresentar o desempenho do amplificador óptico híbrido com controle automático de ganho em software de simulação óptica, operando em um sistema DWDM reconfigurável composto por um único enlace de $75 \mathrm{~km}$ de fibra SSMF (G.652), e logo em seguida operando em sistemas DWDM reconfiguráveis compostos por múltiplos enlaces SSMF (75-125 km).

Para embasar a discussão acerca do desempenho do amplificador óptico híbrido em redes DWDM reconfiguráveis (enlace único e múltiplo), esta seção também tem como objetivo apresentar o desempenho da topologia de amplificação óptica mais utilizada atualmente para fornecer ganho espectral plano (EDFA-VOA-EDFA com controle de ganho acoplado) nas mesmas configurações de redes e realizar a comparação de desempenho entre as topologias de amplificação óptica testadas.

As caracterizações das topologias de amplificação óptica no enlace único de $75 \mathrm{~km}$ de fibra SSMF são apresentados por meio do desempenho de máscara de potência de figura de ruído, planicidade espectral de ganho, precisão de controle de ganho ao longo de toda região de operação do amplificador, em conjunto com a OSNR na saída (amplificador operando em saturação). Os desempenhos de ambos os amplificadores serão comparados e discutidos. 
A simulação em múltiplos enlaces de comunicações ópticas DWDM reconfiguráveis consideram enlaces de 75-125 km (escolhidos de acordo com os ganhos alvos de 15-25 $\mathrm{dB}$ ), onde, nos entroncamentos da rede, cada nó é composto pelo amplificador em teste (EDFA-VOA-EDFA ou amplificador híbrido), ROADM (sem e com equalização espectral na saída) e um EDFA de potência operando em seu ganho nominal plano aproximadamente igual à perda causada pelo ROADM ao sinal que o transpassa. Os desempenhos de ambos os amplificadores serão comparados em uma cascata de até 30 nós, e os resultados apresentados serão discutidos.

O amplificador óptico com controle de ganho acoplado e plano (EDFA-VOA-EDFA), utilizado nesta seção, é o mesmo amplificador desenvolvido na seção 4.3.3, porém operando na faixa de ganho de 15-25 dB.

\subsubsection{Enlace Único}

As paletas de teste das topologias de amplificadores ópticos a serem testadas em enlace único de $75 \mathrm{~km}$ de fibra SSMF são ilustradas na Figura 5.10. A avaliação de desempenho de cada topologia foi realizada utilizando uma fonte de sinais compostas por 40 lasers equalizados em potência, com frequências localizadas na banda $\mathrm{C}$ variando de $192,1 T H z(1560,61 \mathrm{~nm})$ à $196,0 T H z(1529,55 \mathrm{~nm})$ e espaçamento espectral de $100 \mathrm{GHz}$. Para avaliação das topologias do amplificador óptico híbrido e EDFA-VOA-EDFA, os mesmos foram avaliados obedecendo seus limites da máscara de potência: ganho mínimo $15 d B$, ganho máximo $25 \mathrm{~dB}$, potência total de saída máxima $21 \mathrm{dBm}$, potência total de entrada mínima de $-28 \mathrm{dBm}$ e granularidade de $1 \mathrm{~dB}$ para incremento da potência e ganho ao longo da caracterização da máscara de potência.

A Figura 5.10(a) ilustra a paleta de simulação de avaliação do amplificador óptico híbrido (Raman/EDFA) em um sistema óptico DWDM reconfigurável composto por um enlace de fibra SSMF e 40 canais (ao longo da Banda C). O amplificador híbrido inserido na Figura 5.10(a) é detalhadamente descrito na Figura 5.7(b), enquanto a Figura 5.10(b) ilustra a mesma paleta de simulação, porém para avaliação do amplificador linha (EDFAVOA-EDFA), que foi detalhadamente descrito pela Figura 4.17.

Visando fornecer informações mais precisas com relação a planicidade espectral de ganho dos amplificadores avaliados no sistema de comunicações ópticas DWDM, a reconfiguração do sistema com o decorrer da caracterização foi feita com base na variação da potência total dos canais transmitidos (mantendo os 40 canais sempre) em vez de realizar-se a remoção de canais (pois ambos visam a redução da potência), com o objetivo de evitar medidas enganosas de planicidade espectral de ganho, pois esta pode variar bruscamente dependendo da quantidade e alocação espectral dos canais sobreviventes. Então, ao considerar-se sempre 40 canais alocados ao longo da banda-C, teremos sempre a medida de planicidade espectral de ganho considerando toda a banda $\mathrm{C}$ (abrangendo sempre o pior caso).

Para o amplificador EDFA-VOA-EDFA avaliado no sistema de comunicações ópticas DWDM reconfigurável, foi considerado o enlace de $75 \mathrm{~km}$ de fibra SSMF (G.652), obtendo-se o resultado ilustrado na Figura 5.11, apresentado por meio das máscaras de potência de figura de ruído, planicidade espectral de ganho e precisão de controle 


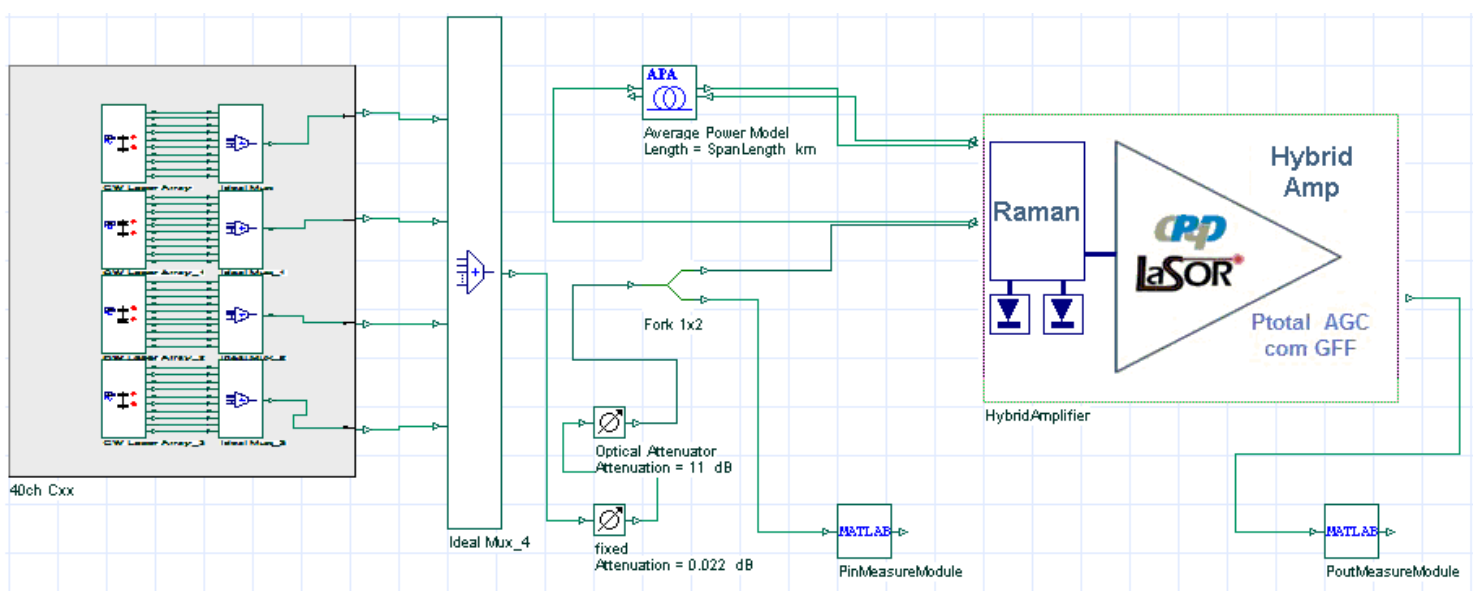

(a)

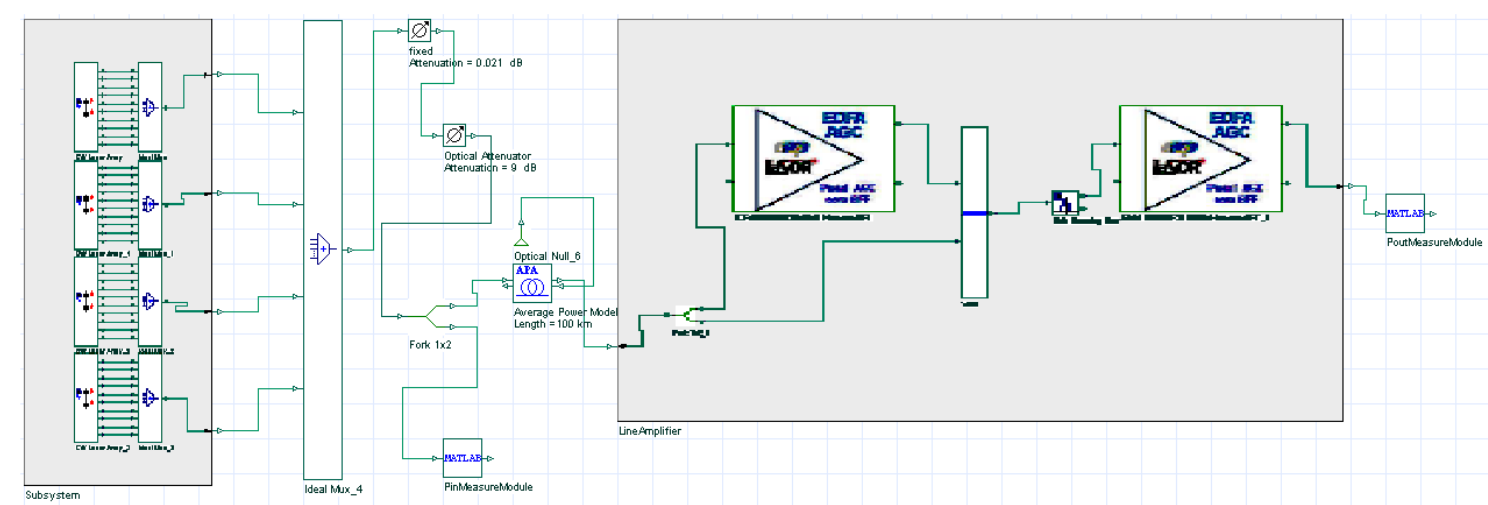

(b)

Figura 5.10: Paleta de simulação para caracterização/avaliação da propagação do sinal ao longo de um enlace de $75 \mathrm{~km}$ de fibra SSMF para o amplificador Híbrido (Raman/EDFA) (a) e para o amplificador EDFA-VOA-EDFA (b)

automático de ganho ao longo de toda região de operação do amplificador. Devido a entrada do enlace de teste com comprimento de $75 \mathrm{~km}$ antes do amplificador, foi necessário fornecer uma potência total de lançamento na fibra de até $21 \mathrm{dBm}$, para alcançar a potência mínima desejada $(6 \mathrm{dBm})$ após propagação ao longo do enlace, no pior caso.

Comparando o desempenho do EDFA-VOA-EDFA ilustrado na Figura $5.11 \mathrm{com}$ o desempenho do EDFA-VOA-EDFA ilustrado na Figura 4.20, nota-se claramente que o padrão da figura de ruído é o mesmo, porém, devido a mudança da faixa de operação de ganho de $17-27 d B$ para $15-25 d B$, a figura de ruído aumenta de $5,50-10,02 d B$ para $5,93-11,31 d B$, pois, para atingir essa faixa de ganho $(15-25 d B)$, o atenuador óptico variável aumenta sua atenuação, consequentemente aumentando o nível de figura de ruído.

Com relação à planicidade espectral de ganho, nota-se que o EDFA-VOA-EDFA apresenta desempenho de planicidade espectral aproximadamente igual ao do EDFA-VOAEDFA, quando o amplificador opera em potências de entrada total menor ou igual a $0 \mathrm{dBm}$, ou seja, potência lançada na fibra menor ou igual a $15 \mathrm{dBm}(-1 \mathrm{dBm}$ por canal), apresentando uma ondulação mínima de $0,23 d B$ ao longo dos $75 \mathrm{~km}$ de fibra (contra $0,01 \mathrm{~dB}$ sem a fibra) devido basicamente ao coeficiente de atenuação da fibra ser dife- 


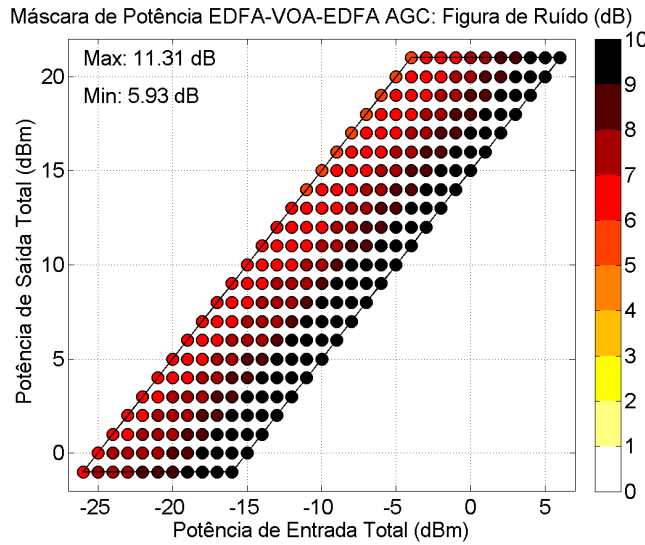

(a)

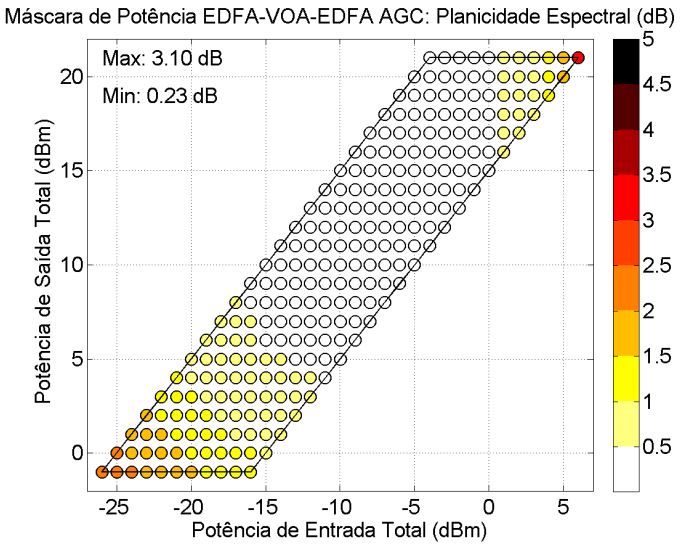

(b)

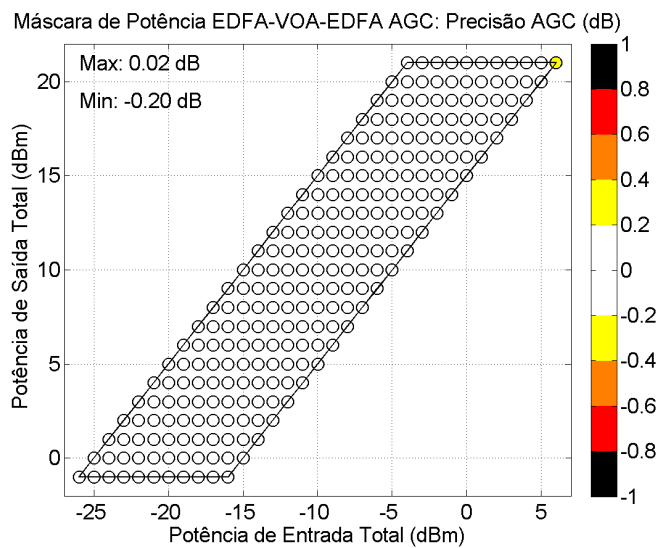

(c)

Figura 5.11: Máscara de potência do amplificador EDFA-VOA-EDFA testado em um enlace de comunicações ópticas apresentando desempenho de figura de ruído (a), planicidade espectral de ganho (b) e precisão do controle automático de ganho (c).

rente para cada comprimento de onda.

Porém com a fibra óptica (SSMF) no sistema, é necessário lançar 16-21 dBm (0-5 $\mathrm{dBm}$ por canal) para obter potência de entrada no amplificador de 1-6 dBm. Por esta razão, a excitação do efeito de ganho Raman entre canais (Headley e Agrawal, 2005) é bastante aumentada. Neste efeito, o mais longo comprimento de onda de sinal sofre ganho devido aos 39 comprimentos de onda anteriores, enquanto o comprimento de onda mais curto não sofre ganho algum devido não existirem canais anteriores a este comprimento de onda, aumentando a variação espectral de ganho em torno de 0,5 à $1,1 d B$. Somado ao fato de que os estágios de amplificação EDFA do EDFA-VOA-EDFA possuem ganho nominal $19 \mathrm{~dB}$ e potência máxima de saída $23 \mathrm{dBm}$, a planicidade espectral de ganho é garantida somente até a potência de entrada de $4 d B m(4+19=$ $23 \mathrm{dBm}$ ). Para as potências de 5 e $6 \mathrm{dBm}$ a topologia de amplificação EDFA-VOA-EDFA garante o ganho alvo, porém o erro de saturação implica em uma variação da planicidade espectral de ganho de até $2 \mathrm{~dB}$ adicionais.

Desta forma o amplificador EDFA-VOA-EDFA apresenta planicidade espectral de ganho de $0,23-3,10 d B$ na região de alta potência de entrada (maior que $0 \mathrm{dBm}$ ), enquanto na região de baixa potência de entrada $(-11 \mathrm{dBm})$ a planicidade espectral de ganho varia 
de 0,01-2, $63 d B$ como o EDFA-VOA-EDFA ilustrado na Figura 4.20.

O desempenho do amplificador óptico híbrido projetado por meio da metodologia de projeto apresentada na seção 5.3 em um enlace de comunicações ópticas DWDM reconfigurável é ilustrado na Figura 5.12 por meio das máscaras de potência de figura de ruído, planicidade espectral de ganho e precisão de controle automático de ganho ao longo de toda região de operação do amplificador. Assim como no teste da topologia EDFA-VOA-EDFA, devido a entrada do enlace de teste com comprimento de $75 \mathrm{~km}$ antes do amplificador, foi necessário fornecer uma potência total de lançamento na fibra de até $21 \mathrm{dBm}$, para alcançar a potência mínima desejada $(6 \mathrm{dBm}$ com lasers Raman desligados) na entrada do amplificador, no pior caso.

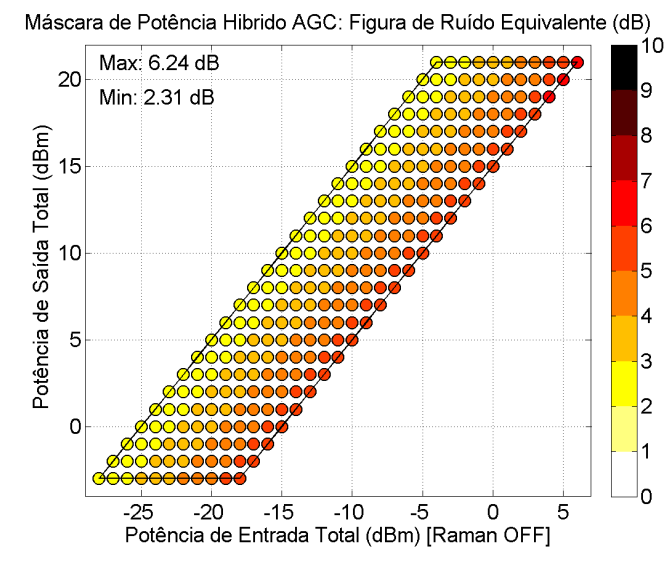

(a)

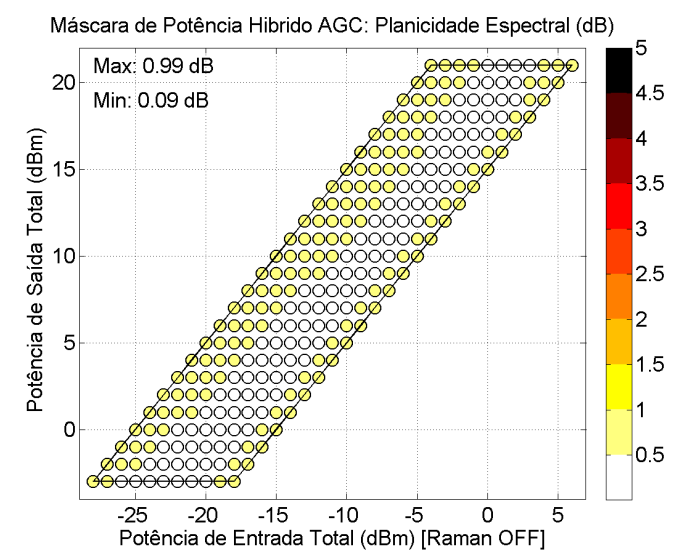

(b)

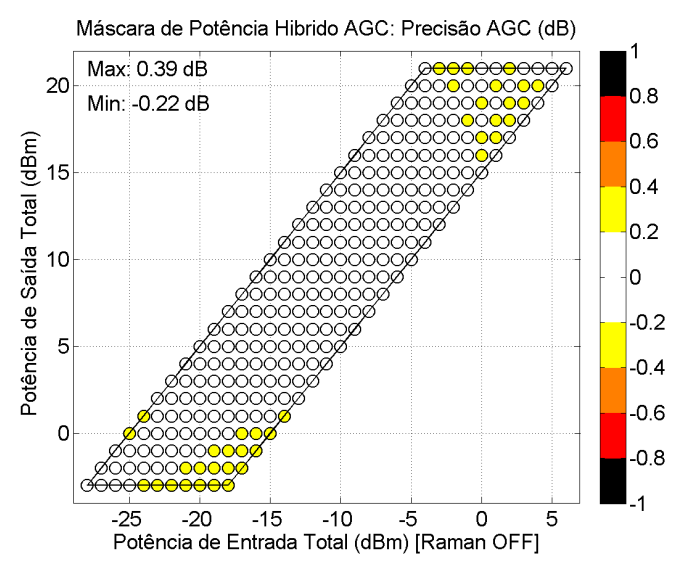

(c)

Figura 5.12: Máscara de potência do amplificador Híbrido testado em um enlace de comunicações ópticas apresentando desempenho de figura de ruido (a), planicidade espectral de ganho (b) $e$ precisão do controle automático de ganho (c).

Considerando os desempenhos de figura de ruído apresentados pelas máscaras de potências do amplificador EDFA-VOA-EDFA ilustrado na Figura 5.11 e o desempenho do amplificador híbrido ilustrado na Figura 5.12, a melhora de OSNR esperada em um sistema de um enlace pode ser calculado pela diferença entre os valores de figura de ruído nos pontos críticos dos amplificadores em questão.

Assim a melhora da OSNR esperada para o ponto P1 (ilustrado na Figura 4.7) com o uso do amplificador híbrido seria a diferença da figura de ruído de 11,31 dB (EDFA- 
VOA-EDFA) e 6,24 dB (híbrido), resultando em aproximadamente 5,07 $\mathrm{dB}$, enquanto para o ponto P2 (ilustrado na Figura 4.7) seria a diferença entre 6,81 dB e 2,38 dB, resultando em 4,43 dB, para o ponto P3 (ilustrado na Figura 4.7) seria a diferença entre $5,93 \mathrm{~dB}$ e 2,31 dB resultando em 3,62 dB, e para o ponto P4 (ilustrado na Figura 4.7) seria a diferença entre $5,92 \mathrm{~dB}$ e $2,44 \mathrm{~dB}$, resultando em 3,48 dB.

Para o teste do amplificador híbrido em um enlace de comunicações ópticas DWDM reconfigurável, foi obtido um desempenho de figura de ruído equivalente de 2,31 á $6,24 d B$, planicidade espectral de ganho de 0,09 á $0,99 d B$ e precisão de AGC de 0,39 á $-0,22 d B$ ao longo de toda região de operação da máscara de potência.

Uma equivalência entre a medida de figura de ruído do amplificador Raman distribuído, ou qualquer outro amplificador híbrido contendo a mesma tecnologia, com relação a figura de ruído de amplificadores discretos (EDFA), é obtida por meio da figura de ruído equivalente (Headley e Agrawal, 2005), permitindo-se a comparação de desempenho da figura de ruído equivalente do amplificador híbrido diretamente com à figura de ruído do EDFA.

Desta forma, nota-se claramente o benefício fornecido pelo amplificador híbrido em termos de figura de ruído com relação ao EDFA-VOA-EDFA, onde o amplificador híbrido apresenta uma melhora de 3,62 à $5,07 d B$, além de ser notável que, em termos de planicidade espectral de ganho, o amplificador óptico híbrido apresenta uma variação máxima ao longo da máscara de potência de $0,99 \mathrm{~dB}$ contra $3,10 \mathrm{~dB}$ do EDFA-VOA-EDFA.

$O$ único parâmetro que o amplificador óptico híbrido apresenta um desempenho inferior ao EDFA-VOA-EDFA é a precisão de AGC. Porém o amplificador híbrido apresenta um erro aceitável, menor que +/- 10\% ou +/- 0, 41dB.

A Figura 5.13 ilustra o ganho por canal para os amplificadores híbrido e EDFA-VOAEDFA avaliados no sistema de comunicações ópticas em ambiente de simulação, nos pontos críticos de desempenho (condições de contorno) analisando o ganho por canal fornecido pelos amplificadores com ganho alvo $15 d B$ para alta potência total de entrada/potência lançada na fibra $(6 \mathrm{dBm} / 21 \mathrm{dBm})$ ponto $\mathrm{P} 1$, e para uma baixa potência de entrada (-18 dBm para o amplificador híbrido e -16 dBm para o EDFA-VOA-EDFA) ponto P2, nota-se que ambos os amplificadores sofrem uma pequena dependência espectral $(0,5 \mathrm{~dB})$ devido ao efeito do ganho Raman entre canais causado pela alta potência lançada na fibra $(21 \mathrm{dBm})$. Porém, devido a forma do perfil espectral de saída do amplificador híbrido, a ondulação espectral de ganho varia somente de $0,87 d B$ para $0,98 d B$, enquanto no EDFA-VOA-EDFA varia de $1,19 d B$ para $3,10 d B$, devido principalmente ao erro de saturação por falta de potência de bombeio para fornecer o ganho nominal do EDFA-VOA-EDFA que garante o controle de ganho, porém não garante a planicidade espectral de ganho, impactando aproximadamente $2 \mathrm{~dB}$ na mesma.

Analisando o ganho por canal dos amplificadores testados para ganho alvo $25 d B$ ilustrado na Figura 5.13(a) para potência total de entrada de $-4 d B m$, ponto P3, e na Figura 5.13(b) para uma baixa potência de entrada de $-28 \mathrm{dBm}$ para o amplificador híbrido e $-26 d B m$ para o EDFA-VOA-EDFA, ponto P4, nota-se que para o ponto P3 a variação espectral de ganho do EDFA-VOA-EDFA $(0,23 \mathrm{~dB})$ é melhor que para o amplificador híbrido $(0,99 \mathrm{~dB})$. Porém, para o ponto $\mathrm{P} 4$, os ganhos por canal não atingem $25 \mathrm{~dB}$ devido 


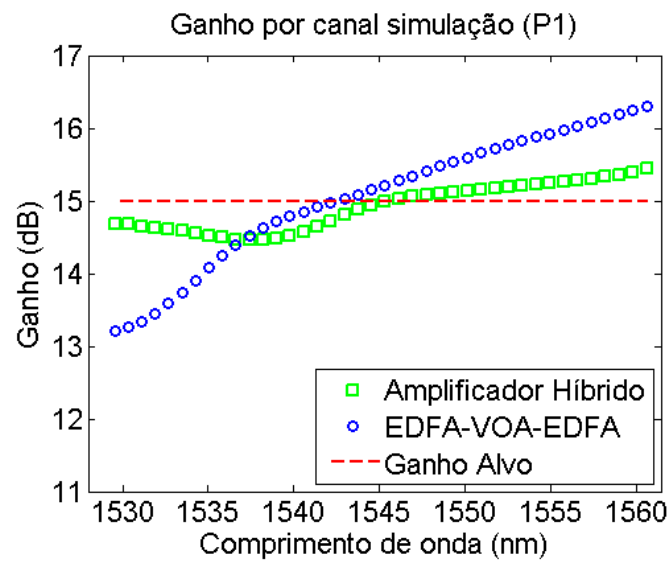

(a)

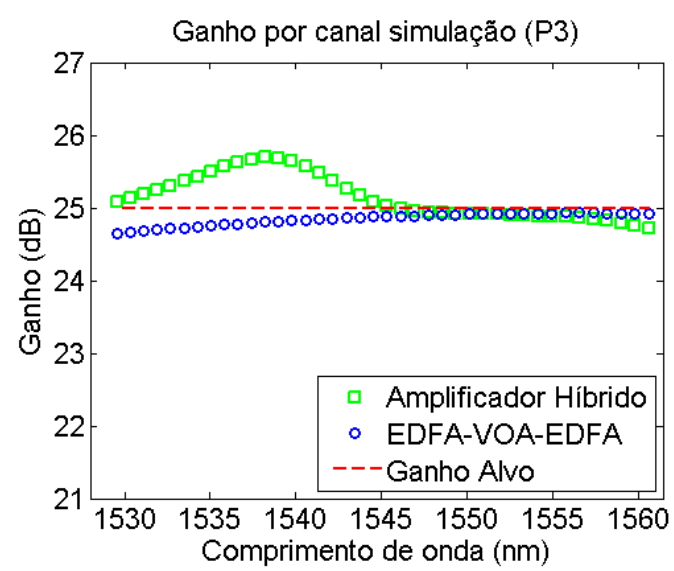

(c)

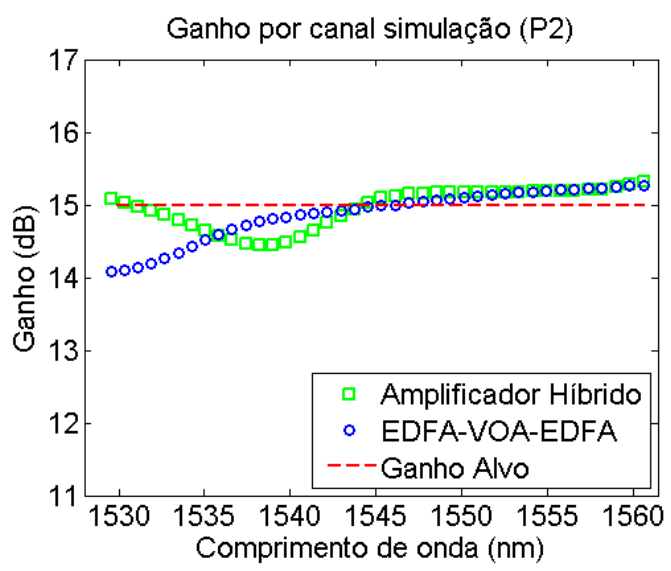

(b)

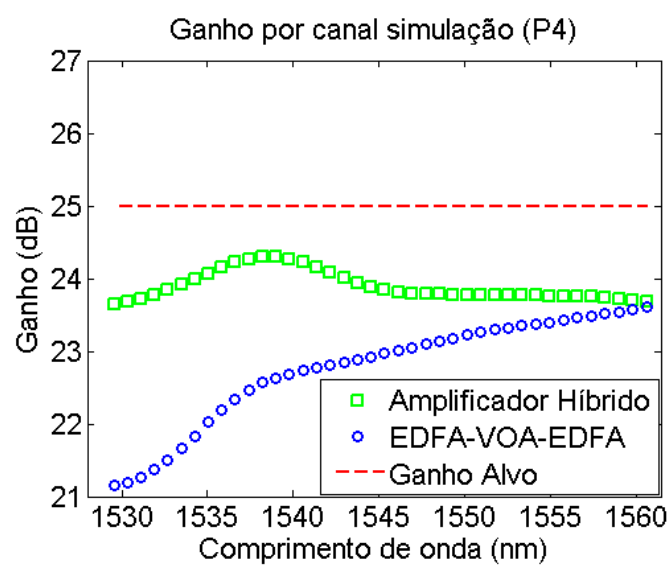

(d)

Figura 5.13: Ganho por canal dos amplificadores testados em simulação óptica nos pontos de críticos da máscara de potência: Amplificador saturado com ganho alvo $15 \mathrm{~dB}-\mathrm{P1}$ (a), amplificador não saturado com ganho alvo $15 \mathrm{~dB}$ - P2 (b), amplificador saturado com ganho alvo $25 \mathrm{~dB}$ - P3 (c), amplificador não saturado com ganho alvo $25 \mathrm{~dB}-\mathrm{P} 4$ (d). 
ao nível de ASE, mas o amplificador híbrido chega bem mais próximo do alvo que o EDFA-VOA-EDFA, com ondulação espectral de ganho de $0,97 d B$ em comparação com uma ondulação de $2,63 d B$ para o EDFA-VOA-EDFA devido ao erro de saturação, pois a potência mínima de bombeio que o mantém ligado fornece ganho além do ganho nominal. Com a correção do ganho alvo no EDFA-VOA-EDFA, a planicidade espectral de ganho do mesmo é afetada neste ponto em torno de 2,4 dB.

A Figura 5.14 ilustra a relação sinal-ruído óptica (OSNR) como função do comprimento de onda para os amplificador híbrido e o amplificador EDFA-VOA-EDFA, avaliados sistemicamente (enlace único) em ambiente de simulação nos mesmos pontos críticos de desempenho da máscara de potência apresentados anteriormente.

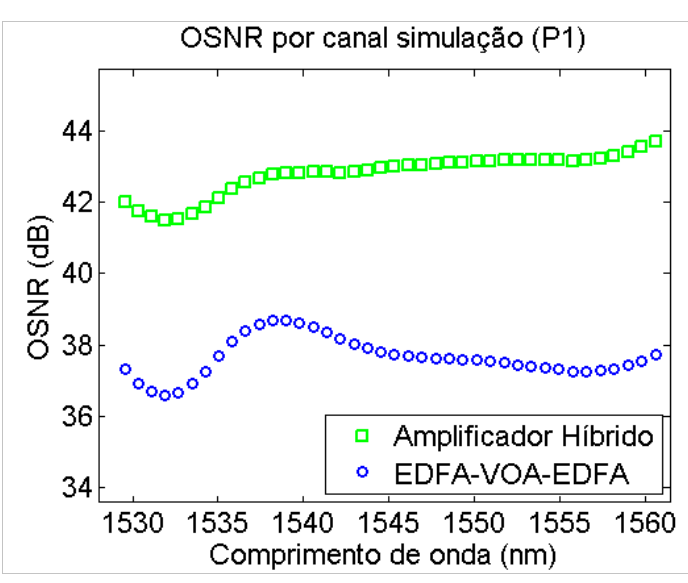

(a)

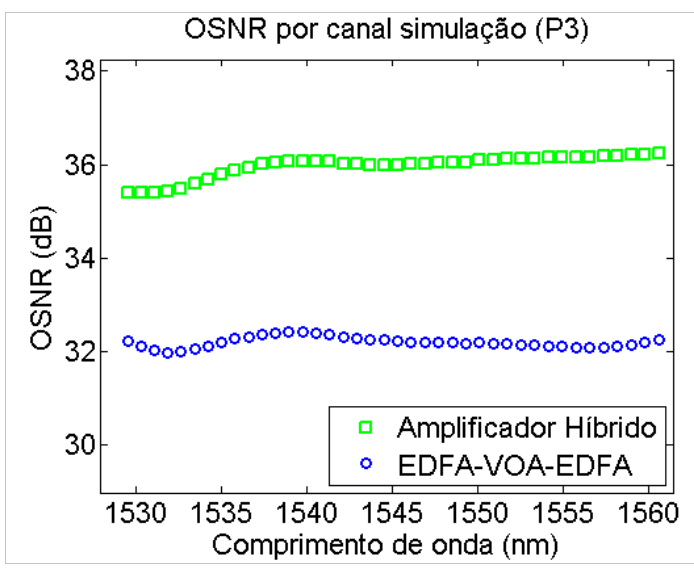

(c)

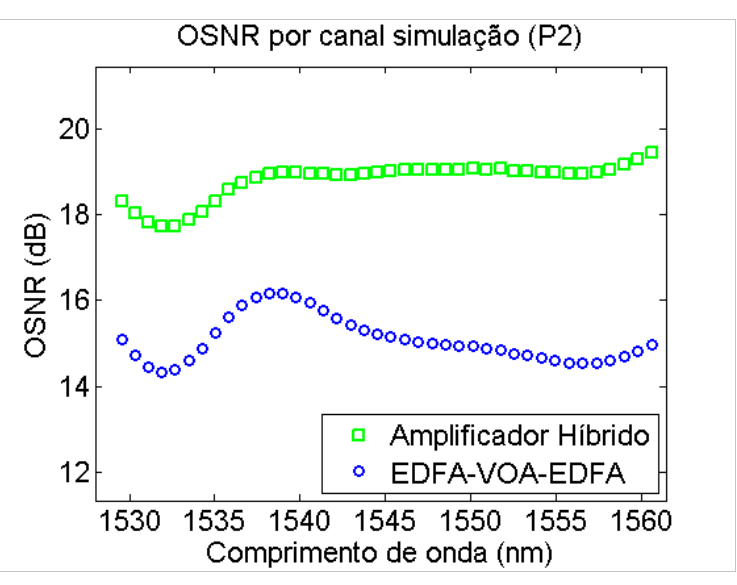

(b)

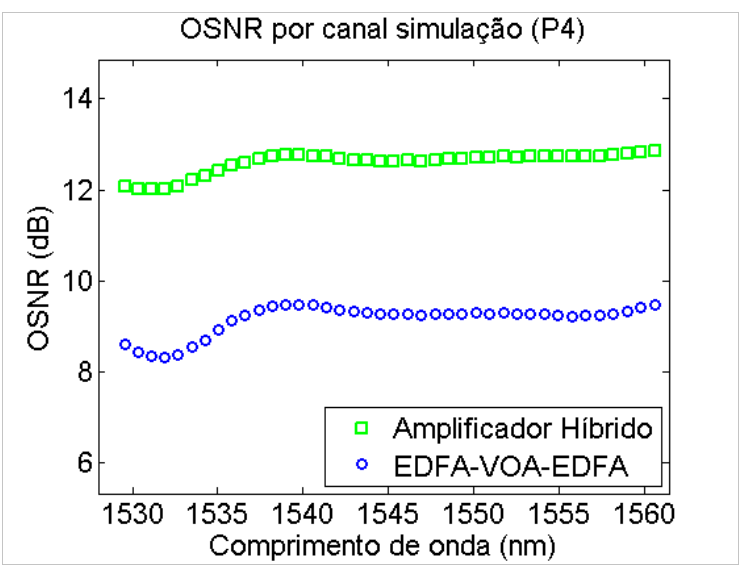

(d)

Figura 5.14: OSNR dos amplificadores testados em simulação óptica nos pontos de críticos da máscara de potência: Amplificador saturado com ganho alvo 15 dB - P1 (a), amplificador não saturado com ganho alvo $15 d B$ - P2 (b), amplificador saturado com ganho alvo $25 d B$ - P3 (c), amplificador não saturado com ganho alvo $25 \mathrm{~dB}-\mathrm{P} 4$ (d).

Na Figura 5.14 são apresentado para os pontos críticos ou condições de contorno de desempenho na máscara de potência P1 e P2 (para o ganho $15 \mathrm{~dB}$ ), P3 e P4 (para o ganho $25 \mathrm{~dB}$ ). A Tabela 5.1 apresenta os dados numéricos relevantes para comparação do desempenho das duas topologias testadas e ilustradas na Figura 5.14.

Comparando os resultados esperados (com base na figura de ruído) com a faixa que vai do mínimo ao máximo aumento de OSNR apresentado para os valores de OSNR 
Tabela 5.1: OSNR média, mínima e máxima para cada topologia de amplificação simulada e seu comparativo (aumento de OSNR).

\begin{tabular}{|c|c|c|c|c|c|}
\hline Amplificador & $\begin{array}{c}\text { OSNR } \\
\text { Média (dB) }\end{array}$ & $\begin{array}{c}\text { OSNR } \\
\text { Mín. (dB) }\end{array}$ & $\begin{array}{c}\text { OSNR } \\
\text { Máx. (dB) }\end{array}$ & $\begin{array}{c}\text { Aumento Mín. } \\
\text { OSNR (dB) }\end{array}$ & $\begin{array}{c}\text { Aumento Máx. } \\
\text { OSNR (dB) }\end{array}$ \\
\hline 2xEDFA-VOA P1 & 37,52 & 35,79 & 38,32 & - & - \\
\hline Híbrido P1 & 42,78 & 41,49 & 43,70 & 4,49 & 5,75 \\
\hline 2xEDFA-VOA P2 & 15,08 & 14,26 & 16,16 & - & - \\
\hline Híbrido P2 & 18,79 & 17,72 & 19,45 & 2,80 & 4,47 \\
\hline 2xEDFA-VOA P3 & 32,19 & 31,86 & 32,38 & - & - \\
\hline Híbrido P3 & 35,97 & 35,39 & 36,35 & 3,34 & 4,02 \\
\hline 2xEDFA-VOA P4 & 10,75 & 9,92 & 11,08 & - & - \\
\hline Híbrido P4 & 13,20 & 12,62 & 13,46 & 2,28 & 2,71 \\
\hline
\end{tabular}

de saída das topologias de amplificação testada, tem-se para o ponto P1 uma faixa de aumento de OSNR de 4,49 a 5,75 dB, onde o resultado esperado de 5,07 dB situa-se dentro da faixa. O mesmo ocorre para o ponto P3 (3,62 dB esperado encontra-se na faixa de 3,34 à 4,02 $\mathrm{dB}$ ), para o ponto $\mathrm{P} 2$ o valor esperado situa-se no limite superior da faixa (4,43 dB esperado encontra-se na faixa de 2,80 à 4,47 dB), e para o ponto $\mathrm{P} 4$ o valor esperado não encontra-se na faixa medida $(3,48 \mathrm{~dB}$ fora da faixa de 2,28 à 2,71 $\mathrm{dB}$ ), mostrando assim que a diferença entre as figuras de ruído entre amplificadores é bom para estimação da melhora de OSNR quando o mesmo opera em saturação, porém não é tão eficiente quando o mesmo opera na região de pequenos sinais.

Observando-se a Tabela 5.1, nota-se claramente que o amplificador híbrido provê um aumento de OSNR do sinal com relação ao amplificador EDFA-VOA-EDFA ao longo da máscara de potência de operação, apresentando no mínimo $2,28 d B$ de melhora na OSNR, chegando até $5,75 \mathrm{~dB}$ de OSNR, comprovando a eficácia do amplificador híbrido.

Nota-se também, por meio da Tabela 5.1, que, para o ponto mais crítico da máscara de potência em termos de OSNR (ponto P4), o amplificador híbrido fornece no mínimo $12,62 d B$ de OSNR enquanto o EDFA-VOA-EDFA fornece no mínimo 9,92dB de OSNR. Desta forma, de acordo com a OSNR necessária para recepção de canais $112 \mathrm{~Gb} / \mathrm{s}$ (INC, 2011) (OSNR mínima 12,6 dB), o amplificador híbrido oferece ao longo de toda a máscara de potência a OSNR necessária recepção do sinais de $112 \mathrm{G}$ enquanto o EDFA-VOAEDFA não o faz.

Além disso, por meio da comparação da OSNR necessária para recepção de sinais $112 \mathrm{G}$ com relação a OSNR necessária para recepção de sinais 10G OOK, que necessitam de 11,2dB de OSNR para recepção dos canais livre de erros (Uniphase, 2009), um sistema óptico que encontra-se no limite utilizando amplificadores EDFA-VOA-EDFA (apresentando OSNR mínima para recepção de canais 10G), precisa melhorar no mínimo $1,4 d B$ de OSNR para todos os canais, para permitir evolução do sistema de 10G para $112 \mathrm{G}$. Isto pode ser facilmente obtido por meio da substituição dos amplificadores EDFA-VOA-EDFA por amplificadores híbridos, sem necessidade de troca de fibra óptica.

A Figura 5.15 ilustra as OSNRs apresentadas para todos os canais nos pontos de saturação do amplificador híbrido e amplificador EDFA-VOA-EDFA para todos os ganhos 
OSNR de saída para amplificador saturado simulado

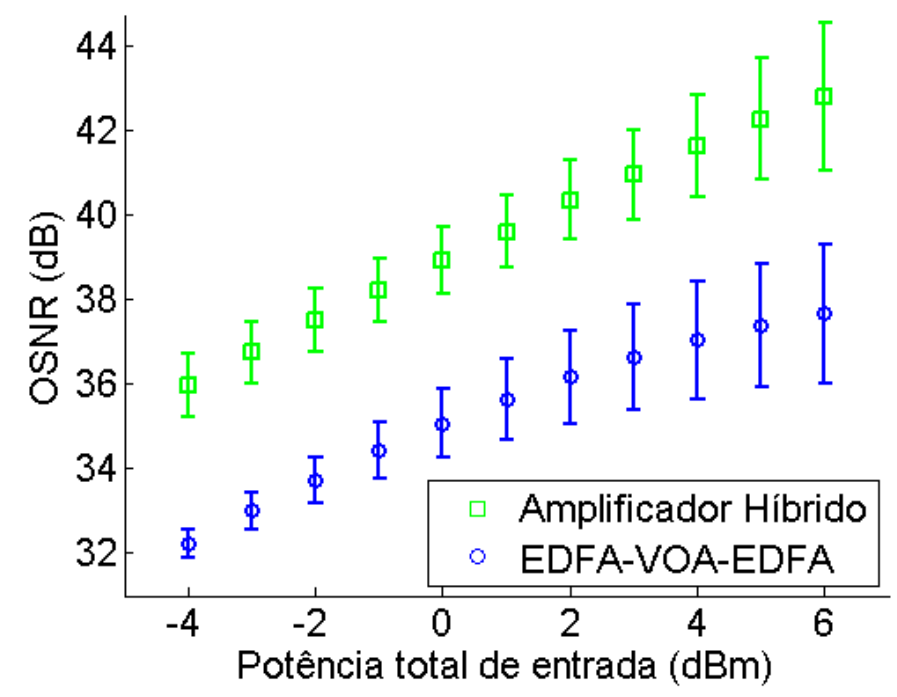

Figura 5.15: OSNR de saída dos amplificadores híbrido e EDFA-VOA-EDFA para todos os ganhos alvo testados com os amplificadores operando em saturação.

de operação (pontos da esquerda para direita representam de $25 \mathrm{~dB}$ até $15 \mathrm{~dB}$ de ganho com granularidade de $1 \mathrm{~dB}$ ).

A dupla formada pelos primeiros e últimos pontos (ponto azul para o EDFA-VOAEDFA e ponto verde para amplificador híbrido), representam os pontos críticos P3 e $\mathrm{P} 1$ respectivamente, simbolizando os pontos de pior e melhor OSNR. Por meio da Figura 5.15, nota-se que para os amplificadores testados em simulação operando em modo saturado, o amplificador híbrido apresenta uma melhora de OSNR mínima de 3,34 dB (para $15 \mathrm{~dB}$ de ganho de operação) e uma melhora máxima de 5,75 dB (para $25 \mathrm{~dB}$ de ganho de operação), representando assim notavelmente o incremento de performance em saturação do amplificador híbrido com relação ao amplificador EDFA-VOA-EDFA.

\subsubsection{Múltiplos Enlaces Concatenados (Rede DWDM Reconfigurável)}

Nesta seção serão avaliados, em simulação óptica, o desempenho dos amplificadores EDFA-VOA-EDFA projetados no capítulo 4 e adaptado para faixa de ganhos alvo deste capítulo na seção 5.4, e o amplificador óptico híbrido (Raman/EDFA) projetado na seção 5.3, em redes DWDM reconfiguráveis baseadas em múltiplos enlaces com nós de entroncamento compostos por pré-amplificadores híbridos ou EDFA-VOA-EDFA.

O objetivo desta seção é avaliar no mesmo cenário de rede óptica DWDM reconfigurável e vários ganhos de operação, qual o alcance obtido pelas estruturas de amplificação híbrida e EDFA-VOA-EDFA, mensurando o benefício do amplificador óptico híbrido sobre o EDFA-VOA-EDFA em termos de número de enlaces cascateados para uma mesma qualidade de sinal (OSNR).

A Figura 5.16 ilustra o orçamento de potência para o teste dos amplificadores híbrido e EDFA-VOA-EDFA em múltiplos enlaces/nós de rede óptica DWDM reconfigurável. Para avaliação do impacto nos sinais em toda banda C, a mesma foi totalmente populada utilizando uma fonte de sinais de entrada composto por 40 Lasers com potência - 12 dBm e frequência de 192, 1 THz até 196, 0 THz (espaçamento de $100 \mathrm{GHz}$ ). 


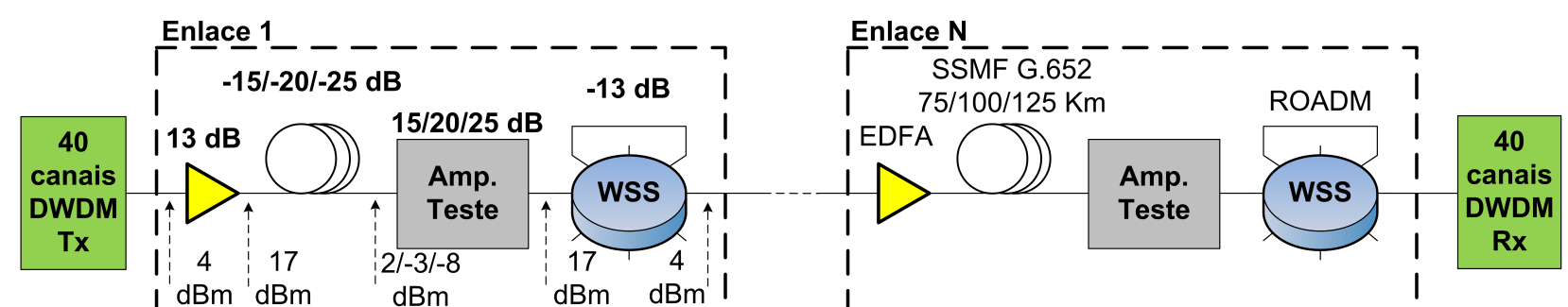

Total: $4 \mathrm{dBm}$

$(-12 \mathrm{dBm} /$ canal $)$

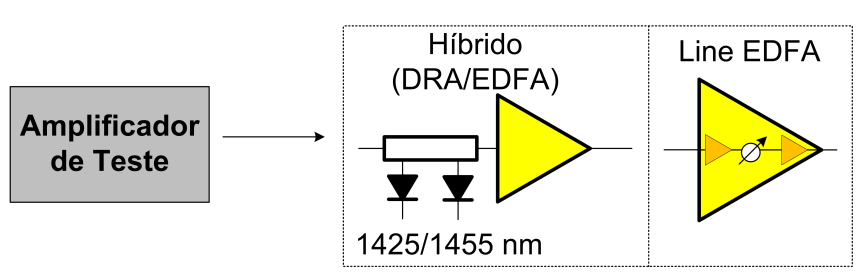

Figura 5.16: Diagrama unifilar da rede óptica DWDM reconfigurável composta por múltiplos enlaces, para teste de desempenho do amplificador híbrido e amplificador EDFA-VOA-EDFA.

Na Figura 5.16, o amplificador de potência contido em cada nó (EDFA) fornece ganho espectral plano (ganho nominal) para o ganho alvo de $13 \mathrm{~dB}$, visando compensar a perda de remoção (perda de um splitter 1x5, 7 dB) e adição (perda de inserção chave WSS 1x5, $6 \mathrm{~dB}$ ) do ROADM, resultando em $13 \mathrm{~dB}$ de perda, devido à ligação em pass-through realizada para que o sinal removido seja re-inserido no mesmo grau e siga adiante na rota, resultando assim em uma potência lançada na fibra de $17 \mathrm{dBm}(1 \mathrm{dBm}$ por canal, potência próxima da ideal para mitigação de efeitos não lineares durante a propagação do sinal da fibra).

Ainda na Figura 5.16, o comprimento do enlace (SSMF G.652, com 0,2 dB/km de atenuação) que se traduz consequentemente em sua atenuação, é dimensionado para o ganho alvo a ser testado pelas topologias de amplificação em simulação óptica. Desta forma, quando o amplificador a ser testado estiver ajustado para o controle de um ganho alvo de $15 \mathrm{~dB}$, o enlace será de $75 \mathrm{~km}$ de fibra SSMF, resultando em $15 \mathrm{~dB}$ de atenuação, e assim consequentemente para $20 \mathrm{~dB}(100 \mathrm{~km})$ e $25 \mathrm{~dB}(125 \mathrm{~km})$.

Desta forma, o orçamento de potência é descrito pela potência total de $4 \mathrm{dBm}$ na entrada do EDFA, que, ao amplificar com ganho plano de 13 dB lança uma potência total na fibra de $17 \mathrm{dBm}$, a qual, considerando as atenuações de 15, 20 e $25 \mathrm{~dB}$, atenuam o sinal de total entrada do amplificador óptico EDFA-VOA-EDFA, ou ainda a potência de entrada com bombeios desligados no caso do amplificador híbrido para 2, -3 e $-8 \mathrm{dBm}$ respectivamente, que, amplificados pelos ganhos 15, 20 e $25 \mathrm{~dB}$ (dos amplificadores em teste), atingem $17 \mathrm{dBm}$, atenuado para $4 \mathrm{dBm}$ devido a $13 \mathrm{~dB}$ de perda da conexão de pass-through no ROADM WSS, finalizando o primeiro enlace e nó, e seguindo adiante até o número de enlaces desejado como alvo de simulação.

Desta forma, considerando as potências de entrada de 2, -3 e -8 dBm e seus respectivos ganhos de 15, 20 e $25 \mathrm{~dB}$, a Figura 5.17 ilustra os pontos nas suas respectivas máscaras de potência (denominando como ponto I, II e III para os ganhos alvo 15, 20 e $25 \mathrm{~dB}$, respectivamente), para cada topologia de amplificação óptica.

Considerando o diagrama da Figura 5.16 e os pontos de operação da Figura 5.17, a Figura 5.18 ilustra as paletas de simulação para ambas as topologias de amplificação a serem testadas. Para poder simular múltiplos enlaces com os amplificadores ópticos 


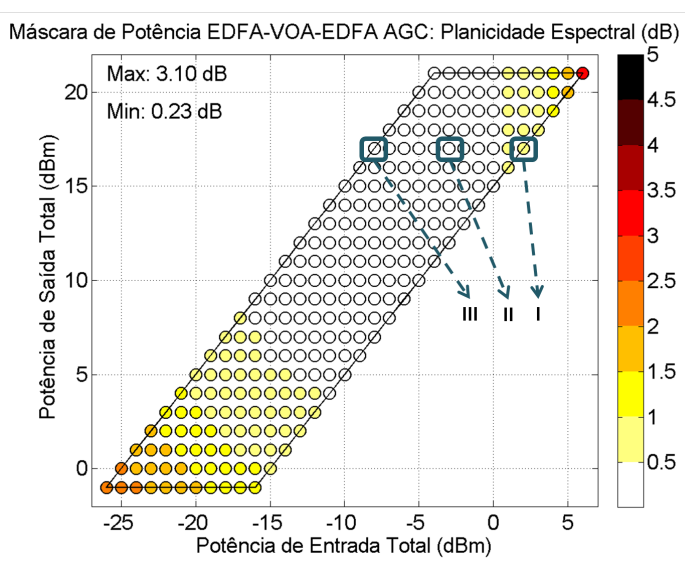

(a)

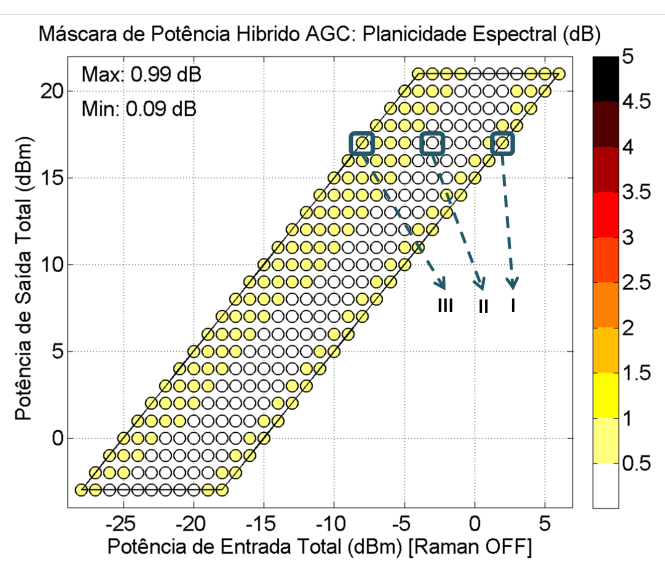

(b)

Figura 5.17: Pontos de operação das topologias de amplificação óptica ilustrados em sua respectiva máscara de potência para o amplificador EDFA-VOA-EDFA (a) e amplificador Híbrido Raman/EDFA (b).

EDFA-VOA-EDFA e Híbrido em simulação óptica evitando utilização excessiva de recursos computacionais, a simulação foi realizada em múltiplos de cinco enlaces. Ao fim de cada cinco enlaces, o sinal óptico de saída é salvo para servir como sinal de entrada para os próximos cinco enlaces.

Desta forma, a Figura 5.18 ilustra a paleta de simulação de múltiplos enlaces contendo o amplificador de teste, ilustrado na Figura 5.18(a). Nesta paleta tem-se a geração dos sinais de entrada compostos pela bancada de 40 lasers DWDM, o sistema DWDM reconfigurável, e o amplificador de teste é exemplificado pelo amplificador híbrido Raman/EDFA (no caso do teste do EDFA-VOA-EDFA, troca-se somente o amplificador de teste), enquanto a Figura 5.18(b) ilustra a paleta subsequentes, na qual, ao invés da geração dos sinais, tem-se uma interface para carregamento do sinal gravado ao fim de cada simulação anterior junto com o sistema e o amplificador de teste, exemplificado pelo amplificador EDFA-VOA-EDFA (no caso do teste do amplificador híbrido, troca-se somente o amplificador de teste). Os amplificadores a serem testados são os mesmos utilizados na seção 5.4.1 e detalhados e seções anteriores.

A simulação de múltiplos enlaces concatenados é realizado por meio das paletas ilustradas na Figura 5.18. Porém como ilustrado na Figura 5.17, existe um residual perfil espectral de ganho não equalizado (com pico máximo menor que $1 \mathrm{~dB}$ ), que pode afetar a avaliação de múltiplos enlaces dos amplificadores testados. Desta forma, o mesmo pode ser compensado por meio da equalização local de potência espectral em um nó ROADM, o que ocorre em redes reconfiguráveis. Então, a Figura 5.19 ilustra os perfis espectrais de atenuação impostos pelos ROADMs para manutenção do ganho espectral plano, e avaliação das topologias de amplificação inseridas nos sistemas ópticos de forma consistente.

Assumindo as premissas citadas acima, a simulação óptica é executada, considerando cada topologia de amplificação óptica seus respectivos ganhos-alvo e comprimentos de enlace. Para cada topologia de amplificação, ganho alvo e comprimento de enlace, foram simulados a propagação ao longo de 30 enlaces como ilustrado na Figura 5.16. 


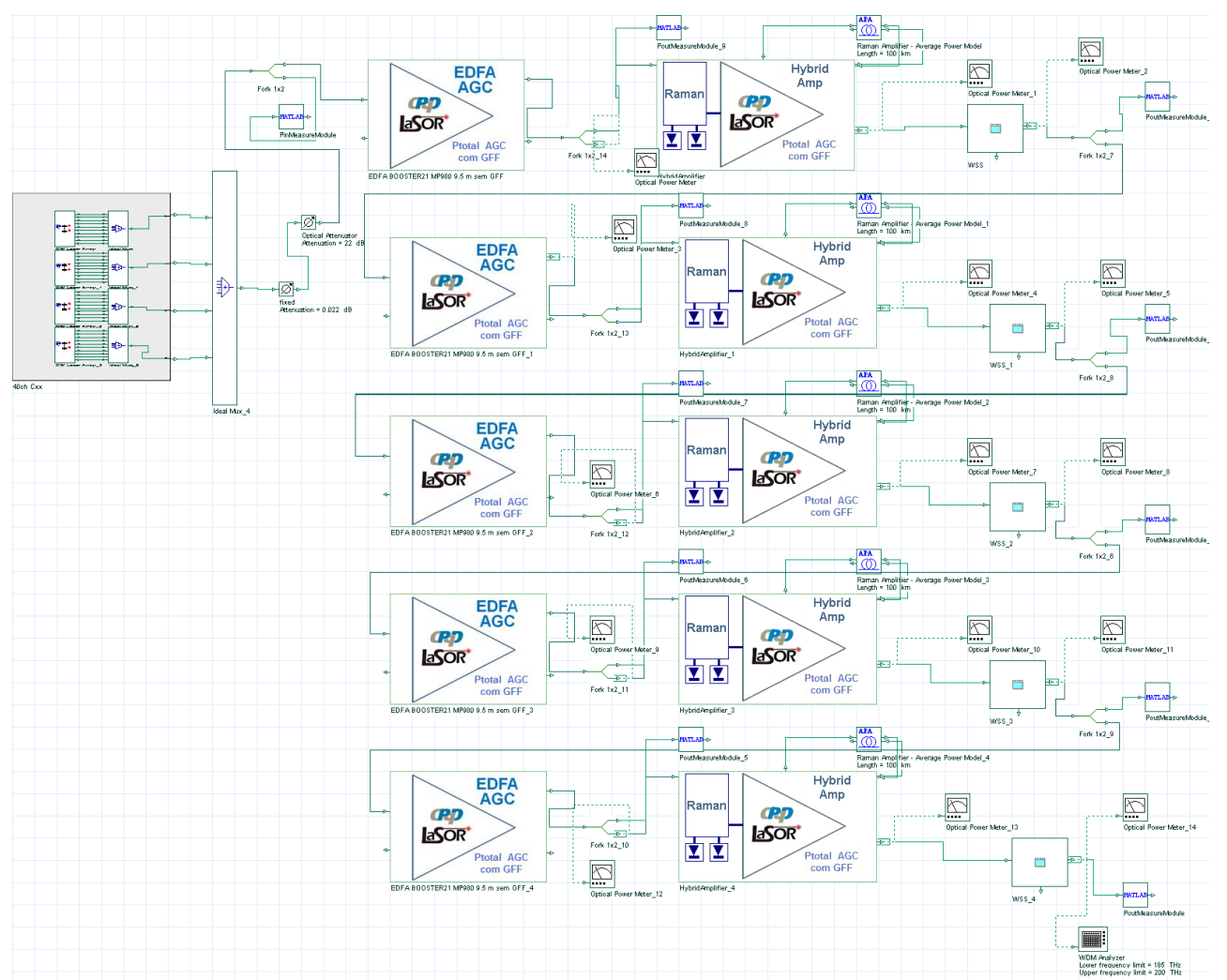

(a)

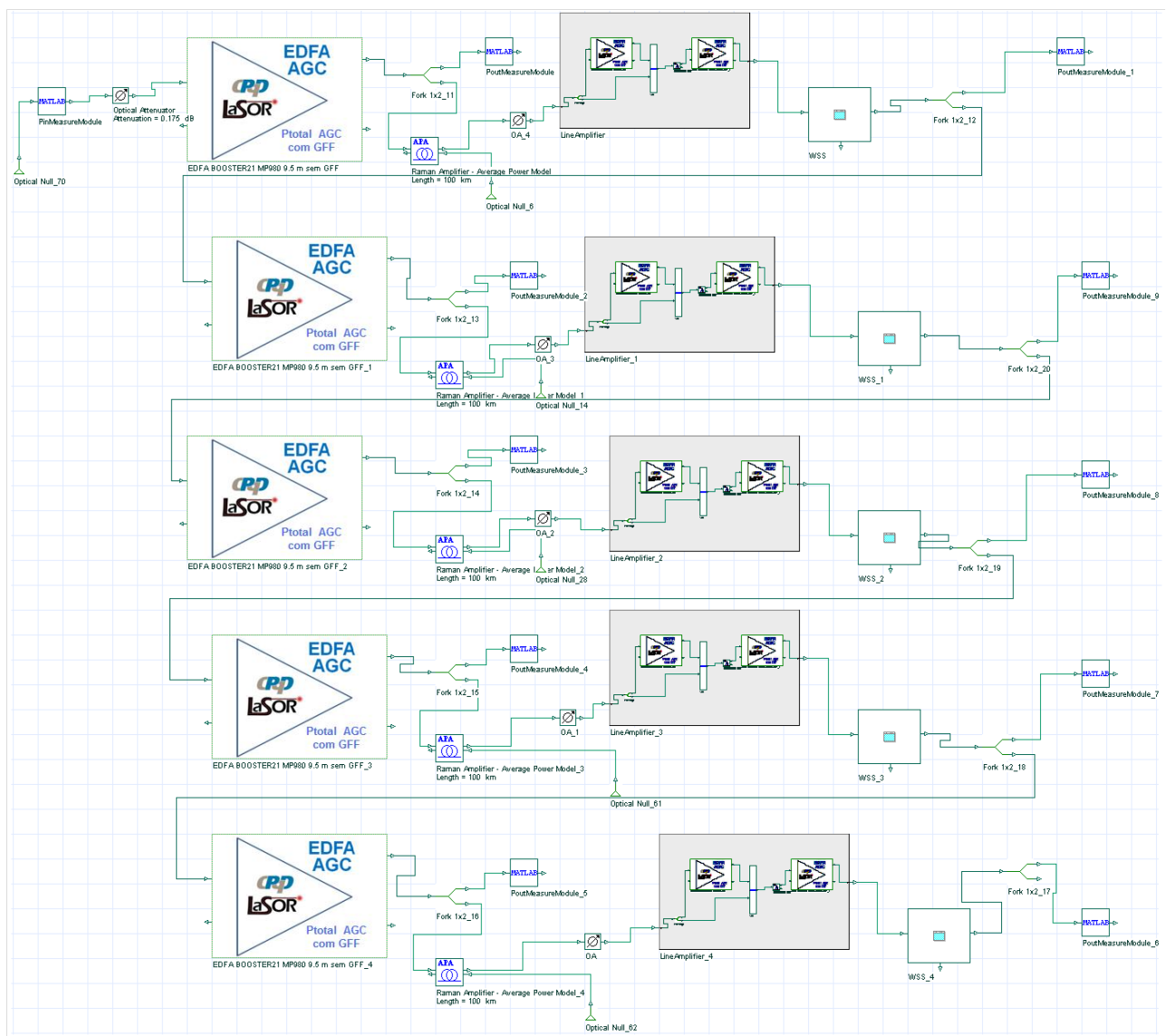

(b)

Figura 5.18: Paleta de simulação para avaliação da propagação do sinal nos primeiros cinco enlaces do sistema DWDM com o amplificador Híbrido (Raman/EDFA) (a), Paleta de simulação para avaliação dos enlaces seguintes com o amplificador EDFA-VOA-EDFA (b) 


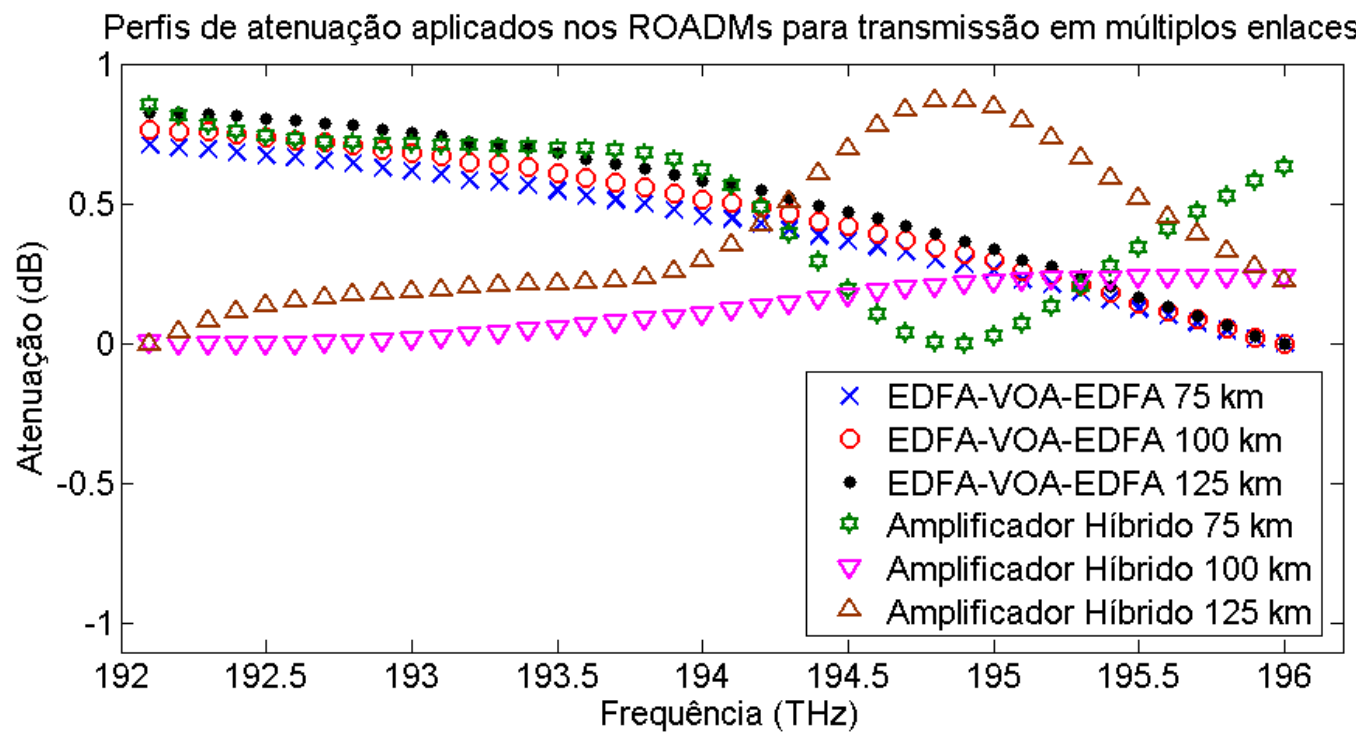

Figura 5.19: Perfis de atenuações espectrais aplicado pelos nós de ROADMs para equalização espectral de potência por canal em um nó.

Tabela 5.2: OSNR média e mínima no fim do $30^{\circ}$ enlace, e máxima para cada topologia de amplificação simulada e seu comparativo (aumento de OSNR).

\begin{tabular}{|c|c|c|c|c|}
\hline Amplificador & $\begin{array}{c}\text { OSNR média } \\
30^{\circ} \text { enlace } \\
(\mathrm{dB})\end{array}$ & $\begin{array}{c}\text { OSNR mínima } \\
30^{\circ} \text { enlace } \\
(\mathrm{dB})\end{array}$ & $\begin{array}{c}\mathrm{N}^{\circ} \text { enlace } \\
\text { 2xEDFA-VOA } \\
\text { mín. OSNR 30 } \\
\text { enl. híb. (dB) }\end{array}$ & $\begin{array}{c}\text { Alcance para } \\
\text { mínima OSNR } \\
30^{\circ} \text { enlace } \\
\text { híbrido (km) }\end{array}$ \\
\hline 2xEDFA-VOA 75km & 18,18 & 16,86 & 9 & 675 \\
\hline Híbrido 75km & 22,35 & 22,01 & - & 2250 \\
\hline 2xEDFA-VOA 100km & 16,27 & 15,04 & 11 & 1100 \\
\hline Híbrido 100km & 20,13 & 19,78 & - & 3000 \\
\hline 2xEDFA-VOA 125km & 13,57 & 13,10 & 11 & 1375 \\
\hline Híbrido 125km & 17,10 & 16,86 & - & 3750 \\
\hline
\end{tabular}

Os resultados são ilustrados e discutidos em seguida.

A Figura 5.20 ilustra a OSNR de saída (e a sua faixa de variação) ao longo dos múltiplos enlaces no mesmo sistema de comunicações ópticas ilustrado na Figura 5.16, apenas substituindo-se o amplificador de teste para o EDFA-VOA-EDFA (curva vermelha) e amplificador híbrido Raman/EDFA (curva azul), considerando os ganhos alvos de 15, 20 e $25 \mathrm{~dB}$ para seus respectivos comprimentos de fibra SSMF de 75, 100 e $125 \mathrm{~km}$.

A Tabela 5.2 resume os resultados obtidos para todos os pontos de operação de ganho alvo, comprimento de enlace e topologia de amplificação.

Analisando a Figura 5.20(a) e a Tabela 5.2, nota-se que os sistemas ópticos com topologia de amplificação híbrida com enlace de $75 \mathrm{~km}$ de SSMF e ganho $15 \mathrm{~dB}$, atingem o trigésimo enlace com 4,17 dB de OSNR média adicional ao mesmo sistema com amplificadores EDFA-VOA-EDFA, que mantem a mesma qualidade de sinal ao propagar ao longo de somente nove enlaces, fazendo com que o sistema com o amplificador híbrido alcance $2250 \mathrm{~km}$ contra $675 \mathrm{~km}$ do mesmo com EDFA-VOA-EDFA (incremento de 1575 


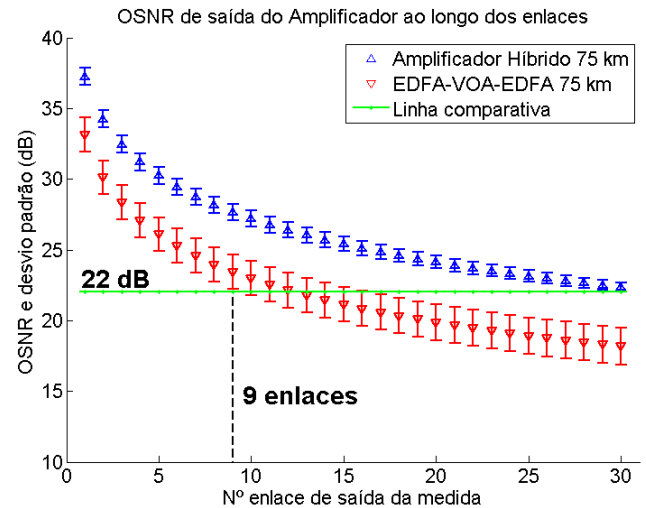

(a)

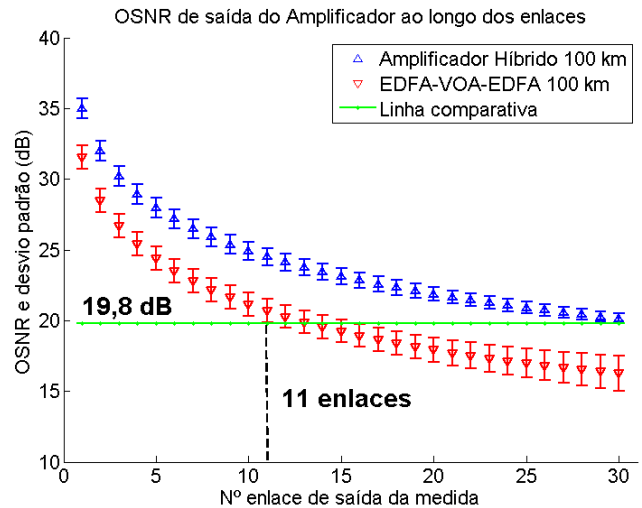

(b)

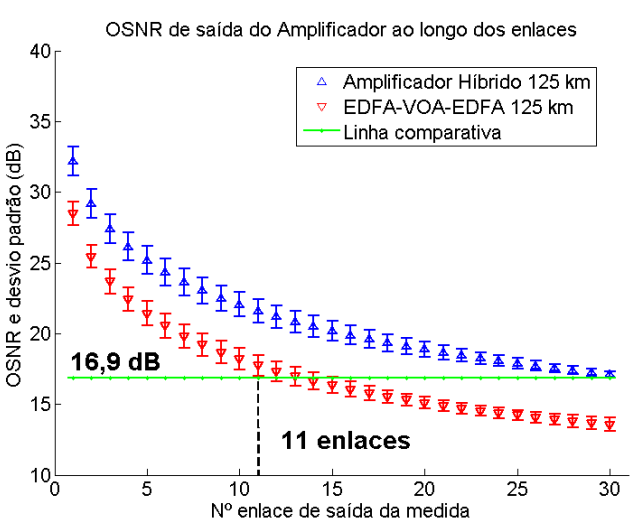

(c)

Figura 5.20: OSNR de saida das topologias de amplificação híbrida e EDFA-VOA-EDFA ao longo de múltiplos enlaces considerando: Ganho $15 \mathrm{~dB}$ e enlace de $75 \mathrm{~km}$ de SSMF (a), Ganho $20 \mathrm{~dB}$ e enlace de $100 \mathrm{~km}$ de SSMF (b), Ganho $25 \mathrm{~dB}$ e enlace de $125 \mathrm{~km}$ de SSMF (c). 
룰

Optical Spectrum Analyzer

를

Optical Spectrum Analyzer

불

Optical Spectrum Analyzer

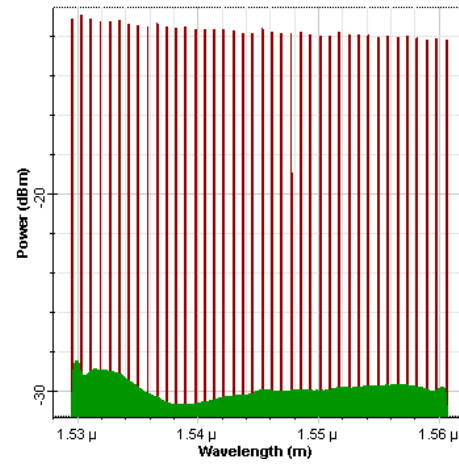

(a)

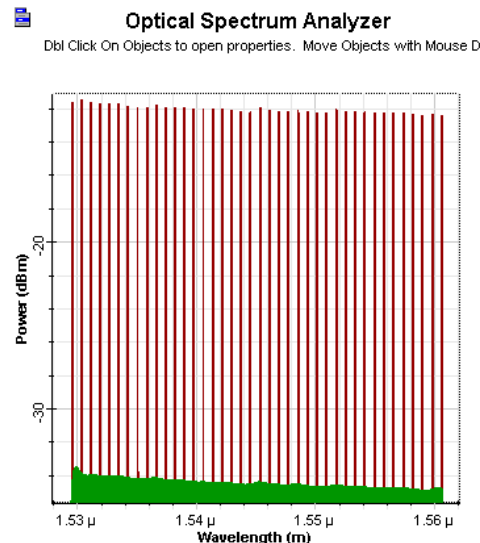

(d)

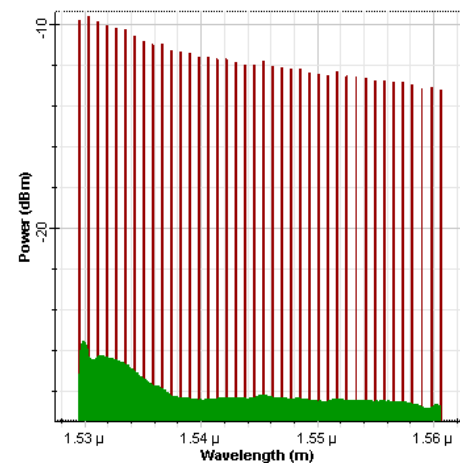

(b)

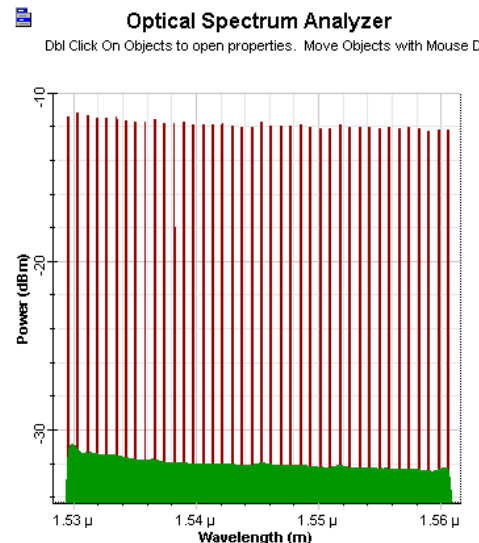

(e)

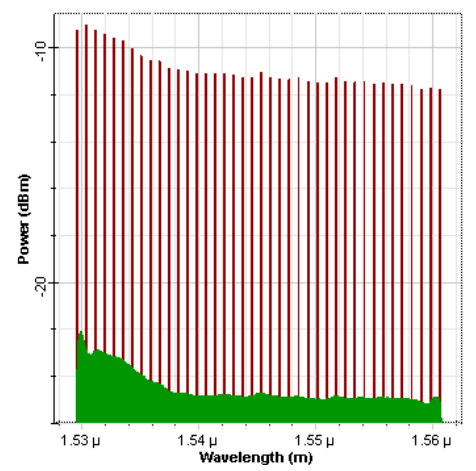

(c)

룹 Optical Spectrum Analyzer

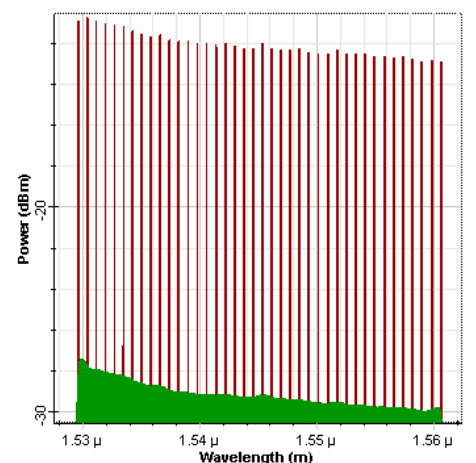

(f)

Figura 5.21: Espectros de saída ao fim do $30^{\circ}$ enlace da rede óptica testada com a topologia de amplificação óptica EDFA-VOA-EDFA com enlace de $75 \mathrm{~km}$ (a), $100 \mathrm{~km}$ (b) $125 \mathrm{~km}$ (c) e com a topologia de amplificação óptica híbrida com enlace de $75 \mathrm{~km}$ (a), $100 \mathrm{~km}$ (b) e $125 \mathrm{~km}$ (c).

$\mathrm{km})$.

Analisando a Figura 5.20(b) e a Tabela 5.2, os sistemas ópticos com a topologia de amplificação híbrida em enlace de $100 \mathrm{~km}$ de SSMF e ganho $20 \mathrm{~dB}$, atingem o trigésimo enlace com 3,86 dB de OSNR média adicionalmente ao mesmo sistema com amplificadores EDFA-VOA-EDFA, que atinge a mesma qualidade de sinal ao propagar ao longo de somente 11 enlaces, fazendo com que o sistema com o amplificador híbrido alcance $3000 \mathrm{~km}$ contra $1100 \mathrm{~km}$ com EDFA-VOA-EDFA (incremento de $1900 \mathrm{~km}$ ). Com relação a Figura 5.20(c), os sistemas ópticos com a topologia de amplificação híbrida com enlace de $125 \mathrm{~km}$ de SSMF e ganho $25 \mathrm{~dB}$, atinge o trigésimo enlace com 3,53 dB de OSNR média adicionalmente ao mesmo sistema com amplificadores EDFA-VOA-EDFA, que atinge a mesma qualidade de sinal ao propagar ao longo de somente 11 enlaces, fazendo com que o sistema com o amplificador híbrido alcance $3750 \mathrm{~km}$ contra $1375 \mathrm{~km}$ do mesmo com EDFA-VOA-EDFA (incremento de $2375 \mathrm{~km}$ ).

A Figura 5.21 ilustra os espectros de saída no fim do $30^{\circ}$ enlace da rede de comunicações ópticas testada com as topologias de amplificação óptica EDFA-VOA-EDFA e amplificação óptica híbrida, para diversos pontos de operação de ganho alvo (15, 20 e $25 \mathrm{~dB})$, e seus respectivos comprimentos de enlace $(75,100$ e $125 \mathrm{~km})$. 


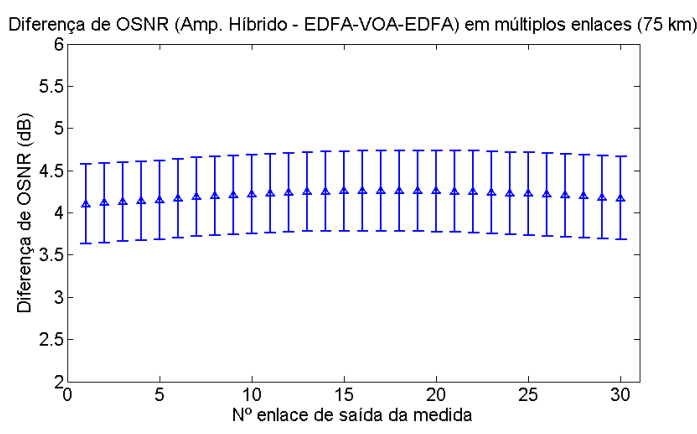

(a)

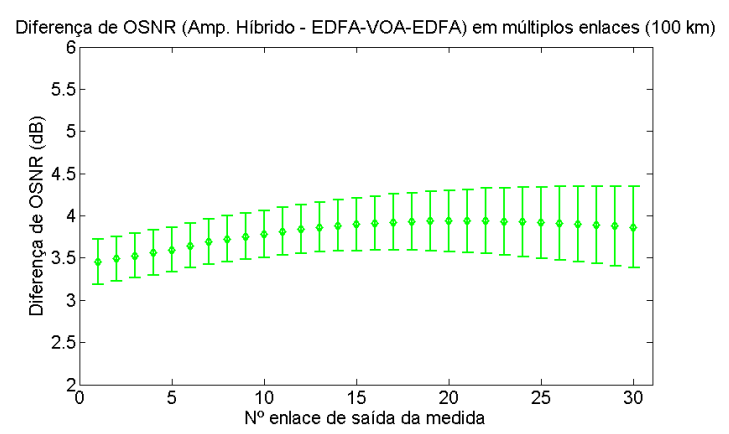

(b)

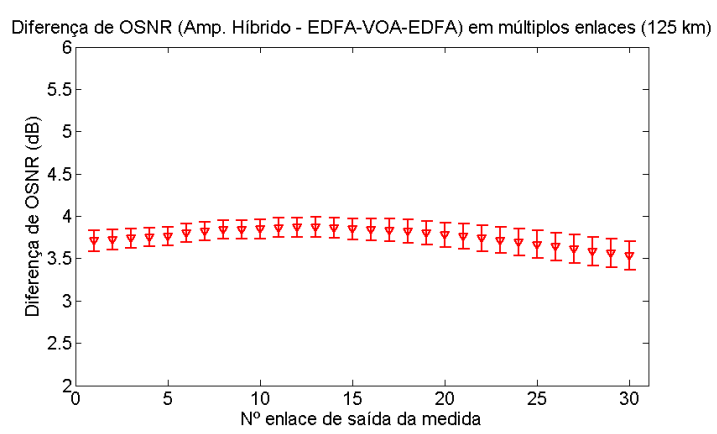

(c)

Figura 5.22: Diferença de OSNR ao longo dos múltiplos enlaces de comunicações comparando o amplificador híbrido e o amplificador EDFA-VOA-EDFA operando no ganho alvo de $15 \mathrm{~dB}$ com enalce de $75 \mathrm{~km}$ (a), ganho alvo de $20 \mathrm{~dB}$ com enalce de $100 \mathrm{~km}$ (a) e ganho alvo de $25 \mathrm{~dB}$ com enalce de $125 \mathrm{~km}$ (c).

Nota-se por meio da análise das Figura 5.21(a), (b) e (c), que, mesmo com a equalização espectral local em cada nó da rede, com a propagação ao longo de 30 enlaces de comunicações ópticas, é produzida uma desequalização espectral na saída do amplificador EDFA-VOA-EDFA que varia de 2 à $4 \mathrm{~dB}$ respectivamente para os pontos de operação de 15 e 25 dB de ganho alvo. Já realizando a mesma análise com base na Figura 5.21(d), (e) e (f), o amplificador híbrido apresenta uma desequalização após propagação ao longo 30 enlaces variando de 1 à $3 \mathrm{~dB}$.

A Figura 5.22 ilustra a diferença de OSNR ao longo dos enlaces dos sistemas comparando o desempenho do amplificador híbrido e amplificador EDFA-VOA-EDFA. Nota-se na Figura 5.22 que a diferença de OSNR é praticamente constante ao longo dos enlaces. Porém esta diferença varia de $4 \mathrm{~dB}$ (enlaces de $75 \mathrm{~km}$ ) para 3,5 dB (enlaces de $100 \mathrm{~km} \mathrm{e}$ $125 \mathrm{~km}$ ) e a variação dessa diferença ao longo dos canais é reduzida de acordo com o aumento do comprimento de enlace e ganho fornecido pelas topologias de amplificadores testadas.

\subsection{Desempenho Experimental}

Esta seção apresenta o desempenho experimental das topologias de amplificadores óptico EDFA-VOA-EDFA e do amplificador óptico híbrido com controle automático de ganho projetado por meio da metodologia apresentada na seção $5.3 \mathrm{em}$ um único enlace DWDM em fibra SSMF G.652 com $100 \mathrm{~km}$ de comprimento para três pontos de ganho, 
cobrindo a faixa de ganho alvo. O comprimento do enlace foi ligeiramente maior que o simulado $(75 \mathrm{~km})$ devido a disponibilidade em laboratório somente de rolos de fibra de $50 \mathrm{~km}$ (neste caso foram usados 2 rolos para compor os $100 \mathrm{~km}$ ).

O esquema óptico do amplificador híbrido experimental foi guiado pelo projeto resultante da metodologia aplicada na simulação. Porém devido a algumas limitações de recursos laboratoriais durante a realização do experimento, este foi construído o mais próximo possível do amplificador simulado, e as diferenças serão explanadas ao longo desta seção. O amplificador óptico com ganho plano (EDFA-VOA-EDFA) utilizado nesta seção, também foi construído o mais próximo possível do mesmo amplificador desenvolvido na seção 4.3.3. As diferenças entre o amplificador experimental com relação ao simulado serão devidamente descritas ao longo desta seção.

Devido às diferenças apresentadas entre o amplificador híbrido e EDFA-VOA-EDFA com relação ao mesmo construídos em simulação óptica, a faixa de ganho de operação foi de 17-27 dB (2 dB a mais de ganho na faixa alvo simulada que foi de 15-25 dB).

Desta forma, nesta seção os desempenhos dos amplificadores experimentais são apresentados operado na rede DWDM composta por um único enlace de comunicações ópticas, descrito pelas máscaras de potências de figura de ruído, planicidade espectral de ganho, precisão de controle de ganho e OSNR dos canais de saída para os pontos críticos (P1, P2, P3 e P4), além da OSNR para cada ganho da faixa, considerando os amplificadores operando em modo saturado.

\subsubsection{Enlace Único}

As topologias de amplificação óptica experimentais foram avaliadas em um sistema óptico composto por um enlace único de $100 \mathrm{~km}$ de fibra SSMF (G.652).

O amplificador EDFA-VOA-EDFA montado tem seu circuito óptico descrito pela Figura 4.3, composto por dois estágios de EDFA co-propagante (visando minimização da figura de ruído) com 12,5 m de EDF (MP980), bombeio de $600 \mathrm{~mW}$ (comprimento de onda $980 \mathrm{~nm}$ ), acopladores WDM de entrada combinados com tap (99\%/1\%) e isolador (TAP/ISO/WDM) com perda de inserção de sinal de 1,4 dB e perda de inserção de bombeio de 0,6 dB, e isolador de saída seguido de tap (99\%/1\%) combinado com fotodetector, e um estágio intermediário composto por um GFF e atenuador óptico variável com fotodetector de entrada e saída. O laço de controle executado pelo amplificador EDFA-VOA-EDFA experimental é o mesmo ilustrado na Figura 4.4, onde os estágios de amplificação EDFA são controlados por malha de controle realimentado sempre com seu ganho alvo igual ao seu ganho nominal ( $17 \mathrm{~dB}$ ) e o controle do VOA é responsável pelo ajuste do ganho alvo desejado.

O amplificador híbrido Raman/EDFA montado experimentalmente e ilustrado na Figura 5.23(b), tem seu circuito óptico descrito pela Figura 5.1, onde o estágio de amplificação EDFA é exatamente igual ao estágio EDFA do amplificador EDFA-VOA-EDFA (ganho nominal $17 \mathrm{~dB}$ ) e o estágio de amplificação Raman contra-propagante é composto por bombeios baseados em lasers semicondutores com comprimento de onda $1425 \mathrm{~nm}$ e $1452 \mathrm{~nm}$, cada um com potência nominal de $300 \mathrm{~mW}$, os quais, combinados pelo acoplador contra-propagante de dois bombeios com sinal (composto por um combinador de 


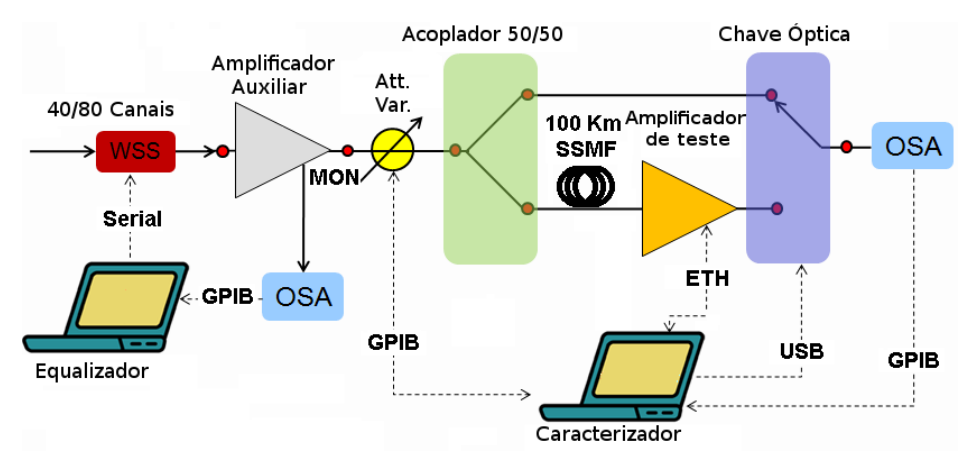

(a)

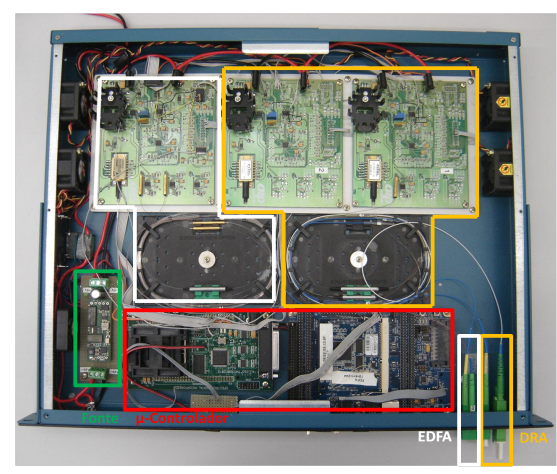

(b)

Figura 5.23: Configuração experimental construida para avaliação do amplificador Híbrido (Raman/EDFA) (a), visão interna do amplificador óptico híbrido (b)

polarização, PBC e um acoplador de bombeio com sinal contra-propagante com perda de inserção de 1,75 dB) apresentam uma saída combinada dos bombeios na fibra de 400 $\mathrm{mW}$ (200 mW por bombeio), fornecendo ganho on-off de 0 à $10 \mathrm{~dB}$, seguidos por um tap com fotodetector para monitoração da potência de saída do amplificador Raman.

Devido ao estágio EDFA possuir ganho nominal $17 \mathrm{~dB}$ e o estágio Raman fornecer ganho on-off 0-10 dB, torna-se necessário redefinir a faixa de ganho de operação da máscara de potência para o teste dos amplificadores experimentais com relação aos amplificadores simulados, variando a faixa de ganho de 15-25 dB para 17-27 dB.

Com esta nova faixa de ganhos alvo e a estrutura do EDFA-VOA-EDFA, o ganho máximo fornecido para o amplificador experimental passa a ser $34 \mathrm{~dB}(17+17 \mathrm{~dB})$, necessitando de um nível de atenuação de 7-17 dB para cobrir a faixa de ganho alvo 17-27 $\mathrm{dB}$, enquanto no amplificador simulado o ganho máximo fornecido era $38 \mathrm{~dB}(19+19 \mathrm{~dB})$ necessitando de mais atenuação (13-23 dB) para cobrir a faixa de 15-25 dB de ganho. Desta forma, da maneira como o amplificador EDFA-VOA-EDFA foi experimentalmente construído, espera-se um nível de figura de ruído bem menor que o simulado, devido principalmente à redução do nível de atenuação intermediária em aproximadamente metade da atenuação considerada na simulação (implicando em redução de figura de ruído de aproximadamente até $3 \mathrm{~dB}$ ).

Por outro lado, devido às limitações do amplificador híbrido com relação ao ganho nominal do EDFA (17 dB) e o nível de ganho on-off Raman fornecido (0-10 dB), esperase que o amplificador híbrido experimental forneça um nível menor de aumento de OSNR com relação ao amplificador híbrido simulado.

A Figura 5.23(a) ilustra a configuração experimental construída, exatamente igual ao apresentado na seção 4.2 (mesmo amplificador auxiliar, WSS para equalização dos 40 canais na banda C distribuídos de 192.1-196 THz com espaçamento de $100 \mathrm{GHz}$ ) para avaliação experimental dos amplificadores EDFA-VOA-EDFA e Híbrido desenvolvidos em protótipos experimentais.

A Figura 5.23(b) ilustra o protótipo experimental do amplificador óptico híbrido (Raman/EDFA), onde o setor marcado em branco se refere ao estágio de amplificação EDFA composto pela placa de controle de potência e temperatura do Laser de bombeio de 600 $\mathrm{mW}$ no comprimento de onda $980 \mathrm{~nm}$ e o circuito óptico do EDFA. O setor marcado 


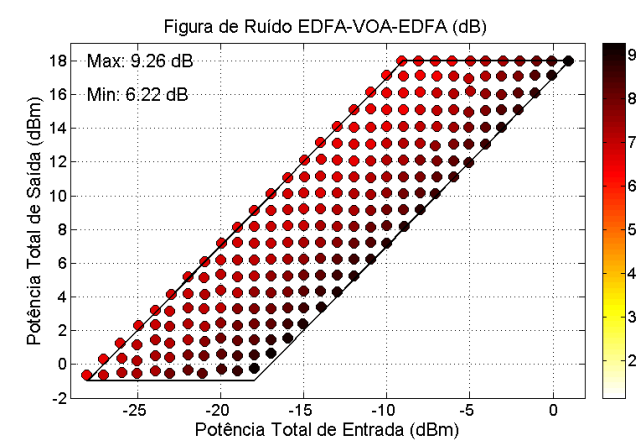

(a)

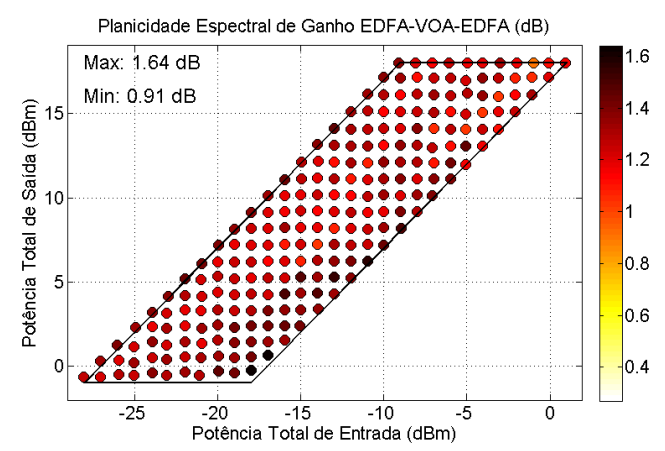

(b)

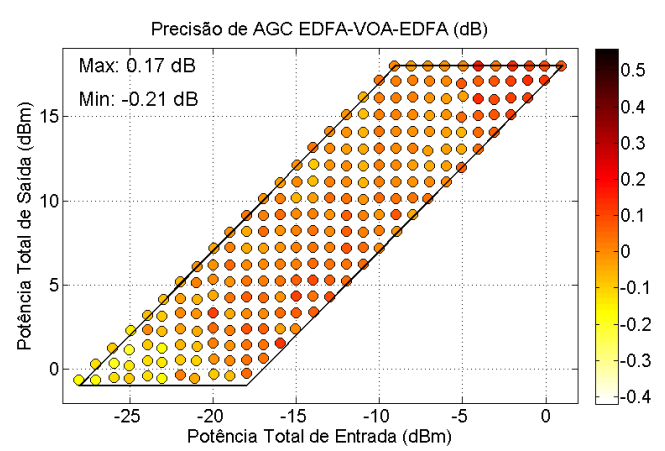

(c)

Figura 5.24: Máscara de potência do amplificador EDFA-VOA-EDFA experimental apresentando desempenho de figura de ruído (a), planicidade espectral de ganho (b) e precisão do controle automático de ganho (c).

de laranja se refere ao amplificador Raman contra-propagante distribuído composto por duas placas de controle de potência e temperatura dos lasers de bombeio de $300 \mathrm{~mW}$ nos comprimentos de onda de 1425 e $1452 \mathrm{~nm}$, o setor verde representa a fonte de alimentação do amplificador e o setor vermelho trata-se do micro controlador onde é executado o controle de ganho do amplificador óptico híbrido.

Para o protótipo experimental do amplificador EDFA-VOA-EDFA avaliado no sistema de comunicações ópticas DWDM composto por um enlace de $100 \mathrm{~km}$ de fibra SSMF (G.652), foi obtido, por meio do caracterizador ilustrado na Figura 5.23(a) o desempenho ilustrado na Figura 5.24 descrito pelas máscaras de potência de figura de ruído, planicidade espectral de ganho e precisão de controle automático de ganho (AGC) ao longo de toda região de operação do amplificador.

Para o teste do amplificador EDFA-VOA-EDFA experimental, foi obtido um desempenho de figura de ruído equivalente de 6,22 à $9,26 \mathrm{~dB}$, ondulação espectral de 0,91 à $1,64 d B$ e precisão de $\mathrm{AGC}$ de 0,17 à $-0,21 d B$ ao longo de toda região de operação da máscara de potência.

Substituindo-se o EDFA-VOA-EDFA pelo protótipo experimental do amplificador híbrido, a Figura 5.25 ilustra o desempenho do amplificador neste sistema por meio das máscaras de potência de figura de ruído, planicidade espectral de ganho e precisão de AGC ao longo de toda região de operação do amplificador.

Para o teste do amplificador híbrido experimental, foi obtido um desempenho de figura de ruído equivalente de 1,12 à $6,53 d B$, ondulação espectral de 0,27 à $1,12 d B$ e 


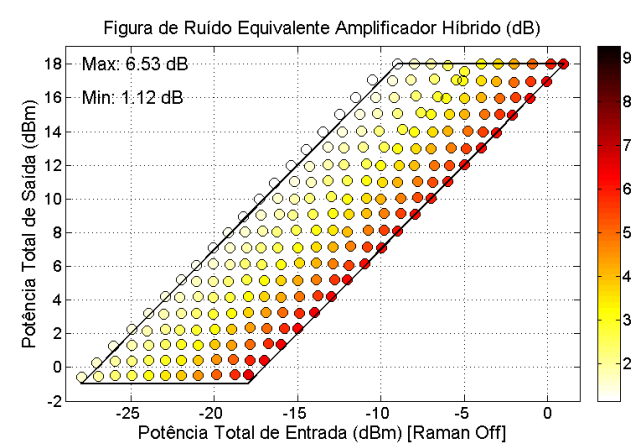

(a)

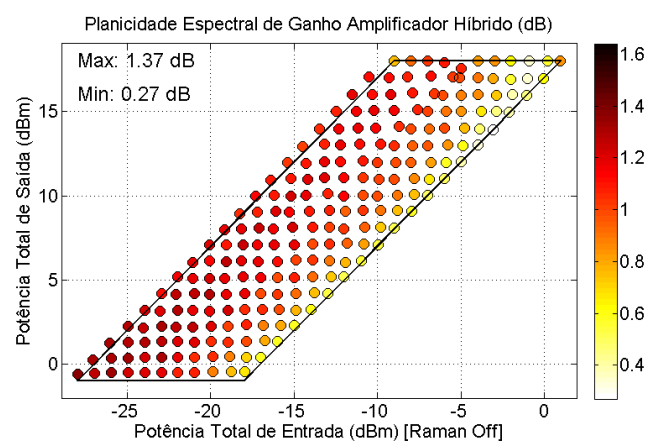

(b)

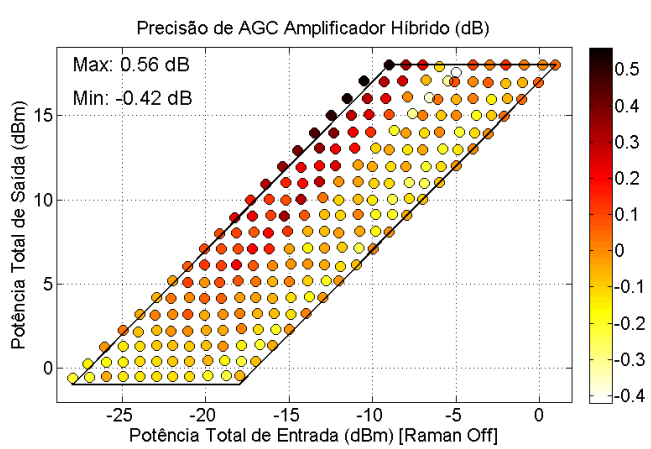

(c)

Figura 5.25: Máscara de potência do amplificador híbrido (Raman/EDFA) experimental apresentando desempenho de figura de ruído (a), planicidade espectral de ganho (b) e precisão do controle automático de ganho (c).

precisão de AGC de 0,56 à $-0,42 d B$ ao longo de toda região de operação da máscara de potência.

Desta forma nota-se agora experimentalmente o benefício fornecido pelo amplificador híbrido em termos de figura de ruído com relação ao EDFA-VOA-EDFA, pois o amplificador híbrido apresenta uma melhora de 2,73 à $5,1 d B$ de figura de ruído, além de ser notável que, em termos de planicidade espectral de ganho, o amplificador óptico híbrido apresenta uma variação máxima ao longo da máscara de potência de $1,12 d B$ contra $1,64 d B$ do EDFA-VOA-EDFA, lembrando que a variação de $1,1 \mathrm{~dB}$ de planicidade espectral de ganho $(0,27$ à $1,37 \mathrm{~dB})$ ocorre juntamente com o aumento da potência lançada na fibra de 11 para $21 \mathrm{dBm}$, onde a potência de $21 \mathrm{dBm}$ induz significativo efeito Raman entre canais, sendo o grande responsável pela variação espectral de ganho neste caso.

Assim como realizado na simulação do sistema de enlace único simulado, a melhora de OSNR esperada para os pontos críticos (P1 e P3) pode ser calculada pela diferença das figuras de ruído de cada ponto para as duas topologias de amplificação óptica avaliadas. Para o ponto P1, com o uso do amplificador híbrido espera-se um aumento de OSNR de 2,73 dB (diferença de 9,26 dB do EDFA-VOA-EDFA e 6,53 dB do amplificador híbrido), enquanto para o ponto $\mathrm{P} 3$ seria a diferença entre 6,22 e 1,12 dB, resultando em 5,1 dB.

A Figura 5.26 ilustra os espectros de entrada e saída para ambas as topologias de amplificação óptica testadas (EDFA-VOA-EDFA e amplificador Híbrido) para os pontos críticos de desempenho do sistema (P1, P2, P3 e P4) de comunicação com propagação em enlace único. As Figuras 5.26(a), (c), (e) e (g) ilustram os espectros de entrada e saída 


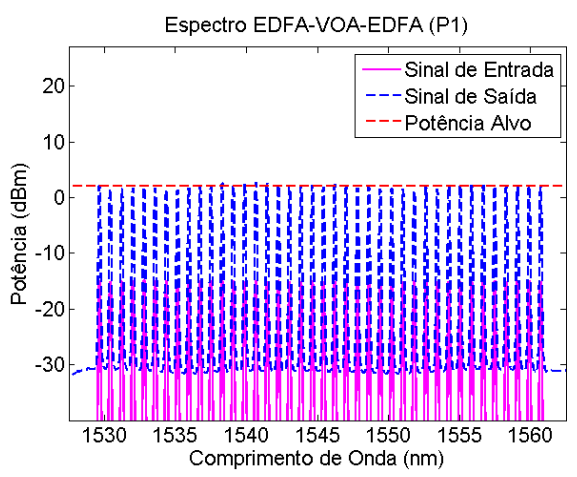

(a)

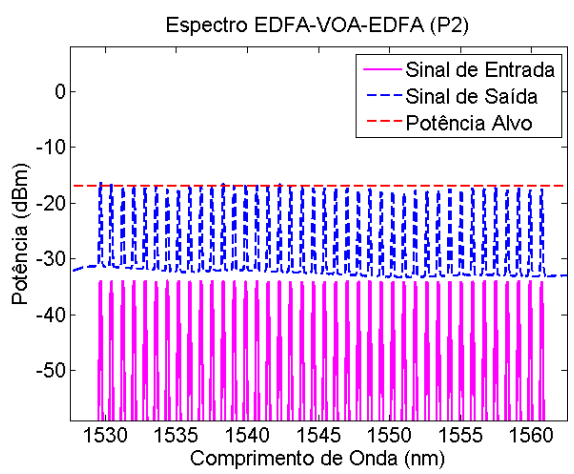

(c)

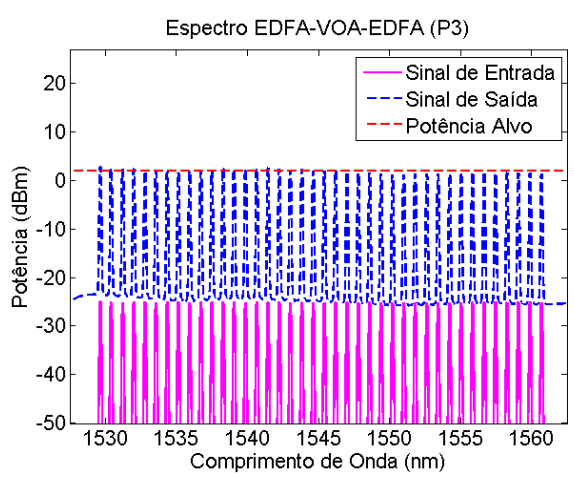

(e)

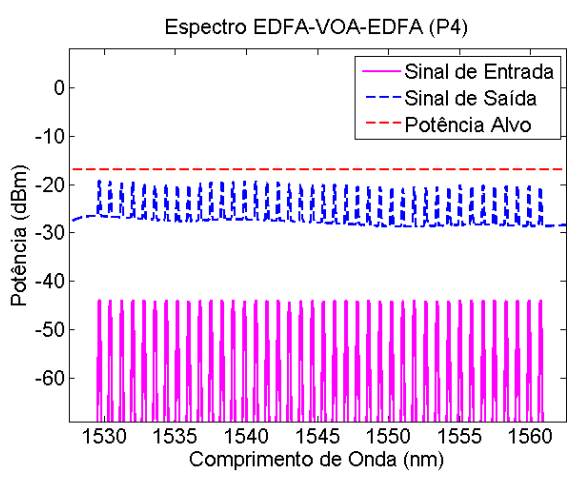

(g)

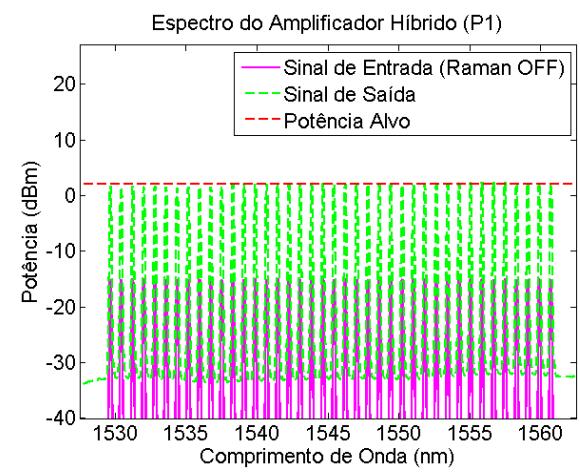

(b)

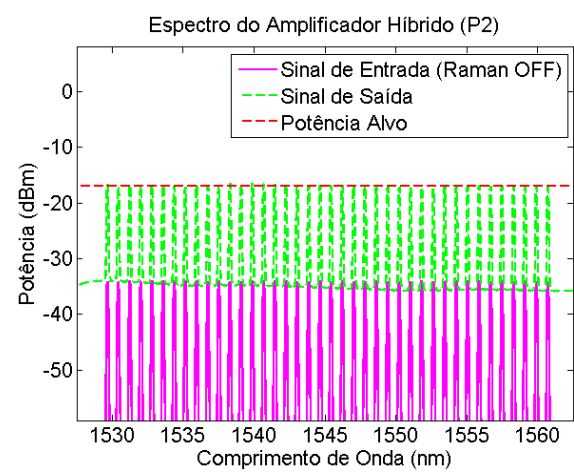

(d)

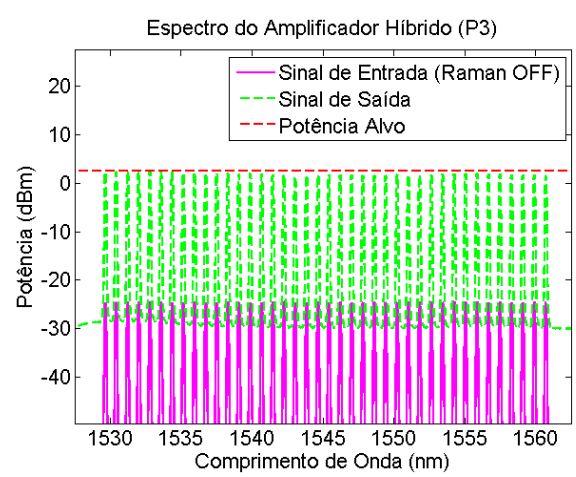

(f)

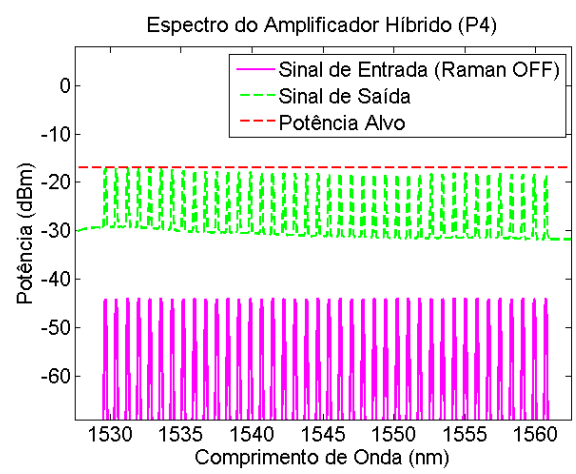

(h)

Figura 5.26: Espectros de entrada, saida e potência alvo para os pontos críticos de desempenho na máscara de potência, para as topologias de amplificação EDFA-VOA-EDFA P1 (a), P2 (c), P3 (e) e P4 (g), e a topologia de amplificação hibrida P1 (b), P2 (d), P3 (f) e P4 (h) respectivamente experimentadas. 


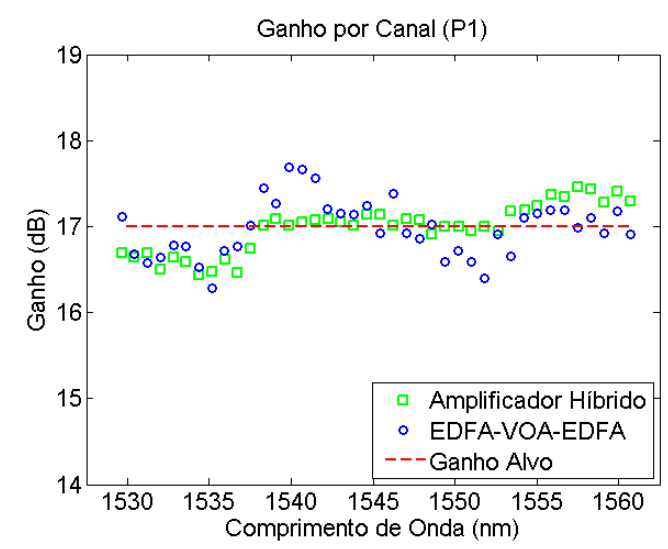

(a)

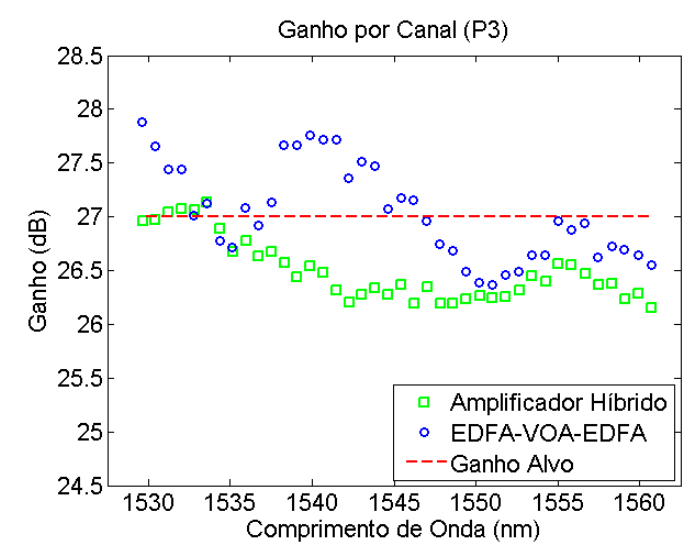

(c)

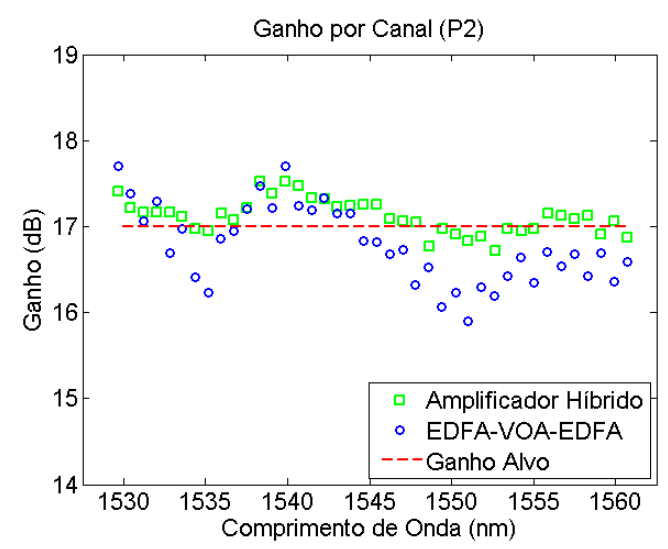

(b)

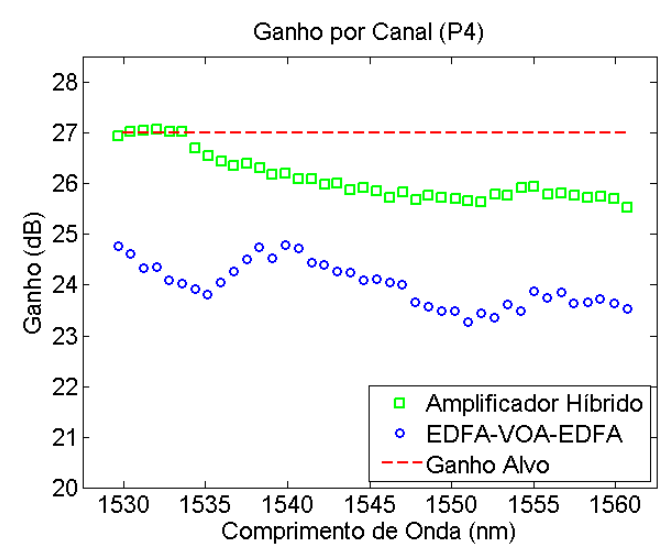

(d)

Figura 5.27: Ganho por canal para ambas as topologias de amplificação experimentadas (EDFAVOA-EDFA e amplificador híbrido) para os pontos críticos da máscara de potência P1 (a), P2 (b), P3 (c) e P4 (d).

obtido na avaliação do amplificador EDFA-VOA-EDFA e as Figuras 5.26(b), (d), (f) e (h) ilustram o mesmo obtido na avaliação do amplificador híbrido.

Analisando a Figura 5.26 nota-se que a melhora de figura de ruído e consequentemente de OSNR é mais notável para os pontos P2 e P4 (ganho $27 \mathrm{~dB}$ ) do que para os pontos P1 e P3 (ganho $17 \mathrm{~dB}$ ). Isso se dá porque para o ganho $27 \mathrm{~dB}$ o amplificador híbrido operar com ganho on-off Raman máximo, enquanto para o ganho $17 \mathrm{~dB}$ o mesmo é totalmente desligado.

A Figura 5.27 ilustra os ganhos como função do comprimento de onda para ambas as topologias de amplificação testadas (EDFA-VOA-EDFA e amplificador híbrido) nos pontos críticos de desempenho da máscara de potência (P1, P2, P3 e P4).

Analisando o ganho apresentado pelo amplificador EDFA-VOA-EDFA e amplificador híbrido na Figura 5.27, nota-se que, além do amplificador híbrido apresentar uma menor variação de ganho fornecido, o padrão de variação é mais suave que o padrão de variação de ganho do EDFA-VOA-EDFA.

Além disso, é notável que neste ponto o amplificador híbrido se comporta, da mesma forma que se comporta para os demais pontos críticos, o EDFA-VOA-EDFA erra o ganho por canal para este ponto (P4) em até $2 \mathrm{~dB}$, principalmente pelo controle de ganho ser realizado com base na potência total, e o ruído neste ponto ser equiparável ao sinal. 


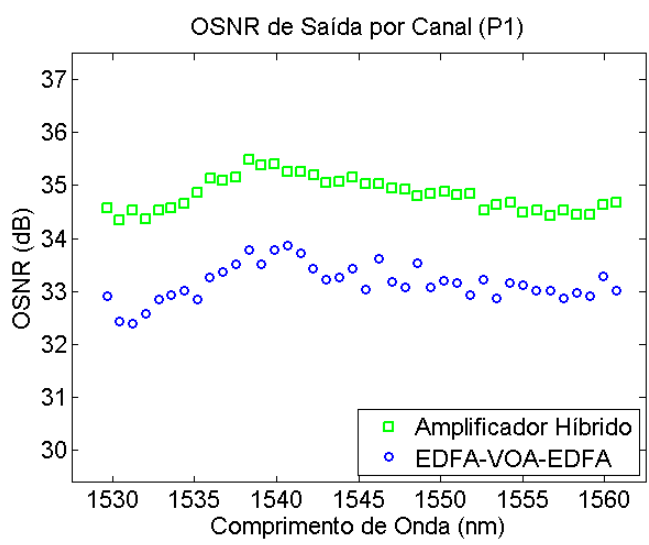

(a)

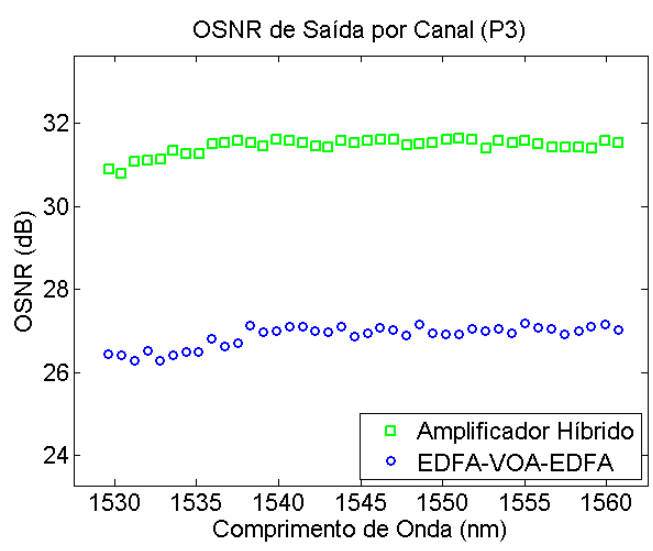

(c)

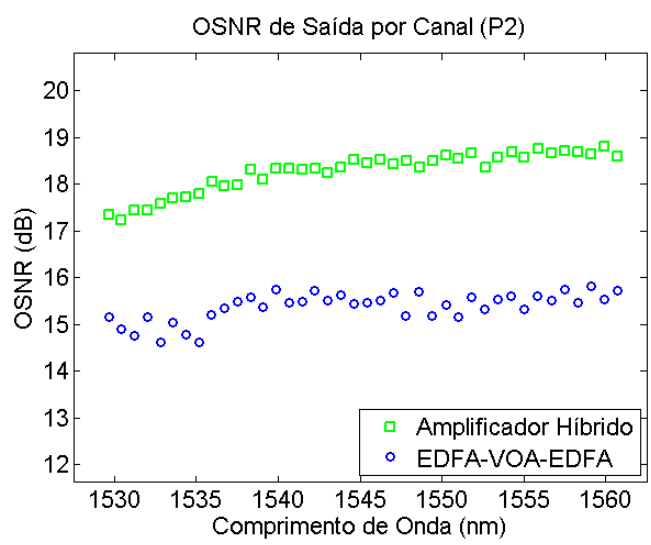

(b)

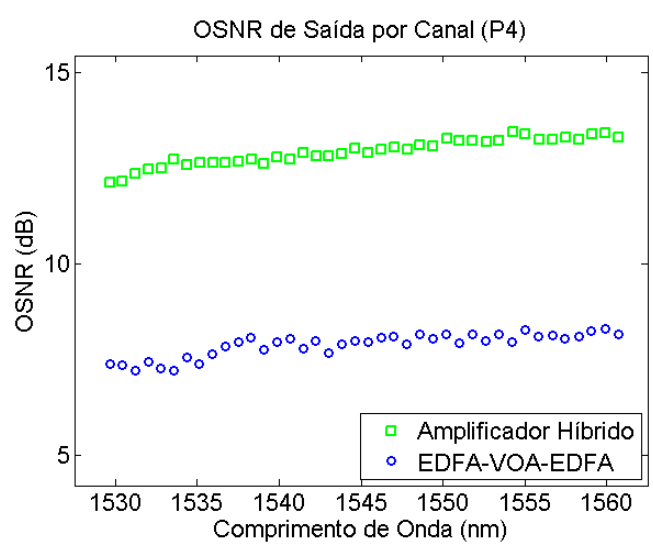

(d)

Figura 5.28: OSNR de saída por canal para ambas as topologias de amplificação experimentadas (EDFA-VOA-EDFA e amplificador híbrido) para os pontos críticos da máscara de potência P1 (a), P2 (b), P3 (c) e P4 (d).

Desta forma, o controle de ganho não faz a distinção de sinal e ruído, controla a potência total com sucesso, porém erra em termos da potência por canal.

A Figura 5.28 ilustra a relação sinal-ruído óptica (OSNR) para os amplificador híbrido e o amplificador EDFA-VOA-EDFA, avaliados experimentalmente (enlace único) nos mesmos pontos críticos de desempenho da máscara de potência (P1, P2, P3 e P4).

O desempenho de OSNR para o ponto P1 ilustrado na Figura 5.28 fornece uma melhora de OSNR de 1,67 dB com o uso do amplificador híbrido ao invés do amplificador EDFA-VOA-EDFA, para o ponto P2 fornece uma melhora de OSNR de 2,89 dB, para o ponto P3 fornece melhora a OSNR em $4,57 \mathrm{~dB}$ e para o ponto P4 melhora a OSNR em $5,04 \mathrm{~dB}$.

Devido a ambos os amplificadores contarem com a mesma montagem do estágio de amplificação EDFA, em P1, a melhora de OSNR de 1,67 dB quando usado o amplificador híbrido com relação ao EDFA-VOA-EDFA para operação no ganho mínimo $(17 \mathrm{~dB})$ é devida basicamente à diferença de se usar um estágio adicional de EDFA com VOA no EDFA-VOA-EDFA (fornecendo um nível de figura de ruído adicional) em comparação com somente a perda de inserção de sinal do acoplador de bombeio Raman que aparece antes do estágio EDFA no amplificador híbrido. Enquanto isso para operação no ganho máximo $27 \mathrm{~dB}$ em P3, temos essa mesma melhora de OSNR citada anteriormente em 


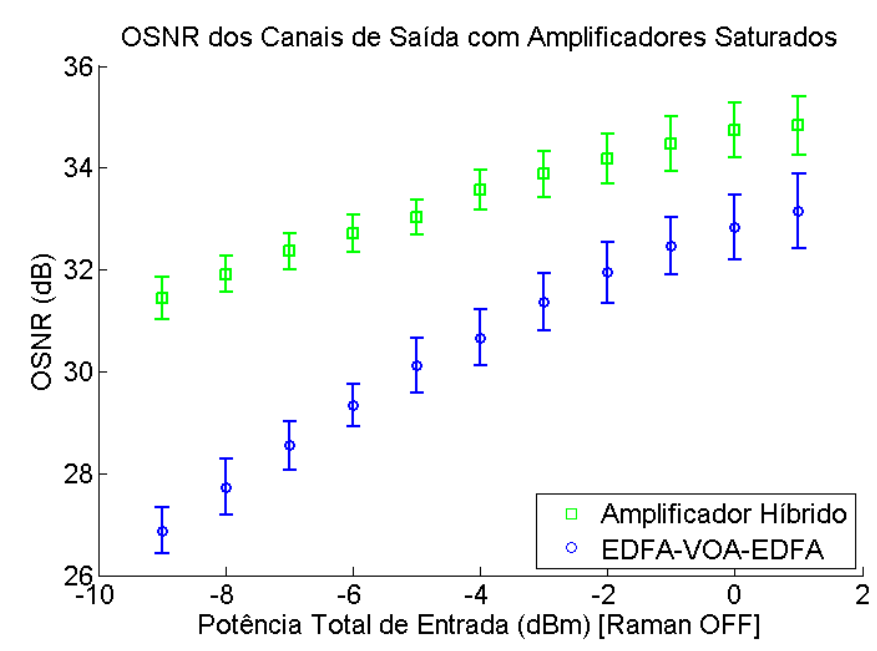

Figura 5.29: OSNR de saída dos amplificadores híbrido e EDFA-VOA-EDFA experimentados para todos os ganhos alvo testados com os amplificadores operando em saturação.

conjunto com a melhora de OSNR devido ao ganho on-off Raman fornecido (ganho alvo $10 \mathrm{~dB}$ ), totalizando $4,57 \mathrm{~dB}$ de melhora de OSNR.

Com o uso do amplificador híbrido experimental, enquanto o valor esperado com base na diferença de figura de ruído era $2,73 \mathrm{~dB}$, foi obtido, com base na diferença de OSNR de saída uma melhora de 1,67 dB. Para o ponto P3 o valor esperado era de 5,1 $\mathrm{dB}$, enquanto foi obtido uma melhora de 4,57 dB de OSNR com base na diferença de OSNR. Apesar da diferença entre os valores esperados e obtidos, os mesmos variaram somente em aproximadamente 0,5-1,0 dB.

A Figura 5.29 ilustra as OSNRs apresentadas para todos os canais nos pontos de saturação do amplificador híbrido e amplificador EDFA-VOA-EDFA para todos os ganhos de operação (pontos da esquerda para direita representam de $27 \mathrm{~dB}$ até $17 \mathrm{~dB}$ de ganho com granularidade de $1 \mathrm{~dB}$ ).

A dupla dos primeiros e últimos pontos (azul para o EDFA-VOA-EDFA e verde para amplificador híbrido), se referem aos pontos críticos P3 e P1 respectivamente, representando os pontos de pior e melhor OSNR. Por meio da Figura 5.15, nota-se que para os amplificadores testados experimentalmente operando em modo saturado, o amplificador híbrido apresenta uma melhora de OSNR mínima de 1,67 dB (para $15 \mathrm{~dB}$ de ganho de operação) e uma melhora máxima de 4,57 dB (para $25 \mathrm{~dB}$ de ganho de operação).

Comparando a OSNR necessária para recepção de canais $112 \mathrm{~Gb} / \mathrm{s}$ (INC, 2011) (OSNR mínima 12,6 dB) e a mesma necessária para recepção de sinais 10G OOK, ou seja, 11,2dB (Uniphase, 2009), a diferença de OSNR para realização de uma evolução de $10 \mathrm{G}$ para $100 \mathrm{G}$ é de $1,4 d B$, que pode ser obtida facilmente por meio somente da substituição dos amplificadores EDFA-VOA-EDFA por amplificadores híbridos, sem necessidade de troca de fibra óptica.

Além disso nota-se por meio da Tabela 5.3, que o amplificador EDFA-VOA-EDFA não garante OSNR suficiente quando operando no ponto $\mathrm{P} 4$, nem para transmissão de sinais 10G nem para transmissão de sinais de 100G devido a OSNR de 7,89 dB estar muito abaixo do valor mínimo necessário. Porém, com a utilização do amplificador híbrido, este problema pode ser desconsiderado por fornecer OSNR suficiente para transmissão 
Tabela 5.3: OSNR média, ganho médio, planicidade e aumento médio de OSNR para cada topologia de amplificação experimentada.

\begin{tabular}{|c|c|c|c|c|}
\hline Amplificador & $\begin{array}{c}\text { OSNR } \\
\text { Média (dB) }\end{array}$ & $\begin{array}{c}\text { Ganho } \\
\text { Médio (dB) }\end{array}$ & $\begin{array}{c}\text { Planicidade } \\
(\mathrm{dB})\end{array}$ & $\begin{array}{c}\text { Aumento Méd. } \\
\text { OSNR (dB) }\end{array}$ \\
\hline 2xEDFA-VOA P1 & 33,16 & 16,97 & 1,41 & - \\
\hline Híbrido P1 & 34,83 & 16,43 & 1,03 & 1,67 \\
\hline 2xEDFA-VOA P2 & 15,38 & 16,78 & 1,81 & - \\
\hline Híbrido P2 & 18,27 & 17,12 & 0,80 & 2,89 \\
\hline 2xEDFA-VOA P3 & 26,87 & 27,03 & 1,51 & - \\
\hline Híbrido P3 & 31,44 & 26,49 & 0,99 & 4,57 \\
\hline 2xEDFA-VOA P4 & 7,89 & 24,01 & 1,52 & - \\
\hline Híbrido P4 & 12,93 & 26,11 & 1,52 & 5,04 \\
\hline
\end{tabular}

de canais $100 \mathrm{G}$ neste mesmo ponto crítico P4 $(12,93 \mathrm{~dB})$.

\subsubsection{Análise de controle de ganho com supressão de transientes}

Visando avaliar o desempenho dinâmico das tecnologias de amplificação óptica com controle automático de ganho apresentadas ao longo desta tese, esta seção apresenta o transiente de potência (no canal sobrevivente) em amplificadores ópticos com controle automático de ganho, considerando as topologias de amplificação EDFA e híbrida (Raman distribuído/EDFA), considerando a propagação em um único enlace DWDM em fibra SSMF G.652 com $100 \mathrm{~km}$ de comprimento e considerando a adição/remoção de até 7 em 8 canais presentes no sistema DWDM (9dB).

Para que o controle automático de ganho em um amplificador óptico possa suprimir o transiente de potência no canal sobrevivente, o mesmo deve ser mais rápido que o processo dinâmico do próprio amplificador, ou seja, no caso do EDFA o carregamento/esvaziamento do nível meta-estável. Foi visto em (Desurvire, 1994; Zyskind e Srivastava, 2011) que a dinâmica de carregamento e esvaziamento do nível meta-estável (inversão de população) em uma EDF é da ordem de unidades de mili-segundos para um EDFA operando no modo não saturado, e centenas de micro-segundos para um EDFA operando em condição de saturação, tornado necessário que o ciclo de controle de ganho seja da ordem ou menor que centenas de micro-segundos para que seja possível realizar o controle de ganho com supressão de transientes.

Visando atingir este ciclo de controle de ganho de amplificadores ópticos em torno de micro-segundos, foi desenvolvido uma plataforma pré-industrial de amplificação óptica (EDFA e/ou Raman) ilustrada na Figura 5.30. A plataforma pré-industrial de amplificação é composta por uma placa óptica ilustrada na Figura 5.30(a), onde são possíveis alocar até quatro lasers de bombeio, cinco foto-detectores, dois VOAs e vários componentes ópticos passivos para montagem da topologia de amplificação óptica desejada.

A Figura 5.30(b) ilustra a placa eletrônica da plataforma de amplificação óptica, composta pelos circuitos eletrônicos necessários para controle do laser de bombeio, VOA, além dos circuitos de condicionamento dos sinais para medida da potência óptica detectada nos fotodetectores. Nesta placa eletrônica encontra-se o sistema em um único 


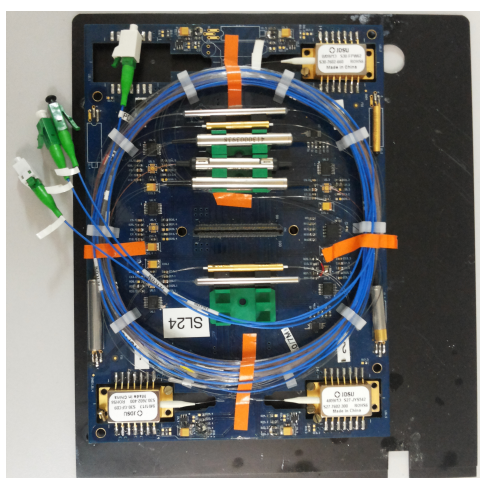

(a)

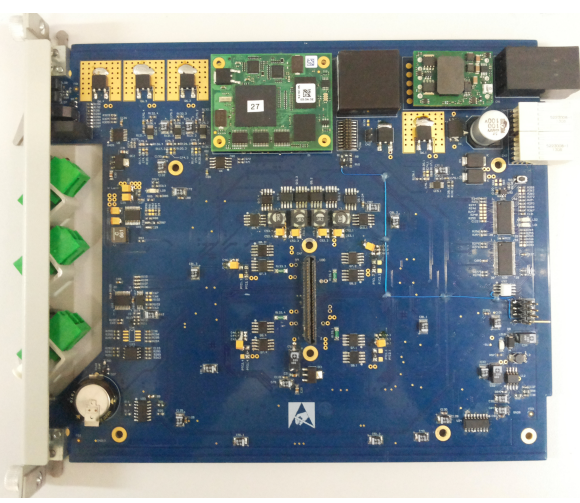

(b)

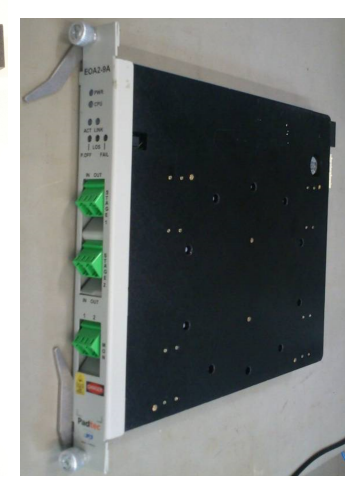

(c)

Figura 5.30: Placa óptica (a), placa eletrônica (b) e protótipo pré-industrial amplificador óptico híbrido montado (c).

chip phyCORE $($-Vybrid, um processador de duplo núcleo (um núcleo composto por um microprocessador $\mathrm{ARM}(\mathrm{R}$ Cortex-A5 @ $500 \mathrm{MHz}$ e outro núcleo composto por um microcontrolador $\mathrm{ARM} \otimes$ Cortex-M4 @ $167 \mathrm{MHz}$ ).

O núcleo microcontrolador $(A R M \cap C o r t e x-M 4 @ 167 \mathrm{MHz})$ foi utilizado para execução do laço de controle de ganho do amplificador em tempo real, executando um ciclo de leitura dos foto-detectores, cálculo do controlador proporcional-integral de ganho e atuação no laser de bombeio em torno de 10 micro-segundos, tempo bem menor que a dinâmica do amplificador óptico, assim podendo possibilitar o controle de ganho com supressão de transientes.

A Figura 5.30(c) ilustra a montagem final combinando as placas óptica e eletrônica para composição do protótipo pré-industrial da plataforma de amplificação óptica juntamente com o suporte mecânico com os conectores de entrada e saída dos sinais ópticos.

Na Figura 5.31 é ilustrado a configuração experimental para avaliação do transiente de potência no canal sobrevivente em um amplificador óptico com controle automático de ganho.

Para avaliação do transiente de potência em um amplificador óptico com controle automático de ganho, a configuração experimental da Figura 5.31 utiliza uma bancada de 80 lasers de sinais agressores (banda C), que é equalizada e amplificada espectralmente por um conjunto chave WSS e EDFA respectivamente, podendo realizar a adição/remoção de 1 a 79 canais (3 a 19 dB).

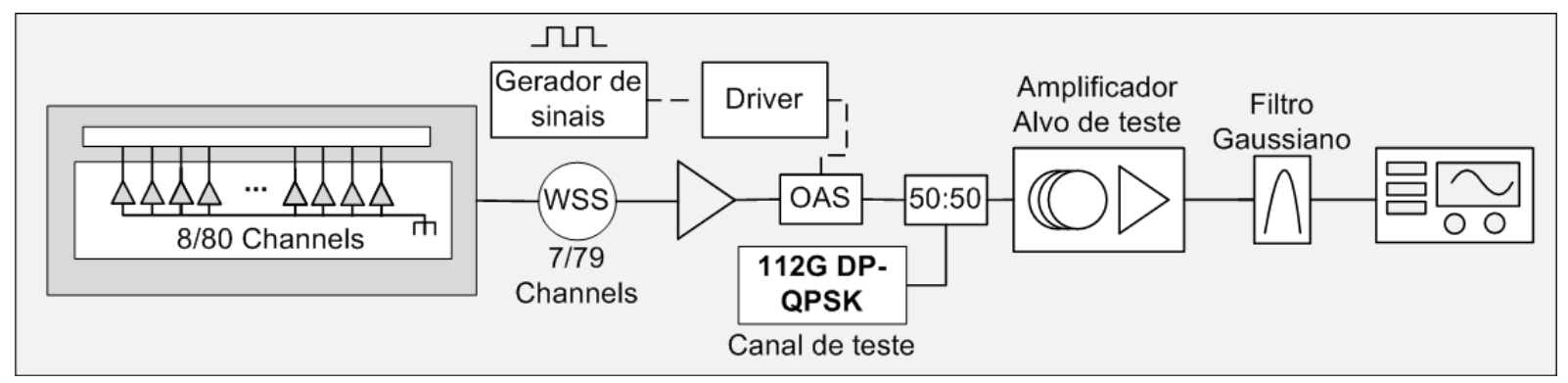

Figura 5.31: Setup experimental para teste de supressão de transientes em amplificadores ópticos. 
Em seguida na Figura 5.31 os sinais agressores (sinais a serem adicionados e removidos) são inseridos em uma chave acustico óptica (OAS), que tem seu chaveamento controlado por um conjunto gerador de sinais com driver elétrico para coordenar os eventos de adição/remoção dos canais agressores, que são combinados com o canal de teste (112 Gb/s DP-QPSK) antes de seguir para entrada do amplificador óptico (ou conjunto fibra e amplificador óptico) em teste.

Finalizando, na Figura 5.31 após os canais agressores serem combinados juntamente com o canal de teste, os mesmos passam pelo amplificador com controle automático de ganho em teste, o sinal de saída do amplificador é filtrado por um filtro sintonizável com perfil gaussiano com $100 \mathrm{GHz}$ de largura espectral, em torno do comprimento de onda do canal de teste (1550nm), seguindo para um osciloscópio com entrada óptica para análise temporal do transiente de potência na saída do amplificador em teste.

Para análise do transiente de potência nas topologias de amplificadores ópticos, foram avaliadas duas topologias de amplificação óptica a serem avaliadas (precedidas por 100km de fibra SSMF G.652), o amplificador óptico EDFA estágio simples com controle automático de ganho, e o amplificador óptico híbrido (DRA/EDFA) com controle automático de ganho proposto nesta tese.

O amplificador de teste precedido pela fibra do enlace foi inserido na configuração experimental da Figura 5.31, em seguida o experimento do transiente de potência foi realizado por meio da adição e remoção de canais para diferentes ganhos de operação, onde os resultados obtidos foram os diagramas de tempo do transiente de potência para cada condição de ganho alvo e cada topologia de amplificação testada.

A Figura 5.32 ilustra as evoluções temporais do transiente de potência óptica no canal sobrevivente para os eventos de adição/remoção de 7 de 8 canais (9dB), avaliados para os ganhos alvos de operação de 15 e $25 \mathrm{~dB}$, nas topologias EDFA estágio simples com AGC e amplificador óptico híbrido (Raman/EDFA) com AGC desenvolvido nesta tese.

Em todas figuras contidas na Figura 5.32(a-d), são ilustrados os transientes de potência óptica do canal sobrevivente ao longo do tempo (para um evento de adição/remoção de $9 \mathrm{~dB}$, ou seja, 7 de 8 canais), na saída do amplificador óptico em teste (EDFA de estágio simples ou amplificador híbrido Raman/EDFA), sem AGC, ou seja, bombeio fixo (linha tracejada azul) e com AGC com supressão de transientes (linha preta sólida).

Para o ganho alvo de operação de $15 \mathrm{~dB}$ (ganho alvo mínimo), o transiente de potência do amplificador EDFA estágio simples ilustrado na Figura 5.32(a) indica um overshoot de aproximadamente $1,42 d B$ (supressão de $7,58 \mathrm{~dB}$ em comparação com a condição bombeio fixo) e um undershoot abaixo de $1 d B$ (supressão maior que $8 d B$ ). Nesta mesma condição, o transiente de potência do amplificador híbrido (Raman/EDFA) ilustrado na Figura 5.32(c), indica um overshoot de aproximadamente $1,48 d B$ (supressão de 7,42dB) e um undershoot abaixo de $1 d B$ (supressão maior que $8 d B$ ). Comparando os resultados obtidos com ganho alvo mínimo, tem-se que o desempenho de supressão de transientes é aproximadamente igual para ambos os amplificadores considerando o ganho alvo mínimo da faixa de ganhos de operação.

Isso ocorre devido o controle automático de ganho do amplificador híbrido quando 


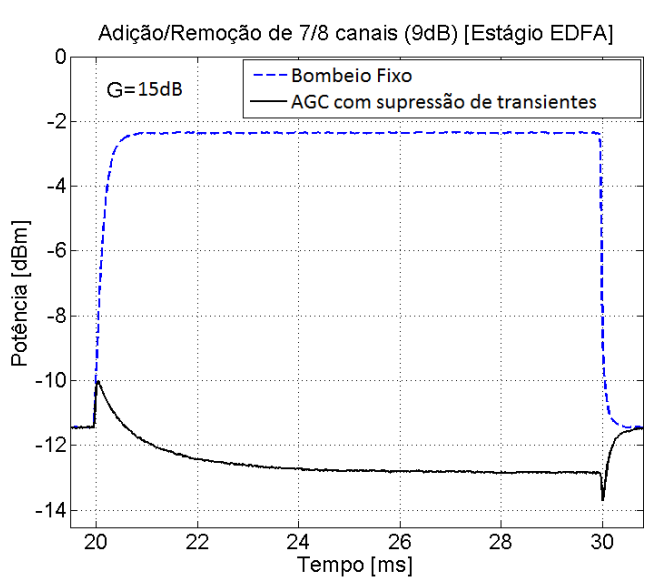

(a)

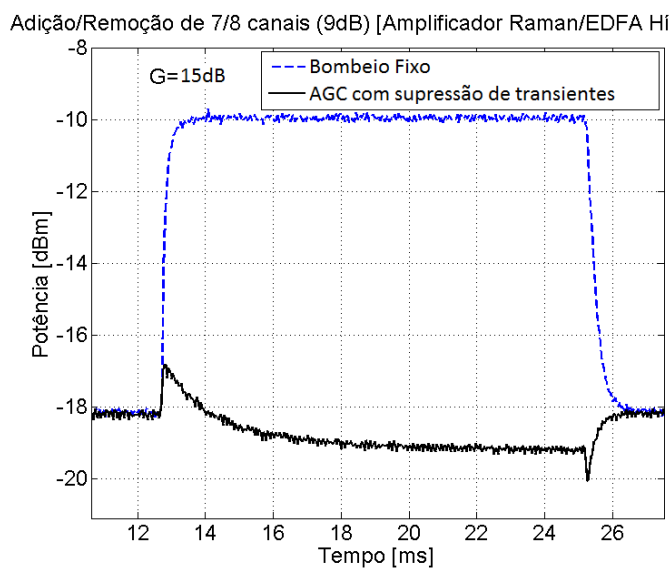

(c)

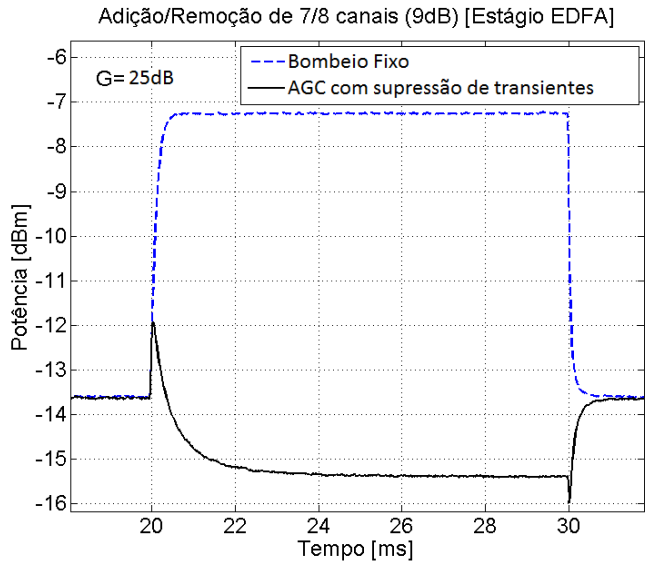

(b)

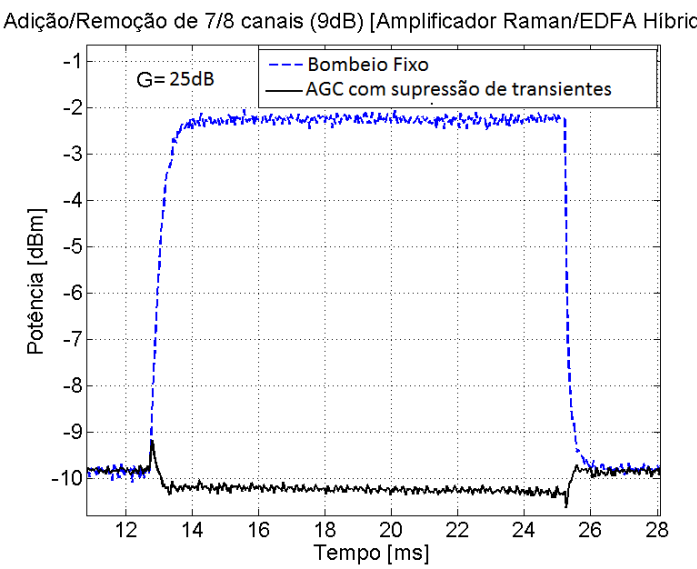

(d)

Figura 5.32: Transiente de potência no canal sobrevivente, testado para $9 \mathrm{~dB}$ de adição/remoção, sem/com AGC (com supressão de transientes) no amplificador EDFA de estágio simples com ganho $14 d B(a) / 24 d B(b)$ e amplificador óptico híbrido com gnaho $15 d B(c) / 25 d B(d)$.

requisitado a operar com ganho alvo mínimo, fornece ganho somente por meio da tecnologia EDFA, ou seja, o AGC do amplificador híbrido desliga o amplificador Raman e opera somente com o EDFA, justificando o desempenho semelhante do amplificador híbrido em comparação com o EDFA estágio simples.

Agora para o ganho alvo de operação de $25 \mathrm{~dB}$ (ganho alvo máximo), o transiente de potência do amplificador EDFA estágio simples ilustrado na Figura 5.32(b) indica um overshoot de aproximadamente $1,7 d B$ (supressão de $7,3 d B$ em comparação com a condição bombeio fixo) e um undershoot abaixo de $1 d B$ (supressão maior que $8 d B$ ). Nesta mesma condição, o transiente de potência do amplificador híbrido (Raman/EDFA) ilustrado na Figura 5.32(d), indica um overshoot de aproximadamente $0,65 d B$ (supressão de $8,35 d B$ ) e um undershoot abaixo de $0,5 d B$ (supressão maior que $8,5 d B$ ). Comparando os resultados obtidos com ganho alvo máximo, tem-se que o desempenho de supressão de transientes do amplificador híbrido é notavelmente melhor que o mesmo no amplificador EDFA estágio simples.

Como descrito na referência (Lee et al., 2005), amplificadores Raman possuem uma forte tolerância a eventos dinâmicos (adição e remoção de canais) desde que os mes- 
mos operem em regime de bombeio não depletado, que trata-se exatamente do regime de operação do amplificador Raman distribuído inserido na topologia de amplificação óptica híbrida. Além disso é também descrito na referência (Lee et al., 2005) que amplificadores EDFA operando em condição saturada (com níveis de bombeio relativamente altos) sofrem menos excursão de potência.

Desta forma o transiente de potência reduzido obtido na topologia de amplificação óptica híbrida é explicado com base na topologia do amplificador híbrido, que por contar primeiramente com a tecnologia de amplificação Raman seguida pela tecnologia de amplificação EDFA, quando operando em seu ganho alvo máximo (25dB), os bombeios Raman operam em alta potência (consequentemente operando em regime de bombeio não depletado) reduzindo o efeito do transiente de potência como descrito em (Lee et al., 2005), e em seguida, como o sinal de saída da tecnologia Raman chega a tecnologia EDFA com maior intensidade devido amplificação fornecida pela tecnologia Raman, o EDFA do amplificador híbrido opera em um nível de saturação maior que somente a tecnologia de amplificação EDFA testada previamente, reduzindo ainda mais o efeito do transiente de potência segundo (Lee et al., 2005), assim justificando a supressão de transiente melhorada para o amplificador óptico híbrido desenvolvido nesta tese.

\subsection{Conclusões Parciais}

Neste Capítulo foi apresentada a topologia do amplificação óptica híbrida (Raman distribuído/EDFA) para sistemas ópticos reconfiguráveis com repetição, seu respectivo método de controle automático de ganho e sua metodologia de projeto otimizada que leva em consideração o efeito espectral combinado das tecnologias de amplificação contidas no amplificador híbrido, visando maximizar a planicidade espectral de ganho com baixa figura de ruído para todos os pontos de operação do amplificador.

Após projeto do amplificador óptico híbrido em simulação numérica, o mesmo foi comparado em termos de desempenho óptico em enlace simples e múltiplos enlaces com relação a topologia de amplificação EDFA-VOA-EDFA. Os resultados obtidos na avaliação dos amplificadores em enlace simples mostraram melhoras de OSNR de 2, 28 a $4,49 d B$, enquanto o resultado obtido na avaliação de múltiplos enlaces mostram que com a utilização do amplificador híbrido em sistemas com repetição é possivel obter um alcance 3 vezes maior do que o mesmo obtido com o amplificador EDFA-VOA-EDFA.

Com o amplificador híbrido e o amplificador EDFA-VOA-EDFA experimentais desenvolvidos, foi realizada a comparação de desempenho em enlace único, mostrando que a melhora obtida na avaliação em simulação numérica é suportada pela investigação experimental, onde o amplificador híbrido apresentou uma melhora de OSNR comparado com o amplificador EDFA-VOA-EDFA variando de 1,67 a $5,04 d B$.

Por fim foi realizada a análise de supressão de transientes entre o amplificador híbrido experimental e um EDFA estágio único experimental, e foi constatado que para o amplificador híbrido operando próximo do ganho mínimo alvo, o desempenho de supressão de transientes fica próximo ao EDFA estágio único, porém, para o amplificador híbrido operando próximo do ganho máximo alvo, o desempenho de supressão de tran- 
sientes é notavelmente melhor que o mesmo avaliado para o EDFA estágio único.

Com base nos resultados apresentados neste Capítulo, foi comprovado que o amplificador óptico híbrido desenvolvido por meio da metodologia de projeto e controle automático de ganho descritos nesta tese, apresenta um desempenho melhorado de planicidade espectral de ganho, figura de ruído e OSNR de saída dos canais transmitidos ao longo de toda região de operação dinâmica do mesmo, tanto quando analisado em enlace simples assim como quando analisado em vários enlaces em cascata, e quando comparado com a topologia de amplificador óptico mais usada atualmente para fornecimento de ganho plano (EDFA-VOA-EDFA) em sistemas com repetição DWDM. 


\section{Capítulo 6}

\section{Conclusões}

Foi apresentado nesta tese um estudo experimental abrangente sobre topologias de amplificadores ópticos híbridos para sistemas DWDM, sendo reportada uma transmissão de 4,48 Tb/s ao longo de $302 \mathrm{~km}$ de fibra SSMF sem repetição, apresentado produto banda $\mathrm{x}$ distância no estado da arte. Especificamente, uma das contribuições desta tese foi o alcance do produto banda x distância no estado da arte, e a determinação da topologia de amplificação óptica híbrida composta pelas tecnologias Raman distribuída e EDFA, como a melhor topologia em termos de desempenho para os sistemas de 112 Gb/s DP-QPSK em sistemas ponto-a-ponto DWDM sem repetição.

Em seguida, nesta tese, foram descritas/desenvolvidas as metodologias de projeto das topologias de amplificação óptica EDFA (estágio único e duplo estágio com VOA) e Raman com controle automático de ganho utilizados em sistemas ópticos com repetição reconfiguráveis atuais. As metodologias de projeto otimizado de EDFAs (estágio único e duplo estágio com VOA), a metodologia de projeto otimizado de amplificador Raman distribuído, e um método de análise de desempenho dos amplificadores ópticos em redes dinâmicas via máscara de potência de planicidade espectral, figura de ruído e AGC. Além disso, foi desenvolvida e apresentada como contribuição, uma técnica de controle automático de ganho on-off para amplificador Raman distribuído, baseado em estimação cega da potência lançada na rede óptica.

Com base na análise de desempenho de cada topologia de amplificação óptica com AGC investigada nesta tese, foi proposto como contribuição original, uma topologia de amplificação óptica híbrida para redes reconfiguráveis com repetição e sinais de alta eficiência espectral, baseada na concatenação das tecnologias Raman distribuída e EDFA, com um novo algoritmo de controle de ganho (AGC), visando maximizar desempenho da figura de ruído e planicidade espectral de ganho para toda região de operação do amplificador.

Determinada a topologia do amplificador óptico híbrido Raman distribuído/EDFA para sistemas ópticos DWDM reconfiguráveis com repetição, foi desenvolvido nesta tese seu respectivo método de controle automático de ganho e sua metodologia de projeto otimizado que leva em consideração o efeito das tecnologias de amplificação entre si visando maximizar a planicidade espectral de ganho com baixa figura de ruído para todos os pontos de operação do amplificador.

Foi também avaliado nesta tese o amplificador óptico híbrido e a topologia de am- 
plificação EDFA-VOA-EDFA desenvolvidos em simulação óptica numérica, em termos de desempenho óptico em enlace simples e múltiplos enlaces. Os resultados obtidos na avaliação dos amplificadores em enlace simples mostraram melhoras de planicidade espectral de ganho e figura de ruído, enquanto o resultado obtido na avaliação de múltiplos enlaces mostram que com a utilização do amplificador híbrido em sistemas com repetição é possível obter um alcance 3 vezes maior do que o mesmo obtido com o amplificador EDFA-VOA-EDFA. Por meio do amplificador híbrido e o amplificador EDFA-VOA-EDFA experimentais desenvolvidos nesta tese, a melhora obtida na simulação numérica foi suportada pela investigação experimental.

Por fim foi realizada a análise de supressão de transientes entre o amplificador híbrido experimental e um EDFA estágio único experimental, e foi constatado que para o amplificador híbrido operando próximo do ganho mínimo alvo, o desempenho de supressão de transientes fica próximo ao EDFA estágio único, porém, para o amplificador híbrido operando próximo do ganho máximo alvo, o desempenho de supressão de transientes é notavelmente melhor que o mesmo avaliado para o EDFA estágio único.

A topologia de amplificação híbrida Raman contra-propagante/EDFA com sua respectiva metodologia de controle automático de ganho desenvolvido nesta tese, garantiu o desempenho superior com relação às topologias de amplificação óptica utilizadas atualmente em redes ópticas DWDM reconfiguráveis. A melhora de desempenho alcançada pelo amplificador híbrido alvo desta tese, permite que os sistemas DWDM com canais de $10 \mathrm{~Gb} / \mathrm{s}$ que encontram-se no limite de seu desempenho, sejam evoluídos para sistemas de $100 \mathrm{~Gb} / \mathrm{s}$ apenas por meio da troca dos elementos de amplificação para o amplificador óptico híbrido com o seu devido controle automático de ganho, evitando dispendiosas trocas da infraestrutura de fibras ópticas.

\subsection{Trabalhos Futuros}

Em seguida, são sugeridos alguns temas para trabalhos nesta linha de pesquisa

1. Avaliação experimental do desempenho do amplificador óptico híbrido com as topologias de amplificação óptica EDFA, EDFA acoplado com VOA e Raman (sem controle de ganho) com EDFA em sistemas de comunicações ópticas DWDM reconfiguráveis.

2. Avaliação de desempenho experimental do amplificador óptico híbrido em loop de recirculação com relação as topologias de amplificação óptica para redes DWDM reconfiguráveis utilizadas atualmente.

3. Estudo de compensação automática da planicidade espectral de ganho por meio do controle dos níveis dos bombeios do amplificador óptico híbrido Raman/EDFA.

\subsection{Publicações Referentes a Tese}

Até o presente momento foram publicados os seguintes artigos referentes ao trabalho desenvolvido nesta tese: 
1. Rodrigues Fernandes de Oliveira, J.; de Moura, U.C.; Rodrigues de Paiva, G.E.; Passos de Freitas, A.; Hecker de Carvalho, L.H.; Parahyba, V.E.; Rodrigues Fernandes de Oliveira, J.C.; Araujo Romero, M., "Hybrid EDFA/Raman Amplification Topology for Repeaterless $4.48 \mathrm{~Tb} / \mathrm{s}$ (40 x $112 \mathrm{~Gb} / \mathrm{s}$ DP-QPSK) Transmission Over $302 \mathrm{Km}$ of G.652 Standard Single Mode Fiber,"Lightwave Technology, Journal of , vol.31, no.16, pp.2799,2808, Aug.15, 2013. DOI: 10.1109/JLT.2013.2273438.

2. OLIVEIRA, Juliano R. F.; MOURA, Uiara C.; OLIVEIRA, Júlio C. R. F. and ROMERO, Murilo A.. Hybrid distributed Raman/EDFA amplifier with hybrid automatic gain control for reconfigurable WDM optical networks. J. Microw. Optoelectron. Electromagn. Appl. [online]. 2013, vol.12, n.2, pp. 602-616. ISSN 2179-1074. DOI: 10.1590/S2179-10742013000200028.

3. de Oliveira, J.R.F.; de Moura, U.C.; de Oliveira, J.C.R.F.; Romero, M.A., "Experimental hybrid optical amplifier with flat spectral gain and improved NF using novel hybrid gain control scheme for dynamic WDM networks,"Microwave \& Optoelectronics Conference (IMOC), 2013 SBMO/IEEE MTT-S International , pp. 1,5, 4-7 Aug. 2013. DOI: 10.1109/IMOC.2013.6646591.

4. Oliveira, J.R.F.; Freitas, A.P.; Moura, U.C.; Rosa, E.S.; Diniz, J. C M; Oliveira, J. C R F; Romero, M.A., "Advanced modulation formats and receiver filtering analysis of optical WDM systems with optimized distributed Raman amplifiers,"Microwave \& Optoelectronics Conference (IMOC), 2011 SBMO/IEEE MTT-S International , pp.705,709, Oct. 29 2011-Nov. 1 2011. DOI: 10.1109/IMOC.2011.6169357.

5. Juliano R. F. de Oliveira, Getúlio E. R. de Paiva, Uiara C. de Moura, Alexandre P. Freitas, Marcelo L. da Silva, Júlio C. R. F. de Oliveira, Murilo A. Romero, "Amplificador Óptico híbrido para redes WDM reconfiguráveis com formatos de modulação avançados e recepção coerente,"Periódico Cadernos CPQD Tecnologia, Vol.7 No 2, pp 59-74, 2011.

6. Juliano R. F. de Oliveira, Uiara de Moura, Júlio Oliveira, Murilo Romero, "Hybrid Distributed Raman/EDFA Amplifier with Novel Automatic Gain Control for Reconfigurable WDM Optical Network,"MOMAG 2012, João Pessoa, Brasil.

7. Juliano Oliveira, Uiara de Moura, Alexandre Freitas, Júlio Oliveira, "Metodologia de Projeto de Amplificadores Raman Distribuídos: Minimização de Bombeios Considerando Restrições dos Componentes,"SBrT 2011, Curitiba, Brasil. 


\section{Referências Bibliográficas}

Abu Bakar et al.(2011) MH Abu Bakar, SJ Sheih, FR Mahamd Adikan e MA Mahdi. Variable gain-flattened 1-band erbium-doped fiber amplifier. Laser Physics, páginas $1-7$. Citado na pág. $71,72,83,94,95$

Agrawal(2002) Govind P. Agrawal. Fiber Optic Communication Systems. John Wiley, $3^{\circ}$ edição. Citado na pág. 2, 3, 10

Agrawal(2007) Govind P. Agrawal. Nonlinear Fiber Optics. Academic Press, San Diego, CA, USA, $4^{\circ}$ edição. Citado na pág. 62,183

Ahmad et al.(2008) A. Ahmad, M.A. Mahdi, MI Md Ali e AK Zamzuri. Investigation of hybrid gain-clamped raman-fiberamplifier/edfa utilizing pump reuse technique. Laser Physics Letters, 5(3):202-205. Citado na pág. 3, 77

Alferness et al.(2000) Rod C. Alferness, Herwig Kogelnik e Thomas H. Wood. The evolution of optical systems: Optics everywhere. Bell Labs Technical Journal, 5(1):188-202. Citado na pág. 14

Alfiad et al.(2009a) Mohammad S. Alfiad et al. A comparison of electrical and optical dispersion compensation for $111 \mathrm{gb} / \mathrm{s}$ polmux rz dqpsk. J. LIGHTW. TECHNOL., 27: 3590. Citado na pág. 40

Alfiad et al.(2009b) M.S. Alfiad, Dirk Van den Borne, F.N. Hauske, A. Napoli, A.M.J. Koonen e H. de Waardt. Maximum-likelihood sequence estimation for optical phaseshift keyed modulation formats. Lightwave Technology, Journal of, 27(20):4583-4594. ISSN 0733-8724. doi: 10.1109/JLT.2009.2025148. Citado na pág. 64

Becker et al.(1999) P. C. Becker et al. Erbium Doped Fiber Amplifiers Fundamentals and Technology. Academic Press, San Diego, CA, USA. Citado na pág. 82, 175, 176, 182

Bigo et al.(1999) S. Bigo, S. Gauchard, A. Bertaina e J.P. Hamaide. Experimental investigation of stimulated raman scattering limitation on wdm transmission over various types of fiber infrastructures. Photonics Technology Letters, IEEE, 11(6):671-673. Citado na pág. 74

Bilal et al.(2012) SM Bilal, M. Zafrullah e MK Islam. Achieving gain flattening with enhanced bandwidth for long haul wdm systems. Journal of Optical Technology, 79(2): 80-83. Citado na pág. 77

Bouteiller et al.(2003) J.-C. Bouteiller et al. Dual-order raman pump. IEEE PHOTON. TECHNOL. LETT., 15:212. Citado na pág. 191

Breuer et al.(1998) D. Breuer, H.J. Ehrke, F. Kuppers, R. Ludwig, K. Petermann, H.-G. Weber e K. Weich. Unrepeated 40-gb/s rz single-channel transmission at $1.55 \mathrm{um}$ using various fiber types. Photonics Technology Letters, IEEE, 10(6):822-824. Citado na pág. 14 
Bromage(2004) J. Bromage. Raman amplification for fiber communication systems. J. LIGHTW. TECHNOL., 22(1). Citado na pág. xxii, 3, 182, 183

Carniglia(2000) C. K. Carniglia. Design of thin-film interference filters for telecommunications applications. Em Optical Fiber Communication Conference, 2000, volume 2, páginas 93 vol.2-. doi: 10.1109/OFC.2000.868250. Citado na pág. 69

CHANG et al.(2013) DO-IL CHANG, Pallavi Patki, Sergey Burtsev e Wayne Pelouch. $8 \times 120 \mathrm{gb} / \mathrm{s}$ transmission over a cascade of two spans with a total loss in excess of $120 \mathrm{db}$. Em Optical Fiber Communication Conference/National Fiber Optic Engineers Conference 2013, página NM2E.6. Optical Society of America. doi: 10.1364/NFOEC.2013.NM2E.6. URL http://www.opticsinfobase.org/abstract.cfm? URI=NFOEC-2013-NM2E.6. Citado na pág. 37

Coskun et al.(2003) T.H. Coskun et al. Automated optimization tools help to design gain flattened broadband raman amplifiers. Relatório técnico. Citado na pág. 99, 102, 103

Cowle(2010) G.J. Cowle. Challenges and opportunities for optical amplifiers in metro optical networks. Em Proceedings of SPIE, volume 7621, página 76210B. Citado na pág. $68,78,84$

Dawson e Rogerson(1984) P. Dawson e S. Rogerson. An undersea fiber-optic regenerator using an integral-substrate package and flip-chip saw mounting. Selected Areas in Communications, IEEE Journal on, 2(6):966-972. Citado na pág. 15

de Barros et al.(2000) M. R. X. de Barros et al. Amplificadores Ópticos a fibra Óptica dopada com Érbio. Curso de Amplificação Óptica e Sistemas DWDM. Citado na pág. 175

de Moura et al.(2012) Uiara de Moura, Juliano Oliveira, Rafael Amgarten, Getulio Paiva e Júlio Oliveira. Caracterizador automatizado de máscara de potência de amplificadores Ópticos para redes wdm reconfiguráveis. Em SBrT 2012 0, Centro de Convenções Ulysses Guimarães. URL http://XXXXX/98890.pdf. Citado na pág. 68, 79, 80, 81

de Oliveira et al.(2013a) J. R. F. de Oliveira, U.C. de Moura, G.E. Rodrigues de Paiva, A. Passos de Freitas, L.H. Hecker de Carvalho, V.E. Parahyba, J.C. Rodrigues Fernandes de Oliveira e M. Araujo Romero. Hybrid edfa/raman amplification topology for repeaterless $4.48 \mathrm{tb} / \mathrm{s}$ ( $40 \times 112 \mathrm{gb} / \mathrm{s} \mathrm{dp}$-qpsk) transmission over $302 \mathrm{~km}$ of g.652 standard single mode fiber. Lightwave Technology, Journal of, 31(16):2799-2808. ISSN 0733-8724. doi: 10.1109/JLT.2013.2273438. Citado na pág. 37, 58, 61

de Oliveira et al.(2013b) J.R.F. de Oliveira, U.C. de Moura, J.C.R.F. de Oliveira e M.A. Romero. Experimental hybrid optical amplifier with flat spectral gain and improved nf using novel hybrid gain control scheme for dynamic wdm networks. Em Microwave Optoelectronics Conference (IMOC), 2013 SBMO/IEEE MTT-S International, páginas 15. doi: 10.1109/IMOC.2013.6646591. Citado na pág. 115

de Oliveira et al.(2011) Juliano R. F. de Oliveira, Getúlio E. R. de Paiva, Uiara C. de Moura, Alexandre P. Freitas, Marcelo L. da Silva, Júlio C. R. F. de Oliveira e Murilo A. Romero. Amplificador óptico híbrido para redes wdm reconfiguráveis com formatos de modulação avançados e recepção coerente. Cadernos CPQD Tecnologia, 7(2): 59-74. Citado na pág. 68, 83, 115

de Oliveira(2008) Juliano Rodrigues Fernandes de Oliveira. Controle automático eletrônico de ganho com supressão de transientes aplicado a edfas em redes Ópticas wdm. Dissertação de Mestrado, Universidade de Campinas (UNICAMP). Citado na pág. 2, 67, 69, 70 
de Oliveira(2004) Júlio César Rodrigues Fernandes de Oliveira. Projeto de edfas com controle automático de ganho totalmente Óptico para aplicaÇões em redes wdm. Dissertação de Mestrado, Universidade de Campinas (UNICAMP). Citado na pág. xxii, 2, 67, $69,177,178$

de Oliveira(2007) Júlio César Rodrigues Fernandes de Oliveira. Amplificadores Ópticos com Controle Automático de Ganho para Aplicação em Redes Ópticas Reconfiguráveis. Tese de Doutorado, Universidade de Campinas (UNICAMP). Citado na pág. 2, 67, 69

der Borne(2008) D. Van der Borne. Robust Optical Transmission Systems: Modulation and Equalization. Tese de Doutorado, Technische Universiteit Eindhoven. Citado na pág. 2,73

Desurvire(1994) E. Desurvire. Erbium-Doped Fiber Amplifiers - Principles and Applications. John Wiley and Sons, New York, USA. Citado na pág. 154, 175, 176, 182

Desurvire et al.(1987) E. Desurvire et al. High-gain erbium-doped fibre amplifier. Optics Letters, 12(11):888. Citado na pág. 1

Dung et al.(2009) J.C. Dung, Y.R. Jian e B.S. Wu. All-optical gain-clamping dispersioncompensated raman/edfas for wdm systems. Em Lasers and Electro-Optics, 2009 and 2009 Conference on Buantum electronics and Laser Science Conference. CLEO/BELS 2009. Conference on, páginas 1-2. IEEE. Citado na pág. 3, 77

Electric(2012) Furukawa Electric. Fol 1437 series - 14xx-nm pump with fbg for raman application up to $500 \mathrm{mw}$. Relatório técnico. Citado na pág. 22

Emori e Namiki(2001) Y. Emori e S. Namiki. Broadband raman amplifiers for wdm. IEICE Transaction on Communications, E84-B:1219-1223. Citado na pág. xxii, 187, 188

Emori et al.(2002) Y. Emori et al. Broadband flat-gain and low-noise raman amplifiers pumped by wavelength-multiplexed high-power laser diodes. Optical Fiber Technology, 8(2):107-122. Citado na pág. 99, 103

Eskildsen et al.(1996) L. Eskildsen et al. Capacity upgrade of transmission systems by raman amplification. Optical Amplifiers and Their Applications. Citado na pág. 182

Essiambre et al.(2010) R. Essiambre, G. Kramer, P.J. Winzer, G.J. Foschini e B. Goebel. Capacity limits of optical fiber networks. Lightwave Technology, Journal of, 28(4):662701. ISSN 0733-8724. doi: 10.1109/JLT.2009.2039464. Citado na pág. Xv, 11

Essiambre et al.(2002) R.-J. Essiambre et al. Broadband flat-noise raman amplifier using low noise bi-directionally pumping sources. J. LIGHTW. TECHNOL., 14:914. Citado na pág. 190

Europe(2012) Fujitsu Semiconductor Europe. Fujitsu digital to analog converter - leia 55/65 gsa/s 8-bit dac. Relatório técnico. Citado na pág. 23

Felinskyi(2006) G. Felinskyi. Nonlinear fitting of the complex raman gain profile in single-mode optical fibers. Em 11th Int. Conf. on Mathematical Methods in Electromagnetic Theory, página 378. Citado na pág. 102

Feng et al.(2004) X. Feng, W. Zhang, X. Liu e J. Peng. A novel control method for on-off gain and gain tilt of fiber raman amplifiers. Chinese Optics Letters, 2(4):196-199. Citado na pág. 74

Feng et al.(2005) X. Feng, X. Liu, W. Zhang e J. Peng. Investigation of dynamical pump control for backward-pumped fiber raman amplifiers. Optics communications, 245(1): 211-225. Citado na pág. 74 
Fludger(2000) C. Fludger. Dynamic gain tilt of a gain flattened distributed raman amplifier under saturation in a dwdm system. Em Optical Amplifiers and Their Applications. Optical Society of America. Citado na pág. 73

Fludger et al.(2001) C. R. Fludger et al. Fundamental noise limits in broadband raman amplifiers. Optical Fiber Communication Conference. Citado na pág. 190

Glingener(2011) Christoph Glingener. Optical networking trends and evolution. Optical Fiber Communication Conference. Citado na pág. 22, 24

Gloge et al.(1980) D. Gloge et al. Bell Systems Techinical Journal, 59:1365. Citado na pág. 14

GmbH(2011a) Innolume GmbH. Ld-12xx-fbg-500 - fiber bragg grating wavelength locked high power laser diode. Relatório técnico. Citado na pág. 22

GmbH(2011b) Innolume GmbH. Ld-13xx-fbg-250 - fiber bragg grating wavelength locked high power laser diode. Relatório técnico. Citado na pág. 22

Gnauck et al.(2012) A.H. Gnauck, P.J. Winzer, A. Konczykowska, F. Jorge, J. Dupuy, M. Riet, G. Charlet, B. Zhu e D.W. Peckham. Generation and transmission of 21.4gbaud pdm 64-qam using a novel high-power dac driving a single i/q modulator. Lightwave Technology, Journal of, 30(4):532-536. Citado na pág. 2

Hansen et al.(1997) P. B. Hansen et al. Optimal design of flat-gain wide-band fiber raman amplifiers. IEEE PHOTON. TECHNOL. LETT., 9:262. Citado na pág. 182

Headley e Agrawal(2005) C. Headley e G. P. Agrawal. Raman Amplification In Fiber Optical Communication Systems. Academic Press, San Diego, CA, USA. Citado na pág. xxii, 3, 40, 79, 82, 102, 132, 134, 184, 185, 186, 189

il Chang et al.(2012) Do il Chang, P. Patki, S. Burtsev e W. Pelouch. Realtime processed $12 \times 120 \mathrm{gb} / \mathrm{s}$ unrepeatered transmission over $383.5 \mathrm{~km}$ psc fiber and $342.7 \mathrm{~km}$ smf without ropa. Em Photonics Conference (IPC), 2012 IEEE, páginas 856-857. doi: 10.1109/IPCon.2012.6359264. Citado na pág. 37

INC(2011) FUJITSU NETWORK COMMUNICATIONS INC. Beyond 100g. Relatório técnico. URL http://www.fujitsu.com/downloads/TEL/fnc/whitepapers/Beyond-100G. pdf. Citado na pág. 137, 153

Ip e Kahn(2008) E. Ip e J.M. Kahn. Compensation of dispersion and nonlinear impairments using digital backpropagation. Lightwave Technology, Journal of, 26(20): 3416-3425. ISSN 0733-8724. doi: 10.1109/JLT.2008.927791. Citado na pág. 64

ITU(2012a) ITU. G.694.1 - Spectral grids for WDM applications: DWDM frequency grid. International Telecommunications Union, February 2012a. Citado na pág. 25

ITU(1998) TELECOMMUNICATION STANDARDIZATION SECTOR OF ITU. Recomendation g.651 optical fiber - characteristics of a 50/125 mm multimode graded index optical fibre cable. Relatório técnico, ITU-T. Citado na pág. 13

ITU(2009a) TELECOMMUNICATION STANDARDIZATION SECTOR OF ITU. Recomendation g.652 optical fiber - characteristics of a single-mode optical fibre and cable. Relatório técnico, ITU-T. Citado na pág. 13, 16, 21

ITU(2010) TELECOMMUNICATION STANDARDIZATION SECTOR OF ITU. Recomendation g.653 optical fiber - characteristics of a dispersion-shifted, single-mode optical fibre and cable. Relatório técnico, ITU-T. Citado na pág. 13 
ITU(2012b) TELECOMMUNICATION STANDARDIZATION SECTOR OF ITU. Recomendation g.654 optical fiber - characteristics of a cut-off shifted single-mode optical fibre and cable. Relatório técnico, ITU-T. Citado na pág. 21

ITU(2009b) TELECOMMUNICATION STANDARDIZATION SECTOR OF ITU. Recomendation g.655 optical fiber - characteristics of a non-zero dispersion-shifted single-mode optical fibre and cable. Relatório técnico, ITU-T. Citado na pág. 16, 21

Jacobs e Stauffer(1980) F. Jacobs e J. R. Stauffer. A metropolitan trunk lightwave system. Proceedings of the IEEE, 68(10):1286-1290. Citado na pág. 14

JACOBS(1995) IRA JACOBS. Lightwave system development: Looking back and ahead. Opt. Photon. News, 6(2):19. Citado na pág. 14

JDSU(2011) JDSU. WaveReady WRA-217: Multichannel Erbium-Doped Fiber Amplifier (EDFA). JDSU, 2011. Citado na pág. 69, 78

Jones(1852) Alexander Jones. Historical Sketch of The Electric Telegraph. Putnam, New York, USA. Citado na pág. 10

Kado et al.(2002) S. Kado et al. Gain and noise tilt control in multiwavelength bidirectionally pumped raman amplifier. Optical Fiber Communication Conference. Citado na pág. xxii, 190, 191

Kim e Park(2005) P. Kim e N. Park. Semianalytic dynamic gain-clamping method for the fiber raman amplifier. Photonics Technology Letters, IEEE, 17(4):768-770. Citado na pág. 3,75

Kodo et al.(2001) S. Kodo et al. Broadband flat-noise raman amplifier using low noise bi-directionally pumping sources. European Conference and Exhibition on Optical Communication. Citado na pág. 190, 191

Labrunie et al.(2001) L. Labrunie et al. Unrepeated transmission over $321 \mathrm{~km}$ using second order pumping distributed raman amplification. Optical Amplifers and Their Applications. Citado na pág. 3, 191

Lang et al.(2011) Felix Lang et al. A 6 bit $25 \mathrm{gs} / \mathrm{s}$ flash interpolating adc in $90 \mathrm{~nm} \mathrm{cmos}$ technology. Ph.D. Research in Microelectronics and Electronics (PRIME). Citado na pág. 20

Lee et al.(2005) J. H. Lee et al. A detailed experimental study on single-pump raman/edfa hybrid amplifiers: Static, dynamic, and system performance comparison. J. LIGHTW. TECHNOL., 23(11):3484-3493. Citado na pág. xvi, 3, 28, 30, 31, 32, 74, 76, 77, 157,158

Liaw et al.(2010) S.K. Liaw, Y.S. Huang, H.K. Hung, N.K. Chen, K.C. Hsu, Y.L. Yu, T. Wang, A. Manshina e Y. Tver'yanovic. Dispersion management and gain flattened for a bridge-type hybrid amplifiers in a pumping recycling mechanism. Em Ultra Modern Telecommunications and Control Systems and Workshops (ICUMT), 2010 International Congress on, páginas 1180-1182. IEEE. Citado na pág. 3

Maeda et al.(1990) M.W. Maeda, W. Sessa, W.I. Way, A. Yi-Yan, L. Curtis, R. Spicer e R.I. Laming. The effect of four-wave mixing in fibers on optical frequency-division multiplexed systems. Lightwave Technology, Journal of, 8(9):1402-1408. ISSN 07338724. doi: 10.1109/50.59171. Citado na pág. 62

Mahdi et al.(2009) M.A. Mahdi, S.J. Sheih e F.R.M. Adikan. Simplified ase correction algorithm for variable gain-flattened erbium-doped fiber amplifier. Optics Express, 17 (12):10069-10075. Citado na pág. 71, 72 
Martinelli et al.(2002) C. Martinelli et al. Analysis of bidirectional and second-order pumping in long-haul systems with distributed raman amplification. European Conference and Exhibition on Optical Communication. Citado na pág. 191

Martini et al.(2009) M. M. J. Martini et al. Multi-pump optimization for raman+edfa hybrid amplifiers under pump residual recycling. International Microwave and Optoelectronics Conference (IMOC). Citado na pág. xvi, 31, 32, 33

Masuda et al.(1999) H. Masuda et al. Wide-band and gain-flattened hybrid fiber amplifier consisting of an edfa and a multiwavelength pumped raman amplifier. IEEE PHOTON. TECHNOL. LETT., 11(6):647-649. Citado na pág. Xv, 26, 27

Mateo et al.(2008) Eduardo Mateo, Likai Zhu e Guifang Li. Impact of xpm and fwm on the digital implementation of impairment compensation for wdm transmission using backward propagation. Opt. Express, 16(20):16124-16137. doi: 10.1364/OE. 16.016124. URL http://www.opticsexpress.org/abstract.cfm?URI=oe-16-20-16124. Citado na pág. 62

Mermelstein et al.(2002) M. D. Mermelstein et al. IEEE ELECTRON DEVICE LETT., 38: 403. Citado na pág. xxii, 189

Metz(1975) S. Metz. The avalanche phototransistor - a novel type of radiation detector and its potential use in optical communication systems. Electron Devices, IEEE Transactions on, 22(8):617-619. Citado na pág. 15

Mowla e Granpayeh(2009) A. Mowla e N. Granpayeh. Optimum design of a hybrid erbium-doped fiber amplifier/fiber raman amplifier using particle swarm optimization. Applied optics, 48(5):979-984. Citado na pág. 77

Nakazawa et al.(2010) M. Nakazawa et al. High Spectral Density Optical Communication Technologies, volume 6. SpringerLink. Citado na pág. 2, 20

Namiki e Emori(2001) S. Namiki e Y. Emori. Ultrabroad-band raman amplifiers pumped and gain-equalized by wavelength-division-multiplexed high-power laser diodes. Selected Topics in Quantum Electronics, IEEE Journal of, 7(1):3-16. Citado na pág. 3, 73, 74

Oliveira et al.(2013a) J. C. R. F. Oliveira, R. Silva, E.P. Silva, L. H. H. Carvalho, M. L. Silva, J. M. C. Neto e A. Paradisi. Crosstalk penalties analysis in mixed line transmission rates (10g-ook/40g-dqpsk/112g-dp-qpsk/224g-dp-16-qam) optical flexible grid networks. Microwave and Optical Technology Letters, 55(1):119-122. ISSN 1098-2760. doi: 10.1002/mop.27269. URL http://dx.doi.org/10.1002/mop.27269. Citado na pág. 62

Oliveira et al.(2013b) J. R. F. Oliveira, U. C. Moura, J. C. R. F. Oliveira e M. A. Romero. Hybrid distributed ramanedfa amplifier with hybrid automatic gain control for reconfigurable wdm optical networks. Journal of Microwaves, Optoelectronics and Electromagnetic Applications, 12(2):602-616. Citado na pág. 75, 76, 115

Oliveira et al.(2012) Juliano Oliveira, Uiara de Moura, Júlio Oliveira e Murilo A Romero. Hybrid distributed raman/edfa amplifier with novel automatic gain control for reconfigurable wdm optical networks. Em MOMAG 2012 0. URL http:/ XXXXX/100792.pdf. Citado na pág. $68,75,76,79,81,115$

Oliveira et al.(2011a) Juliano R. F. Oliveira et al. Metodologia de projeto de amplificadores raman distribuídos: Minimização de bombeios considerando restrições dos componentes. Brasil. SBrT. Citado na pág. 83, 99, 188 
Oliveira et al.(2011b) Júlio C. R. F. Oliveira et al. Transmissão de 32x112gb/s com modulação nrz-dp-qpsk por $4050 \mathrm{~km}$ em redes wdm com alta eficiência espectral. Citado na pág. 39

Otani et al.(1995) T. Otani et al. $5.3 \mathrm{gbit} / \mathrm{s} 11300 \mathrm{~km}$ data transmission using actual submarine cables and repeaters. IEEE ELECTRON DEVICE LETT., 31:380. Citado na pág. 17

Paiva et al.(2012) Getulio Paiva, Juliano Oliveira, Uiara de Moura, Rafael Amgarten e Júlio Oliveira. Metodologia de projeto de edfas de alto desempenho para redes wdm reconfiguráveis. Em MOMAG 2012 (). URL http://XXXXX/100797.pdf. Citado na pág. 68, $70,71,72,73,83,85$

Pal et al.(2007) M. Pal, S. Bandyopadhyay, P. Biswas, R. Debroy, MC Paul, R. Sen, K. Dasgupta e SK Bhadra. Study of gain flatness for multi-channel amplification in single stage edfa for wdm applications. Optical and Buantum Electronics, 39(14):12311243. Citado na pág. $71,83,89,90,94$

Phillips(2003) G.M. Phillips. Interpolation and Approximation by Polynomials. CMS Books in Mathematics. Springer. ISBN 9780387002156. Citado na pág. 122

Ramaswami e Sivarajan(2001) R. Ramaswami e K. N. Sivarajan. Optical Networks: A Practical Perspective. Academic Press, London, England, second edição. Citado na pág. 10

Razeghi(1995) M. Razeghi. Ingaasp/gaas diode laser, Jan 1995. URL https://www. google.com/patents/US5384151. US Patent 5,384,151. Citado na pág. 191

Reichmann et al.(2006) K.C. Reichmann, P.P. Iannone, Xiang Zhou, N.J. Frigo e R.R. Hemenway. 240-km cwdm transmission using cascaded soa raman hybrid amplifiers with 70-nm bandwidth. Photonics Technology Letters, IEEE, 18(2):328-330. ISSN 1041-1135. doi: 10.1109/LPT.2005.861979. Citado na pág. 26

Renaudier et al.(2010) J. Renaudier, O. Bertran-Pardo, L. Pierre, P. Tran, H. Mardoyan, G. Charlet e S. Bigo. Nonlinear tolerance of ultra-densely spaced $100 \mathrm{gb} / \mathrm{s}$ coherent pdm-qpsk channels. Em Optical Communication (ECOC), 2010 36th European Conference and Exhibition on, páginas 1-3. doi: 10.1109/ECOC.2010.5621411. Citado na pág. 62

Renaudier et al.(2011) J. Renaudier et al. Will $100 \mathrm{gb} / \mathrm{s}$ resist higher bit rates? European Conference and Exhibition on Optical Communication. Citado na pág. 24

R.J. Mears et al.(1987) D.N. Payne R.J. Mears et al. Low-noise erbium-doped fibre amplifier operating at $1.54 \mathrm{~mm}$. IEEE ELECTRON DEVICE LETT., 23(19):1026. Citado na pág. 1

Roberts et al.(2010) Kim Roberts et al. 100g and beyond with digital coherent signal processing. IEEE COMMUN. MAG., 48(7):62-69. Citado na pág. 1, 2

Rottwitt et al.(1999) K. Rottwitt et al. Transparent $80 \mathrm{~km}$ bi-directionally pumped distributed raman amplifier with second order pumping. European Conference and Exhibition on Optical Communication. Citado na pág. 190

Runge et al.(1982) P. K. Runge, C. A. Brackett, R. F. Gleason, D. Kalish, P. D. Lazay, T. R. Meeker, D. G. Ross, C. B. Swan, A. R. Wahl, R. E. Wagner, J. C. Williams e D. P. Jablonowski. 101-km lightwave undersea system experiment at $274 \mathrm{mb} / \mathrm{s}$. página PD7. Optical Society of America. Citado na pág. 14 
Sakamoto et al.(2006) T. Sakamoto, Shin ichi Aozasa, M. Yamada e M. Shimizu. Hybrid fiber amplifiers consisting of cascaded tdfa and edfa for wdm signals. Lightwave Technology, Journal of, 24(6):2287-2295. ISSN 0733-8724. doi: 10.1109/JLT.2005. 863243. Citado na pág. 26

Sargent(2004) Robert B. Sargent. Recent advances in thin film filters. Em Optical Fiber Communication Conference, página TuD6. Optical Society of America. Citado na pág. 69

Savory(2008) Seb J. Savory. Digital filters for coherent optical receivers. Optics Express, 16(2):804-817. Citado na pág. 1, 20, 21, 35, 40

Savory(2010) Seb J. Savory. Digital coherent optical receivers: Algorithms and subsystems. IEEE Journal of Selected Topics in Guantum Electronics, 16(5):1164-1179. Citado na pág. 4,24

Seimetz(2009) Matthias Seimetz. High-Order Modulation for Optical Fiber Transmission. Springer Berlin Heidelberg. Citado na pág. 2

Seo et al.(2005) H. S. Seo et al. A novel hybrid silica wide-band amplifier covering s + c + 1 bands with 105-nm bandwidth. IEEE PHOTON. TECHNOL. LETT., 17(9):1830-1832. Citado na pág. xvi, 3, 27, 29

Stark et al.(2012) A.J. Stark, Yu-Ting Hsueh, S. Searcy, T.F. Detwiler, Cheng Liu, M.M. Filer, S. Tibuleac, Gee-Kung Chang e S.E. Ralph. Scaling 112 gb/s optical networks with the nonlinear threshold metric. Lightwave Technology, Journal of, 30(9):12911298. ISSN 0733-8724. doi: 10.1109/JLT.2012.2185037. Citado na pág. 62

Stolen et al.(1972) R. H. Stolen et al. Applied Physics Letters, 20:62. Citado na pág. 182

Stolen et al.(1973) R. H. Stolen et al. Applied Physics Letters, 22:276. Citado na pág. 182

Takeda et al.(2002) Y. Takeda et al. Hybrid amplifier configuration of c-band edfa and distributed raman amplifier with temperature insensitive gain profile. European Conference and Exhibition on Optical Communication. Citado na pág. xvi, 26, 27, 28

Tiwari et al.(2009) U. Tiwari, K. Thyagarajan e MR Shenoy. Simulation and experimental characterization of raman/edfa hybrid amplifier with enhanced performance. Optics Communications, 282(8):1563-1566. Citado na pág. 3

Uniphase(2009) JDS Uniphase. Full tunnable transponder 10.7gbps. Relatório técnico. URL http://wircom.com.ua/content/1730/7500ttdscmsae.pdf. Citado na pág. 137, 153

Uniphase(2011) JDS Uniphase. S34 series - up to 450mw fiber bragg grating stabilized $14 \times x$ nm pump modules. Relatório técnico. Citado na pág. 22

Vodhanel et al.(1990) R.S. Vodhanel, A.F. Elrefaie, M.Z. Iqbal, R.E. Wagner, J. Gimlett e S. Tsuji. Performance of directly modulated dfb lasers in 10-gb/s ask, fsk, and dpsk lightwave systems. Lightwave Technology, Journal of, 8(9):1379-1386. Citado na pág. 14

Way(2012) Winston I. Way. Optimum architecture for mxn multicast switch-based colorless, directionless, contentionless, and flexible-grid roadm. Em National Fiber Optic Engineers Conference, página NW3F.5. Optical Society of America. Citado na pág. 25

Wuth et al.(2008) T. Wuth, M.W. Chbat e V.F. Kamalov. Multi-rate $(100 \mathrm{~g} / 40 \mathrm{~g} / 10 \mathrm{~g})$ transport over deployed optical networks. Em Optical Fiber communication/National Fiber Optic Engineers Conference, 2008. OFC/NFOEC 2008. Conference on, páginas 1-9. Ieee. Citado na pág. 20 
Yamada et al.(1981) J. I. Yamada et al. $2 \mathrm{gbit} / \mathrm{s}$ optical transmission experiments at 1.3 $\mu \mathrm{m}$ with $44 \mathrm{~km}$ single-mode fibre. IEEE ELECTRON DEVICE LETT., 17:479. Citado na pág. 14

Zhou et al.(2006) X. Zhou, M. Feuer e M. Birk. A simple feed-forward control algorithm for fast dynamic gain profile control in a multiwavelength forward-pumped raman fiber amplifier. Photonics Technology Letters, IEEE, 18(9):1004-1006. Citado na pág. 75, 76

Zhu et al.(2013) B. Zhu, P. Borel, K. Carlson, X. Jiang, D.W. Peckham e R.J. Lingle. Unrepeatered transmission of 3.2-tb/s (32 x 120-gb/s) over 445-km fiber link with aeff managed span. Em Optical Fiber Communication Conference and Exposition and the National Fiber Optic Engineers Conference (OFC/NFOEC), 2013, páginas 1-3. Citado na pág. 37

Zyskind e Srivastava(2011) John Zyskind e Atul Srivastava. Optically Amplified WDM Networks. Academic Press, $1^{\circ}$ edição. Citado na pág. 1, 2, 25, 32, 69, 70, 154 
REFERÊNCIAS BIBLIOGRÁFICAS 


\section{Apêndice}

\section{A Tecnologias de Amplificação Óptica}

Nesta seção serão apresentados os fundamentos das tecnologias de amplificação óptica mais utilizadas em redes de comunicações ópticas DWDM reconfiguráveis de nova geração, e alvo de estudo desta tese. Dentre as diversas tecnologias de amplificação óptica existentes, esta seção dará foco nas tecnologias com maior potencial de uso nas redes de comunicação óptica atuais e futuras. Desta forma serão apresentadas as seguintes tecnologias: amplificador a fibra dopada com Érbio, amplificador discreto Raman, amplificador distribuído Raman e amplificador óptico híbrido, operando em sistemas onde o meio de transmissão é composto basicamente por fibra monomodo padrão (SSMF G.652).

\section{A.1 Amplificador a Fibra Dopada com Érbio}

O grande salto na capacidade dos sistemas de comunicações ópticas baseados na multiplexação de comprimentos de onda foi possivel graças ao advento dos amplificadores ópticos baseados em fibra dopada com érbio (EDFA).

Com o advento dos lasers de bombeio com alta potência, a amplificação totalmente óptica realizada nas fibras dopadas com érbio tornou-se viável, passando a substituir rapidamente os onerosos regeneradores opto-eletrônicos (OEO e 3R). A grande vantagem do EDFA está em prover uma vasta largura de ganho espectral relativamente plano e transparente aos formatos de modulação empregados.

Os EDFAs funcionam em uma faixa de comprimentos de onda nas bandas S, C e L. Os elementos básicos dos EDFAs são a fibra dopada com érbio, o laser de bombeio e o acoplador WDM (de Barros et al., 2000). A configuração, quantidade e características destes elementos dependem da aplicação do amplificador.

\section{Principios Básicos de Funcionamento}

O Érbio apresenta uma série de faixas espectrais de absorção que determinam os comprimentos de onda de bombeio permitidos neste tipo de amplificador. Na prática, apenas dois comprimentos de onda de bombeio são usados, devido a uma maior disponibilidade de lasers nestas regiões. Estes comprimentos de onda estão em torno de 980 e $1480 \mathrm{~nm}$.

Em condições normais na fibra dopada com érbio, a energia advinda da luz incidente é absorvida pelo material. Se esta energia for correspondente à diferença entre dois niveis de energia do dopante no material, alguns dos elétrons absorvem os fótons incidentes e saltam para um estado mais alto de energia (processo de absorção de fotóns) (Becker et al., 1999; Desurvire, 1994).

Com a absorção de energia do laser de bombeio pela fibra dopada com érbio, e o tempo elevado de permanência no estado excitado é assegurado, uma maior densidade de elétrons no nível excitado (com relação ao nível fundamental), caracterizando uma inversão de população. Nessas condições, um sinal incidente na fibra dopada com Érbio 
consegue estimular o decaimento dos elétrons e, dessa maneira, os fótons são emitidos de maneira coerente, mimetizando a direção de propagação, fase e frequência do sinal, culminando na amplificação do mesmo (Becker et al., 1999; Desurvire, 1994).

Os elétrons dos níveis excitados que voltam ao nível fundamental, sem fornecer amplificação ao sinal incidente na fibra, emitem fótons de maneira espontânea (ruído ASE), ou seja, com direção fase e comprimento de onda aleatórios, representando a principal fonte de ruído dos EDFAs (Becker et al., 1999; Desurvire, 1994).

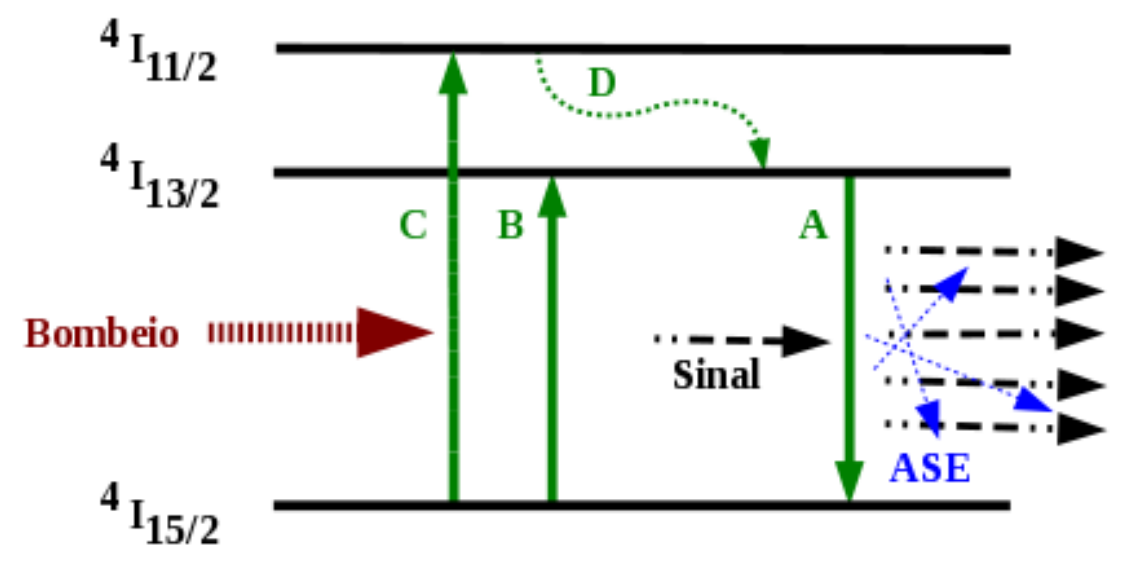

Figura A.1: Níveis de energia envolvidos na amplificação a fibra dopada com érbio.

Para a construção de EDFAs são empregadas fibras cuja matriz de silício é dopada com íons de $\mathrm{Er}^{3+}$. Estes íons apresentam quatro transições eletrônicas empregadas na promoção da inversão de população e emissão estimulada (Figura A.1):

A ${ }^{4} I_{13 / 2} \rightarrow{ }^{4} I_{15 / 2}$ (emissão estimulada em $1550 \mathrm{~nm}$ )

B ${ }^{4} I_{15 / 2} \rightarrow{ }^{4} I_{13 / 2}$ (absorção em $1480 \mathrm{~nm}$ )

C ${ }^{4} I_{15 / 2} \rightarrow{ }^{4} I_{11 / 2}$ (absorção em $980 \mathrm{~nm}$ )

D ${ }^{4} I_{11 / 2} \rightarrow{ }^{4} I_{13 / 2}$ (decaimento predominantemente não radioativo)

No início da utilização comercial dos EDFAs, realizava-se bombeamento com lasers de $1480 \mathrm{~nm}$ para promover a transição B e assim levar o amplificador à condição de inversão de população. Posteriormente, devido a melhor eficiência de bombeio (menor potência requerida para atingir a inversão de população) e menor figura de ruído apresentada, passou-se a utilizar lasers em $980 \mathrm{~nm}$ que promovem a transição C e, consequentemente, a transição D antes da transição A (Becker et al., 1999; Desurvire, 1994).

Uma vez que o tempo médio de decaimento do nível ${ }^{4} I_{13 / 2}$ para o nível ${ }^{4} I_{15 / 2}$ é superior ao tempo médio de decaimento do nível ${ }^{4} I_{11 / 2}$ para o nível ${ }^{4} I_{13 / 2}$ (aproximadamente $10 \mu \mathrm{s} \times 1 \mu \mathrm{s})$, a quantidade de íons acumulada no nível ${ }^{4} I_{13 / 2}$ é superior à quantidade de elétrons que migra do nível ${ }^{4} I_{13 / 2}$ para o nível ${ }^{4} I_{15 / 2}$ e, dessa maneira, a condição de inversão de população é rapidamente atingida (Becker et al., 1999; Desurvire, 1994).

Para realizar simultaneamente o acoplamento do sinal e bombeio na fibra dopada com Érbio, usa-se um acoplador multiplexador de comprimento de onda, também denominado acoplador (D)WDM. Trata-se de um dispositivo com 3 (ou 4) portas ópticas, desenhado para combinar duas faixas de comprimentos de onda específicos injetados nas duas portas de entrada. Por exemplo, um acoplador 980/1550 permite combinar o bombeio em $980 \mathrm{~nm}$ e o sinal em $1550 \mathrm{~nm}$ em uma única fibra.

A configuração básica de um amplificador a fibra dopada com érbio é apresentado na Figura A.2. No amplificador óptico, isoladores são usados para reduzir reflexões advindas dos conectores de entrada e de saída. 


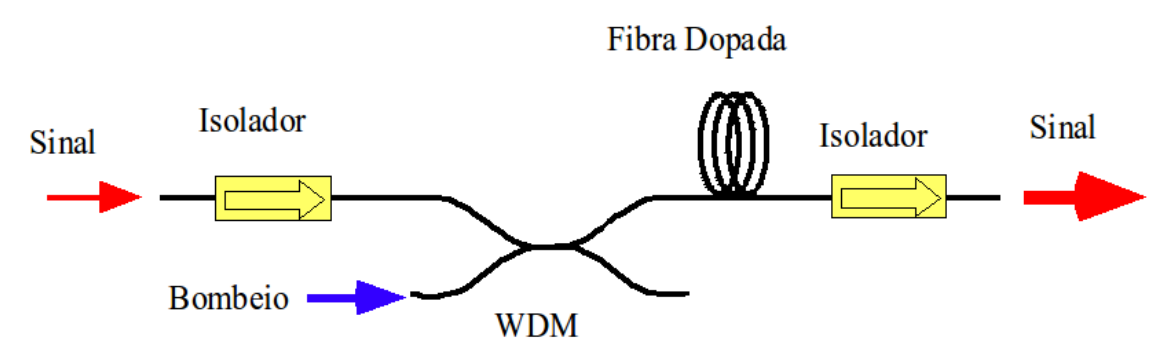

Figura A.2: Configuração básica de amplificador a fibra dopada com érbio. Extraido da referência (de Oliveira, 2004).

Os dispositivos ópticos que compõem o amplificador óptico podem ser conectados em várias possíveis configurações que permitem otimizar diferentes características do amplificador. Além disso, outros dispositivos ópticos podem ser necessários na montagem do amplificador, dependendo da aplicação para a qual o amplificador será projetado.

Vale mencionar também que a emissão espontânea gerada no amplificador se propaga ao longo da fibra e é amplificada, gerando ruído na saída do amplificador. Este ruído é chamado de emissão espontânea amplificada ou ASE (Amplified Spontaneous Emission). A potência óptica da ASE apresenta uma variação com o comprimento de onda, conforme ilustrado na Figura A.3.

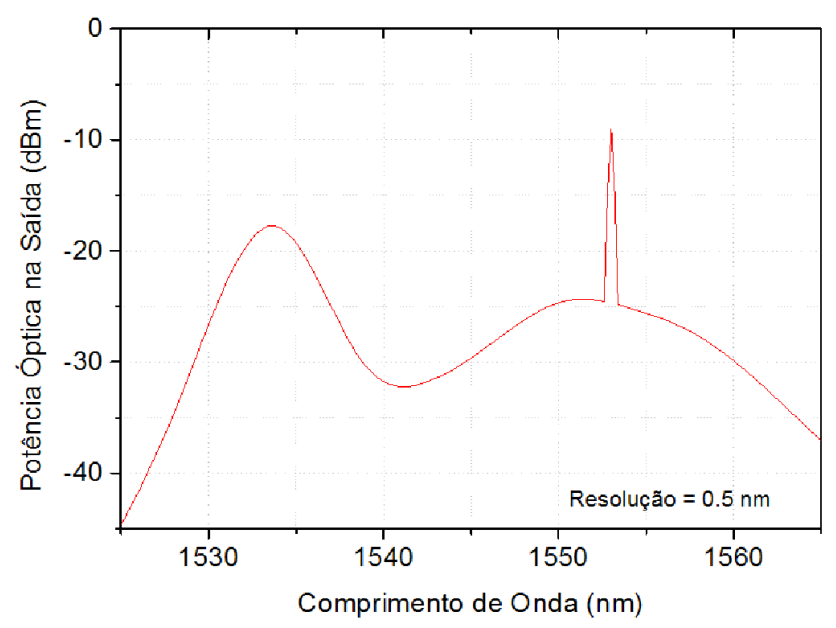

Figura A.3: Espectro de saída de um amplificador óptico a fibra dopada com Érbio, sinal e emissão espontânea amplificada. Extraido da referência (de Oliveira, 2004).

\section{Parâmetros Fundamentais}

Os três parâmetros básicos para a caracterização de amplificadores a fibra dopada com érbio são ganho, figura de ruído e potência de saída.

O ganho, em dB, é definido como o logaritmo da razão entre a potência do sinal na saída e potência do sinal na entrada, dadas em $\mathrm{mW}$, isto é:

$$
G(d B)=10 \times \log \frac{P_{S}(m W)}{P_{E}(m W)}
$$

A potência do sinal na entrada é medida através de um medidor de potência ou de um analisador de espectro óptico. A medida da potência do sinal na saída do amplificador requer necessariamente o uso de um analisador de espectro óptico, pois na saída está presente também a ASE, ou emissão espontânea amplificada. Para obter a potência do sinal na saída, é necessário subtrair o nível de ASE no comprimento de onda do sinal 
da potência total de saída.

O ganho depende do nível de sinal na entrada no amplificador. Para potências de entrada abaixo de um certo valor, o ganho é constante e esta é a chamada região de operação linear do amplificador. Com o aumento da potência de sinal na entrada, o ganho passa a diminuir, isto é, o amplificador começa a apresentar saturação. Esta variação é ilustrada na Figura 4(a), que mostra a dependência do ganho em função da potência do sinal na entrada do amplificador óptico. Observamos que, para este exemplo específico, o ganho é constante para uma potência de entrada de até cerca de $-35 d B m$. Para potências de entrada acima deste valor, o ganho começa a decrescer.

O ganho de pequeno sinal é o valor de ganho para uma baixa potência de sinal injetado no amplificador, ou seja, para a região de operação linear do amplificador. No exemplo da Figura 4(a), o ganho de pequeno sinal é de $40 \mathrm{~dB}$. Quando o valor do ganho de um amplificador é dado, este corresponde ao ganho de pequeno sinal, a menos que se indique para que valor da potência do sinal de entrada (ou de saída) foi obtido este valor de ganho.

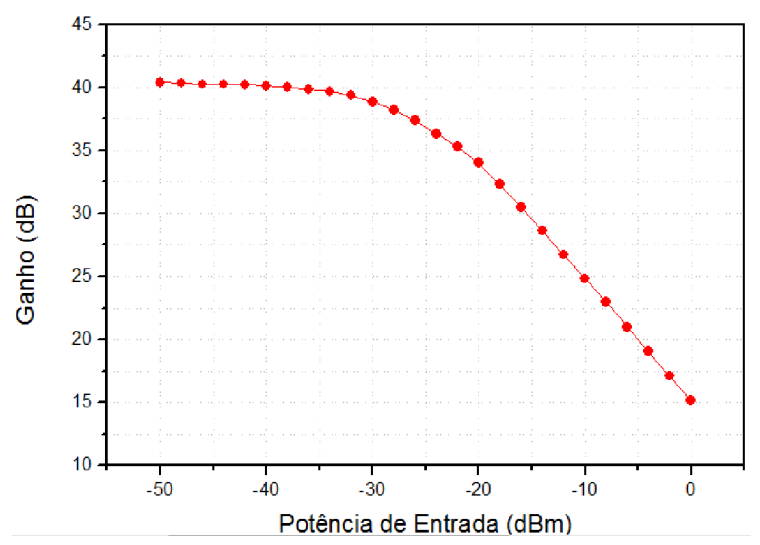

(a)

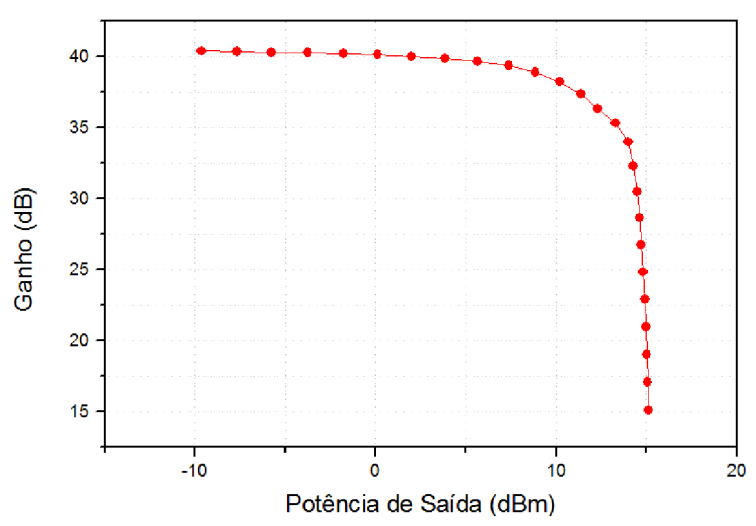

(b)

Figura A.4: (a) Curva de ganho em função da potência do sinal na entrada e (b) Curva de ganho em função da potência do sinal para um amplificador a fibra dopada com Érbio. Extraido da referência (de Oliveira, 2004).

É importante observar também que, no amplificador a fibra dopada com érbio, o ganho depende do comprimento de onda. Portanto, o valor do ganho é medido para um dado comprimento de onda. A dependência do ganho de pequeno sinal com o comprimento de onda é semelhante à variação espectral da potência da ASE, representada na Figura A.3. O ganho na região saturada é bem mais plano do que o ganho de pequenos sinais, isto é, apresenta muito menos dependência com o comprimento de onda do sinal na entrada.

A figura de ruído indica a degradação da relação sinal-ruído causada pelo amplificador. A principal fonte de ruído introduzida pelo amplificado é a ASE emitida pela fibra dopada com érbio. A expressão que define a figura de ruído e descrita da Equação A.2.

$$
N F=\frac{S N R_{I}}{S N R_{O}}
$$

onde $S N R_{I}$ e $S N R_{O}$ são respectivamente as relações sinal/ruído elétricas na entrada e saída do amplificador.

A figura de ruído pode ser medida de várias formas diferentes. A técnica mais usada consiste em medir a figura de ruído com base no nível de ASE no comprimento de onda do sinal. Para medir o nível de ASE no sinal, faz-se uma interpolação do nível de ASE medido no OSA, no comprimento de onda do sinal, e calcula-se a figura de ruído 
utilizando a expressão da Equação A.3.

$$
N F=10 \times \log \frac{P_{A S E}}{\hbar v(G-1) \Delta v}
$$

onde $P_{A S E}$ é a potência da ASE no comprimento de onda do sinal, G é o ganho do amplificador, $\hbar$ é a constante de Planck reduzida, $v$ é a frequência óptica do sinal, e $\Delta v$ é a largura de banda óptica usada para a medida da ASE.

Na Figura A.3 é ilustrado o espectro de saída do amplificador a fibra dopada com érbio quando injetamos sinal na entrada, no comprimento de onda de $1553 \mathrm{~nm}$.

Conhecendo a potência de entrada e analisando a Figura A.3, pode-se obter todos os parâmetros necessários para o cálculo da figura de ruído, utilizando a Equação A.3. Dados a potência de saída em $-9 d B m$ e de entrada em $-30 d B m$, temos ganho de $21 d B$. Como o comprimento de onda do sinal é $1553 \mathrm{~nm}$, a resolução espectral é $0,5 \mathrm{~nm}$ e o nível de ASE no comprimento de onda do sinal é $-25 \mathrm{dBm}$, a figura de ruído calculada através da Equação A.3 resulta em 5, $99 d B$.

A potência de saída de um amplificador óptico é a potência amplificada para uma dada potência de entrada. Uma definição importante é a potência de saída saturada, que é definida como sendo a potência medida na saída, na condição de $3 d B$ de compressão de ganho, isto é, no ponto em que a potência de entrada é tal que o ganho sofra uma redução de $3 d B$ em relação ao ganho de pequeno sinal.

Para obtenção da potência de saída saturada do amplificador óptico, traça-se a curva de ganho em função da potência de saída e observa-se qual a potência de saída para qual o ganho caiu $3 d B$. Esta curva é chamada de curva de saturação do amplificador. A Figura 4(b) ilustra uma curva de saturação de um EDFA. A potência de saída saturada do amplificador cuja curva de saturação é ilustrada pela Figura 4(b) é de $10 d B m$. A máxima potência de saída que se pode obter com este amplificador é $15 \mathrm{dBm}$.

\section{Aplicações dos EDFAs}

Existem basicamente três tipos de amplificadores, que diferem entre si de acordo com suas aplicações no sistema de comunicações ópticas. Suas funções estão relacionadas ao posicionamento no enlace que determina sua aplicação como amplificador de potência, pré-amplificador e amplificador de linha conforme ilustrado respectivamente nas Figuras 5(a), 5(b), e 5(c).

Os amplificadores de potência são posicionados na saída dos transmissores, permitindo um aumento da potência injetada na fibra óptica de transmissão. O parâmetro de desempenho mais importante é a maximização da potência de saída. Os amplificadores de potência desta forma, trabalham sempre na condição de saturação do ganho. Em primeira aproximação, quanto maior a potência injetada na fibra, mais longo o enlace que se pode utilizar até o próximo amplificador ou até o receptor. Na prática, existe um limite de potência, acima do qual começam a aparecer efeitos não lineares que passam a causar degradação da qualidade do sinal, penalizando o sistema.

Os amplificadores de potência operam com alto nivel de sinal na entrada. Um valor típico de potência de entrada de operação para amplificadores de potência está em torno de $0 d B m$. Como estes amplificadores estão em condição de saturação, eles apresentam baixo ganho, quando comparado ao ganho de pequeno sinal. Por outro lado, o amplificador apresenta baixo nivel de ASE, pois o alto nível de sinal na entrada favorece a emissão estimulada contra a emissão espontânea, reduzindo consequentemente o nível de ASE. Os amplificadores de potência atuais chegam a atingir potências de saída de até $40 \mathrm{dBm}$.

Os pré-amplificadores possuem baixa figura de ruído, e são posicionados antes dos receptores ópticos, com o intuito de aumentar a sensibilidade da potência recebida. Os 


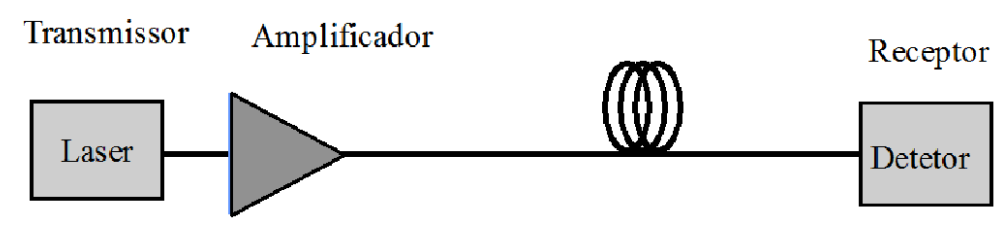

(a)

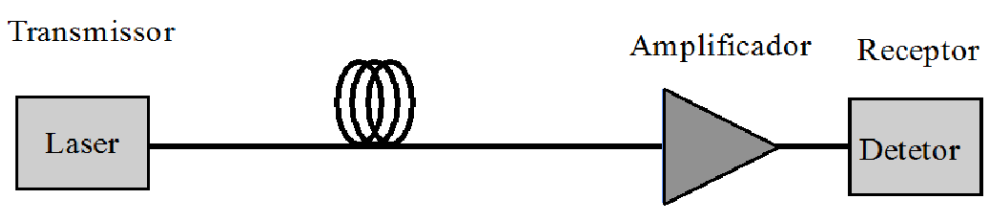

(b)

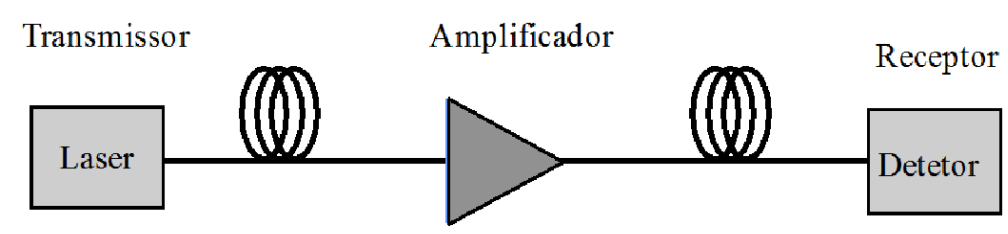

(c)

Figura A.5: Posicionamento do (a) amplificador de potência, (b) pré-amplificador e (c) amplificador de linha em um sistema de comunicações ópticas.

pré-amplificadores operam na região linear da curva de ganho ilustrada na Figuras 5(b). Nos pré-amplificadores, o parâmetro mais crítico é a figura de ruído, pois a sensibilidade do receptor depende da quantidade de ruído incidente. Neste tipo de amplificador, o ganho também é de grande importância, pois quanto maior o ganho, maior o aumento na sensibilidade propiciado pelo pré-amplificador. Como os pré-amplificadores operam em regime de pequeno sinal, apresentam alto ganho e baixa potência de saída. Além disso, o nível de ASE nestes é maior do que nos amplificadores de potência. Um valor típico do nível do sinal na entrada é da ordem de $-35 \mathrm{dBm}$.

Os amplificadores de linha são amplificadores que buscam um compromisso entre baixa figura de ruído e alta potência de saída. Os amplificadores de linha são posicionados ao longo da linha de transmissão, para compensar a atenuação devido a propagação do sinal ao longo da fibra óptica. Os amplificadores de linha são também usados em redes do tipo ponto-multi-ponto para compensar perdas relacionadas à distribuição do sinal.

Os amplificadores de linha requerem alto ganho e alta potência de saída, para que seja possível obter o maior espaçamento no enlace de comunicações ópticas. A importância da baixa figura de ruído pois, em caso contrário, a ASE irá se acumular e o sinal chegará na recepção com um nível de ruído muito alto.

Os amplificadores de linha apresentam valor de ganho e de sinal de saída intermediários entre os amplificadores de potência e os pré-amplificadores. Um valor típico para o nível de sinal na entrada do amplificador de linha, seria em torno de $-20 d B m$. Os amplificadores de linha operam com compressão de ganho em torno de $3 d B$. Nesta condição, um aumento do sinal de entrada produz redução do ganho e uma queda de nível do sinal de entrada produz aumento de ganho. Portanto, nesta região de operação o amplificador compensa variações do nível do sinal de entrada, mantendo a potência total de saída praticamente inalterada. 


\section{Otimização do Desempenho em EDFAs}

Os amplificadores a fibra dopada com érbio comerciais são usualmente bombeados em dois comprimentos de onda diferentes, tipicamente um laser de bombeio em $980 \mathrm{~nm}$ ou $1480 \mathrm{~nm}$. Os amplificadores bombeados por diferentes comprimentos de onda, apresentam diferentes características, que serão discutidas a seguir.

Nos primeiros amplificadores a fibra dopada com érbio, usava-se o comprimento de onda do laser de bombeio em 1480nm. O laser neste comprimento de onda já se encontrava desenvolvido, fabricados a partir de mudanças na composição do material do laser de sinal, que emite em torno de $1550 \mathrm{~nm}$.

Com a utilização do laser de bombeio em $980 \mathrm{~nm}$, observou-se uma séria de vantagens comparativamente ao laser de bombeio em $1480 \mathrm{~nm}$. Como a radiação do laser $980 \mathrm{~nm}$ fica mais confinada no núcleo da fibra dopada, isso faz com que a absorção em $980 \mathrm{~nm}$ seja maior, permitindo espectralmente uma fibra mais curta para a fabricação do amplificador.

Mais uma vantagem se dá ao fato do comprimento de onda do sinal, $1550 \mathrm{~nm}$, estar mais afastado de $980 \mathrm{~nm}$ do que $1480 \mathrm{~nm}$. Neste caso, quando a fibra é bombeada em $1480 \mathrm{~nm}$, há re-emissão deste comprimento de onda, o que leva a uma redução da eficiência para baixas potências de entrada e uma consequente degradação da relação sinal-ruído. Como consequência, a figura de ruído de amplificadores bombeados por laser em $980 \mathrm{~nm}$ pode chegar a ser até $2 d B$ menor do que aquela obtida bombeado por laser em 1480nm.

Existem outras vantagens não diretamente relacionadas à fibra dopada com érbio. Uma delas é que o laser de $980 \mathrm{~nm}$ fornece uma dada potência operando em uma corrente menor do que seria necessário para o laser de $1480 \mathrm{~nm}$. Outra vantagem se dá pela razão de extinção em acopladores WDM 980/1550 ser maior que a mesma nos acopladores WDM 1480/1550.

O bombeio em $980 \mathrm{~nm}$ apresenta também algumas desvantagens. Uma delas é que fibras monomodo em $980 \mathrm{~nm}$ apresentam diâmetro de núcleo menor. Com isso, as perdas por curvatura em $1550 \mathrm{~nm}$ são maiores. Na montagem de um amplificador isso reflete na necessidade de um maior cuidado ao posicionar a fibra dopada, para que esta não apresente curvaturas com diâmetro muito pequeno.

Existem três configurações básicas para o bombeio de fibras dopadas com Érbio, que otimizam parâmetros diferentes. Assim, cada configuração de bombeio é mais indicada para cada uma das aplicações.

Em relação ao sentido de propagação do bombeio na fibra dopada com érbio, o bombeio é classificado com relação ao sentido de propagação do sinal, e pode ser do tipo co-propagante (mesmo sentido de propagação do sinal), contra-propagante (sentido contrário de propagação do sinal), ou bidirecional. Para obtenção destas configurações, é necessário posicionar acopladores WDM e isoladores adequadamente no circuito óptico.

A configuração de bombeio co-propagante é indicada para projeto de pré-amplificadores, pois minimiza o nível de ASE na saída do amplificador, consequentemente reduzindo sua figura de ruído. Esta configuração é indicada também para compor o primeiro estágio de amplificação de um amplificador de linha.

A configuração de bombeio contra-propagante maximiza o nível da potência de saída do amplificador (em detrimento de figura de ruído), devido a máxima potência de bombeio estar acoplada na saída da fibra dopada. Com isto, esta configuração é indicada para aplicação em amplificadores de potência.

$\mathrm{Na}$ configuração de bombeio bidirecional são necessários dois acopladores WDM, para acoplar bombeio em ambas as extremidades da fibra. Pode-se usar dois lasers de bombeio ou um único laser de bombeio compartilhado via divisor de potência, para fornecer potência de bombeio para cada uma das extremidades da fibra dopada. $\mathrm{O}$ amplificador com bombeio duplo apresenta alto ganho e alta potência de saída, podendo 
ser utilizado em configurações de amplificadores de potência e amplificadores de linha.

O amplificador ideal apresentaria alto ganho e baixa figura de ruído. Entretanto, usando qualquer uma das configurações descritas anteriormente, não é possível obter ambas as características simultaneamente. Uma solução que mais se aproxima de tal requisito é baseada na utilização de amplificadores de múltiplos estágios de amplificação. Para isto, são utilizados dois ou mais trechos de fibra dopada, bombeados por diferentes lasers de bombeio ou um laser de bombeio compartilhado, permitindo otimizar cada parâmetro separadamente.

O amplificador de duplo estágio pode ser utilizado também para inserirmos elementos tais como compensadores de dispersão ou add-drops ópticos entre os estágios. Como o segundo estágio funciona em saturação, a perda do dispositivo não será compensada por um aumento do ganho deste estágio, porém, caso o elemento inserido entre os estágios adicione perda ao sinal, a figura de ruído será afetada.

\section{A.2 Amplificadores Raman Discretos e Distribuídos}

As perdas acumuladas ao longo da transmissão de canais em fibras ópticas é um dos principais fatores limitantes no alcance dos enlaces de comunicações ópticas. Ao longo do tempo os regeneradores de sinais evoluíram partindo de regeneradores elétricos a amplificadores ópticos. Surgiram vários tipos de amplificadores ópticos, entre eles o EDFA (Becker et al., 1999; Desurvire, 1994) e os amplificadores Raman (Eskildsen et al., 1996; Hansen et al., 1997; Stolen et al., 1972, 1973).

Os amplificadores Raman requerem dezenas de mili-watts de bombeio por $\mathrm{dB}$ de ganho em comparação a décimos de mili-watts de bombeio por dB de ganho requisitados pelos EDFAs.

No meio da década de 1990, com o aprimoramento da tecnologia de fabricação dos lasers de bombeio e consequente aumento de potência, os amplificadores Raman tornaram-se um meio importante para expansão da capacidade de transmissão e do comprimento dos enlaces de comunicações ópticas, principalmente por utilizar como meio de amplificação a própria fibra de transmissão do enlace.

A Figura A.6, ilustra o aumento exponencial do produto "capacidade versus distância"ao longo dos anos para os enlaces experimentais reportados nas sessões de post deadline papers da OFC (Bromage, 2004). Os experimentos são classificados pelo comprimento dos enlaces de fibra para sistemas com repetição, menores de 80 quilômetros para aplicações submarinas e maiores ou igual a 80 quilômetros para as terrestres. Na Figura A.6, os experimentos que utilizaram amplificadores Raman são representados por círculos e o primeiro reportado foi realizado em 1999.

Uma das características mais importantes da amplificação Raman é não utilizar fibras especiais como meio de amplificação, o que permite a utilização das fibras de transmissão dos enlaces ópticos como meio de amplificação. Por outro lado, a potência de bombeio para prover amplificação Raman é maior do que a dos EDFAs e são necessárias potências em torno de $500 \mathrm{~mW}$ para se obter um ganho de amplificação distribuída útil.

Entre as principais vantagens dos amplificadores Raman pode-se destacar a redução efetiva do ruído na amplificação distribuída dentro da fibra de transmissão, o que permite maior extensão dos enlaces. Outra vantagem dos amplificadores Raman é a amplificação em fibras compensadoras de dispersão, que provê amplificação com compensação de dispersão cromática nos sinais transmitidos.

Uma outra característica importante é a capacidade de obtenção de amplificação em diferentes regiões do espectro de comunicações ópticas. Como a amplificação Raman não dependente de fibras dopadas com terras raras, que somente operam em determinadas regiões do espectro, pode-se construir amplificadores para diferentes regiões, 


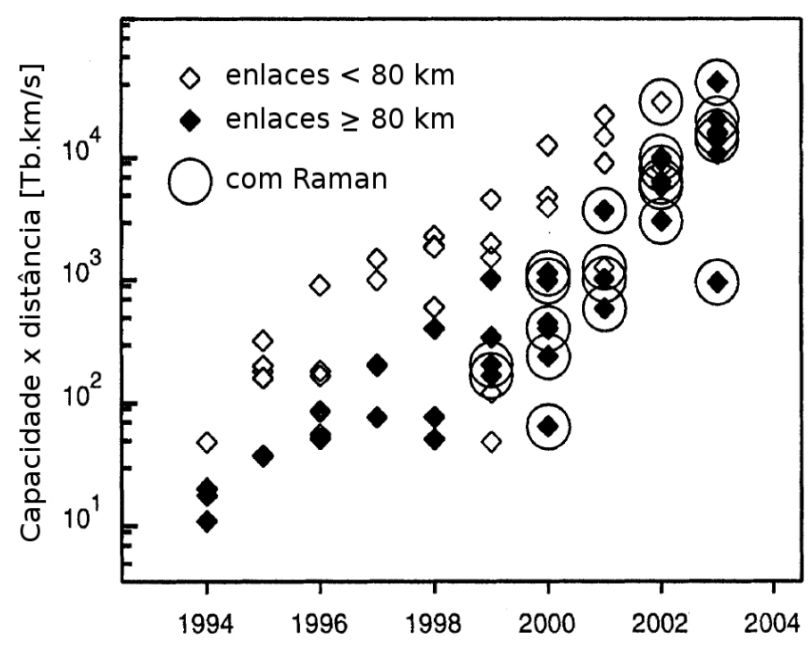

Figura A.6: Produtos capacidade x distância ao longo dos anos dos enlaces experimentais. Extraido e adaptado da referência (Bromage, 2004).

dependendo somente da frequência de emissão do laser de bombeio. Além disso, amplificadores Raman podem ser alimentados por um conjunto de lasers de bombeio, de diferentes comprimentos de onda, que permite a amplificação plana em largas regiões do espectro.

\section{Conceitos Básicos}

O efeito não linear conhecido como espalhamento Raman espontâneo foi descoberto por Chandrasekhara Venkata Raman, que recebeu por isso o Premio Nobel de Física de 1930. Este mecanismo de espalhamento pode transferir, em um meio molecular, uma pequena fração de potência (tipicamente $10^{-6}$ ) de um campo óptico para um outro, cuja frequência é reduzida da frequência do fônon gerado pelos modos vibracionais do meio (Agrawal, 2007).

Os amplificadores Raman se baseiam no fenômeno físico do espalhamento Raman estimulado (SRS - Stimulated Raman Scaterring), que pode ser obtido a partir da luz de um sinal em uma frequência apropriadamente deslocada da frequência da luz de bombeio. Neste processo, a luz do sinal e do bombeio são coerentemente acopladas pelo efeito Raman.

O SRS pode transformar fibras ópticas em amplificadores de banda larga ou em lasers sintonizáveis como, também, pode degradar o desempenho dos sistemas ópticos de múltiplos canais, transferindo energia de um canal para canais vizinhos. Diferentemente dos amplificadores EDFAs e SOAs, o efeito da amplificação é obtido pela interação não-linear, dentro de uma fibra, entre os fótons do sinal e os de um laser de bombeio. A Figura A.7 ilustra o diagrama do processo quântico do espalhamento Raman.

O espalhamento Raman pode ser descrito pela mecânica quântica como o espalhamento por uma molécula de um fóton de energia $\hbar v_{p}$ para um de menor frequência com energia $\hbar v_{s}$. Ou seja, o fóton do bombeio, $v_{p}$, excita uma molécula para um nível virtual mais alto (estado não ressonante), sendo que esta decai rapidamente para um nivel mais baixo de energia, emitindo no processo um fóton de sinal, $v_{s}$. A diferença na energia entre o fóton do sinal e do bombeio é dissipada por um fônon gerado pelas vibrações moleculares do material hospedeiro (núcleo da fibra). Esses níveis de vibrações determinam a frequência do deslocamento e a dependência espectral da curva de ganho Raman. A curva de ganho Raman é razoavelmente larga nas fibras ópticas devido a natureza amorfa da sílica.

As seguintes propriedades fundamentais do ganho Raman podem ser destacadas: 


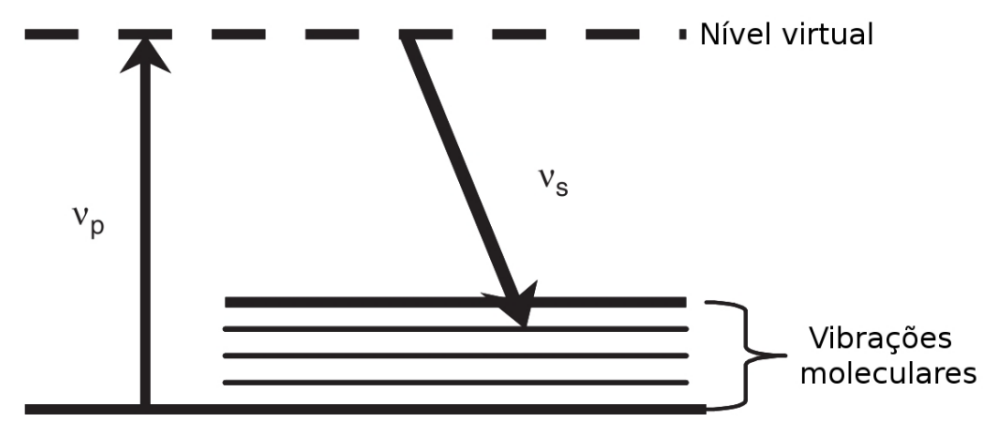

Figura A.7: Diagrama esquemático do processo quântico do espalhamento Raman. Extraido e adaptado da referência (Headley e Agrawal, 2005).

1. O ganho Raman possui uma característica espectral que depende da separação de frequência entre o bombeio e o sinal, e não da frequência absoluta.

2. O ganho Raman não depende da direção relativa entre o bombeio e o sinal.

3. O ganho Raman pode ocorrer para qualquer comprimento de onda de sinal, dependente da escolha do comprimento de onda do bombeio.

4. O ganho Raman é dependente da polarização. O pico da intensidade de acoplamento entre o sinal e o bombeio é aproximadamente uma ordem de magnitude maior se forem co-polarizados, quando comparado ao caso ortogonalmente polarizado.

5. O espalhamento Raman é um processo rápido (fração de pico segundo) por não ser ressonante.

6. O espalhamento Raman pode ocorrer em qualquer tipo de fibra.

A Figura A.8 ilustra o diagrama esquemático de um sistema de telecomunicações que utiliza amplificadores Raman. Do diagrama da Figura A.8, nota-se que o sinal propagase do transmissor (Tx) para o receptor $(\mathrm{Rx})$. Quando o bombeio viaja na mesma direção do sinal, este é chamado de bombeio co-propagante ou direto, se o mesmo viaja na direção contrária a do sinal, é chamado bombeio contra-propagante ou contrário.

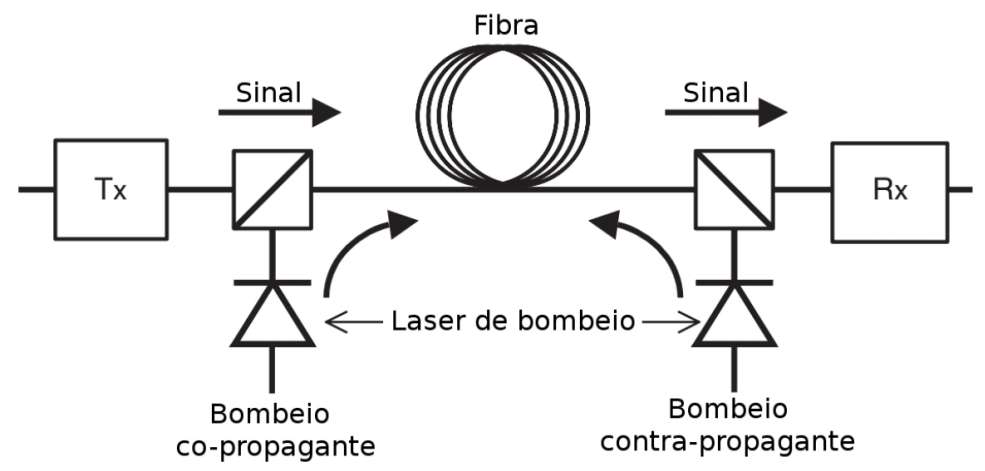

Figura A.8: Sistema óptico com amplificação Raman. Extraido e adaptado da referência (Headley e Agrawal, 2005).

Se a fibra bombeada é o enlace de transmissão, que liga dois pontos, esta configuração é referida como amplificação Raman distribuída. Se a amplificação Raman ocorre em uma fibra contida num dispositivo localizado no transmissor ou receptor, este sistema é chamado amplificação Raman discreta. 
Tipicamente, amplificadores Raman distribuídos precisam de comprimentos de fibra de enlace maiores que $40 \mathrm{~km}$ enquanto amplificadores discretos possuem comprimentos em torno de $5 \mathrm{~km}$. Fibras com área efetiva reduzida e composição química diferente são utilizadas em amplificadores discretos, para fornecerem coeficiente de ganho Raman maior que as fibras de transmissão, permitindo comprimentos de fibra reduzidos, para prover o mesmo nível de ganho que os fornecidos pelos amplificadores distribuídos.

Como os amplificadores distribuídos fornecem ganho ao longo da fibra de transmissão (que possuem geralmente longos comprimentos), eles oferecem baixos valores de potência de saída, porém, fornecem melhor figura de ruído que os amplificadores discretos. Os amplificadores discretos por sua vez, podem fornecer altos valores de potência de saída. Além disso, amplificadores Raman discretos implementados em fibras compensadoras de dispersão (DCF), fornecem ganho ao sinal aliado a compensação de dispersão cromática.

Considerando as equações de evolução da potência de bombeio e sinal apresentadas em (Headley e Agrawal, 2005), se a depleção do bombeio for ignorada, para o caso contra-propagante, as equações podem ser facilmente resolvidas, gerando a equação da potência de sinal ao longo da fibra com amplificação Raman A.4.

$$
\begin{gathered}
P_{s}(L)=P_{s}(0) e^{\left(g_{R} P_{0} L_{e f f}-\alpha_{s} L\right)} \equiv G_{N}(L) P_{s}(0) \\
L_{e f f}=\frac{1-e^{\left(-\alpha_{p} L\right)}}{\alpha_{p}}
\end{gathered}
$$

Na equação A.4 $G_{N}$ é o ganho de rede, $g_{R}\left(W^{-1} m^{-1}\right)$ é o coeficiente de ganho Raman da fibra, normalizado em relação a area efetiva da fibra, $P_{0}$ é a potência de entrada do bombeio e $L$ o comprimento da fibra. Esta equação é uma aproximação de primeira ordem da evolução do sinal na fibra. Em fibras SSMF, onde a perda é de aproximadamente $0,25 \mathrm{~dB} / \mathrm{km}$ em $1455 \mathrm{~nm}$, o comprimento efetivo $\left(L_{e f f}\right)$, onde ocorre amplificação Raman, é aproximadamente $17 \mathrm{~km}$ para enlaces maiores que $60 \mathrm{~km}$.

Na Figura A.9 é ilustrado o espectro de ganho Raman para três diferentes tipos de fibras ópticas: Fibra monomodo padrão, fibra de dispersão deslocada e fibra compensadora de dispersão (Headley e Agrawal, 2005). A diferença de frequências (ou comprimento de onda) entre o fóton de bombeio e do sinal $\left(v_{p}-v_{s}\right)$ é chamada de deslocamento de Stokes, e o seu pico de frequência ocorre em torno de 13, $2 T H z$ para o caso das fibras ópticas padrão com núcleo dopado com Germânio.

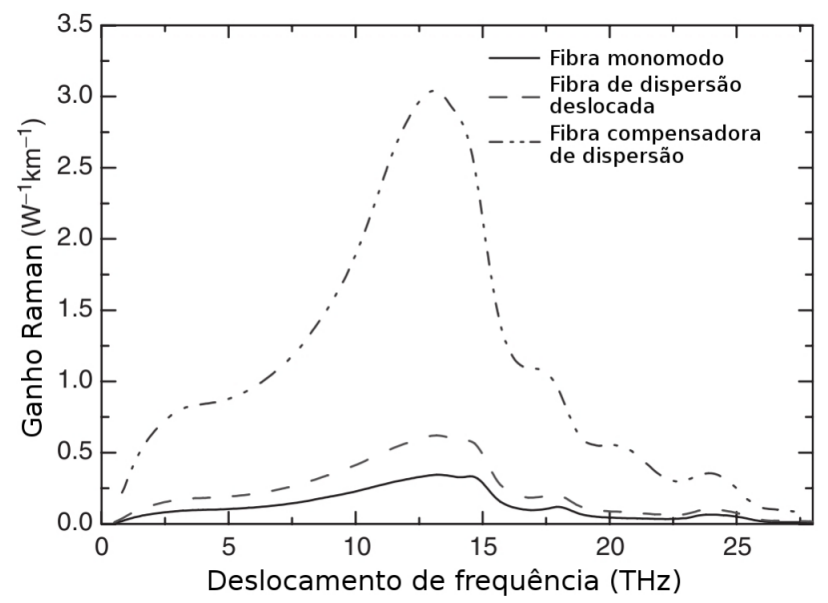

Figura A.9: Perfis de ganho Raman para três diferentes tipos de fibra e bombeio de $1510 \mathrm{~nm}$. Extraido e adaptado da referência (Headley e Agrawal, 2005).

Na Figura A.9 nota-se uma clara diferença entre os espectros de ganho das fibras tes- 
tadas, destacando-se a faixa de valores de pico de 0,29 a $3,2\left(W^{-1} \mathrm{~km}^{-1}\right)$. Esses valores dependem das áreas efetivas e do grau de sobreposição entre os modos do bombeio e do sinal, que são inversamente proporcionais a área efetiva do modo do sinal. As diferenças também são resultado das composições do material das fibras. O óxido de germânio, utilizado para incrementar o índice de refração do núcleo, aumenta a eficiência do ganho Raman. Deste modo, para a obtenção do espectro de ganho para uma dada fibra, necessita-se levar em consideração a sobreposição dos modos do sinal e do bombeio e a composição do perfil radial da fibra.

\section{Figura de Ruido Equivalente}

A amplificação Raman, quando comparada com outros tipos de amplificações ópticas, apresenta como vantagens a baixa figura de ruído equivalente e o ganho plano sobre uma larga faixa do espectro.

A figura de ruido $(N F)$, de um dispositivo é a relação entre a relação sinal ruído (SNR) de entrada pela SNR de saída, e mede o quanto um dispositivo degrada a qualidade do sinal.

Porém, em um sistema com amplificação Raman distribuída, não é possível medir a figura de ruído do amplificador devido à ocorrência de ganho ao longo da própria fibra de transmissão. Desta forma, a figura de ruido destes amplificadores é medida através da figura de ruído equivalente $\left(N F_{e q}\right)$. A figura de ruído equivalente representa o valor da figura de ruido de um amplificador discreto, que colocado em frente ao receptor, na ausência de amplificação Raman, fornece a mesma SNR, que seria obtida utilizando-se a amplificação Raman distribuída. Em amplificadores Raman discretos, assim como em EDFAs, o parâmetro de figura de ruído pode ser calculado de forma direta.

Na Figura A.10 são apresentados os dois sistemas, amplificador Raman distribuído e o sistema para medição da figura de ruído equivalente. Nesta figura, a perda do sinal no enlace é $\alpha_{s} L$, assim, o ganho do enlace é $G=\left(\alpha_{s} L\right)^{-1}$ e a figura de ruido do enlace não bombeado é igual a $\alpha_{s} L$.

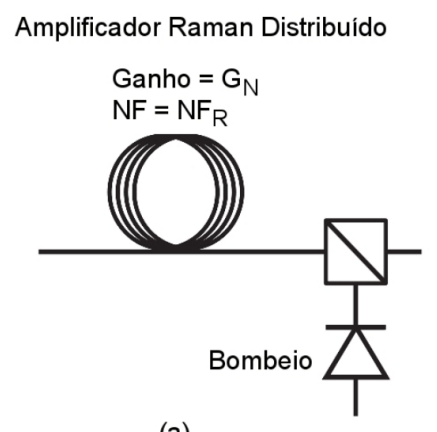

(a)

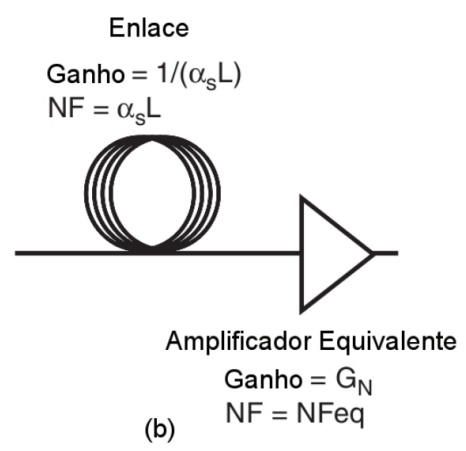

(b)

Figura A.10: Diagramas esquemáticos: (a) sistema amplificador Raman distribuído, (b) sistema equivalente enlace + EDFA. Extraido e adaptado da referência (Headley e Agrawal, 2005).

Uma expressão bem conhecida para a figura de ruído de dois amplificadores em cascata é dada pela equação A.6.

$$
N F_{\text {sys }}=N F_{1}+\frac{\left(N F_{2}-1\right)}{G_{1}}
$$

Onde $N F_{1}$ e $N F_{2}$ são as figuras de ruído do primeiro e segundo amplificador respectivamente e $G_{1}$ é o ganho do primeiro amplificador. Para o sistema equivalente, representado na Figura A.10(b), aplicando o mesmo na equação A.6, temos:

$$
N F_{\text {sys }}=N F_{\text {eq }} \alpha_{s} L
$$


Igualando a figura de ruído do sistema com amplificação Raman com a do sistema equivalente, tem-se a figura de ruído equivalente dada:

$$
\begin{gathered}
N F_{e q}=\frac{N F_{R}}{\alpha_{s} L} \\
N F_{e q}^{d B}=N F_{R}^{d B}-\left(\alpha_{s} L\right)^{d B}
\end{gathered}
$$

onde o sobrescrito $\mathrm{dB}$ indica a variável expressa em decibéis.

Da Equação A.9 nota-se que é possivel obter um resultado menor do que zero, representando um amplificador não realizável fisicamente, que é um indicativo do desempenho superior da amplificação Raman distribuída, o qual não pode ser obtida por um amplificador discreto colocado após o enlace.

Em um sistema com elevados níveis de amplificação distribuída Raman, devido a amplificação ocorrer na fibra de transmissão, a figura de ruído sistêmica pode ser menor figura de ruído do enlace sem amplificação Raman, justificando a possibilidade de obtenção de valores negativos através da equação A.9.

\section{Planicidade de Ganho}

Em sistemas WDM de comunicações ópticas é importante que todos os sinais que trafeguem na fibra tenham uma potência óptica similar (sinais equalizados em potência). Caso isso não ocorra, os sinais com maior potência serão beneficiados com maior ganho ao passarem nos amplificadores. Esta variação no ganho para os múltiplos comprimentos de onda é medida pela planicidade do ganho.

Pode-se obter um perfil espectral plano em amplificadores Raman distribuídos, através da escolha adequada de múltiplos comprimentos de onda de bombeio. O espectro de ganho Raman depende principalmente do comprimento de onda do bombeio, da magnitude do bombeio, e do tipo de fibra de transmissão (Emori e Namiki, 2001).

A Figura 11(a) ilustra os perfis de contribuição de ganho espectral dos comprimentos de onda de bombeio individuais (1420, 1435, 1450, 1465 e $1480 \mathrm{~nm})$, e sua superposição em escala logarítmica, a curva de ganho resultante e a mesma com a interação bombeio-bombeio, para um enlace de fibra de dispersão deslocada de $25 \mathrm{~km}$. As potências de bombeio acopladas foram de respectivamente 61, 55, 48, 47 e $142 \mathrm{~mW}$.

O maior nível de ganho do amplificador Raman distribuído multi-bombeios é proveniente do maior comprimento de onda. Contudo, as potências dos bombeios requeridas não podem ser obtidas simplesmente a partir da superposição do espectro de ganho dos bombeios individuais, devido aos diversos efeitos adicionais que ocorrem na amplificação Raman, entre eles a interação entre bombeios onde os mesmos com comprimentos de onda mais baixos amplificam bombeios de comprimentos de ondas maiores que consequentemente amplificam o sinal com maior intensidade. Este efeito é mostrado na Figura 11(a), na qual a curva marcada como interação bombeio-bombeio mostra uma inclinação maior que $3 \mathrm{~dB}$ no espectro de ganho quando a amplificação Raman entre bombeios é considerada.

A interação bombeio-bombeio também afeta a evolução da potência de bombeio como ilustrado na Figura 11(b). Nela, mostra-se a evolução da potência de bombeio ao longo de um enlace de fibra de DS de $25 \mathrm{~km}$. Neste caso, para uma potência acoplada de $100 \mathrm{~mW}$ para cada comprimento de onda de bombeio, inicialmente ocorre um aumento da potência de bombeio com o maior comprimento de onda devido interação Raman bombeio-bombeio com os comprimentos de ondas mais curtos.

Simulações numéricas são necessárias para calcular os comprimentos de ondas dos bombeios e as potências requeridas para projeto de um amplificador Raman com boa planicidade espectral de ganho. Isto é necessário devido a presença de efeitos não linea- 


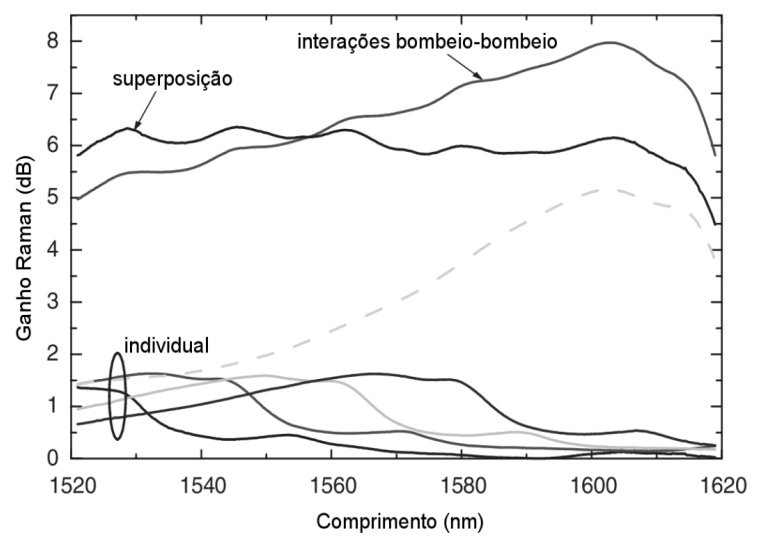

(a)

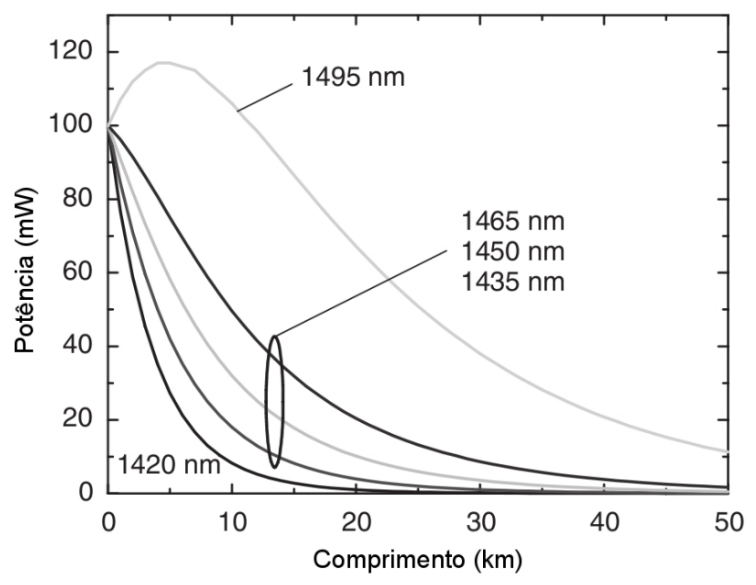

(b)

Figura A.11: (a) Contribuição individual para o ganho de diferentes comprimentos de onda de bombeio, resultado da superposição de todas as contribuições individuais e curva do ganho resultante levando em consideração as interações bombeio-bombeio, (b) Simulação da evolução da potência do bombeio em um amplificador Raman. Extraido e adaptado da referência (Emori e Namiki, 2001).

res tais como a interação bombeio-bombeio. Vários algoritmos foram desenvolvidos para se determinar e/ou otimizar o número de bombeios, seus comprimentos de onda e suas potências para realizar um projeto de amplificador Raman com alto ganho e planicidade espectral de ganho (Oliveira et al., 2011a).

\section{Limitações da Amplificação Raman}

A amplificação Raman apresenta várias vantagens já mencionadas nos itens anteriores, mas em contrapartida possui algumas desvantagens: interferência multi-percurso, transferência de ruído do bombeio para o sinal e variação espectral da figura de ruído. Nesta seção serão descritos essas limitações da amplificação Raman.

\section{Interferência Multi-percurso}

Devido ao espalhamento Rayleigh na fibra, dependendo da intensidade da luz, a mesma pode ser espalhada até duas vezes. Neste espalhamento duplo, o primeiro espalhamento ocorre na direção contra-propagante ao sinal (retro espalhamento), que pode provocar o segundo espalhamento na direção co-propagante, como mostrado na Figura A.12.

Este espalhamento Rayleigh duplo (DRB) aparece no receptor como uma fonte de ruído adicionado ao sinal transmitido. Esta luz duplamente espalhada é problemática pois suas reflexões ocorrem ao longo de todo o comprimento da fibra provocando flutuação de fase. Além disso, se a diferença de caminho entre o sinal e o DRB exceder o comprimento de coerência da fonte, mudanças de fase ocorrerão devido a mudanças de fase na fonte. A interferência de múltiplos sinais leva a flutuações de intensidade, que são conhecidas como interferências de multi-percursos (MPI).

Os longos comprimentos de fibra utilizados pelos amplificadores Raman distribuídos fazem com que o DRB seja um grande desafio a ser enfrentado. Com o aumento do ganho no amplificador a MPI pode eventualmente limitar o ganho obtido. 


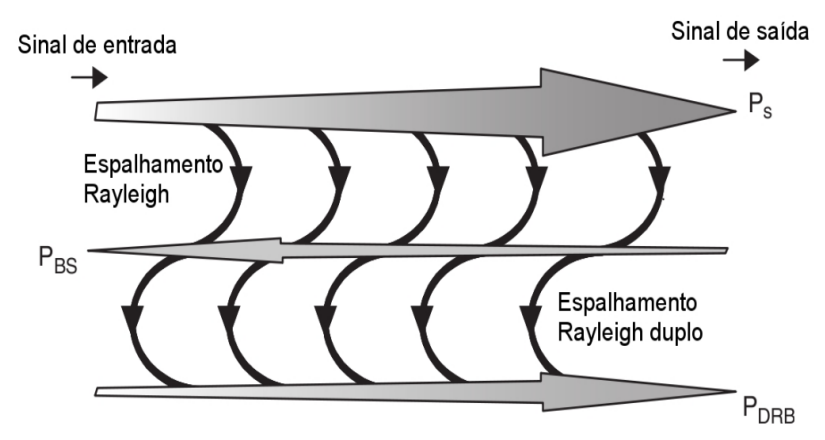

Figura A.12: Diagrama esquemático representando o crescimento do espalhamento Rayleigh duplo em uma fibra. $P_{B S}$ é a potência do espalhamento Rayleigh e $P_{D R B}$ a potência do espalhamento Rayleigh duplo. Extraido e adaptado da referência (Headley e Agrawal, 2005).

\section{Transferência de Ruído do Bombeio}

O processo de ganho Raman é extremamente rápido e qualquer flutuação de intensidade nas frequências de bombeio (menores que $1 \mathrm{THz}$ ) pode provocar alterações no ganho e deste modo produzir variações na potência do sinal (Mermelstein et al., 2002). Este efeito é normalmente conhecido como transferência do ruído de intensidade relativa (RIN) do bombeio para o sinal. O RIN é uma medida padrão de ruído de lasers. A quantidade da transferência de ruído entre o bombeio e o sinal depende da configuração do bombeio e da frequência do ruído. Na Figura A.13 são ilustradas duas curvas da função de transferência do RIN, que mede o quanto da modulação do bombeio é transferido para o sinal, em função da frequência do ruído. As curvas mostradas são para os casos de bombeio co- e contra-propagante.

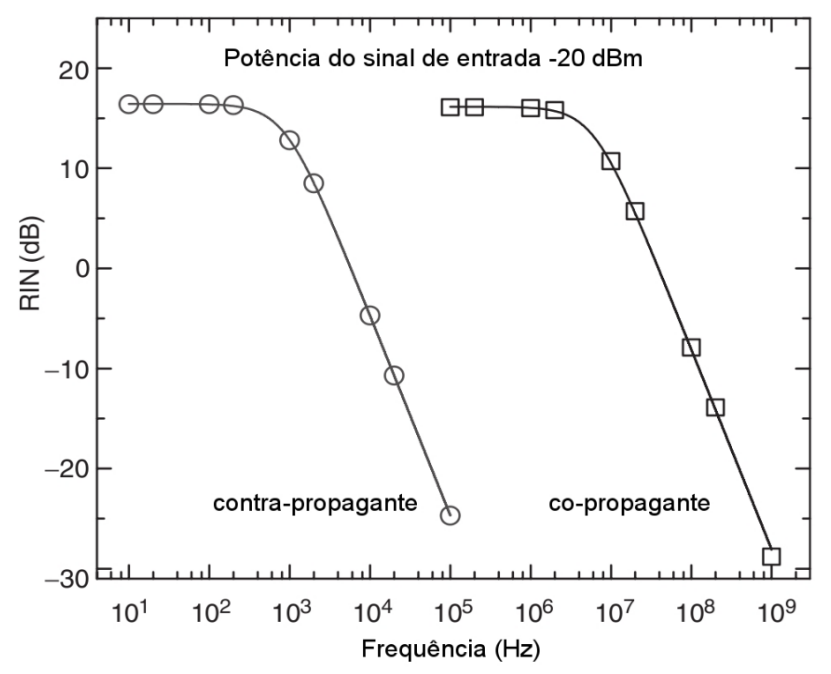

Figura A.13: Espectro do RIN calculado para as configurações contra e co-propagante. Extraido e adaptado da referência (Mermelstein et al., 2002).

Das curvas da Figura A.13, observa-se que, para o caso das baixas frequências, o RIN é amplificado $(R I N>0 d B)$, e para altas frequências é atenuado. A menor transferência de ruído ocorre nas altas frequências devido ao fato que a separação (walk-off) entre o bombeio e o sinal é mais significativa.

A transferência do RIN entre o bombeio e o sinal é reduzida para o caso da configuração contra-propagante, devido ao ruído do bombeio ser uma média diluída ao longo de todo o comprimento do enlace. 


\section{Planicidade Espectral da Figura de Ruído}

Como descrito anteriormente, a significativa interação Raman entre os bombeios de comprimentos de onda diferentes resulta numa amplificação dos bombeios com comprimentos de onda maiores em detrimento dos comprimentos de onda menores, como mostrado na Figura 11(b).

Como consequência disso, os canais de comprimentos de onda maiores possuem um ganho maior e mais bem distribuído ao longo da fibra e, deste modo, uma melhor figura de ruído (NF) quando comparada com a dos canais de comprimento de onda menores.

Um segundo efeito que influi na planicidade espectral da NF é a dependência da quantidade de ASE gerada, devido à diferença de frequência entre o bombeio e o sinal (Fludger et al., 2001).

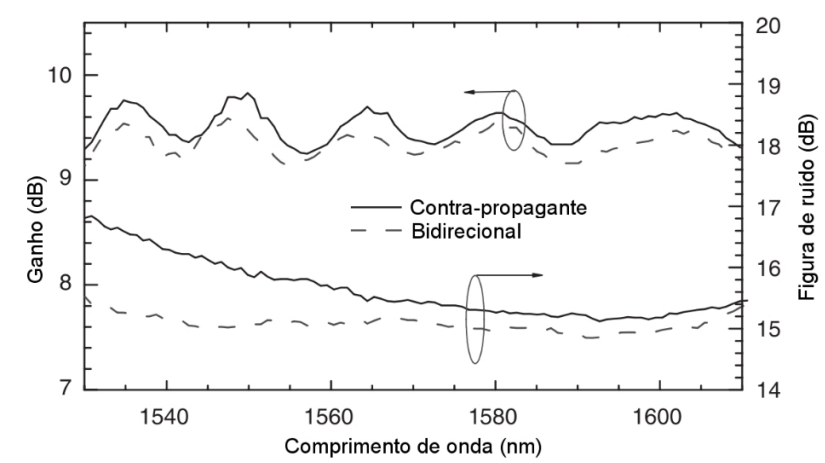

Figura A.14: Medição do ganho e da figura de ruído em função do comprimento de onda. Extraido e adaptado da referência (Kado et al., 2002).

Na Figura A.14 é ilustrado o espectro de ganho Raman, medido experimentalmente, obtido de um bombeio contra-propagante numa fibra monomodo padrão de $80 \mathrm{~km}$ (Kado et al., 2002). Na Figura A.14, observa-se um ganho de aproximadamente $9,5 d B$ e uma variação na figura de ruído de quase $1,5 d B$ na faixa espectral de $1530 \mathrm{~nm}$ a $1590 \mathrm{~nm}$.

\section{Aprimoramentos na Amplificação Raman}

A seguir, são apresentadas algumas técnicas de aprimoramento do desempenho dos amplificadores Raman (ganho, planicidade de ganho, figura de ruído, entre outras características).

\section{Bombeio Bidirecional}

Como descrito anteriormente, nos amplificadores Raman a figura de ruído efetiva é menor para o bombeio co-propagante, devido o ganho do sinal ocorrer próximo da entrada da fibra. Porém, neste caso, o próprio bombeio pode limitar o ganho do amplificador, visto que ganhos altos na entrada da fibra podem produzir efeitos não-lineares intensos. Isto aponta para a necessidade de bombeio bidirecional, para se possa obter uma figura de ruído efetiva mais baixa (bombeio co-propagante) com alto ganho (bombeio contra-propagante) (Essiambre et al., 2002; Kodo et al., 2001; Rottwitt et al., 1999).

Um problema que ocorria inicialmente com o bombeio bidirecional era a transferência de ruído entre o bombeio e o sinal, o que atualmente é superado pelo desenvolvimento de lasers de bombeio com baixo valor de RIN. Em adição a melhoria efetiva da figura de ruído, o bombeio bidirecional também reduz a dependência espectral da NF na fibra, como ilustrado na Figura A.14, mostrando-se aproximadamente $1 \mathrm{~dB}$ de melhora na inclinação da figura de ruído quando comparada ao caso do bombeio contra-propagante.

A melhoria na figura de ruído resulta da escolha do comprimento de onda do bombeio co-propagante, que determina a dependência espectral da $\mathrm{NF}$, enquanto o bombeio 
contra-propagante determina principalmente o perfil de ganho Raman. Além disso, o bombeamento bidirecional também diminui a penalidade MPI, reduzindo o efeito DRB.

\section{Bombeios de Alta Ordem}

Nas topologias de amplificação Raman discutidas anteriormente, o comprimento de onda do sinal está sempre deslocado de aproximadamente um Stokes do comprimento de onda de bombeio. Isto é conhecido como amplificação Raman de primeira ordem. Nas configurações de bombeio de alta ordem, um ou mais bombeios deslocados de dois ou mais Stokes do sinal são utilizados para amplificar principalmente os bombeios de primeira ordem, que subsequentemente amplificam o sinal (Bouteiller et al., 2003; Kodo et al., 2001; Labrunie et al., 2001; Martinelli et al., 2002). Quando o bombeio é deslocado do sinal de dois Stokes, este é denominado como bombeio Raman de segunda ordem e assim por diante para as configurações de bombeios de ordens superiores. Bombeio de alta ordem reduz a NF dos amplificadores Raman devido à distribuição mais uniforme do ganho ao longo do comprimento da fibra.

Exemplos de bombeios de segunda ordem contra-propagante e bidirecional são mostrados na Figura A.15. Da figura observa-se uma melhoria de $1 \mathrm{~dB}$ para o bombeio contra-propagante de segunda ordem e de $0,5 \mathrm{~dB}$ para o bidirecional quando comparados com os bombeios de primeira ordem.

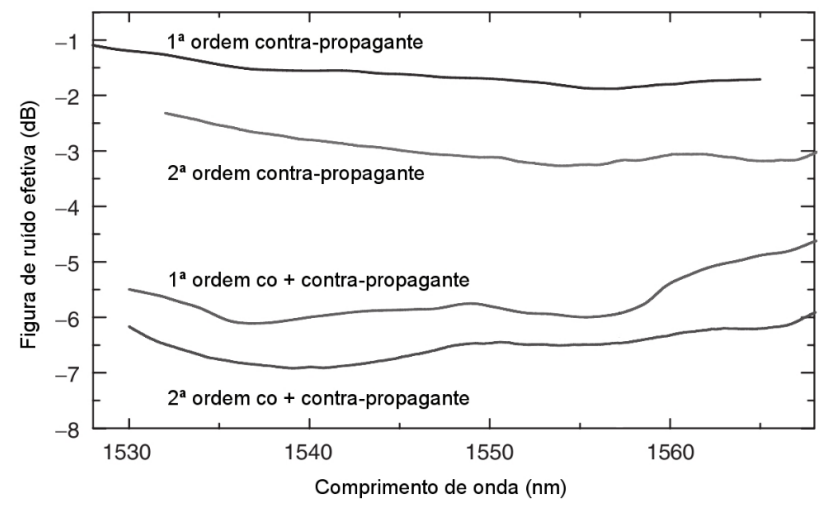

Figura A.15: Medidas de figura de ruído para quatro diferentes configurações de amplificadores. Extraido e adaptado da referência (Kado et al., 2002).

\section{Fontes de Bombeio}

O amplificador Raman é viabilizado pela existência de fontes de bombeio de alta potência. Para a amplificação na janela de comunicações ópticas de 1500 a $1600 \mathrm{~nm}$, necessita-se de fontes de bombeio na região de $1400 \mathrm{~nm}$. Atualmente, existem duas fontes de bombeio que operam nesta região, diodo laser semicondutor e laser Raman a fibra (RFL).

O diodo laser semicondutor de bombeio fornece potência acoplada na fibra maior do que $100 \mathrm{~mW}$, porém, laser com nível de potência de 400 a $500 \mathrm{~mW}$ sendo mais adequado para fornecer alto nível de ganho Raman. O laser deve operar na faixa de 1400 a $1500 \mathrm{~nm}$ para fornecer amplificação aos sinais nas bandas C e L (1530 a $1620 \mathrm{~nm}$ ). Diodos laser de alta potência de InGaAsP, operando nessa faixa de comprimentos de onda, foram desenvolvidos a partir nos anos 90 (Razeghi, 1995). Algumas características do módulo de bombeio diodo laser semicondutor para amplificadores Raman são enumeradas abaixo:

1. O módulo de bombeio é constituído de vários diodos lasers, com diferentes comprimentos de onda, para se obter um ganho Raman uniforme em uma extensa largura 
de banda;

2. Os comprimentos de onda dos bombeios devem ser estabilizados através de grades de Bragg posicionadas diretamente no pigtail que é utilizado para acoplar a saída do laser;

3. Para reduzir a dependência de polarização do ganho Raman deve-se utilizar dois lasers polarizados ortogonalmente acoplados em um combinador de polarização (PBC) no mesmo comprimento de onda, ou inserir um des-polarizador na saída do módulo de bombeio.

Lasers Raman a fibra fornecem altas potências de saída, porém são de implementação complexa e possuem tamanho físico bem maior que os lasers de bombeio semicondutores. 